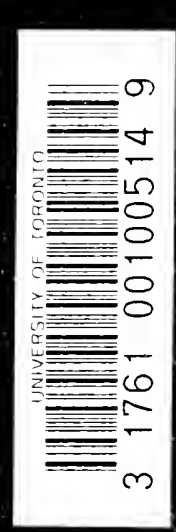

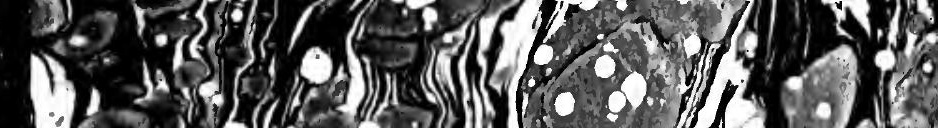

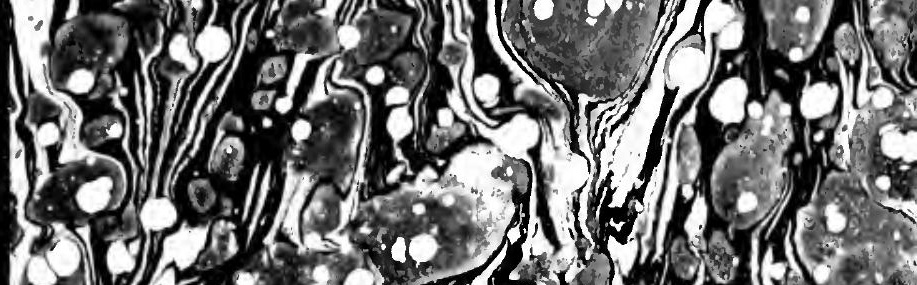
(2)

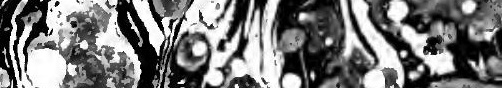

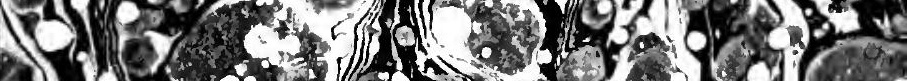

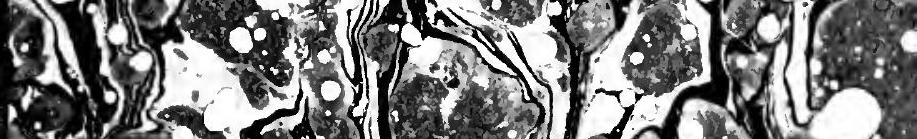
(3.

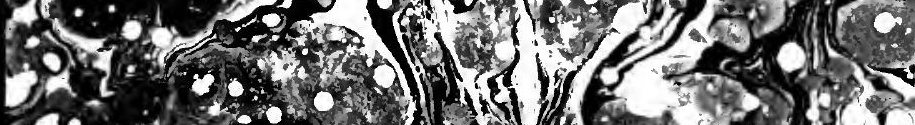

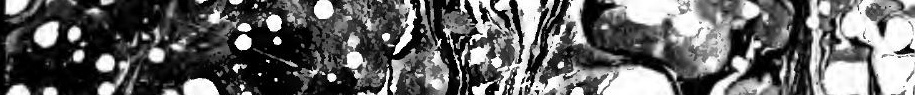
(16)

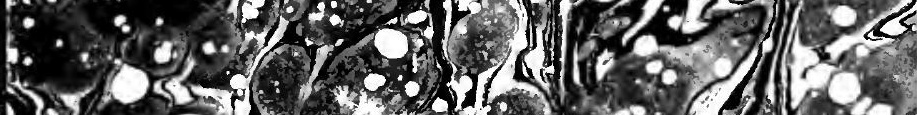

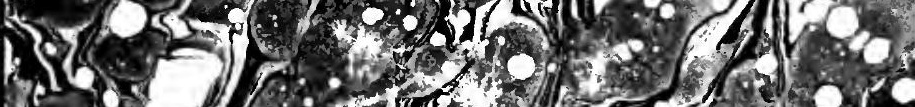

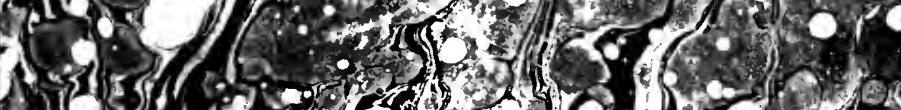
(1) $17 \%$.

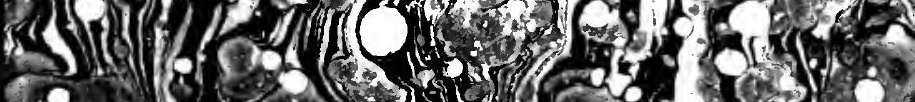

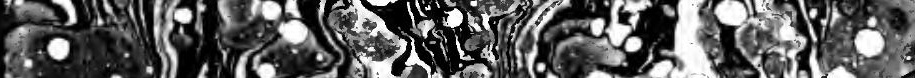

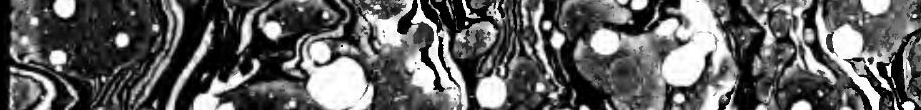

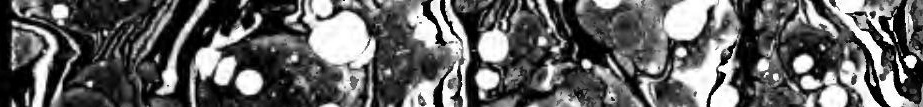

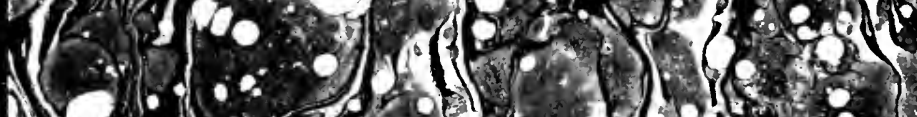

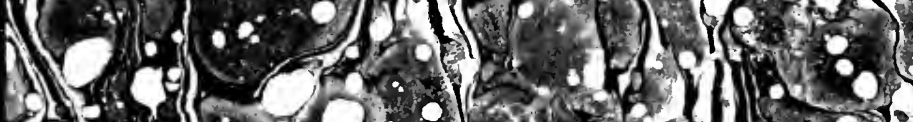

UNIV. OF TORONTO LIBKARY 


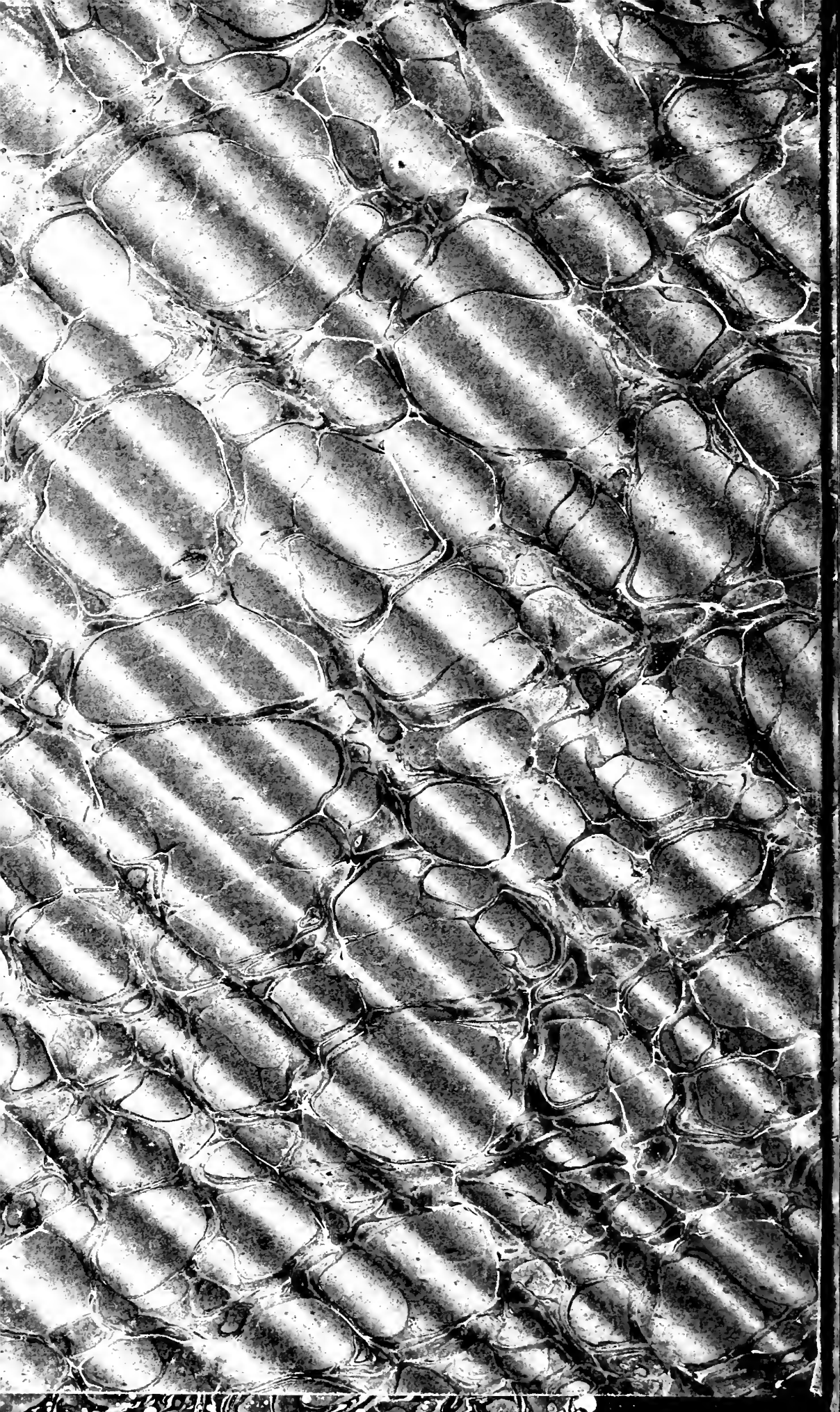







LHOWIE CRININEL 



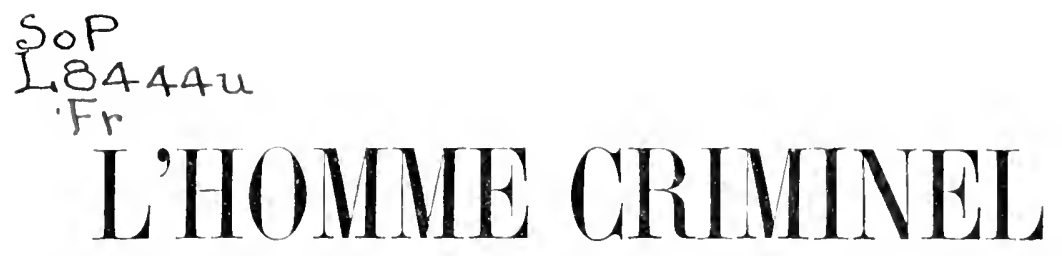

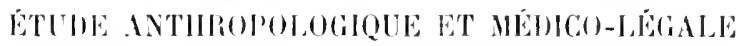
inat

\section{(ESARE LOMBROSO}

TRIDLIT

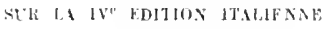

I. IF

M G. REGNIER "M A. BORNET

AVEC I'RÉTCE

l'A I:

M. LETOURNEA U

IRIIIXEI-XE- FOL HUIII.

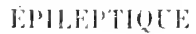

PARIS

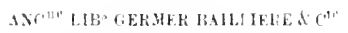

FÉLIX ALCAN
T UR I N

iiUHE - FLORENEE - NIHLH

BOCCA FRELES 
Trues rivits inserers

$$
\frac{22963}{211^{5 / 92}}
$$

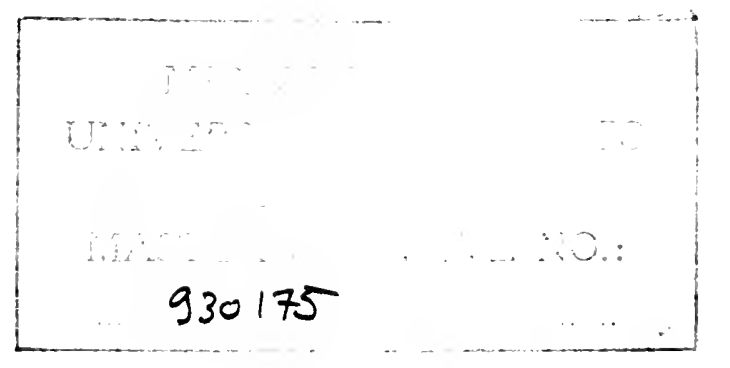




\section{PRÉFAGE}

Les editeurs de cet ouvrage ont bien voulu me charger de le présenter au public français, mais c'était prendre un soin presque inutile. L'Uomo delinquente a eu trois éditions en Italie et il est connu en Europe de tous ceux qu'intéresse la philosophie du droit pénal. Néanmoins j'essayerai de reconnaitre l'honneur qui m'a été fait, en résumant l'idée générale du livre de M. Lombroso.

Mais, pour bien comprendre cette idée, il est nécessaire de connaitre l'origine et l'évolution du sentiment de justice, inné aujourd'hui chez la plupart des civilisés. Comme toutes les origines, celle-ci est fort simple; le premier mobile, qui a suscité, dans la couscience de nos sauvages ancêtres, un vague sentitiment de justice, a été simplement la nécessité de se défendre, la détente réflexe, qui, chez l'homme et l'animal, fait instinctivement rendre coup pour coup. Chez l'animal, il en r'ésulte des actes machinalement exécutés et ne laissant dans la conscience que des traces fugitives. Chez l'homme, si grossier qu'il soit, mais vivant en société, la répétition des agressions et des résistances tinit par donner l'idée de contrebalancer plus ou moins exactement les torts subis et les rengeances assouries. 
L'antique seience juridique se bornait a compulser et à eommenter les textes. Une nonvelle éeole est née, l'école anthropologique, qui, laissant de eôté les codes et les formules, s'est mise à étudier l'homme an point de vue de la eriminalité. C'est l'éeole d'anthropologie juridique on eriminelle; elle a de dis. tingués représentants dans tous les pays d'Europe; elle en a surtout en Italie où MM. Lombroso, Garofalo, Ferri, ete., ont eréé tonte une littérature spéciale et a jamais ruiné les théories vénérables et vermoulues de l'aneienne criminalité.

Cette enquête seientifique, minutieusement faite et longtemps continuée a mis en lumière un fait de la plus haute importance: l'existence d'un type humain voné au erime par son organisation même, d'un eriminel-né, formant les gros bataillons de ce que l'on a metaphoriquement appelé "l'armée du erime ». C'est a la description, à l'étude de ce criminel-né, au triple point de vue physique, moral et intelleetuel, qu'est consaeré le présent onvrage.

Le eriminel complet, réunissant la plupart des caraetères de son type, a généralement une faible capacité crànienne, une mandibule pesante et développée, une g'rande eapacité orbitaire et un indice orbitaire analogne a celui des crétins, des arcades sonreilières saillantes. Son cràne est souvent anormal, asymétrique. La barbe est rare ou absente, mais la ehevelure est abondante. L'insertion des oreilles est eommunément en anse. Assez souvent le nez est tordu ou eamus. La physionomie est d'ordinaire féminine ehez l'homme, virile chez la femme. La saillie mongoloïde des areades zygomatirues n'est pas rare.

Les eriminels sont sujets au daltonisme; la proportion des gauchers est, chez eux, triple. Leur foree museulaire est faible, it la main et à la traetion, mais ils sont fréquemment d'une extraoldinaire agilité.

Les décénérescences alcooliques ou épileptiques les frappent dans une large proportion.

Les éléments histologiques de leurs centres nervenx sont dans une grande mesure atteintes de pigmentation, de dégénération ealeaire, de selérose, etc.

Ils rougissent diffieilement et toutes les variétés de la sensibilité sont, ehez eux, plus obtuses. 
Leur déchėance morale correspond à leur déchéance ol'oganirue: ce sont des fous moran.

Leurs tendances criminelles se manifestent des l'enfanee pal' lonanisme, la cruauté, le penchant au vol, une excessive vanité, la ruse, le mensonge, leur aversion pour les habitules de famille, leur rétivité à l'éducation, leur caractère impulsif. Ces traits moraux persistent et domnent au erininel arlulte une physionomie mentale toute particulière. Le criminel-ne est envieux, vindicatif; il hait pour laîr; il est indifférent aux punitions et sujet à des explosions de fureur sans canse, qui parfois sont périodirues.

Le criminel-né est paresseux, débauché, imprévoyant, mobile et poltron, joueur.

Il n'est pas susceptible de remords et souvent s'abandonne avec joie à ses instincts coupables.

Les eriminels ont un rif et précoce amour pour le tatonage, qui est souvent cynique et pratiqué mème sur les organes sexuels.

Leur écriture, quand ils savent écrire, est souvent toute particulière; leur signature compliquée, ornée darabesques.

Les argots des criminels, très-répandus et très-analogiues dans les divers pays, ont pour principaux caractères les abréviations et la tendance à désigner les objets par un de leurs attributs; malgré leur apparente mobilité, ees argots sont pleins d'archaïsmes.

Dans leurs associations, les criminels reviennent aux formes sociales primitives, à la dictature et à des codes draconiens.

J'ai résumé, aussi brièvement que possible, les grands résultats des belles études contenues dans le livre de $\mathrm{M}^{\mathrm{r}} \mathrm{C}$. Lombroso. Que, par bien des traits, le portrait du criminel-né rappelle celui des races inférieures, on ne le samrait nier. A quelles causes générales faut-il attribuer la persistance, au sein des sociétés dites civilisées, de ce type inférieur, criminel? A l'atavisme? Sûrement. Il n'est plus douteux que nous descendions d'ancètres aussi grossiers, aussi sauvages que les plus arriérées des races contemporaines; et nous savons que, dans les soriétés primitives, la plupart des actes, aujourd'hui réputés criminels, sont parfaitement licites et même parfois admirés. En Sanscrit, nous dit Pictet, il existe une centaine de racines 
rien que ponr exprimer l'idée de tuer et de roler. Mais l'atavisme n'explique pas tout. Beancoup de traits caractéristiques du criminel-né sont pathologiques. Ce sont des arrèts de déreloppement ou des dégénérescences.

Contre les retours atariques nous sommes désarmés, mais en est-il de même contre la dégénération alcoolique ou épileptique? Nullement. Ici les facteurs nuisibles sont áordre social et par conséquent nous arons prise sur eux.

Mais voyons dabord quelles conséquenees pratiquess lí. Lornbroso ct son école tirent de leurs intéressantes enquêtes.

Tont d'abord ils constatent l'impuissance des mesures répressives et du régime pénitencier en vigueur dans la plupart "les itats civilisés. Rien, en effet, ne proclame plus haut cette intpuissance que le chiffre des récidives, toujours croissant at nussure quon est plus habile et plus soignenx a les enregistrer et qui atteint $40^{\circ} \mathrm{I}_{0}$ en Franee (1877-78) et $70^{\circ} \mathrm{T}_{0}$ en Belginue.

Considerant le crinincl-ne, comme absolunent incorrigible. la nourelle école d'anthropologie juridique réclame hardinent pour lui la détention papétuclle, et en mème temps l'abolition des mises en liberté provisoire et du droit de graice. Lon me semble aller ici un pen loin. Il inporte, je crois, de ne par remplacer la saurage et inintelligente cruaute des rienx coles par une sonte de dureté impitorable. décrétée au nom de lia science. Lincurabilité dum bon nombre de erinuincls n'est pas encore sullisamulent demontréc et elle ne le sera pas arant que, suivant le vou très-sensé de M. Lombroso, on n'ait soigne? et traité les criminels-nés dans des asiles spécianx, analognex ì nos asiles d'aliénés.

Actnellement, dit M. Lombroso, l'instruction domée dans nos itablissements pénitentiaires n'a d'antre effet que do mienx armer le criminel et dangmenter le nombre des lécilives. car c'est une instruction purement alphabétique et tout-il-fait insurfisante. Sur ce point M. Lombroso me semble aroir enticrenent raison et sa critique porte plus loin rue les écoles pénitentiaires. La proportion plus grande des délits franduleux. des empoisomnements, etc., au sein des classes dites éclairées proure assez. que l'alphabct ne fait pas de miracles et que l'éducation intullectuelle a besoin d'ètre double par l'éducation morale. 
Lat nourelle école propose, encore, ot ici on ne sambit que lapprouver. de eorriger l'insufrisanee les mesures ripressives actuelles par ee que M. Ferri appelle les sostitutivi menali, saroir: par de bounes lois sur la production et le débit de l'aleool, sur le divoree, pau la diffusion des écoles lä̈ques arec maîtres maliés; par des récompenses aceordées aux actions rertueuses. des taxes mises sur los comptes-rendus des proees criminels: par l'itablissement l'asiles pour l'enfance, etc. ete.

A coup sul tout cela est anssi lonable que desirable, maik il Y lant joimlle nue róforme profonde et intelligente du régime pénitentiaire et des reformes sociales non moins ralicales. si l'on velt combattle le mal a la tois dans ses effets et dans ses callses.

La nourelle école me semble trop portée à considelel le lécidivisme, comme une incurable plaie. Pourtant M. Lombroso constate lui-nème, nais sans s̀ ar àter. que le système de la pénalité graduée et individualisante (Zwickau-Irlande) réluit la proportion des récidives à $10^{\circ} \mathrm{I}_{0}$ et même moins, à 2,68 ${ }^{\circ} \mathrm{I}_{0}$. Mais ramener la proportion des récidives à 2,68, cela équirant presiple at les faire disparaitre: cela démontro en outre que les criminels-nés, absolmment incorrigibles, sont en assez petit nomble.

A ce sujet, je ne puis que reproduire quelques réflexions. qui me firent inspirées jadis par une risite au pénitencier de Nenchatel (suisse): «Nos clininalistes enrages, nos législateurs inexpérimentés, pour qui la punition du eriminel est une représaille. une rengeance sociale, tons ces esprits légers on étroits, à qui il ne faut pas se lasser de répéter que. suirant l'expression de Quételet, c'est la société qui prépare les crimes: tous ces areugles pilotes des états modemes, pour qui l'hommo n’est ni modifiable, ni élucable, qui mettent partout la sentimentalité et la routine à la place de l'utilité sociale, pourraient roir, tout près de nous, au pénitencier de Neuchàtel, ce que I'on peut olstenir arec le systeme si humain et si scientifique de W. Crofton. Là, bien loin de considérer le conlammé comme un réprouré, on s'applique à éreiller dans son cceur l'espérance, à lui montrer que l'on ne ressent contre lui ni haine, ni eolère, à lui bien persuader qu'il est, dans une large mesure, 
l'arbitre de son sort. On le traite, non pas comme un monstre qui doit souffrir et expier, mais comme un malade, comme un ami égaré, que l'on veut remettre dans le bon chemin. On l'instruit; on l'élève moralement: on lui donne une profession; on le fait passer graduellement de la prison cellulaire à la libération conditionnelle avec surveillance bienveillante. En un mot, on en fait un homme. Seulement à cette besogne, il faut des pliilantlrropes éclairés; il est plus commode de n'avoir que des geỏliers ».

Cela, c'est le régime curatif. Le vrai régime prérentif ne saurait consister que dans de profondes réformes sociales. Le criminel-né serait sûrement très-rare, s'il n'était créé par la société elle-mème. Ses grands facteurs sont la misère et l'alcoolisme. Or, ces deux fléaux sont en corrélation étroite arec l'inégale répartition des richesses, considérablement aggravée par le triomple et l'extension de la grande industrie.

Dans un rapport ruasi-officiel, MM. Cardani et Massara nous ont appris que le paysan iombard, le famiglio, n'a qu'un salaire journalier de fr. 0,80, arec lequel il lui faut virre, lui et sa famille. Nous savons, d'autre part, qu'il y a, en Lombardie, des centaines de milliers de femmes, filant huit heures par jour et gagnant 1 frane par semaine. M. Romuzzi, de Milan, affirme que, dans la province de Còme, 1900 enfants au-dessous de neuf ans travaillent jusqu'à quinze heures par jour, moyennant un salaire de 10 à 15 centimes.

Ces faits ne sont pas spéciaux à l'Italie. Rien ne serait plus facile que d'en trouver d'équivalents et en plus grand nombre dans les autres pays civilisés oì le régime industriel triomphe plus cruellement encore.

La statistique nous apprend que des millions de prolétaires européens ne consomment pas, claque année, 25 kilogr. de viande par persomne, que le nombre des indigents ra croissant toujours et en mème temps le chiffre de la consommation alcoolique.

En résumé, nous savons tous que notre salarié moderne est souvent plus abandonné ، plus misérable, plus sacrifié que l'esclave antique. A défant de sentiments humanitaires, le propriétaire de ce dernier lui portait au moins le genre d'intẻrêt 
que lon a pour un animal domestique, représentant une certaine valeur.

Je marrète, nayant point ici a iusister sur ces graves questions.

Que le nombre des criminels-nés puisse ètre plus ou moins diminué par les mesures prérentives ou curatives, ce type nen existe pas moins et tout le monde en sera convaincu, apres aroil lu les belles, minutieuses, ingénieuses et consciencieuses: etudes de M. Lombroso.

J'ai cru deroir indiquer, en passant, quelques-unes des rétlexions, qui ne pent manquer de susciter cette intéressante lecture, mais elle en pent susciter bien d'autres. L'espace me manque pour m’y arrèter. Elles naitront, d'ailleurs, spontanément dans l'esprit des lecteurs de ce lirre.

CH. LETOURNEAL. 



\title{
PRÉFACE DE L'AUTEUR
}

\author{
i M QUATRIEMAF EDITION
}

monman

Ce livre, pareil à l'humble insecte qui transporte, à son insu, le pollen fécondant, a vivifié un germe qui n'aurait, peut-être, porté ses fruits qu'après de longues années. Il a domuć naissance a une nouvelle école qui, gràce aux travaux de MM. Liszt, Kraepelin, Biliakow, Troiski, Körnfeld, Knecht, Holtzendorf, Sommer, Kirchenhein, Mendel, Pulido, Echeverria, Zanches, Drill, Kowalewski, Likaceff, Minzloff, Kolokoloff, Espinas, Letourneau, Tonnini, Reinach, Soury, Corre, Motet, Orchanski, Manouvrier, Fioretti, Le Bon, Bordier, Bournet, Roussel, Ribot, Heger, Albrecht, Warnott, Lenlossek, Tamburini, Frigerio, Laschi, Mayor, Majno, Renelli, Fulci, Pavia, Aguglia, Sergi, Tanzi, Campili, Barzilai, Pugliese, Morello, Lessona C., Cosenza, Lestingi, Colucci, Turati, Marro, Venezian, et surtout gràce à MM. Lacassagne, Flesch, Benedikt, Beltrani-Scalia, Virgilio Morselli, Garofalo, Puglia et Ferri, a comblé les trop nombreuses lacunes des premières éditions de ce livre, en même temps qu'elle en déterminait les applications pratiques au point de vue juridique.

Je ne saurais trop reconnaître ce que je dois à ces illustres savants.

Grâce à enx, pour la première fois, j'ai pu distinguer avec exactitude le criminel-né, non seulement du criminel d'occa- 
sion, mais encore du fou et de l'alcoolique, à qui je consacrerai des monographies spéciales. Grâce à eux, encore, j’ai pu étendre mes recherches sur les formes primordiales du crime, dans le sauvage, l'enfant et l'animal, en compléter l'étude anatomique, en commencer l'étude physiologique, surtout pour ce qui touche aux anomalies de la sensibilité, de la réaction vasculaire et réflexe, phénomènes qui nous expliquent cette surabondance paradoxale de santé, que nous rencontrons, aussi souvent, chez des individus pourtant infirmes dès leur naissance, comme le sont les criminels.

C'est ainsi que j'ai pu démontrer comment la maladie se compliquait en eux de l'atavisme: et que j’ai pu opérer la fusion entre les deux concepts du criminel-né et du fou moral, fusion déjà entrevue et affirmée par MM. Mendel, Bonvecchiato, Sergi, Virgilio, mais que l'on ne pouvait admettre arec certitude, aussi longtemps que les contours en restaient mal précisés; et manquaient d'une vraic description scientifique.

Si je n'ai en qu'à me loner de mes critiques et de mes collaborateurs, je n'ai pas été moins heureux avec mes adversaires, parmi lesquels il me suffira de nommer MM. Tarde, Baer, Messedaglia. Ettingen, Brusa, Ungerm-Sternberg. Il est beau d'être combattı, et mème d'être vaincu par de tels hommes; aussi je croirais manquer a toutes les convenances si je n'essayais de leur répondre:

"Vous abusez trop, dans ros déductions, des faits isolés", m'objectent ces sarants éminents; \&si vous rencontrez, p. ex., un crâne asymétrique, des oreilles écartées, etc., chez un sujet, vous vous hâtez d'en conclure à la folie ou au crime; or, cenxci n'ont aucun rapport direct ni certain avec pareilles anomalies ». - Je ne répondrai pas, qu'on ne rencontre jamais dans le cristal humain une formation anormale, qui n'ait sa raison d'être, surtout dans l'arrêt de développement; je ne dirai pas, non plus, qu'il existe une école de savants alienistes, qui ne craint pas de se fonder, bien des fois, sur une seule de ces anomalies, pour diagnostiquer les folies dégénératives; je me contenterai de rappeler que je ne fais pas de telles déductions $a$ priori, mais après les avoir vues en proportion plus grande .chez les criminels que chez les gens homnêtes; je dirai que, 
pour moi, les anomalies isolées ne sont qu'un indice, une note musicale, dont je ne prétends, dont je ne puis tirel 131 accord qu'après l'avoir trouvée jointe à d'autres notes plysirues on morales. Et n'est-ce rien, at leur aris, que l'aroir commis un crime ou d'en être soupçonné?

Il est rrai qu'on m'objectera: "Comment pourez-vous parler d'un type chez les criminels, quand, de ros propres traraux, il resulte que $60^{\circ} \mathrm{I}_{0}$ en manquent complètement?». - Mais. outre que le chiffre de $40^{\circ}{ }^{\circ}$ n'est pas a dédaigner, le passage insensible d'un caractère a un autre se manifeste dans tous les ètres organiques: il se manifeste mème d'une espèce à l'autre; a plus forte raison en est-il ainsi dans le champ anthropologique, oil la variabilité individuelle, croissant en raison directe du perfectionnement et de la civilisation, semble effacer le type complet. Il est difficile, par exemple, sur 100 italiens, d'en trouver s qui présentent le tỵpe de la race; les autres n'en ont que des fractions, qui se manifestent seulement quand on les compare à des étrangers; et, pourtant, il n'y a persomne qui songe à nier le type italien.

A mon aris on doit accueillir le type avec la même réserve qu'on met à apprécier les moyennes dans la statistique. Quand on dit rue la vie morenne est de 32 ans, et que le mois le plus fatal est celui de décembre, persome n'entend par lat que tons les hommes doirent mourir à 32 ans et an mois de décembre.

Loin de porter atteinte à l'application pratique de nos conclusions, cette façon restreinte d'envisager le tỵpe lui est favorable; en effet, la détention perpétuelle, la peine capitale, qui sont les derniers mots de nos recherches, seraient impraticables à l'égard d'un grand nombre d'hommes, mais on peut, les appliquer fort bien à un nombre restreint. Et, à propos de quelques-uns, on pourra, sans aroir l'air de soutenir un paradoxe, conseiller de regarder comme un indice de criminalité la présence de ce type chez des individus suspects.

Autre accusation grave qu'on nous impute à propos de ce type, c'est que nous le déduisons de l'examen de quelques milliers de criminels, tandis que les malfaiteurs existent par millions, et qu'une loi ne peut être considérée comme bien fondée si elle ne s'appuie pas sur les grands nombres (ЕTтINGEx). 
Il ne sera pas inutile de rappeler, ici, une loi biologique, qui doit précisément, selon M. Ferri, se combiner avec celle des grands nombres: "En général, les données biologiques de haute importance sont celles qui éprourent les variations les moins considérables. Un exemple fera mieux comprendre notre pensée: tandis que la longueur des bras peut varier, d'homme a homme, de plusieurs centimetres, la largen: du front ne pent varier que de quelques millimètres. D'où il résulte aree évidence que, dans les questions d'antlhropologie, la nécessité de gros chiffires est en raison directe de la variabilité des caractères étudiẻs, et, par conséquent, en raison inverse de leur inportance biologique 》 (Nuovi orizanti, 1883).

Les gros chiffres sont utiles quand on s'oceupe des plrénomènes que chacun pent enregistrer. Mais quand il s'agit de connaitre non pas le sexe, ni l'àge, ni la profession, mais le caractère psychique ou la conformation crûnienne d'un groupe de criminels, il est impossible de joner avec des chiffres élevés.

Jans ces questions délicates qui exigent une culture spéciale. les grands nombres recueillis par la statistique officielle, cuvre, pour la phupart du temps, d'employés ignorants, ont bien moins de valeur que les observations elairsenées, à la vérité, mais dues à dest hommes competents. Ici la sunreté des reeherches vant bien mienx que leur quantité.

Voyez ce qui a lien, par exemple, pour un lait cependant bien simple à relever': la récidive. Si l'on s'en tient à une statistique de plus de 80.000 condannés, dressée par l'homme le plus compétent d'Italie en ce gemre, M. Beltrani-Scalia, elle se liniterait à $18{ }^{\circ} \mathrm{I}_{0}$ dans les bagnes, a $2 \gamma^{\circ} \mathrm{I}_{0}$ dans les prisons, chiffres prodigiensement inférieurs à ceux que fomrnissent la France $\left(4 \cdot{ }^{\circ} \mathrm{I}_{0}\right)$ et la Hollande $\left(80^{\circ} \mathrm{I}_{0}\right)$. Ce n'est pas tout: la reécidire, toujours d'après ce tableau, semblerait perdre du terrain dans les parties de l'italie ou se commettent le plus de crimes; tandis que l'on tronrerait dans l'ancien royaume Lombardo-Vénitien la proportion de 59 à $5 \mathrm{l}^{\circ} \mathrm{T}_{0}$, on s'arrèterait dans le Sud à 10 , à $14{ }^{\circ} \mathrm{T}_{0}$. Heurensement que des cas peu nombrenx, il est vrai, mais absolument sur's, en faisant commaitre a fond le malfaiteur, en éclairant d'un grand jour les associations eriminelles, ont permis de corriger, ici, comme Ettingen l'a déja 
fait en lissie, l'erreur que l'on commottrait en se basant miquement sur les grands nombres (I).

"Vons niez, mobjecte M. Tarde, qu'il y ait la moindre analogie entre le eriminel-ne et l'aliene; et puis vous finissez pal' confond le le premier arec le fou moral. Mais, ainsi, vous perdez de vue l'atarisme, qui n’a ricn a faire avec la maladic » (2). - Il ny a pas là de contradiction. Le fon moral n’a rien de connmun arec l'aliêné; il n'est pas un malade, il est un crétin du sens moral. Du reste, dans cette édition, j'ai lémontré qu'outre les caractères rraiement atavistiques, il y en avait d'acquis, et de tont-i-fait pathologiques: l'asymétrie faciale, par exemple, qui n’existe pas chez le sauvage, le strabisme, l'inégalité des oreilles, la dyschromatopsie, la parésie mnilatérale, les impulsions irrésistibles, le besoin de faire le mal pour lui-mème, etc., et cette gaité sinistre qui se fait remarquer lans leur argot, et qui, alteluant avec une certaine religiosité, se trouve si souvent chez les épileptiques. Ajoutez-y les méningites, les ramollissements du cerveau, qui ne proviement certainement pas de l'atavisme. Et je suis venu de lá à renoner le fon moral ct le criminel-né dans la branche des épileptoïdes.

Certes, une théorie qui s'ar'rèterait à l'atavisme pour expliquer l'origine du criminel serait bien plus séduisante; mais que de fois le vrai est moins beau que le faux!

A l'oljection, très-juste, de M. Tarde, que les sauvages ne sont pas toujour's bruns, ni d'une taille élevée, et que la fossette occipitale moyenne peut se rencontrer cliez des peuples peu portes au crime, comme les Arabes, et faire défaut chez d'autres plus barbares, j'ai déja répondu en citant cette loj, que les anthropologues devraient mieux obsel'ver:

A savoir: que les anomalies atavistiques ne se rencontrent pas toutes avec la même abondance dans les races les plus sauvages; mais que, plus fréquentes néammoins chez elles que chez les peuples plus civilisés, elles varient dans la proportion, et sans que l'absence de l'une ou de l'antre puisse être regardée comme une marque d'une plus grande infériorité dans la race.

(1) Garofalo, Archivio di psichiatria e scienze penali, vir, 4, 1880.

(2) T'ARDE, daus son beau livre: Criminalité comparée, 1886. Mlcan, éd. 
Ainsi, deux anomalies ataristiques, celle de l'os de l'Inca et de la fossette occipitale, se reneontrent ensemble chez des races a demi civilisées, comme la race américaine, et sont rares ehez les nègres, pourtant plus barbares (Anutchine, Bull. soc., Moseou, 1881).

Du reste, saus répéter que la maladie bien souvent obseureit tonte trace datavisme, il faut se souvenir que, quand on veut retrouver les lois de l'atarisme dans les phénomènes humains, mème là où elles sont le mieux établies, dans l'embryologie, par exemple, on risque souvent de s'égarer. Il en est comme de certains contours figurés des nuages qui disparaissent quand on les regarde de trop près; ou eomme de ces tableaux modernes, que j'appellerai Hollandais au relsours: vus de près, il vous ont l'air de croûtes surchargées de couleurs: à distance, ils présentent d'admirables portraits. Dans les deux cas, toutefois, la ligne existe; seulement, pour la saisir, il faut reeuler le point de vue. En voulez-vous la preuve? Adoptez eette opinion, et vous verrez aussitôt s'ouvrir devant vous mille roies nouvelles qui, s'éclairant l'une l'autre, éclaireront, en même temps, le sujet, tandis que le eontraire devrait se produire si tout cela n'était qu'illusion pure.

Je répondrai, maintenant, à une autre aceusation que je me permets, aree M. Turati (Archivio, I11), de trouver bien singulière: "Cette école, disent quelques adversaires, a été fondée par des hommes etrangers à la science du droit, par de véritables intrus ». - Nais ees contradieteurs, rui reproclient à des médecins-légistes d'avoir appliqué de la médecine légale, à des anthropologues d'avoir appliqué l'anthropologie aux questions sociales on juridiques, oublient que de mème les ehimistes font de l'industrie, les mécaniciens de l'hydraulique et de la teehnologie: ils oublient que pour la première fois Buckle et Taine ont fait de l'histoire sérieuse quand ils ont fondu avec la chronologie historique l'économie politique, l'ethnologie comparée, et la psychologie; ils oublient, enfü. que la physiologie moderne n'est pas autre chose qu'une série d'applieations de l'optique, de I'hylraulique, etc. Mais, voyez la bizarrerie! Pendant que ces mèmes critiques protestent contre toute tentative faite pour supprimer le danger de légiférer sans aroir étudié l'homme 
et sans le eomnaitre, et cela uniquement par horreur d'une allianee ètrangère, on voit la plupart d'entre eux subir, rechercher même, non pas seulement l'alliance, mais la dictature d'une science étrangère au droit, et pent-être à toutes les sciences: je veux parler de la métaphysique. Et ils ont eu le courage d'établir sur elle, même dans ses hypothèses les plus combattues, dans celle du libre arbitre, par exemple, les lois lont depend la sécurité sociale!

lei, je me vois arrèté par d'autres juristes, qui me reprochent de réduire le droit criminel à un chapitre de psychiatrie, et de bouleverser en entier la pénalité, le régime des prisons! Cela n'est vrai qu'en partie. Pour les criminels d'occasion je me renferme, tout-à-fait, dans la sphère des lois communes, et me contente de demander qu'on étende, davantage, les méthodes prérentives. Quant aux eriminels-nés et aux fous criminels, les changements proposés par moi ne feraient qu'ajouter à la sécurité sociale, puisque je demande pour eux une déten$\mathrm{i}$ on perpétuelle, c'est-à-dire la prison à vie, moins le nom.

La noureauté de nos conclusions les plus combattues est-elle done si grande? Pas du tout. Et vous trouverez des eonclusions analognes dans l'antiquité, chez Homère quand il fait le portrait de Thersite, ehez Salomon quand il proclame (Eccles., xin, 31) que le cour change les traits du méchant. Aristote et Avicemne, G. B. Porta et Polémon, ont déerit la physionomie de l'homme criminel; les deux derniers sont même allés plus loin que nous. Citerai-je encore les proverbes qui, nous le verrons plus loin, aboutissent à des conclusions bien plus radicales que les miennes, et nous viennent évidemment des aneiens?

Il y a bien des siècles déjà que le peuple a signalé l'incorrigibilité des eoupables, surtout des voleurs, et l'inutilité des prisons (1).

Celles de nos théories qui paraissent les plus hardies ont mème été mises en pratique dans des temps qui sont bien loin de nons: MNI. Valesio et Loyseau eitent un édit du moyen-âge prescrivant, dans le cas où deux individus seraient soupçonnés, d'appliquer la torture au plus laid des deux. - La Bible dis-

(I) V. Archivio di psichiatria, ecc., 111, p. $45 \mathrm{l}$. 
tingue déjà le criminel-né et ordonne de le mettre à mort dès sa jeunesse. - Solon a trouvé dans le Dictérion un préventif social contre le viol et la pédérastie.

Je suis, dit-on, un révolutionnaire. Cela ne m'importe guère; car, à cette accusation, j'en puis opposer une autre également portée contre moi, celle d'avoir, dans mes conclusions dernières (nécessité du crime, théorie de la défense sociale), ressuscité une tliéorie démodée, ou qui, du moins, n'est plus en vogue auprès de ceux que j'appellerais volontiel's les petits-maîtres de la seience, qui d'ordinaire attendent, pour se faire une opinion scientifique, la dernière mode de la sorlsome ou de la foire de Leipzig. Cette accusation, d'ailleurs, tombe à faux, car des savants illustres - Breton, Ortolan, Tarde, Ribot, Despine en France, -- Holtzendorf, Grollmann, Hoffmann, Hommel, Ruf, Fuerbach en Allemagne, - Wilson, Thompson, Bentham, Hobles en Angleterre, - Ellero, Poletti, Serafini en Italie, - soutiennent, tous, avec des armes nouvelles, l'antique tradition, due à l'initiative vigoureuse de Reccaria, de Carmignani et de Romagnosi.

Mais, admettons que cette accusation soit fondée; serait-ce un motif pour rejeter une vérité? Le vrai n'a-t-il pas pour principal caractère de subsister éteruellement? de reparaitre plus fort et plus vivace justement alur's qu'on le croit étouffé sous les oripeaux de la mode, et sous les obstacles accumulés par les rhéteurs ou par les stériles efforts de quelyues grands esprits fourvoyés? Est-ce que la théorie du mouvement moléculaire, de l'éternité de la matière, n'est pas encore anjourd'hui fraiche et vivante, bien qu'elle remonte au temps de Pythagore?

Ces objections, pourtant, sont sérieuses; elles ont pour auteurs des savants respectables; mais il en est une autre, lancée par des hommes bien inférieurs en savoir et en bonne foi, et qui, pour ètre anonyne, vague, impalpable et pen digne de réponse, n'en est pas, eependant, la moins dangereuse: c'est celle que j’appellerai l'objection de la légende.

La légende veut: que ces travaux tendent à détruire le code pénal, à laisser toute liberté aux brigands, à saper la liberté humaine. 
Ne roit-on pas, cependant, que si nous diminnons la responsabilité de l’individu, nous y substituons eelle de la socićté, dui est bien plus exigante et plus serve? Que, si nons l'iduisons la responsabilité d'un groupe de eriminels, loin de protendees adoucir leur eondition, nous réclamons pour eux me detention perpétuclle? Cette detention perpetuelle, la soeieté modrue la repousse, pour rendre hommage a des principes therdiques; mais ce nest point sans sexposer at de grands périls. Et d'ailleurs, ne la voit-on pas alopter, avec infiniment phus d'incertitude, d'irrégularité et d'injustice, une demi-continuité do la peine, sons forme de colonie pénale, de surveillance, de residenee forcée, etc., mesures ineompletes, d'une ellicacité donteuse. mais an moyen desquelles elle se flatte d'obtenir la séenrité que les lois ne peurent lui fournir?

Les nouvelles mesures pénales que nous proposons exchent la note infamante, jen conviens; mais eelle-ci, nos juristes mente ne la eroient plus néeessaire; ils la considerent comme une transformation ataristique, un reste de lantique vengeance, qui va disparaissant toms les jours. - Et qui done oserait repousser de tels arantages dans l'unique but de justificr un sentiment si odieux? Qui ne roit que notre temps a pour érangile la maxime de $\mathrm{M}^{\mathrm{w}}$ de Stä̈l: Tout connaitre est tout pardonner!

Reste l'argument tiré de l'exemple. Mais l'exemple sulssisterait, puisque la détention perpétuelle signifie quelque chose de bien pénible; d'ailleurs, l'exemple n'est plus le but principal que poursuit le législaten, tont le monde en convient.

on eraint de porter atteinte à la morale, en réduisant, l'un còté, l'estime, de l'antre le mépris qui s'attacheraient à des aetes soustraits au libre arbitre. Mauraise raison! D'ałord, il paraît peı sérieux d'établir un frein de cette importance sur un fait controversé; ensuite, nul ne songe a entamer le monde dı sentiment, et, le voudrait-on, on n'y réussirait pas.

Le critérium du mérite ne changera point, lorsque la plıpart des rertus et des rices seront reconmus pour des eflets d'un ehangement moléculaire. Refuse-t-on d'admirer la beanté, quoiqu'on voie en elle un phénonène tout-à-fait matériel et indépendant de la volonté humaine? Le diamant n'a aucun mèrite a briller plus que le eharbon; quelle femme, toutelois, jetterait 
ses diamants, sous prétexte qu'ils ne sont, au fond, que du charbon?

Prenez tous les anthropolognes-criminalistes; ancun deux ne roudrait serrer la main d'un scélérat: aucun ne mettrait, sur le mème pied, le crétin et l'homme de génie, bien qu'il sache que la stupidité de l'un et lintelligence de l'autre ne sont qu'un résultat de l'organisme. All revoir, donc, le peuple, qui ne comprend rien à ces idèes.

Nous couromerons de fleurs les tombes des grands hommes, et nous jetterons au rent les cendres des malfaiteurs.

Prétendre quon ruine la liberté lumaine, en niant certains principes de morale, c'est renouveler l'exemple de ceux qui reprochaient à Galilée et à Copernik de troubler et de détruire le systeme solaire, quand ils enseignaient que la terre tourne et que le soleil reste immobile. Le système solaire dure toujours; il en sera de mème dn monde moral, quel que soit le critérium employé pour l'examiner. Les doctrines restent dans les lirres, les faits poursuivent leur cours. La chose n'est, hélas! que trop prouvée.

Jajouterai mème que le mépris ne s'attache pas toujours au crime, ni à la peine. On méprise la femme adultère: on admire. prescue, l'homme qui se troure dans le mème cas. Les escroqueries des banquiers puissants s'appellent de beaux coups. Les crimes et délits politiques ne méritent ancun mépris, et pourtant ils sont risés par le code pénal: et la peine qui les frappe est justifiée par la nécessité de la défense sociale (1).

D'un autre còté, le mépris peut bien contribuer à détourner du crime un homme non encore corrompu, mais les criminelsnés, les criminels d'habitude, n'y attachent aucune importance; il se sentent plutòt excités par la rumeur, même d'opposition, qui se fait antour d'eux.

Il est, d'ailleurs, bien vrai que, si l'on admet l'identité du fou moral et du criminel-né, si l'on recomnait l'existence des demi-fous, des gens possédés de folies srrstématisées (V. vol. II). larocat habile, plaidant devant un juge qui fait du libre arbitre le fondement de la pénalité, pourra paralrser l’œurre de

Lombros's e Laschi, Del delitto politico. Fratelli Bocca, $185 \%$. 
la justice. en montrant un malade là oì dautres royaient un coupable.

Mais quoi? Derrons-nous lalsitier, rejeter le vrai, par ce que la loi, au lieu de ladmettre, se sera engagée dans une fausse roie, par ce quelle aura étudié le erime sans étudier le conpable? Nest-il pas plus juste, dans eette alternatire, de nodifiel les lois contormément aux faits. que de falsifier les faits pour les accommoder aux lois, et cela dans l'unique but de ne pas roubler la tranquilité sereine de quelques hommes, à qui il déplait daecorder leur attention à ce nouvel élément dont s'est enrichi le champ de nos etudes?

On patienterait encore, si les mesures prises en dehors de nos conclusions et en opposition arec elles, aboutissaient du moins à la securité sociale, but suprème de tout lèislateur. Mais qui ne sait que les pénalistes les plus honnètes et les plus intelligents, dans la pratique conviennent que loeurre de la justice est en quelque sorte un travail de sisyphe. une immense tatigue qui naboutit à aucun résultat, que les moyens suggéres par les écoles les plus modernes. la liberté prorisoire. le jury, la libération conditionnelle. au lien de diminuer le crime. laugmentent bien des fois, ou. tout au moins, se bornent à le transformer?

Que penser, egalement, de ces autres mesures que l"un donne pour le dernier mot de la science. et qui sont au contraire la plus claire demonstration du manque absolu de sens pratique? Je remx parler. ici, de ladoucissement des peines appliquées aux réeidivistes (1), de limpunité acquise anx simples tentatires délictueuses, de lextension du jury aux affaires correctiomnelles.

En peuton lire autant des conclusions pratiques sontenues par notre école? Dira-t-on quelle ne conjure en rien le péril, quelle est absurde. quand elle propose de creer des asiles criminels, des prisons pour les ètres incorrigibles. de remplacer la première condamnation à la prison par une amende ou un chatiment corporel? Traitera-t-on de mème ses projets de loi sur le dirorce, sur le trarail des entants. sur l*abus de l'aleool, qui ont pour lut de prérenir le riol, laaultère et le meurtre?

(1) Luechini et Buceellati. 
ses diamants, sous prétexte qu'ils ne sont, au fond, que du charbon?

Prenez tous les anthropolognes-criminalistes; aucun d'eux ne roudrait serrer la main d'un scélérat; aucun ne mettrait, sur le mème pied, le crétin et l'homme de génie, bien qu'il sache que la stupidité de l'un et l'intelligence de l'autre ne sont qu'un resultat de l'organisme. Au revoir, donc, le peuple, qui ne comprend rien à ces idèes.

Nous couronnerons de fleurs les tombes des grands loommes, et nous jetterons au vent les cendres des malfaiteurs.

Prétendre qu'on luine la liberté humaine, en niant certains principes de morale, c'est renouveler l'exemple de ceux qui reprochaient à Galilée et à Copernik de troubler et de détruire le système solaire, quand ils enseignaient que la terre tourne et que le soleil reste immobile. Le système solaire dure tonjours; il en sera de même dı monde moral, quel que soit le critérium employé pour l'examiner. Les doctrines restent dans les livres, les faits poursuivent leur cours. La chose n'est, hélas! que trop prouvéc.

J'ajouterai même que le mépris ne s'attache pas toujours au crime, ni à la peine. On méprise la femme adultère; on admire, presque, l'homme qui se trouve dans le mème cas. Les escroqueries des banquiers puissants s'appellent de beaux coups. Les crimes et délits politiques ne méritent aucun mépris, et pourtant ils sont visés par le code pénal; et la peine qui les frappe est justifiée par la nécessité de la défense sociale (1).

D'un autre côté, le mépris peut bien contribuer à détourner du crime un homme non encore corrompu, mais les criminelsnés, les criminels d'habitude, n'y attachent aucune importance; il se sentent plutòt excités par la rumeur, même d'opposition, qui se fait antour deux.

Il est, d'ailleurs, bien vrai que, si l'on admet l'identité du fou moral et du criminel-né, si l'on reconnait l'existence des demi-fous, des gens possédés de folies systématisées (V. vol. II), l'avocat habile, plaidant devant un juge qui fait du libre arbitre le fondement de la pénalité, pourra paralyser l'œurre de

Lombroso e Laschi, Del delitto politico. Fratelli Bocca, 1887. 
la justice, en montrant un malade là oì d'autres voyaient un conpable.

Mais quoi? Devrons-nous falsifier, rejeter le vrai, par ce que la loi, an lien de l'admettre, se sera engagée dans mue fausse roie, par ce qu'elle aura étudié le erime salıs étudier le eoupable? N'est-il pas plus juste, dans cette alternatice, de modifier les lois conformément aux faits, que de falsifier les faits pour les accommoder anx lois, et eela dans l'unique but de ne pas troubler la tranquilité sereine de quelques hommes, à qui il déplait d'aecorder leur attention à ce nonvel élément dont s'est enrichi le champ de nos ètudes?

On patienterait eneore, si les mesures prises en dehors de nos eonclusions et en opposition avec elles, aboutissaient du moins à la séeurité soeiale, but suprème de tont légrislatem. Mais qui ne sait que les pénalistes les plus honnêtes et les plus intelligents, dans la pratique conviemnent que l'œurre de la justice est en quelque sorte un travail de Sisyphe, une immense fatigue qui n'aboutit à aueun résultat, que les moyens suggèrés par les écoles les plus modernes, la liberté provisoire, le jury, la libération eonditionnelle, au lien de diminuer le crime, langmentent bien des fois, on, tout an moins, se bornent a le transformer?

Que penser, également, de ees autres mesures que l'on donne pour le dernier mot de la seience, et qui sont an contraire la plus elaire démonstration du manque absolu de sens pratiqne? Je venx parler, ici, de l'adoueissement des peines appliquées aux réeidivistes (l), de l'impunité acquise aux simples tentatives délietueuses, de l'extension du jury aux affaires correetionnelles.

En peut-on dire antant des eonelusions pratiques sontenues par notre éeole? Dira-t-on qu'elle ne conjure en rien le péril, qu'elle est absurde, quand elle propose de créer des asiles criminels, des prisons pour les êtres incorrigibles, de remplacer la première condamnation a la prison par une amende on un châtiment corporel? Traitera-t-on de même ses projets de loi sur le divoree, sur le travail des enfants, sur l'abus de l'aleool, qui ont pour but de prévenir le viol, l'adultère et le meurtre?

(1) Lucchini et Buccellati. 
Dira-t-on que nous avons tort de demander que le coupable soit astreint à réparer le dommage causé, en raison de sa force et de sa richesse?

Eh! nierez-rous, aussi, que, dans les procès de pédérastie, d'empoisonnement, de meurtre, où les prenves font souvent défaut, l'introduction du critérium anthropologique puisse être d'une utilité bien plus grande qu'un simple trait anatomique, ou qu'une de ces léactions chimirues dont charque annee voit la chute et la résurrection?

Qui peut nier, par exemple, que, dans certains eas, le tatonage, par lobscénité des dessins, par la partie du corps où il a été pratiqué, révèle le crime de pédérastie bien mieux que toutes les lésions anatomiques, comme nous le démontrera ici Lacassagne?

Mème dans les ruestions de droit pur, ces études trouvent une large application. Ainsi, la théorie qui substitue le droit de la défense sociale à la doctrine religieuse du péché, qui remplace le libre arbitre par la erainte des dangers que peut faire couril le coupable, fournit une base solide at la philosophie pénale qui jusque là oscillait, sans cesse, d'un côté à l'antre, sans produire ancun résultat. Prenez, une bonne fois, pour critérium, la crainte du coupable, pour indices, les caractères physirues et moraux du eriminel-ne, et vous anrez la solution du problème relatif à la tentative, anx faits d'inertie coupable suivie de mort, qu'il faut punir ruand il s'agit d'un de ces êtres misérables (Garofalo, Criminologia, 1885).

Vous apprendrez, aussi, par ce moyen, rue les facteurs du crime rariant selon les elimats, la nature des chattiments doit subir une variation analogue, faute de ruoi, la loi, placée en contradiction aree lopinion pulsirne, restera lettre morte. Et c'est bien de lí que résultent ces acruittements qui, au fond, constituent un nouveau code regional en opposition arec le code écuit; c'est bien lá une démonstration pratique, malheureusement trop répétée et fort dangereuse, de l'influence du climat sur la morale. De là vient que les jurès des régions méridionales regardent certains groupes de crimes arec un œil bien différent de ceux du Nord, "Dans la prorince d'Aoste, écrirait Morano, le jury fait plus de cas de la vie que de la bourse; 
dans la rallee de Mazzara, il est plus indulgent pour les attentats à main armée; de là rient que les jurés prononeent les verdicts les plus divers dans les deux régions ».

On pourrait en dire autant du viol, de la camorra et de la matia, qui sont jugés arec beancoup plus d'iudulgence au sud que dans le Nord d'Italic.

En roila assez pour répondre à ceux de mes adversaires qui, sans nier le resultat de mes recherches, prétendent qu'elles ne peurent être appliquées ni aux sciences juridiques, ni aux sciences sociales.

Quant a ceux qui nous accusent, tout doucement, ile rechercher par cette noureauté, les applandissements populaires, ils feignent d'ignorer que les fonles, qu'elles viennent des académies ou des places publiques, ont été et restent toujours les ennemies les plus acharmées de tonte noureauté, et que le progr'ès ne s'efrectue guère qu'aux dépens de son auteur; ils feignent d'ignorer rue nous arons été signalés aux ressentiments des réactionnaires, aux moqueries faciles de petits maitres anx yeux desquels une chose nouvelle n'est bonne que si, toute superficielle, connme la mode, elle n'exige ni fatigue, ni travail sérieux.

Il est, encore, plus étonnant de voir de tels adversaires se domner pour défenseurs de la liberté, sous prètexte qu'ils soutiement le libre arbitre. Je n'ai qu'un mot à leur répondre: Qu'ils jettent les yeux autour d'eux, et qu'ils nient ensuite que la théorie du libre arbitre ne soit la doctrine préférée des ennemis de la libre pensée, et de toute église orthodoxe! Oh! qu'ils nient, s'ils le peuvent, que leurs diseiples se trouvent moins souvent parmi les vietimes que parmi les complices du despotisme!

Mais, quelque peine que je me sois donnee, je ne puis me flatter d'avoir atteint, mème de loin, la solution idéale du problème. Plus j'avance dans la voie que je me suis tracée, plus je ressemble à l'homme qui, debout sur un sommet, voit l'horizon s'élargir devant lui, mais s'effacer, en même temps, les contours de la plaine.

Ainsi, entre le criminel de génie et la foule des malfaiteurs, il y a un interralle qu'il serait bien difficile de combler. La mème distance sépare le monde des escrocs de celui des assassins. 
En outre, étranger à la science du droit, je ne puis me flatter d'avoir entrevu tontes les applications que l'on peut faire de mes recherehes; et je n'ignore pas que la pratique seule consacre les théories.

Mais ces lacunes sont amplement comblées par un certain nombre de revues: les Archives d'anthropologie criminelle, de Lacassagne; la Zeitsch. f. gesammte Strafsrecht, de Liszt; la Rivista sperimentale di freniatria, de Reggio; la Rivista di filosofia scientifica, de Morselli; l'Archivio di psichiatria, scienze penali e antropologia criminale, de Turin; les Archives psychiatriques et légales, de Kowalewshi; le Messager de psychiatrie, de Mierzejewski; le Bulletin de la Société danthropologie, de Bruxelles; la Revue philosophique, de Paris; la Revue scientifique, de Richet. Toutes ces publications signalent au publie les decouvertes faites all jour le jour par ces hommes de talent qui ont bien voulu me venir en aide.

Pour compléter et consolider' encore l'édifice, j'ai à ma disposition une bibliothèque entière: la Criminologia, de Garofalo; l'Omicidio, de Ferri, et ses Nuovi orizanti di diritto penale; l'étude anthropologique et juridique. Sull'aborto ed infanticidio. de Balestrini; l'étude de Marro, Sur les caractères des criminels; Le tatouage, de Lacassague; la Criminalité comparée de Tarde: les Maladies de la volonté, de Ribot; les Sociétés animales, d'Espinas; les travaux anatomiques de Fleseh, de Benedikt, de Sommer et de Knecht; les ouvrages puissantes de Drill et de Roussel sur les jeunes criminels, de Gryau, de Fonillée, de Letourneau sur la morale, ete.

La compagnie de tous ces savants me soutient et m'assure plus que les fatigues que m'a coutée mon œuvre.

Pent-ètre ne restera-t-il, bientôt, de celle-ei pierre sur pierre: mais l'idée qui lui a donné naissance, transmise de main en main et reeonfortée par ces penseurs vigourenx,

..... cursores, qui vitce lampada tiadunt,

(LUCRÉCE)

cette idée ne périra point.

Turin. 10 novembre 1886.

C. LOMBROSO. 


\title{
PREMIERE PARTIE
}

\section{EMBRYOLOGIE DL CRIME}

CIILPITRE PREIIER

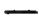

Le crime

et les organismes inférieurs.

\author{
1.

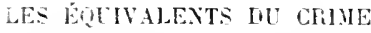 \\ DAYS LFS PLASTES ET CIEZ LES ANMHAX.
}

1. - Iprès qu'Espinas, Letourneau et Vignoli enrent appliqué l'étude de la zoologie aux sciences sociologiques, Cognetti de Martiis et Rabbeno à l'économie politique et Ilouzeau it la psychologie, il était naturel que la nouvelle école pénale, qui suit arec tant d'intérèt les études modernes sur l'évolution, cherchàt ì son tour de les appliquer ì l'anthropologie criminelle et tachât même d'en faire le premier fondernent de cette science. En effet, mon premier essai a cet égard a été suivi immédiatement d'un 
autre de Lacassagne et d'une étude de Ferri qu'on pourrait presque dire complète (1).

De prime abord la tâche scmble très-facile: on dirait même, si l'on se borne à jeter un coup d'ceil superficiel sur ces phénomènes, en se laissant guider par les critères humains les plus communs, que les actes selon nous les plus iniques sont les plus naturels du monde, tant ils sont répandus chez les espèces animales et même dans les plantes, de sorte que nous pourons bien dire avec Renan que " la nature nous offre l'exemple de la plus implacable insensibilite et de la plus grande immoralité v.

Qui ne connaît les belles observations de Darwin (2), Drude, Kohn, Rees et Will sur les plantes insectivores?

Toutes ces plantes commettent de véritables meurtres sur les insectes. Quand p. ex. un insecte, si petit qu'il soit, ne pesât-il qu'un 124 millième de grain, se pose sur le disfue d'une feuille de Rossolis ou Drosera (et il paraît que cela n'arrive pas toujours par pur hasard, mais qu'il y est altiré par l'odeur que sćcrète la feuille), il est presque immédiatement englué dans une sécrétion visqueuse et comprimé par les tentacules nombreux,

(1) Lombroso, Archivio di psichintrin, Torino, 1881, vol. II, fasc. 4. Il delitto negli animali. - Roner, Notions ilenentrives de vetérinaive militaire, Paris, 1847. - Hoczenu, Éturtes sur les frecultés mentates

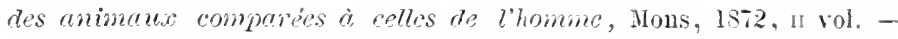
Espins, Des sociétes mimales, etude de psychologie compare.e. Paris, 1878, denxieme édition. - Lacassagne, De la criminalité chez les animaks, dans la Revere scientifique, 14 janvier 1832. - 1D. Lyon, 1852, P. 32. - Romases, Animal intelligence, London, 1882. - FerRI, Dorl'omicidio, 1884. - VIGNoLr, Della legge fondumentale dell' intelligenza nel regno anivede, 1878, Milano.

(2) Darwa, Insectivoroms plants, 1850. - I\%. 0. Drude, Die insertenfressenden Pfonann dans le Hanmuch der Botanik, publie par le pro-

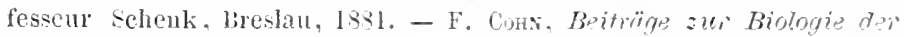

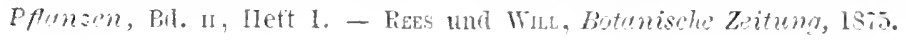


environ 192 par feuille, qui se replient sur lui en 10 secondes et atteignent en une heure et demie le centre de la feuille, qui ne liche point prise avant que la virtime soit morte et en partie digérée, à la fareur d'un acide et d'un ferment tris-analogue à notre pepsino, sécrétés en grande quantité par les glandes et agissant sur les tentacules voisins par un mouvement semblable, selon Darwin, all mourement réllexe des animaux.

Quand l'insecte s'arrête sur un rôté du disque, les tentacules se courbent vers le point d'excitation, de quelque côté qu'il se troure; l'impulsion motrice, partant d'une ou de plusicurs glandes, traverse le disque, se propage jusqu'à la base des tentacules roisins, igit it son tour sur le point d'excitation, augmente la sécrétion des glandes et la rend acide, et celles-ci à leur lour agissent sur le protoplasma.

Dans la Dionea muscipula les contractions des soies meurtrières ne sont provoquées ni par l'air ni par les liquides, mais seulement par les corps solides azotes et humides. En outre les soies entrecroisées laissent échapper les menus insectes qui ne sauraient servir à la nutrition de la plante.

Le Genlised ornate saisit les insectes tout comme font les pécheurs, lorsqu'ils prennent au piège les anguilles.

L'Utricularia neglecta attire les.insectes par des appendices quadrifides; en jouant avec elles, l'insecte s'engage dans une valre élastique qui se ferme derrière lui, et l'emprisonne dans un utricule où il meurt.

Je cite, en détail, ces faits, ou je crois entreroir la première ébauche du crime; car si l'on ne connaissait pas leur dépendance absolue des conditions histologiques, on pourrait soupconner ici la préméditation, le quet-apens, lo meurtre par cupidité, et même jusqu'à un certain point cette liberté dans le choix (refus des 
insectes trop petits et des matières non azotées) dont plusieurs théoriciens du droit se sont avisés, bien à tort, de laire la base de la responsabilité.

2. - L'analogie ressort avec bien plus d'évidence quand on passe an monde animal. Rien que pour le meurtre chez les animaux Ferri (l. c.) a pu distinguer jusqu'i 22 espèces, dont plusieurs analogues aux espèces visées lans nos codes.

linsi le meurtre pour se procurer des aliments; ainsi rncore les maurais traitements ef le meurtre pour avoir le commandement de la tribu, faits qui correspondraient à nos délits par ambition etc. et qui s'ohservent chez les cheraux, les taureaux, les cerl's. - Dès qu'un noureau singe entre dans les cages des jardins zoologiques, les compagnons examinent ses museles et ses dents, afin de roir s'il faut le respecter, ou bien si l'on peut le maltraiter impunément. - Un exemple de meurtre par aridite nous est offert par les fourmis qui élèvent et font paitre des aphides pour en sucer la sécrétion sucrée et qui mème quelquefois préfèrent se procurer ces troupeaux par la rapine en massacrant leurs proprićtaires, comme Forel l'a ru chez la formica exsecta. Nous trouvons anssi des exemples de cannibalisme simple. En dépit du proverbe qui pretend le contraire, les loups se mangent entre eux. Les souris champètres, dès qu'elles tombent dans la trappe, se dévorent l'une l'autre. Les rats en font autant et aussi les dyliscus et les gyrimus. La roracité el le cammibalisme des brochets sont bicn connus. Deux grillons mis dans une cage se dévorent souvent entre eux. Il y a quelques années, au jardin zoologique de Londres, deux serpents boas vivaient dans la même cage; un jour le gardien cut ì peine le temps de sauver le plus petit, déjì à demi avalé par son compagnon. Les marsonins 
a les lapins se divorent entre cux, mêmo quaml on loum donne me nourribure alondamte (Lacassagno).

II y a quelques mois, au laboratoire du professment bizozero un chien, aboutamment noumi, dichimais a devorait son compagnon.

Le Chaclocompa processione el lo Thyalira vivent all rommmn; mais les individus plus lorts derorent les plus lables et ceux qui sont engourdis par une alimentation surabondante; il en est de mème des mantidies, des scorpionides, des fourmis à miel du Méxique. Les fourmi. landis qu'elles ont soin des cadarres de lours anies mortes en combaltant, déchirent ceux de leurs annemics et en sucent le sang. Une marmotte du jardin zoologique de Vienne, ch ayant trouré une antre dans sa tanière la tua el la dérora. Les loirs se divorent l'un l'autre des qu'ils ont faim.

Enfin nous rencontrons chez les animanx le eambibalisme aree infanticide et parricide. Les rêveries str lat voix innce du sang, sur l'anour maternel et filial, sont démenties chez les animaux, ainsi que l'observent Honzeau et Ferri (l. c.), par la simple olserration des faits.

La femelle du erocodile mange quelquefois ses petit. qui ne sarent pas encore nager. Mais il faut noter que chez beaucoup d'animax, comme chez quelques peuples barbares, une mauvaise conformation du corps provoque la honte et le mépris. J'ai vu une poule dont plusieurs poussins étaient nés chétifs et estropiés abandonnel un jour son nid avec les poussins plus robustes, sans se préoccuper. des paures petits qui restaient.

Comme certains oiseaux brisent leurs ceufs et detruisent leurs nids quand ils s'apercoivent qu'on y a touchí, de même il y a des rongeurs, la femelle du rat p. ex., qui dérorent leurs petits quand leur nid a été dérangí. 
Parmi les singes, les femelles des Ouistitis mangent quelquefois la tète à un de leurs petits; elles écrasent aussi leur's petits contre un arbre quand elles sont lasses de les porter.

Parmi les chats, les lièvres, les lapins, il en est qui mangent leurs petits. Nême chez la femelle du chien, dont l'instinct semble pourtant plus accessible aux affections domestiques, on observe quelquefois le cannibalisme infanticide. - Le cannibalisme et le parricide se rencontrent chez les renards "dont les jeunes sentremangent souvent at quelquefois mème dévorent leur mère » (Bren, ). 
II.

\section{LE VGRITABLE EOCIVALENT DY GRIME}

ET UE LA PEINE CIIEZ LES ANIMAIY.

Cependant si nous presentions comme de véritalıles crimes ces meurtres commis par des animaux, de même que le vol habile et par association chez les singes, le rol domestique chez le chat, chez la pie, l'enlèvement de mineurs chez les fourmis rouges, la substitution du petit chez le concon qui dépose son œuf dans le nid du moineau, et, pour mieux tromper celui-ci, enlève quelques-uns des cufs qui s'y trouvaient; cela ne semblerait guère sérieux; car on concoit aisément que ces aetions, qui nous paraissent des méfaits, sont au contraire les résultats nécessaires de l'hérédité, de la structure organique, ou sont imposés par la concurrence vilale (meurtre des bourdons), par le clioix sexuel, par la nécessité sociale d'empêcher les discoldes (meurtre des chefs) et par le besoin d'aliment chez les animaux trèsroraces, tels que les loups, les souris, on bien par les guerres qui en dérivent et forcent les animaux à se conduire comme nous le faisons nous-mêmes alors que nous combattons des ennemis - ou quand nous nous permettons de manger les poules et les bœufs sans craindre le moins du monde d'être pour cela incriminés. Même quand ces actes tendent à la destruction de l'espèce, on doit les considérer comme entrant dans les habitudes de celle-ci, tant ils sont commis sur une vaste échelle. Cependant ils servent à nous démontrer la vanité de l'idée absolue de justice et nous aident à comprendre pourquoi les ten- 
dances criminelles renaissent si obsinément au milieu inême des peuples les plus civilisés, nalgré les obstactes toujours croissants qui leur sont opposés, et pourquoi elles renaissent sous des formes qui rappellent les phufirouches parmi les espèces animales. Il nous expliquent. aussi, pourquoi dans l'antiquití on condamnait selon toutes les formes juridiques les animaux nuisibles on profanateurs des choses sacrées pour l'homme (1).

P'our se rapprocher un peu plus du criminel humain, envisagé sous un point de vue qui n'est plus celui de nos bons ancêtres du moyen-âge, il faut considérer surtout les animaux domestiques et ceux dos animaux saurages qui rivent en groupes, formant (commo dit Expinas) ces sociétés animales, qui offrent les promicrs éléments des sociétés humaines el en présentent aussi toutes les monstruositis.

L'éducation imposée par nous el transformée par l'hiridite en instinct, les hesoins et les rapports de la rie

(1) La loi mosaique (Exone, xxi) condamnat al la lapidation le borkt qui avait eansé la mort d'un lomme; et si le fait se répetait, le prom priétaire lui-même itait lapidé. Au moyen-âge on condamnait les animanx lomicides ou nuisibles à l'agriculture (Lacissane, l. c.). Toutefois sous François $I^{r}$ on leur donnait 111 avocat. En 1356 à Falaise une truie qui avait dévoré nue enfant fut condamne à mourir de la main du bourrean. L'évêque d’:ntun excommunia des rats qui araient ronge des objets sacrés. Benoist Saint-Prix enregistre so condamnations de ce genre qui avaient frappe tontes sortes d'animanx, depuis l'ane jusqu’ì la cigale. Lal municipalité de Turin achetait du Saint-Siege (par l'intermediaire de lambassadeur) me malediction contre les chenilles; et l'evêque, en grande pompe et assisté dı maire et res assesseurs, la lançait du haut d'une estrade clevée sur la place du châtean. Les procès de ee genre étaient aussi frequents. A Verceil il $s$ ent un long debat sur la question de savoir, si certaines chenilles devaient être jugees par le tribunal civil ou par les tribunaux ecclesiastiques, parcequ'elles avaient endommagé les vignes de la paroisse. Voil Lessom, I nemici del vino, Loescher édit., 1880, Turiu). 
en commun, tout cela a engendrio dos haloitudes spireiales anxquelles les individus ne manquent que dans des cilconstances exceptionnollos, tout comme il arrice do mos rerimincls.

2. - Criminels nes aves des amomalies dil crime. - Uno tendinne crinunelle trè-remarquable, duesins foute à des altiontions congranitales du corvean, se lencontre cluez los especes domestiques les plus dociles. linsi, parmi les cheraux de tronpe, on on lloub quelques-uns, lubelles à la discipline, rui lont to sontraire de ce qu'on leur commande, et conservent m souvenir très-rif des matrais traitements, n'oubliant pas, des mois entiers, coux yui les oni liappís. Ils ont beaucoup d'intelligence, mais ils en abusent pour soustraire à leurs compagnons lem portion. (guelques-uns (roir Rodet: Nolions élimentaine de vélirimaire), sont trailres el ne laissent échapper aurune occasion de faire du mal à l'lomme ou à leus compagnons, sans la moindre provocation; et néanmoins ils se tiennent à merreille dans les rangs.

Contrairement à ce qui arrive pour l'homme, il n'y at eu jamais le moindre doute parmi les vétérinaires que tes maurais instincts ne fussent déterminés par une organisation vicieuse du cerveau; on reconnaît même ces clıevaux à la forme du crâne, au front étroit et furant comme chez le lièrre, particularité qui leur a valu le nom de chevaux a nez busque. Et l'on est tellement conraincu de la transmission héréditaire de ces maurais instincts, que les arabes en tiennent note a part et n'admettent pas dans leurs harás les descendants des chevaux qui en sont affectés (Cornerin).

On observe semblable chose chez les éléphants. Colui qui par bizarrerie s'éloigne de son troupeau, 
celui qui est échappé à l'esclavage, est obligé de mener une vie solitaire. Il peut paitre près du troupeau, visiter les mèmes lieux, boire à la mème source, il peut suivre les autres; mais il doit toujours se tenir a une certaine distance et il n'est jamais vraiment admis dans la famille. S’il s'avise d'y pénétrer, les coups pleurent sur lui de toute part; mème la femelle, qui est d'un naturel plus doux, le frappe de sa trompe. Les indiens appellent ces éléphants Gundah, ou, s'ils sont méchants, Rogres. On les craint généralement. Tandis que le troupeau suit tranquillement et en silence son chemin, evite l'homme et ne l'altaque que dans le cas de nécessité extrème, tandis qu'il respecte mème la propriété, les Rogues ne connaissent pas ces égards. Lenr vie solitaire, contre nature, les aigrit et les rend furieux. On organise contre eux dans les Indes des chasses spéciales, et personne n'en a pitié. (Lacassagne, l. c.).

3. - Meurtres par antipathie. - Quelque difficile ru’il soit d'isoler les différents motifs psychologiques qui poussent au crime - car le crime est rarement provoqué par une seule passion distincle - il l'aut reconnaitre toutefois que, mème chez les animaux, l'antipathie entre les espèces différentes on entre les individus de la même espéce conduit souvent a la violence et quelquefois an meurtre.

Il y a des femelles qui ont une aversion invincible pour les individus de leur espèce et de leur sexe. Cela s'observe, par exemple, chez les singes anthropomorphes et surtout chez les Orangs-outans, dont les femelles traitent leurs semblables avec une animosité instinctive, les battent et arrivent mème jusqu'à les tuer. (Houzeau, 2). 
Jack, le bon et pacifique guépard de Brehm, devint furieux par pure antipathie, quand on le mit à coté d'un léopard, et l'on dut les sćparer pour qu'ils ne se tuassent pas l'un l'autre ( 11,141 ). Parmi les Paradoxures quelques-uns vivent en paix avec leurs semblables, tandis que d'autres se battent entre eux jusqu'it la mort.

Dans ses voyages en Perse, Lessona fut averli un jom de ne pas s'approcher avec son cheval de celui de son compagnon, parce fu'ils itaient ennemis. Il voulut s'en convaincre; et en effet son cheval, qui était pacifique avec tous les autres, devint furienx, dès qu'il se trouva à coté de son adversaire, et chercha ì le frapper.

4. - Vieillesse. - On sait que chez les hommes la vieillesse détermine l'égoïsme ot la dureté du coeur. Les animanx aussi, avec l'àge, deriennent ombrageux, hargneux etc.; pour cela mème ils sont souvent chassís par leurs compagnons, et alors, dans l'isolement, ils deviennent de plus en plus méchants. Cela s'ohserve, selon Brehm, chez les bouquetins, les chèrres saurages et les éléphants. Ces derniers deviennent alor's tris-dangereux, car, dominés par une espèce de frénésie, ils sont portés a poursuivre l'homme ou les animaux pour les massacrer. (Pierquin it; Ferri p. 41).

Une chatte d'Angora avait toujours été tendre envers ses petits; en vieillissant elle devint laide et fut négligée et maltraitée par les domestiques; son caractère s'en aigrit, elle refusa le lait à ses petits et en dévora un.

5. - Accès de rage. - Le 4 août 1833, un dimanche, vers 2 heures de l'après-midi, une femme conduisait une vache dans la rue Montmartre. Tout-à-coup la vache est prise d'une fureur épouvantable et se lue contre 
tout ce qu'elle rencontre. Elle blesse et tue un grand nombre de personnes, renversant à droite et à gauche rous les obstacles, jusqu'à ce qu'un coup de fusil vienne l'atendre roide norte. (Perocix II, 505).

6. - Il laut peul-ôtre reporter à ces mênes catégolies les cas assuz fréquents, ou tes animaus, tout comme Jos hommes, tuent leurs semblables sans aucun motif, dorogeant aux habitudes de la plupart d'entre enx et nuisant aux interrêts de l'espèce.

Cela ressmble absolument à ce que les anciens julistes nommaient méchanceté brulale (nequitas efferata); carr a cet egard Zanetti a tort d'affirmer que « les animaus de la mône espèce ne se battent entre enx que pour des causes instantanécs comme pour se disputer la nourlutue ou la possession des femelles, et jamais par haine implacable et innée ».

Tres-sourent les animaux sont pris d'une fureur belliqueuse que rien ne justifie, n'explique ni ne modère, et cela sans aucun motif extérieur, sans la moindre provocation. Nos animaux domestiques, surtout le chien, en offrent des exemples fréquents. Gall raconte qu'un barbet, trés-aimé de son maitre qui le nourrissait abondamment, cherchait partoul, dans les rues, l'occasion de se battre. Tous les jour's il rentrait avec de nouvelles blessures. On essaya de l'enfermer pendant des semaines entières: à peine remis en liberté, il se jetait sur le premier chien qu’il rencontrait, et luttait jusqu'à ce qu'il l'eût vaincu ou qu'il fùt mis lui-même hors de combat.

Les hamsters se mordent et se tuent entre eux par pure méchanceté. Chez les cerfs, on roit des màles qui maltraitent les femelles sans aucun motif. (FErRi l. c.). 
7. -- Delits per passion. - Dans d'antres cas la lendance an erime est délerminio, comme chez liomme, done manière irrésistille, par les passions smescitios, surlout par l'amour, la cupiditi el la haine. Les dromadaires, dit Ronsse, qui pourtant sont si paticnts, fimissent, quand on les agace, par levenir furienx a foulent aux pieds colui qui leur a fait du mal; mais dis quils croient avoir assouvi leur rengeance, ils redevionnent paisibles. Aussi les drabes ont-ils l'habiude en pareil cas d'òter leurs hahits of de les jeter a l'animal pour quil reverse li-dessus sa fimemr, aprés quoi il reprend tranquillement son travail. (Bucuner, c. III).

dinsi les fourmis ne dévorent pas lem's aphides, mène quand elles manquent d'autre aliment. Mais Lenret raconte le cas d'une fourmi rui, impatientée par la résistance d'une de ses aphides, la tua et la dévora.

Le délit par emportement furienx ost très-fréquent chez les foumis amazones de l'espece Formica mubartis: Il arrive souvent apres le combat que les gnerrières soient prises d'une véritable fureur qui les pousse a mordre aveuglement tout ce qu'elles trouvent autour d'elles, les larves, les compagnes et jusru'aux esclaves qui cherchent a les calmer en les saisissant par les pattes et en les tenant immobiles jusqu'i ce que leur fureur ne soit passée. (Forel, Les Foumis, 1874). Dans la saison très-chaude les esclaves noir-cendrées (Formica fusca) des fournis amazones, lasses d'ètre poussées par leurs rnaitresses qui leur demandaient continuellement à manger, les prenaient par une jambe et cherchaient à les tirer hors du nid, les mordaient mème quelquefois; mais souvent les maitrosses irritées saisissaient les rebelles par la tète qu'elles serraient toujours plus fort entre leurs mandibules jusqu'a les tner. (Idem). Voilá un líger délit pour les fourmis, comme laurait jadis été pour 
une matrone romaine le meurtre d'une esclave; toutefois cet acle portait préjudice à l'espèce même, en la prirant d'une assistance puissante; et en étant aussi contraire à leurs habitudes, il derrait constituer un crime dans la jurispludence des fourmis.

Tout le monde sait que l'éléphant proportionne sa rengeance à l'injure; qu'il inonde, souille de bone ou foute aux pieds celui dont il a ḋ se plaindre, selon la gravité de l'offense. Récemment un éléphant lua d’un coup de sa trompe le cornac qui lui avait donné du tabac. - Un ours que j'avais légèrement frappé sur une patte cherchait à me saisir et n'y réussissant pas mordait sa patte et la grille de la cag̣e où il était renfermé.

Un chien, obligé à partager sa pitance avec un pore, le prit en aversion, brisa sa chaine, se jeta sur lui et lui déchira le ventre.

On observe aussi des meurtres causés uniquement par la peur. - Brehm raconte qu'au Prater de Vienne, parmi un grand nombre de cerfs, il y en avait un, très-apprivoisé, qui se promenait au milieu de la foule en quête de friandises et de caresses. Un jour il s'engagea avec ses bois dans une chaise et s'effraya tellement qu'il se mit à fuir en blessant et tuant plusieurs de ses compagnons.

8. - Douleurs physiques. - Une autre cause fréquente résulte des douleur's pliysiques. Il suffit pour s'en convaincre d'assister au spectacle donné en public avec le microscope geant. Les aselles, les crelopes, les daphnies, aupararant si pacifiques, deviennent féroces, à mesure que le milieu s’échauffe, et se inordent les unes les autres.

9. - Meurtres par amour. - Mais peut-être chez los animaux, comme chez les houmes, les crimes par pas- 
sion les plus fréquents sont ceux qui ont pour cause l'amour. Ainsi l'éléphant, si prudent d'ordinaire, entre en fureur à la moindre excitation, quand il est en rul. - Chez les gallinacos polygames le besoin de la reproduction supprime tous les autres besoins et émousse les sens; ils semblent sourds et aveugles; ils attaquent l'homme. (Breun, 399). Le serin mâle des Canaries ditruit sourent en pareil cas son propre nid, et disperse les oufs (Iloczeau II, 394); il tue la femolle, et pour le dompter il faut lui en donner deux. - Le coq cédron, quand il est amoureux, devient furieux et se jette même sur l'homme. (Breirs, 320).

Cornerin raconte fu'une jument, docile d'ordinaire, devenait intraitable pendant le rut et manqua une fois de lui casser un Jras.

Une chatle d'Ingora, excessirement féconde et atteinte de nrmphomanie, aimait avec frénésie ses petits, comme la plupart des animaux domestiques; mais toutes les fois qu'elle était grosse, elle les prenait en arersion, les battait et les mordait quand ils folâtraient autour d'elle.

Burdach et Marc comparent la fréquence des infanticides sans motif chez les accouchées aux tendances homicides qu'on observe chez les vaches et les juments nymphomanes, non seulement à l'époque du rut, mais aussi longtemps après.

Au jardin zoologique de llambourg un kanguroo tua sa femelle et son petit dans un accès de fureur érotique. - Le chameau en rut devient très-méchant et mord tout le monde, même les fenclles. - Dans quelques espices d'araignées la femelle qui est plus grosse tend des pièges au mâle et le tue après l'accouplement.

Ifuzard fils fat mention d'une jument dont la fureur utérine ne se manifestait que de temps en temps arec do longues trères. Très-docile dans les interralles des 
accès, elle devenait intraitable pendant l'érétisme qui durait souvent un jour on deux, quelquefois mème trois.

Rice a vu un troupeau de huflles qui après avoir flairé le sang d'un tigre blessé en suivirent avec furem les traces, parcoururent et dévastèrent la forêt, fouillèrent la terre, et enfin, arrivés au dernier paroxysme de la fureur engagèrent entre cux le combat, malgré les eflorts te lemr gardien. (Brenu, 11, jy).

On observe aussi chez les animanx, des adultères, quelquefois suivis, comme chez les lommes, dn meurtre de l'époux.

Charles Vogt raconte que depuis quelques annćes un couple de cicognes faisaient lem nid dans un village près de Salette. Un jour on nota que quand le mile était à la hasse, un autre, plus jeune, venait courtiser la femelle. D’abord il fut repoussé, puis toléré, puis aceueilli; et i la fin les deux adultères volírent $m$ matin sur la prairie ou le mari chassait aux grenoulles, et le tucrent ì coups de bec. (Figuier, Les oisemu, 1877).

Hène la colombe, linnocente colombe, est quelquefois adultere et envieuse et méchante envers ses compagnes devant lesquelles elle cache sous ses ailes l'aliment dont elle n'a pas besoin. - Qnand on enlève à un mille sa colombe, il vole aux colombiers voisins et force les femelles des autros à le suivre.

10. -...- Atglomérations. - lei je noterai une autre analogie arec les causes des cimes chez les hommes: ce sont les grandes agglomérations.

Linstinct amoureux non satisfait, comme cela arrive dans les icuries, dans les itahles, dans les sociétís d'hyménoptères, chez les gallinacés domestiques, pousce ces animanx aux plaisirs contre nature. 
Un crime comparable, pour les conditions organiques, au viol sur des mincurs, ou mieux encore a la blessure grave suivie de mort, a été obscrvé par lluber chez les fourmis mâles. Quand elles manquent de femelles, clles violent les ouvrières qui, ayant des organes sexuels atrophićs, en souffrent gravement el en menrent. (Huber, Sur les abeilles, t. 11, p. 443). - Un exemple plus frappant encore a été observé par Houzcau: un coq viola un jeune poulet mâle qui en resta souffrant pendant plusieurs jours (II, 291).

Lessona a vu en Egypte, dans les clos oủ l'on renfermait pendant la nuit plusieurs ànes ensemble, ces animaux commettre des actes sodomiques, quand les femelles leur manquaient.

An musée de Turin on conserve encore deux mélolontes màles accouplés et momifiés (Cauerano).

Les vaches taureliennes sont ainsi nommées parcequ'elles remplacent le taureau auprès de leurs compagnes. Dans les grands poulaillers, oủ les mâles sont peu nombreux, la poule se comporte souvent comme un coq: de même, on observe des actes semblables entre les mâles dans les grands haras où les juments font défaut (SCARcey).

Un délit, analogue à la bestialité chez l'homme, est l'accouplement du cygne avec l'oie, de l'élan ou du bison avec la vache, accouplement qui donne des produits stériles et qui constitue des actes nuisibles aux deux espèces. (Hovzeau, iI, 295). Houzeau a vu des chiens s'accoupler avec des louves et mème un chien épris d'une tigresse. Aux environs de Turin on voit souvent des crapauds répandre leur sperme sur les ceufs des grenouilles qui habitent les mèmes marécages. (Lessona).

Ainsi Espinas (Sociétés animales, p. 380), parle de mules qui, pour obéir à un instinct morbide de ma- 
ternité, savent par des artifices soustraire des poulains á leurs neères, se font suivre d'cux; et, ne pourant les nourrir, les laissent mourir de faim, en commettant, ainsi, un rapt de mineurs suivi d'infanticide.

Les perroquets, bien que frugivores d'ordinaire, se jettent quelquefois sur leurs compagnons et leur vident le cerveau avec le bec. (Brenu, il, 42).

Brehm (IV, p. 694), raconte que les cigognes massacrent souvent les petits de leurs compagnes sous leurs yeux, de même qu'elles tuent les membres de la tribu qui au moment de l'émigration se refusent à les suire ou sont incapables de partir. Il ajoute que si, parmi ces oiseaux, il en est qui tolèrent le voisinage de leurs semblables, et s'y complaisent même, il y en a d'autres qui ne veulent les roir pas mêne de loin.

11. -- Association de malfaiteurs parmi les animaux. - Les castors sont ordinairement doux et sociables. Toutefois Figuier raconte que trois castors sétaient établis ensemble dans un endroit convenable au bord d'un fleuve et y araient bâti leur édifice, tandis qu'un quatrième vivait solitaire. Ils allèrent un jour le trourer et en eurent un accueil hospitalier. Mais quand le solitaire vint leur rendre la visite, ils le tuèrent.

On lit dans Gioia qu'un petit chien, maltraité par un dogue, amoncela pendant plusienrs jours de suite des os dans la cave de la maison, après quoi il invita au banquet quantité de chiens du voisinage; quand ils furent bien repus, il les excita à le renger de son ennemi et atteignit son but (Groma).

On voit, ici, que chez les animaux domestiques et chez ceux qui vivent en troupes se dessinent déjà les germes de l'association de malfaiteurs, phénomène qu'on croirait essentiellement propre it l'espece humaine; et ces 
germes sont éridemment déterminés par les grandes agglomérations. En roici d'autres preures:

L'amiral Sullivan racontait à Darwin, qu'il arait transporté un jeune étalon anglais et lunit juments dans les îles Falkland, où se trouraient déjì deux étalons sautvages, clacun aupres d'un petit troupeau de juments. Ces deux étalons, qui ne se rencontraient jamais sans se quereller, cherchèrent d'abord à combattre, chacun en particulier, le cheral anglais et à chasser ses juments. Ny ayant pas rénssi, ils s'associèrent ensemble et vainquirent l'intrus.

Un fait semblable a été observé an parc de Chillingham; plusieurs bœufs sauvages s'y disputaient la suprématie; un jour on vit deux des plus jeunes boufs attaquer de commun accord le vieux chef, le renverser et lo laisser roide sur le terrain, si bien que les gardiens le croyaient mortellement blessé. Mais quelques jours après l'un des deux jeunes bœufs s'approcha seul du bois oủ était tombé le vaincu; et voila que celui-ci, qui arait couvé sa rengeance, sort du bois et tue en peu de temps son jeune adversaire.

12. - Escroquerie. - De même que l'association de malfaiteurs, l'escroquerie ne se manifeste qu'au milieu des grandes agglomérations d'animaux domestiques, el seulement parmi les plus intelligents, tels que les chevaux de troupe, les singes et les chiens apprivoisés.

Nous ne pouvons oublier, dit Lacassagne, qu'il y a des cas authentiques de simulation et de tromperie, ¿̀ laquelle certains animaux recourent pour íviter une faligue ou pour se procurer un avantage. 
Ainsi, dit-on, il n'est pas rare de rencontrer dans les écuries militaires des chevaux qui feignent de boiter (1) pour ne pas aller à l'exercice. (Lacassagne).

La Coste raconte qu'un chien, pour détourner ses compagnons d'une certaine place au coin du feu, où il aimait à se coucher, allait faire un vacarme effroyable dans la cour, et tandis qu'ils accouraient en masse, reprenait tranquillement sa place favorite.

Un chimpanzé malade avait élé nourri avec des gàteaux; quand il fut rétabli, il faisait souvent semblant de lousser pour se procurer ces friandises. (Lombroso, Uomo bianco, Padova, 1871).

On lit dans la Revue scientifique, 1884, l'histoire d'un chien qui avait été habitué à aller s'acheter chaque jour lui-mème un gàteau en déposant un sou à la boutique. Mais un jour, au lieu de monnaie, il laissa un bouton métallique, et sans attendre qu'on lui donnat le gàteau, il le saisit lui-même et s'enfuit. Le lendemain son maitre voulut bien lui donner le bouton pour monnaie, mais il le lefusa.

13. - Vol. - Le Cercopithecus monas est un véritable filou. Tout en recevant vos caresses, il glisse ses mains dans vos poches, vous vole et cache les objets volés dans les draps, dans les couvertures (Breun).

Un glos chien à Rennes (2) était soupconné de voler et de nanger des moutons; mais son maitre le niait,

(1) Ce même fait m’a étè attesté par X. le capitaine Aglieri, vétérinaire militaire, et pas .1 . Arachequesne capitaine de cavalerie. Cependant MII. Jes professeurs Lessona et Lombardini, auxquels j’ai communiqué les éprenves de ce chapitre, dontent fort de l'exactitude du fait.

(2) Ce fait anssi est jugé peu vraisemblable par Albrecht, Lessona, Lombardini, et j'en laisse toute la responsabilité à M. Rousse, en observant tontefois que le fait pent vrament s'être produit par une de ces conditions individuelles fort rares (gínie), qui se rencontrent bhez les animaux domestiques comme chez l'homme. 
paree qu'il ne lavait jamais trouvé sans museliće. Une fois il le surveilla attentivement et vit quau tomber de la nuit il détachait de lui-même sa muselière et après aroir dévoré sa proie, se lavait le museau dans l'eau, se rrmettait la muselière el retournait vite au chenil. (Rousse, l. c.).

Ce serait bien là un exemple de vol avec préméditation el en opposition avec les résultals désormais héréditaire: obtenus par l'éducation chez ces espèces domestiques.

In fait semblable s'observe chez l'abeille, le plus laborieux des animaux: quelques tribus s'adonnent peu à peu au rol et deriennent sourent de véritables criminels d'habitude.

Buchner dans sa Vie psychique des bétes parle des abeilles voleuses qui, pour s'épargner la peine, attaquent en masse les ruches bien fournies, font violence aux sentinelles et aux habitants, pillent les ruclıes et en enlèvent les provisions. Après avoir répété ces entreprises, quelquefois sans succès, elles prennent goût au pillaggo et à la violence, dont elles font, comme dans les pays où règne le brigandage, une véritable propagande; elles recrutent des compagnes toujours plus nombreuses, et finissent par constituer de véritables colonies d'abeillesbrigandes. Il y a aussi des individus isolés qui viven de rapine et cherchent à s'introduire inapercus dans les ruches étrangères; leur allure timide prouve qu'ils sont forcés de se cacher et qu'ils ont conscience de leur méfait.

On a vu les babouins s'associer par centaines pour mieux piller les vergors d'accès difficile: le plus âgé el le plus rusé, après aroir étudié le terrain, s'avance le premier et laisse une sentinelle au point le plus menacé; puis ils se disposent en chaîne et se transmettent l'un à l'autre la proie que le dernier de la chaîne dépose dans une cachette commune; quand la sentinelle 
aperçoit quelque danger, elle donne le signal, la chaine se rompt, tous les babouins fuient, portant chacun un fruit dans la bouche, en main et sous les bras. Si le danger augmente, ils jettent d'abord le fruit qu'ils portent sous le bras, puis celui qu'ils ont dans la main et en dernier lieu celui qu'ils tiennent dans la bouche (Frankin).

Nais it faut remarquer, à ce propos, qu'on n'observe pas chez les animaux la différence trouvée par Spencer (Revue philosophique, 1881) pour le penchant au crime lans les socićtés printitives, qui y sont plus enclines si elles sont guerrières et moins si elles sont industrielles. Souvent, en ellet, on rencontre $m$ instinct criminel très-prononé chez la fourmi, chez l'abeille ct chez l'éléphant, qui pourtant représentent dans le monde zoologique de vériables sociétés industrielles.

14. - Boissons rlcooliques etc. - Une autre canse de crime, commmne aux hommes et anx animaux, est l'usage des boissons alcooliques et d'autres substances qui irritent les cellules nerveuses. Les animaux intelligents montrent plus de penchant que les autres ì ce vice et ell deviennent, comme les hommes, plus portés aux actes criminels. Ainsi nous avons parlé des abeiltes voleuses par penchant naturel.

Or, Buchner dit qu'on peut produire artificiellement de ces abeilles voleuses a l'aide d'un alinent consistant en $\mathrm{m}$ mélange de miel et d'ean de vire Comme l'homme, les abeilles prennent bientòt goùt à cette boisson qui exeree sur elles la neme influence pernicieuse: elles deviennent irritables, irrognes, et cessent de traviller. La laim se fait-elle sentir? elles tombent, comme l'homme, d'un vice dans un antre el se livrent sans serupule an pillage et an vol. 
Les foumis narcotisces par le chlorotorme ont tont le corps paralysé, sauf la tèle arec laquelle elles mordent tout ce qui vient ì lem porlíe. (Foret, Les (ourmis).

Les pasteurs d'. Dbyssinie avaient observé que les chèves mangeaient la fève parfumée d'un arbre de leurs montagnes; apres en avoir goùté elles devenaient plus vives, plus animies: elles folitraient dans les rochers, se poursuivaient l'me l'autre et se livraient quelquefois à des lntles acharnées. L'homme goula de ce fruit et troura Io calé. (lloczeau, II).

On sait que dans la secte des Assassins d'orient la fureur homicide était excitéc par un mélange de graines le chanve et d'opium. Awsiter ent l'occasion d'observer "e même phénomène dans les vaches. (Pierocix).

Magnan a vu les chiens les plus dociles derenir méthants apres un usage contimu de boissons alcooliques. Moi-mème j'ai observé un fait semblable chez des roqs rmpoisonnés avec du maïs gaité, tandis qu'auparavant, itant nourris avec du maïs bien conservé, ils élaient très-pacifiques.

15. - Aliments. - C'ne autre cause commune du penchant au crime chez l'homme et chez les bètes est l'usage de la viande. Xon seulement les carnivores sont los plus féroces de tous les animaux, mais encore les animaux d'un naturel doux, tels que le chien, l'éléphant, deviennent indomptables et cruels lorsqu'ils sont nourris de substances animales.

Les ćléphants dits mustof, employés dans les Indes orientales comme bourreaux, sont expres nomris de chair (JACOLLIOT, I, p. 225 ).

A Alfort des chiens et des chevaux sonmis à un pareil légime, devinrent féroces. 
16. - Education. - Comme chez l'homme, une éducation spéciale, un dressage, peut développer des instincts criminels chez des animaux qui n'en ont pas naturellement. L'homme a sourent dressé les animaux au meurtre: les Indiens l'ćléphant, les Ilotentots le bœuf. Borecillo, le chien des Francais à saint-Domingue, qui dévorait les Indiens el recerait la paie de trois soldats, est devenu célèbre. Dans ces cas cependant le crime serait plutôt de l'homme dresseur que de l'animal dressé par lui (Lacassagie, I. c.).

17. - Cette série d'actes a éridemment beaucoup plus d'affinití avec ceux que l'homme civilisé appelle des crimes; clle s'en rapproche par ce pliénomène, que je pourrais appeler de l'individualité, en opposition ouverte avec les luabitudes plus générales, innées et acquises, que l'on trouve dans la même espèce; elle s'en rapproche encore par le fait que ces actes nuisent à l'espèce ou à l'individu même, comme les vengeances violentes des fourmis contre leurs compagnes ou contre les aphides, le meurtre de la femelle ou des petits, la sodomie.

Quand on réfléchit (comme dit très-justement M. Ferri) que sur cent chiens, cheraux ou éléphants, ce ne sont pas tous ces animaux, mais seulement un ou deux, qui se montrent méchants, querelleurs, indomptables; que sur cent chats il y en a bien peu qui négligent ou tuent leurs petits et on ne peut nier que cette perversité ne soit due à une tendance toute personnelle et inconnue aux autres individus de la même espèce auxquels, grâce à leur tempérament individuel, le meurtre de leurs semblables répugne tout autant qu'il plait aux premiers.

Il y a aussi un rapprocliement à faire quant à la forme du crime, comme par exemple dans la préméditation 
avec guet-apens (chicns roleurs et singes) et dims lit tendance all vol des abeilles qui, une fois acquise, se perpétue ensuite et s'étend arec l'impunité, prenant le caractère du crime habituel et présentant a la fois la première ébanche du brigandage; par contre il y a encore un rapprochement dans l'instantanéite d'autres actes, déterminés par' des caluses violentes, instantanéité qui est propre aux délits produits par la passion, par le point d'honnemr, par l'antipathie, etc.

Mais l'analogie la plus frappante est celle des causes qui rues à grands traits paraissent les mêmes chez la bête el chez l'homme: elles sont la rengeance ou l'amour, l'açglomération, l'usage d'aliments spéciaux, de la viande, de l'alcool, ou encore l'hérédité.

Ce qui paraìt ensuite de la plus hante importance, co sont les cas ou le erime et la folie, tout comme nous allons roir chez l'homme, se confondent d'une manière inextricable. Tel est le cas ou l'on voit les tendances criminclles naìtre soit inopinément après les couches, dans la vieillesse, soit dès la naissance, gràce à l'hírédité et surtout par suite d'une conformation vicieuse du crâne qui est précisément la cause la plus fréquente du penchant inné au crime (microcéplaalie frontale des chevaux), en donnant lieu, chez les bêtes aussi, à une perversité sans motif extérieur et en contraste complet arec le caractère des autres individus de lem espèce.

18. - Météores. - Peut-être une étude plus longue et dirigée par une main plus habile permettra-t-elle de décourrir d'autres analogies; comme par exentple l'influence des conditions atmosphériques, qui est si grande chez les hommes. Du reste quelques obserrateurs ont déjà signalé le fait que les animaux de la mème espèce on d'espèces roisines sont plus féroces 
lans la zone torride que dans les régions moins chaudes de l'Amérique (Rousse 1. c.) et que les lions de l'Atlas sont beaucoup moins redoutables que ceux du désert. On sait anssi que dans la saison la plus chaude, surtout a l'approche d'un orage, les boeufs sont quelquefois pris d'un véritable accès de furemr, durant lequel ils s'élancent contre les personnes et contre les arbres, jusqu'i ce que l’orage éclate ct qu'une pluic torrentielle vienne les calmer.

19. - Misonisme. - Lhorreur de la nowveauté.Pent-itre, comme nous le verrons chez les peuples barhares, une autre cause de délit est-elle fournie aux animaux intelligents par l'antipathie qu'ils tŕmoignent four tonte nouveauté qui les surprend ct les effraie et que probablement ils considèrent comme une offense personnelle, pent-ètre mème comme un attentat. Bret Ilarte a sonvent observé chez les chiens un véritable fanatisme conservateur: ils aboyaient el s'acharnaiont contre les chemins de ler, le gaz, la musique, quand ils les rencontraient pour la première fois. Certains rhevaux, haloitués à être montés par des officiers en uniforme, se cabrent et jettent at terre leur cavalier s'il n'a pas an moins mne casquelte militaire. Un singe couvert d'un habit de femme, une poule blanche vernie de vert furent repoussés rudement par leurs compagnons qui auparavant leur tómoignaient de l'amitis. (Revue Sciontifique, 1884).

20. - Nous avons vu des analogies fort curicuses dans la conformation du crine. Il se peut bien qu'une étude rxacte des individus nous révèle une dilférence dans la physionomie; et ici je rappellerai que les especes les plus 
féroes ont souvent une plyssionomie spriciale qui présente en germe quelque analogie avee celle des criminels: ainsi l'œil injecté de sany dı ligre, de l'hyène, est rraiment propre aux assassins. "Les oiseaux de proie, dit Brehm (N. 5), ont le bec court, recourbe, la michoire supérieure sourent munie d'une dent pointue ¿ laquelle correspond dans la michoire infírieure une entaillure; l'orbite grande (comme chor les criminels), "t injecté de seng ". Chez les inscetes, auxpuch manque la physionomie par suite de l'immobilití de la face, la force des mandibules désigne les espéces qui vivent de proie, et nous rerrons que c'est lì un caractire des criminels.

21. - Quoipu'on s'efforce d'établir des distinctions, il faut bien l'arouer: il y a une continuité, un passage insensible de plusieurs de ces actes que nous appelons crimincls at ceux qui ne constitueraient un erime que pour thomme. Ainsi les vols des singes, les vengeances des chiens, les meurtres des fourmis peurent, jusquà un certain point, rentrer dans la catégorie dn meurtre accompli sur un champ de batailte, de colni qui a pour but la conquète des aliments, ou qui résulte de la lutte pour l'existence - tout comme le meurtre par cupidité, qui, par conséquent, doit ètre ramené à la première catígorie. Bien des meurtres avec cannibalisne, bien des parricides et des inlanticides qui s'observent par exemple chez quelfues espices de Chuelocompa, chez les ours, les loups, sont déterminés, comme dans nos disettes, par la concurrence vitale; car la fécondité exessire finit par ètre nuisible à la prospérité de l'espèce. Dans ces cas la destruction des individus sert à maintenir l'espèce. Il en est de mème dans les cas où sont sacrifiés les noureanx-nes maladifs qui offrent peu de 
chances de vitalité, comme chez les poules. La fréquence même de ces actes chịz quelques espèces prouverait qu'ils ne sont pas toujours anormaux. Cette férocité même, non provoquée, qui reproduit chez les animaux domestiques le type de la méchanceté brutale des criminels peut s'expliquer très-bien par la reproduction des tendances ataviques (comme cliez le chien qui se rattache au loup), par un effet des conditions organiques du cerveau, conme cela se trouve évidemment dans les cheraux à nez busqué. - Et alors quelle différence peut-il $y$ aroir entre ces actes et les meurtres que les Rossolis et les Dionées commetlent à cause de leur structure organique?

Comment ne pas conclure que, dès sa première manifestation, le crime est lié aux conditions de l'org:tnisme, qu'il en est l'effet direct? 


\section{$\$ 3$.}

ÉQUiYaleNt DE LA PEINE

CHEZ LES ANINACX ET CIEZ L'HOMNE.

1. - La peine. - Il y aurait encore une différence bien marquée dans les deux séries, s'il était rrai, comme plusieurs juristes, par exemple, notre Ferri, semblent disposés à l'admettre, que certains animaux tímoignent une sorte de repentir des fautes commises. Il est positif que les aheilles voleuses hésitent avant et après leurs exploits, comme si elles craignaient une punition.

II. Ilarachequesne me racontait qu'un singe qui lui appartenait, laissé seul au logis, avait fait de grands dégàts dans la maison: lorsque ses maitres rentrèrent, il se cacha si bien qu'on eut toutes les peines du monde a le retrouver: après avoir été grondé et chàtié il resta huit jours sans vouloir prendre de nourriture.

Brehm nous décrit la scène charmante d'un singe qui commettait un vol dans sa chambre, tandis qu'il leignait de dormir: l'animal regardait avec hésitation autour de lui: et s'arrètait toutes les fois que son maître faisait quelque mouvement et semblait sur le point de s'éreiller.

Chaillu possédait un chimpanzé qui pour lui voler des bananes sapprochait de son lit, épiant ses mourements pour s'assurer s'il était bien endormi; Chaillu venaitil à s'éveiller? le singe s'enfuyait en jetant le fruit volé; mais, s'il en avait le temps, il remettait le fruit 
à sa place el venait faire mille caresses à son maître pour lui donner le change.

A mon avis, tous ces actes ne sont dus qu'à la peur du châtiment qui suit ordinairement la faute, - juste comme cela s'observe chez les voleurs habituels.

Ici on pourra mobjecter que les animaux infligent eux-mêmes de ríritables punitions à leurs petits et à leurs sujets.

Quand les singes sont réunis en troupe, écrit Brehm, une lutte s'engage entre eux pour le commandement; le plus robuste l'emporte; et si l'un d'eux refuse ensuite d'obéir, on le met de force à la raison; coups de poing et coups de dent pleurent sur lui. Entreprennentils en cachette une expédition? ajoute l'auteur; si quelque petit crie et fait du tapage, les vicux, pour le punir, le frappent et le soufflettent.

Toutefois, ici encore, il me semble qu'il s'agit tout. simplement d'un mouvement d'impatience des parents ou des chefs, qui se roient mal compris et désobéis de leurs petits ou de leurs inférieurs. C'est ce qui nous arrive plus souvent que nous ne croyons, lorsque, it l'igard de nos enfants, nous nous donnons l'air de venger un droit, tandis qu'an fond nous sommes bien loin d'obéir à un principe d'éducation ou à un sentiment de justice, mais ne cherchons te phus souvent qu'un prétexte pour justifier nos emportements.

Je suis encore moins disposé à admettre l'existence de peines dictées et infligées par les animaux réunis en société, peines analogues a celles inscrites dans nos codes ou plutôt à celles des tribus saurages qui prodiguent la mort pour la moindre faute.

Neander raconte que dans la bourgade de Tangen en Bavière plusicurs cigognes vivaient en hon accord entre clles. Un jour copendant une fomolle se laissa soduire 
grar un jeune mâle, en l'absence de son époux. Celui-ci, zerenu à l'improviste se voyant trahi, l'aurait fait comparaitre' derant un tribunal composé de toutes les cigognes de l'endroit, qui étaient justement réunies pour leur voyage antomnal, et qui firent justice en déchirant la coupable (Figuier, l. c.).

Dans l'Ecosse septentrionale et dans les îles de Feroë, on voit souvent des troupes de corneilles mettre à mort ¿quelques-unes de leurs compagnes coupables (lD.).

Limnée raconte qu'une lirondelle, étant retournée it son nid, le trouva occupé par un moincau. Tous ses efforts pour l'en déloger restèrent infructueux. Elle eut, alors, recours à ses compagnes qui arrivèrent portant dans leur bec du mortier et murèrent l'intrus dans lo nid usurpé.

Les cynocephales sont des voleurs accomplis. Quand ils mettent au pillage une plantation, ils placent une sentinelle qui, à l'approche de l'homme, pousse le cri d'alarme; cette sentinelle est toujours très-vigilante, car elle sait que ses compagnons lui infligeraient la peine de mort, si cllc manquail à son deroir.

Les habitants de Smyrne, qui savent jusqu'ì quel yoint les cigognes mâles poussent le sentiment de l'itnour conjugal, s'amusent à mettre dans les nids de ces oiseaux des ceufs de poule. A la vue de ce produit insolite, le mâle entre en furcur et livre son épouse aux autres cigognes qui accourent et la déchirent (FiGUIER, l. c.).

Éridemment c'est de notre part une interprétation touse gratuite, que de vouloir reconnaittre dans les autres animaux la même horreur de l'adultère et les mêmes rites et coutumes judiciaires qui existent parmi les hommes, surtout parmi les hommes civilisés; car chez les animaux l'adultère pourra tout au plus provoquer 
un acte de colère de la part de l'époux outragé (et nous verrons cornbien cela est dejả rare chez l'homme sauvage qui pendant longtemps ne le considéra point comme un délit); mais la tribu restera certainement impassible, n'y voyant, après tout, aucun de ses intérêts lésé. Et si chez les cynocéphales la tribu entière condainne a mort une sentinelle négligente, il me semble qu'ici encore il ne s'agit que d'un mouvement de vengeance provenant du coup manqué, du danger qu'on a couru. Mais cela ne prouve en rien la conscience d'un droit, ni la délibération d'une peine, pas plus qu'on ne saurait reconnaitre ce caractère dans les homicides commis par les brigands sur leurs compagnons pour des causes semblables, ou dans les entrainements de la fureur popnlaire qui n'ont, certes, rien à démèler avec le sentiment du droit.

Supposant que ces faits soient vrais, je n'y verrais qu'un nouvel exemple de ces associations de malfaiteurs parmi les animaux dont on a donné plus haut des preuves nombreuses, associations qui, dans ces circonstances, se transforment de fait, sinon d'après les intentions des individus, en actions juridiques.

En d'autres termes, si dans les faits exposés plus haut, nous apercevons l'embryon du crime, ici nous entrevoyons celui de la peine, bornée encore à la phase Le la vengeance et précisément de la vengeance par association, comme chez les peuples barbares qui nous ont transmis le jury, mais sans arriver jamais à la phase de l'indemnité qui est une création de saurages un peu plus avancés dans la civilisation (v. le chap. II).

2. - La peine chez les animaux domestiques; les succédunés prinaux. - Il est certain qu'à l'aide des châtiments nous réussissons à modifier dans certains animaux 
quelques-unes de leurs habitudes; non toutes cependant, ni chez tous les sujets. Nous cherchons à développer chez cux une certaine moralité qui consiste à nous procurer le plus grand profit avec le moindre dommage; ct nous atteignons ce but tantôt par des moyens cruels, tantôt par la rusc.

Allen raconte que dans les Indes les singes lui di:robaient continuellement son sucre. Ne pouvant à cause les prójngés du pays, les punir avec sévérité, il imagina de prendre quelques-uns de leurs petits, les saupoudra de sucre mêlé d'émétique, puis les rendit ì la liberté. Les parents, que ce rapt arait fort aflligés, furent transportés de joie a leur retour et se mirent à les lécher. Ils le faisaient d'autant plus volontiers, qu'ils y trouraient le goût du sucre. Mais bientôt ils furent pris de crampes et de romissements, et dès lors ils ne retournèrent plus chez celui qu’ils regardaient comme un traitre (Bremy, I, 100). Ce qui rend ces animaux si audacieux et si voleurs dans les Indes, c'est justement la superstition des indigènes qui les considèrent comme des ètres sacrés et se gardent bien de les punir. M. Ferri raconte qu'un jeunc homme, pour déshabituer son chien de se tenir continuellement à ses pieds durant ses repas, recourut au stratagème suivant: toutes les fois qu'on mettait la table, il fermait les portes de la salle à manger, et, montrant au clien la nappe blanche, le frappait à tour de bras. A partir de ce moment, le chien se sauvait aussitòt qu'il apercerait de loin la nappe. (L. Ferri, La teorica dell'imputabiliti e la negazione del libero arbitrio. Bologna, 1881 ).

Mais il y a des animanx, dit Brehm, chez lesquels ni les menaces, ni les peines les plus cruelles, ne réussis- 
sent à extirper certains instincts, devenus organiques par suite d'une longue hérédité.

Ainsi tout le monde sait que les chats malgré une longue domesticité et des punitions réitérés, ne perdent jamais l'habitude du vol. - Parmi les singes, les babouins se laissent dresser arec les menaces ot le fouet; sur les cynocéphales, an contraire, les tentatives de dressage n'aboutissent presque à rien (Brenn, I, 120, 109; Ferri, 1. c.).

Pour ce qui concerne l'efficacité des peines, l'observation exacte a démontré que chez les animaux susceptibles de domesticité on obtient sourent bien plus arec un bon traitement ou des mesures indirectes qui flattent leur ranité ou leur gourmandise, qu'avec les tortures, souvent d'autant moins efficaces qu'clles sont plus cruelles.

Un muletier me racontait quau Nont Cenis les mulets et les ânes chargés se refusent à marcher sur une route qu'ils ne connaissent pas; s'ils sont babitués à prendre leur repas dans un endroit détermine, il est absolument impossible de le leur faire dépasser à jeune. On a beau les fouetter, ils se cabrent et n'arancent pas, quand même il ne s'agirait que de parcourir l'espace de quelques mètres. Or, en pareil cas, me disait le muletier, on réussit beaucoup mieux en leur donnant tout de suite à manger qu'en les fouttant. Quand il s'agit d'une route nourelle qu'ils refusent de suivre, le mieux est, pour vaincre leur obstination, de leur faire d'abord parcourir cette route sans fardeau en leur donnant à manger à l'arrivée; cela fait, ils reprennent la marche arec la charge, sans opposer la moindre résistance.

Il y a bien des annies que Lessona (Sullu conformasione csterna del cavallo, 1829) faisait cette observation: 
"Quand un cheral commet aceidentellement une faute, il ne faut pas l'en punir, à moins que celle faute ne lui devienne habituclle; car la peur des punitions trop friquentes l’y fait retomber encore plus souvent.

"En général, si l'on attend jusqu'it l’àge du déreloppement complet, si l'on a recours avec discernement aux punitions ligères, mais surtout si l'on traite l'animal arec douceur, on obtient bien plus que par les maurais traitements, dont le résultat le plus clair est de rendre l'animal vindicatif $\pi$.

Mème arec les chevaux les plus méchants, dit Rodet (l. c.) la douceur fait plus que la sérérité: celle-ci réussira peut-être à modifier les individus faibles; mais les plus vigoureux résisteront à tous les efforts.

Tout cela confrme déjà pour le monde animal ce que nous allons roir chez l'homme, le peu d'utilité des peines et la possibilité d'obtenir des résultats meilleurs par des moyens moins brutaux - par les succédanés de la peine dont nous parlerons dans la dernière partie de cet ourrage. 


\section{CIIAPITRE II}

\section{Le crime \\ et la prostitution chez les sauvages. (1)}

Quand on veut étudier le crime chez les sauvages ef chez nos premiers ancêtres, on rencontre la mème difficulti qui se présente dans l'étude des animanx. Comme chez ces derniers, le crime chez les sauvages n'est plus une exception, mais la régle presque générale. Iussi n'y est-il consideri par personne comme un crime et se confond-il dans ses origines avec les actions les moins criminelles.

Cela se voil dijai dans les langnes.

(1) Pott, Aetimologische Fonschungen, 186i. - Pötruın und Roth,

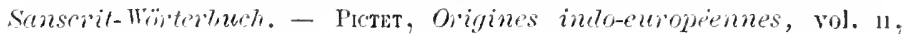
p. 490. - Pernos, Leicicon linguce coptice. - Gesenius, Lexicon lin-

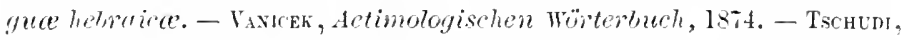
teber dir Krelu-Spmache, 1862. - Ferri, Omicidio, 1883. - Marzolo, Monumenti storiri ricelati coll analisi delle parole, 185i. - Lonproso, L'womo lianco e t'womo di colore, Padova, 1870. - Joly, L'homme arant les mitam, 1882. - Radiquer, Les acrnies's saurages, 1881 . Hovelasie, Les debris de l\%umanite, Paris, 18S1. - DAdara, Fiaggi nell'dmerisa, 1835. - Iufour, Histoive de la prostitution, 1830. Bar, Deutsrhes Strafrerht, Berlin, 1882. - Jetourneau, Science ct materialisme, Paris, 1859. - Id., La Sociologie d'après l'Ellenographie, Paris, 188n. - lunbock, I tempi preistorici e l'origine dell'incirili-

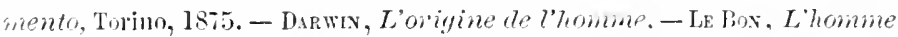

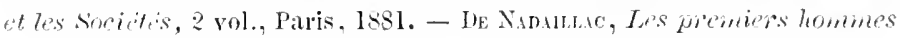
et les tmps preflistoriques, Paris, 1881. - Hovzeau, 1. c., vol. n. -

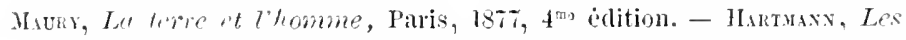

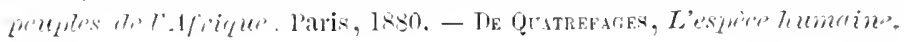


Suirant Pictet le mot crimen (crime) dériverail du mol salnseril karman qui épuivant a action - liri, faire. (Vanicek nadmet pas celle étymologie et fail diriver crimen de kru, entendre; crocmen, accusatio). Dilns tous les cas il y a le mol apas qui veut dire en sanserit piché el qui semble correspondre a apas, aurre, opus - (et le mol latin facinus vient de facere) - culpa déliverait, selon Pictet et Pott, de kalp, kitrp, en sansurit fitive, ceseculer.

Il n'y a done pas dans l'origine une difference bien nelle entre l'action el le crime.

Selon Pictet « il y a dans le sanscrit une centaine de racines qui expriment lidéc de tuer, de blesser (quelquesunes sont alrivées jusquä nous, comme par exemple matr, mori, nac, tan), sans compter les dérivations secondaires. liest lì, dit-il, un phénomène difficile à expliquer". - Pour nous, nous le trourons au contraire tres-naturel, considirant qu'il on est de mème des alrgots. Les synonymes abondent pour les actes qui se ripetent le plus souvent.

Toutes les langues s'accordent í nous présenter la rapine et le meurlre comme la souree première de la propriéte. - En latin prodium dirive de prodari.

Paris, 1879. - ID., Histoive des Tasmaniens, Jourual des savants, 1878. - Dictionnare des sciences anthropologiques, Paris, 1881, 1882. Spexcer, Prinripes de soriologie, Paris, 1878. - TrLok, La civilisation prinitice, Paris, 1876-is, 2 volumes. - C. Vogt, Anthropophagie et sacrifices humains, Bologne, 1873. (Extrait des comptes-rendus du Congrès international d'Anthropologie et d'Archeologie préhistoriques). N. Mrarselu, Oigini dell'umanità, Torino, 1879. - Inumas, Le's chevaux du Sahara, 1853. - Schortт, Transaction of the Elnological Socipty, vir. - Davr, Ceylan. - Earse, Residence.in New Zealand. - NovakaReise, Wien, 1857-58. - Lolseletr, Les crimes et les jeines, 1883. 
En sanscrit lishi exprime lidée d'anéantir, de finir', de tuer, de dévaster, de posséder. - Slit-Slii, ksit, signifient habiter, rendre habitable, el ska, offenser, anćantir; slii, voler. (VAxicek, II; Böttulvgr).

Amahi (copte) a le sens d'arracher, chasser, posséder; moon (copte) celui de pêcher, chasser au rivago, prendre par force, demeurer.

Jarass en hébreu veut dire prit, expulsa, posséda; Bazan et alias arracha, pilla, posséda. - En péruvien (Tscildn , !. c.) coran signifie chassa, guerroya, posseda etc. - En tahitien tao, lance et propriétí; champi, liŕros et voleur.

Le mot sanscrit gur, vaincre et manger - deux actes communement associés dans les contumes des tribus nègres - rappelle le pau tahitien, qui veut dire itre vaincu, ètre mangé, et fait entrevoir quel but moral araient les batailles. De mème lo mol sansurit ga-vishta, guerre et recherclie de vaches, démontre le but des entreprises guerrières de l'époque.

Le fur latin, voleur (qui selon Tanicek dérive de bahr, porter), comme le ganav hébreu, comme le sten sanscrit, correspond à mettre de côtí, cacher, courrir (gonaw). De mème $x \lambda \in \pi \tau \omega$ en gree veut dire cacher et voler et dériverait à son tour de harp-hlap rui signifie en sanscrit cacher et roler. (VAxicek, op. cit.). Et lo teıpaw gree (d'oì vient le mot pirate) veut dire risquer.

En allemand stelten, voler, a le sens étymologiquo de cacher; le sbiäla suédois, cui s'employait autrefois pour rendre l'idée de cacher, a acquis, aujourd'hui, la signification de voler. En latin latro (-onis) vient de latet, ètre caché; cola se rapporte du reste i l'habitude qu'ont les voleurs de se cacher pour tendre des pièges, des guet-apens. 
Mcine la mythologie, cette science próluistorique, nous fait assister an triomphe dn erime dans le ciel.

Dans les îles Fidji il y a le dieu des adultères (Tumanbanga) et celui des assassins (Ravuvavu). La déese (Laverna) était la déesse des voleur's (chez les Romains). - Les Péruviens avaient la déesse des parricides, des infanticides. On adorait en Grèce et à Rome la Vínus divaricatrix, la Péribasia ou cullatrix, la Callipyge, la Lubrica, a laquelle on offrait des phallus d'or, et la Castina, la Vínus des sodomites. 
Il.

IIOMICIDE (1).

1. - Avortement. - L'accroissentent excessif de la population, comparativement aux moyens naturels de subsistance, est, dans la vie sanvage, un péril continuel. Cula nous explique la plupart des homicides qui, chez les peuples primitils, non seulement se commettent avec impunité, mais encore sont ordonnés sourent par la morale et la religion, et fournissent un titre de gloire.

L'avortement prémédité, inconnu aux animaux, est très-commun chez les sauvages; il faut arriver jusqu'au Lend-Avesta, pour trouver les premières prohibitions à cot égard.

Chez les Tasmaniens, les femmes ne consentent à devenir mères qu'après plusieurs annees de mariage; pour conserver leur fraicheur, elles tentent ou provoquent l'avortement en se l'rappant à coups redoublés sur le ventre. Il en est de même dans la Nouvelle-Calédonie.

L'arortement est fort usité en Amérique, à la baie dlludson et dans le bassin de l'Orénoque. A la Plata, les Payaguas font avorter leurs lemmes dès qu'elles ont eu leur deuxième enfant; ainsi font encore les llbayas, leurs voisins. Chez les Papous, les femmes meurent jeunes, par suite de l'usage général de se faire avorter après le premier ou le deuxième enfant.

(1) V. Herk, (Sull'Omiridio), et Letourate, (Sociologie, 1. I45, 132, - e seqq.). - Ploss, (Das Weib, 1, 1884). 
Jais c'est surtout dans les îles, où l'on rencontre moins de ressources, que l'homicide el l'arortement sont permis. A Formose, où pourtant la barbaric est moindre, l'avortement est commandé par l'utilité et la morale publiques: les fenmes n'y peuvent être méres arant d'aroir atteint l'age de trente-six ans; on place à còté d'elles des prêtresses chargèes de laire aror'ter toutes celles qui deviennent enceintes arant cette époque.

2. - Infanticide. - La mème cause rend, chez les sauvages, l'infanticide fréquent. On sacrifie ceux qui viennent après le premier-né, ou le second, et, de préfërence, les filles. (Letocriesu, p. 134). Il en est ainsi dans l'Australie et la llélanésic.

Dans l'Inde, de Ceṛlan à l'Ilimalaya, l'inlanticide est consacré par la religion; et cela, non seulement chez les aborigènes, qui sont les plus barbares, mais encore dins la classe noble, chez les Radjpoutas. Cenx-ci se croiraient déshonorés, s'ils gardaient à la maison une fille non mariće. Les insulaires de Tikopia tnent de préférence les enlants màles: de lá leur polygamie.

Au Japon et en Chine, comme le racontait jadis Ilarco Polo, l'infanticide était, el est encore, une facon violente d'appliquer les doetrines de Malthus. - Il en est de mème chez les habitants des iles Sandwich, chez les Boschesmanns, les Hottentots, les Fidjiens, les Indiens de l'Amérique du Nord.

A Tahiti, s'il faut en croire les missionnaires, les parents araient toute liberté de tuer jusqu'aux deux tiers de leur progéniture. - Dans beaucoup de tribus du Paraguay, les femmes n'éleraient chacune qu'un fils, et il leur arrivait maintes fois de rester sans enfants. 
Quelques tribus de l'Afrique méridionale usent assez souvent de leurs enfants comme d'un appàt pour prendre les lions; dans certaines régions de l'Australie, on les tue, et leur graisse est employéc pour les hamecons.

Les mères Guaranies, raconte d'Azzara, tuent souvent quelques-unes de leurs filles pour donner plus de prix anx survivantes. (Voyages en Amérique, 1835).

La mort de la mère est encore une autre cause d'infanticide, car l'usage veut alors que les enfants soient enterrés avec elle, chez beaucoup de sauvages, par exemple chez les Tasmaniens, les Peaux-Rouges, les Esquimaux. La religion leur enseigne que la mère, du fond du Khillo, séjour des morts, appelle son fils; et, d'ailleurs, ils ne croient pas qu'il leur soit possible d'élever le pelit orphelin.

Il y a encore d'antres causes: les prëjugés par exemple, l'aversion pour les jumeanx. On se dit que l'homme ne peut avoir à la fois qu'un fils, et l'on regarde la naissance de deux jumeanx cornme une preuve de l'infidélité de la fernme. Ainsi pensent les Tasmaniens, les Moxos, les infligínes du Péron, les Peaux-Roug̨es. Les Ibos, dans l'Afrique orientale, exposent les jumeaux aux bètes, et chassent la mère de la société. Chez les Hindous, la femme restéc longlemps stérile sacrifie son premier né à la déesse Donrga. A Madagascar, on laisse mourir de faim, ou manger aux bètes, los enfants nés un jour néfaste.

C’est, quelquefois, la nécessité qui pousse à linfanticide. Stanley a raconté qu'en Afrique, chez les Bari, souvent décimés par la famine, les femmes, désespérant d'úlever leurs enfants, les précipitent dans les cours d'ean.

Enfin chez les anciens Mexicains, la société des lxquimani, el, it Tahiti, celle des Arreoi, composéc de la 
lleur de la population, avaient rangé parmi leurs préceptes l'infanticide; la femme qui arait élevé un enfant en était expulsée, avec la tétrissure de "porteuse d'onfints $)$.

Les mères Assiniennes ayant neuf enfants rivants sont obligées de tuer le dixiène. On explique cela par l'impossibilité qu’il y amrait à les nomrir tous (l. c.).

3. - Meurtre des vicillards, des femmes el des malades. - L'abandon et le menrtre des individus incapables de travailler, que nous royons aussi clez les animanx, résultèrent d'abord d'un exces de population. Ils se sont ensuite conservés par transmission héréditaire, comme un deroir pour les fils ou les amis lors même rüil n’on clait plus besoin.

Fitzroy dit des Tahitiens qu'ils ne se faisaient nul serupule de mettre à mort ceux des leurs qui étaient vieux on malades, sans excepter même les auteurs de leurs jours. Cette coutume rigne dans toute la llélanésie. Dans la Polynésie, on les cliasse de la maison; quelquefois mème on les cnterre rivants, comme en Nouvelle Calédonic. Líl, néanmoins, on les laissc plutòt mourir à l'abandon. Ainsi font encore les Cafres Matcapi, les IIottentots, et les Américains de la haie de Iludson à la Terre de Feu.

A la Nouvelle Calédonie, les victimes trourent la chose naturclle el demandent elles-mêmes la mort; elles mar'chent délibérément vers la fosse ou l'on doit les jeter après les avoir frappées d'une massuc à la têtc. Aux îles Fidji, cet usage était encore plus répandu: la religion enseignait que l'on entrait dans la vic future au même état où l'on était en quittant la terre. Le missionnaire llunts, invité par un jeune homme aux funérailles de sa 
mère, se rendit à l'invitation: à l'apparition du cortège funèbre, il fut surpris de ne point voir le cadavre. Comme il en demandait la raison, le jeune homme lui montra sa mère qui marchait dans les rangs, anssi gaie que les autres. "C'est par amour pour elle que je fais cela, »ajouta-t-il; ce même amour nous pousse à l'enterrer au "plus tôl; c’est pour nous un devoir sacré. Elle est notre " mère, nous somnes ses enfants; il faul done que nous ) Iui procurions la mort ». Le capitaine Wilkes, entro dans une ville qui comptail plusieurs centaines d'habitants, n'y vit pas un homme au dessus de quarante années; il demanda où éaient les vieillards; il lui fut répondu qu'on les avait tués et mis en terre. Celle coutume se rencontre également chez les Esquimaux, les Koriaks, el les peuplades du Kamtschatlia.

Au reste, l'usage de tuer les vicillards et les nalades n'est pas exclusif aux saurages; il fut également pratiqué en Europe, avant que les idées de morale el de droit eussent atteint le degré d'évolntion des derniers siècles. Ainsi llérodote raconte que les Massagètes tuaient leurs vieillards. Elien le dit des Jyperboréens; Platon, d'une peuplade de la Sardaigne; Strabon, des labitants de l'antique Bactriane, qui dressaient des chiens à dévorer les vieillards et les infirmes; Suétone parle des liomains qui exposáient leurs esclaves malades dans une île du Tibre; les Spartiates exposaient leurs enfiants dillormes; une antique tradition Scandinave parle de guerriers malades qui se précipitaient du haut de l'Alternis-stapi, ou rocher de la famille; en Suède, on a conservé jusqu'en 1600 de grandes massues, dites Alla-Klubbor (massues de famille), avec lesquelles les vieillards et les malades incurables étaient jadis tués 
solennellement par leurs parents eux-mèmes. (IetourxEAU, 148).

4. - Autres causes d'homicide. - Outre le meurtre des plus faibles, le monde saurage nous offie le spectacle te menrtres continuels d'hommes forts et adultes, soit commandés par la religion, soit inspirés par ces inslincts féroces que nul frein ne retient dans l'homme saurage.

a) Homicide par colère. - Dans le llétambo, les querelles conjugales finissent par le meurtre de la femme. Le mari, après l’avoir tuéc, mange son coem accommodé avec une fricasséc de chère. (Livingstone, l. c.).

Les sauvages Peaux-Rouges passent de ienr impassibilité habituelle à des accès terribles de fureur sanguinaire, pendant la chasse aux bisons. Dans les Criks, on observe la facilité dı suicide et mème de l'homicide pour la moindre contrariété. (PÉrez, Psychol. de l'cnfant. 1882).

b) Homicide par caprice. - Speke entendit un jour un roi du Kouareg ordonner à son page de tuer un de ses courtisans, dans le seul but d'éprouver la qualité d'un fusil qu'on lui avait donné.

Il ne se passait point de jour qu'il ne vit trainer an supplice quelqu'une de ses femmes, quelquefois trois, rquatre, et toujours pour des causes ridicules, pour lui avoir, par excmple, présenté une flemr.

c) Homicide à propos de funérailles. - Quand un grand malheur les frappe, les sauvages ne manquent pas d'y voir un indice de la colère divine. Par suite, ils s'efforcent de l'apaiser, d'abord en s'infligeant à cux-mèmes des souffrances et des privations, puis en tourmentant d'autres persomnes qui ont quelque rapport 
avec la rictime de la disgrâce. Ainsi chez les Achantis, en Afrique, à la mort du roi, les fils, les frères et les neveux du défunt, en proie à une folie simulée, se précipitent hors du palais royal, et déchargent au hasard leurs fusils sur tous ceux qu'ils rencontrent. (Ferri, 1. c.).

llais e'est particulièrement dans les rites funéraires que l'homicide devient une pratique commune aux races les plus diverses; on sacrifie les femmes, les parents les plus proches, les esclaves du défunt. Bahodu, roi du Dahomey, fit ígorger, lors des funérailles et, plus lard, longtemps après la morl de son père Gezo, un nombre considérable de victimes humaines. Selon Fyun, une immense foule, derrière laquelle marehaient les légions guerrières du despote, suivit le cortège d'Unmanda, mère de Chaka, roi des Zoulous, qu'une dyssenterie avait emportée. On vit égorger à ces funérailles de nombreuses victimes; on y vit des soldats, dans leur exaltation, se mutiler eux-mèmes; et cola ne cessa que lorsque 7000 corps eurent jonché le sol. Le cadavre de la vieille reine fut ensuite placé dans une fosse ouverte, où dix des plus belles filles furent enserelies vivantes aree elle. Tous ceux qui n'araient pas assisté à ces funérailles furent poursuivis et mis à mort; on traita de même tous les enfants nés pendant la première année du denil, et la plupart des auteurs de leurs jours. Peu s'en fallut que le féroce despote ne sacrifiàt à sa mère le peuple tout entier. (Hartuars, p. 159).

I la Nouvelle-Zílande, la femme qui refuse de survisre à son mari est l'oljet d'une grande admiration. Dans quelques tribus, elle est forcée de se donner la mort; on l'étrangle sur la tombe du défunt, ainsi que fuclques esclaves. 
En Amérique, les Natchez qui habitent les bords dı Mississipi, étaient jadis gourernés par un grand chef, frère dı soleil. Ses femmes, ses esclares, deraient être immolés sur sa tombe. Au Pérou, al la mort d'un Inca, on tuail ses serviteurs, ses conculines, ses favorites; 10 nombre des rictimes sélevail par fois à mille.

Les Mongols ensevelissent leurs rois et leur's principaux ehefs dans une vaste nécropole souterraine, et ne ménagent ni l'argent, ni les hommes. Autour du cadavre principal ils disposent, dans l'attitude méditative des adorateurs de Boudha, des enfants empoisonnés pour la circonstanee, et qui tiemnent, l'un l'érentail, l'autre la pipe, etc., du mort.

Il est, je crois, inutile, après cela, de rappeler le meurtre des reures, en usage dans l'Inde.

d) Homicides ayant pour cause des sacrifices religieux. - Les homicides de ce genre se rencontrent chez presque tous les peuples barbares. A Taliti, Bougainville a ru sacrifier à la Lune des victimes humaines. Cook a assisté à un sacrifice au cours duquel le prêtre offrit alı chef de la tribu l'œil gauche de la rictime; mais le cannibalisme étant tombé en désuétude, cette offrande fut repoussée, et présentée aux dieux avec le reste du corps.

Dans le Larriba (bassin du Niger), lr prêtre du Fétiche déclare, quelquefois, que son Dicu réclame une victime humaine.

Les plus affreuses boucheries ont lieu, de nos jours encore, dans l'Afrique centrale. "Les sacrifites humains du Dahomes ct du Vieux-Calabar sont célèbres par le grand nombre des rictimes immolées. Ce sont en rieilité des fêtes commémoratives en l'honneur des morts. Comme, d'après leurs croyances, les mânes des aïcux 
boivent le sang répandu, ils leur en offrent le plus possible, et le nombre des malheureux sacrifiés à un roi rappelle celui des soldats sacrifiés à l'étiquette enropéenne dans une bataille où le monarque commande en personne.

Les tribus Indiennes Natchez du Mississipi et celles de la plaine de Bogota, sacrifiaient à leurs dieux des victimes humaines. - Au Mexique toutes les fêtes religieuses exigeaient des sacrifices semblables: des milliers de victimes étaient déchirées avec les couteaux sacrés on jetées dans les flammes. Les moines franciscaines qui, après la conquête, s'établirent dans la Nouvelle Espagne, portent à 2500 le nombre des personnes immolées chaque année. Un Inca tombait-il malade? il offrait à la divinité un de ses fils et la priait de l'accepter' à sa place.

Les Gonds, dans l'Inde, offraient périodiquement des victimes humaines à Béra, déesse de la Terre: ils lui sacrifiaient des individus enlevés aux autres tribus, mais, au besoin, ils ne reculaient pas devant le sacrifice de leurs propres enfants. Il y avait précisćment une caste, celle des Pauvas, uniquement adonnée au rapt des hommes et des enfants pour fournir une proie à la déesse.

Quand les Européens arrivèrent aux iles de la Société (Polynésie), ils y trouvèrent l'usage d'apaiser les dieux par des rictimes lumaines depuis longtemps établi. Et cet usage s'est perpétué longtemps encore chez des peuples qui avaient atteint un haut degré de civilisation.

Les Grecs anciens calmaient les vents en leur offrant des enfants. Hérodote raconte que Nénélas s’était attiré la colère des Egyptiens pour avoir sacrifié deux enfants sur leur territoire: il avait espéré, par ce moyen, faire 
tomner le rent contraire. Plutarque dil de Thémistocle, qu'il fit tuer plusicurs prisonnicers pour se rendre les dieux favorables, arant de se mettre en campagne contre les Perses. L'histoire ancienne de Sparte enregistre ruclques sacrifices lımmains. Les Romains agissaient de même: Tite Live raconte que, sous le consulat de PaulÉmile et de Térentius Varron, deux Gaulois et deux Grees furent enterrés vivants dans une citerne creusée $\therefore$ cet effet. Plutarque rapporte un fait un peu plus ancien. Augnste et ILéliogabale immolèrent des victimes humaines, le premier aux mânes de César, l'autre à une divinité syrienne qu’il avait introduite à Rome.

La Bible parle de sacrifices humains chez les ILébreux; ainsi ceux d'Isaac, de la fille de Jephté, eic.

Les Carthaginois saerifiaient à Kronos (Moloelı) les enfants les plus nobles et les plus beaux de la contrée; mais, plus tard, ils les remplacèrent par des enfants achetés et nourris dans ce but. Mis en déroute par Agathocles, ils erurent que la divinité était irritée, et, pour l'apaiser, immolèrent 200 enfants pris parmi les plus nobles. Ainsi faisaient les Phéniciens, les Egyptiens, les Crétois, les Cypriotes, les Phodiens et les Perses.

L'usage de la circoncision, chez les Itébreux, montre combien les sacrifices humains étaients fréquents. Gette cérémonie est en effet, comme l'a démontré Spencer, un reste de ces sacrifices, réduits à leur phus simple expression. (Revue Philos., 1878).

Ainsi, parmi les peuples de l'Europe septentrionale, les Massagètes, les Seythes, les Gètes, les Sarmates, les Seandinaves, croyaient ne pouvoir olstenir ni prospérités, ni faveurs, šils ne sacrifiaient des hommes à Odin ou à Thor. L'ile de Rugen, dans la Baltique, et spécialement $U_{1} s a l$, itaient célèbres par des sacrifices 
de ce genre; de même l'Irlande et la Zélande. Les Gaulois et les Germains ne commencaient aucune entreprise avant d'avoir offert à leurs dieux des victimes humaines. La forêt Hercynie et celle des Ardennes avaient gardé un renom terrible des sacrifices.

e) IIomicides commis par brutalité ou des motifs futiles. - Tandis que ces homicides «sans motif apparent, 》 comme dit Romagnosi, sont, chez les peuples civilisés, l'effet de conditions anormales qui affectent quelques individus, ils sont très-fréquents chez les sauvages, parceque l'humanité primitive tient fort peu compte de la vic humaine, surtout dans les rapports entre chefs et sujets, entre croyants et prêtres.

Les Australiens ne font pas plus cas de la vie d'un homme que de celle d'un crapaud. On peut en dire autant de la Mélanésie entière, comme nous le verrons en traitant du cannibalisme. A Fidji, on a ru un homme dévorer sa femme après l'avoir fait cuire sur un brasier qu'il lui avait ordonné d'allumer. Il commit cette atrocité uniquement pour se distinguer, pour acquérir de la notoriété. Dans ce pays, tuer un homme est un acte qui no tire pas ì conséquence et qui, an contraire, donne du relief au meurtrier. Aussi les indigènes ontils soin d'être toujour's armés.

Au dire d'un ancien royageur, Niccolò Conti, qui écrivait en 1430, l'homicide, pour un Malais, était une simple plaisanteric. "Quand l'un d'entr'eux faisait l'acquisition d'un sabre, il l'éprouvait volontiers en le plongeant dans la poitrine du premier venu ». L'opinion publique n'y trourait pas à redire; on louait même la légèreté de main du meurtrier, si le coup était porté arec art. 
Les Achantis ne se contentent pas même de tuer, ils veulent faire souffrir la victime avant de lui ôter la vic.

bans l'Afrique centrale, comme en Mélanésie, la fomme est tućc par son mari pour le motif le plus frivole.

Le fameux monarque Mltesa fait périr chaque jour des odalisques de son harem; il suffit pour cela ru'olles aient cessé de Ini platre. (Stanter, Le Continent Noir, 1879).

Cameron, parlant du chef de tribu Kassango, dit qu’il fut surpris « de voir, parmi ceux qui l'entouraient, un si grand nombre de gens mutilés, et, plus encore, d'apprendre que beaucoup de ces mutilations avaient éte faites par simple caprice du maitre, ou pour donner une preuve de son pouvoir ». Parlant d'un autre chef, il dit: "Faire couper des nez, des lèvres, des oreilles, ne suffisait pas à ce misérable: il avait voulu étendre ses vivisections à wne femme qui était sur le point d'accoucher; il lui avait fait ourrir le ventre pour satisfaire une curiosité monstrueuse ».

f) Homicides causés par un désir de gloire. - Pour le sauvage, un étranger est presque toujours un ennemi; le tuer n'est pas un délit, mais souvent même un titre de gloire.

Williams, qui a étudié les îles Fidji, dit "qu'être un assassin célèbre est la chose la plus ambitionnée d'un Fidjien, » si bien que, dans ces tribus, les actes qualifiés par nous de crimes ont été en quelque sorte divinisés. "Aux îles Fidji, les noms des dieux font connaitre leur caractère. Ainsi, Tumanbanga est le dicu de l'adultère, Ndauthina celui qui enlève les belles, Kumbunaranua celui qui se plait aux querelles, Mbatimona le mangeur de cervelles, Ravuravu l'assassin, Maina- 
tavasara celui qui fait un massacre, etc. ». A Bornéo, parmi les jeunes gens, nul ne trouve à se marier s’il n'a tué all moins un homme.

La conscience, dit Burton, n'existe pas dans l'Afrique orientale; le remords n'est que le regret de n'avoir pn commetre un crime. Le vol rend un homme honorable; l'lomicide, surtout, s'il se présente accompagné de circonstances atroces, fait de lui un héros.

II. Galhraith, qui passa plusieurs années chez les Sioux, comme agent du Gourernement des Etats-Unis, les dipeint de la sorte: "Ils sont bigots, harbares, et, en somme, très-superstitieux. Le vol, l'incendic, le rapt, l'assassinat, sont considérés par eux comme des moyens de se signaler; ils disent à leurs propres fils, au sortir de la première enfance, que l'assassinat veut être regardé comme la plus grande de toutes les vertus. Dans les danses, dans les banquets, les guerriers chantent leurs assassinats, qu'ils regardent comme des prouesses; la plus grande, je dirai même, la seule ambition d'un jeune lomme courageux, est de pouvoir porter "la plume " qui est la décoration accordée à qui a tué ou aidé à tuer une créature humaine, serait-ce une femme ou um enfant; et, quand il est arrivé à posséder sa première "plume, il désire ardemment en augmenter le nombre; si bien que le courage d'un indien se mesure au nombre des plumes dont il orne son front».

On observe précisément la même chose chez les Manyema, ou les homicides sont fort nombreux. Beaucoup tuent seulement pour pouvoir se vêtir de la peau du chat musqué, et se coiffer arec une plume de perroruet, (Livingstone, de Zanzibar à Titombu). Lì, sur les places publiques, dit-il, j’ai vu souvent quelqu'un jeter à terre une plume de perroquet; qui veut s'en 
parer doil tuer un homme, le premier qu'il renconten. (lD.).

g) Homicide inspiri par la vengeance. - L'opinion publique de la tribu impose le devoir de répandle du sang pour se renger. On applaudit it l'homme qui, ayant perdu un membre de sa famille, poursuit sans relitehe celui quon accuse d'en être le meurtrier.

si, par exemple, un indigène a été offensé par un Hilne, il lui suffira de se venger sur un lomme de même couleur, füt-ce sur le premier venu. Pour I'Australien, il n'y a pas de mort naturelle; toute mort résulte de quelque maléfice el veut être vengée; de là, pour lui, une série sans fin de devoirs sanguinaires, fortement gravés dans son cour.

I Tahiti, le meurtricr élait assailli par les amis du defunt. Etait-il raincu? sa maison, ses meubles, ses terres devenaient la propriaté de ceux qui l'araient atlaqué, et réciproquement. De nos jours encore, à Noulialiva, le sangs se payait par le sang̣.

5. - Cannibalisme. - Né du besoin de se nomrir, surlout dans les iles, consacré ensuite par la religion, excité par la fureur des armes et rendu héréditaire par une odieuse gloutonneric, le cannibalisme est, de toutes facons, le dernier degré de la férocité lıumaine. 11 alcompagne souvent l'homicide, en prend les divers asprects plus ou moins rebutants, et supprime en ce point toute différence essenticlle entre l'homme et la bèle. (Ferri).

On a contesté, - M. de Ilortillet, par exemple, tout récemment encore, - que le cannibalisme ait jamais été pratiqué dans l'Europe préhistorique. Mais la grande majorité de ceux qui s’appliquent à la paléontologie, 
de Spring à Capellini et à M. de Nadaillac, en ont donné des preuves irrécusables.

On trouve en abondance chicz les races supérieures, la mongole et la blanche, des traditions concernant cette affreuse coutume. Dans la Bible, on rencontre quelques allusions à l'anthropophagie, (Deutérovone, c. VIII, v. 53; JÉRÉMIE, c. XIX, v. 9); on en rencontre ígalement dans l'Odyssée (c. Ix, v. 287-298, c. v, v. 116 124). Hérodote attribue cette contume à quelques tribus roisines des Scythes, les Androphages et les Issedons (1. Iv, c. xvin, xxxrI, etc.); Aristote, à plusicurs peuplades des bords de la Mer Noire (Polit., l. viII, c. III, trad. Churot, Paris, 1824, t. II, 515); Diodore de Sicile, aux Salates (1. v, c. xxxis). On lit dans Strabon: "Les Irlandais, plus sanvages que les Bretons, sont anthropophages; à la mort de lenrs parents, ils se font gloire de les manger ». (Georr., l. IV). Borlin dit la même chose des Thraces. (De republ. l. I, c. v).

Ces coutumes exécrables ont disparu devant la civilisation; mais on les voit reparaitre de loin en Ioin, dans les situations extrêmes, par exemple dans les siegres, dans les famines, dans les naufrages; quelquefois même sans que l'aiguillon de la faim se fasse sentir, sous le coup d'ıne grande passion.

Le lendemain de la mort du maréchal d'Anere, son cadave fut déterré et mis en pièces. Un des exécuteurs posthumes se léchait les doigts ensanglantés; un autre lui arraclıa le coemr, le fit griller, et le mangea sur la place publirque. Dans l'Italie méridionale, ruand sévissait le brigandage, on vit des scènes de véritable cannibalisme: les cadavres des carabiniers étaient coupés à morceanx, leur chair vendue et dévorée. 
Ce n'est plus maintenant que chez les samvages, que nous pouvons étudier dans son érolution naturelle celle horrible forme de l'homicide.

a) Cannibalisme par nécessité. - C'est la forme la plus commune: on la trouve surtout dans les pays où les animaux qui servent ì la consommation sont, ou du moins, étaient, en fort petite quantité. Pressís par la faim, les labitants de l'Muspralic tuent les femmes pour en faire lemr nomriture. Ils ront jusqu'a diterrer les mdavres.

Quand ces derniers font défaut, ils tuent mo femme, une petite fille, un enfant. A Tahiti, me époque de disctte était appeléc «la saison de manger les hommes y.

Les Cafres, en Afrique, ne touchent à la chair humaine qu'en temps de famine; mais, alors, ils en repremnent l'habitude. La même observation peut s'appliquer anx Fneggiens. Les Esquimanx, enx anssi, ne deviennent anthropophages que poussés par la nécessiti; celle de leurs tribus qui a le plus à souffrir de la faim en attaque mne autre, déchire les cadavres et en mange la chair, sans se donner la peine de la faire cuire on mème de la réchauffer.

b) Cannibalisme par religion. - Vraiment, on ne pourrait pas dire qu'il soit provoqué toujours directement par la religion: il arrive bien plus souvent que la religion consacre les passions invétérées chez les penples qui s'y livrent. Les Gonds ont de riches moissons, el pourtant, en l'honneur de leur déesse Bera, ils mangent des centaines d'hommes, et leurs villages, tonjours en gnerre, s'accordent senlement pour trouver de nouvelles victimes. 
“Aux îles Fidji, un festin anthropophagique marquait chaque solennité, comme, par exemple, l'inauguration d'un temple». A la Nourclle-Zélande, la religion a sanctifié le cannibalisme. (Letounsead, 192, 193). Un chef est-il tué dans un combat? le droit des gens exige qu'on remette sur le champ la femme du mort au parti vainqueur; car elle aussi doit être tuéc. Puis les cadirres sont rôtis et mangés avec recueillement dans une círémonie religiense. Les arikis, on prêtres, donnent l'exemple, en goûtant avec solennité un petit morceau des victimes. (Letourneau, 192, 193). A Tahiti, l'anthropophagie a maintenant disparu; mais Cook y assista jadis à un sacrifice humain et vit le prêtre offrir au chef de la tribu l'mil ganche de la victime; c'était la part ríservée au roi. En vent-on une demi-preuve? Le véritable nom de la reine Pomaré "Limata "signifie nanger l'oil.

C'est an Dexique surtout que le cannibalisme religieux, les sacrifices lumains, ont alteint le plus haut degré de cruantí. "Là, on étendait la rictime sur la pierre du sacrifice; Ie Grand-Prêtre (Papa Topitzine), qui prenait pour la fête le nom même de son Dieu, onvrait rapidement la poitrine du malheureux à l'aide d'une picr'e tranchante, en arrachait le cocur et l'offrait généralement au Soleil, plus rarement à la Lune. Seuls, les plus âgís d'entre les prêtres avaient droit de manger ce morceau. Le cadavre était ensuite précipité au bas des degrés, où la foule, en prières, attendait pour le dívorer. S'il arrivait que la victime appartint à des particuliers, ils l'emportaient chez eux pour un repas de famille.

Chez le Gonds du centre de l'Inde, et cela jusqu'ia des temps rapprochés, on avait conserve l'habitude de 
condure la victime, après des cérémonies nombreuses, dans un bois sacré; on lui rompail les os des bras et des jambes pour prévenir toute résistance, et on lui adninistrait, pour l'engourdir, de l'opium et du stramonium. Ensuite le jani, ou prêtre, la frappait avec sà propre hache. Aussilôt après, la foule s'élançait: tous vonlaient s'emparer d'un lambean de chair; en un elin d'ail, les os étaient mis à nu et abandonnés sur le sol. (Lubrock, 637).

c) Cannibalisme par préjugé. - Une autre cause d'anthropophagie, se liait aux croyances religieuses; c'itait le préjugé selon lequel on croyait s'assimiler le courage d'un ennemi en mangeant son cœur, sa perspicacité en mangeant son oeil, sa virilité en mangeant ses parties génitales el prévenir sa vengeance en dévorant son corps tout enticr. Voilit pourquoi le plus grand malheur, pour un habitant de la Nourelle-Zélande est d'etre mangé par un autre; car, de cette facon, son corps et son àme sont à jamais détruits. Par contre qui mange son ennemi u'a plus rien à craindre de lui dans la vie éternclle.

Chez quelques peuplades australiennes, le cannibalisme n'est en usage que pour certaines cérémonies magifues. Aux iles Sandwich, quand un bon prince mourait de mort naturelle, on mangeait son corps pour le mettre à l'abri de toute profanation: cela s'appelait "manger le chef par amour ». (Maury, 761).

d) Cannibalisme par piété filiale. - Ce sentiment de piété filiale, que nous arons signalé dans le meurtre des vieillards, est encore une cause de cannibalisme; on croit ainsi rendre meilleure leur condition dans la vie future. 
Les Batta de Sumatra sont assurément moins sauvages que bien d'autres peuples. Eh bien! celui d'entre eux qui, devenu vieux, se trouve las de vivre, prie ses enfants de le manger, et ceux-ci se gardent bien de lui désobéir. Au jour fixé pour la cérémonie, le vieillard s'établit sur un arbre, ses parents et ses aınis l'entonrent, frappant en cadence le trone de l'arbre et chantant un hymne funèbre dont le sens est celui-ci: Voici la saison venue, le fruit est mûr, il doit tomber. Puis le vicillard descend, ses proches parents le tuent et mangent pieusement ses restes. Et c'est lá un devoir de piélé filiale!! (Letourneau, 199).

D'ailleurs, s'il faut en croire Hérodote (Hist. Iv, 26), dans l'Europe orientale, la pitié poussait les Massagètes a tuer leurs vieux parents. Ils en mangeaient ensuite la chair dans un grand banquet, après l'aroir mêlée à des pièces de bétail. Ils épargnaient ainsi aux auteurs de leurs jours la lionte d'être dévorés par les vers. Ainsi faisaient encore les Issedons; toutefois, ils ne devancaient pas l'heure marquéc par la mort. Strabon raconte aussi que les Derbis de l'Asie septentrionale ́gorgeaient les vieillards qui avaient dépassé l'àge do 70 ans, et que les plus proches parents se parlageaient le cadavre.

e) Cannibalisme dans la guerre. - La férocité primitive, le cas ì peu pris nul que l'on faisait de la rie humaine, la fréquence des guerres, devaient certainement pousser l'homme sanvage à ce genre d'anthropoplagie, qui est, à coup sûr, le plus commun, après celui qui se lie au sentiment religieux. Il y a même tes peuples qui font la guerre dans le seul but de manger les vaincus: mais, en ce cas, le mobile psychologique est moins la fureur guerrière que la gloutonnerie. 
Laplace, à la Nouvelle-Zélande, put voir le retour triomphal d'une flotille de pirognes. Les vainqueurs portaient les cadarres des vaincus, ou plutôt une partie de ces cadares, car ils en araient mangé quelquesuns le long de la route; ce qui restait suffit pour un grand banquet nocturne. Ces mêmes Néo-Lélandais coupaient par quarticrs, sur le champ de bataille, leur ennemi vaineu et couvert de blessures; ils n'avaient, pas mème, la patience d'attendre qu'il fût mort.

La coutume de manger à la guerre ses ennemis dtait répandue dans toute l'Amérique, du Nord an Sud. Le père Brébœuf a vil les Ilurons manger un de ses néophytes; et Charleroix raconte que vingt-deux llurons furent mangés en sa présence pár les Iroqucis. Au Sud, les Guaranis en général, les Tapuyas, les Tupinamba, les Aymari, dévoraient les vaincus. Les Caraïbes manreaient sur le champ de bataille leurs ennemis morts, et gardaient leurs prisonniers pour s'en repaitre chez eux; le cœur était la portion réservée au plus vaillant. Iu Brésil, Chévet a entendu un chef se vanter davoir dévoré, pour sa part, cinq mille prisonniers. Il s'en glorifiait: "J'en ai tant mangé, disait-il, $j$ ai tué tant de leurs femmes et de leurs enfants, que je puis, grâce it mes exploits, me ranter dêtre le plus grand morbicka qui ait jamais paru chez nous ».

Liexécution des prisonniers de guerre, chez les Indiens de l'Amérique du Nord, offre un spectacle affrenx. Liée à un poteau, la victime est soumise aux tourments les plus atroces: on lui arrache les ongles, les dents, jusqu'à des lambeaux de chair. Les bourreaux se partagent quelquefois cette chair rôtic sur l'homme rivant encore, et la dérorent par morceaux, se barbouillant le visage avec le sang de la victime, pour se donner 
un air plus terrible.... Après de longs tourments, le chef donne enfin le coup de grâce, et la tragédie se termine par un odieux banquel. (IIovzead, l. c. II, 14).

Un ancien voyageur Hindon raconte qu'en $\Lambda$ sie les peuples du Boutan mangeaient jadis le foie des ennemis qu ils araient tués, aprés l'aroir couvert de beurre et de sucle. (Letounseau, 202).

f) Cannibalisme par gloutonnerie. - Le cannibalisme est si invétíré clıez les Fidjiens, qu’ils «ne peuvent faire un plus grand éloge d'un hachis qu'en disant de lui: il est tendre comme un homme mort». Telle est en outre la dílicatesse de leur palais, qu'ils dédaignent la chair des blancs, préfèrent la chair de la femme à celle de l'homme, et considèrent l'avant-bras et lit cuisse comme les morccaux les plus délicats. Dans les festins royaux, on sert toujours un plat de chair humaine. Les corps des ennemis tombés sur le champ de bataille sont toujours mangés; mais le nombre en est insuffisant, el l'on engraisse des esclaves pour les vendre au marché. Alors on les rôtit vivants pour les manger de suite; en d'autres cas, on conserve leurs corps jusqu à un état assez avancé de décomposition.

Parmi les naturels de la Nouvelle-Calédonic, le désir de manger de la chair humaine était une des causes les phus fréquentes de guerre entre les diverses tribus. En ce pays la chair humaine lournissait un régal; on la mangeait par friandise. On voyait parfois des chefs se faire servir en famille un de leurs sujets, et non seulement l'opinion publique n'élait pas sérère pour ces banquets princiers, mais encore elle les tenait en grande estime. Après une rencontre heureuse, les chefs NéoCaledoniens, qui s'étaient fail, dans la sauvagerie humaine, la part dı lion, avaient lıâte d'expédier des 
morceaux aux amis douteux pour sassurer de leur alliance.

Tous les cannibales saccordent à dire que la chair humaine possède un goùt exquis. «Dites toujours, rípondait un chef Batta ì un missionnaire qui lui adressait les reproches à ce sujet, dites toujours que c'est infame; mais ne dites pas que ce n'est pas bon ». (Togt, 13). Certaines tribus Cafres, que le besoin avait rendues anthropophages, conservèrent dans la suite cette habilude par gloutonnerie; Gardines l'a constaté chez les Zoulous. Il y a peu d'années que les Cafres Basoutos se nourrissaient exclusivement de chair humaine, au sein d'une contrée fertile et giboyeuse. "Un désastre les avait d'abord contraints de recourir à cette extrêmití; puis, à la longue, ils en gardèrent l'habitude, et en 1868, ils ne s’en étaient pas encore corrigés. Dans l'Afrique équatoriale, les Pan pratiquent paisiblement le cannibalisme; c’est même une branche de leur commerce; ils ne veulent pas manger les morts de leur tribu et les échangent contre ceux des tribus voisines.

En Amérique, les Moxos et autres tribus de Guaranis étaient cannibales; ils avaient coutume d'engraisser leurs prisonniers et de les traiter avec le plus grand soin avant de les manger. I.es Mexicains, relativement civilisés, avaient des cages spéciales où ils engraissaient leurs prisonniers avant de les immoler pour leur table.

Aux îles Jarquises, on préfère les femmes aux enfants; elles ont, parait-il, plus de saveur. Bien plus, on lédaigne celles du littoral, auxquelles on trouve un goût de poisson pourri. Les Européens paraissent aussi trop salés. Les prètres d'ailleurs ont droit aux morceaux les plus succulents, à la partie de derrière. (RAdiguet). 
g) Vanité. - I toutes ces causes vient s'ajouter la vanité, l’idée d’augmenter sa propre supériorité en s'assimilant les rertus de l'ennemi, en jouissant d'un privilége réservé en certains pays aux hommes seuls, en d'autres aux nobles ou aux chefs, comme récompense de leurs exploits, ou pour célébrer des victoires, comme au Mexique.

1) Lutte pour l'existence. - En certains pays, chez les Fueggiens par exemple, la lutte pour la vie a contribué à développer le cannibalisme. Elle diminuait le nombre des coneurents, fournissait à ceux qui survivaient une nourriture plus réconfortante, plus convenable à des guerriers que le régime régétal. Ainsi, cette abominable coutume avait son antidote dans son extension mème, puisqu'elle décimait la population. Peut-on en douter, si l'on pense à ce chef qui avait mangé, pour sa part, 500 individus?

i) Cannibalisme judiciaire. - Letournean emploie cette expression pour désigner le cannibalisme appliqué au chàtiment des malfaiteurs. Nous pouvons aussi l'appliquer au cannibalisme inspiré par la vengeance, qui, nous le savons, est le germe du chàtiment lui-mème.

A l'époque oủ Cook visita l'archipel de Tahiti, le cannibalisme n’y régnait déjà plus; il n’en restait quelques traces que dans les cérémonies religrieuses. Toutefois, de temps en temps, et uniquement par esprit de vengeance, on faisait ròtir et lon mangeait encore une partie de l'ennemi raincu. On peut dire eependant qu'en général la morale publique condamnait l’anthropophagie.

Chez quelques Indiens de l'Anérique du Nord, le cannibalisme se présente comme une suite naturelle de la vengeance exercée sur un ennemi. Aujourd'hui en- 
core, pour les naturels de la Guyane, l'anthropophagie n'est pas autre chose quiun acle de vengeance.

A l'ile Bow, on mange les assassins; c'est le seul point de la Polynésie où rous puissiez constater ce genre de cannibalisme. Selon Bourgarel, la vindicte publique, ¿ la Nourelle-Calédonie, l'applique aux condamnés à mort. Mareo Polo raconte quil en était de même chè les Tartares.

6. - Telles sont donc les conditions psychologiques et juridiques de l'état sauvage; on voit qu'elles sont en tous points contraires à celles qui distinguent les peuples civilisés. Or rien, dans la nature, n’étant immobile, nous pouvons discerner dans ces conditions mèmes où elle place le sauvage, un double progrès d'évolution; d'une part, il arrive par degrés à une férocité moins grande; de l'autre, il sent se développer en lui les germes des sentiments moraux et des institutions juridiques. Ciest ce qu'on remarque ensuite dans l'évolution historique de l'homicide. (Ferri).

En fait, pendant que cette classification des diverses formes de l'homicide, pour faire mieux ressortir le contraste entre l'homme primitif el l'homme civilise, les a présenties dans une progression croissante de férocití, leur évolution naturelle, au contraire, se termine par une diminution continuelle et de plus on plus rare des formes les plus odieuses. Le meurtre inspiré par le désir de la renommée ou par une méchanceté brutale, le cannibalisme guerrier et celui qu inspire la seule gloutonnerie, deviennent tous les jours moins fréquents; on voit persister, au contraire, l'homicide et le cannibalisme inspirés par la religion; c'est d'abord le corps entier, puis une partie seulement de la victime, que l'on mange; l'homme est 
ensuite remplacé par des animaux, et enfin par des figures symboliques (voyez, chez les Mexicains, l’imagre du dieu Quetzalcoatl, pétrie de farine et de sang; chez les Chinois, les figures de papier brûlées dans les cérémonies; chez les Romains, des statuettes analogues nommées oscilla). L'hostie des catholiques est la manifestation dernière et inconsciente de ce symbolisme, comme le remarquent fort justement IVaitz et Wogt. (FERRI).

Ce n'est pas tout: l'homicide et le cannibalisme inspirés par la vengeance revêtent, même aux époques primitives, une apparence morale et juridique qui en fait véritalılement l'embryon du droit social de répression, et le remplace quand celui-ci n'est pas encore organisé. 
III.

YOLS ET AUTRES DËLITS.

Les tribus sauvages, les peuples primitifs, ne possidant raiment rien en propre, nont pas lidée de la propriété, et encore moins celle du vol qui, exercé sur les étranger's, procure du profit ì leurs propres membres.

En Egypte, la profession de voleur était reconnue par l'Etat. Celui qui voulait l'exercer inscrivait son nom sur une tablette quion exposait en public; il portait ensuite dans un endroit désigné tous les objets qu'il avait dérobés, pour que leur's propriétaires pussent les rccourrer en payant une certaine redevance (1). Les Germains voulaient que leur jeunesse, pour ne pas languir dans l'oisireté, s'exerciat à roler chez les peuples roisins de leurs frontières (2). Thucydide atteste que les Grees el tous les peuples barbares des îles et du littoral, s'adonnaient à la piraterie, el que loin d'en rougir, ils s'en faisaient gloire. I Sparte, le vol était permis; si le voleur surpris en flagrant délit recevait une correction, ce n'était point pour le vol, mais pour la maladresse.

Mème chez les peuples à demi-civilisés, la propriété privée fut longue à šétablir; au Pérou, au Hexique, arant les Aztèques, on vit se maintenir longtemps les

(1) A. Geln. 1. XI, e. 18: Egyptiis omnio furta licita et impunite.

(2) CESAr, Bell. Gull., 1. vi, c. 21: Latrocinia nullam halsent infamiam, que extra fines cujusque civitatis fiunt, atrue es jurentutis exercendice ac desible minurute couse feri prodicant. 
casas grandes, huttes immenses sous lesquelles vivaient ensemble des familles nombreuses.

Aux ìles Pelew, les habitants ne possèdent en propre que leur maison et leur pirogne; tont le reste appartient au roi.

En Chine, il y a de cela 2205 ans, tout était en commun; les chefs faisaient la répartition des terres selon l'ìge de leurs sujets. Il en fut de même à Sparte jusqu'à la guerre du Péloponnèse.

D'après Cook, le mot demi rasé, signifiant voleur, šintroduisit dans une île de l'Océanie, après qu'il se fut avisé, pour ehàtier un indigène coupable de vol, de lui raser la moitié de la tête. Cela prouve sans aucun doute que, jusque là, ils n'avaient pas la moindre notion du délit.

Dans l'Afrique orientale (écrit Burton, p. 176) les voleurs jouissent de l'estime générale.

Dites à un Ilakolo, écrivail Livingstone: Pourquoi voles-tu dı bétail? Il éclate de rire et répond: Je ne fais rue le détourner.

Alon Rongatura (Australie) avait été surpris à voler, et un voyageur lui demandait šil ne craignait pas d'ètre puni par les dieux; "Oh! non, dit-il; quand les dieux étaient sur la terre, ils faisaient de même, et les pères aiment à être imités par leur's enfants ". (Novara Reise, Anthropol. Theile, p. 39, 1865).

Sur la Caramance, en Afrique, tout auprès des Bagnous, peuple saurage, mais pacifique et probe, adonné à la culture du riz, sont établis les Balantis, qui virent de chasse et de rapine; ils tuent les voleurs quils rencontrent dans leurs villages, mais cela ne les empêche pas de voler leurs voisins, (Revuc d'anthropol., 1874). Chez eux, les roleurs habiles sont fort estimés; on les 
paic pour quils enseignent leur art aux cnfants, ef mème on les prend pour chefs dans les expéditions.

Les Beni-llassan, du Maroc, ont arce eux beancoup d'analogie. Le vol est leur occupation principale; ils sont disciplinés, ils ont des chefs que le Gouvernement reconnaît et dont il se sert quelquefois pour ravoir les ohjets volés. Ils se divisent en voleurs de blé et voleurs de rhevaux; ils opèrent dans les viilages et sur les routes. Montés sur des chevaux rapides, ces bandits sont presque impossibles a atteindre. Ils emploient la ruse; s'introduisent nus, enduits de graisse, dans les cabancs, se dissimulent sous des branches d'arbres pour ne pas effrayer les chevaux. Ils s'adonnent au brigandage dès leur huitième année. (DE Aurcis; Marocco, p. 205).

Chez les Arabes Bédouins, il y a des tribus honnêtes el laboricuscs, mais il y en a anssi beaucoup vivant aux dépens des autres, connues pour leur amour des arentures, leur courage impréroyant, leur besoin de changement continuel, leur manque absolu d'occupation, cnfin leur tendance an vol.

L'Arahe pillard croit que Dieu l'assiste dans ses entreprises. (Gén. Dauas). Là, non seulement il est permis, mais il est glorieux de voler un ennemi. Avant de s'engager dans une de ces expéditions, ils distribuent des aumônes aux pauvres, et font à Sadi-Abdallah, un de leurs saints, cette promessc: Si nous retournons sains et sallfs, tu auras ta part.

Dans la tribu des Zacka-Ḱhail, peuple de l'lnde, le vol est unc profession. Quand un enfant mâle vient au monde, son père le consacre cn le filisant passer par une brêche pratiquée dans le mur de sa maison et en répétant par trois fois: Sois un volcur. 
A Noukahiva, le vol prouvait l'habileté, consacrait le mérite.

Les Guaranis sont aussi tous des voleurs. Il est vrai qüils nemploient jamais la violence; mais ils se font gloire d'enlever avec dextérité des objets de peu de valcur; dans leur langue, cela sappelle cueillir ou prendre. (D'Azara, Voy. Am. Mér., 1835).

Plus tarl, avant l'apparition de la propricté individuelle, mais quand la propriété collective existait déjả, quand la tribu posséda, par exemple, des territoires de chasse, ou que son chef les posséda pour elle, on regarda comme coupable celui qui dérohait les biens de la tribu; mais il resta encore permis, lonorable même, de voler les étrangers. Ainsi, charpe tribu, dans la Tasmanie, dans la Colombie, avait son territoire de chasse: tout ctranger qui s'y aventurait était mis it mort.

Les Gaulois netaient pas taxés d’infamie pour un vol commis hors de leur cití (De bello Gallico, xi). Nous en avons dit autant des Germains, p. 74.

Les Esquimanx sont honnites dans leurs transactions réciproques; jamais avec les étrangers. (P.rer, $3^{e}$ Voy.).

2. - Autres crimes. - En dehors du vol, bien peul de nos crimes étaient réputés tols par ces législateurs barbares.

Plus tard, quand la propriété se développa et que la tribu recut une meillewe organisation, surtout sons le despotisme des rois on des prètres, la catégorie des rrimes sútendit, ontre le vol, au lapt, à ladultère, et par dessus tout aux injures proférées contre les chefs, les dieux, ou la tribu elle-mème. Fn Germanie, les seuls crimes punis par letat ćtaient la trahison et la déserlion, que l'on punissait par la corle, et la sodomic, 
dont les conpables élaicut étouffés dins la bone. (Ibali, l. c.).

Le Justinien des lncas, Pachacutec, avait porté des lois contre la hestialiti, l'lomicide, le parricide, la trithison enver's l'Etat, l'adultere, le rapt et le viol, surtont šil s’agissail des vierges sacrées, la séduction, linteste, le vol, la sollomie, la cormption des juges. Prespluc tous ces crimes étaient punis de mort. Mais le pire de tous ciait l’atultere arec une femme des Incas. l'our celui-li, le châtiment itait terrible: on ne se contentail pas de frapper les deux coupables, on faisait nonrir avec eux leurs enfants, leurs csclaves, leurs patrents, tous les labitants de la ville ou ils demeuraient; lit ville elle-même élail détruite et ensevelic sous un antis de rochers. (Garcilasso, IIist. des Jncas, I, 346).

Chez les Battas, l’anthropophagie judiciaire est réglé par un véritable code: sont condammés à être mangés lis adulteres, les voleurs de nuil, les prisonniers de guerre importants, ceux qui prennent femme dans leur tribu, ceux qui atlarquent en trahison, soit les personnes, soit les demeures.

Aux îles Fidji, les actes jugés dignes d'ôtre punis sont en fort petit nombre. Ce sont: le vol, l'adultère, le rapt, la sorcelleric, l'incendie, l'outrage à ume personne de marque. Tout cela revient à dire: offense au maître, allentat à la propriété. On sait en effet que chez tous les saltrages, quelle que soit lcur race, ladultère et le rapt sont punis comme des attentats à la propriété du mari sur sa femme. (Letourneau).

Les Aztèques mettent aussi, au rang des crimes l'ivrognerie et les efforts tentés pour corrompre les juges; les $\Lambda$ ssiniens, la sorcelleric et l'empoisonnement. 
Chez les Juifs, les principaux crimes étaient le faux lémoignage, l'inceste, la sodomie, les blessures, mais, par dessus tout, l'idolâtrie, qui était à leurs yeux le plus grand de tous. "Les cités oủ règne l'idolâtrie sont anathèmes; leurs habitants sont passés au fil de l'épée en lhonneur du vrai Dieu. On ne peut même, sans se rendre coupable, prononcer le nom du Très-IIaut ». 
IV.

LES VÉRITABLES CRINES CIIEZ LES SAUVAGES

CONTRE L'USAGE.

lci se révèle le víritable earactère de la criminalité chez les saurages. Pour eux, alors même qu’ils jouissent déja d'une honne organisation, les vrais crimes se réduisent à un très-petit nombre, et même ils ne sont distingués que fort tard et d'une facon irrégulière. Souvent ce que nous regardons comme un crime ne l'est point à leurs yeux; d'autres faits qui leur paraissent très-graves sont loin de nous sembler tels. Je veux parler des manquements à l'usage établi, ou des fautes religieuses, toutes choses qui, étant donnée la tendance grénérale des religions à perpétuer les usages, quels qu’ils soient, et à les rendre sacrés, finissent par être inséparables.

Ainsi, en Australie, les vieillards seuls et les chef's ont le droit de goûter à la chair de l'Emou. Sil arrive qu'un jeune homme honnête, cédant à la tentation, tue el mange un de ces animaux, il est pris de remords, tombe dans une profonde mélancolie, et demande lui-même à être puni. (Stuart, Hist. universelle des voy., 43).

Il en arrive, autant, à l'Hindou qui boit certaines bières destinées au seul Brahmane, au Juif qui mange du porc, a la Chinoise qui se prostitue volontiers, mais ne peut laisser voir son pied sans se couvrir de honte.

Cette même morale, qui règle la distribution de l'Emou, règle aussi la vengeance, mais de la façon la 
plus areugle. Ainsi, qu'un naturel soit offensé par un blanc, il se vengera, non sur celui dont il aura à se plaindre, mais sur tous les blancs quil rencontrera.

Ainsi encore, en Australic, il n'est pas de mort qui ne soit causée par un maléfice, ei qui, par conséquent, ne réclame une vengeance.

Un Australien, raconte Sander, (Letolficad, l. c.), perdit sa femme à la suite d'une maladie et déclara qu'il devait tuer une femme d'une autre tribu. On le menara de la prison; dès lors il resta silencieux, en proie au remords, poursuivi par l'idée qu'il manquait à son deroir; il finit par disparaittre et, quelques jours après, rentra satisfait: il s'était acquitté de ce qu'il appelait une obligation sacrée. On voit, ajoute ici Letourneau en guise de commentaire, que certaines associations d'idées se sont lentement gravées dans nos centres nerveux et doivent fatalement se faire jour à un moment donné.

Mieux que cela, ajouterai-je à mon tour. Il en est ainsi parceque, si l'homme accueille arec un rif plaisir une innovation de peu dimportance, il ressent du dégout et de l'effroi, quand il se tronve en présence d'innovations trop radicales. Il entre, pour beaucoup, dans ces sentiments, je crois, la douleur que fait naître en lni la nécessité d’imposer à son cerveau des évolutions plus rapides et auxquelles il n'est point accoutumé; car le commun des hommes, tout comme les animaux, se plait à l'inertie, à la répétition des mouvements déjà exécutés, qußils soient propres à l'individu ou qu'ils proviennent de l'atavisme. C'est ainsi que nous arons ru les animaux domestiques protester et réargir contre toute nouveauté considérable, contre le gaz, par exemple, ou la vapeur (p. v. s. 24). De même l'enfant, qui certaine- 
ment aime fort à jouer, s’irrite et éprouve de vérilables accès de fureur quand on le change d'appartement (j’on ai fait moi-même l'observation sur deux enfants le mes amis); de même encore il a peur de tout meuble nouveau, et reut revoir toujours la même image, entendre raconter la même histoire dans les mêmes termes.

Ne roit-on pas la femme, esclave de la mode, se montrer partont l'adversaire la plus tenace de toute innoration sociale, religiense on politique?

Ne sait-on pas encore que le vulgaire tourne en ridicule on regarde avec frayeur toute proposition tendant à changer les vieilles contumes, quelrue condamnables, quelque absurdes quielles soient?

les peuples actifs et fort cultivés, comme les Juifs, se montrent à cel égard intraitables; ils regardent comme un criminel, comme un ennemi de la morale, quiconrue, parmi eux, se soustrait a la circoneision, ce rite de cannibales! - Bien plus, les hommes doctes, les académiciens, donnent trop souvent des marques de ce travers, en protégeant cenx qui trourent de potites vérités sans importance, et en poursuivant à oultrance toute découverte radicale. - Et tous vous disent: " linsi faisaient nos pères". C’est lì, paraît-il, le meilleur de tous les arguments, puisqu'en effet il répond à une tendance innée de notre organisme.

Voilà pourquoi j’ai pu démontrer ailleurs (1) que l'homme, naturellement, éternellement, conservateur, n'aurait jamais progressé sans la coïncidence des circonstances extraordinaires qui l'ont forcé à surmonter la douleur de l'innovation pour apaiser d'autres plus grands douleurs; et sans l'aide d'hommes extraordinaires, tels

(1) Genio e Follia $4^{\text {s }}$ édit. 
que les fous de génie et les demi-fous (mattoidi). Ceux-ci doués d'une organisation anormale, ayant un altruisme exagéré et une activité cérébrale bien supérieure à celle de leurs contemporains, prériennent les érènements, et, sans se soucier d'eux-mêmes, entraînent aux innovations, le peuple qui trop souvent se venge d'eux en les tuant; ces hommes, ressemblent à ces insectes qui volent d'une fleur à l'autre et transportent un pollen auquel il aurait fallu bien du temps et bien d'orages pour devenir fécond.

Les peuples sauvages ou primitifs, en qui l'esprit est moins actif que dans les races civilisées, poussent au plus haut degré la réaction contre toute nouveauté, jusqu'à en faire regarder les auteurs comme eriminels de la pire espèce.

La Bible, en plusieurs endroits, et le code si ancien de Manou (1. I, art. 108,9) ont admirablement rendu cette idée.

« La coutume antique est la prineipale loi quapprouve la tradition révélée; en conséquence, quiconque désire le bien de son âme doit toujours se conformer à la coutume antique.

"C'est pour cela que les Muni, sachant que la loi s'appuie sur les coutumes antiques, ont fondé là-dessus tout leur système d'austérités ".

Comme la religion était officiellement la conservatrice par execllence des usages, et comme elle tint d'abord pour une offense à la morale et une insulte à Dieu toute infraction à l'usage, il arriva peu à peu que les gardiens de la religion, prêtres, mages, médeeins, sorciers, etc., avant même d'ètre devenus ehefs de la tribu, ou du pays, ou de la nation, furent eonsidérés comme des personnages sacrés; ils jouirent d'une impunité presque absolue; toute offense à leur égard passa pour 
le plus grand des crimes, et l'on regarda comme crime loute transgression aux lois qu'eux-mêmes avaient introduites, quelle qu'en fît l'absurdité.

Nous arons vu que, d'après le code de Manou, le lirahmine commet une faute très-légère en donnant la mort à un Condra; tuer un Brahmine est au contraire le plus affreux des crimes. On lit encore dans ce code (chap. Ix, 3171): "Que le roi fasse verser de l'huile houillante dans la bouche et les oreilles de l'impudent qui osera détourner les Brahmines de leur devoir. Que le roi se garde bien de tuer un Brahmine, quand même celui-ci aurait commis tous les crimes possibles; qu'il le chasse du royaume, mais qu'il le laisse emporter ses richesses et ne lui fasse aucun mal».

(Un Brahmine connaissant tout le Righ-véda ne serait pas souillé, eût-il massacré tous les habitants des trois inondes, cùt-il partagé le repas de l'homme le plus vil $)$.

Le Moyen-Age disait: Unde laici decollantur, inde clerici degradentur. - Unde laici detruncantur, ibi clerici ab officio degradentur. (Pentz, leg. II, 30. - Bar, Deutsche Strafrecht, I, 1882).

Dans les théocraties étrusque, druidique, indienne, égypticnne et juive, toute offense à la divinité était un erime, et l'action du prêtre se substituait à celle du citoyen et de l'Etat.

L'ambition et l'avidité des despotes, les intrigues des prêtres, jointes à la crainte aveugle de la populace et à l'habitude de regarder comme un crime tout changement apporté aux coutumes des ancètres, se sont donné la Inain pour forger les lois les plus étranges. Par exemple, en Océanie, e'est un crime, tabou, que de toucher le corps du chef; c'est un crime pour la femme, que de 
porter la main sur la tête ou les instruments de son mari, ou d'un homme, quel quill soit, ou même d'entrer dans une pirogue. Puis, le tabou s'est développé; on ne peut, sous peine de mort, porter un voile blane, parler mal des prêtres, changer son nom pour celui d'un animal, sortir de sa hutte, après la mort du chef, avant que l'on ait sacrifie une victime humaine, manger d'un pore à poil blane el roux. (Rudiguet, p. 555).

La loi saxonne punit de mort quiconque brûle un cadavre au lieu de l'enterrer. (Du Bors, l. c.).

Dans le code de Manou, au milicu des prescriptions les plus justes, on en voit d’incompréhensibles pour qui ignore oú peut mener la folic religieuse.

L'homme qui disperse un amas de terre, qui coupe un brin dherbe avec les ongles, ou qui rogne ses ongles, est perdu, tout comme le calomniateur et l'homme impur (liv. v).

La Bible prononce la peine de mort contre celui qui travaille le jour du sabbat (Exode, 31), qui twe un animal consacri, rui mange le sang ou la graisse des animaux (Lévitioue, ch. vis, 24 à 28). La même peine est infligée à linceste, à l'homicide, an faux prophète, à celui qui approche de sa femme à l'époque de la menstruation, (LÉVIT., xvilı, 19), ou qui mange dı pain levé pendant la fète de la Pàque!!

D'après deux papyrus contenants des prescriptions judiciaires, on roit qu'en Egypte, tuer un animal sacré, profaner une tombe, étaient des fautes graves assimilées à l'homicide.

En Chine, en 1840 un batelier s'était avisé d'adapter à sa barque une ancre à l'européenne; le Gouvernement fit détruire la barque et infliger à llhomme un châtiment. 
PRINCIPES DE LA PEINE (1).

D’après tout ce qui précède, on pent déjà entrevoir quelle a été l’origine des peines: elles résultent de l'abus mème du mal, et aussi des crimes nouveaux qui peu à peu se sont manifestés.

Comme, dans les premiers temps, on navait ancune idée du crine, on ne songeait nullement à une sanction pénale. La vengeance n’était pas seulement permise; on la considérait comme un devoir.

2. - Vengeance privée. - Les Arabes Bédouins ne souffrent pas que lhomicile soit puni par le sourerain:

(1) All. du Bors, Histoire du droit criminel de's peuples anciens, Paris, 1845. - ID., Hist. du droit crim. des peuples modernes, t. I, Paris, 1854.:- J. J. Thosıssex, Études sur l'onganisution judiciaive, le droit pénal et la procedure criminelle de l'Eqypte ancien, Bruxelles, 1868. - In., Études sur l'histoive du droit criminel des peujles anciens, Inde Bruhmanique, Egypte, Judee, 2 vol., Bruxelles, 1869. - J. Tissot, Le droit penal, ir edit., t. 1, ch. xxvir, Paris, 1880. - Lolseleur, Les cjimes et les peines, 1843. - Fr. v. Holtzendorff, Hunduch des Deutsch. Strafrechtes, P. I, \$9 e seg., Berlin, 1Sil. P. Den Giunice, La cendette nel divitto longobardo, nell Archivio storico lombardo, 1875, p. 217. - A. Pertue, Storia del diritto italiano, vol. v, Padova, 1877. - A. Axpreozzi, Le leggi penali degli antichi Cinesi, Firenze, 18is. - Fubr, Sullevolusione del diritto penale. 1883. - Pugla, Sullevoluzione del divito penale, Messiua, 1882. FERri, sull'Omicillio, Bologna, in corso di stampa. - WlARDa, Gesehichte una Ausleg. der Salische Gesetze, 1801. - Bar, Deutsch. Strafrecht, 1882. - Zastrow, Zur Strufrecht Stell. der Sclaren, 18is. -- Waitz, Deutsch. Veifassungsgeschichte, 1880. 
ils veulent lui faire eux-mêmes la guerre, à lui, à sa famille; ils veulent frapper qui il leur plaira, et même le chef de la famille, fût-il de tous points innocent. Les Abyssins, de nos jours encore, abandonnent le meurtrier au plus proche parent de la victime, afin qu'il puisse le punir à son gré. - Chez les Kourdes, si personne ne se plaint d'un meurtre, le crime reste ordinairement impuni: ce sont les voisins qui doivent en demander et en obtenir réparation; mais il est plus honorable de se venger soi-même que daroir recours aux tribunaux. (Letournead).

Chez les Kourankos, l'homicide est puni de mort; mais le condamné peut toujours se racheter en indemnisant les parents et les amis du mort; l'affaire est regardée comme toute privée, et personne ne songe à l'intérêt social. Cette conception si rudimentaire de la justice existe un peu partout dans l'Afrique centrale. Il n'y a pas crime, mais seulement dommage causé au chef ou à un particulier.

Les Australiens sentent très-fortement la passion de la vengeance; ils la satisfont indifféremment sur le premier venu de la tribu à laquelle appartient l'offenseur. Si, par exemple, un indigène a recu une injure d'un blanc, il lui suffit de se renger sur un blanc, quel qu'il soit. Nous arons déjà vu plus haut comment pour cux toute mort résulte d'un maléfice et doit être vengée; de là, une série non interrompue de devoirs sanguinaires, qui sont fortement sentis.

Chacun réagissait par lui-même et appliquait une sanction pénale; plus tard seulement, il s'entendit pour cela avec sa tribu. La vengeance à laquelle aboutissait cette réaction devenail un deroir religieux et civique. 
3. - Vengcance religieuse et juridique. - La vengeance était la passion des dieux du Walhalla, du dieu des Juifs, et des héros de l'Edda; Gudruna, qui, pour venger ses frères tués par Attila, égorgeait le fils do celui-ci el lui en servait le cœur, était considérée comme un modèle de vertu. La Bible (Nombres, 6) reconnaît aux particulier's le droit, et même le devoir, de venger le sang, c’est-à-dire mêne le meurtre résultant du hasilld scul ou de l'imprudence.

Les anciennes lois germaines ne posaient aucune linite à la vengeance: "Qu'il tombe maudit et sans venreance, el que nulle punition ne soit encourue, soit qu'on le blesse, soit qu'on le tue ». Faidam portet. Que la gllerre lui soit déclarée. (WILDA, Strafrecht, p. 157).

Dans le code bavarois, la vengeance occupe une place olficielle: secundum leges vindicte fur comprehensus $j u-$ dici tradalur (s'il n'est pas surpris en flagrant délit).

En dehors des offenses au roi ou à l'Elat, les Germains des premiers temps ne croyaient pas que la paix publique fùt violée par les autres méfails; éétait, pensaient-ils, affaire entre particuliers. L'Etat ne se défendait qu'en ce qui concernait les crimes politiques ou militaires, tcls que la trahison, la làcheté. (BAr, l. c.).

Chez les sauvages, comme chez les animaux, la peine a d'abord le caractère de la vengeance, et ressemble à une espèce de crime. Quand il s'agit de poursuivre des individus plus forts et plus puissants, on est poussé à s'associer pour exercer des représailles. Or, s'il arrive que ces associations triomphent, le crime devient à son tour un instrument mis au service de la morale.

Mais cette vengeance, tout d’abord, n'était pas la justice; elle ćtait une réaction qui variait selon la gravité de l'offense, el, chose pire, selon la susceptibilité de 
la victime et de ses amis. Aussi, aboutissait-elle presque toujours à la mort ou à la peine du talion, oeil pour ail, dent pour dent (Deutèr., 19); on coupait les doigts aux coupe-bourses (Maxou).

On peut voir, encore aujourd'hui, nos enfants incapables de se contenir, tant quils ne se sont pas vengés des coups qu'ils ont reçus et qu'ils n'ont point frappé leur adversaire à l'endroit précis où ils ont été frappés enx-mêmes.

4. - Puissance supérieure des chefs. - Crimes contre la propriété. - Comme la vie liumaine a peu de valeur chez les peuples primitifs, le meurtre ne provoquait que peu ou point de ressentiment; il ne devenait un crime grave que s'il étail commis sur un chef ou sur mn prêtre, représentant de Dieu sur la terre, ou si le coupable était étranger à la tribu. A l'inverse, il était regardé tonjours comme de peu d'importance s’il avait pour auteur un chef ou un prètre.

En Afrique, chez les Ashantis, tuer un esclave est un acte tout-i-fait indifférent; mais le meurtre d'un grand personnage est puni de mort. On permet toutefois au coupable de se tuer lui-mème. En revanche, quoiqu'il ait fait, le fils du roi n'est jamais frappé de la peine capitale (1). Nous arons fait la mème remarque à propos de l'adultere.

Aux îles Fidji, la pénalité juridique résulte de la hiérarchie qui règle la société; ot la gravité d'un srime varie selon la position sociale du coupable, comme dans nos lois du Moyen-Age. Un vol commis par un

(1) 11 en est de mêne encore aujourd'hui dans les vieux Etats monarchiques. La rite io re l'affitto, (Belli). 
homme du peuple est chose bien plus grave qu'unmeurtre commis par un chef.

Les Bambaras punissaient de mort le voleur, l'adıl tère et l'assassin; mais cette peine neétait appliquíc ni an fils dı roi, ni anx ouviers qui travaillaient le fer.

Dès que, par l'aceroissement du despotisme et par la force des armes, dans les invasions, les chefs se furent rendns propriétaires a la place de la tribu, le rol commis i leur préjudice fut, pour la première fois, ronsidéré comme un crime; ensuite, comme cètaient eux qui dictaient et appliquaient les lois, il devint le plus grand des crimes, comme d'ailleurs l'adultère quand il souillait leur maison. - Puis, de ce premier cas tout personnel, on passa ì l'application des mesures coercitives en fareur de la pluralilé.

Qu'en résulta-t-il ? C'est que le vol fut toujours regardé comme plus criminel que l'assassinat, qui ne lésait ni la propricti, ni les intérèts des chefs. Il y a mème des races, dit très-bien M. Ferri, les Dayacki, par exemple, chez qui l'homicide est encore en honneur, et qui l'éprourent le rol et le mensonge. - Le code de Manou, en même temps quil définit le meurtre un délit secondaire, analogue au délit que l’on commettrait en abimant une. plante, ordonne de coupcì en morceaux, avec un rasoir, l'orfèrre qui aura trompé son client. - Les Douze Tables condamnaient à la potence quiconque, pendant la nuit, coupait les bles d'autrui; elles condamnaient les incendiaires au supplice du feu. Il était permis de couper en morceaux le corps d'un déhiteur; le père arait le droit de tuer son fils; on pourait, pour 300 as, se faire absoudre daroir rompu les os à un homme libre, et pour 150, d’aroir infliĝ̣́ le mème traitement à un esclave. 
Dans la Polynésie s'était établic une morale grossière. Le vol et l'adultère y étaient tenus pour les plus grands des crimes, et souvent punis de mort. A la NouvelleZélande, le voleur était décapité et sa tête suspendue a une croix. Enfin, comme les chef's centralisaient la justice, ils ne l'exergaient que pour punir les méfaits dont eux-mêmes avaient à souffrir.

En Afrique, chez les Cafres, le vol est assez régulièrement frappé d'une amende, sourent même puni de mort. L'adultère cst poursuivi de la même façon, mais seulement à titre de rol. En retour, la vie humaine reste presque sans protection. "Un mari peut tuer sa femme pour les motifs les plus liutiles ». (Letourneau).

Enfin en Asie, chez les Mongols, au 'Tlibet, en Birmanie, le rol est considérć comme un méfait bien plus grave que l'lomicide (1).

Chez les Germains, le vol, quand on l'annonçit d'avance par des cris ou à son de trompe, n'était pas considéré comme un délit. - Cela prouve bien qu’on était fort éloigné de l'idée pure de la justice à renger; une autre preuve encore est tiréc de l'inégalité du traitement subi par les coupables selon leur rang dans la société.

5. - Transformation de la peine. - Le duel. - Au début, la vengeance et la peine se confondaient; elles revenaient à tuer ou à faire une blessure suffisante pour donner à la victime ou a ses amis une compensation du dommage subi ou de la douleur éprouvée. Mais cette peine s'appliquait au hasard, comme il est naturel, ou plutôt selon la passion ou les instincts de chacun. Le public ne pouvait qu'y perdre beaucoup.

(1) Lefourneau, Sociologie, 433, 436, 438, 450, 452, 455, 467, 471, 478. - Truol, Rerue scientifique, 18it, 1. 1204. - Ferer, Omicidio, 1. c. 
Comme, selon toute probabilití, les riations toujours plus violentes qui se succedaient auraient fini par faire disparaitre la tribu, celle-ci, afin de pouvoir so maintenir dans son organisation, voulut a ces riactions, í ces vengeances, imposer une règle, je dirai même, un rituel, qui se rapplochait fort de la coutume premiere, mais qui présentait dijà un adoucissement, une limitation juridique. C'est ainsi que nous voyons it Tahiti le meutrier attaqué par les anis du défunt; il se défend armé seulement d'un bouclier; s'il est vaincu, son bien devient leur propriété, el réciproquement. Il y a lì évidemment une reproduction en grand de la vengeance personnelle.

Chez les Germains, comme chez les Australiens, on levait tuer son adversaire, mais loyalement; et selon fa loi Ripuares, il fallait ensuite veiller son cadare, ou du moins se tenir en mesure d'indiquer aux parents l'endroit où il gisait.

Les chatiments, dans leur ensemble, prennent l'aspect des rixes ou mieux des duels, on encore des battailles qui, dans ces contrées, ressemblent fort à des duels. Ainsi, la tribu qui veut en attaquer une autre, la prévient lout dabord et lui fournit les armes nécessaires; à un signal donné, chaque parti lance des traits; puis, après un nombre de morts détermine, on se donne la main et tout finit par un Jal. (TrLor, 108). Ou bien encore les deux armées se placent en face l'une de l'autre, les combattants sortent des lignes, par groupes, et se Iancent le javelot. On ne frappe jamais plus d'un coup, on vise toujours a la tète, et il est defendu de parer.

Les premières formes d'un chitiment, réglé par la loi, furent certaincment, des duels, on des combats 
livrés par plusieurs hommes à l'individu présumé conpable, comme nous l'avons observé chez les animaux. Ce furent en somme, des rixes qui, plus tard, la justice règlementa (1).

6. - Amende, restilution. - Les esprits s'adoucissant de plıs en plus, la vie humaine, et, en mème temps, la propriété acquérant plus de prix, on en vint í chereher la compensation, non plus dans les blessures, mais dans la valeur on dans la restitution, rue la tribu dut garantir.

La compensation fut sonmise aux mìmes règles que la vengeance; elle variait de mème suivant la position sociale de l'offensenr et de "l'offensé.

Che\% les Assiniens et les Achantis, lo voleur était frappé d'une amende; s'il ne la payait pas, ses parents ou son villag̣e répondaient pour lui. Et mìme, an Thibet, les parents du voleur subissaient leur part du chatiment, on plutôt de l'amende.

Les Achantis émasculent celui qui vole le roi et flétrif ses esclares; celui qui viole ses femmes on qui porte une fausse arcusation est condamné à mort.

Quand l'homme ne possédait en propre que son corps, la compensation, pour tout délit, était la mort ou une blessure recue en ducl; mais quand la propriété s'étendit, comme, dans le délit, on considérait par dessus tout lo dommage causé, on troura dans les objets de prix une compensation plus fructueuse. C'est ainsi que te nos jours encore, nous l'avons vu, les Mfghthans donnent 12 femmes pour racheter un homicide, 6 pour la mutilation d'une main, d'une oreille ou du nez, 3 pour

(1) lei je rappelle que VAvoces, l. e., fait venir bellume de thellum. 
une dent. (Lleninstone, Tubleau du royaume de Cuboul, $1,156)$.

La loi des Donze Tables admettait déji la composition en argent.

Si membrum rupel, nisi cum co pacil, talio esto.

Chez les Germitins, l'offense privé, le menrtre, n'itaicut pas justiciables du pouroir public; l'tat nontervenait que si les parents du mort renongaient alu droit de vengeance privée et se contentaient d'une composition en argent: cétait le wehrgeld, ou rachat de la vengeance. Plus tard, au wehrgeld s'ajouta l'anende proprement dite, fredum.

Sclon Sumner llaine (Droil ancien, ch. I), combaltu aujourd'hui par Pantaleoni (Rasserna nazionale, mai

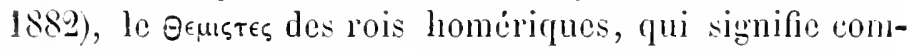
mandement, sentence, inspiration divine, a aussi le sens de tribut. (Iliade, $x, 756$ ). Ce mot est le pluriel de Thémis, la déesse Thémis, qui a dû bien naturellenent dans la suite se montrer vénale, si telle a été son origine. - Pour moi, je trouve l'explication de ce sens contradictoire et qui présente un si frappant contraste, dans la nature des peines alors en usage; car prespue toutes elles se réduisent à une compensation.

Dans l'Iliade, ne voyons-nous pas Achille égorger douze Troyens? C'est une nown pour le meurtre de Patrocle. Irais on regoit, dit Ajax, la compensation pour le meurtre d'un frère ou d'un fils. - Le meurtrier', apres l'avoir payée, retourne parmi les siens, el celui qui l'a resue renonce à toute idée de rengeance. (Ilomène, Iliade, $\mathrm{x}, 682$ ). La nown ou la peine, dérive de $K$ rena, de $K i$, vérifier, compler, frapper d'une amende. (VAxicek, l. c., 152). 
De ces amendes rint, également en Altemand, l'homophonie des deux termes, skel, tuer, et skal être débiteur (Grinu, Gesch.der Deuts. Sprach., 1840), - et de mordrum, homicide el droit qui se paie all juge, droit de confiscalion (Bors); - la langue russe a un vieux mot, vina, qui signifie peine et dette, preuve que la peine élait presque toujours une espèce de pajement.

A cela contribua certainement un intérêt bien entendu et la néccssité. Les peuples commerçants, qui roulaient aroir des relations arec les autres, renoncèrent ì les piller pour éviter l'interruption des échanges, et derinrent, ensuite, honnotes par habitude.

Il y ent encore une autre influence: quelques races, comme chez nous, certains enfants, se sonl fait rentarquer par des moeurs douces, qui les ont poussées it alındonner les habitudes guerrières. On s'explique ainsi que les Todos, les Santales, les Aino soient doux, serupuleux, et rendent une somme supérienre à celle qui leur a de confiéc; on comprend comment il se fait qüi une faible distance des Balantis rapaces rivent les Bagnous, ces pacifiques cultivateurs de riz.

Il y a lá une influence de race. Il y a aussi, des influences tout-it-fait individuelles.

Chez les Ilottentots et les Cafres, on roit par exemple, des individus plus saurages que les autres, incapables de tout travail, virant des faligues d'autrui, menant unc cxistence vagabonde; ils sont appelés par les Cafres Fingas, et Sonquas par les Ilotientots. (Maymew, l. c.).

7. - Autres causes de la compensation. - La mansforunation de la vengeance en compensation fut encore facilitée par l'exagíration mème de la vengeance, qui naturellement ctaif toujours disproportionnéc à la cause et 
devait par là même être une source de haines et llagitations continuclles.

Ainsi, la loi Mosaïrque permeltait de renger par la mort un lomicide par imprudence (Devtéroxone, $\$ 19$ ), mais clle arait la précaution de désigner trois citís ou les malleureux pourraient se réfugier. En outre, dans le lirre des Nombres, xxxy, il est fait mention l'ume espéce d'arbitre populaire - qu'alors l'assembléc soil juge - qui devait être un des germes du jury.

Les Fueros Juzco d'Espagne nadmettaient pas le talion pour les blessures faites it la títe, parceque la réparation anrait été supérieure à l'offense. (Du Bors, l. c.) On ne l'accordait pas non plus, s'il ne s'agissait de venger un très-proche parent.

Mais ce changement résulta surtout de l'accroissement des richesses, de la possession d'une propriété, grâce ì laquelle il était possible de réparer le dommage dans une proportion plus équitable. Et cette institution, à son tour, angmenta le pouvoir des chefs qui araient pour mission de la déterminer et de l'infliger.

Une fois que se fut introduit l'usage de la composition pour la vengeance, pour l'homicide, on vit naturellement se produire l'intervention d'une tierce personne, celle de l'antorité, qui en devait fixer le chiffre; le même système fut étendu à tous les autres crimes on délits qui étaient toujours ramenés à la conception d'un dommage éprouré par le roi.

8. - Les chefs. - Ajoutez que les chefs et les prêtres s’appliquèrent do leur mienx à maintenir les peines, quand celles-ci se furent transformées en compensations; car ils y trouvaient de grands avantages. 
A Uganda (v. Speke) un homme était condamné à nort pour s'être assis devant le roi en laissant voir un pouce de sa jambe nue, pour n'avoir pas noué son vêtement d'écorce, pour n'avoir pas salué avec la précision voulue par l'étiquette, pour avoir touché, même par lıasard, le trône ou le vêtement du roi. Il paraît certain que la plupart de ces crimes ont été inventés par ces rois, comme ils le furent plus tard par les Césars de Ronte, pour des raisons financières. Speke en domne la preuve: "Un officier, dit-il, qui se présente ¿ la Cour dans une tenue négligée, encourt la peine de nort; toutefois, cette peine est remplacic par une amende en gros bétail, en chèrres, en poulets et en fils de laiton.

Dans le mème voyage, Speke vit un de ces curieux b.changes entre la peine de mort el la compensation. Un courrier de M'tesa s'était, contre tout droit, couvert les ćpaules d'une peau de tigre, insigne de la Famille royale. "Si je le dénonce, dit un chef à Speke, il ne perdra pas moins que la tôte n. Et le coupable fut enchanté de payer cent génisses!

10. - Religion. - Comme la religion sait toujours perpétuer à son profit les coutumes, c'est elle qui d'abold répandit la compensation, dans les pays où l'élénent théocratique l'emporta sur l'ćlément guerrier, c'est elle qui l’a perpétuée jusqu’a nos jours.

Voila pourquoi, apres les chefs, on ne trouva pas d'hommes mieux disposés à réprimer les crimes (en donnant, bien entendu, la préférence à ces actes que la superstition faisait considirer comme des crimes et qui ne seraient pas même pour nous des contraventions) que les Prêtres, Koen, Toa, Tabib, Nigrata, ete., réu- 
nissaient presque toujours les professions de médecins et de derins, et, seuls ou s'appuyant sur les chefs, prenaient prétexte non sculement de tout délit on de toute faute, mais encore de tout désastre, de toute mort, de toute saison de l'annie, pour montrer qu'il y arait quelque faute i racheter, quelque victime is choisir. En poursuirant les criminels, rrais ou supposés, ils augmentaient leur autorite propre, mais souvent, pourtant, an miljen des nombreuses injustices ru’ils commettaient, ils parvenaiont i frapper un vai coupable.

L'influence théocratique nous explique pourpuoi dans la Bible, on trouve les mots péché el faute, Hatá et mution, synonymes parfaits du sacrifice offert pour racheter le péché ou la faute. On peut faire la même observation dans l'Inde: le mot sanscrit lilevesa signifie péché el sacrifice; médailles philologiques, d'après lesquelles on voit bien que l'idée du crime vint à l'homme après seulement qu’il eût subi une peine pour ce crime mime. C'est ce qui arrive au criminel-né, comme nous le verrons plus loin.

Cette influence théocratique a également produit, au Moven-Ige, ces fameux jugements de Dieu, que nous royons si uniformément adoptés par toutes les peuples primitifs. (Toir leepreuve du panda, de la tanghinia, dı Calabar dans l'Afrique, de l'eau, du feu dans l'Inde, chez les Calmurues). - Quand des témoins réridiques faisaient défaut, pourait-il ne point sembler juste à ces populations, qui confondaient la religion avec la justice, les juges arec les prêtres, de s'en rapporter à leur Dieu, le chef des chefs, de qui dépend le destin des humains?

Naturellement, l'intervention des prêtres n'était jamais gratuite. "Quiconque, lisons-nous dans le Lévitique, ch. v, aura été témoin d'un péché ou aura touché 
à la souillure d'un homme, doit, pour racheter sa faute, offrir au Seigneur une brebis ou une clièrre, ou tout au moins deux tourterelles, ou deux pigeons, l'un pour le sacrifice, l'autre pour l'holocauste. Qu'il les porte au prêtre, qui offrira d'abord l'animal destiné à racheter la faute en lui tordant le cou, etc. Si, le coupable na pas à sa disposition deux tourterelles, qu'il porte la dixième partie d'un épha de fine farine. Celui qui aura retenu des choses consacrées au Seigneur devra d'abord les restituer, puis présenter pour le sacrifice un béliep sans tache, et en sus un cinquième de la valeur de l'oljjet. De mème, si quelqu'un manque it la parole donnée, s'il garde un dépôt confié, sil se rend coupable d'un faux serment, etc. ".

En somme, tout cela, pour un examinateur attentif, n'est que simonie; et foumbrie de la part des prêtres et des chefs, qui veulent ainsi s'enrichir on étendre lemr ponvoir. Néanmoins, c'est gràce à ces moyens et i d'autres du mème genre, que la rraie morale a pénétré dans les sociétés humaines, qui auraient pent-être bít rebutées par une vertu trop sévère et trop absolue.

Ciest ainsi que nous arons ru un pen plus haut it quel absurde abus de pouvoir avait conduit la pratipue du tabou; el pourtant ce fut à elle, sclon Radiguet, que l'on dut de ne pas mourir de faim; car elle défendait de tuer les animaux utiles et de détruire les plantes, quand celles-ci menaraient de disparaître. Elle empècha, ainsi le dépeuplement des côtes poissonneuses: interdit le mariage entre parents trop proches, fit respecter la propriété et la conserva. Elle multiplia les rapports sociaux en défendant, par exemple, comme chez nous dans le mojen-ìge de nuire à un ennemi que l'on aurait convié à une fète. 
Selon Du Boys, ce fut aussi le tabou qui mit le premier frein au vol, passion commune ì tous les peuples de l'Océanie.

Selon Du Boys encore (l. c.), l'homicide eommenera it devenir moins fréquent, cliez les Germains, sriàce an culte de la díesse Freya. Durant les lëtes (Freda) célébrées en l'honneur de colte divinité, il y avait des trèves entre les cnnemis; ces trìves protégeaient mème les faibles (femmes, enfants, etc.) contre les puissants. Dans ces intervalles de paix, s'établirent des foires et des marehés provisoires, qui devinrent dífinitifs à mesure que la sécuriti ful phus grande, et donnèrent naissance à des cilés comme celles do la Ligne IIanséatique, où s'est perpétné l'esprit commercial. C'est. ainsi que la religion, se mèlant anx intérêts matéricls, contribua it diminuer les crimes et it introduire unc législation pénale. Quiconque, en effec, rompait la Freda, était puni de mort.

La religion, en somme, en sappuyant tout d'abord sur l'intéret, mème peu arouable, d'un petit nombre de gens habiles, puis sur celui des masses, qui, par ricochet, en retiraicnt un avantage sérieux, étal,lit, en mème temps que des superstitions nombreuses, l'idéc morale de la fante; elle introdusit et répandit des peines qui d'abord pent-itre tournaient it l'avantage unirque des législateurs, mais ne tardèrent pas à profiter aussi à l'humanité toute entière. En effet colle-ci, sans autre frein que la force des muscles, n'aurait jamais pu se donner une réritabie organisation.

11. - Sectes. - Cotte transformation et celte introduction du chàtiment ont anssi une autre origine. Elles ont quelquefois été produites par certaines associations 
secrètes, d'apparence souvent religieuse, que l'on roit pulluler chez les races les plus barbares, comme dans les pays civilises quopprime la tyrannie. Ce sont, presque toujours, les faibles qui, pressés par le besoin de reagir contre les forts et les puissants, conmettent des dilits qui, dans le fond, ne sont pas autre chose qu'une application grossière de la peine; cest un instrument fort impur, il est rai, mais pourtant efficace de la morale, et qui, pour cette raison même, finit souvent pall triomplier.

Telle fut à l'origine la camorra. Telles sont en Afrique les Sindungi, sociétés secrètes qui se proposent de forcer les débiteurs à payer leurs dettes. Au Sénégal, les associations des Mumbo Djembo contre les adultères, se sont formées de la même manière. (Hartuanx, Les peuples de l'A frique, p. 219). C'est encore ainsi que chez les Duni on royait des sociétes qui favorisaient l'arortement et l'infanticide. (ID.).

Mais, de quelque faron que ce soit, celles mênes de ces associations qui ont pour but la morale sont, au fond, dans l'action criminelles; leurs membres, par exemple, n'hésitent pas à metlre à mort quiconque vient les troubler dans leurs réumions. (Ihartuax, 219).

12. - Plus brutal, assurément, mais également injuste et criminel, fut cet autre moyen de répression que Lelourneau désigne sous le nom d'anthropophagic juridique. Nous avons vu les voleurs de nuit, les adultères, elc. chez les Battas, condamnés à être mangés par le peuple; le mari avait droit au meilleur morceau. (LETOLRNEAU).

A l'ile Bow on mangeait les assassins. Ciest le seul point de la Polynésie où l'on ait constaté le canniba- 
lisme juridique, qui, an dire de Bourgarel, s'appliquait également dans la Nouvelle-Calédonic aux condamnés a mort, et que Hareo Polo nous montre aussi en usige, chez les Tartares.

Qui peut savoir combien de sentenees de ce genre ont eté conscillées par la gommandise, par la savem d'une grillade de chair humaine? Et dire que cetle priatique odiense et criminelle, rui s'est maintenue mìme après m commencement de civilisation, a pu contriluer il faire disparâtre les crimes!

Qui sait combien de jugements iniques a fail prononcer à des hommes passionnés la coutume de l'antique Latium concernant l'adultère soumise an coitum de toute la communanté?

13. - Conclusion. - Rappelons-nous, avant tout, que la passion qui contribua le plus a la répression du crime fut celle de la vengeance: que la promiscuité de l'amour disparut gràce à l'inceste introduit par le désir de contracter des alliances nobles, grice à la polyandric et à la polygamic, qui résultèrent de la rareté ou de l'ahondance des femmes, et plus encore de la prédilection du chef de la tribu, ou d'un homme puissant, pour une farorite; el plus tard grâce an rapt ou a la puissance supérienre dun chef, si hicn qu'il $y$ arait crime a toucher sa femme, tandis qu'on pourait avoil commerce avec celles des autres sans être coulpable (v. s.). Songeons que le vol commenca à ètre puni quand s'ouvrit l'ère des concuètes, quand les chefs plus puissants ont roulu conserver ce ru'ils avaient pris et refusé de le partager avec leurs compagnons plus faibles, en sorte que la répression du vol, comme celle de l'adultere, se horna longtemps aux propriétés des chefs. 
Aprés tout cela nous sommes bien en droit de conclure, sans blasphémer, que la moralité et la punition du crime sont nées, en grande partie, du crime, qu'elles étaient, même, un crime.

\section{4. - Vestiges des anciennes tendances criminelles. -}

II y a chez nous des muscles rudimentaires qui atlestent leur préexistence, sur une plus grande échelle, dans les organismes inférieurs ou dans l'embryon; ainsi certaines habitudes, maintenues pour la plupart par la religion, cette conservatrice obstinéc des coutumes les plus anciennes, rappellent l'existence d'usages plus barbares et en font revivre les divers degrés jusqu'à l'époque contemporaine, alors même qu'elles ont perdu leur marque originelle.

C'est ainsi qu'un reste du cannibalisme et de l'infanticide consacrés par la religion s'est conservé dans la circoncision, le rite le plus révéré des Juifs; e’est ainsi encore que le dialecte vénitien emploie le mot orecchiotto pour signifier une portion, et litalien dit coppa pour une lasse qui dérive de liopf en allemand tête. On peut faire la même remarque à propos de l'hostie des chréliens.

La prostitution, qui précéda les unions légitimes, et surtout la prostitution sacríe, se trouve à des époques plus récentes, dans les fôtes des Dionysiaques, des Lupereales, dans les termes hébraïques kadessà, sainte et prostituée, Kadessud, maison de tolérance et sacristie, et dans nombre de sectes qui ont confondu la religion avec la prostitution et même avec les pratiques sodomitirques. Voir les Adamites, les liänites, les Nicolä̈tes, ele.

Le rapt, on mieux le viol, antérieur au mariage, ont laissé leur trace dans le rite nuptial de presque tous les peuples, et jusque dans celui de l'ancienne 
Rome, qui, on le sait, marque le début de son histoire par un de ces enlèvements (v. s.).

En voyant l'homicide et le vol si répandus dans les sociétés primitives, on comprend qu'en des temps moins ruels ces crimes aient dû sourent être comptés pour de véritables facteur's historiques.

Au temps de slachiavel, et plus encore pendant le Ioyen-ige, le meurtre politique était une arme pour les diplomates; aussi voyons-nous des historiens rélıabiliter les Borgia et les Ezzelin.

15. - Vestiges des châtiments. - On peut faire les mèmes considérations touchant les idées primitives de justice et la procédure pénale en usage chez les sauvages.

Le duel, qui fut un premier pas vers le châtiment, la vengeance légale et la gouerre, a persisté jusqu'à nos jours, bien que réduit à des formes moins sanguinaires et bien qu'il ne soit sourent qu'une convention ridicule. Il est probable que sa persistance chez les peuples les plus cirilisés est due, non pas seulement à ce qu'il fournit une issue plus noble et plus tempérée aux passions surexcitées, mais encore à un reste d'atavisme qui remonte aux temps les plus reculés. N'est-ce pas ce nième atavisme qui a tant de fois justifié à nos yeux les guterres entreprises contre des peuples faibles? Or ces guerres ne sont à tout prendre que des meurtres, accomplis légalement sur une grande échelle.

L'instinct de la vengeance, qui présida à une si grande part des délits et des peines, est encore aujourd'hui très-rivace au sein des classes inférieures. Ce n'est pas seulement au fond du cœur qu'il serpente involontairement; il apparait, comme un lapsus lingua, dans les Aiscours des hommes chargés de rendre la justice. Au- 
jourd'hui encorc, comme chez les sauvages, celui qui s'attaque à un chef provoque une réaction bien plus grande, est frappé d'une peine bien plus forte, que s'il avait pris à partie un homme du commun. Ajoutons que les condamnations sont toujours d'autant plus rigoureuses, que la date de la faute est plus rapprochée.

Lamende sacrée, qui servait jadis à racheter les crimes, est restée en rigueur dans le monde pendant bien des siècles, ct l'abus que l'on en faisait fut une des principales causes de la réforme de Luther. Il n'y a pas bien longtemps encore que toutes les fautes étaient publiquement taxées; on avait dressé pour cela un tarif (I) qui, ne différait en rien, au point de vue moral, du tarif en usage chez le peuple le plus sanvage.

Telle était celte bulle de composition ou componenda, dont jaa publié le texte dans mon Incremento al delitlo, et qui fut en pleine vigueur en Sicile, jusqu'à l'annèe 1860; il fallut les décrets de Crispi et de Taiani pour la faire tomber (2).

Un reste de cette justice primitive que le peuple exercait dans un moment de fureur, et que nous avons reconnue chez les animaux, se retrouve dans le jury. Aujourdhui encore, surtout dans les pays chauds, le même jury qui frappe un voleur acquitlera un homicide. Cela no rappelle-t-il pas les premiers crépuscules de la justice?

Cette forme criminelle de la justice s'est reproduite à la lettre, en Imérique, avec la loi de Lynch quiun

(1) Les tases re la S. Penitencerie Ajostolique, trarluction nouvelle en regard du texte latin, par I. St. André, ete., sur l'idition approurée par les superieurs et munie d'un privilige pour trois ans, faite à Paris cn 1550, chez Toussaint Denis. - Paris, (r. Fisehbacher éditeur, 1570.

(2) $\mathrm{V}$. Ineremento del delitto in Italia, in ediz., p. 148-149. 
publiciste défnit: une explosion de la colère populaire, affectant une forme de justice, et s'appliquant d'une manière fort différente aux blanes et anx gens de conleur. - Bien souvent elle a pour canse, comme le cannibalisme guerrier, une satisfaction barbare, un plaisir cruel de roir une exécution et d'y mettre la main.

Je dirai plus: cette complaisance que l'on trouve dans le public mème pour la condamnation d'un aliéné coupable d'un acte de sauvígerie etc., est un reste de l'antique sentiment de rengcance, qui, at son tour, nous le verrons plus loin, est la source de la plupart des crimes, ear il persiste, en proportion bien plus grande, dans le criminel-né.

L'opposition acharnée que rencontre la nouvelle école anthropologico-criminelle qui, regardant les coupables comme des malades, veut, pour cela mème, leur appliquer la dítention perpétuelle, provient, sans nul doute, de ce sentiment qui se cache et couve, pour ainsi dire, en chacun de nous, mème dans ceux qui s'en dífendent avec le plus d'énergie. On ne trouve pas que la détention simple soit une satisfaction convenable; on veut la compensalion föroce de voir souffrir à son lour celui qui a fait souffrir; on reut le talion, mais seulement par pudeur, on en change le nom et lapparence.

16. - Nous avons établi qu'à un moment domé le crime élait universellement répandı, quil se prit ensnite insensiblement à disparaitre, gratce à des crimes nouveatix, mais en laissant les traces de son origine jusqu'à notre éporgne et surtout dans la peine. Cela, mieux encore que l'étude des crimes chez les animaux, peut nous faire douter de la prétendue juslice éternelle des métaplysiciens - et nous faire comprendre que si le crime 
n'a cessé de se produire même dans les races les plus ulutivées, la vraie cause en réside dans l'atavisme.

Pour finir, je dirai que l'origine impure de la justice peut nous servir à expliquer l’inégalitè avec laquelle elle est distribuée de peuple à peuple, et chose pire, de classe à classe. On le sait, pendant qu'au parquet et dans la chaire on déclame sur la justice éternelle, égale pour tous, le paurre n'obtient réellement justice, on peut le dire, que par exception et comme par chalite; le riche, au contraire, dispose de moyens nombreux pour y échapper ou du moins pour obtenir un chattiment plus doux. - Souvenez-vous que la justice fut sowvent une émanation du eaprice d'un despote, ou d'un prêtre, ou de la fureur populaire; et rous comprendrez comment il se fait que les peuples ne soient pas encore délivrés du droit de grâce, droit absurde, mais qui résulte de l'atavisme; vous comprendrez qu'ils soient encore soumis au jury, cette institution si contraire au but poursuivi, si incertaine, si facile à colrompre, mais dont lorigine est la même que celle du droil de gràce. 


\section{CIIAPITRE III}

\section{La folie morale \\ et le crime chez les enfants.}

11 est un fait qui a peut-ètre échappé à bon nombre d'observateurs, précisément par sa simplicité et son universalite, et que Moreau, Perez et Bain ont à peine aujourd'lui dégagé clairement; e’est que les germes de la folie morale et du crime se rencontrent, non fall exception, mais d'une facon normale, dans les premières années de l'homme, comme dans l'embryon se rencontrent constamment certaines formes qui dans un adulte sont des monstruosités; si bien que l'enfant représenterait un homme privé du sens moral, - ee que les aliénistes appellent un fou moral, et nous un criminel-né. En roici des preuves convaineantes.

1. - Colère. - Perez (1) a démontré la fléquence et la précocité de la colère chez les enfunts. "Dans les deux preniers mois, il manifeste par les mourements de ses sourcils et de ses mains une réritable colère fuand on veut le laver, ou lui enlever un objet. A un an, sa colère va jusqu'à battre les personnes, à briser los plats, à les lancer contre ceux qui lui déplaisent. Il est en cela semblable aux sanvages, aux Dacotah, qui

(L) Psychotrgie de l'nfunt in ediz., Paris 1882. 
entrent en fureur quand ils tuent les Bisons, aux Fidjiens, qui, dans leurs émotions, se montrent trèsirritables, mais sans beaucoup de suite \%. (Pérez).

Lenfant s'emporte quand il éprouve une doulem, quand il ressent le besoin de dormir ou de se mouvoir, quand il ne peut se faire comprendre, quand on interrompt ses habitudes ou qu'on vent l'empècher de se plaindre, d'exhaler sa mauvaise humeur; quand, enfin, on loblige à fèter un étranger, on qu'on le fait punir par les domestiques, ou qu'il voit deux camarades aux prises et veut s'interposer. Mais, le plus souvent, la cause de sa colère est absurde; car deux sentiments, comme le remarque justement Pérez, dominent en lui: l'obstination el l'impulsivité; ceux qui ont soin de lui, qui le lavent, l'habillent, le déshabillent ou le mettent au lit, sen apercoivent fort bien. Sa colère prend alors lexpression aigïe du caprice, de la jalonsie, de la vengeance; elle nuit à son développement, surtout quand il a une prédisposition anx maladies convulsives, cl elle alleint, en ce cas, des proportions épouvantables.

Certains enfants, dit Horeau (De l'homicide chez les enfants, 1882), ne peuvent attendre, un moment, ce qüils ont demandé sans entrer dans une colère extraordinaire. Perez a connu um enfant de lunit ans, dune grande intelligence, qui, à la moindre observation de ses parents ou mème des étrangers, éprouvait une violente colère, se faisait une arme de ce qui lui tombait sous la main, et, quand il se sentait impuissant, hrisait tous les objets qu'il pouvait saisir.

the pelite fille, en qui on remarquail le mème caraclère, devint bonne, tout-i-coup, à l'igge de deux ans. ( P'́nez, l. c.). 
Let Priez ijoute: "Jen ai ru une de onze mois devenil furieuse, parcequ clle ne pouvait artiver à prendre le nez de son grand-père; une autre, âgée de deux ans, eut un accés semblable pour avoir vu aux mains d'un enfiul une poupée qui ressemblait a la sienne; elle s'efforgait de le mordre; elle en fit une maladie de trois jour's ".

"Lne autre, de deux ans, avail de tels alces de rag" quand on la couchail, que les voisins devaient renil pour la calmer" ».

"Un garçon de quinze mois mordait sa mère quand elle le lavait. Ln autre, de trois ans, renvogé de la salle it manger, se couchait en travers de la porte el poussait des cris de fureur ».

Lit colère est done un sentiment inni chez l'homme: on doit diriger ce sentiment, mais on ne peut espérel le faire disparaître.

9. - Vengeance. - Ces faits nous montrent déja combien est fréquent el précoce le sentiment de la rengeance dans les enfants. Il n'est pas rare de roir un enfant de sept à huit mois égratigner sa nourrice quand clle essaie de lui retirer le sein, et lui rendre les coups qu'elle lui a domnés. J'ai connu un petis garon lígèrement liydrocéphale, d'un développement tardif et d'une intelligence obtuse, qui suirritait de la moindre admonition, de la correction la plus légère: il n'avait que sept ans. S'il pouvait frapper l'auteur de son chagrin, il se calmait aussitôt; mais dans le cas contraire, il continuait de crier, de se mordre les mains. Souvent il réagissait plusieurs lieures après qu'on l'arait irrite, et toujours il visait à l'endroit de l'adversaire où on l'arait frappé lui-même. 
Sa violence étail sans bornes, quand il pensait avoir été injustement puni ou qu'il se croyait victime d'une haine supposée. Il n’était moins sensible à la raillerie. $-\mathrm{A}$ dix ans, il devint meilleur.

Un autre enfant qui, ì quatre ans, était d'une mechanceté extrême et hatlait sa mère cn pleine rue, devint docile et bon quand il atteignit sa onzième annéc.

3. - Jalousie. - Elle est commune à tous les animaux, et se fait roir dans les hommes mème les plus calmes: tantòt elle éclate comme un incendie, tantôt clle conve sous les cendres; elle peut être excitée par l'amour, mais elle l'est surtout par l'instinct de possession, elle est violente chez les enfants. Pérez en a ru un qui était jaloux, non seulement de tous cenx qui approchaient sa nourrice, mais encore de son biberon. - On roit bien des fois les enfants briser un objet plutôt que de le céder ì leurs camarades.

Fénelon a dit (Éducation des filles, ch. v): "La jalousie est plus riolente dans les cnfants gu'on ne sallrait se l'imaginer; on en voit quelquefois qui dépérissent d'une langueur secrète, parceque d'antres sont plus aimés et plus caressés qu'eux ».

Tiedemann arait un fils îgé de vingt-deux mois; it remarqua que cet enfant voulait être flatté quand on flattait sa sœur, et qu'il la battait si clle ne lui cédait sur le champ ce qu'on lui donnait.

Un enfant de trois ans parlait aree un grand plaisir de la sœer ru'il allait avoir. Qnand clle fut néc et qüil la vit caresser, il demanda tont-it-conp "si elle ne mourrait pas bientòt $\%$.

J'ai vu ce sentiment de jalousie développé chez une petite fille, dés les premiers jours qui suivirent sa nais- 
sance: elle refusait de téler quand elle royait à l'aulde scin sa sorur jumelle, et il fallut les séparep. 1 quatre ans, elle cessait de manger si, par la fenètre, elle voyia dans la rue un enlant vêu comme elle. De quator\% it quinze ans, a la suile d'une grave maladie, elle parul s'adoncir; plus lard néanmoins, i 25 ans, elle étail moins bonne ru'hypocrite. Elle était d'ailleurs liydrocéplate et alteinte d’une hỵpéresthŕsic hystérique: rétail la fille d'un fou moral.

Valbust (Jorewu, p. 57) raconte qu'un cnfant de six ans, jaloux de son petit frère, présentait sourent un coutean à ses parents pour qu'ils voulussent bien le lui tuer.

4. - Mensonge. - Montaigne a dit que le mensonge et l'obstination croissent chez les enfants en mème remps que leur corps.

Tous les enfants, écrit Bourdin, sont menteurs, mais plus que tous, les enfants trouvés, qui mentent par jeu.

Pérez en donnait pour cause première la facilité arec laquelle nous trompons les enfants, dès les premiers mois, pour les tranquilliser, les laver.

Les enfants mentent pour obtenir ce qu'on leur a refusé d'abord: sonvent pour éviter un reproche, pour ne point paraître le mériter; ainsi un cnfant appelait vilaine sa mère qui le lavait. "Qui veux-tu insulter? lui demandat-elle. - "Je l'ai dit á l'eau, " répondit-il en se reprenant. - D'autres fois, ils mentent pour obtenir une friandise, qu'ils prétendent n'avoir pas mangée, on sous l'impression d'une Corte douleur, après une chîte, ou pour se montrer forts, ou parcequ'ils voudraient se tromper eux-mêmes sur l'humilité de leur sitnation, on par jalousic (c'est ainsi qu'une fillette, royant que sa 
mère caressait son petit frère, imagrina de dire qu'il avait frappé le perroquet, pour lui attirer des reproches) ou par poltronnerie; par exemple: quand ils feignent d'ètre malades pour ne pas se rendre à un endroit désigné. Je me rappelle aroir moi-même, sous un prétexte semblable, esquivé une ennuyeuse lecon d'arithmétique; jarais alors cing ou six ans; je trompai tout le monde, jusqu'aux médecins.

Iprès avoir atteint l'ìge de trois, quatre ans, ils mentent par crainte d'être punis, et sont farorisés en cela par notre manicre de les interroger et par l'attitude que nous prenons pour les faire répondre.

Souvent même ils mentent par jeu ou par vanité.

«Fullcbam, dit St. Angustin en parlant de lui-même, inmumerabilibus mendaciis pedagogos amore ludendi etc.». On en roit qui, pour satisfaire lemr ranité, s'attribuent des récompenses imaginaires; une petite fille se passait la fantaisie de se raconter à elle-même des fables on clle devenait reine; cette pensée l'alsorbait tout le reste du jour.

Tne des raisons qui les portent si fréquemment à mentir, est leur impulsiviti, leur sentiment moins complet, moins profond de la vérilé; par suite, il leur en coûte moins qu'ì d'autres de dissimuler, d'altérer la vérité pour le motif le plus léger, comme font les sauvages et les malfaiteurs.

Aussi les voyons-nous mettre en ceurre un art de dissimulation dont souvent nous ne croirions pas capables mème des hommes faits.

Jai connu une fillette qui, à quatre ans, dérobait du sucre avec une telle habileté, qu'il était impossible de la surprendre; elle meltait ensuite le rol sur le compte de la servante. 
Un pas de plus et nous en voyons une autre qui, pour faire du bruit autour d'elle, feignait d'avoir émis un os par le vagin, et trompait plusieurs anmées de suite les médecins les plus habiles. Une autre de cinq ou six ans, entendit un jour sa mère adoptive lire dans un journal le compte-rendu d'un procés scandaleux; pen de jours apres, elle prétendit alvoir été victime d'obscénitís de la part de son père ef de son oncle; tme action trèsgrave s'engageait déjà, quand un examen attentif démontra que tout cela était une fable inventée par elle, et que le vrai, l'mnique motil qui l'arait poussée, était le désir de faire parter d'elle dans les jomrnaux (1). (Botross, l. c.).

Bourdin, qui a traité aussi de la fréquence du mensonge chez les enfunts (Les enfants menteurs, Paris, 1883) nous raconte le fait suivant: Dans un collége, un petit garcon imagina, pour se faire renvoyer, de dire qu'il avait un pois dans l'oreille; il criait si fort, que plusieurs persomnes en furent convaincues. - Un autre, dans le même but, simula une chorie trèsviolente.

Deux enfants de cinf ou six ans, à table, avaient convenu de cacher à leur mère un léger méfait commis par l'un d'eux (il s'agissait d'un peu de vin répandu sur la nappe), à condition que l'autre ne prétendrait pas l'empecher d'aller au théitre, plaisir quion avait promis d'abord à lui seul.

Une petite fille de trois ans, à qui sa mère avait défendu de demander à manger, priait une dame de salisfaire sa gourmandise. "Je ne dirai pas à ma mère

(1) Rẻeemment Kosiek a noté un fait analogue à (iraz, voir Aus deir Papieien eines Vertheidiger's, 1885, (iraz. 
que j’ai accepté, » ajoutait-elle. Elle était ambitieuse et, désirant de beaux habits, disait à sa mère: "La dame qui habite au dessus m'a reproché d'ètre mal mise ». Or rien de cela n'était vrai. Il faut ajouter que, lorsqu'on lui faisait honte de ce noureau mensonge, elle niait effrontément. Cie cas est fréquent chez les enfints.

5. - Sens moral. - Il n'est pas douteux que le sens moral ne manque aux enfants dans les premiers mois de leur existence, el même jusqu'à la fin de la prenière année. Pour eux, le bien et le mal sont les choses permises ou défendues par le père et la mère; mais, pas une seule fois, ils ne comprennent d'eux-mêmes si une chose est bonne on mauvaise.

«Il est vilain, disait un enfant à Pérez, de mentir et de désobéiu; cela déplait à maman ". Mais le même enfant croyait bonne toute aclion qüil voyait faire chaque jour auprès de lui.

«Quand je pleme, disait un enfant, maman me unet an lit, et alors elle me donne un oreiller \%. Ils font ainsi pour les actions morales; ils croient bon tout 'e qui leur vant des éloges. Ciest ainsi que j’ai vu un enfant bien élevé refuser de se soulager dans une chambre; il considérail cela comme une faute.

Un enfant de deux ans et cing mois, qui pensait aroir fait une bonne action, disait: "Le monde dira: c'est un bon gargon ». (Pérez).

Un enfant de quatre ans avait menti, et sa mère pour le punir, l'avait enfermé dans une cave. Comme clle traversait cetle prison, il lui disail: "Mais je mérite une peine plus forte». Au contraire, sa grande mère l'ayant un jour simplement enfermé dans une chambre 
obscure, il nacceptait pas le chitiment, se regaldait comme injustement puni, et poussait des cris de rage.

La douleur causće par le chitiment varic donc chez les enfants, selon les personnes qui le lem infligent et qu'ils ont offensées. Nous avons fait la mème obserration sur les saurages. (Cir. 11).

En somme l'idée de justice, de propriété, fait son apparition chez l'enfant quand celui-ci a éprouré une perte, ou fuand il a entendu dire que telle ou telle chose est manvaise. Il déteste, en général, l’injustice, surtout quand il en souffre lui-même; pour lui elle ne consiste que dans un désaceord entre la manic̀e hahituclle dont il est traité et ce qui lai arrive accidentellement.

Qu'une circonstance nouvelle se présente, il sera plein d'incertitude. C'est ainsi ru'un enfant, transporté de la maison de sa mère ehez le docteur Pérez, modifia ses habitudes en clangeant de milieu. Il commenca it manifester ses exigences en poussant des cris furienx; il n'obéissait quau seul maitre de la maison.

Le sens moral est, done, une des facultés les plus suseeptibles d'ètre modifiées par le milien moral.

La notion du bien et du mal, qui en est le germe intellectuel, ne se constate pas avant laige de six à sppt mois; le sens moral s'accuse pour la première l'ois quand le sujet comprend certaines attitudes, certaines inflexions de roix qui ont un but de répression, quand il commence à obéir par peur ou par habitude.

L intérèt, l'amour propre, la passion, le dévcloppement de l'intelligence et de la réflexion élablissent avee précision la distinction du bien el du mal. La sjmpathie, la force de l'exemple, la penr des reproches, $y$ contribuent peut-ètre plus encore. C'est de tous ces élé- 
ments que se dégage la conscience morale. L'enfant peut être plus ou moins bien dirigé selon les aptitudes de son caractère et les accidents du moment. (PÉREz, l. c.).

La fille de Louis Ferri lui disait un jour: "Je sens qu'iujourd'hui je ne puis être bonne».

6. - Affeclion. - L'affection est rare clıez eux. Ils éprouvent surtout de la sympathie pour les jolis visages, ou pour ce qui leur procure un plaisir, par exemple, pour les petits animaux qui se laissent prendre et tourmenter par eux. Ce qui leur répugne le plus, ce sont les objets nouveaux et qui les effraient; mais l'affection leur est étrangère; vous voyez des enfants de sept ans oublier leur mère qu'ils paraissaient pourtant aimer beaucoup. Trop souvent il arrive que des enfants de deux ou trois ans insultent, sans s'en rendre compte, aux douleurs des plus grandes. J'érez, conduit devant le lit où reposait le cadare de sal sceur, ne pensait qu'à une chose, à la ressemblance qu'il lui tronvait avec la sour de son camarade, et il courait vers sa mère pour lui faire part de son observation. - Un autre enfant, âgé de quatre ans perdit son ami le plus cluer; le père du mort le prit dans ses bras en sanglotant; mais lui, se dégageant tout à coup: "Maintenant que Pierre est mort, dit-il, th me donneras son cheval et son tambour, nicst-ce pas?»

Quand vous eroyez qu'ils vous aiment, semblables au fond aux femmes rénales, ils sont attachés à rous par les dons que vous leur avez faits et par l'espoir d'en recevoir de nouveaux; rien de plus. Ils cessent de vous aimer, quand cette espérance a disparu.

Il y a assurémeut des exceptions. - Et tu étais de celles-là, ô mon ange, dont les yeux si doux, si bril- 
lants milluminent encore du fond de ton sépulcre, toi qui ne semblais te réjouir que du plaisir d'autrui! Hais la rareté des cas, comme celle de la bonté chez quelques sauvages, chez les Wedas, les Santala (v. s.), confirme la rigle; d'autant micux que presque tonjours, soit parcerne ce sont des exceptions, soit parceque cet excès précoce de sensibilité ne peut permettre un bon léveloppement des organes, ils nous sont alors enlevís de bonne heure. - Trop souvent, liélas!

7. - Cruauti. - «Cet âge est sans pitié, " a dit à propos des enfants Lafontaine, ce peintre fidèle de la nature.

La criauté, en effet, est un des caractères les plus communs de l'enfance. Il n'est pas d'enfant, dit Broussais (Irrilation el folie, p. 20), qui n'abuse de sa force pour opprimer les êtres plus faibles que lui. C'est lí son premier mouvement. Toutefois les plaintes de sa victime l'arètent quand il n'est pas d'un naturel féroce, et cet arrèt dure jusqu'au moment où une impulsion nouvelle lui fera commctre unc seconde fante.

En général, il préfére le mal au bien; il est cruel plus souvent que bon, parcequ'il éprouve ainsi une émotion plus grande, parceque, faible, il peut faire montre d'un pouvoir illimité; et voila pourquoi on le voit briser avec plaisir les objets inanimés. Il se plait à blesser les animanx, à noycr les mouches. Il bat son chien, il étouffe son passereau; on en voit qui enduisent de cire brûlante des escarbots, des cerfs rolants, pour les habiller en soldats et prolongent, ainsi, lenr agonie pendant des mois entiers.

C"est l'enfant, qui a invente la cage de jone on d'osier, les trappes, les filets à papillons, et mille antres petits engins de destruction et de torture. 
Jai vu, dit le docteur Blatin, d’ingénieux petits dròles jouer au volant avec de jeunes lapins, qu'ils se renvoyaient gaiement de l'un à l'autre à coups de raquette. (Buatix, Nos cruautés envers les animaux, page 414).

Au mois de juillet 1865, dans l'arène de Mont-deMarsan, on a vu des enfants de dix ans s'acharner contre des taureaux à moitić morts, et les achever à coups d'épée.

A Murcie, en Espagne, on a ru des jeunes filles deseendre dans l'arène et remplir l'office du Matador.

8. - Paresse, oisiveté. - Un autre trait de ressemblance entre l'enfant et le criminel-né est une certaine paresse d'esprit qui n'exclut pas l'activité pour les plaisirs et les jeux. Ils se refusent à un travail soutenu, et par dessus tout à un travail nouveau et pour lequel ils ne se sentent pas l'aptitude. - Lorsque, contraints a l'étude, ils ont rempli une certaine tache, ils la reprendraient volontiers, mais ils se refusent à toute autre par suite de cette même loi d'inertie qui les porte à ne pas changer d'appartement et à ne pas faire de nouvelles connaissances: c'est que notre intelligence souffre de toute sensation nouvelle un peu forte, tandis que les anciennes lui procurent du plaisir. Quelquefois vient s'ajouter la paresse du corps, et clle est telle parfois qu'ils n'hésitent pas à salir leur couche pour éviter la peine de se lever. - C'est là un contraste, mais non une contradiction, avec celte tendance à changer continuellement de place, à poursuivre de nouveaux amusements, ì rechercher la société de nombreux compagnons sans qu'il $y$ ait pour cola une grande affection mutuelle; mais on veut faire ensemble des orgies de gestes et de mots, 
et souvent aux dépens de pauvres vieillards, de crésins, ou de leurs compagnons plus faibles. Ce penchant, pas plus chez eux que chez les criminels, n'est en opposition avec la paresse: ils deviennent actifs quand il s'agit d'un plaisir plus facile à se procurer à III moment donné; ils aiment les nouveautés, quand elles ne fatiguent pas leur cerveau, et quand elles donnent satisfaction à ce plaisir d'un contact nutuel qui n'a aucun rapport direct avec une affection profonde, et qui se remarque aussi souvent chez les crimincls.

9. - Argot. - Cette habitude a introduit parmi eux une espèce d'argot: ils se font des signes avec la main ou se parlent avec les syllabes des mots renversés ou d'une autre facon pour se soustraire à la surveillance de leurs chefs. J'ai remarqué cette coutume dins nombre de colléges et d'écoles publiques parmi des enfants de sept à douze ans.

10. - Vanité. - Ce fondement de la megalo-manie el de la tendance au crime, qui est la vanité excessive, la préoccupation de soi-mème, a une grande force chez les enfants. - Dans deux familles où les principes de l'égalité sont comme innés chez les pères, on a vu les fils, dès l'àge de trois ans, traiter les paures arec luauteur, et avoir des égards pour les enfants qui appartenaicnt à des familles riches et titrées. On voit cela, du reste, chez les animaux, chez le chien de garde, par exemple, rui aboic contre les personnes mal vêtues.

Une fillette fort taciturne, d'une intelligence peu développée, élevée par une mère excellente et qui écartait d'efle toute idéc de noblesse, se promenant avec la fille de sa femme de chambre, lui imposait de prétendus 
services et ne cessait de la gronder. Il y a dans ce fait un pen d'imitation, mais surtout beaucoup de ces idées de grandeur.

Tous les enfants, dés quils ont atteint sept ou huit mois, sont fiers de leurs bottines, de leurs chapeaux neufs, et boudent quand on veut les leur ôter. Jai ru quelques enfants, même de ceux qui plus tard devaient se montrer fort peu intelligents et pen précoces, se plaindre a neuf ou dix mois, quand on ne leur dommait pas un vêtement élégant et riche. L'un d'eux, âgé de vingldeux mois, voulait toujours son habit bleu; un autre réclamait sans cesse l'habit de marié.

lls se vantent, a bans, d'avoir un pìre professeur, d'appartenir à une famille noble ou riche.

Les plus ignorants ne recomnaissent, jamais, avoir élé justement réprimandés par leurs maittres; ils expliquent les reproches qu'on leur adresse par de mauvaises raisons, toujours étrangères à leurs propres torts.

Tous se croient supéricurs aux autres dans leurs petites entreprises. Ainsi Pérez a observé un petit gargon qui, jollant à l'escarpolette criait: "Oh! voyez comme je me lance bien, comme je suis léger; personne ne pourrait faire si bien!) Et cependant ses compagnons ne restaient pas en arrière. Voilà, dit avec raison Pérez, une illusion produite par l'amour propre.

La personnalité, chez le petit enfant, va jusqu'à l'égoïsme, à la prósomption, au pédantisme, et souvent avec des tendances à la sympathic, à la tendresse, ḋ la crédulité. C'est ce qui, plus tard, favorisera le déreloppement du sens moral.

Lidée de la personnalité est à peine ébauchée dans la première année, de même que chez les animaux. De deux à quatre ans, le sentiment personmel s'affirme, 
et va jusqu'ì l'exagération. Un enfant de vingt-six mois poussail des eris i la moindre égratignure. Il se corrigea par amour propre; el, même lorsqu'on le battait, loin de se plaindre, il tomrnait la chose en plaisanterie; un jour il refusa de lire devant des jeunes filles, disant «qu'elles se moquaient le lui ».

11. - L'alcoolisme et le jeu. - Ceux qui vivent dans la bounc société ne se doutent pas de la passion quiont les enfants pour les boissons alcooliques; mais, dans les classes populaires, on n'a que trop l'occasion d'olsserver avec quelle volupté des nourrissons boivent lo vin et les liqueurs, tandis que leurs parents s'amusent de lew ébriété. (Moreau, p. 115). Bien souvent des criminels m'ont raconté que tout enfants ils s'énivraient, poussés at cela par leurs parents.

La passion du jeu est aussi un trait caractéristique du jeune àge, sur lequel il n'est pas besoin d'insister.

12. - Prédispositions à l'obscénité. - Bien qu'elles soient limitées et incomplètes, les tendances obscènes se font jour dans la première enfance, dès l’àge de trois ou quatre ans. Nous aurons bientòt occasion de l'observer.

Dans toutes les écoles enfantines on m'a montré un ou deux petits garçons qui se livraient à l'onanisme. Comme nous le verrons plus bas, toutes les amours étranges et monstreuses, de même que presque toutes les tendances au crime, ont eu leur principe dans la première enfance.

13. - Imitation. - La démarche et la parole, a dit Pérez, sont en grande partie, chez les enfants, un 
rósultat de limitation, el naturellement ils imitent le mal comme le bien.

Une petite fille avait un père bilieux: à quinze mois elle commencait a froncer les sourcils, comme son père, et à crier comme lui. A trois ans, elle disait à son partenaire, dans une conversation: "Mais tais-toi, tu ne me laisses pas achever ma phrase; " absolument comme son pire.

Prosper Lucas cite l'exemple d'un enfant de six à huit ans qui étrangla son frère moins àgé que lui. Quand le père et la mère, à leur retour, s'en aperçurent, il se jeta dans leurs bras, pleurant ef déclarant quil avait voulu imiter le diable qu'il avait vu étrangler Polichinelle.

Peu sen est lallu, dit Mare, qu'un de mes amis, encore enfant, ne fül victime d'un jeu cruel: avec quelques camarades, il avait assisté à Metz, à une exécution: ils voulurent la reproduire. On le choisit pour patient, un second fut le confesseur, deux autres furent les bourreaux. Ils le pendirent au barreau d'une échelle, et, comme on vint les déranger, ils prirent la fuite, abandonnant le pauvret qui n'en serait certes pas revenu, si quelques personnes, arrivées à temps, ne l'eussent détaché.

14. - La prévoyance. - Comme les crimincls, les enfints manquent absolument de prévoyance; un avenir qui n'est pas immédiat ou ne parait pas tel, n'a aucune influence sur leur imagination; qu'une partic de plaisir soit remise à huit jours ou à une année, ils n'y voient pas la moindre différence.

La connaissance de ces faits explique naturellement comment la folie morale se trouve tonjours dans les 
dospotes, comment elle se troure, en tous, dis lionfance, el comment, pour tous, elle se continmerait dans laige min', si l'edncation ne venail y mettre ordre.

Ces enfints, dit Campagne dims sa Folic raisonnante, eni il traile des mialates prédisposis a la folie morale, sont insensibles aux bloges et aux punitions, ils ne comprennent pas combien lem conduito peut afliger leur fimille, ils restent indiseiplinés, sans soin, querelleurs. Loisiveti, lonanisme et li rébauche, les surexcitations the tout genre, sont les grandes stations quils parcourent pour arriver a cettc exaltation particulière, dite folie raisonnante, qui les porte irrésistiblement à laction. Mlors, à la paresse succede une témérité sans bornes; le moindre reproche leur arrache des eris fupienx; ils brisent tout ce qui leur tombe sous la main et liapent les personnes qui les entourent.

Lil cruauté fut remarquéc dans la premiere enfance de Caracallat, de Caligula, de Commode, qui, à treize ans, fit jeter au four un esclave pour une faute ligère; se Lonis XI, te Charles IX, qui faisaient torturer les animaux, el de Louis XIII, qui écrasait lentement sutre deux pierres la tête d'un petit oiseau, et qui nontra une telle fureur contre un gentillıomme qui lui itait antipathique, que l'ont dut, pour le calmer, Vaire semblant de tuer ce gentilhomme. Devenu roi, il atmait il suivre l'agonic des protestants condamnes it mort.

La folie morale el les tendances criminelles étant indissolublement liées, on sexplique pourquoi presque tous les grands coupables ont manifesté leurs mauvais instincls dis leur plus tendre enfance.

Toute pelite, la Lafirge prenait plaisir ì étouffer des ponlets. Feuellack, parlant d'un parricide, dit qu’il 
s'amusait. a faire tourner des poulets autour de lui après leur avoir crevé les yeux.

Dumbey, à sept ans et demi, était déjà un voleur.

Le brigand B., à neuf ans, s'atlonnait au larcin et an viol.

Cartouche volait dès l’ige de onze ans.

Crocec, a trois ans, plumait vifs de petits oiseaux.

A onze ans, Lasagna clonait la langue des baufs sur in banc.

Locatelli a observé que la tendance an vol se manifeste dans l'âge le plus tendre; ce sont d'abord de petits méfaits, commis dans la maison, puis, insensiblement, le vol devient plus sérieux. Au contraire, les assassins se révilent subitement, et quelquefois de trésbonne heure.

Roussel a fait une remarque analogue, dans sa monumentale Enquête sur les enfants abandomis, vol. I, 1882, pour ce qui a trail en France à la prostitution, ou l'on rencontre une grande proportion de mineures: 1500, par exemple, sur 2582 qui ont été arrêtées en 1877. On a remarqué i Bordeaux, continue notre auteur, que, si 461 femmes se sont prostituies par suite de leur position de famille, on parcequ'elles étaient directement corrompues par leurs parents (32 se tronvaient dans ce dernier cas), il y en arait bien 4 qui avaient été uniquement perdues par leurs instincts pervers. - Parmi elles étaient la fille d'un ingénieur et celle d'un riche propriétaire! 
II.

CASUISTIQLE.

Et roici pourquoi la cote des crimes clez les enfants est si chargie.

1. - Vimont (Traité de Phrénol., 1838) raconte qu'un garon de onze ans en arail engagé un antre de cinr a le suirre près d'un marais; lì, il le frappe, le souille, lui introduit un baton dans l'anus, et cnfin le noie. Acusé de ce crime, non seulement il niait, mais il détounait l'accusation sur d'autres enfants.

2. - Le 15 juin 189', à Bellesme, on retira d'un puits le cadarre d'une petite fille de deux ans. Deux jours après, on relirait du même puits un garçon de deux ans et demi. Une fillette de onze ans, connue dans le pays pour ses habitudes perverses, ne rencontrait jamais des enfants plus faibles qu'elle sans les battre ou les tourmenter de mille manières. C'était elle qui arait attiré et poussé successivement les deux petits dans ce puits. (Moneau, l. c.).

3. - La Cour d'Assises du Doubs eut à juger un incendiaire de huit ans qui avait mis le feu aux maisons de son rillage, et tout-cela, comme il l'arouait, dans l'unique lout de s'amuser et d'éclairer les enfants. (IorEAL). 
4. - Un brigand écossais, condamné pour anthropophagie, avait laissé une fille qui à douze ans, nontrait les mêmes goûts féroces. "Et pourquoi, demandait-elle, en avoir du dégoût? Si tous savaient quelle saveur a la chair lumaine, lous mangeraient. leurs enfants $n$. (Moreau).

5. - A. M., âgé de onze ans, est arrêté comme vágabond pour la huitieme fois. Il reconnaît que ses parents le nourrissent bien et prennent soin de lui, mais déclare que, malgré lui, il ne peut résister an désir d'utre libre; on aura beau, dit-il, le ramener à sa mère, il échappera toujours. Il a cette passion dans le sang; plutòt que de rester clıez lui, il ira dans une maison le correction.

6. - A Lagny, deux enfants, l'un de treize, l'autre de dix ans, gardaient rancume ì un de leurs camarades qui élait dans sa septieme annéc. Hls l'invitèrent à se baigner dans la Marne, dans im endroit écarté; ils lo jetèrent dans un trou profond et, à coups de picd, it coups de pierre, l'empêchèrent de se sauver. Le lendemain, un des deux coupables, le plus jemne, confessait son crime. (Moreau).

Nous trouverions encore nombre de cas ou l'idée dhe crime paraît rraiment innée dans l'îge le plus tendre.

7. - A treize ans, un certain B. A., ultra-brachyciphale, index 87, oxycephale, ayant les yeux obliques, les pommettes saillantes, la machoire très-développée, les oreilles à anse, gooitreux d'ailleurs, frappa mortellement l'un coup de couteau au cour un camarade qui refusait de payer une dette de jeu. Des litge de douze ans 
il fréquentait déjil les maisons mal famécs. Il subit six condamnations pour vol. Son frère étail un roleur, sa mère une crintinelle, sa smur se livrail it la prostilution. Il arait des sentiments religienx, fréfunentait tont an moins les églises. D'aillen's, il ne dit rien à son confesseur du crime qu'il avail commis (1).

8. - Mainero était un garçon de physionomic prócow, mais peu développé yuant au reste du rorps, si bien "fu'i douze ans il en paraissail six. On pouvail donner son signalement ainsi qu'il suit: taille $1, \mathscr{Q} 4$, circonférence crânienne 0 , 490, index céphalique 80 , orcilles ì anse, pommettes saillantes, regard tress-vif; à huit ans il commenca de roler'; neveu d'un assassin, il se vantait d'aroir accompagné son oncle dans ses expéditions, d'aroir organisé des handes pour dévaliser les trones des églises ot les poulaillers, el d'aroir sourent dérobé la part de ses petits complices, qui, pour se venger, le dénoncèrent (1).

9. - L. B., de Gênes, a le crûne large, le fronı étroil; il porte sur les bras un tatonage aree ces mols: Mort aux lâches et vive la solidarité! Dès huit ans, il faisait to méticr de coupe-bourse. Il a sept frères, dont trois sont en prison (1).

10. - Un certain G., de famille honnête, était prognate et oxycéphale. A sept ans il commetlail déjà des rols à l'école, dépouillant jusqu'à ses maîtres. Il avait réussi devant la police, à accuser ses parents de maurais traitements pour les faire incarcérer; il a encore une sœur qui est querellense el portéc au rol (1).

(1) Memonie del laborat. di med. leyale, prof. Losmaso, 1883, Tovino. 
11. - L. P., un garçon qui à dix-neuf ans se montra un si habile fripon, qu'il fut poursuivi pour vol et tentative de meurtre, était d'une parfaite apathie morale; il avait la taille élevée, la tête étroite et allongée, sans barbe, avec un nez disproportionné et crochu. Son père élait alcoolique, sa mère débauchée, son grand père maternel sietait suicidé. I trois ans, allant au marchí arec les domestiques, il volait dijä dans les paniers de l’argent, des fruits, des poissons.

12. - Le brigand anthropophage F. Salratore, de Ciltane, qui à trois reprises se fit passer pour fou, m'a laissé un mémoire manuscrit où il ratconte comment, à six ans déjà, il volait des vivres à ses parents pour régaler ses camarades; et plus tard, à neul ans, parrenait a soustraire des frontages entiers dans une hôtellerie; en luttunt par jeu avec un ami, il lui déchira un bout d'oreille; et pourtant son pire était un parfait honnète homme, qui le bàtonnait souvent pour le corriger. Cela ne l'empêcha pas d'ailleurs, à quatorze ans, de porter un violent coup de couteau à un compagnon de jeu. Il se servait de fausses clés pour dérober de l'argent à son père. A dix-neuf ans il tua un homme.

13. - Jai connu une famille, où la nère ciait hystérique ef d'une grande intelligence, le père très-intelligent aussi, mais d'humeur bizarre et fatigué par un travail excessif; il y avait, enfin, deux oncles, l'un doué d'un grand esprit, l'autre aliéné. De celte famille étaient issus quatre fils: l'un fut d'une honnêleté parfaite, le second, extrèmement lascif, se donna la mort aprés avoir commis un meurtre sous l'impulsion d'une passion ardente; le troisième, trìs-sûr dans les affaires de cont- 
merce, avait daus son enfance commis quelques larcins et repoussé tonte espèce d'étude; le quatrième enfin, enfant rachitique, arec le front fuyant, fut tellement possédé de la passion du vol, qu'il dérobait dans les colléges les montres et tous les objets qui lui tombaient sous la main. On avait usé vainement, pour le corriger, des chatiments les plus sévères; à scize ans il devint Jonnête.

14. - Un enfant qui, lès làge de trois ans, était déjà porté à l'onanisme el éprouvait du plaisir à voir égorger les animaux, se montrait, à cinq ans, trèshabile i mal faire. Il vit un jour son petit frère qui perdait du sang par le nez, et en profita pour le faire tomber la face contre terre; il trempait ses mains dans ce sang et criait: Je veux tuer ce petit, je veux voir du sang, cela seul me procure du plaisir.

Comme on lui demandait s’il oserait tuer sa mcre: "Issurément! répondit-il; et comment pourrais-je l'aimer, si je ne m'aime moi-même? Oh! je veux bien la tuer, et si je ne puis le faire aujourd'hui, j’attendrai d'ètre grand ».

15. - Verga (Rendiconto Istituto Lombardo, 1883), signale un petit paysan de onze ans, aux pommettes saillantes, intelligent et instruit pour sa condition. Ce jeune scélérat, poussé par la haine, avait d'abord roué de coups et menacé de mort un de ses camarades; finalement, il le tua pour une botte d'herbe. Armé d'une faucille, il le frap a à coups l'edoublés, et ne fut arrêté un monent que par la difficulté qu'il rencontra à faire pénétrer dans le cràne de sa victime la pointe recourbée de son instrument. Il jeta ensuite le cadavre dans un fossé où il se lava les 
mains, et, pour se diseulper inventa une fable. Tous les deux, disait-il, avaient été menacés par un garde champètre el avaient dû, pour fuir, se jeter à l'eau. Il ne se décida à avouer qu'après avoir appris que, grâce à son àge, il ne serait frappé que d'une peine légère.

16. - Obscénité. - Jai déjà fait remarquer plus haut que les cas d'obscénité précoce sont loin d'être rares. Depuis longtemps jarais remarqué (L'amour chez les fous, 1881) que tous les as monstrueux dans l'amour sexuel (si l'on excepte ceux que produit la décrépitude), sont en germe dans le cervean de l'enfant, el s'y mêlent aux autres tendances eriminclles.

Tel étail le eas du voleur Bor..., un jeune fripon qui, à neuf ans, était sujet à des éreclions continuelles, et à qui il suffisail, pour être porté au viol, de voir flotter un linge blanc. Il avait présenté ce symptôme étrange dès son plus jemne âge, à trois ou quatre ans, quand, allant à l'école, il voyait ses petits camarades vêtus d'un tablier blane. Plus tard, le froissement seul du linge lui donnait antant de plaisir que le contad d'une femme.

Il faut, toutefois, noter que tout enfant, il arait reç a la tête un coup violent, et cette blessure l'avait fait longtemps souffrir; el que, comme à l'ordinaire dans ces cas, il deseendait de parents néropathes.

Je ne crus pas, tout d'abord, à la véracité de ses areux, car il s'agissait d'un criminel qui pouvait avoir intérêt ¿ feindre; mais je tombai sur une histoire racontée par Magnan et Charcot, et dont l'analogie aver la mienne est si évidente qu'elle la rend non pas senlement probable, mais certaine. (Archives de neurologie, n. 11, 1882). 
17. - Il sagit d'un certain C., paysan igé de trentesept ans, dont le père était alcoolique, l'oncle aliéní, la mère el la søur hystériques, portées í la mélancolic, qui arait un frère fon el élail lui-même plagiocéphale.

A quinze ans, royant sur le sol un tablier blane, il s'en empara, le lia autour de ses reins et s'en servit pour se masturber. Depuis ce jour, il ne pouvait roir un tablicr sans l'employer an mème usage, après quoi il l'abandonnait. Voyait-il quelqu'un arec un tablier? pen lui importait le sexe, la vine seule de ce rètement l'entrainait; il en suivait le proprictaire et essayait de l'en dépouiller.

En 1861, ses parents, pour en finir, le mirent sur un raissean; et de fait, ne royant phus de tabliers, il samenda; mais en 1864, pendant $n$ congé, il fut repris de cette passion extraordinaire, et commit de noureaux méfaits. La nuit, il rèvait tabliers; le jonr, il se reprísentait sa première rencontre of se sentail poussé it roler des tabliers, pas autre chose. - Vous auriez pu lui offrir des milliers de francs, il les rùt laissés pour s'emparer d'un tablier.

Quatre fois cette mème passion le fit condamner, pour rol, à des peines lígères.

On croira plus aisément à ces amours hizarres, si l'on songe à leur analogie arec d'autres faits de mème genre que jai signalés et décrits chez les aliénés (L'amour chez les fous, 1881); si l'on songe surtout (ct cela est bien plus important) à l'analogie réciproruc. Tous ces faits ont été obscrvés chez des nérropathes, ou chez des criminels, et toujours, ou presque toujours, on les voit aller de front aree la masturluation; dans tous on surprend, comme il arrive pour les manies impulsives et pour les 
idées fixes, une sensation initiale, qui les saisit à un instant donnć de leur enfance, réveille, chez le plus grand nombre, l'éréthisme comme anneau secondaire, par l'association des idées, puis se substitue à l'idée mère; et peu à peu, à la facon de certains virus, non seulement se fixe, mais envahit de plus en plus l'ensemble de leur organisme, s'en rend souveraine maîtresse, devient irrésistible et les pousse aux actes les plus climinels.

18. - Amours précoces. - Mais toutes ces amours sont organisées ou du moins en germe, dans la première cnfance; car la précocité est un de leurs caractères.

Lat perversion du sens génital s'est presque toujours fait remarquer de bonne heure, à luuit ans, par exemple, dans le nialade de Westplat.

a) - Une enfant que j'ai soignée, d'une physionomie très-précoce, fille d'une honnête femme, mais comptant dans sa parenté une grand-mère lascive, un cousin criminel et un aïeul alcoolique, manifesta, dès l'àge de trois ans, une tendance i la masturbation. Reproches, mcnaces, soins médicaux, rien n'y faisait; elle employait même ì se masturber l'instrument dont on se servait pour lui injecter des anti-aphrodisiaques.

b) -. Zambaco (Encéphale, n. 1-2, 1882) nous a donné le portrait d'une jeune fille victime d'une étrange passion pour l'onanisme et le crime.

. R., âgée de dix ans, avec un air de maturité précoce dans les traits du visage, remplie de ranité et d'orgueil, se faisait pardonner ses violences par son amabilité et les caresses qu'elle prodiguait surtout aux petits gargons, olyjets de ses préférences. Dès sa cin- 
quième année, elle manifesta des tendances an vol, dérobant mème des objets qu'elle aurait pu avoir pour rien; le rol commis, elle le niait avec obstination.

Donce dune imagination ardente, elle aimait le beau, mais se moquait de Dieu; a sept ans, elle eut it souffrir d'une leucorrhée, que l'on attribua aux oxyures; en mème temps elle maigrissait à vue d'wil. On remarqua, des lor's, qu'elle cherchait à s'isoler dans une cabane arec des enfants pour joner..... an mariage; a neuf ans, l'excès de la masturbation provoqua un gonflement de la vulve. On essaya du fonet. Mais cela l'hébétait, la rendait fausse et méchante, sans aucun profit; on n'eut pas plus de succès arec la chemise de force, ni ayec l'eau froide qu'elle employait d'abord elle-mine pour se calmer.

La partie supérieure de son corps dépérissait; mais la prartie inférieure se développait d'autant plus. Elle portait les mains sur elle derant tout le monde: "Pour'fuoi me priver d'un plaisir si innocent?" disait-elle.

Souvent elle manifestait du repentir, et pleurait en royant les larmes de sa mère, mais elle succombait bientôt à de nouveaux accès; et elle ajoutait: "Je sais que c'est honteux, mais je ne puis m'en empècher ».

Un prètre essaya de la moraliser; mais pendant qu'il parlait elle se masturbat avec sa soutane. On roulut lui appliquer un cautère au clitoris; mais on n'obtint par là aucun résultat.

«Il est affreux, disait-elle, de vouloir le faire et d'en ètre empèchée; c'est à devenir folle. Je serais capable de tuer quiconque me ferait obstacle. Dans ces momentslà, je suis prise d'un vertige. Je ne rois rien, je ne crois rien, il faut que je me satisfasse ». 
Elle avait eu, toute petite, une gouvernante qui se masturbait devant elle. Plus tard, une autre maitresse, en lui défendant de se toucher le pubis, éreilla sa curiosité. Dès lors elle y portait la main, sans éprouver de plaisir, il est rrai, mais par pure curiosite; puis elle se figura qu'elle itait malade et, pour s'amuser, s'appliqua aux parties honteuses des cataplasmes d'herbe, de sable; elle les frictionnait avec un bâton. Les désirs vinrent à l'heure marquéc par la nature.

Elle corrompit sa sour qui arait quatre ans, et qui ne put éprourer de plaisir que plusieurs annécs après; el se perdit ensuite arec des jeunes gens.

c) - On trouve dans Esquirol un cas trés-curieux oủ Yon observe, à côté de penchants obscènes, et causée en partic par eux, une idée fixe de parricide. - Le sujet était doué d'une intelligence claire et précoce, et nous fournit ainsi un exemple complet de folie morale et de criminalité à l'état naissant, comme diraient des chimistes.

La fillette, dont il fait le portrait, avait l'air vif, les chereux chàtains, le nez camus; dès sa cinquième année, elle parut en proie à l'idée fixe de tuer sa mère afin de pouroir se mêler en toute liberté aux petits garçons. La douleur que lui causait la découverte de tels penchants ayant rendu sa mère malade, elle lui aroua que sa mort ne lui déplairait pas. - Je pourrai ainsi entrer en possession de ros robes. - Quand ces rètements seront usés, comment feras-tu? - Avec rotre argent j'en achèterai d'autres. - Et après? - J'irai arec les hommes. Tu ne sais ce que c'est que la mort; si je mourais ce soir, je ressusciterais demain. Le Seigneur n'est-il pas mort et ressuscití? - Le Seigneur est ressuscité frarce- 
qu'il était Dieu, mais rous ne ressusciterez pas; ma seur nest pas revenue. - Comment feras-tu pour me douner la mort? - Si rous allez dans une forèt, je me cacherai au sein d'un hallier, sous les feuilles, et, quand rous passerez, je vous ferai tomber et vous plongerai un poignard dans le cour. - Crois-tu que j'aitle jamais dans un bois pour me faire tuer! - $\mathrm{hl}$ ! maman, cest pour moi un bien grand chagrin; mais je pourrai encore rous tuer pendant la nuit aree un couteau. Et pourquoi ne l'as tu pas fait quand j'étais malade? Ilaman, parcequ'on vous veillait toujours. - El pour¿noi ne l'as-tu pas fait depuis? - Parceque rous avez le sommeil léger et que vous auriez pu me voir prendre le couteau. - Mais, si tu me tuais, tu n'aurais pas nes robes, tout appartient à ton père. - Oh! je le sais trop bien, que papa me ferait mettre en prison; mais j'ai l'intention de le tuer aussi.

Un jour qu'on la questionnait, elle tenait les yeux obstinément fixés sur une épingle qui ornait la cravate de son interlocuteur. On lui demanda pourquoi; elle répondit qu'elle tuerait volontiers cette personne pour avoir son brillant. Ln autre jour entendant parler, chez elle, d'une cuisinière qui s'était couverte de sangr en coupant la gorge at un enfant, elle resta un monent muelte et pensive. Pen après, on l'entendit s'écrier qu'elle arait trouvé mu moyen de donner la mort sans se salir: il suffisait d'employer l'arsenic avec lequel elle arait ru empoisonner des poulets à la campagne. Elle se tenait presque toujours assise, les mains croisées; à peine se royait-elle soule, qu'elle se lirrait à la masturbation. Tout fut mis en ourre pour la corriger: simples réprimandes, coups répétés, prirations de tout genre, rien n’y fit. Elle ré- 
pondait toujours à son père qu'elle ne changerait pas, dût-elle y perdre la tête.

Et tout cela sans aucune cause psychique, sinon qu'elle avait entendu une vieille parente tenir quelques maurais propos sur le compte de sa mère. On reconnaissait en elle une intelligence nette, un mobile très-clair du crime, une préméditation des plus astucieuses. - Si l'on eût fait abstraction de l’àge, qui aurait pu se douter quil sagissait d'une folle, et non d'une criminelle? Donnez. un peu plus de force a ces muscles, un peu plus d'énergie à ces instincts, et vous aurez les plus cruelles formes de ces manies impulsives et raisonnantes, toujours unies à l'esprit le plus lucide.

Et l'on a beau dire que ce sont là des cas de folie: res cas, chez des adultes, seraient bel et bien appelés des crimes. De toute façon ils prouvent que, dans leur première manifestation, le crime et la folie morale n'offrent aucune différence. 
III.

STATISTIQVE ANTIIROPONÉTRIQLE.

Un petit nombre d'anecdotes ne suffiraient cependant pas à prouver que l'instinct du crime se rencontre chez les enfiuts au mème degré et plus cncore que chez les adultes. Aussi, nous a-t-il paru bon de compléter nos recherches eu visitant les maisons de correction el les écoles enfantines, et de roir si les jeunes criminels présentent les anomalies physiques déja rencontrées par nous chez les arlultes.

1. - Criminels. - Sur 79 enfants de moins de douze ans, renfermés dans des maisons de correction, parmi lesquels 40 voleurs, 27 maurais sujets on vagabonds, 7 homicides, 3 dont on ne nous a pas dit la faute, nous arons trouvé par ordre de fréquence les anomalies suivantes:

30 avec les oreilles à anse.

21 avec le front petit et bas.

19 plagiocéphales.

16 à pommettes saillantes.

15 il sutule relevie.

14 à machoire proéminente.

T avec des sinus frontaux saillaints.

6 hydrocíphales.

5 arec le regard oblique.

5 atteints de strabisme.

5 avee arrêt de direloppement.

4 avee les ehcreux tris-ipais.

4 avee la physionomie sinile.
4 nltradolychoce phales.

3 avee le front saillant, aussi bien que l'angle orbital.

3 aree oreilles grosses et allongiess.

3 avec blessures à la tête.

2 nitiabrachyeephales.

2 ave bonclie diformie.

It avee des asymetries faciales.

10 avee le front eorvert.

li) aree la physionomie des erétins.

9 goitrenx.

9 all nez difforme.

8 anx yeux petits et vitrenx. 
2 atteints de proguatisme.

2 avee le nez de travers.

2 avec le menton effacé.

2 avec le regard sombre.

2 avec vice cardiatue.

2 serofuleux.

2 avec la suture metopique couservée.
1 platicéphales.

I oxycéphale.

I avec précocitíde cheveux blanes

$I$ avec une face inorme.

1 avec dents superposées.

1 exophthalmie.

1 nistagme.

1 anx pupilles inigales.

Un en a rencontré seulement sept $(8,9010)$ n’avant rien d'anormal dans la constitution. L'un d'cux n'était vaiment criminel, mais il était rictime de ses parents qui l'avaient enfermé dans la maison de correction pour le punir de sa paresse. Il y arait en outre, 1 homicide involontaire; 2 roleurs; dont l'un épileptirue.

Quant a l'hírédité, on n'a pu recueillir de notes que sur 59 sujets.

Chez le père et la mère, ou chez les plus proches parents de 27 d'entre eux, on a trouré des anomalies du svis̀me nerreux. Saroir:

Dans 3, maladies mentales, une fois chez le père u deux fois chez un oncle;

Dans 1, bizarrerie étrange d'un oncle;

Dans 3, instincts violents: une fois chez la mère, deux fois chez le père; dans l'un, à ces instincts, se joignait l'alcoolisme;

Dans 4, des maladies nerreuses, saroir: trois fois chez le père (1 épileptique par suite d'alcoolisne, 1 sourd, 1 affecté de saturnisne), une fois chez la mère, atteinte de eiphalalgie chronique;

Dans 5, tendances criminelles ou équivorues; dans 4, tendances au brigandage: deux fois chez le père qui 
clait en même temps alcoolique, une fois chez le frère et une fois chez un oncle; une fois, tendances à la prostiution (chez une sour);

Jans 4, immoralite sans désignation spéciale: uno fois dans toule la famille, une fois chez la mère, deux fois chez le fière;

Dans 7 d'entre cux on remarquaif la tendance à l'ivrosnerie, six fois chez le père, une fois chez le frère, sans compter quatre autres cas déji signalés dans les ratégories précidentes (dont 12 voleurs, 1 violent et 1 ipileptique), ce qui porterait à 11 le nombre des alcooliques.

It ressortiait de cette élude que le type criminel, caractérisé par les oreilles à anse, le front bas, la plagiocéphalic, la proéminence des machoires, l'asymétrie faciale, la pélurie, etc., peut s'elever, chez les mineurs à 59010 ; la proportion même irait jusqu'ì $910_{10}$ $\therefore$ I l'on tenait compte de l'une ou de l'autre de ces anomalies, isolíes. - Et, mème, les influences héréditaires te l'alcoolisme, de la folie, et du crime prévalent en eux dans une proportion bien analogue à celle des criminels adultes.

Reste, cufin, un nombre assez considérable de criminels précoces, $540_{10}$, qui niont pas d'anomalies héréditaires distinctes.

l'our compléter cette étude en faisant la preuve au lobours, c'est-a-dire en examinant les jeunes gens qui ne sont pas incriminés, nous avons lait des recherches dans un certain nombre d'ícoles.

L'examen de 160 enfants des ícoles communales, que nous arons directement étudiés l'un après l'autre, nous donne les résultats suivants: 


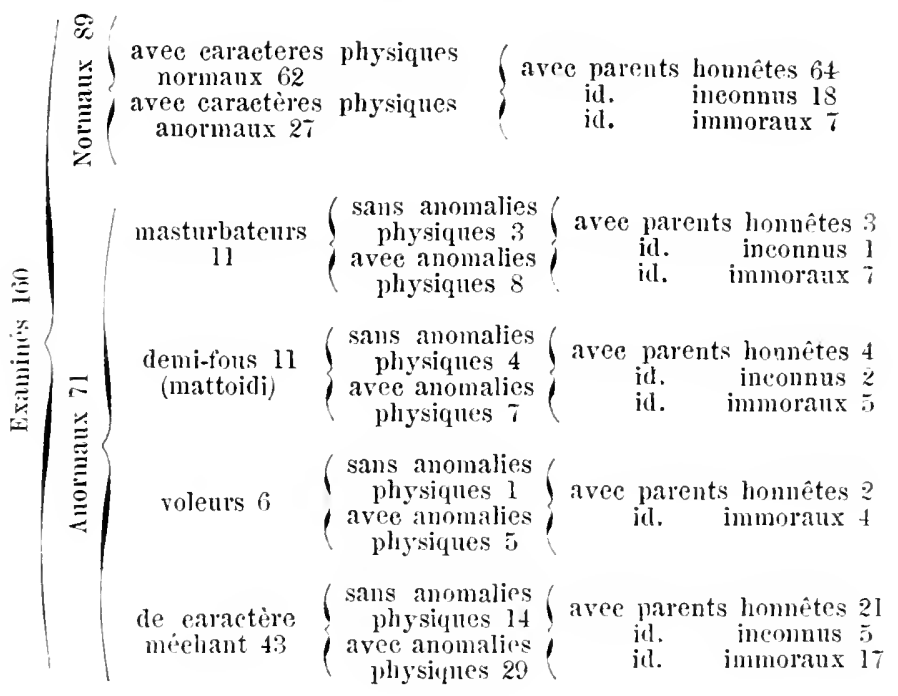

Le premier fait qui se détache de ce tableau est le nombre excessif des anomalies morales que l'on rencontre chez les enfants, et qui, avec le temps, derront disparaitre.

Un per moins de la moitie des enfants examines, 4.4 $0_{10}$, nous présentaient des tendances morales anormales, telles qu'une irritabilité extrème, l'amour dı vagabondage, l'obstination à mentir, ou encore une propension bizarre à se remuer sans cesse, à déchirer leurs habits, etc., de sorte, ì le faire considérer mème par leurs maitres comme des demi fous. Ln 17, $100_{10}, \mathrm{se}$ ınanifestaient mème, les tendances propres aux criminels, rol, lasciveté précoce, ete.

On voit, par là, que chez les enfants crimincls les caraclises morlides physiques l'emportent de plus dı double, 690 , sur ceux yui nont aucune anomalie morale, cher 'fui les anomalies physiques s'idevent seulement it 30010 . 
On peut dire la même chose de l'hérédité morhide chez les enfants immoraux; parmi cux, $520_{10}$ en seraient alteints, tandis que les autres n'offriraient qu'une chiffre de $150_{10}$. La diflérence paraîtrait encore plus sensible, si l'on étudiait les enfants que nous pourrions appeler des demi-délinquants, e'est-it-dire les masturbateurs et les roleurs, en qui les anomalies physiques atteignent les chiffres respectifs de 72 et 83010 , et les hérédités morbides le 70 et 66010 .

Que conclure de ce fait, sinon que l'influence de l'hérédité morbide dans la production des anomalies de caractère est considérable, bien que, d'autre part, au moins pour 150 I0, elle n'empêche en rien les caractères normaux de se développer!

De même les anomalies physiques se rencontrent do lréférence chez les individus de caractère immoral, quoiqu'elles puissent quelquefois faire acte de présence chez les sujets doucis de moralité, et manquer chez les autres.

3. - Quant aux caractères morbides rencontrés chez les parents qui ont transmis cette triste hérédité à leur progéniture, on voit que l'alcoolisme a prévalu dans 11 cas, l'irascibilité dans 7, létat convulsionnaire ou herpétique du père et l'immoralité de la mère dans 5, la demi-folie dans 3, l'impudicité dans 2, la sénilité dans 2 , la scrofule dans 1 , la surdité jointe au mutisme dans 1, et l'immoralité dans un oncle.

En regard des caractères pliysiques morbides qui prévilent chez les enfants atteints d'anomalies morales, nous trouvons: 
8 fois la physionomie sinile.

8 fois la machoire proéminente.

6 fois la suture relevée.

6 fois la plagiocéphalie.

6 fois la face asymetrique rachitique.

i fois les sinus frontaux hypertrophiques.

+ fois le prognatisne.
4 fois le front étroit, bas on fuyant.

3 fois la trococéplatie.

3 fois le front velu.

2 fois un arrêt de dèveloppement.

2 fois le regard sombre.

2 fois les oreilles $\dot{a}$ anse.

et 1 fois les pommettes saillantes. la tête grosse, la bonche déformie.

Plusieurs fois (8) trois de ces caractères se sont trouvís ríunis dans le mème enfant, savoir: dans 4 d'entre eux, plagiocéphalie, regard féroce, strabisme; dans 2, sinus frontaux développés, machoire proéminente, el pommettes énormes; dans 1, soudure des sutures, trococéphalic, front fuyant - caractires que nous remarquerons dans le criminel-né.

Une étude minutieuse faite dans un bablissement privé de jeunes gens riches, le Collige International de 'T'urin, nous a donné, sur 100 sujets, 59, absolument normaux au physique et au moral, et havee quelqu'un des caractères de dégénérescence. Parmi ces 44, 6 senlement araient quelques tendances immorales, violence, amour des querelles, négligence pour l’étude, mensonge. Par contre, 2, malgré ces caractères, étaient l'un excellent naturel, et 5, en outre (et parmi eux I plagiocéphale), étaient doués d'une intelligence remarquable. Cela montre qu'une anomalie physique n'en entraine pas toujours nécessairement une psychirfue.

Mais si, dans ee Collégre, les anomalies psychiques btaient rares, cela n'infirme en rien nos observations. Il s'est rencontré là, gràce aux intérèts de la société et des pédagogues, puisqu'il s’agissail d'élèves payants, une véritable sélection qui ne se retrouve pas dans les autres écoles, surtout dans les communales; à la moindre 
fante ils étaient renvoyés, et de fait, on nous a monlré le portrait d'un enfant renvoyé l'anníc précédente da la suite d'un rol; eh bien! il avait tous les caractères llícrits plus hant: oreilles grosses et écartíes, oxycéplialir, front petit, pommettes tres-saillantes.

Finalement, une étude sur 35 aveugles-nés et 50 sourds-muets nous a révélé que tontes ces altérations physiques se rencontrent dans une proportion yui dipasse 75010 , mime chez les adultes, mème chez les individus soumis a une certaine sélection (sourr-muets riches).

Et maintenant la conclusion est facile. Les anomalies morales qui dans $u n$ adulte constitueraient la criminalité, se manifestent chez les enfants dans des proportions bien plus grandes et avec les mêmes signes, grice surtout aux causes hérúditaires; ces mèmes anomalies sont sujcttes plus tard ì disparaitre, en partie grice aux secours d'une éducation convenable, sans froi on ne s'expliquerait pas la petite proportion des types criminels chez les adultes, mème si l'on tient compte des différences résultant de la mortalité et du nombre de ceux qui échappent à l'action des lois.

Les anomalies physiques se trouvent en proportion double, et atteindraient mème un chiffre plus élevé chez ces jeunes gens entachés d'immoralité (rappelez-vous la comparaison de 69 à 300 [0 prise parmi les normaux), et l'hérédité, chez les mèmes, s'élèverait à plus du triple (52 à 15). - Mais il est un fait bien établi; cest que les anomalies physiques et l'hérédité peuvent se rencontrer, bien qu'en proportion moindre, chez les plus intacts, comme nous avons pu bien des fois remarquer des jeunes gens très-honnètes issus de parents mauvais. En ontre, elles se manifestent moins encore 
chez les criminels que dans certaines autres affections probablement connexes avec l'arrêt de développement, par exemple chez les aveugles-nés et les sourds-muets.

4. - Cela nous a été confirmé par des recherches qui, naturellement, devaient rester fort restreintes, sur le cours de la vie de quelques enfants (29) suivi jusquı̀ l'ige adulte. - Je vais les résumer tout de suite:

11 enfants ne présentaient aucune anomalie physique; 3 entr'eux furent méchants dès leur jeune àge, paresseux, violents et cruels, mais s'amendèrent dans la suite; 8 bons dès l'enfance, se maintinrent tels dans l'àge adulte.

18 offraient les différents caractères physiques des criminels. - Sur ce nombre, 4 , bons dès l'enfance, se conservèrent tels encore dans l'àge adulte; 2, au contriare, en prenant de l'ìge, devinrent immoraux.

12 présentaient à la fois des anomalies physiques et morales: 4 étaient violents, 3 jaloux, 1 vindicatif, 2 voleurs, 3 se livraient à la masturljation; 6 de ceux-ci s'amendèrent avec le temps.

Ici encore on voit que si l'anomalie physique coïncide la plupart du temps avee les tendances immorales, elle n'exclut pas pour cela la possibilité d'une transformation heureuse, que nous avons vu se produire en 6 sujets sur 12. - Níanmoins, quand elle est absente, le caractère a plus de facilité à se réformer, quelle que soit sa perversité première.

On pourra, il est vrai, mobjecter qu'une hypocrisie raffinée, se couvrant du masque de la vertu, peut mavoir fait enregistrer des réformes qui n'étaient qu'apparentes: je ne rois pas la possibilité d'écarter absolument cette hypothèse. 
IV.

CHATIMENT ET MOYEXS PRÉVEsTtFs DE CRIME

CIIEZ LES EXFANTS.

Il reste donc démontré qu un certain nombre de criminels sont tels dès le premier íge, quelle que soit la prart faite aux causes héréditaires; disons mieux, si quelques-uns sont les produits d'une mauraise éducation, dans beaucoup la bonne n'y influe en rien.

Toutefois, son action bienfaisante est précisément mise en lumière par ce fait, que les tendances criminelles sont générales chez les enfants; en sorte que, sans elle, on ne saurait expliquer le phénomène qui se produit dans le plus grand nombre de eas, et que nous appellerons leur métamorphose normale.

Du reste, par éducation, nous n'entendons pas les simples instructions théoriques, rarement utiles aux. adultes mêmes, que nous voyons si peu influencés par la littérature, l'éloquence, les arts dits moralisateurs; nous entendons, moins encore, les violences pédagogiques, qui engendrent le plus sourent des hypocrites, et, loin de changer le vice en vertu, le transforment en un autre vice. L'éducation est pour nous une série d'impulsions réflexes, substituées lentement à ces autres qui ont directement engendrés les tendances dépravées ou du moins en ont favorisé le développement. On doit pour cela s'aider de l'imitation, des habitudes graducllement introduites par la vie commune avec des personnes honnêtes et par des précautions sagement prises pour empiccher à l'idée fixe que nous arons vue derenir 
$\therefore$ fatale dans l'enfance (v. s.), de jaillir dans un terrain trop fertile.

lci encore, la peine, par elle-mème, ne se montre pas aussi efficace que certains moyens préventifs, tels que des conditions farorables d'air, de lumiere et d'espace, une nourriture où l'on ferait prédominer, par exemple, les substances végétales, la privation de liqueurs alconliques, l'abstinence complète et, en certains cas donnés (․ cas re Zambac), une gymnastique sexuelle qui privienne les excès solitaires(1). Il importe: d'éviter les jalousies faciles pour empècher les violences impulsives; de raprimer lorgueil précoce au moyen des preuves palpalles, si faciles it trouver et ì produire, de l'infériorití lumaine, surtout dans l'enfance; il importe de euitiver l'intelligence par la voie des sens et le coeur par la voin de l'intelligence, comme le fait d'une faron si admirable le système de Froebell. - Il y a des enfants tristes, violents, portés à la masturbation, par suite de maladirs, le rachitisme, on à cause des vers, etc.; les dépuratil's, los vermifuges deviennent alors les seuls moyens de correction.

Empècher l'union tristement féconde des alcooliques ct des criminels, union qui, nous le savons, est une

(1) Galumbur, dans son livre qui a pour titre: Comment le traiteinent homoropathique pout cméliorer le caractère, Paris, 1882, prétena avoir gueri, avee des substances hommepathiques, eertaines tendanees immorales; avee le platine et la noix vomique les tendances lascives d'me jeune fille; avec t'origanum majoranum, chez trois antres, une propension irrésistible à la masturbation; avee le chlorure de sodium la miehaneeti d'nue fillette qui allait jusqn'a battre sa mère, etc. Mais tes histoires mêmes trahissent le peu de sírienx de telles assertions, car une idée fixe, une tendance eongénitale ne pourrait se modifier que par un traitement longtemps poursuivi, et non par des doses infinitisjmales administries en une seule fois on du moins à de rares intervalles. 
si large sonree de criminels précoces, serait l'unique moyen de faire disparaitre le criminel-né, ce mallenreux qui, d'après les faits que nous rapporterous, est absolument incurable.

Et si, partant de lì, nous nous rencontrons avee Roussel, Barzillai et Ferri pour blimer les maisons de correction, que l’on pourrait, hélas! appeler justement des officines de corruption, nous croyons qu il y amrait pour le pays un immense avantage à fonder à leur place des maisons pour les fous criminels, ou, mieux encore, In asile perpétuel pour les mineurs affectés de tendances criminelles obstinćes ou de folie morale.

Pour eux, lasile criminel devient utile autant et mème plus que pour les adultes, car il étoufle dès leur naissance les effets de ces tendances auxifuclles nous ne prètons, malheureusement notre attention que quand elles sont devenues irrémédiables et fatales.

Et ce n'est point là une idée nouvelle on révolutionnaire; sous une forme plus radicale et moins humanitaire la Bible l’avait déjá proclamée, quand elle ordonnait an père de faire lapider par les Anciens son fils mécliant, ivrogne et rebelle à la voix de ses parents et ì leurs corrections (1). L'éducation peut, en effet, empêcher une bonne nature de passer du crime infantile et transitoire an crime habituel - mais elle ne peut changer ceux qui sont nés avec des instincts perrers.

(1) Deuter. ххг. 



\title{
SEGONDE PARTIE
}

\author{
$?$ \\ ANATOMIE PATHOLOGIQLE \\ ET ANTHROPOMÉTRIE DU CRIME
}

\section{CIIAPITRE PREIIER}

\section{Examen de 383 crânes de criminels (1).}

Dans une étude anthropologique sur' l'homme criminel on doit nécessairement prendre pour point de départ les caractères anatomiques; mais lo grand nombre des individus examinés et les conditions spéciales des lecteurs auxquels ce livre sadresse nous conseillent de ne donner ici que les résultats sommaires de nos recherches, tandisque dans un supplément spécial, à la fin de cet ourrage, nous exposerons les donníes sur lesquelles ces résultats s'appuient.

(1) Covgnet e De Pand, Su $2 \theta$ crani di criminali. Archivio di psichiatria, scienze penati, ecc., 1882, p. 107). - Borbler, Etudes anthropologiques sur une série de cieines d'ussessins. (Revue d'unthropologie, II série, fase. 11). - AunEs, Crani di assassini e considerazioni di cranivogia psichiatriconcriminate. Archicio di jsichiatia, sciense 
1. - Capacité crênienne. - Par une étude comparée des crânes de 12I crimincls italions, mâles, et des crûnes de 328 italiens en étal normal (voir tav. 1) nous avons trouvé que pour les capacités minimes (de 1101 à 1200) les criminels l'emportent sur les autres; il en est de mème pour les capacités de 1251 a 1300 ; its sont, d'après nos études, presque en proportion igale pour les capacités de 1401 à 1450, et un peu supéricurs à partir de 1351 ¿ 1500. Par rapport aux capacilés de 1501 à 1550 ils sont en infériorité; au contraire, ils sont en proportions égales aux personnes en étal normal pour ce qui

wonti, ece., 1883, p. 98). - Frkr1, Studi di antropmetria su mimimali, paszi e sani. (1881). - Lombroso e Maxubl, Cianiometia di 39 delinquenti e 66 nomali del Piemonte. 1881). - Borito e Colmo, Tipi di delinquenti mattoidi. (1881). - Lexhosser, Crani di delinquenti rumeni, ungheresi, e croati. 1880). - IE PaL, Quattro crani di delinquenti. (1880). - Tex-Kate e Pawloski, Sur quelques cranes de criminels. (Fevue d'antlir., 1881, p. 116). - M. Fusch, Cntersuchungen übor Vevbrecher Gelime, Wïrzburg, 1881. - Conke, Crines de criminets. (Bullctin de la Sor. donthr., 1881). - Ardoun, Craniologie des rssrossins. (Bulletion de la Soc. (l'anthr., 1879). - Heger e Dallemane, Etudes sur les caractires craniologiques d'ussassins exerutes en Betgique, 1881. - Fucosss, Taricti delle civconvolusioni delluomo, 1S8I. -- PeL, Intorno alla craniologia degli alienati, 1882. - SchwEKENDLk, Lntersuchungen an sehn Gehinnen von Verbrechern und Selhsmönden, Wurzburg, 1881. - I. I. Bexedit, Anatomische Studien an Ierbrecher Gehimen, Wien, 1879. - ID., Schädelmessung-Kranio und Cephorlometile, Wien, 1883. - D. A. Wersbach, Beiträge sur Fentniss der Schädelfonmen asterreirliseher Tölker. (W'iener med. Jahr-

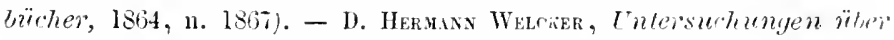
IFachsthum und Ban des menschelichen Shädels, 1852. - Ema Keschie, Schëdel, Hirn und stegle nach Alter, Geschlertei und Race, 1854. D. E. Zuckelikanne, Morphol. des Gesichtswhädels, Ixi7. - Messungen

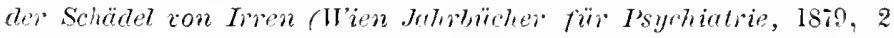
Helt). - E. Horseld, Ciritica e riformu del metodo in antropologin,

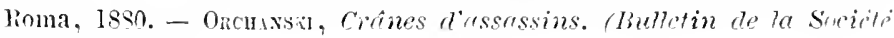
"Anthir., ISs?. 


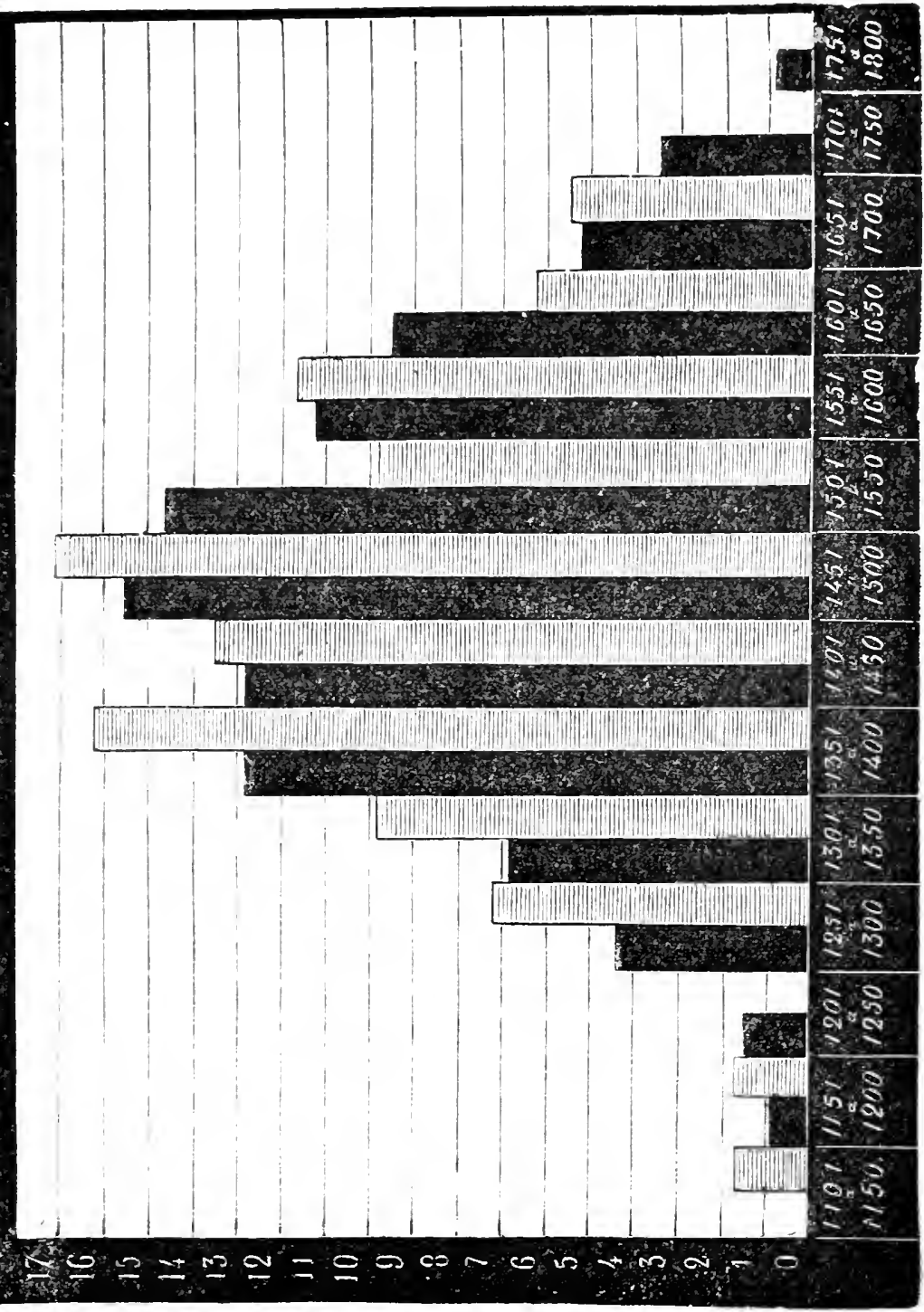

Tablean de la capreité crânienne chez 121 criminels mâles. lignes noires indiquent les individus en état normal, les branches les criminels. 
est des capacités de 1551 à 1600 et de 1651 à 1700. Nous trouvons les eriminels en nombre inférieur potir les eapaeités de 1601 à 1650; pour les eapacités supérieures à 1700, ils font défaut.

Donc, excepté pour les ehiffres de 1451 à 1500, les petites capacités l'emportent et les très-grandes sont rares, malgré que les eriminels aient une taille plus ćlevée que les honnêtes gens, et quoique mes mesures aient été prises avec du sable, et que de cette faron mes mesures soient supérieures aux autres le 100 c. c.

2. - Capacité selon les crimes. - En séparant les eriminels (1) nous trouvons que si pour les eapacités minimes de 1101 à 1200 les voleurs sont en nombre bien plus grand, c'est pourtant le contraire qui arrive pour les capacités de 1551 à 1700. La capacité de 1451 à 1550 serait la plus commune chez les voleurs (le 17,6 $0_{10}$ ), tandis que chez les assassins on trouverait plus fréquemment

I)

I. cub. 1101-1150

Id. 1151-1200

Id. 1201-1250

Id. 1251-1300

1d. 1301-13\%0

Id. 135! -1400

Id. $1401-1450$

Id. 1451-150

1A. 1501-1550)

Id. $155 \mathrm{l}-\mathrm{l} 600$

Il. $1601-1050$

Id. 1051-1700

Id. 1701-1750

Id. 1751-1500

Jd. 1801-2000
Assassin: Voleurs Individus

010

0

0

0

11,3

9.4

16.9

11,3

15,0

5.4

11,3

13,2

5,4

010

2,9

11,7

0

2,9

$11, \pi$

11.7

11,7

$17, ;$

17,6

$\therefore, 6$

0

2,9

sains

$$
0
$$$$
0,9
$$$$
1,7
$$$$
4,3
$$$$
6,9
$$

12,9

12.9

15,5

14,6

11.2

9.5

5,2

3,4

0,9
Epilépt-

dues

0,5

0

0

2,0

1,0

7,2

8.8

14,4

20,1

16,1

21,3

11,9

3,62

1,52

2,59 
une capacité arrivant de 1351 a 1400 , et de 1451 à 1500. $\Lambda$ partir de la capacité de 1551 à 1600 , la proportion des voleurs serait inférienre à celle des honnêtes gens el même à celle des assassins, ce qui se vérifie encore mieux à partir de la capacité de 1600.

En comparant séparément les assassins italiens arec les personnes jouissant d'un esprit sain, nous royons que celles-ci sont cn proportion tant soit peu plus forte pour les capacités minimes de 1151 a 1250 ; et quielies sont en proportion un peu moindre pour les capacilé: de 1951 à 1350. Entre 1501-1550, mojennes normales, elles dépassent du triple les assassins; ceux-ci font complètement défaut au dessus de 1700 , et ils sont en infériorité dans la proportion de 13 à 9 ou à 10 quant aux capacités maximes et aussi, selon Imadei, dans les catégories de 1401 à 1450 .

Quant aux capacités minimes de 1101-1200, les voleurs l'emportent sur les individus bien conformés dans la proportion de 1'́ à 1. Pour les capacités un peu plus grandes et pour les très-grandes, on trouve moins de voleurs que d'assassins.

Même dans la moyenne arithmétique qui pour les individus en état normal est de 1474 à 1550 , les criminels présenteraient une infériorité; c'est-à-dire une capacité de 1455; et les assassins (1457) présenteraient, à cet égard, une faible supiriorité sur les roleurs (1449).

Nous n'arons eu que deux cas de crimincls par passion, et nous les éludiàmes à part; nous trouvàmes une capacité de $135 j$ el une de 1520 .

En fait de capacités très-pelites j’ai trouvé chez 60 femmes criminelles une proportion presque double vis-à-vis des femmes normales (comme 41 est à 29 ); mais il n'y 
aurait pas de différence pour les capacités un peu plus grandes - 1251 à 1400. - Dans les chiffres (1) plus élevécs leur tantième, sauf pour quelques exceptions, serait śridemment inférieur (comme 14 est à 29).

La moyenne irithmétique (1272) des criminelles, (1295 pour les brachicéphales et 1266 pour les doligocéphales) est quelrue peu inférieure à la normale - 1310 ou 1316. Elle est de 1180 dans 2 complices en viol, de 1253 et de 1255 dans 3 filles prostituées et 10 assassines; de 1238 dans 19 meurtrières; de 1280 dans 11 infanticides; de 1261 dans 12 voleuses; et de 1384, le maximum, dans 5 empoisonneuses.

Chez les criminels allemands nous trouvons: une superiorité numérique pour les capacités minimums (dans la proportion de 18 à 6); parallélisme pour les capacités de

(1) Capacités

1000-1050

10511100

1101-1150

1151-1200

$1201-1250$

1251-1300

1301-1350

1351-1400

1401-1450

1451-1500

1501-1550

1551-1600

1601-1650

1651-1700

$1701-1750$
Femm. crim. 010

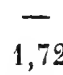

6,89

12,25

20,60

25,86

12,25

10,34

5,17

3,44
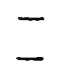

1,72

$-$
Femm. nol'm.

010
Femm. foll.

0,91

1,82

5,45

10,0

10,9

10,9

20,0

10,9

9,09

6,36

5,45

5,45

1,82

0,91

$\begin{array}{cc}- & - \\ 1,1 & 2,50 \\ 4,6 & 3,54 \\ 4,6 & 3,93 \\ 9,2 & 8,21 \\ 20,7 & 13,57 \\ 14,0 & 19,63 \\ 16,1 & 17,49 \\ 8,0 & 15,35 \\ 5,7 & 10,00 \\ 6,9 & 3,21 \\ 5,7 & 1,43 \\ 2,3 & - \\ 0 & 1,07 \\ 1,1 & -\end{array}$


1305 à 1600, infériorité pour les autres (1). Cependant selon hanke (Beilräge zur plysichen Anlrop. der Bayern, 1883) chez les assassins Bavarois, si on trouverait beaucoup de capacités minimums (2) (25 pour 19 des normaux), ce nombre serait compensé par une certaine supériorité en fait de capacités maximums 18 à 6 ; mais, comme on to voit, ces études ne se rapportent qu'à des assassins, et peut-être faut-il tenir compte du crétinisme qui, comme on le sait, est très-répandu dans cette partie de l'Allemagne, et favorise les macrocéphalies.

(1) Criminels Allemands de Weisbach:

\begin{tabular}{|c|c|c|c|c|}
\hline \multicolumn{2}{|c|}{ Individus norm. (216) } & \multicolumn{2}{|c|}{ Criminels $(175)$} & Criminels \\
\hline Capacité & 010 & Capacité & 010 & célèbres \\
\hline $1000-1100$ & 0 & $1000 \cdot 1100$ & 2,3 & - \\
\hline $1101-1150$ & 0,4 & $1101-1200$ & 2,3 & - \\
\hline $1151-1200$ & 1,7 & $1201-1300$ & 15,5 & 1 \\
\hline $1201-1300$ & 4,0 & $1301-1400$ & 30,8 & 4 \\
\hline $1301-1450$ & 29,5 & $1401-1500$ & 24,9 & 4 \\
\hline $1451-1600$ & $4 \pi, 6$ & $1501-1600$ & 13,2 & 2 \\
\hline $1601-1750$ & 14,8 & $1601-1700$ & 6,8 & 3 \\
\hline $1751-2000$ & 3,6 & $1701-1800$ & 3,5 & - \\
\hline $2001-2100$ & 0,4 & $1801-1900$ & 0 & - \\
\hline$-\quad-$ & - & $1901-1920$ & 0,6 & - \\
\hline
\end{tabular}

(2) Ranke (1883) a trouvé:

$\begin{array}{ccc}\text { La capacite } & \begin{array}{c}\text { Sur } 100 \\ \text { criminels }\end{array} & \begin{array}{c}\text { Sur } 100 \text { sains } \\ \text { Bavarois }\end{array} \\ \text { de } 1200 \text { à } 1300 & 3,0 & 2,8 \\ \text { de } 1301 \text { à } 1400 & 22 & 17 \\ \text { de } 1401 \text { à } 1500 & 22 & 35 \\ \text { de } 1501 \text { à } 1600 & 19 & 21 \\ \text { de } 1601 \text { à } 1700 & 15 & 18 \\ \text { de } 1701 \text { à } 1800 & 9 & 6 \\ \text { dle } 1801 \text { à } 1900 & 9 ; & 0\end{array}$


Bordier (Revue anthropologique, 1879) prétendrait que la capacité moyenne des crànes chez les criminels est supérieure à la normale, mais il n’a étudié, lui aussi, que les assassins; et si l'on déduit la capacití du crâne anormal (2076) on a une proportion presque śgale (1581) au normal.

Pourtant il faut convenir qu'avec les méthodes sériaires on trouve bien de fois dans les criminels une supériorité dans les grandes capacités (1). Cela résulte, aussi, d'une récente étude de Manouvrier selon lequel il n'y aurait chez les assassins d'autre différence des crines normaux qu'un certain nombre de capacités énormes (audessus de 1900).

Bref: le plus grand nombre des crines petits, et, peut-être aussi, des trop grands serait un des caractères des criminels. C'est la même chose qui arrive pour les fous; mais ceux-ci présentent une tendance bien plus marquée à excéder dans les capacités trèsgrandes.

En général, lorsque la grande capacité crìnienne des criminels n'est pas due à une hydrocéphalie, elle est justifiée par une intelligence très-développée. Ainsi, .

(1) Criminels Français:

$\begin{array}{ccc}\text { Capaeité } & \text { Cimetière de l'ouest } & \text { Assassins } \\ 1300-1400 & 21,87 & 11,42 \\ 1400-1500 & 18,75 & 14,28 \\ 1500-1600 & 43,75 & 28,57 \\ 1600-1700 & 3,12 & 22,85 \\ 1700-1810 & 6,55 & 16,66 \\ 1800-1900 & 3,12 & 2,77 \\ 1900-2000 & 3,12 & 0 \\ 2000-2100 & 0 & 2,77\end{array}$


dans les cas que j'il pu étudier, on doit compter parmi ceux qui dépassent la moyenne et qui arrivèrent ¿ 1600 c. c.: Artusio féroce, mais intelligent chef de brigands piémontais et un de ses complices tout anssi rusé que lui, Violini; Mendaro qui tua sa femme avec I'aide d'une complice el sut, pendant longtemps, éluder la justice; I... de Verecil, voleur de grands chemins doué de beaucoup de talent; la C... de Vérone empoisonneuse aussi très-rusće; Soldati qui à l'àge de 70 ans arait encore toules ses sutures intactes et arait réussi a se soustraire à toutes les recherches de la justice malgré un grand nombre de meurtres et de viols.

Parmi les criminels à grande capacité crânienne cités par' Ileger et Bordier, nous trouvons Rooxel et Jansens qui dans les assassinats avaient plutôt joué le rôle d'ol'donnatcur's que celui d'cxécuteurs, el Minder-Krafft 1631, Pascal 1770, qui avaient introduit dans leurs bandes une sorte d'organisation burocratique.

Ten-Kate et Pawloski trouvèrent l'énorme capacité de 19.5̆ chez un certain Le Pelly, qui assassina un agent de change; Le Pelly étail si rusé qu'il passait aux yeux de lous pour un modéle de vertu.

3. - Circonférence. - La circonférence du crîne des criminels dans les chiffres minimums est parallèle, ¿̀ pen près, à celle des individus sains; les criminels sont moins nombreux à partir de 481, jusqu'à 500; depuis 501 jusqu'a 510 au contraire ils l'emportent presque du double; entre 511 et 530 les roleurs sont moins nombreux, les assassins le sont plus; de 530 à 540 les roleurs sont en nombre égal, les assassins présentent une infériorité numérique. Dans les proportions les plus fortes, les rolemrs manquent tout-à-fait, les 
assassins atteignent ou dépassent la proportion des individus sains (1).

Pour l'Allemagne, si l'on compare les 215 crânes de Weisbach avec les 164 crânes de criminels de Bonn et avec ceux des 83 fous de Zuckerkandl (2), on voit que les fous surpassent les criminels dans les proportions les moins élevées, qu'ils les égalent ou qu'ils les surpassent de peu jusqu'aux proportions de 53 , et qu'ils présentent une infériorité dans les dimensions plus grandes. Les criminels surpassent, les individus sains

(1)

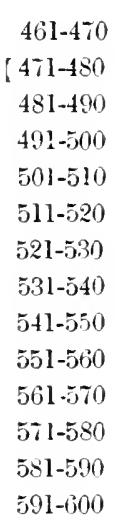

(2)

$47,6-48,0$

$48,5-49,0$

$49,1-50,0$

$50,1-51,0$

$51,1-52,0$

$52, \mathrm{l}-5,30$

$53,1-54,0$

$54,1-55,0$

$55,1-56,0$

56,1-57-0

$57,1-57,4$

Assassins
1,6
0
6,6
13,3
38,3
15,0
36,0
3,3
3,3
3,3
0
1,6
0
0

$\begin{array}{cc}\text { Voleurs } & \text { Indiv. sains } \\ 0 & 1,0 \\ 0 & 1,0 \\ 8,6 & 11,1 \\ 11,1 & 15,5 \\ 44,4 & 17,5 \\ 13,8 & 17,5 \\ 11,1 & 17,5 \\ 11,1 & 11,1 \\ 0 & 3,1 \\ 0 & 0 \\ 0 & 0 \\ 0 & 3,1 \\ 0 & 0 \\ 0 & 0\end{array}$

Sains p. $00^{0}$

0
1,9
12,6
20,0
31,1
18,2
13,0
2,8
0
0
0,5

Criminels p. 010

Fous p. $0_{10}$

$0 \quad 1,2$

$\mathbf{1 , 8}$

0

1,3

8,5

9,6

22,9

22,0

22,9

22,6

18,2

24,1

8,4

11,5

5,5

0,6

9,6

1,2

1,8

0

0 
dans les dimensions les plus fortes, a partir de 54; leur nombre est un peu inférieur entre 52 et 53, il est de beaucoup inférieur entre 51 et 52.

Les criminels, de leur côté, seraient infélieurs aux personnes normales de 49 ì 53 , inférieurs aussi aux fous jusqu’i 51 ; ils égaleraient ces derniers entre 51 et 52; a partir de 53 ils dépasseraient de beancoup les individus sains et les fous.

La moyenne - 492 - de nos 60 criminelles italiennes est presque égale à la moyenne des italiennes honnètes - 491 .

En cxaminant les chiffres de Bordier qui a comparé les crînes d'assassins avec ceux de domestiques, de nobles, de bourgeois et de savants, nous trouvons que pour les circonférences de 51, 52, les assassins donnent le 5,50 [ 0 , proportion forte que les autres n'atteignent pas; ces derniers seraient même inférieurs entre 53,54 et 55 . Les savants et les domestiques présenteraient, all contraire, un contingent plus fort de 56 it 57; les savants seuls conserveraient cette supériorité jusquà 57 à 58 (1).

(1) Français (Bordier).

$\begin{array}{lccccc} & \begin{array}{c}\text { Savants } \\ \text { p. } 010\end{array} & \begin{array}{c}\text { Bourgeois } \\ \text { p. } 010\end{array} & \begin{array}{c}\text { Nobles } \\ \text { p. } 0[0\end{array} & \begin{array}{c}\text { Domestiques } \\ \text { p. } 0[0\end{array} & \text { Assassins } \\ 51-52 & 0 & 0 & 0 & 0 & 5,55 \\ 52-53 & 0 & 0,6 & 0 & 1,8 & 8,33 \\ 53-54 & 2,0 & 1,9 & 3,7 & 5,4 & 13,8 \\ 54-55 & 4,0 & 6,2 & 9,2 & 5,4 & 25.8 \\ 55-56 & 6,0 & 14,0 & 12,8 & 33,9 & 13,5 \\ 56-57 & 18,0 & 24,0 & 28,5 & 42,8 & 16,6 \\ 57-58 & 36,0 & 24,5 & 22,0 & 10,7 & 11,11 \\ 58-59 & 18,0 & 14,0 & 12,0 & 0 & 0 \\ 59-60 & 8,0 & 7,0 & 8,0 & 0 & 2,61 \\ 60-61 & 6,0 & 3,3 & 1,8 & 0 & 2,61 \\ 61-62 & 2,0 & 1,8 & 0 & 0 & 0 \\ 62-62,5 & 0 & 0,7 & 0,9 & 0 & 0\end{array}$


Cependant Heger et Dallemagne nous donnent la moyenne de $529 \mathrm{~mm}$. pour les assassins de Liége, de 527 pour ceux de Gand et de 534 pour ceux de Bruxelles; ces chiffres surpassent de bien peu la moyenne normale (525) de Bruxelles.

4. - Demi-circonférence du crâne, etc. - Bordier a voulu donner une grande importance à la différence que présente la demi-circonférence antérieure par rapport à la postérieure qui serait notablement plus fortc; c'était une chose facile à présumer en tenant compte de l'étroitesse du front. J'ai trouvé, en effet, dans mes 93 criminels, que dans l'un de ceux-ci il n'y a pas de différence; dans 76 cas la courbe préauriculaire est plus petite que la postérieure; dans 16 cas, seulement, la courbe préauriculaire est notablement supérieure.

5. - Projection antéricure. - L'étude des projections crìniennes est peut-être plus concluante. Orchanski sur Q'. assassins francais aurait trouvé:

As. Proj. de la face moyeme 143 Européens sains 64,0 Nègres I3، Id. du crâne antér. $355 \quad$ ld. 409 Id. 361 Id. id. postér. 502 Id. 525 Id. 501

ce qui donnerait des différences bien nettes en faveur de la projection antérieure.

Quant à la Belgique Ileger en est arrivé aux mêmes résultats:

$$
\text { Proj. ant. Proj. post. Diffërence }
$$

$\begin{array}{lrrr}\text { Meurtriers de Bruxelles } & 82,0 & 100,5 & 18,5 \\ \text { Moyenne normale id. } & 83,6 & 93,7 & 10,1\end{array}$

6. - Ares et courbes. - Bordier dans son travail sur les crànes des assassins étudie les diverses parties de 
la courbe antéro-postérieure; en donnant it la totalité de la courbe la valeur de 100 , il tronve:
C. sous-cérébrale Frontale
Parietale
Occipitite
Criminels 7,32
26,92
$3 i, 41$
31,35

tandis que chez les individus sains il olsserva
C. Innocents 4,80
29,90
33,74
31,56
"Ouest . 5,16
29,66
33.39
31,79

Chez les criminels, il en conclue, la portion parićtale l'emporterait de beaucoup sur la frontale.

Dans notre collection, toutefois, nous avons obtenu:

C. sous-cérébrale Frontale Pariétale Occipitale

$\begin{array}{llll}\text { Meurtriers } 6,37 & 29,22 & 34,29 & 30,27 \\ \text { Voleurs . 6,61 } & 29,76 & 33,49 & 29,98\end{array}$

Or si ces chiffres montrent un certain avantage quant aux pariétaux, quant au frontal, elles n’indiquent aucune différence d'avec les mesures que Bordier y a trouvées chez les individus normaux.

Cluez les assassins de Bruxelles on trouve, pour la courbe pariétale, une différence contradictoire.

Benedikt en comparant les crînes des criminels de Bonn avec les crânes de Königsberg aurait trouvé:

Arc frontal Arc pariétal Arc occigital

$\begin{array}{llll}\text { Chez } 216 \text { normaux } \quad \text {. . 12,4 } & 12,2 & 11,4 \\ \text { Chez les } 164 \text { crim. de Bonn } 12,9 & 12,6 & 11,8\end{array}$

ce qui ne donnerait aucune différence appréciable. J'insiste à regret, sur ces détails, à cause de l'importance exagérée que leur ont prêtée certains auteurs qui vont jusquu à parler de races pariétales à propos de criminels!!

7. - Indice céphalique. - Quant à l'indice céphalirue, tout ce que l'on peut conclure de nos calculs, c'est 
qu'il subit généralement l'influence régionale en l'exagérant: brachycéphalie exagérée dans le Piémont - 4/4 sur 55, - dolichocéphalie dans la Sicile, dans la Sardaigne et Calabre - 39 sur 39.

Cela se voit mieux en comparant, en détail un groupe de 49 criminels et 83 honnètes de Piémont

\begin{tabular}{|c|c|c|c|}
\hline Dolichocéphales & . & . $\quad 8010$ & 10 \\
\hline Mésaticéphales & . & . $12 "$ & 19 \\
\hline Brachycéphales & . & . 80 & 69 \\
\hline
\end{tabular}

Il y a donc, de la part des criminels, une certaine supériorité dans les brachycéphales et unc remarqualsle infëriorité en fait de mésocéphales ct de dolichocéphales.

On observa aussi que la brachycéphalic chez quelques assassins des Romagnes et surtout chez les meurtriers du Piémont arrive à un indice de 90 à 88 .

Ce fait très-curieux qui se vérifie aussi chez les crétins, et qui nous sera confirmé par les études sur les vivants, avait été entrevu et mis à profit par les phrénologues qui, selon leur habitude, en exagérèrent la portée et en avaient déduit que l'organe de la cruauté résidait dans le lobe temporal.

Toutefois il faut noter que Cipolla et Gasparone, brigands fameux, ont un indice céphalique de 72, et que si la féroce Bouhors, si les assassins Matzket et Flegel avaient un indice de $89,86,82$, par contre Blank était dolichocéphale ainsi que Lacenaire 76 , Hélouin 79, Avril 72, Lemoine 73, Noreau 72, (Orchansii, Bullet. de la Soc. Anthropol.). Et de même pour les dolichocéphales (qu'on trouve pour une simple coïncidence plus nombreux, 25 sur 42, dans les escrocs et dans les voleurs) on voit qu'ils prédominent là oủ la dolichocéphalie est physiologique, sauf l'exagération des indices qui vont à 
68,70. Aussi les Sardes criminelles nous donnent un moyen de 70,9 an lieu de 72,3 que '/annetti trouva pour les honnêtes, ou de 74 que donne Calori. Et nous avons, lii, le $0_{10}$ pour $0_{10}$ des dolichocéphales au lieu de 90 p. 0 0 que donne Calori pour les Sardes normaux.

De tout cela on ne peut conclure, je le repete, autre chose, si ee n'est quill y a dans les crimincls une tendance à l'exagération des indices ethniques.

8. - Diamétre vertical et indice vertical. - Bordier a donné beaucoup d'importance au diametre vertical des crànes chez les assassins, mais, ici non plus, je n'ai pu relever aucune différence notable, car j’ai trouvé dans 40 criminels des indices qui de 61-62 allaient jusqu'ì 71 , à 78, à 81, dans 60 eriminelles des indices qui allaient de 80,1 (viol), à 78,5 (incendies), à 74,5 (rol), a 71,3 (meurtre), et à 70,4 (empoisonnement).

Et pendant que Ileger avait trouvé pour les assassins à Bruxelles les diam. vert. 130, indice vert. 69, il vérifiait chez les individus sains les diam. vert. 131, indice 71 .

A Paris, Orchanski sur 24 crânes d'assassins a trouvé un indice moyen de 75,3 , et dans les cas ordinaires un de 72, précisément l'inverse d'Ileger.

9. - Indice frontal. - Je ne trouve pas, non plus, qu'il y ait une différence bien nctte pour l'indice frontal; Heger a obtenu une moyenne de 66,7 à 67,8 chez les criminels et une moyenne de 67,7 chez les personnes honnêtes.

Chez les 60 femmes coupables, je tronve les plus grandes indices frontaux

Dans le viol . . . . . . 75,43

Id. l'infanticide . . . . 71,47 
Dans l'homicide . . . . . $70_{6} 39$

Id. l'empoisonnement • . 70,28

Id. l'incendie . . . . . 69,18

Les moindres indices on les notait

Dans l'assassinat $\quad$. . . . 68,87

Id. les blessures . . . . . 68,87

Id. la prostitution . . . 67,97

Id. le vol . . . . . 67,76

Sur des crànes de criminels mâles piémontatis comparés aux honnêtes du même pays j'ai trouré:

49 Criminels

De 60 à 65,2

De 66 à 70

De 72 à 73

De 75 a 78
32010

44 .

$16 "$

4 "
60 Individus honnètes 36010

36

$26 "$

4 "

Ces chiffes prouveraient, tout au plus, que les crânes des criminels ont plus souvent que les autres des indices courtes et un peu moins souvent qu'eux d'indices hautes.

10. - Indice crânio-mandibulaire. - Manouvrier (Bulletin de la Société Zoologique, 1882) amrait conclu que les meurtriers présentent un indice erânio-mandibulaire (14,78 en moyenne) plus élevé que celui gu'on troure sur les français normanx $(13,4$ a 12,8). D'après mes recherches cette différence ne serait pas appréciable, car la moyenne serait de 13,1 pour les criminels, toutà-fait comme pour les honnêtes gens, 13,1; elle serait de 12,2 pour les fous.

11. - Face. - Le diamètre frontal minimum a présenté des différences notables; il atteint une moyenne de 96 chez des criminels piémontais tandis qu'il va 
jusqu'a 109 chez les piémontais honnêtes. Avee la míthode sériale on trouve bien moins fréfuents cliez les eriminels que chez les derniers les chiffres de 96 i 105 , tandis quion y trouve bien plus souvent les chiffres de $97,7,106$ il 115 (I).

12. - Hauteur de la face. - La hanteur de la face atteint chez les criminels une moyenne (92) qui dépasse la moyenne ordinaire $(86)$; et cela se voit mieux dans la séric.

La largeur apparaittrait tout-ì-fait semblab]e; mais arec la méthode sériale on trouve dans les chiffres minimums une très-grande infériorité chez les criminels, et de mème dans les chiffres maximums.

\begin{tabular}{|c|c|c|c|c|c|c|}
\hline & IIauteur & la fa & & & Largeur & la face \\
\hline & $\rho \frac{\dot{\bar{E}}}{\underline{\underline{E}}}$ & 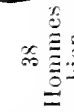 & & & 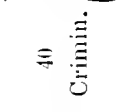 & 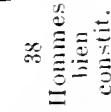 \\
\hline $71-80$ & $5,0 \quad 0[0$ & 18,1 & $0_{10}$ & -116120 & $0,0 \quad 0[0$ & 2,$1 ; 0$ \\
\hline $81-90$ & 32,5 & 63,1 & $"$ & $-121-125$ & 5,0 & $10, \overline{5}$ \\
\hline $91-100$ & 55,0 & 21,0 & $"$ & $-125-130$ & 27,5, & 28,8 \\
\hline $101-110$ & $7,5 \|$ & 2,6 & $"$ & $-131-135$ & 32,5 & 36,0 \\
\hline $14-120$ & 2,5 & 0,0 & 1 & $-136-140$ & 35,0 & 13,1 \\
\hline- & - & - & $"$ & $-141-145$ & 0,0 & 5,2 \\
\hline
\end{tabular}

(1) Diamètres frontaux minimmms.

\begin{tabular}{|c|c|c|c|c|c|c|}
\hline \multirow[b]{2}{*}{ De $85-90$} & \multicolumn{3}{|c|}{46 Criminels } & \multicolumn{3}{|c|}{60 Individus sains: } \\
\hline & 1 & 2,10 & & 2 & 3,3 & \\
\hline Id. $91-95$ & 10 & 21,7 & " & 10 & 16,6 & $"$ \\
\hline Ill. $96-100$ & 15 & 32,6 & $»$ & 29 & 48,3 & $»$ \\
\hline Id. $101-105$ & 13 & 28,2 & . & 17 & 28,3 & \# \\
\hline Id. $106-110$ & 5 & 18,8 & $\gg$ & 2 & 3,3 & * \\
\hline Id. $111-115$ & 1 & 2,1 & $\Rightarrow$ & 0 & 0 & \# \\
\hline Ill. $116-120$ & 0 & 0 & $»$ & 0 & 0 & * \\
\hline Ill. $121-125$ & 0 & 0 & » & 0 & 0 & - \\
\hline
\end{tabular}


13. - Indice nasal. - Les indices les moins élevés sont chez les criminels deux fois plus rares que chez les individus normaux, tandisque les indices les plus élevés (46-55) sont presque deux fois plus fréquents (1).

14. - Mâchoire inférieure. - Généralement la màchoire est plus développée chez les criminels; chez eux elle atteint le poids de $84 \mathrm{gr}$., tandisque chez les fous le poids en est de $78 \mathrm{gr}$, chez les honnêtes gens de $80 \mathrm{gr}$.

Quant au diamètre (2), nous voyons prévaloir chez les criminels les chiffres de 100 et 110 , en même temps que nous royons une absence des chiffres inférieurs, de 80-90, que nous trouvons par contre chez les individus bien constitués et plus souvent encore chez les fous. Les diamètres infimes, de 70 à 80 , se trouveraient bien plus souvent chez les fous qui présentent une infériorité pour les diamètres les plus grands.

(1) Indices nasaux.

$\begin{array}{cccc} & & \begin{array}{c}\text { Individus sains } 43 \\ \text { (Pièmontais) }\end{array} & \begin{array}{c}\text { Criminels } \\ \text { (Pièmontais) }\end{array} \\ \text { Indices de } & 31-35 & 2,3 & 7,5 \\ \text { Id. } & 36-40 & 6,9 & 17,5 \\ \text { Id. } & 41-45 & 23,2 & 32,5 \\ \text { Id. } & 46-50 & 44,1 & 35,0 \\ \text { Id. } & 51-55 & 20,9 & 7,5 \\ \text { Id. } & 56-60 & 2,3 & 0\end{array}$

(2) Diamètre mandibulaire.

Individus sains
Distance
$110-120-1$
$100-110-14$
$90-100-11$
$80-90-3$
$70-80-0$

$\begin{array}{cc}\begin{array}{c}\text { Fous } \\ \text { Distance }\end{array} & \begin{array}{c}\text { Criminels } \\ \text { Distance }\end{array} \\ 110-120-1 & 110-120-0 \\ 100-110-22 & 100-110-29 \\ 90-100-24 & 90-100-15 \\ 80-90-4 & 80-90-0 \\ 70-80-1 & 70-80-1\end{array}$


La moyenne de ce diamètre serait en résumé:

$$
\begin{aligned}
& \text { Chez les individus sains de . . . } \quad 98,2 \\
& \text { Id. criminels . . 103,9 } \\
& \text { Id. fous . . . . } 97,8
\end{aligned}
$$

Après avoir mesuré la hauteur de la symphyse du menton chez 44 fous, chez 38 criminels et chez 28 personnes honnètes, nous avons trouvé que la moyenne est pour les criminels de 30,4, moyenne qui est un peu inférieure à la normale $(31,3)$; les fous donnent une moyenne quelque peu moindre 29,1.

Par la méthode sériale, nous trouvons que dans les chiffres inféricurs, de 30-24, les fous dépassent tous les autres. Viennent ensuite les criminels; pour les chiffres très-grands, les fous seraient en plus grand nombre; mais pour les moyennes de 31-39 ceux-ci seraient dépassés par les individus sains et par les criminels (1).

Orchanski (Bullet. Soc. Anthrop., 1882) dans son étude sur 24 assassins Français confirma le fait du plus grand développement de la mâchoire que nous avons trouvé dans les criminels, et l'analogie que, sous ce rapport, ils présentent avec les sauvages. Voici ses preuves numériques vraiment éloquentes:

(1) Hommes sains Hauteur p. 010

20-23- $0 \quad 0$

24-27- $2 \quad 7,1$

28-31-13 46,4

$32-35-10 \quad 35,7$

$36-59-3 \quad 10,7$
Fous

Hauteur p. $0_{10}$

20-23- $2 \quad 4,5$

$24-27-17 \quad 38,6$

28-31-15 34,0

32-35- $3 \quad 18,0$

$36-39-0 \quad 0$

40-43- $2 \quad 4,5$

\section{Criminels}

Hauteur p. 010

20-23- $1 \quad 4,6$

24-27- $9 \quad 23,6$

28-31-15 39,4

$32-35-10 \quad 27,3$

36-39- $3 \quad \tau, 8$

40-48- $0 \quad 0$ 
Larg. bigoniaq. Assassins 99,4 bi-mentonn. 46 Hant. de la symphy. 32,9

Id. Européens 95 id. Europ. 45 id. Européens 31

Id. Mongols 98 id. Nègres 46 id. hab. Nonv. Cal. 33

Iarg. des branches Ass. 66,4 largeur . . 33 Indice . . . . . 50

Id. Européens 57 id. Enrop. 30 id. Européens . . 53

Corde moyenne Assass. 86 chez les Europ. 82 chez les Nègres . 89

En résumé, on trouve chez les criminels un poids plus grand, une largeur plus considérable et une plus grande hauteur des branches du maxillaire inférieur, ce que nous pourrions mettre en rapport avec les résultats de Quatrefages sur les crànes préhistoriques.

15. - Indice facial. - Mis en comparaison des individus normaux, les criminels présentent peu d'indices de 50 à $6 j$, tandis qu'ils en présentent beaucoup d'élevés et de très-hauts; mais, comme nous arons déjà ru, cela ne dépend que d'une augmentation dans la hauteur, la largeur se maintenant presque la mème chez les criminels comme chez les autres (1).

Chez les Belges, entre 61 et 64 nous trourons un plus grand nombre de personnes honnêtes et un nombre plus grand encore entre 66 et 67 . Au contraire, de 72 à 78 le nombre des criminels l'emporte.

\begin{tabular}{ccc} 
& Criminel & Hommes sains \\
$61-6,5$ & $9,10[0$ & $23.50[0$ \\
$66-69$ & $27,3 " 3,8 \%$ \\
$70-78$ & $38,1 \%$ & $5,8 \%$ \\
\hline
\end{tabular}

(1)

4l Crimin. Piemont. 3\$ In s sains Piémont.

\begin{tabular}{|c|c|c|c|}
\hline $50-55$ & 2,50 & & 0 \\
\hline $5(j-60$ & 0 & $n$ & 18,4 \\
\hline $61-65$ & 17,5 & » & 36,8 \\
\hline $66-70$ & 55,0 & 》 & 29,2 \\
\hline $71-75$ & 17,5 & 》 & 14,0 \\
\hline $76-80$ & 2,5 & 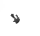 & 0 \\
\hline
\end{tabular}


16. - Superficie du trou occipital, capacité orbitaire et indice céphalo-spinal. - La superficie du tron ocipital a donné plus de $800 \mathrm{~m}$. q. chez 14 voleurs; chez 4 meurtriers elle surpassait 1000; elle était de moins de 700 dans les 7 assassins, et 5 voleurs.

Varaglia et Silva ont trouvé chez 60 femmes coupables des délits sllivants:

\begin{tabular}{|c|c|c|c|c|c|}
\hline $\begin{array}{c}\mathrm{N} .{ }^{\circ} \\
\text { examin. }\end{array}$ & Crime & $\begin{array}{l}\text { Sup. du trou } \\
\text { occip. }\end{array}$ & $\begin{array}{c}\text { Indice } \\
\text { céph.-spin. }\end{array}$ & $\begin{array}{c}\text { Cap. orbit. } \\
\text { c. c. }\end{array}$ & $\begin{array}{l}\text { Intice } \\
\text { céph. orth }\end{array}$ \\
\hline 3 & Incendie. & 790 & 16,7 & 51 & 26,3 \\
\hline 4 & Blessures . & $i 67$ & 17,4 & 53 & 25,1 \\
\hline 5 & Empoisonnem & hent 767 & 18.0 & $5 i$ & 24,3 \\
\hline 12 & Vol & . 748 & 17,5 & 52 & 24,3 \\
\hline 10 & Assassinat & 739 & 17,0 & 54 & 23,4 \\
\hline 11 & Infanticide & 733 & 17,6 & 52 & 24,9 \\
\hline 10 & Homicide & 728 & 17,0 & 53 & 25,1 \\
\hline 2 & Viol (compl.) & 710 & 16,6 & 53 & 22,2 \\
\hline 3 & Prostitution & 705 & 17,8 & 52 & $23, \pi$ \\
\hline
\end{tabular}

Ce qui fixerait son étendue maximum chez les incoudiaires, son étendue minimum dans les prostituées. - La moyenne serait chez les femmes de 731 (minimum 580).

Quant à la capacité orbitaire, Bono dans son beau travail Della capacitì orbitale e cranica (Archivio di Psichiatria, Torino, 1880) a trouvé sur 50 criminels une moyenne de 59,2 et sur les criminelles une moyenno de 53,5. Il a trouvé:

Chez les Lombards honnêtes la cap. orb. 56,5 id. les Piémontais 5,65

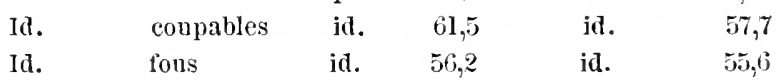

Les criminels se rapprochent des crétins qui ont une capacité orbitaire de 58 avec un indice de 25,0 , pour les 
hommes, de 24,5 pour les femmes; tout à l'opposé de ce qui arrive pour les fous $(55,6)$; ces derniers en effet, ne présentent pas de différence d'avec les individus sains.

27 sur 49 criminels (14 assassins et 13 voleurs), étudics avec la méthode sériale dépassaient la capacité ordinaire, arrivant à 60-78, tandisque 6 seulement restaient au dessous de la capacité ordinaire, c'est-à-dire, au dessous de $48 \mathrm{~cm}$. c.

Ce plus grand développement de la capacité orbitaire s'explique, comme chez les oiseaux de proie, par la coordination des organes en suite d'un exercice plus fréquent; c'est pourquoi cette capacité paraît encore plus développée chez les voleurs que chez les assassins.

Dans les criminelles on ne trouve ici de notable que la grande capacité des empoisonneuses et des assassines.

L'indice céphalo-spinal, mesuré sur 20 criminels, a élé trouvé plus grand que d'ordinaire et arrivait jusqu'à 34,4. Chez 6 autres il était au dessous de la moyenne, de 17 à 21 .

Chez les 60 criminelles la moyenne de l'indice est de 17,7. Elle est inférieure de beaucoup à celle des normaux; l'indice minimum se trouve chez les incendiaires et les complices en viol; le maximum chez les empoisonneuses et les prostituées.

L’indice céphalo-orbitaire est en moyenne:

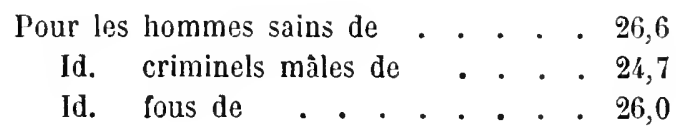

On voit done que cet indice dans les fous se rapproche plus de celui des hommes sains que de celui des cri- 
minels lequel est tout-à-fait inférieur. Il est plus grand dans les coupables d'incendie, blessure, homicide, vol, et moindre dans les crimes de viol.

17. - L'angle facial n'atteignit que trois fois $80^{\circ}$, $81^{\circ}$ dans 40 criminels et chaque fois il s'agissait d'assassins ou de chefs de brigands qui présentaient tous les plus grandes capacités cérébrales.

Chez les 38 autres la mesure de cet angle n'atteignit pas la moyenne ordinaire, et cela presque sans différence ethnique; ainsi chez deux meurtriers Piémontais, il y arait $69^{\circ}$, chez deux faussaires et voleurs Lombards, $70^{\circ}$, et même chez un Sicilien $68^{\circ}$, chez un voleur Lombard $69^{\circ}$, chez un Romain $72^{\circ}$, et clrez des Toscans $74^{\circ}$. Et il faut observer que les Romains et les Toscans sont en Italie ceux qui présentent l'angle facial le plus ample. Chez 60 femmes criminelles on a trouvé:

\begin{tabular}{|c|c|c|c|c|c|c|c|}
\hline \multicolumn{3}{|c|}{ Empoisonnement } & & . & $\begin{array}{r}\text { Max. } \\
. \quad 80^{\circ}\end{array}$ & $\begin{array}{l}\text { Min. } \\
75^{\circ}\end{array}$ & $\begin{array}{l}\text { Moy. } \\
76^{\circ}, 2\end{array}$ \\
\hline Blessures & . . & . & & . & . $78^{\circ}$ & $75^{\circ}$ & $76^{\circ}$ \\
\hline Incendie & . & . & . & . & . $79^{\circ}$ & $71^{\circ}$ & $75^{\circ}$ \\
\hline Vol . . & . & . & . & . & . $78^{\circ}$ & $72^{\circ}$ & $74^{\circ}, 9$ \\
\hline Infanticide & 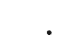 & . & & . & . $79^{\circ}$ & $70^{\circ}$ & $74^{\circ}, 9$ \\
\hline Assassinat & . & . & $\cdot$ & . & . $77^{\circ}$ & $71^{\circ}$ & $74^{0}, 3$ \\
\hline Homicide & . & . & - & . & . $81^{\circ}$ & $69^{\circ}$ & $72^{\circ}, 9$ \\
\hline Viol . . & . & . & & . & . $73^{\circ}$ & $72^{\circ}, 5$ & $72^{n}, 7$ \\
\hline Prostitution & n. & . & & . & . $73^{\circ}$ & $70^{\circ}$ & $71^{\circ}$ \\
\hline
\end{tabular}

Les angles plus amples se trouvent dans les empoisonneuses et dans les condamnées par blessures; les moindres dans les crimes sexuels et dans les meurtrières.

Résumé. - L'importance de ces recherches n'a pas répondu complètement à notre attente: il ressort, en 
effet, seulement de ces études que l'atypie se rencontre dans les mesures de la face, surtout dans l'hauteur ef largeur faciale, dans l'indice nasal, dans l'indice céphalo-spinal et dans la capacité orbitaire; viennent, ensuite, la diminution (qui n'est pas pourtant constante), de la capacité et de la circonférence crûnienne et l'exagération de l'indice céphalique, du diamètre et poids mandibulaires, l'exiguité de l'angle facial et du diamètre frontal minimum, de la demi-circonférence antérieure; encore ces deux dernières anomalies ne sont elles pas toujours constanles. 
Nous arons par contre une large moisson dans l'élude des anomalies; on peut s'en faire une idée en jetant un coup d'œil sur le tableau suivant oủ j'ai tàché de réunir toutes les observations faites par les savants de l'Europe, et oủ jai réuni dans une seule colonne (des Italiens) les ohservations d'Amadei et celles de De Paoli, de Cougnet et de Bono et les miennes.

Fn considérant les résultats que nous donnent ces 389 cràncs, on trouve que les lésions les plus fréquentes sont: une grande proéminence des areades sourcilières, 58,2 $0_{10}$; l'anomalic dans le développement des dents de sagesse $44,6 \quad 0_{10}$; la diminution de la capacité du crìne 32,50 0 0 ; la synostose des sutures 28,90 0 0 ; le front fuyant 2800 ; l'hyperostose des os $28,90[0$; la plagiocéphalie $23,1 \quad 0_{[0}$; les os wormiens $29,0 \quad 0_{[0}$; la simplicité des sutures 18 , $40[0$; la proéminence de la protubérance occipitale 16,600 ; la fossette occipitale moyenne $16,00_{l} 0$; les sutures symboliques 13,6010 ; l'aplatissement de l'occipital $13,20_{[} 0$; les ostéophytes du clivus $10,10_{[} 0$; l'os d'Incas ou épactal $10,50_{[0}$.

Dans des proportions moindres on trouve les trococéphalies $9,00_{10}$; le front petit, étroit $8,60_{0} 0$; les os cràniens minces 8 , $40_{[0}$; la déformation du trou occipital 7,3010 ; des traces de lésions traumatiques $6,60_{[0}$; des anomalies dans le développenent des canins $6,20,0$; la sulsscaphocéphalie $6,100_{00}$; des pertes de substance résultat d'ostéite $5,60[0$; le chevauche- 
ment des os 5, $50[0$; les ostéomes du rocher et de l'os occipital 4,8 $0_{10}$; l'oxicéphalie 4,5 $0_{0} 0$.

Le fait le plus important de tous, c'est-i-dire l'aspect complètement tératologique dû à la réunion de beaucoup d'anomalies dans un même crâne, se ren-

\section{A NOMALIES}

OBSERVÉES DANS LES CRANES DE MALFAITEURS

Arcades sourcilières et sinus frontaux proéminents Anomalies dans le développement des dents de sagesse Crânes pathologiques

Soudure partielle ou complète des sutures Front fuyant

Grande épaisseur des os, ostéoporose

Plagiocéphalie et asymétrie

Os wormiens

Crânes anormaux

Sutures frontales très-simples

Proéminence de la protubérance occipitale

Fosse occipitale moyenne

Augmentation de la capacité du crîne

Renflement du frontal

Sutures festonnées ou symboliques

Suture médio-frontale

Ostéophytes du clivus

Os d'Incas ou épactal

Trococéphalie

Front petit, étroit ou aplati

Os du crîne très-minces

Exagération de la rondeur ou de l'obliquité du trou occipital

Asymétrie ou obliquité de la force

Traces de lésions traumatiques.

Anomalies dans le développement des dents canines

Subscaphocéphalie

Pertes de substance, suite d'ostéite

Chevauchement des os du crâne

Ostéome du rocher et de l'os occipital

Oxycéphalie 
contre dans la proportion de 43010 , tandisque les anomalies simples, isolées, ne s'y présenteraient que dans la proportion du 21010 .

IIais nous navons pas encore cité toutes les anomalies que l'on y peut rencontrer. Déjà en jetant un coup

\begin{tabular}{|c|c|c|c|c|c|c|c|c|c|}
\hline \multicolumn{9}{|c|}{ MOY EN N E S } & \multirow{2}{*}{ 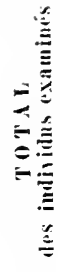 } \\
\hline 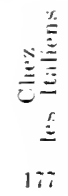 & 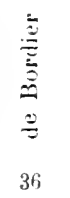 & 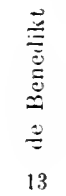 & 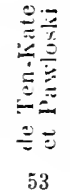 & 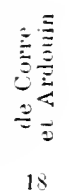 & 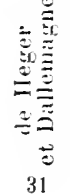 & 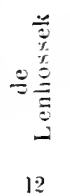 & $\begin{array}{l}\frac{\pi}{2} \\
\stackrel{2}{2} \\
\stackrel{0}{=}\end{array}$ & 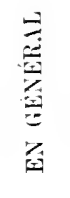 & \\
\hline 66,9 & 60,0 & " & " & , & 13,0 & $n$ & ): & 52,2 & 206 \\
\hline 57,0 & $n$ & $"$ & $n$ & 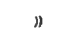 & H & 8,0 & $n$ & 41,6 & 47 \\
\hline 40,1 & 58,0 & 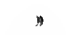 & $"$ & $n$ & " & $"$ & $n$ & 43.7 & 189 \\
\hline 37,0 & $n$ & 53,8 & 3,7 & 22,2 & 25,8 & 8,3 & $"$ & 28,9 & $30 \%$ \\
\hline 31,7 & 33,0 & " & $"$ & 5,5 & " & $"$ & $n$ & 28,0 & 228 \\
\hline 60,9 & 39,0 & $n$ & 39,6 & $\|$ & 9,6 & " & 42,8 & 43,4 & 290 \\
\hline 14,9 & 37,0 & 23,0 & $"$ & 33,0 & 13,0 & 12,0 & $"$ & 23,1 & 289 \\
\hline 21,0 & 38,0 & 7,7 & 20,5 & 17,0 & 32,0 & 8,3 & ) & 2,0 & $31:$ \\
\hline 18,8 & 33,0 & $n$ & " & $"$ & $n$ & $"$ & $n$ & 21,3 & 183 \\
\hline 18,7 & " & $n$ & 9,5 & D & 32,0 & $"$ & $n$ & 18,4 & 260 \\
\hline 3,8 & 2,7 & $n$ & $"$ & נ & " & $"$ & 46,4 & 16,6 & 90 \\
\hline 15,4 & " & 7,7 & $"$ & $"$ & $n$ & 33,0 & $"$ & 16,0 & 193 \\
\hline 10,3 & 45,0 & $"$ & $n$ & " & 6,4 & $"$ & 1) & 15,0 & 232 \\
\hline 17,1 & 8,3 & $"$ & $"$ & $"$ & ") & $"$ & ") & 14,1 & 106 \\
\hline 10,7 & 25,0 & $"$ & $n$ & " & $y$ & 8,3 & $"$ & 13,6 & 169 \\
\hline 12,0 & 19,5 & 7,7 & $9, \tilde{5}$ & 11,0 & 16,0 & $"$ & 1 & 12,7 & 299 \\
\hline 10,3 & $"$ & 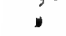 & $n$ & $"$ & $n$ & 8,3 & 1 & 10,1 & 118 \\
\hline 4,5 & $"$ & 23,0 & $"$ & * & 16,0 & 8,3 & $n$ & 10,5 & 136 \\
\hline 10,0 & $"$ & 1) & $"$ & $D$ & " & 16,0 & 3,5 & 9,0 & 110 \\
\hline 9,3 & $"$ & ") & $"$ & 5,5 & $"$ & " & " & 8,6 & 93 \\
\hline 10,0 & " & " & 7,5 & $"$ & $"$ & " & 7,1 & 8,4 & 131 \\
\hline 7,0 & $"$ & 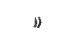 & $"$ & " & $n$ & 8,3 & $"$ & 7,3 & 82 \\
\hline 7,6 & 3,0 & $"$ & $"$ & $n$ & 9,6 & $"$ & n & 7,1 & 236 \\
\hline 7,0 & $n$ & ") & 1,8 & 11,0 & $"$ & $"$ & 10,7 & 6,6 & 242 \\
\hline 6,0 & ” & " & 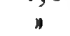 & 1) & * & 8,0 & " & 6,2 & 96 \\
\hline 4,0 & 5,5 & 15,3 & $"$ & ") & $y$ & $"$ & " & 6,1 & 98 \\
\hline$n$ & 11,0 & 1) & 0,9 & d) & " & " & " & 5,6 & 99 \\
\hline 4,0 & 11,0 & $b$ & $"$ & 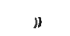 & i) & $"$ & " & 5,5 & 161 \\
\hline 4,0 & 8,0 & $"$ & $"$ & $"$ & $n$ & " & $"$ & 4,8 & 62 \\
\hline 6,0 & $"$ & 7,6 & 1,8 & $5, \overline{5}$ & $"$ & $"$ & $"$ & 4,5 & 133 \\
\hline
\end{tabular}


d'œil sur le tableau précédent, on peut supposer que beaucoup d'observateurs ne relevaient pas certaines altérations, non qu'elles eussent fait défaut, mais parcequ'ils s'arrêtaient plutôt aux caractères extérieurs du crâne et spécialement de la voûte. Par conséquent, dans le résumé, afin d'éviter les erreurs produites par les omissions involontaires, nous n'avons déduit la moyenne que dans les cas où l'on pouvait être sûr que l'on avait réellement observé une certaine anomalie, soit que les résultats fussent positifs, soit ru'ils fussent négatifs.

Il est impossible, par exemple, que le front fuyant n’aît été remarqué que par Corre et par moi; comme il est aussi impossible que sur les 35 crânes de TenKite et de Pawloski, un, au moins, n'eût pas été plagiocéphale.

De même si l'on pense aux rapports qui existent entre un crâne plagiocéphale et une face asymétrique, il est impossible que Benedikt et Corre qui trouvèrent tant de crînes plagiocéphales n’aient rencontré aucun cas d'obliquité de la face. Cela vient, aussi, de ce que chaque anthropologue a une prédilection pour certaines anomalies; et voilà pourquoi, à moins que nous ne tenions compte des études faites seulement en Italic, nous pouvons arancer qu'il n'y a que les os wormiens et les sutures dont on puisse dire quils ont été étudiés uniformément, car ils se denoncent plus facilement. Aux études faites en Italie on doit recourir forcément pour une longue série d'anomalies laissées de côté par les savants étrangers. Quclques unes d'entre elles sont tris-importantes: le prognatisme par exemple 690 010; l'eurignatisme $36,10_{[0}$; la mâchoire inférieure volumineuse $19,80_{10}$; et l'obliquité des orbites $19,20_{10}$; 
viennent, ensuite, la petitesse des orbites $13010 ;$ le menton rentrant $12,80_{[} 0$; la fosse canine dépriméc $11,70_{[} 0$; les excavations laissies des glandes de l'acchioni 11,8 $0_{10}$; l'enfoncement de l'elhmö̈de dans les fosses orbitaires $110_{10}$; la suture malaire 10,3010 ; la saillie de l'angle orbitaire de l'os frontal $9,1 \quad 0_{10}$; le double trou sous-orbitaire 8,5010 ; le développernent anormal des os de la face $6,0 \quad 0_{10}$; la synostose de l'athas $7,90_{10}$; l'apophise temporal du frontal 9,4010 ; lat nanocéphalie 2,7 $0_{10}$; le bec frontal du coronaire 2,0010 .

2. - Anomalies des criminels mâles et femelles comparées avec les normaux. - Mais l'étude plus superficielle de ces chiffes vous donnera la conviction du peu de valeur qu'on peut leur assigner, si on ne se donne pas la peine de les comparer avec les normaux du même pays, et avec ceux des sauvages; et surtout, si on ne tache de les distinguer par crime et par scxe. - Pour cela je donne dans cette table les proportions des anomalies trouvées par moi chez 66 criminels et 60 criminelles, les chiffres trouvés par Legge sur 1770 crànes normaux et par moi et Amadei sur 1320 soldats morts à Solferino.

Pour les anomalies dont Legge et moi-même n'avons pas étudié les proportions, j’ai supplée avec une étude sur 44 soldats et 29 femmes en les marquant avec un * J'y mets à côté les proportions trouvées chez 170 fous par moi et par Sommer, et celles trouvées dans les races plus sauvages par Anutchine, Gruber, etc., en tenant compte ici seulement des chiffres plus élevós (1).

(1) Anutchine, Ueber eine Anomalien des Mensch. Schädel., 1880. ID., De l'os des Incas (Bull. des Amis des sciences nat. de Moscou, 1881-82). 


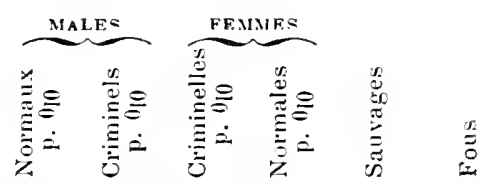

Asynétrie et plagiocéphalie $20,0 \quad 42,0 \quad 21,0 \quad 17,2 \quad ? \quad 24,0$

Sclérose crânienne . . . . 18,0 $31,0 \quad 31,0 \quad 17,2 \quad 100 \quad 50,0$

Sutures soudées . . . $25,0 \quad 37,0 \quad 26,0 \quad 13,3 \quad 8,0 \quad 28,0$

Suture métopique . . . . $9 \begin{array}{rrrrrr}9,0 & 12,0 & 5,1 & 10,0 & 5,0 & 9,0\end{array}$

Os wormiens . . . . $28,0 \quad 59,0 \quad 46,0 \quad 20,0 \quad$ " $\quad 68,0$

Os épactal . . . . . . . $\begin{array}{cccccc}0,5 & 9,0 & 1,7 & 6,8 & 5,4 & 3,8\end{array}$

Fusion de l'atlas avec l'occi-

pital . . . . . . . . $0 \begin{array}{cccccc}0,8 & 3,0 & 3,2 & 0,0 & \text { y } & 2,7\end{array}$

Fossette occipitale moyenne $\quad 4,1 \quad 16,0 \quad 3,2 \quad 3,4 \quad 26,0 \quad 14,0$

Trou de Civinini . . . 27,0 15,0 . 8,1 " "

Front fuyant . . . . $18,0 \quad 36,0 \quad 6,8 \quad 10,0 \quad$ "

Apophyse frontale du tempor. $\begin{array}{llllll}1,5 & 3,4 & 6,6 & 0,0 & 12,0 & 2,3\end{array}$

Arcades sourciliaires et sinus

développés . . . . . 25,0 $62,0 \quad 29,0 \quad 19,0 \quad 100 ? \quad 67,0$

Anomalies des dents infér. . $6,0 \quad 2,0 \quad 3,2 \quad 0,5 \quad 40,0$ "

Machoires volumineuses . . 29,0 $3 \overline{7}, 0$ 25,0 6,5 " "

Id. très-volumineuses $4,5 \quad 10,6$ " " 100 ?"

$\begin{array}{llllll}\text { Traces de la sut. intermaxil. 52,0 } & 24,0 & 3,3 & 0,0 & n & 60,0\end{array}$

Oxicéplıalie . . . . . $2,0 \quad 7,5 \quad 3,3 \quad$ " " "

Trou sous-orbitaire double . $6,0 \quad 18,0$ " " " "

Subscaphocéphalie . . . 6,0 6,0 " " "

Prognatisme . . . . 34,0 $34,0 \quad 32,0 \quad 10,0$ 100? "

Apophyses zygomatiques sail-

lantes . . . . . . $99,0 \quad 30,0 \quad 7,6 \quad 6,9 \quad$ " "

Glabelle nasale fortement de-

primée . . . . . $13,0 \quad 31,0$ " " "

Platicéphalie . . . . . 15,0 22,0 $33,0 \quad 0,1 \quad$ " "

Assymétrie de la face. . 6,0 25,0 " " " "

Chevauchement des dents . 6,0 1,0 " " "

Saillie des os temporaux . . 27,0 43,0 " " " "

Bec frontal de la sut. coron. $2,0 \quad 9,0$ " " "

Dépression des glandes de

Pacchioni . . . . $29,0 \quad 50,0$ " " " 80,0 

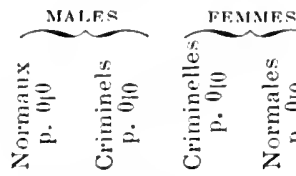

$\stackrel{\%}{\tilde{\sigma}}$

Os wormien du Pterion . 16,0

Anomalies du trou occipital

2,5

22, 0

3,0 "

Féminilité . . . . . 15,

$10,011,5 \quad$

Virilité

Saillie de l'angle orbitaire de

l'os frontal. $.15,0 \quad 46,0$

3. - Normaux. - En comparant les criminels avec les normaux nous trouvons que beaucoup d'anomalies perdent de leur importance, car on les trouve en proportion lresque égale ou même supérieure chez les derniers; par exemple le trou de Civinini, les ailes externes ptérigoïdiennes exageérées, le prognatisme, les traces de la suture incisive, l'eurignatisme, la saillie des temporaux. Mais il y en a d'autres, au contraire, qui se présenlent en proportion double ou triple chez les criminels. Telle est, par exemple, la sclérosis, l’os épactal, l'asymétrie, le front fuyant, les sinus frontaux et les arcades sourciliaires, l'oxicéphalie, la suture internasale ouverte, les dents anomales, les asymétries de la face, et surtout la fossette occipitale dans les mâles, la fusion de l'atlas et les anomalies du trou occipitale.

4. - Anomalie suivant le sexe. - On roit, tout de suite, combien est plus grande la proportion des anomalies chez les criminels mâles. Non seulement chez les fenmes criminelles il y a absence complète de subscaphocéphalie, on presque complète d'oxicéphalie, des os Incas, d'asymétrie de la face, des os wormiens du ptérion, mais encore une proportion inférieure, plus que la moitié, 
vis-à-vis des criminels mâles, des asymétries et des sinus frontaux, de machoires volumineuses, de sutures soudées et de métopisme, et une proportion de 6 à 4 fois inférieure de la saillie de l'angle orbitaire du frontal, des fronts fuyants et de la fossette occipitale moyenne. Il n'y a de supériorité chez les femmes que dans les platicéphalies, dans les anomalies du trou basilaire et de l'apophyse frontale du temporal; il y a égalité dans la sclérosis, dans la soudure de l'atlas avec l'occipital el dans le prognatisme.

Si on compare, toutefois, les criminelles arec les femmes normales, on voit que les criminelles se rapprochent beancoup plus des males normaux ou criminels que des femmes, surtout quant aux arcades sourciliaires, $\dot{a}$ la sondure des sutures, aux machoires, aux anomalies du trou occipital; tandis que le contraire (la féminilité) ne se rencontre dans les criminels mâles que dans une proportion inféricure au normal. - Les criminelles sont égales ou presque égales aux l'emmes normales quant aux apophyses zygomatiques, à la saillie de la ligne crotaphitique, à la fossette occipitale moyenne.

5. - Anomalies suivant le crime. - Les chiffres sont trop petits pour nous permettre de conclure avec certitude si les anomalies des crànes sont plus ou moins fréquentes chez les voleurs que chez les assassins (1). Il

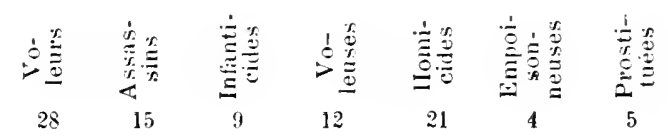

Front fuyant p. $01039,2 \quad 13,3 \quad 11,0 \quad$ \% $\quad 4,7 \quad \% \quad 30,0$ Sclérose . . . $\begin{array}{lllllll}28,5 & 6,6 & 11,1 & 33,3 & 5,9 & \text { * } & 20,0\end{array}$ Fosse occipitale moyenne . $\begin{array}{rrrrrrr}28,4 & 13,3 & \rightarrow & 8,0 & 24,0 & 75,0 & 40,0\end{array}$ 
semble toutefois que chez les voleurs soient phus friquents les submicrocéphalies, les synostoses, les fronts fuyants, la trococéphalic, l'oxicéphalie, la sclérose du crine, l'ampleur exagérée des cavités orbitaires; chez les assassins on trouve nombre de mâchoires volumineuses, d'os wormiens, de platicéphalies et de sutures medio-frontales (1).

Chez les femmes meurtrières et les prostituces on (1) a trouvé le plus grand nombre de fronts fuyants, et chez les premières d'os wormiens; chez les infanticides, j'ai noté la plus grande fréquence des sinus frontaux saillants et la moindre des fosses occipitales et des fronts fuyants.

Je n'ai trouré qu'un seul criminel d'occasion (Salvador, d'Ardouin) (Bull. de la Soc. d'anthr., 1879) qui devint tout-á-coup voleur de commercant honnête qưil ctait, et cela après une infidélité de sa femme; il avait capacité grande, 1457 , ct une forme armonique du cràne. Dans 2 criminels par passion nous n'avons trouvé d'autre anomalie que le front fuyant.

6. - Comparaison avec les fous. - La dernière table nous montre bien clairement que dans toutes les anomalies les criminels surpassent et de beaucoup les fous, hormis dans les dépressions Pacchioniennes, dans les os wormiens et dans la sclerose crinienne; mais sur celle-

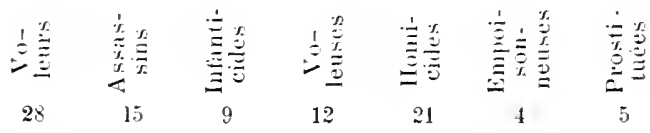

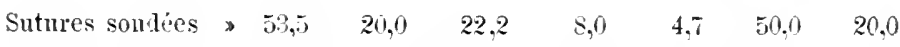

$$
\begin{aligned}
& \text { Os wolmiens } \quad * \quad 25,0 \quad 64,2 \quad 66,6 \quad 66,6 \quad \text { it,4 } \quad 75,9 \quad 40,0 \\
& \text { Platicíphalie . }>0,0 \text { > } 0,6 \text { > > }
\end{aligned}
$$$$
\begin{array}{llllllll}
\text { Sinus front. saill. " } & 60,7 & 73,0 & 55,5 & 16,6 & 4,7 & 50,0 & 40,0
\end{array}
$$

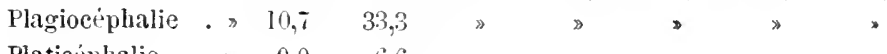


ci nous avons des données qui portent la balance aussi dı còté des premiers. J'ai trouvé, en effet, le poids moyen de 600 dans les crànes des normaux, de 701 dans les fous, de 746 dans les crimincls; ce que se voit micux encore avec la méthode sérielle (1).

II en est de même dans l'étude sériale de la capacité dı crâne (v. s.), de la courbe frontale el pariétale; mais cela se voit, surtout, dans l'étude des anomalies; les criminels avec la fosse occipitale moyenne sont plus nombreux que les fous chez lesquels on rencontre plus souvent la synostose préeoce des sutures; la submicrocéphalie n'est pas plus rare chez les criminels que chez les fous; il on est de mème de la permanence des sutures intermaxillaires.

Mais la suture médio-frontale est plus fréquente chez les délinquants que cliez les fous. Les criminels offrent, aussi, un peu plus fréquemment la synostose de l'atlas, le développement de la màchoire, l'eurignatisme, le prognatisme etc. Los fous se rapprochent aux hommes normaux plus que les criminels quant aux mensurations des orbites, de la màchoire, de la circonférence crânienne (p. 156-171), de la face, de la fossette occipitale moyenne, ce qui ne doit point étonner quand on songe quune grande partic des fous ne naissent pas tels, mais le deviennent, tandis que c'est le contraire pour les criminels.

\begin{tabular}{|c|c|c|c|}
\hline Poids & 42 Criminels & 42 Fous & 72 Sains \\
\hline $400-500$ & $0,0 \quad 0\left[\begin{array}{ll}10 \\
0\end{array}\right.$ & 0,0010 & $19,4 \quad 0_{[0}$ \\
\hline $501-600$ & 14,2 & 11,9 & 40,2 \\
\hline $601-700$ & $19,0 \gg$ & 26,0 & 29,2 \\
\hline $701-800$ & 30,9 & 35,0 & 8,4 \\
\hline $801-900$ & 26,0 & 23,8 & 2,8 \\
\hline $901-1000$ & 9,5 & 2,3 & 0,0 \\
\hline
\end{tabular}


7. - Analogie entre le sauvage et l'homme normal. Létude de ces anomalies rapproche le délinquant encore plus au fou qu'au sauvage, surtout en ce qui concerne l'os frontal, le développenrent de la michoire, la saillie de l'arcade sourciliaire, et en particulier la fosse occipitale médiane, qui n’est très-développéc que chez les Américains.

Celle fossette je lai trouvéc, chez 1320 Européens sains, dans la proportion de 4,1010 .

Sur 126 crânes antiques (Egyptiens et Etrusques) 10010

Id. 16 id. de Nègres . . . . . . . . 6 "

Id. 40 id. Américains (Aymara) . . . 26 "

Id. 9 id. Sémites . . . . . . . 20 "

1d. 28 id. Paponas (Virchow) . . . . 1 "

Id. 11 jı. Péruviens . . . . . . . 18 "

Les os wormiens du ptírion qui chez les délinquants, les fous et les hommes normaux de l'Europe sont dans lc rapport de 23 à 18 à 16 , sont en Australic, d'après Anutchine, dans le rapport de 280 I0, dans les Finnes de 66, dans la Mélanesie de 25, dans la Malaisie de 10, au Pérou de 60 I0.

L'apophyse temporale du frontal serait normalement, d'après Sommer, de 1,4010. D’après Anutchine chez les Européens on trouve 1,6, tandisque chez les Nègres $120_{10}$, chez les Mongols 3,7 , chez les Américains 1,9. Quant à nous, sur 58 délinquants nous avons trouvé la proportion de 3,4010 .

Ici une sérieuse crilique de Calucci (Jure penale $e$ frenatria, Venezia, 1876) moblige à faire une digression. S'appuyant sur les assertions de quelques anthropologues qui attribuent aux hommes samvages une grande capacité crìnienne, l'illustre juriste nie l'existence des 
caractères de véritable infériorité dans les crànes préhistoriques et chez cenx des sauvages. Cet argument lui semble ruiner toute ma doctrine. Or, les preuves qui la soutiennent sont peut-être au contraire trop nombreuses.

Les races humaines primitives, écrit Darwin, présentent des structures qui les rapprochent plus des animaux que non les nodernes. (Darwix, Orig. de l'homme, p. 23). La perforation de l'olecrane fut trouvé par Broca de $40_{10}$ dans les cimetieres de Paris, par Dupont de 30010 pendant la période du Renne, de 250 l0 dans les dolmens d'Argenteuil. La capacité crànienne n'est nullement supérieure chez le saurage ou chez l'homme de couleur; règle générale, elle est même toujours inférieure.

Mantegazza sur 3 crânes de Néo-Zèlandais tronve un reste de l'os intermaxillaire qui persiste constamment chez les mammifères. (Arch. per l'antrop., 1872, p. 177). Les nombreuses anomalies de la fosse oceipitale moyenne fréquentes chez les criminels le sont aussi cliez les sauvages. - Mais il y a des anomalies qu'on rencontre plus fréquemment chez certaines races que chez d'autres, sans qu'il soit possible de dire que l'une ou l'autre soit pour cela vraiment inférieure. Il en est ainsi pour la fosse occipitale moyenne et pour les os épactals trèsabondants dans les Américains et très-rares dans les Papouas, qui ont, à leur tour, un nombre bien plus grand d'apophises temporelles dil frontal.

Un grand nombre de crines próhistoriques sont, il est vrai, tout-à-fait semblables aus modernes; mais crâne préhistorique n'est pas complètement synonyme de crìne de sauvage. Le cràne de Gibilterra, du reste, est dolichocéphale, avec d'énormes areades sourciliaires, un front petit et fuyant, et comme chez les pithéciens il manque de fosse canine. (Broca, Mémoires, il, p. 150). 
Les crànes des Eyzies ont une grande capaciti, un notable développement du front, un prognatisme trèsaccusé, un développement énorme de la branche ascendante du maxillaire et la régularité des sutures. (ID. p. 163).

Les crines de Forbes, Quary, et en Espagne de Cueva de la Mujer, ont un front fuyant, des courbures frontales énormes, des occipitaux saillants, des orbites très-larges de 0,066, haules de 0,039, profondes de 0,051. (Crania ethnica). Quatrefage a aussi observé la fréquence des os wormiens sur les crines de Hentone, de Grenelle, de Cantalupo et de Cro-Magnon. La grande profondeur du crine, le front fuyant arec les arcades sourcilières proéminentes sont très-fréquents sur les crànes préhistoriques de Borris, de Neander, de Cro-Magnon, de la Cueva, de la Mujer et de l'Australie.

Les crines des Parias (Rev. anthr., 1871) offrent une capacité de 1337 pour les hommes, de 1114 pour les femmes, et une orbite plus grande que celle de toutes les autres races. Ce sont les ancètres de nos Zingares.

Le volume considérable de la mâchoire et celui de l'orbite sont très-fréquents chez les sauvages et sur les crânes préhistoriques, par exemple, chez ceux de Solutré (Crania ethnica).

Sur le crine de Cro-Magnon la largeur de l'orbite est énorme, 0,44 , sa hauteur de 0,027 , son indice de 7 (Quatrefages, 1882); sa màchoire est rolumineuse, son épaisseur à la șmphise est de 0,017, arec la branche montante large de 44 .

La mâchoire de Naulet et de Clichy présentent une épaisseur de 0,015 au niveau du menton el de 0,016 au niveau de la grosse molaire. 
Celte tendance atavique nous explique un autre fait que nous révélèrent Varaglia et Silva dans l'étude de 60 crànes de eriminelles: la plus grande analogie de ces crânes avec les crânes antiques des mêmes régions.

En effet 3 sur 4 crìnes de l'Emilie présentaient comme les anciennes Felsiniens, et à l'inverse des Bolognais modernes, un plus grand développement de la partie postauriculaire. L'un d'eux est analogue à l'étrusque antique dans l'indice dolichocéphalique 79,5 dans la capacité du cràne, 1386, dans la carène medio-frontale.

Ainsi toutes les criminelles Sardes se rapprochent davantage des Sardes antiques dans la moyennc des diamètres antéro-postérieur, transversal maximum, frontal minimum et bi-zigomatique, et dans les courbes du crìne (1). Nous trouvons en cela une preuve anatomique de la stratification de la criminalité, c'est-it-dire de la tendance chez les coupables à hériter des formes non seulement de l'homme sauvage, préhistorique, mais, aussi, de l'homme antique, historique.

Quelques autres données, comme les fosses occipitales moyennes, les deux faces articulaires du condyle occipital, l'aplatissement du palais, la concavité des apophyses basilaires, l'emboitement de l'ethmoïde, le

(1)

\section{Courbe}

\begin{abstract}
biauricul.
\end{abstract}
$\begin{array}{cc}\text { Sardes autiques } & .292,50 \\ \text { Id. modernes } & .303,17 \\ \text { Id. criminels } & .281,00\end{array}$

Id. criminels . 281,00

Courbe occip.-front. 100

Courbe horizontale 100

part, ant. part. post. part. ant. part. post.

$\begin{array}{cccc}33,53 & 66,47 & 49,26 & 50,74 \\ 29,95 & 70,05 & 50,36 & 49,64 \\ 33,61 & 60,39 & 45,73 & 54,37 \\ \text { D. L. } & \text { D. T. } & \text { Front. M. } & \text { D. Bizy. } \\ 176 & 132 & 92,5 & 116 \\ 180 & 143 & 91,5 & 111 \\ 178 & 127 & 92,0 & 120\end{array}$


prognatisme exagéré, la persistance de la suture intermaxillaire et l'énorme capacité orbitaire pourraient condure à un préatarisme encore plus éloigné jusque aux rongeurs.

L'atavisme, pourtant, ne nous permet d'explirguer ni la fréquente obliquití du crâne et de la face, ni la fusion et la soudure de l'atlas arec l'occipital, ni la plagiocéplıalie, ni la sclérose éxagérée, anomalies qui semblent être le résultat d'une erreur dans le développement du crìne fétal, ou un produit de maladies ayant lentement éroluées dans les centres nerreux.

8. - Détails. - Entrant maintenant dans quelques détails (voir pour les chiffres le $\mathrm{nI}^{\mathrm{e}}$ vol.), nous rappelons que chez $\mathbf{4 4}$ les sutures se trouvèrent soudées, 11 fois complètement, de facon à ne plus laisser de trace quoiqu'ils ne fussent pas arrivés à l'àge mûr. Chez un carabinier de Turin qu'un amour adultère avait poussé ¿̇ l'homicide, la sagittale était soudée, et cependant la poignée du sternum ne l'était pas encore.

Nous arons trouvé sur

60 assassins 20 sutures normales, 26 soudées précoc. (4 compliq.)

21 voleurs 16

4 fripons 2

3 maquer. 0 id.

id.

id.
5

2

3 id.

id.

id.

(3) id.

La suture frontale chez 22 sur 100 ctait d'une remarquable simplicité; elle présentait un vrai zigr-zag chez les 7 vieux dont il est parlé plus luaut (1). Chez Lemoine à 19 ans on royait déjà la synostose de la sagittale, et à 20 ans chez Arnioni, à 30 ans chez lassassin Brusa-

(I) L'un d'eus avait la sagittale oblique. 
Ferro et de mème chez Iloffmann coupable de viol a 31 ans, chez Francois l'assassin (Ardouin), et Lacenaire à 34 ans (Bordier).

La ligne crotophitique du temporal qui ordinairement est à peine marquée dans les crânes normaux, se dessinait remarquablement chez $26 \mathrm{sm} 66$. Elle était en eux beaucoup plus rapprochée de la sagittale qu'elle ne l'est habituellement; sur 16 elle forme des saillies osseuses. Chez presque tous, les ares sus-orbitaires, ou les sinus frontaux sont extraordinairement développés. L'assassin Soldati est le seul qui n'en portît pas de trace; tous les autres en avaient plus ou moins.

La synostose de l'atlas avec l'occipital s'associait, chez le calabrais Villela, ì une fosse occipitale moyenne très-grande et à une obliquité du crîne et de la face; il en était de même chez un assassin de Trapani qui avait, lui aussi, une fossette occipitale, mais beaucoup plus petite, et dont le crìne était oblique. Enfin mème remarque chez Amadei, un assassin de Bologne, qui arait une énorme brachicéphalie, obliquité du crìne, sclírosis, abondance d'os wormiens.

9. - Fossette occipitale. - Chez 16 p. 0|0 se trouva me fosse occipitale moyenne, 11 fois avec les dimensions ordinaires, comme il arrive chez 4,1010 des lommes normaux. 6 de ces 11 étaient des voleurs, jo des assassins; jo ces 11 avaient des os wormicns, 2 la fusion de l'atlas. Chez le nommé Villela, calabrais, voleur dune très-grande agilité, qui à l'ìge de 70 ans présentait encore les sutures ourertes, cette fosse apparaissait le dimensions vraiment extraordinaires: longue de $\mathbf{3 / 4}$ millimètres, large de 29, profonde de 11, et s'associait it l'atrophie des fosses occipitales latérales, el à l’ab- 
sence complète de l'épine occipitale interne qu'elle remplaçait et ì la fusion de l'atlas (1).

Elle etait limitée des deux côtés par des saillies osscuses, qui se dirigeaient d'ahord parallèlenent, lui domnant ainsi une figure trapézol̈de, et finissaient en se rapprochant du trou occipital par un petit promontoire triangulaire. Ces faits permettent à l'anatomie comparée et à l'embryologic de conclure quiil s'agissait ici d'une rraie hypertrophie du vermis, d'un vrai cervelet moyen; de sorte que cel organe descendrait de l'échelle élevée des primates au niveau des rongeurs, des lemuriens, ou bien de l'homme entre le troisième et le quatrième mois de la vie foetale; je peux l'assurer d'autant plus que jai trouvé arec Foà, Calori, Romiti et Tenchini, sur 107 cadarres, la coïncidence de l'une et de l'autre anomalie (fosse occipitale et rermis hypertroplique) dans la proportion de $60 \mathrm{p}$. $0_{\mathrm{I} 0}$.

10. - La plagiocéphalic ou asymétric est vraiment un des caractères les plus éclatants chez les criminels; malheureusement si on voulait en établir les vrais proportions, on risquerait de se tromper en se livrant à des impressions personnelles presque subjectives. C'est ainsi

(1) Voir Lombroso e Bergonzoli, La fossetta occipitale mediana studiata in 181 alienati, ecc., Napoli, 1874. - Calori, Di tve anomalie del cerrello, Bologna, 1874. - Vardeld, Su un'anomatia del cervelletto in un cretino, Bologna, 1874. - Fos, Fossetta occipitale mediana con ipertrofia del vermis, 1874. - ALBRECHT, Intorno alla fossetta voormiana, 1884. - VERGa, Della fossetta cerebellare media dell'osso occipitale, 18\%2, p. 2\%3. - Tелchin, Della fossetta occipitale mediana, Milano, 1882. - Roмıт, Due casi di fossette occipitale mediana, 1883. - Les 31 eas de fosses oceipitales observẻes jusqu’à présent se divisent en 10 eriminels, 6 épileptiques, 14 fous, 2 aleooliques, 1 suieide, 1 avec palais bifide, 2 normaux. Des 10 criminels 8 voleurs, 2 meurtriers. 
que nous royons Bordier la calculer 37 p. $0_{[0}$ et Lenhoffek 12, tandis que moi, partant du même point de vuc, j'ai trouré:

42,0 p. 010 pour les criminels

21,0 "id. les criminelles

20,0 "id. les normaux.

C'est seulement dans ces dernier's jours que M. Amadei a mis de l'ordre dans cette question en fixant l'indice de l'asymétrie. Cet indice résulte du rapport entre les deux diamètres obliques dont lo plus long serait égal ¿ 100 .

Après cela on peut signaler deux faits importants dans l'étude de cette anomalie chez les criminels:

$1^{\circ}$ Son exaguration; ainsi Amadei a trouvé lindex de:

$$
\begin{aligned}
& 99,5 \text { chez R. assassin } \\
& 98,7 \text { id. W. parricide } \\
& 98,6 \text { id. C. brigand } \\
& 96,3 \text { id. B. assassin. }
\end{aligned}
$$

2e La prédominance de l'asymétrie à gauche; tandis que pour les personnes saines suivant Manouvier les proportions des asymétries sont les mêmes des deux còtés, et que chez les fous, suivant Sommer, 75 fois p. 0I0 elles prédominent du côté droit, chez 44 criminels j'ai trouvé:

Prédominance à droite dans 41 p. $0[0$

Id. à gauche id. 20 "

Symétrie đans . . . . 38 "

excepté pourtant les femmes criminelles chez qui j’ai trouvé, avec Silva et Varaglia, 14 sur 23 asymétries a gauche, 7 à droite. 
La fréquence des sinns frontaux, des lronts linyants et des ares soureiliaires développés est raiment singulière, comme on pent le roir sur les photographices de tous nos crìnes (Table I, Vol. II). Elle nous explique l'étrange analogic des crìnes eriminels italiens, francais et allemands dessinés par Ileger et Flechs, toul-ifait comme chez les microcéphales ct chez les crílins.

La sclérose du crìne est un caractère saillant qui dans un cas simulait un rrai ostíome; chez un voleur illustré par Flechs elle reduisait la capacité crìnienne i 1080 c. c. et donnait an visage un aspect de lion; dans un autre crìne donnait un poids de gr. 11 保, presque le double du normal.

Cos altérations ne se rencontrent pas isolées, mais 43 fois sur cent, clles sont groupées et présentent un nombre d'altérations rraiment singulier sur un seul indivilu. Ciest ainsi que nous pouvons voir chez Vilella, non sculement les synostoses at l'atrophie de l'atlas, mais une atrophic des fosses occipitales latírales, une hypertrophic de la fosse médiane, une obliquiti du crìne, etc. Sur un assassin de Trapani presque microcéphale (1130) existaicnt la synostose de l'atlas, l'obliquité au cràne, de la face et do la fosse occipitale moyenne. Sur un voleur, de Parie, microcéphale aussi, on troura l'emboitement de l'chmoïde, des synostoses précoces, de la sclérose crìnienne, du prognatisme, un front fuyant, des temporaux élevés, et un grand nombre d'os wormiens.

Le calabrais Gatti, présentait une vraie microcéplıalie, l'emboitement de l'ethmoïde, la sclerose du crâne, l'atrophic des lobes frontaux.

Lacenaire avait soudure des sutures, ostéoporose, asymétric (Bordier). - B., roleur turinais, avait un cràne arec un grand développement des os de la face, 
diploé abondant, suture soudée, oxicéphalie et submicrocéphalie, prognatisme alveolaire, arcade sourcilière saillante, mâchoire inférieure fort développée, nombreux os wormiens correspondant à l'apoplissie mastoide gauche (1). Chez Brusaferro, vénitien, assassin célèbre, mort après avoir commis 99 homicides, la face était très-petite comparée au grand développement du crâne, la suture était complètement soudée; il y avait des traces de suture malaire, subscafocéphalie, saillie des temporaux, plachiocéphalies, pariétale gauche (2). Chez Scissak outre la nanocéphalie, il y avait du progénéisme, de la trococéphalie. (Lenhossek, loc. cit.).

Est-il possible que des individus frappés d'un si grand nombre d'altérations, aient le même degré d'intelligence et les mêmes sentiments que les hommes à cràne tout-à-fait normal? Et notez que ces altérations cràniennes ne portent que sur les plus visibles modifieations du centre intellectuel, les altérations de volume et de forme. 


\section{CHAPITIE II}

\section{Anomalies du cerveau et des visceres chez les criminels.}

1. - Cervecu. - Poids. - Bischoff nous a donné une étude sur le poids de 137 cerveaux de criminels comparés à 422 normaux (Hirngewicht des Menschen, 1880). On y roit égalité dans les chiffres les plus faibles (jusqua a 1300) arec prépondérance des plus petites chez les criminels (voyez fig. 1, page suivante): différence considérable dans les chiffres faibles de $\mathbf{1 3 0 1}$ à 1400 , où les hommes ordinaires dépassent les coupables comme de 38,6 à 34,3 . Le contraire arriverait de 1400 à 1500 . Ici la proportion des criminels serait de $24,80_{10}$ et celle des gens lionnêtes de $20,3 \quad 0_{10}$. De 1500 a 1600 les premiers descendraient dans la proportion de 6,5 à 7,3 ; de 1600 au dessus ils seraient supérieurs de quelques fractions $-3,6$ à 3,3 . Bref, les criminels différeraient de peu des normaux dans les plus petits chiffres; ils leur seraient inférieurs dans les moyens; et ils les surpasseraient, de quelque peu, dans les plus grrands; mais cette dernière différence s'efface, en grande partie, si l'on pense qu'il s'agit d'hommes de haute stature (royez plus haut) et chez qui le genre de mort le plus fréquent (la pendaison) favorisait le plus grand poids du cerveau. On a remarqué que la différence de poids des deux hémisphères du cerveau 
chez les criminels et les hommes ordinaires differe de peu. Seulement l'hémisphère droit est plus souvent égal ou supéricur au gauche. En effet le seul cerveau criminel de Bischoff chez lequel les tleux hémisplières furent pesés séparément, donna un chiffre supérieur de $21 \mathrm{gr}$. pomr le droit; et le criminel étudic par Ferrier avait, lui aussi, l'hémisphère droit plus petit de $40 \mathrm{gr}$. Sur 49 voleuses homicides dont les cerreaux furent pesés par Giacomini, 20 avaient le lobe droit plus pésant, et 18 le lobe gauche; les 4 autres avaiont les hémisphères d'un poids égal.

Ce sont, pourtant, des chilfres peu décisifs, mais l'étude des asymétries les complètent. Nous les avons trouvés, en effet, prédominant à droite sur $410_{10}$ et Talle graphique du poids de 137 à gauche sur 200 0; 0 ;

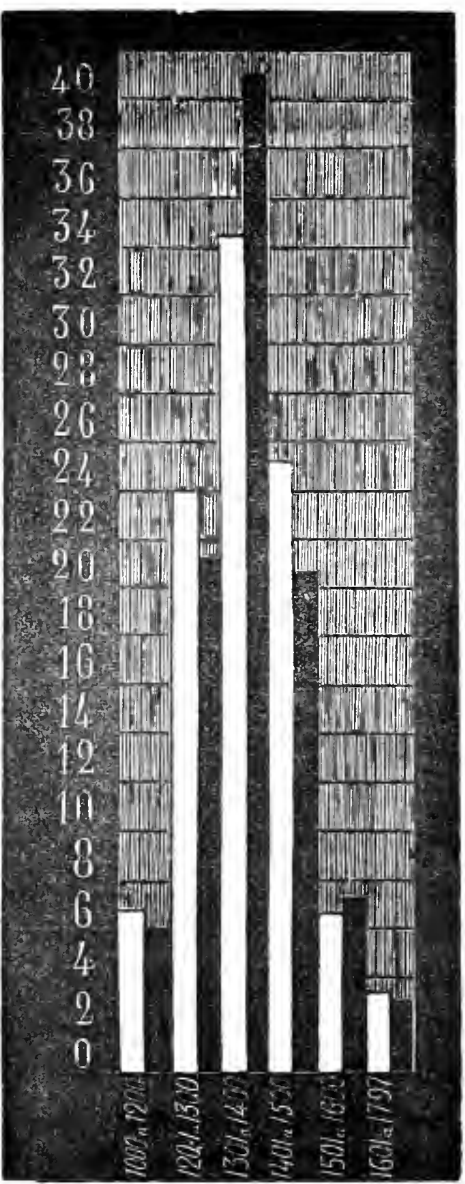
Fin. 1 . étaient égaux, tandis que dans les asymétries physiologiques on troure toujours des chiffres égaux des deux còtés. 
Ce qui est plus certain, cest que le poids du cervelet, de la protubérance annulaire et des pídoncules est supérieur chez les crimincls. Il résulte, en effet, des études de Varaglia et Silva que, landis que chez les femmes du peuple le poids en est de 141, il est chez les criminelles de 155. (Sudi su 60 crani, 1885, Torino), ce qui peut bien s'accorder arec la grande agilité que nous allons vérifier chez ces malheureux et avec la présence, aussi fréquente, de la fosse occipitale moyenne.

2. - Circonvolutions. - Plusicurs autcurs crojaicnt avoir trouvé dans la disposition anormale des circonvolutions le secret des tendances criminelles. Sans remonter aux exagérations de Gall, qui n'étaient, cependant, pas toujours sans fondements, nous royons encore, de nos jours, répéter la mème affirmation.

Chez Guitcau on aurait trouvé la scissure centrale divisée par un petit pont de celle de Sylvius - ainsi que l'occipital-transvere el l'intér-pariétale. Dans l'hémisphère droit la région pariétale était atrophiéc, et le lobule paracentral très-petit; la circonvolution postcentrale rapetissée de plus d'un quart. Liinsula de Reil présentait 7 sillons a gauche et 5 'il droite, 5 tours à gauche et 6 à droite. (Nender, Nevrol. Centralbl., 1882).

Chez l'assassin Prévost, àgé de 43 ans (Broca), le premier pli de passage occipito-pariétal était profond des deux côtés, de sorte que la scissure occipitale interne se continuait avec l'externe; le lobe occipital se détachait comme chez les singes sous la forme de calotte. A gauche, le second sillon temporal et le troisième occipital se fondaicnt en se prolongeant et nc formaient plus qu'un seul sillon sans interruption de la 
pointe du lobe temporal à l'extrémité du lobe occipital. (Bulletin de la Socićté d'anthropologie, 1880).

Huschke, chez une féroce uxoricide, troura des ostéomes de la grande faux; de plus la circonvolution pariétalc antérieure gauche y était interrompue dans la moitié de son parcours. C'était le seul cas dans lequel il eût observé une pareille anomalie.

Le prof. Villigk a étudié le cerveau de Freud, un juif aubergiste, âgé de 25 ans, qui sans avoir jamais donné signe d'aliénation mentale, s’était adonné au rol et à l'assassinat, et qui finit pendu. Il trouva que le corps calleux, qui ordinairement a te 22010 de la longueur de l'hémisphère, n’en avait que 1'80/0. La première circonvolution frontale présentait tout d'abord 47 millimètres de largcur; après cela, elle s'amincissait d'arrière en avant, assez rapidement, sans s'unir à la seconde circonvolution frontale qui forme arec elle, a sa pointe, les deux passages obliques. (Suivant les études d'Ecker, la mème chose arriverait chez les singes cercopithèques). La seconde circonvolution frontale sunissait par un court passage obliquc à la troisième. La scissure calcarine marche d'abord avec les scissures pariéto-occipitales, puis se plie à angle droit de 15 millimètres en avant, pour se diviser en forme de fourche en ses deux branches. C'est un parcour's toutà-fait analogue à celui du Pavian. (Viert. Jahreschr. für Prak. Heilkunde, Praga, 1876, p. 25).

Hanot, sur 11 cerreaux de criminels en trouva 4 avec le dédoublement de la circonrolution frontale moyenne. (Gaz. med., 1880).

Benedikt, à qui l'on doit certainement le réveil de cette question en Europe, dans ses Analomische Stu- 
dien an Verbrecher Gehirnen, Vien, 1879 tenta de réduire en lois ces observations, et de prouver comment les malfaiteurs se distinguent par les anastomoses plus fréquentes des scissures, par le type qu’il appelle des fissures confluentes: "Si nous imaginons, dit-il, que toutes les scissures de ces cerveaux soient des rivières, un flottant pourrait, par ces nombreuses anastomoses, parcourir tous les sillons: sur 38 hémisphères cérébraux de criminels, les scissures postérieures perpendiculaires s'anastomosent arec les horizontales et avec les interpariétales: 21 fois complètement, 6 incomplètement; sur 38 liémisphères il trouva 113 communications de la scissure de Sylvius avec les sillons circonvoisins, 67 anastomoses des sillons inter-pariétaux, 19 de la scissure d'Ippocampe arec la fissure perpendiculaire occipitale, 11 arec la collatérale.".

Il fut fort surpris de roir si fréquemment $(27$ fois sur 83) des lobes frontamx ayant 4 circonvolutions.

Et il trouva 9 fois une communication du sillon calleux marginal arec la scissure occipitale perpendiculaire.

Sur 16 cerveaux, il trouva 6 fois que le cervelet n'était pas couvert par les hémisphères; trois fois il l'était incomplètement.

Dans un cas il nota l'indépendance de la scissure perpendiculaire de la calcarine, comme chez les singes.

Mais toules ces anomalies perdent beaucoup de leur importance après les études de Giacomini (Variclì delle circonvoluzioni cerebrali, 1882, pag. 133); car il en a retrouvé d'analogues chez des individus qui nétaient pas des malfaiteurs, et bien sourent dans des proportions plus grandes. Il troura en effet, sur 164 cerveaux d'hommes honnêtes: 
9 fois la division de la circonvolution frontale superieure 21 id. id. moyenne 14 id.

id. inférieure

sur 56 criminels:

1 fois la division de la circonvolution frontale supérieure id. id. moyenne 2 id.

id. inférieure

Flesch e Sehwekendiek trouvent chez plusieur's criminels l'interruption de la circonvolution centrale supéricure dans la moitié de sa longueur comme dans le cas de IIuschke; une fois ils trouvèrent la séparation de la calearine d'avec l'occipitale; et bien souvent la formation d'un opercule du lobe occipital et l'ouverture de la seissure de Silvius; ils trouvèrent aussi, souvent, l'interruption des scissures par suite de plis anastomotiques, en même temps qu'une tendance aux confluences, tendance qui, toutefois fut observée par Giacomini dans des cerveaux normaux.

Celui-ci admet, cependant, lui anssi, que les plis sont plus fréquents chez les criminels, aumoins dans le lobe droit, ayant constaté chez 28 criminels:

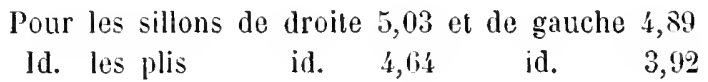

Ferrier trouva, il n'y a pas longtemps, (Archives neurologiques, 1882), dans le cerreau d'une femme tribadique et criminelle, qui arait l'hémisphère droit plus petit que le gauche, le redoublement de la scissure frontale interne dans l'hémisphère gauche. Le droit présentait la seissure de Rolando interrompue par un pli de passage rui faisait suite a la frontale ascendante. 
Celle-ci, a ce point lit, paraissait atrophice et était traversée dans sa moitié par deux scissures.

La pariélale ascendante est, an tiers de sa partie supérieure, trarersée par une profonde scissure, et par une scissure superficielle dans sa partie inférieure.

La denxième frontale est aussi dédoublée. La troisième frontale présente une dépression qui part de bas en haut et d'arrière en avant, an fond de laquelle on remarque beaucoup de plis plus petits et plus consistants que les plis de passage des autres sillons.

La scissure de Sylvius, dans sa partie postérieure, est divisée en deux branches très-longues, contournées par deux plis assez marqués, en sorte que le lobule pariétal est interrompu par trois anses successives.

Ferrier, dans la dépression antérieure du lobe frontal voit les résultats d'une inflammation; mais quant à la déformation de la scissure de Rolando, il la considère comme une anomalie congénitale très-rare, ne l'ayant trouvée que deux fois sur 800 cerveaux normaux.

Récemment Benedikt (Demonstration cines Verbrecher Gehimen, 1883) nous donne l'autopsic de l'assassin Dobrowicki; chez celui-ci la scissure pariéto-occipitale de l'hémisphère gaucle interrompait les plis de passage qui unissent les circonvolutions pariétales avec l'occipitale; ce que Giacomini n'observa qu'une fois sur 732. De plus dans l'hémisphère gauche manquait la branche postérieure de la scissure de Sylvins.

Dans l'hémisphère droit, il nota même l'absence de la branche postérieure ascendante de la scissure sylvienne, et par suite de la circonvolution arcuée correspondante. Il trouva, en même temps, la branche supérieure séparée du sillon falciforme, comme chez les primates et comme Giacomini la vit seulement dans un idiot. 
3. - Cervelet. - La fréquenee des anomalies du cervelet ehez les criminels se faisait déjà soupçonner par celle de la fossette occipitale moyenne, qui s'associe, aussi souvent, à des altérations du vermis, et par les différences du poids.

Dagleur, un roleur libidineux qui avait blessé sa mère, avait un eerveau réduit à $818 \mathrm{gr}$., le cervelet à $20 \mathrm{gr}$., plus petit et plus aplati à gauche qu'à droite, avec peu de sillons superficiels qui se developpaient dans la direction de la ligne sagittale. (Отто, Ein Fall von Verkummerung des Kleinengehirne, Berlin, 1874).

Flesch, chez une voleuse (table iv, vol. II) qui avait une asymétrie crûnienne, de la pachimeningite et la frontale ascendante interrompue à gauche, trouva un vrai lobe moyen cérébelleux conformé comme dans beaucoup de mammifères. Ce lobe avait deux sillons qui passaient à travers la scissure moyenne, s'écartaient en avant, et croisaient dans toute la longueur des hémisphères les circonvolutions horizontales du lobe moyen. (Archivio di Psichiatria, vol. In).

4. - Daprès cela il scrait trop andacieux conclure qu'on a trouvé, enfin, avec certitude, les anomalies spécifiques des circonvolutions eérébrales des criminels; mais on peut bien déjà dire que chez les criminels ces anomalies abondent et sont de deux ordres: les unes qui séloignent de tout type normal mème inférieur, comme les sillons transrersaux du lobe frontal, trouvés par Fleseh dans quelques cas, et tellement relevés qüils no laissent pas roir les sillons longitudinaux; les autres sont des déviations du type, mais qui rappellent celui des animaux inférieurs, comme la séparation de la scissure calcarine de l'occipitale, la fos- 
sette de Sylvius qui reste ouverte, la fréquente formalion d'un opercule du lobe occipital.

5. - Vaisseaux. - L'étude de l'état des vaisseaux cérébraux sera pent-être importanle avec le temps.

Sur 71 cas nous trouvons:

Artères communicantes postérieures grosses 18

Id. cérébelleuses plus petites . . . . 5

Id. communicante antérieure donble . I

Id. basilaire petite . . . . . . . . 1

Id. communicante postérieure manquante 1

anomalies qui, cependant, ne sont pas rares, à l'cxception des deux dernières. Flechs aussi, me dit avoir trouvé l'absence de l'artère communicante postéricure gauche en même temps que l'anomalie fort rare d'une artère d'un corps calleux gauche atrophié, remplacée dans la partie antérieure par la communicante antérieure.

Dans un autre cas la vertébrale droite était atrophiée, et remplacée par une branche anormale de la carotide gauche. 
II.

IIISTOlogie Et anatomie pathologiQre.

1. - Histologie. - La fréquence des anomalies pathologiques que l'on rencontre a peu près chaque fois que l'on procède à une autopsie criminelle laisse moins de doutes.

Dans le cerveau de Guiteau les espaces lymphatiques périvasculaires étaient remplis do masses granuleuses de pigment, résidus d'anciens épanchements sanguins. Les vaisseaux capillaires étaient en voie de dégénéréscence granuleuse sur plusieurs points, particulièrement dans la substance grise. Le corps des cellules nerveuses était tellement pigmenté qu'il cachait souvent le noyau; et il y avait des traces dhyperplasie cellulaire tout le long des faisseaux de la substance blanche, comme dans un nerf optique atteint de nerrite descendante. Tout cela se notait, surtout, dans le corps striè et dans les circonvolutions frontale, pariétale ascendante et pariétale supérieure. (Revue scientifique, 1883).

Golgi trouva chez Gasparone une abondance de granulations pigmentaires dans les cellules nerveuses et jusque dans les connectives. Toute la substance corticale était parsemće d'une certaine quantití de granules amyloïdes.

Dans le cerveau de ce Freud, dont nous avons parlé plus haut, Villigk découvrit une grande quantité de pigment dans la tunique des capillaires, et surtout dans celle des vaisseaux artíriels de la seconde, troisième et quatrième couche de la substance grise. 
Le pigment était moins abondant dans la couche superficielle, dans la substance blanche et dans les ganglions centraux; il était très-abondant dans les lobes frontaux; il manquait dans le cervelet, dans le bulbe rachidien et dans les cellules cirébrales. Au contraire les grandes cellules de Betz, cn étaient surchargées tout près du noyau. Quelques groupes de ces cellules piğmentées, se trouvaient, aussi, dans la circonvolution centrale antérieure. On observa dans la moelle épinièrc l'obstruction du canal central.

Spitzka (Evidence of insanity discoverable in the brain of criminals, 1882, New lork) parle d'un certain Grappot, qui, en plein jour, et en présence de ses fils, tua un de ses roisins dont il était débiteur, et puis tenta de se suicider. Il fut condamné, mais il mit fin lui-même à ses jours; l'adhérence de la dure mère était très-tenace, il y arait des pigmentations dans les noyaux du nerf vague, du facial et de la cinquième paire.

Bergmann troura dans le cerveau d'un assassin des adhérences dans les prolongements occipitaux des ventricules, qui indiquaient qu'une inflammation avait existé précédemment. (Vircirow, Abhandlungen, 1873).

Robin et Broca constatèrent chez Lemaire une asymétrie crânienne, un front étroit, les sutures soudées à 18 ans, la pie-mère adhérente à la substance cérébrale, la duremère épaissic et parsemée de petites exsudations fibrineuses; le cerveau pesait 1183 gr.

Le voleur et parricide Benoist présentait un front fuyant, la pie-mère adhérente à l'hémisphère droit et la dure-mère épaissie.

Momble, Leger, Greeman et Preedy présentèrent, à l'autopsie, la dure-mère épaissie et la pie-mère adhé- 
rente. (Dumouture, Obsery. sur l'état pathologique du crâne, Paris, 1883, Bulletin de la Soc. d'anthrop., 1867).

Dans l'autopsie de Menescloud, Chudzinski remarqua dans le lobe frontal des deux côtés un ramollissement très-prononcé; la première et la seconde circonvolutions temporales étaient aussi rammollies, mais à un degrí inférieur et l'occipitale encore moins.

Le premier pli de passage occipito-pariétal était profond et tendait à prendre la forme d'une calotte; l'arachnoüde et la pie-mère étaient très-ćpaissies. (Revue philosophique, mai, 1881).

Flechs trouva chez deux jeunes criminels des foyers de ramollissenıent dans le lobe frontal, un amas de pigment dans la dure-mère qui indiquait de vieilles hémorragies. Il observa chez une femme de 24 ans nombre de kystes dans les grands ganglions, résidu probablement danciennes embolies; chez un homicide de 21 ans il trouva une sclérose en plaques dans la couche superficielle de la substance grise; il s'y ajoutait une leptomeningite.

Et on doit noter que toutes ces lésions avaient fait leur's cours sans être (comme c'est la règle) accompagnées d'aucune altération des sens ni des mouvements.

Il en fut de mème pour Guiteau qui, en plus des anomalies déjà décrites, avait une énorme asymétrie et de vieilles adhérences des méninges. Prunier, qui avait violé une vieille femme, après l'avoir noyée, et qui cependant n'avait donné auparavant aucun signe d'affection mentale, présentait une énorme épaisseur du crâne, l'adhérence de l'arachnoïde, et l'épaississement de la pie-mère. (Gazette médicale, 1879). Faella qui, d'après l'examen fait par un aliéniste, paraissait en vie tout-ì-fait normal, présentait toulefois, outre une grande asymi- 
trie parjetale, des adhérences de la dure-mère do la pie-mère, et un ostéome épineux long de hí mill. et large de 30 dans la grande faux, au niveau de la cilconvolution frontale. (V. table).

Bref, sur 92 cerveaux de criminels on constala: Dans les membranes centrales

Opacité et athérences . . . . . . . . 10

Inflammations . . . . . . . . . . . . . . . 3

Petites ossifications en direrses parties . . . . . 1

Ostéomes . . . . . . . . . . . . 3

Dins le cerveau

Rammollissement . . . . . . . . . 3

Points hémorragiques . . . . . . . . . 5

Dégénérescence des artères . . . . . . . 4

Tumeurs (1 cancer gélatineux, 1 endothéliome, 1 stphilome . . . . . . . . . . . . 3

Alhérence des cornes postérieures . . . . . . 1

Hémorragies des ventricules latéraux . . . . 2

Abcès du cervelet et du cerveau . . . . . . 2

Flechs sur 28 cerveaux de criminels trouva:

Aleérations des méninges en général 50 p. 0/0, c’est-àdire

Adhérences de la pie-mère à la substance grise . . 4

Id. de la dure-mère . . . . . . . . . 6

Pachỵméningites internes hémorragiques . . . 10

Leptoméningites chez des jeunes gens . . . . . 14

Héningite tuberculeuse de la base . . . . . . 1

Oedème de la pie-mère . . . . . . . . . . . 7

Athérôme des artères basilaires . . . . . . . 8

Mléningite spinale hémorragique . . . . . . . 1

Dedème du cerveau . . . . . . . . . . . . 1

Atrophie de la substance grise . . . . . . . 1

Hémorragie cérébrale . . . . . . . . . 3 
Il tronva sur 26 p. $0_{\mathrm{I} 0}$ des criminels l'opacité de la pie-mère avec des exsudations adhérentes.

Sur 28 cas, il remarqua 3 fois des blessures graves du cràne; un de ces cas était accompagné d'hématôme et de leptoméningite chronique.

Pour comprendre l'importance de ces lésions, il est bon de se souvenir arec Rindfleisch (Pathol. histol., 1373-74), que l'hypérémie chronique de la substance corticale est la base de presque toutes les altérations (\$713) des fous.

9. - Ostếmes. - Nous avons remarqué 3 ostéòmes sur 90 criminels, cest-à-dire 3,3 p. 010 . Sur 1069 fous ohservés par moi, par Raggi et Frigerio nous en avons trouvé 29 , c'est-à-dire 2,3 p. 010 .

3. - Méningites. - Les méningites je les ai rencontrées dans la proportion de $50 \mathrm{p} .0 \mathrm{l} 0 \mathrm{chez}$ les criminels; c'est bien plus que dans les fous.

Sur 180 autopsies pratiquées sur des fous, on en a constaté seulement $320_{[0}$, et d'après Ilofimann $48,70_{[0}$.

4. - Altérations cérébrales. - La proportion, cependant s'intervertit en tenant compte des affections cérébrales. En effet nous trouvons, avec Adriani, dans les fous l'atrophic partielle ou totale d'un hémisphère, d'un lobe cérébelleux, les hémorragies cérébrales, les ramollissements, les scléroses cérébrales donner 49 cas sur 180, sans compter les anémies et les hypérémies.

En somme, les criminels rivalisent arec les fous et quelquefois les dépassent, aussi, pour les maladies du cerveau, comme nous l'avait déjà fait pressentir la grande fréquence des scléroses et des ostéoporoses cràniennes. 
Et pourtant, nous l'avons vu, ils noffrent presque jamais, même aux spécialistes, les symptômes qui accompagnent ordinairement ces grandes anomalies.

Les observations de Soltmann sur le développement et la multiplication graduelle des centres moteurs de la substance corticale, nous montre comment il peut se faire que le cerreau d'un homme puisse être si profondément altéré pendant que dans le cours de sa vie il n'a jamais manifesté de symptômes de maladie; d'après des expériences faites sur des chiens, des lapins, nouveaux-nés, il résulte qu'immédiatement après la naissance, il n'existe aucun point de la substance grise corticale dont l'excitation électrique soit capable de déterminer un mouvement. Hais les centres se développent et se distinguent peu à peu, suivant les divers groupes musculaires, sculement dans les premiers 16 jours. Le défaut de ces centres dans les premières périodes de la vie, nous explique souvent, à ce moment là, comment les maladies cúrébrales peuvent rester latentes; si, en effet, il arrive un temps d'arrêt dans le déreloppement d'une région des hémisphères cérébraux, la multiplication des centres régulateurs des diverses fonctions ne peut plus se produire; mais comme dans la vie fœtale, et dans les premières périodes de la vie extra-utérine, quelques centres, un seul même, peut remplir les fonctions de tous, le travail psychologique moins divisé demeure imparfait, et cest ainsi que le procès pathologique reste latent. 
III.

Axatonie l'ATHOLOGIQUE DE CELR, DU FOIE, ETC.

1. - Flesch nous a révélé un autre fait jusqu'à ce jour inconnu: les altérations splanchnologiques très-fréquentes des criminels parmi lesquclles quclques unes sont congénitales. En effel, sur 50 autopsies:

20 p. 0I0 présentèrent des affections du cœur si graves qu'elles furent la cause directe de la mort, et en calculant les affections accidentelles du péricarde et de l'endocarde la mortalité fut de 50 p. 010 ;

Sur 54, 5 présentaient le trou de Botal ouvert;

3 avaient un retrécissement des vaisseaux avec épaissement des valvules aortiques;

1 présentait une dilatation des grands vaisseaux avec traces de lésions méningitiques;

39 sur 5 présentaient des anomalies dans l'endocarde et dans les valvules; ct enfin 23 sur 27 une artćrite chronique aree dégénérescence athéromateuse, etc.

Il est important de fixer l'attention sur les altérations congénitales des vaisseaux et sur les affections du coeur; car dans toutes ces affections, les criminels sembleraicnt dépasser, ou suirre de bien près les fous.

En comparant les chiffres etablis par Hagen, sur ces lésions chez les fous et les normaux, avec ceux constatés par Flesch chez les criminels, nous trouvons: 


\begin{tabular}{|c|c|c|c|c|c|c|c|}
\hline & & llonnet & etes & Fou & & Crimir & inels \\
\hline Hypertrophie du coeur & & 16,00 & 010 & 10,0 & 0 & 11 & 010 \\
\hline Atrophie du coeur . . & & 1,2 & $"$ & 3,1 & $"$ & 11 & $"$ \\
\hline Dégénérescence graisseust & & $3,1 i$ & $"$ & 5,2 & $"$ & 9 & $"$ \\
\hline Insuffisance valvolaire . & & 3,1 & $"$ & 3,6 & $n$ & 17 & n \\
\hline Adhérence péricardique. & & 2,1 & $n$ & 2,6 & $"$ & 2 & $"$ \\
\hline Affections du cour, en gén & & 25,0 & $"$ & 26,0 & $n$ & 50 & 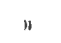 \\
\hline
\end{tabular}

ce qui démontre chez les criminels une curieuse supériorité d'insuffisances valvulaires et d'atrophies cardiaques, et une plus grande analogie avec les fous qu'avec les sains dans l'adiposis et dans l'hypertrophic du cœur. Toutes ces analogies ont une grande importance.

Ilagen a expliqué déjà un cas d'idiotisnı provenant de la petitesse extraordinaire du cœur (Stat. Untersuch., 1873), et signala, comme le fait Mildner lui-même, les nombreux cas de suicide chez les cardiopatles, particulierement chez ceux qui sont alteints d'insuffisance mitrals.

Richter Bildungs anomalien bei Geisteskranken, 1881) troura sur 200 fous 4 qui présentaient l'insuffisance de li mitrale, 1 une stenose de l'aorte.

llendel a constaté récemment que les alfections cardiaques se produisent chez les maniaques dans les proportions de 3,4 a 14 p. 010 , et de 5,5 chez les díments. (Die Manie, 1881).

Vitkowski a signalé chez les cardiopathes l'orgueil, l'égoïsme, l'inquiétude, la tendance à des actes impétueux et des manifestations violentes contre eux-mêmes et contre les autres, particulièremeut chez ceux qui étaient atteints d'hypertrophie ventriculaire. (SCHele, Geistestirank., 1880).

D'Astros (Et. sur l'etat mental des cardiaques, Paris, 1881) d'aprés une étude de 39 cas, a conclu que les cardiaques en général, sont de caractère difficile, ot 
enclins aux altérations mentales. La lésion aortique un peu plus développée détermine un affaissement, plus ou moins prononcé, des facultés psychiques, et un état névropathique qui va jusqu'à l'hystérie. Les lésions mitrales prédisposent à la mélancolie et à des accès de violence; dans la folie cardiaque prédominent les phénomènes de dépression, le délire mélancolique arec hallucinations, avec de courtes oscillations, spécialement dans les attaques de l'assystolie; les formes impulsives s'y trouvent fréquentes.

On doit bien prévoir qu'il en est ainsi, quand on pense ¿l cette étroite connexité qui existe entre les actes psychiques, et la circulation sanguine dont le sphygmographe nous offre des preuves aussi éloquentes. Toutes les données, écrit Rindfleisch (Patholog. histolog., 1873, \$ 712), fournies par l'anatomic pathologique nous indiquent que la base anatomique des affections mentales est essentiellement une anomalie dans la distribution du sang et de ses conséquences.

2. - Foie. - Sur 50 autopsies, Flechs a trouré 6 fois seulement le foie dans un état normal.

C'est-ì-dire:

15 infiltrations et dégénérescences graissenses . . . 29,4 $0[0$

5 atrophies et 6 atrophies brunes . . . . . . . 9,8 "

5 hypérémies avec stase biliaire . . . . . 9,8 "

5 tubercoloses, 2 avec infiltration graissense . . 9,8 "

5 cirrhoses, 1 syphilitique . . . . . . . 9,8"

1 hypertrophie . . . . . . . . . . . 1,9 "

4 foies muscades . . . . . . . . . . . 7,8 »

2 carcinoses, 1 de la vésicule biliaire et 1 du foie 3,9 "

1 hépatite parenchimateuse avec périlıépatite purulente . . . . . . . . . . . . . . 1,9"

1 foie amyloïde . . . . . . . . . . 1,9" 
Il semble donc (et l'alcoolisme en partic nous l'expliquerait) que les affections hépatiques prédominent bien plus dans les criminels, et nous rappcllerons que Milani, Agnoletti et Passanante avaient le foic anssi alleint que le cerveau.

3. - Organes génitaux. - Sur 24 criminels, 9 fois seulement on examina les organes génitaux, et l'on trouva :

1 paramétrite, 1 ovarite, 2 endométrites, 1 hydropisie des tubes et des follicules, 1 cancer de l'ovaire, 1 kyste de l'oraire.

4. - Estomac. - Sur 35 autopsies de l'estomac il a élé constaté:

8 catharres, 2 gonflement de la muqueuse, 4 cancers, 3 hypérémies, 1 dilatation, 1 polype, 1 ulcère rond et 15 estomacs normaux.

Sur 8204 autopsies faites ä l'hòpital de Milan nous trouvons un cancer de l'estomac chez 156, c'est-à-dire une proportion de $1,9 \mathrm{p} .0_{10}$; cancer du foic 0,5 p. $0_{10}$. Ce qui donne moins d'un cinquième des condamnés de Flesch. 


\section{CIIAPITRE III}

\section{Anthropométrie et physionomie de 3939 criminels.}

1. - On pourrait me trouver téméraire si je tirais des conclusions sur la craniologie des criminels seulement d'après des mesures prises sur 350 cadavres; mais ces conclusions s'appuient aussi sur 3939 criminels vivants, étudiés par Ferri, Bischoff, Bonn, Corre, Biliakow, Troyski, Lacassagne et moi.

2. - Mineurs. - Commencons par les mineurs. Une étude comparative de 188 jeunes criminels avee 437 jeunes gens honnêtes du même ìge, et ayant un même genre de vie, a montré que chez les criminels la taille légèrement supérieure à l'àge de 10 à 13 ans, égale de 13 à 16 ans, s'élève de 16 à 18 ans, dans la proportion de 1,54 à 1,51, et subit une légère deseente de 19 à 21 .

Quant au poids, ils l'ont supérieur dans toutes les séries, excepté de 13 à 16 ans, époque à laquelle il est égal à celui des hommes normaux. 
Au contraire, la circonférence crànienne, chez les jeunes criminels de tout âge, est inféricure à celle des hommes normaux (1).

Le diamètre frontal minimum de 12 criminels âgés de 12 à 14 ans fut de 107-108 inféricur à celui de 12 mincurs honnêtes où il était de 111 (Riccardr) (2).

Quant à l'angle facial, Riceardi sur 21 sujets, trouva:

Sur 4 l'angle de $65^{\circ}$ à $68^{\circ}$

Id. 5 id. $70^{\circ}$

Id. 1 id. $71^{\circ}$

Id. 4 id. $79^{\circ}$
Sur 2 l'angle de $73^{\circ}$

Id. 2 id. $75^{\circ}$

Id. 2 id. $70^{\circ}$ à $74^{\circ}$

Quant aux indices céphaliques, ils varient suivant les régions.

La grande envergure étudiée par Riccardi sur 20 criminels, 5 lois est égale à la taille, et pour 15 la dé-

(1) Mesures de la tête, de la taille et du poids

che 188 criminels minewrs et jeunes gens et $\mathbf{4 3 7}$ normaux

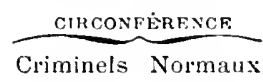

De 10 à 13 ans $-0,514$

De 13 à 16 id. $-0,528$

De 16 à 18 id. $-0,533$

A 19 ans . - - 0,54,9
52,9

54,5

55,4

55,9

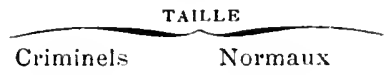

$1,31 \quad 1,304$

$1,41 \quad 1,41$

$1,54 \quad 1,51$

$1,63 \quad 1,56$ (19 à 20 ans)

\section{Poids}

Criminels

Normaux

De 10 a 13 ans $-27,3$

26,4

De 13 à 16 id. - 34,

$34, \pi$

De 16 à 18 id. $-49,6$

43,1

A 19 . . . - 54,9

46,7

(2) Riccardi, Note antropologiche intorno alcuni corrigendi, etc. 
passe 10 fois; sur ces 15 de 3 à 6 centimètres, tandis que chez les hommes normaux ce rapport n'excède jamais $2,3 \mathrm{~cm}$.

3. - Adultes. - Taille et poids. - La taille chez les délinquants adultes reproduit presque toujours le type régional. Très-élevée dans la Vénétie et dans la province de Lucques, elle s'abaisse légèrement à Naples, en Sicile, et surtout en Sardaigne.

On peut en suivre parfaitement les différences dans chaque province, en comparant ces moyennes partielles, région par région, avec celles que donne la conscription pour les hommes sains. On a:

Soldats sains Délinquants sains Délinq. malades (Lombrosol (Vurgilio)

\begin{tabular}{|c|c|c|}
\hline Lombardie & & \\
\hline Calabre. & . & \\
\hline Sicile . & . & \\
\hline Vénétie . & - & \\
\hline Ombrie. & . & \\
\hline Emilie . & . & \\
\hline Marche. & . & \\
\hline Sardaigne & . & \\
\hline Piémont & & \\
\hline Naples . & . & \\
\hline Ligurie . & & \\
\hline Lucques & & \\
\hline
\end{tabular}

166

163

161

162

167

169

169

166

163

158

162

162

150

156

163

162

161

160

171

Si la taille moyenne des criminels - 1,63 - est égale it la moyenne normale, dans presque tontes les régions de l'Italie, au contraire, la taille des criminels est supérieure à la moyenne. 
Cette supériorilé, en contradiction avec les cliffres trouvés par Tlompson (1) et Wilson, mais d'accord avee les recherehes de Bilialiow (2) sur 100 homicides, semble surtout être le propre des voleurs de grand cliemin et des homicides qui offrent la plus petite quantité de tailles basses comparés aux violateurs (3), aux faussaires et aux voleurs.

En groupant, selon la criminalité, les tailles hautes et les tailles basses nous trouvons:

\begin{tabular}{|c|c|c|}
\hline & $\begin{array}{l}\text { Tailles } \\
\text { très-hautes } \\
\text { supérieures }\end{array}$ & $\begin{array}{l}\text { Tailles } \\
\text { très-basses } \\
\text { inférieures }\end{array}$ \\
\hline Sur 786 voleurs de grands & $\dot{a} 1 . \pi 1)$ & a 1,47 et 1,57 \\
\hline chemins et homicides . & 56 & 38 \\
\hline Id. 27 vols. . . . & $2 i$ & 23 \\
\hline Iu. 34 viols & 6 & 2 \\
\hline Id. $\quad 10$ faux & 7 & 8 \\
\hline Id. 27 incendies . . & 9 & 4 \\
\hline
\end{tabular}

Ces chiffres montrent que les tailles élevées abondent chez les voleurs de grand chemin et chez les homicides tout comme chez les voleurs ordinaires, tandis que les tailles petites sont moins fréquentes chez les premiers. Ceci est encore plus évident si on étudie la taille des faussaires, des violateurs, des incendiaires. Ces dernières catégories de criminels, trop peu nombreuses d'ailleurs pour nous occuper, offriraient une somme plus grande de tailles élevées, mais aussi de tailles petites.

(l) Thompson sur 324 Eeossais délinquants a trouvé le poids moyen de 151 livres, de 147 sur 106 Irlandais et de 149 sur 55 Anglais. (Psychol. of Crimin., 1870).

(2) Sur 100 homicides Russes Biliakow à tronvé:

$$
\begin{aligned}
& \text { Taille petite . . . . } 9010 \\
& \text { Id. moyenne . . . } 5 \gamma^{*} \\
& \text { Id. haute . . . } 34 \text { ” }
\end{aligned}
$$

(3) Laprès Lacassagne j'adopte le mot violateur pour auteu de viol. 
Quant au poids, si nous comparons les résultats obtenus (1) par le $\mathrm{D}^{\mathrm{r}}$ Franchini et par moi sur 1331 soldats avec le poids moyen des criminels de chaque région on trouve que, excepté dans les Marches et la Vénétie, les criminels sont d'un poids plus considérable, ce qui confirme les résultats fournis à Biliakow par 100 homicides.

Le poids des criminels dépasse de beaucoup celui des fous: a Pavie, chez 165 fous j’ai trouvé un poids moyen de 59,90, c'est-à-dire inférieur de 10 kilogr. au poids moyen des criminels Lombards.

Si l'on distingue les homicides et les voleurs de grand chemin des autres criminels, voleurs et faussaires, on trouve pour ees derniers des chiffres de beaucoup inférieurs.

Veut-on avoir une idéc plus nette de la diffẻrence de poids chez les criminels? voici des chiffres:

\begin{tabular}{|c|c|c|}
\hline $\begin{array}{c}\text { Poids } \\
\text { supérieur } \\
\text { de }\end{array}$ & $\begin{array}{c}\text { Poids } \\
\text { inférieur } \\
\text { de }\end{array}$ & $\begin{array}{l}\text { Poids } \\
\text { moyens }\end{array}$ \\
\hline 70 à $80 \mathrm{kil}$. & 49 à 54 kil. & d'après Virgilio \\
\hline
\end{tabular}

Sur 567 homicides $115=20010 \quad 47=8010$ Sur 13960 à $61 \mathrm{~K}$. Id. 143 voleurs . $22=15$ " $25=17$ " Id. 7863 " Id. 21 violateurs $3=14 " 4=19 "$ Id. $7 \quad 50$ à 60 " Id. 34 faussaires $7=20$ " $6=17$ " Id. 861 " Id. 23 incendiaires $5=21$ " $3=13$ " Id. $4 \quad 57$ "

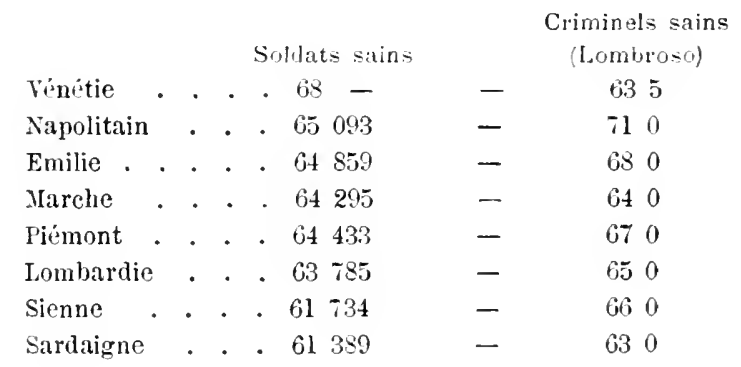


On voit par lá que les faussaires, les incendiaires et les homicides fournissent les proportions les plus élevés de poids maximum; tandis que les homieides et los incendiaires donnent aussi la proportion la plus faible do poids minimum. Les violateurs et les voleurs ont le maximum des poids inférieurs et le minimum des poids supérieurs.

Cette supériorité, en général, du poids et de la taille peut se contròler sur le cadavre - ce qui vaut bien mieux, parceque le vètement peut ètre une cause derreur. En eflet les chiffres fournis par le poids et la taille des 400 cadarres d'hommes normanx et des 194 criminels de Bonn, dont fait mention l'œuvre de Bischoff (Hirngewicht des Menschen, Bonn, 1880) nous montrent que dans les poids les plus petits les hommes honnètes dépassent les brigands, comme 18,6 est à 13,4, (voyez Atlas, tab. $\mathrm{I}^{\mathrm{e}}$ ), tandis que dans les poids moyens (40 a 70 kilogrammes), ce sont les brigands qui l'emportent comme 84 est à 75 .

Dans les poids maximum les gens honnêtes surpassent les criminels dı double, coinme 4 est à 2,2 .

4. - Grande envergure. - Les criminels offrent une supériorité marquée dans la mesure de la grande envergure comparíe à la taille. Cette supériorité déjí entrevue, chez les mineurs, par Riccardi, fut constatée chez les adultos par Lacassagne qui a étudié 800 criminels français. (Arch. di psich., rol. IV, fasc. II). Ces derniers, comme il est démontré dans l'Atlas, tab. $\mathrm{II}^{\mathrm{e}}$, ont bien des fois la grande envergure supérieure à la taille.

En effet sur 800 hommes examinds la grande envergure fut: 
91 fois inferieure à la taille

86 fois égale

id.

623 fois supérieure

id.

Naxime Du Camp a noté la grande longueur des bras chez le sanguinaire communard Verig. Thiebert arait de remarquable, ontre les énormes mâchoires, des bras aussi longs que ceux d'un chimpanzí, comme Cartouche des doigts très-mobiles of très-longs.

\section{5. - Gracilite. - l'ai observé:}

Sur 567 homicides santé délicate 53 taille mal formée 3

$\begin{array}{llrll}\text { Id. } 143 \text { voleurs } & \text { id. } & 19 & \text { id. } & 1 \\ \text { Id. } 21 \text { violateurs } & \text { id. } & 4 & \text { id. } & 3 \\ \text { Id. } 34 \text { faussaires } & \text { id. } & 5 & \text { id. } & \text { 1 } \\ \text { Id. } 23 \text { incendiaires } & \text { id. } & 2 & \text { id. } & \text { 2 }\end{array}$

Les brigands, les homicides, les incendiaires ont le plus souvent une taille ilancíe, une santé robuste, tandisque les voleurs, les violateurs (1) sont pour la plupart des gens frêles, surtout ces derniers: ce qu'expliquent probablement les plaisirs solitaires dont ils portent les traces sur le visage; avec les faussaires et les incendiaires ils donnent un plus grand nombre de bossus ; ainsi se trouverait fondée l'opinion populaire qui met sur le compte de cette infurmité la luxure et la malice.

On ne doit pas s'itonner si les homicides sont plus forts el plus grands: il faut un grand développement de force pour user de la violence et pour attaquer. Au roleur, au contraire, la foree n'est pas nécessaire; la faiblesse même peut être une cause adjurante du crime.

(1) Pour auteurs de ciol en suivant la nomenclature de Lacassagne. 
6. - Amplitude tleoracique. - La mesure de la plus grande amplitude thoracique, chez 384 Yénitiens, a bie de $894 \mathrm{~mm}$. sul les homicides, de 886 chez les incendiaires, de 875 chez les hrigands et faussaires; de 874 chez les voleurs et de 860 chez les violateurs. Done, comme pour la taille et le poids, les criminels dépassent aussi la moyenne pou l'amplitude thoracique $(860 \mathrm{en}$ Mallie, d'après Baroffio).

Biliakow a trouvé chez 100 homicides russes un périneitre thoracique de 88 cent. ì 96 , c'est-à-dire supéfien à la normale de Russie; et il a trouvé:

Pour la taille petite - . 1,60 périm. moy. thor. cent. 84,6 Id. movenne . . 1,70 id. id. 85,0

Id. haute, supérieure à 1,70 id. id. 87,0

linsi les lıomicides lui ont donné un périmètre thoracique non inféricur aux chiffres constatés chez les personnes adonnces aux traraux plus pénibles (1).

7. - Capacité crânienne. - Arrirons, maintenant, à lélude de la capacité crànienne, d'ilprès les donnces des diamètres, des courbes et des circonférences, (Documents, vol. II), quoirue elle ne puisse en donner, ì la vérité, qu'une idée très-grossière.

Le maximum rle la capacité crànienne se reneontre clıez les faussaires; le chiffre atteint par eux est de $1555 \mathrm{en}$ Sicile et dans la Vénétic, de 1582 en Lombardie; dans toutes les régions excepté le Piémont et l'Emilie (où les chiffres sont de 1497-1498) il dépasse celui des autres criminels.

Immédiatement après viennent pour le volume notable du crîne les homicides et les brigands qui, en 11 régeions sur 21, dípassent le chiffre de 1500.

(1) Kuwaterscki, Archir., 1884. 
Les voleurs ont une médiocre capacité crinienne: dans : régions sur 9 ils dépassent le chiffre de 1500; ils sont toujours inférieurs aux autres criminels et n'offrent lo maximum que dans l'Ombrie el les Marches.

Les incendiaires et les violateurs, en tris-petit nombre d'ailleurs, ont une capacité minima.

La capacité crànienne moyenne de 40 fous de Pavie a été de 1508, cest-i-dire inférieure at celle des violateurs, des faussaires, des voleurs lombards et légérement supérieure à celle des briganıls.

Cette étude vient en grande partic corroborer celle dE. Ferri. Ici la statistique est plus étendue, et la méthode súriale porte sur 699 délinquants (divisés en délinquants incorrigibles ou nés délinquants ot en dirlinquants l'occasion), et sur 71l soldats et 321 fous (1).

Les capacités plus grandes se trouvent dans les condamnis par blessure, les moindres dans les pickpokets

(1)

\begin{tabular}{|c|c|c|c|c|c|c|c|c|c|c|c|}
\hline \multirow{2}{*}{$\begin{array}{l}\text { CAPACITE } \\
\text { CRA NIENNE } \\
\text { PROBABLE }\end{array}$} & \multicolumn{4}{|c|}{$\mathrm{T} O \mathrm{~T} \perp \mathrm{L}$} & \multicolumn{3}{|c|}{$\begin{array}{c}\text { NÉG } \\
\text { DEITIQTAN. }\end{array}$} & \multicolumn{4}{|c|}{$\begin{array}{l}\text { DELLINQTANTS } \\
\text { DOCCAION }\end{array}$} \\
\hline & 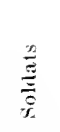 & 泀 & 莺 & 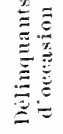 & $\stackrel{\varrho}{\Xi}$ & 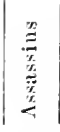 & 总 & 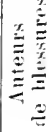 & 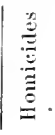 & $\frac{2}{3}$ & 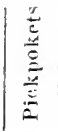 \\
\hline $1381-1421)$ & - & 1,9 & 2,9 & 0,9 & 10,0 & 2,2 & 3,9 & - & - & 0,9 & - \\
\hline $1421-1460$ & 2,8 & 8,0 & 11,6 & 5,0 & 15,0 & 15,3 & 9,0 & $1-$ & 0,1 & 4,1 & 3,5 \\
\hline $1461-1500$ & 18,0 & 25.6 & 26,4 & 21,9 & 30,0 & 32,6 & 27,3 & 19,2 & 13,6 & 25,8 & $34 . \pi$ \\
\hline $1501-1540$ & $3 \pi, \overline{1}$ & 33,0 & 34,8 & 33,4 & 20,0 & 32,10 & 34,2 & 48,6 & 27,3 & 31,4 & 26.9 \\
\hline $15+1-1580$ & 31,9 & 22,6 & 19,1 & 29,9 & 20,0 & $1 ;, 3$ & 19,2 & 29,0 & 50,0 & 28,4 & 23,1 \\
\hline $1581-1620$ & 7,9 & $6, \pi$ & 4,5 & 7,5 & 5,0 & - & 5,4 & - & - & 8,1 & $11, \overline{1}$ \\
\hline $1621-1660$ & $1,+j$ & 1,9 & $0, \overline{7}$ & 1,2 & - & - & 1,0 & 3,2 & - & 1,6 & - \\
\hline $1661-1700$ & 0,1 & 0,3 & $\div$ & 0,3 & - & - & - & - & - & - & - \\
\hline $1701-1740$ & - & - & $0,2^{\circ}$ & - & - & 一 & - & - & - & - & - \\
\hline $\begin{array}{l}\text { Individus } \\
\text { examiness }\end{array}$ & 711 & 301 & 346 & 353 & 20 & 46 & 182 & 31 & 22 & 147 & 20 \\
\hline
\end{tabular}

()) likesem hydrociphale. 
el dans les assassins, les minimmon dans les idiots; los soldats on! le nombe plus petit des submicrocépluales.

lin companant les assassins homicides non récidivistes avec les récidivistes on les accusés de plusicurs crimus dins les mêmes provinces, ferri a trowri une phus pe-

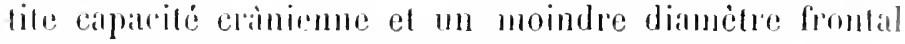
arec un plus grand développement des mâcloires.

S. - Front. - l'our la hauteur du front, d'ipros b. Foni, les series d'individus étudies se résument cu deux groupes: l'un supérieur, soldats et délinquants ¿'oceasion, lautre inférieur, fous el délinquants incorrigubles. Dalpres Ferri le front serail plus haut chez les meurtriers, les alicués, bien plus bas chez les idiols. El quand on les éludie par region les lomicides restent infiricurs aux soldats dans toutes les provinces examinces.

En étudiant lo diamètre minimum frontal (1), l. Ferri confirme l'infériorité des criminels, mais bien plus en111

\begin{tabular}{|c|c|c|c|c|c|c|c|c|c|c|c|c|}
\hline 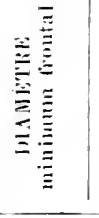 & 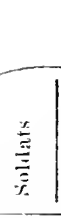 & 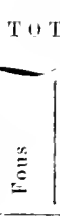 & & 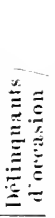 & 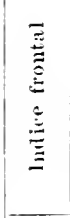 & $\frac{\text { DÉL }}{\text { DÉ }}$ & 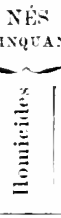 & 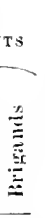 & 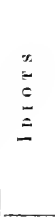 & 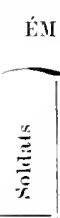 & 兰 & 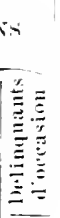 \\
\hline 9 & - & 2,2 & 0.5 & $n, 2$ & 5.58 & - & - & 1,1 & 15,0 & - & - & - \\
\hline $93-95$ & 0,2 & 2,6 & 9,5 & $5, n$ & กิ-62 & 11,1 & 6,2 & 1,1 & 35,0 & 0,9 & 6,3 & 8,1 \\
\hline & 4.1 & $10.1)$ & 16.2 & 13,4 & $63-66$ & 42.4 & 30,4 & 34,3 & 33,0 & 12,1 & 50,0 & 35,1 \\
\hline 101 & 7.5 & 16.9 & 24,6 & 23,3 & $67-70$ & 37,7 & 41,5 & 31.2 & 15,0 & $5,4:$ & $3 \pi, 5$ & 45,0 \\
\hline 04 & 25,2 & $22, \pi$ & 24,6 & 31, & $71-74$ & 4,4 & 21,9 & 30,1 & - & 29,6 & 6,2 & 10,8 \\
\hline liit & 25,2 & $2,1,3$ & 18.3 & 107 & 85 & 4,4 & -1 & 1,1 & - & 7,4 & - & - \\
\hline-110 & 30,6 & $16,1)$ & 4,3 & 7,11 & $79-82$ & - & - & 1,1 & - & - & - & - \\
\hline & 6,4 & 6,8 & 0,5 & 0,2 & - & - & - & - & - & - & - & - \\
\hline & 7,3 & 2,5 & 0,5 & - & - & - & - & - & - & - & - & - \\
\hline $117-119$ & $3, \overline{1}$ & - & - & - & - & - & - & - & - & - & - & - \\
\hline & & 297 & 344 & 253 & - & 45 & 178 & 93 & 20 & 108 & 16 & 37 \\
\hline
\end{tabular}


core celle des délinquants doccasion, spécialcment en rapport an diamètre transiersal maximmom de la tète.

Parmi les délinquants plus graves les assassins sont inféricurs anx homicides et aux roleurs de grands chemins, tandis que le plus grand diamitre frontal so troure sur les meurtriers et les fripons. Chez los idliots se rencontre le diamitre frontal le plus faible, malggré leur plus grand dianètre transrersal de lète. Chez les soldats au contraire les différences notées sont tontes en relations précisément avec ce diamètre, excepté pour les Riomagnols, les Vénitiens et les siciliens.

Ëtudie-t-on region par région, on troure loujours dans toutes los provinces un chiffre inférieur pour los homicides. lei se révèle un fait intéressant; les délinruants d'oceasion ont, dans plusieurs provinces, $n$ diamère frontal intérienr à celui des délintuants majeurs, malgéé leur plus grand dianètre transversal et la plus grancle capacité crimiennr.

9. - Circonférence cranienne. - Si ensuite nons nous mettons à étudier, à part, dans les criminels la eirconférence crinienne, la mesure plus aisément comparable arec celle des individus sains, nous yogons en général, que la plus grande se rencontre diez los faussaires, les brigands et les homicides, la plus petite chez les incendiaires, les volem's of les violateurs.

Pour montrer quelle différence existe entre ces mesures (893) et celles de l'homme sain, nous les comparrpons anx losultats tronvés sur 14.000 soldats par Baroffio et ì cenx que jai trourés arce le doct. Riva sur 202 aliénés de Paric et de Pesaro. Nons royons alors la circonférence crinienne 


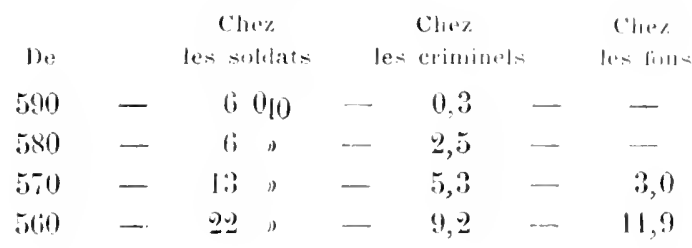

Nons arons, done, trois fois plus de tètes volumineuses chez les indiridus sains que chez les criminels. Et quant anx fous sils ne nous présentent pas la circonférence de 59 et 58, ils sont inférieurs de peu it ces derniers quant a celle de 57, et les dépassent dans celle de 56 .

Troyski a Varsave a trouvé lui aussi une proportion phus grande de circonférences inférieures aux normales, mais me proportion anssi phus grande de cirronférences supériemres exagérées

binn- Ban eriuninels Ruses

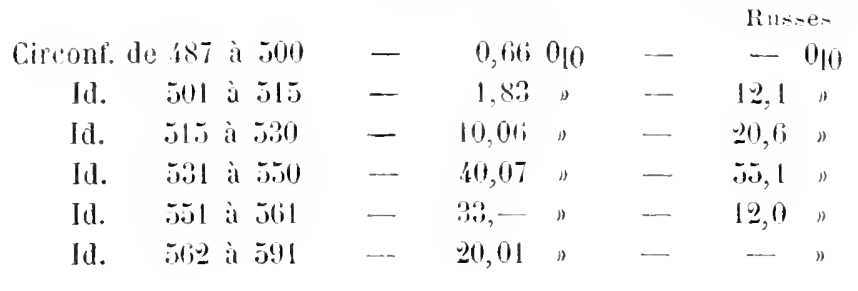

En général les individus qui mothraient de grandes circonférences et de grandes capacités crimiennes étaient des chef's de brigands, des faussaires, ou de très-cilèbres fripons: par exemple le ligme Rosali, dont nous parlerons longuement plus tard, voleur d'un esprit extraordinaire, avait 565 pour la circonférence, 199 pour la longrueur du front, 1559 pour la capacité générale. Le féroce et rusé La Gala avait une circonférence crânienne. de 559, une largeur de front de 150 , et une capariti: générale de liso9. 
Le féroce Davanzo, poète el secrélaire de La Gala, avait une circonférence de 570. Un camorriste fameux de Naples m’a donné une circonférence de 570 et une capacité générale de 1604. Un faussaire de Pavie avait une circonférence de 580 et une capacité générale de 1671. Verzeni, qui pendant fort longtemps échappa à toute recherche de la justice, offrait une capacite de 1577, el une circonférence crânienne de 561. Une circonférence de 590 me fut donnée par un droguiste des plus adroits, qui, dans son pays, filisait tuer ses confrères, et put ainsi pendant longtemps s'enrichir impunément. Suller qui, aux galères réussit à fahriquer un passe port et même de la fausse monnaie, arait une circonférence de 580 (1).

Voici les chilfres comparés des eirconférences fournies par les soldats, les criminels, et les fous:

\begin{tabular}{|c|c|c|c|c|c|}
\hline Circonfërences & Soldats & Crimin & hels: & $\mathrm{Fo}$ & bus \\
\hline 530 & $8,4 \quad 010$ & 11,3 & 010 & 23 & $0_{10}$ \\
\hline 520 & 2,94 & 5,0 & $"$ & 13 & $"$ \\
\hline 510 & 0,00 & 1,9 & $n$ & 6 & $"$ \\
\hline 500 & 0,13 & 0,8 & $"$ & 3 & A \\
\hline 490 & 0,01 & 0,18 & $"$ & 0 & $"$ \\
\hline 470 & - & 0,1 & $"$ & 一 & $n$ \\
\hline
\end{tabular}

Ce qui démontre clairement que los criminels ont une submicrocéphalie deux fois plus fréquente que les soldats, mais plus faible que celle des aliénés. Il u'y a pas là de contradiction avec ce que nous ont revelé les recherches anatomiques. Il ne faut pas oublier que la sclérose crânienne est plus fréquente chez les criminels que chez les fous: ce qui explique comment la capacité

(1) LaUverine, Les Forgats, 1. 353, paris, 1843. 
exteme peut paraitre notable alor's mêne qu'elle est diminuéc à l’intéricur.

La différence de volume de la téte chez les criminels doil paraille d'autant plus considélable que, comme on l'a vil plus haul, la laille el le poids du corps, sont, cliez presque tous, très-élevés.

llolbach et Poncel presentaient mo circonlérence de 470. Lassassin Longerin une de 431 .

Lauverọne (1), qui a étudie des parricides, ajoute que sur 9, trois avilient des tètes pelites el léporines.

Tout celit est confirmé par l'élnde de E. Ferri, qui iei encore établit une distinction entre les criminels-nés (Pesilro) el les criminels d'oceasion (Castelfranco) (2).

L.es plus petites circonférences, selon lui, se rencontrent surtout chez les crimincls; c'est le contraire pour les plus grandes. Mais les criminels d'oceasion et les criminels d'hahitude dépassent les criminels nés dans les circonférences moyennes et s’en écartent dans les circonférences élcrées.

10. - En étudiant la deni-circonférence antérieure chez 1711 individus, Ferri conclut à une infériorité pour la pelite criminalité (voleurs, fripons elc.) et plus encorc pour la grande (assassins, homicides) comparée à celle des soldats.

Parmi les aliénés la grande infériorité des idiots el des imbéciles est évidente, les homicides ont une demicirconférence antéricure inférieurc à celle des soldats en Piémont, dans la Lombardic, dans la Romagne.

(1) Op. cit., p. 80 .

(2) Archir. di psich., vol. 11, et ici même vol. "1, Documents. 
Corre et Roussel se sont livrés à une étude minulieuse, sur 200 eondamnés morts à Brest. Chez les Francais la eireonférence normale étant de 595 millim., et la demi-cireonférence antériemre de 2Til, et la postérieure de 274 millim., les circonférenees des criminels seraient plutòt plus élevées, et les parties antérieures prédomineraient souvent sur les postérieures; on tronverait chez les volems me proportion qui atteint 48 1. 010, pour des cireonférenees allant de 559 à 540 ; et de 220 0 au dessous de 560. Chez les faussaires les deux grandes mesures atteindraient 72000 ; chez les homicides 76010 . Les violateurs donneraient 690 0[0. D'après ces données les faussaires el les lomicides l'emporteraient sur les voleurs et les violatenrs.

Quant it la prédominance antérieure, chez les voleurs nous trouvons 40010 , rhez les faussaires 70 , chez les violateurs 57 el chez les homicides 48000 .

11. - Diamètre de la mâchoire. - Manourrier, Ferri el moi avons noté le développenent exagíré des matchoires, surtout chez les lomicides. Le plus grand diamètre de la machoire, Ferri le constate chez les homieides et chez les petits délinquauls, le plus failıle chez les eompeurs de bourse el les meurtriers; il nost pas très-développé chez les fous, hormis ceux qui sont atteints de monomanie impulsive.

12. - Diamètres zygomatiques. - Ferri el Bilialiow ont trouve le diamètre bizygomatique maximum chez les délinquants comparés aux normaux. Parmi les criminels il est plus grand chez les homicides et moindre chez les coupeurs de bourses. 
13. - Face. - Il résulte que la longuenr de la lines, non seulement en chiffres alssolus, mais encore en rippport pour cent avec la hauteur du vertex au menton, est notablement supérieure chez les eriminels, smltout chez les assassins-lonnicides, comprarés aux soldats; elle est supérieure encore che\% les homicides compares anx mentriers et aux coupeurs de bourses; les homicides ont toujours un déreloppement de lit fice, comparé au crìne, notalilement plus ílevé que che\% les soldtats, spécialement dans le Napolitain, et en Sicile.

14. - Indice céphalique. - L'indice céphalique conserve prescrue toujours congénitalement les traces de l'influence de la région el de la race; très-grande lirachicéphalie, depassant 86,85 en Prímont, 88,93 en Russie, inféricure a 82 en Romagne, dans les Marches, en Lombardie, a 81 dans l'Emilie ct dans lombrie, is so dans la Vénélie el à Gùnes.

Les déformations crimiennes sont phus fréquentes che\% les voleurs et les incendiaires et en particulier chez les mineurs ou elles se rencontrent dans la proportion te 13010 ainsi divisées:

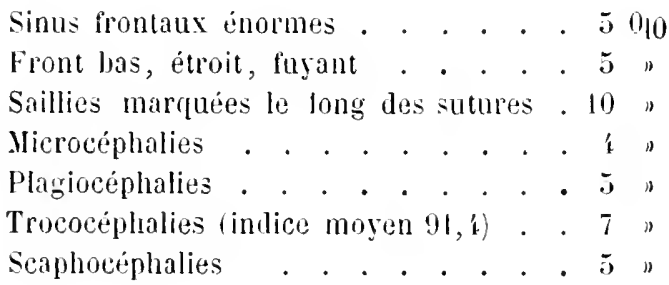

La trococéphalie a étí rencontrée clicz un Romagnol et un Sicilien; le Riomagnol trococéphale élait un enragé violatenr, avec de longues oreilles en anse, le firont bas, 
les yeux obliques, le nez camus, des màchoires énormes, en résumé un type aussi monstrueux que celui que l’on lencontre dans les manicomes, (voir Allas, lab. Jv, 1).

Chez 4 brigands ef 5 homicides, on note un gonflement de la partic supérieure des tempes, un aplatissement de la portion inférieure et de l'occipital, el deux asymétries faciales.

En Russie Biliakow sur 100 homicides a trouvé l'obliquité du front, l’asymćlrie du crâne $\left(580_{10}\right)$, la saillie de la région occipifale el de la partie supérieure du crine $(15010)$, un fort développement de l'apophyse mastoüle $(130[0)$ et des sinus frontaux (420 $0[0)$. D) après lui, la plus petite distance entre les angles de lat màchoire inférieure se trouve le plus souvent chez les hommes sains, la plus grande chez les homicides et les psychopatlıes. - Quant à la distance te l'orifice atriculaire ì la base de la cloison nasale et a la ligne mento-auriculaire, les mesures maxima et minima appartiennent tout d'abord aux délinquants, puis aux psychoprathes, tandis que la mesure oscille pour les lommes sains de 0,3 a 0,4 centim., elle est pour les autres de 0,6 i 0,7 centim. Plus de la moitié des homieides présente un grand développement de la partie supéricure du crine; si on compare au périmètre intérieur du craine la région occipitale el la région frontale, on trouve chez les homicides un fort développement de la première et une diminution notable de la seconde.

I Varsovic, Troysli (1) a donné une table comparative qui montre la différence entre les mesures des crânes normaux et ceux des délinquants et des psyclıopathes.

(1) Arrhive de psychiatrie nevrologie et psycopathologie de humLE'wsin, (Kussie), 1885. 
Diamétre vertical

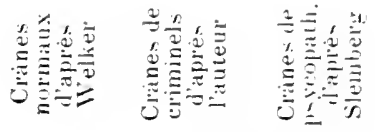

Moins de 68,0 010 platicéphalis

$0,0010 \quad 3,0011 \quad 6,6010$

De . . 68,0 à72 " subplaticéplual. 30,0 " 29,0 " 18,0 "

De . . 72, à 75" mesocéphalie 49,3 " 31,7 " 21,6"

De . 75,1 a $79 "$ ipsicéphalie 26,6 " 31,7 " 28,0 "

De . 79,1 à 8 " oxicéphalie 0,0 " 10,3 " 15,6"

Au dessus de 8in $\quad 0,0 " 0,7$ " 8,2 "

Ce lableau montre la plus grande fréquence de la platicéphalie et de la subplaticéphalie et de l'oxiépplatie cluez les crimincls comparés aux hommes normaux, el leur infériorité chez les fous.

Ces mêmes diamètres ont été étudiés par lui sur 3 catígories de crimincls: $1^{\circ}$ Ifomicides et voleurs de grand chemin; 20 Récidivistes; 9o Criminels entrés en prison pour la première fois.

\begin{tabular}{|c|c|c|c|}
\hline \multirow{2}{*}{ Dianière vertical } & 10 & $=0$ & 30 \\
\hline & IIomicides & Reriblivistes & Non \\
\hline ns de 68,0 & $2,300_{0}$ & 4,7010 & 1,6010 \\
\hline . 68,0 à 汭 & $\{6,3)$ & 20,9 " & 26,5 \\
\hline . 72,1 a $7 \check{\jmath} n$ & $34, \dot{*} n$ & $31,8 n$ & 30,5 \\
\hline . 75,1 à 79. & 27,9 & $32,5 "$ & $32,6 "$ \\
\hline . 79,1 à 8 ' & 2,311 & 0,0 & $0,8 "$ \\
\hline
\end{tabular}

On roit ici, que les ypes extremes de l'indice de la hauteur, la platicéphalie et loxicéphalic se rencontrent plus fréquemment parmi les voleurs de grands chemins et les voleurs récidivistes, et plus rarement chez les voleurs d'oceasion rui ne sont pas les hôtes labituels des prisons.

Knecht, sur 1214 criminels allemands, a trouré plutòt lexcès dans les dimensions erâniennes que le défaul: 
4 fois seulement la microciphalie; 118 fois loxiciphalie, 15 fois la scaphocéphalic; 32 lois le prognatisme, 56 fois l'anomalie dans l'implantation des dents; chez 6 il a noté la division de la luetle, el chez 6 des anomalies aux oreilles.

La paralysie unilatérale de lá face, l'asymétrie faciale ont été notées senlement if fois; et plus rares encore sont les cas de déviation notable du nez.

Le strabisme a été trouvé 7 fois et autant de fois l'inéralité des pupilles. 23 fois il a noté le goître el l'hypertrophie cardiaques el 146 la hernie.

Quant aux organes génitaux le phymosis congénital a été trouví chez 5 individus; 29 présentaient un arrêt de développement des testicules ou du pénis; 2 fois fut observí l'épispadias el 5 fois l'hypospadias.

L’asymétrie crànionne pour' Corre et Roussel (Rev. d'anthrop., 1883) est le caractère prédoninant des criminels français: sur 121 voleurs elle a été observée 81 fois, et 22 fois l'asymétrie faciale. La déformation scaphoïde a été notée sur 21 de ces individus. L'aplatissement pariétal postérieur ils l'ont observé 61 fois, dont 41 sur les crànes asymétriques, et 21 sur les crànes réguliers.

Chez 21 faussaires ou banqueroutiers l'asymétric était un peu moins fréquente $\left(630_{10}\right)$.

Chez 28 violateur's l'asymétrie a été notée 19 fois, soit 700 , 0 , ot 9 fois l'asymetrie faciale, dont 5 fois en rapport avec la crànienne.

L'étude de 25 meurtriers donnerait un nombre inférieur dasymétriques $\left(600_{10}\right)$, el 6 asymétries faciales sculement; au contraire 21 fois l'aplatissement pariétal.

15. - Exceptions. - Mais une certaine partie des crimineis, celle qui peut se dire l'alristocratie du crime, 
ofhe une large capacité cérébrale, de misne quine forme régulièe du crâne, et souvent ces lignes harmoniques et fines, qui sont particulieres aux hommes distingués. Tels rtaient par exemple Brochetta, Lacenaire, Malagutti, de même Carbone, Pace, Franco, Venetuoli st les frères Jacovone, qui ne pourraient se distingu.e. craniométriquement de leurs concitoyens. Les assassins Lebiez et baré, avaient le front élevé, les lignes du crine régulieres. 
II.

PIISIONONIE DES CRIMINELS.

1. - Sur la physionomie des eriminels on fait courit des idées fausses pour la plupart. Les romanciers en font des hommes dun aspect épourantable: barbe jusqu'aux yeux, el le regard scintillant et féroce. Dautres observateurs, Casper par exemple, ront d'un excés à lautre, el ne trouvent aucune différence entre eux et lhomme normal. Les uns et les autres se trompent. Assurément, de mème qu il y a des criminels it capacité crî̀nienne notable, arec d admirables conformations du crâne comme nous venons de le dire, il y en a anssi et surtout parmi les habiles filous el anssi parmi les chefs de bande, dont la phrsionomic est parfaitement régulière. Tel élait lassassin dont parle Lavater et qui ressemblait à l'un des anges dı Gnide. Tel élait ce prétendu colonel Pontis de Sainte-Ilélène qui put pendant longtemps tromper l'autorité et la cour sur les dépouilles de celui qüil avait probablement tué. Tels étaient Holland, Lacenaire, Bouchet, Lemaire, Sutler, et le chef de brigands Carbone, une des plus graeieuses figmres napolitaines. (Voir lable $r^{e}$ ).

Mais ce sont des exceptions qui nous frappent et noms entrainent par leur contraste, et qui s'expliquent quand on rérifie que ces crimincls ont une grande intelligence a laquelle sajoute une certaine gentillesse de manières.

Cerlains caractères particuliers de la phrsionomie des criminels, comme l'absence de barbe, l'abondance de la chevelure, la pâleur, nous font, bien sourent, trourer 
leur physionomie plus délicate el plus gentille quielle ne l'est en réalité. (Voir table $\mathrm{vI}^{\mathrm{e}}, 6, ?$ ).

Quand, il part ces rares exemples qui forment l'oligarchic du délit, on étudie la masse entière de ces mallıenreux, comme je l'ai fait dans les maisons de détention, on conclut que, sans avoir toujours une physionomie barbative et effrayante, ils en ont une toute particulirie et presque spéciale à chaque forme de la criminalité.

Chez les violateurs (qui ne soient crétins) presque toujours l'œil est saillant, la physionomie délicate, les lèrres et les paupières volumineuses. La plupart sont grèles, blonds, rachitiques, et parfois bossus (Atlas XI, 100). Les pédérastes se distinguent souvent par une élégance fíminine, par les cheveux longs et bouclés et par des habits qui conservent, même sous l'uniforme des prisons, une certaine tournure féminine. La délicatesse do la peau, l'aspect infantile, l'abondance des chereux lisses et séparés ì la mode des femmes, qui se rencontrent souvent dans ces malheureux, on les observe aussi chez les incendiaires, par ex. cet incendiaire de Pesaro, qu'on avait surnommé la femme, et qui en avait en effet l'aspect et les mœurs. (Voir Atlas, table vil ${ }^{\mathrm{e}}$, fig. 2; table $\mathrm{xl}^{\mathrm{e}}, 4,4$ (his) et 2 ).

Les meurtrier's, les voleur's arec effraction ont les cheveux crêpus, sont déformés dans le cràne, ont de puissantes mîchoires, des zygomes énormes, et de fréquents tatouages; sont couverts de cicatrices dans la tête et dans le tronc. (Voir table $\mathrm{r}^{\mathrm{e}}, 5$, 4 , et $\mathrm{VII}^{\mathrm{e}}, 1$ ).

Les homicides habituels ont le regard vitrenx, froid, immobile, quelquefois sanguinaire et injecté; le nez souvent aquilin, ou mieux crochn comme celui des oiseaux de proie, toujour's volumineux; les mâchoires sont robustes, les oreilles longues, les pommettes larges, 
(roir tal. vi $\left.\mathbf{e}^{\mathrm{e}}, 3, \mathrm{v}^{\mathbf{e}}, 1,3\right)$, les chcveux crépus abondants et loncés. Assez souvent la barbe est rare, les dents ranines très-développées, les lèvres fines. Souvent il y a lu nystagme el des contractions d'un côté du visilge, qui montrent la saillie des dents canines comme en signe de menace. (Voir Atlas, v, 3, 4, vi, 3, 4).

Un grand nombre de faussaires et d'escrocs que j'ai flu étudier, avaient une physionomie où se peignait une bonhomie singulière, quelque chose de clérical, ce qui daalleurs dans leur triste carrière contribuail à inspircr la confiance à lcurs viclimes. J'en ai conmu avec le visage pâle, des yeux lagards ou très-petits, le nez tordu, avec bien des fois une précoce perte des chevenx et la face de vieille femme; aussi étaient-ils (Marro) bien souvent des fils de vieux. (Voir table $\mathrm{vl}^{\mathrm{e}}, 2,3$ ).

En ginéral beaucoup de criminels ont les oreilles cuarlics, les cheveux abondants, la barbe rare, les sinus frontaux et les màchoires inormes, le menton carré ot saillant, les pommettes larges, les gestes fréquents, cn somme un lype ressemblant au mongol et patfois au nègre. (Voir Allas, lable vil ${ }^{\mathrm{e}}$, 2, et xil ${ }^{\mathrm{e}}$, 1 et 2).

L'llsage assez fréquent chez nos brigands de porter des tresses, et celui des bravi de porter le ciuffo conmme insigne de leur füroce métier, est dù probablenent ì leur splendide cherelure crepue et rebelle a toute coiffure.

Carbone el Caraglia, dont il a été question plus laut, et dont la physionomie est si belte, nont pas de barbe mais des clieveux longs et abondants: cétait lo cas d'Madie. (Toir Allas, lable $\left.v^{\mathrm{e}}, 6,3\right)$.

Giona la Gala a des cheveux louffus el crèpus, de larges ponmettes, la lève mince, l'oeil vitreux el immobile.

Troppmann, Mabille, Ducros, avaient le front luyant et la livre supérieure mince, la barbe rare, la chevelure dure, el les oreilles en anse. 
Dumollard riolatrur et assassin arait lat lére supririeure déformie, la cherelure foncée el trés-fournie.

Billoir avait les cheveux noirs, crêpus et épais.

Casper dicline aroir déconvert sur tous ses assassins IIII regard froill el glacial, presque de marlore, sourmet des cheveux touffus. Il y arait mo notable prognatisme chez IIelm, absence do barbe chez Winck et Lucke, des pommeltes inormes clie\% Z., des lèrres minees che\% lliube, des mains énormes chez lilausen, une bouche fendue chez les deux assassins II. Y. et Polmann: cette dernière prósentait de fréfuentes contractions it la lívre ganche. (llorder Plyysiognomie, 1854).

A. Scheffer nous a peiut Judas arec une face prognatr, de longues oreilles en anse; tel est aussi Judas sculptis farl la main d'un maitre all pied de la "Scala Santa " it Rome.

L'areheologie nous devoile, comme l'a si bien montrí Nayor dans sa Monograpleie des Césars, 1886, que Tibère arait les oreilles en anses, asymetrie faciale, et lit michoire volumineuse. Callignla avait une expression sinistre, cruelle et défiante, rictus menarant au coin de la lèrre supéricure, pâlcur du visage, lères minces, regards fixes et terrihles, màchoires fortes et asymétriques; le còté gauche de la fosse zygomatique plus déreloppé.

Néron avait une isymétrie frappante de la face, do fortes michoires, de grandes oreilles légèrement écartíes, de plus des sinus très-saillants, un front bas (Allis, xiII), et un léger strabisme.

Balzac nous dépeint le fripon du Tillet aree des chereux très-noirs, comme s'ils avaient ché teints.

Bret-Ilarte représente ladultère sous les traits d'une femme extraordinairement pàle, qui ne rougissait jamais. 
9. - Mais l'anthropologic reut des phillies al non dres descriptions isolées el générales; sutoul puand elles doivent sapplipuer à la medecine ligale.

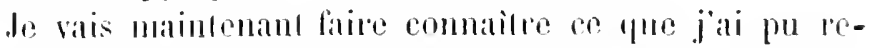
curillir griece, surtoul, it l'aide du doc. Marro qui ra m publier un puissant havail chez 500 criminels (1).

Cheveux. - Lin comparanl 500 hommeles gens i 500

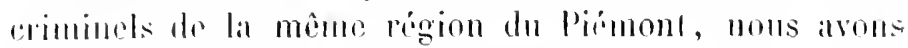
trouvé les chilfres suivantos:

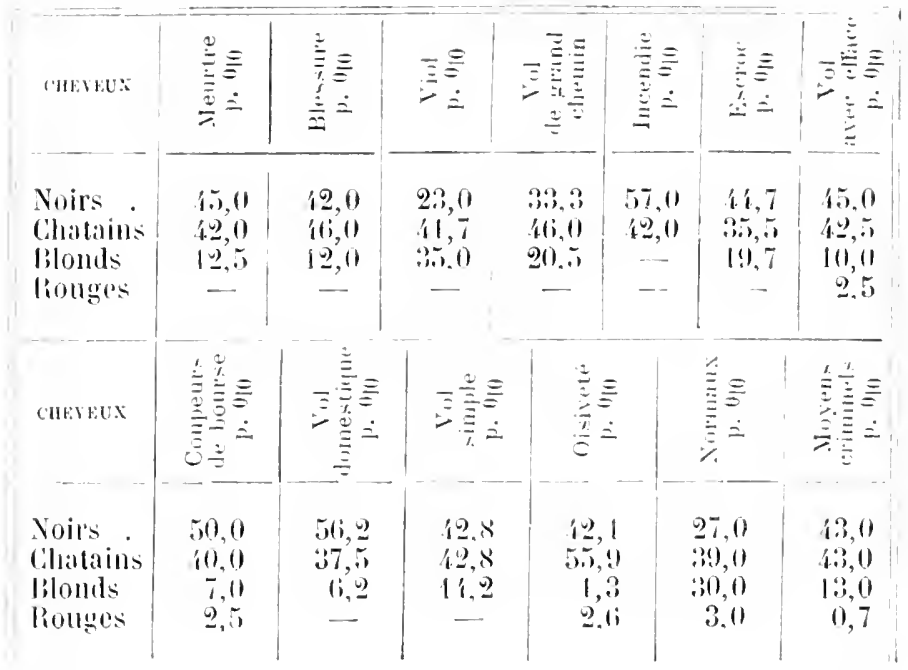

Les chrene now's ef tes chatains sont done phe fréquents plez les eriminets, lamdis que les blonds? sont infiériens d’un liers - 13 is 98 . Le maximum des noirs se tromve dans les incendiaires of dans les voleurs, In minimum dans les violateurs; le maximum lue matrons est domé par les oisifs, hesseurs, ro-

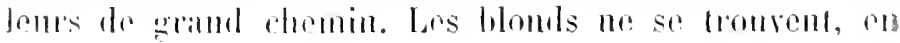

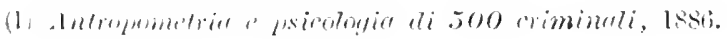


majorité, fue dans le viol et dans lescroc. les rouges (quoiqu'en disent les proverbes) sont très-pen fréquents.

Las chevenx élaient rares chez 6,3010 el blanches chem Io j, 8010 de mes 350 criminels: cest bien moins ynu tans les fous, chauves dans le 2300 , grisomnants lo at) $0_{10}$ (hommes) et le 21010 (femmes).

Marro anssi sur 007 criminels trouva lo 100 a arec les cheveus lares, tandis que le 4 \& 0 |0 les avaront fouflus avec un maximum de 5ij chez les vagabonds el de 470 chez les assassins, les rebellos el les voleurs de grand chemin, et $u n$ minimum de $310 / 0$ chez les escrocs.

La raneté ou l'absence de la barbe, je l'ai constatio chez les crimincls 23 fois 010 , et chez les aliniss seulament 18 fois 010 a Pavie, el 22010 à Pesaro.

Iris. - Bertillon sur 4000 criminels tromve 33,200 arec l'iris de conleur marron, 22,4010 de couleur chàtain sombre, 32,4 jame ou rouge, el 12 impigmentes ou arec tullets rerditres. (Rev. Scicnt., 1885).

Ces chiffres rivelent une certaine fréfuence diris sombres, mais nayant une comparaison avec des normaux je n'en puis tirer des conclusions decisives.

Le strabisme se presentait dans le jo 010 des voleurs et des escroes, dans lo 2,50/0 des assassins (Marro).

Les oreilles écartées ont été notées dans le 28090 ale mes criminels; dans ses 500 eriminels IIarro les a trouvé dans le $7,80_{10}$ avee $u$ maximmm de $15010 \mathrm{cl}$ ez les vagabonds et un minimum de 2010 chez les violateurs.

Sur 2 les oreilles naraient pas d'lólice. Deux fois elles étaient petites ou minces, 3 lois inigales, 3 lois l’une plus basse que l'autre, et 2 fois ratatinécs. Ces anomalies sont d'ailleurs plus fréquentes chez les aliénés.

Nez. - 19 criminels sur 500 araient le nez tordu ou à dioite ou à gauche; précisćment dans la même propor- 
tion que chez les hommes normaux $30_{10}$; des violateurs, $2 \operatorname{sur} 40$ présentaient cette anomalie et 5 autres l'avaient trilobé ou excessivement gros. Cette déformité est encorc plus fréquente chez ceux qui ont le nez camus.

Le nez démesurément long se rencontra 2 fois sur 100 ; ainsi Perello, voleur de Turin, avait un nez long de 4 contimètres.

Dents. - Dans le 4010 des homicides, on a noté le déreloppement démesuré des dents canines. Sur 7 les dents presentaient d'autres irrégularités, telles que l’abseneo les incisives latérales, leur ressemblance avec les canines, la mauvaise direction des canines, ou leur superposition.

La pâleur ln visage a élé nolé par Marro dans $158 \mathrm{sm}$ $507,\left(310_{10}\right)$ arec un maximum de 35010 chez les assassins, el un minimum de $100_{10}$ chez les violatenrs. 9 présentaient la mème physionomic des crélins, el:3 autres avaient le goitte volumineux.

Les génilaix furent trourés anomales par lui dans le 2010 des blesseurs, 2,6010 des escrors, 50010 des violateme, 1010 des voleurs.

Sur 7 la pean arait une coloration plus sombre que la normale, et chez un elle élait bronzíe. Un violateur sicilien, un rolenr, trois assassins araient lobliquilí de l'orbite, la rotondité dı crìne, la saillie et la dislance des zygomes, la mîchoire carréc el épaisse, ot ume teinte jaunâtre de la peau, et présentaient ainsi me réproduction exacte du type mongol (roir Atlas, xur, 1, 2). - Quelques uns, comme Cartouche et 0 . par Ir front fuyant, la petitesse dı crîne, la saillie de la filce se rapprochaient du type simiesfuc. (Voir $\Lambda$ tlas). 
111.

PIOTOGRAPIHES ET TYPES DE CRIMINELS.

1. - A ces recherches nécessatrement incomplètes on a lait, dès le début, de grares, de justes objections. Il y a beancoup, a-t-on dit, de gens honnêtes qui ont bicn souvent on l'un on l'antre de ees caractères.

Aussi arant de lemr attribuer une importance décisive, serait-il bon de voir en quelle proportion on les rencontre chez l'homme normal; ici il fant se rappeler ylur ce n'est pas l'existence d'un ou de deux de ces caracteres, mais bien leur ensemble qui peut révéler les tendanros eriminelles.

Une autre lacune que nous drvons réparer en celte édilion, consiste ì signaler combien de fois le type criminel so manifeste dans son entier, en opposition à ce qu'on voit chez les hounmes normaux, ef combien de fois il se rencontre non seulement chez les criminels célèbres, plusieurs fois récidivistes, mais chez les criminels ordinaires, chez tous cenx yui non senlement sont rirminels anthropologiquement, mais le sont juridiquement.

2. - Photographies. - Pour combler cette lacum or cela sans pouvoir itre accusé de partialité dans le choix des types; et pour que le lecteur puisse juger lui-mème de nos conchusions, jexpose dans l'Mlas (V. tah. vin ${ }^{\mathrm{e}}, \mathrm{I}^{\mathrm{e}}$, $\left.\mathrm{x}^{\mathrm{e}}, \mathrm{xI}^{\mathrm{e}}, \mathrm{xIV}^{\mathrm{e}}\right)$ de cet ouvrage les portraits de 424 criminels; et je donne dans cette table le résumé des olservations sur leurs anomalics, sur celles de 200 étudiants de Lombardie, de 100 du Piémont, et sur 122 criminelles éludiées personnellement. 
220 sont les criminels mâles étudiés, dont 23 américains, 1 anglais, 2 français et belge, 18 italiens, 164 allemands, 8 hébreux, 4 russes; - 204 sont les femmes criminelies, dont 16 américaines, 59 allemandes, 129 italiennes.

Quant aux délits commis on trouve:

IIommes Femmes

Voleurs et coupeurs de bourses
Assassins et meurtriers .

Tahle des anomalies

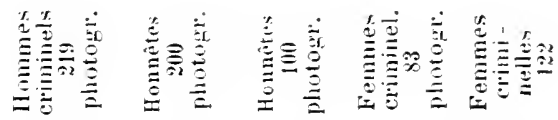

Jachoire développée . $390[0 \quad 7,00[0 \quad 5010 \quad 300[0 \quad 9,8010$

Barbe rare . . . . 32 " 5,0 " 6 " 5 " 0,0 "

Sinus frontaux . . . 28 " 14,0" 31 " 15 " 0,0 "

CEil sinistre et faux . 23 " 1,0 " 0 " 25 "

Chevelure épaisse . . 21 " 1,0 " 2 " 7 " 0,0 "

Oreilles en anses . . 18 " 5,0 " 8 " 3 " 5,8 "

Zigomes proéminentes . 10 " 4,0 " 15 " 12 " 1, , "

Strabismes . . . . 10" 10,4 " 3 " 6 6 " 0,0 "

Front fuyant . . . . 8 " 2, 2 " 10 " 2 " 4,2 "

Prognatisme . . . 4 " 0,2 " 6 " 2 " 0,0 "

Asymétrie faciale - . 3 " 0,0 " 7 " 13 " 0,0 "

Physionomie féminine. 11 " 0,0 " 0 " 0 " 0,0 "

Physionomie virile - . 0 " 0,0 " 0 " 12 " 0,0 "

Eil hagard . . . . 4 " 0,0 " 1 " 3 " 9,8 "

Paupières pliées . . 2 2 " 0,2 " 0 " 0 " 0,0 "

Peluries . . . . . 0 " 0,0 " 0 " 0 " 3,1 *

Yez déforme . . . . 2 " $0,0 " 0$ " 0 " 0 " 0,0 "

Front bas étroit ou petit 3 " 0,7 " 10 " 9 " 4.2"

Lèvres minces . . . 2 " 1,0 " 3 " 14 " 15,4 "

Type criminel . . . 25 " 2,0 " 2,6" 27 " 26,0 "

Alsences des caracteres

morbides . . . $16 " 61,0 "$ ?" $15 \% 0,0$ " 
Dans les màtes la physionomie conserve le type ethnique dims 20 sur 211, tandis qu'elle le perd cliez tous les antres, hormis les 8 juifs qui conservent tous le type sémite.

On observe une physionomie normale et belle chez 96 criminels tris-intelligents, escrocs etc. (Atlas vin, fig. 1 , 5, 6), tel par exemple le $11^{\circ} 224$ de la table $x^{e}$, déja sous oflicier te marine, un voleur trés-rusé, et le ${ }^{\circ} 29$ escroe et voleur de livres; le 11 et le 14 de la table vine doné d'une grande astuce; et chez les 2 bigames américains (1), et le faux monnayem qui était un artiste de génic. (Toir Allits vili, 46).

Chez tous ees gens-la la spécialité du crime explique labsence du type criminel; ce sont ou des intelligences supérienres, on des eriminels d'oceasion. C'est le cas de Peltzer (Allas, table $\mathrm{Ix}^{\mathrm{e}}$, fig. 6 et $\mathrm{Iv}$ ), et du contrebandier qui tua les gendarmes pour sauver sa marehandise.

Cette absence du type criminel ne s'explique guère pourtant chez les brigands de la Sicile et chez 9 roleur's récidivistes.

On peut, dès à présent, constater, et la chose est facile la photographic à la main, que chez les hommes criminels le caractère qui prédomine est le développement énorme de la màchoire, la rareté de la barbe, la dureté du regard, l'abondance de la chevelure, puis en seconde ligne les oreilles en anse, le front fuyant, le strabisme, le nez difforme.

Et dans tous, dans ceux, aussi, qui paraissent normaux on trouve une étrange ressemblance, une rraie affnité anthropologique. Regardez, par excmple, le

(I) Atlas ix, $x$ et $x ı$. Pour tous les antres on trouvera les détails dans l'dtlas. 
$\mathrm{n}^{\mathrm{O}} 20$ et 21 table $\mathrm{xi}^{\mathrm{e}}, 50,51,55,59,60$ table $\mathrm{x}^{\mathrm{e}}$. Cela est bien plus érident dans ceux qui ont le type criminel; c'est à croire bien des fois que ce soit le même personnage. Tel est le cas des $n^{\circ \mathrm{s}}$ 13, 31, 9, 22, 3 et 4 de la table viri ${ }^{\mathrm{e}}, 21,22,14,23,9$ et 11 de la table $\mathrm{xi}^{\mathrm{e}}$, $1,2,7,14,11,10$ de la table $\mathrm{Ix}^{\mathrm{e}}, 20,21,25,15$ et 18 de la table $\mathrm{xi}^{\mathrm{e}}$. - On s'explique par li l'absence du type national, lanalogie des crimincls italiens et allemands; c'est comme dans les crétins où le type etlunique est effacé par la dégénération morbide.

Le type criminel se rencontre dans le 25 p. 010 ; les proportions plus grandes du type nous sont données par les meurtriers 36010 ; et par les voleurs 25010 ; les plus pelites par les criminels d'occasion 170 p0; par les banqueronliers 1 sur 8 (roir Mllas, vin, fig. 1, 2, 3, 4, 5, 6, et l's de la table $\left.1 \mathrm{x}^{\mathrm{e}}\right)$, par les eseroes el bigames 6010 ; or dans cenx-ci la bonhomie de lexpression est un morn nécessaire pour surprendre lit bonne loi des honnêtes gens; c'est mimetique, comme diraient les naturalistes.

bans les criminels libidinenx le type se rencontre 4 fois sur 5. Le criminel classique $n^{\circ} 100$ (Atlas xi), qui viola sa lille et la prostitua, avait les yeux gros et en dehors, les paupières pliées, lus lèves très-grosses ot volumineuses. Les autres ont physionomie cf rètement de fermme.

Pour les autres détails voir les explications de l'Atlas. 
IV.

SUR LES FEMMES CRIMINFLLES.

1. - Nous niavons, jusqu'ici, ébanché que superficicllement les femmes criminelles; mème encore maintenant nous n'en pouvons dire que fort pen de closes, car je n'ai pu en examiner que 258; et encore cet examen a-t-il été phus superficiel que pour les hommes.

llais la lacume ne me semble pas trop grave: car on possède de nombreux renseignements sur des femmes a peu-près identiques quant all moral, les prostituées. dans l'œurre classique de Parent-Duclıitelet, qui abonde en renseignements aussi précieux.

La taille moyenne de 80 criminelles piémontaises mia donné 1,53 arec un maximum de 1,59 et un minimum de 1,45; le poids 52 kil. avec un maximum de 61 et 11 minimum de 35 . - Les poirls de 75 prostituées lombardes étail de 52,900 kilog.

Dans les criminelles j'ai trouví:

\begin{tabular}{|c|c|c|c|}
\hline & 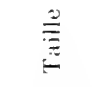 & 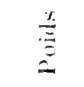 & \\
\hline 65 voleuses. . & $1,5 i$ & 58,0 & 50 \\
\hline 11 infanticides siciliennes . . & 1,53 & 57,2 & 50 \\
\hline 5 femmes coupables d'avortem & $\cdot 1,51$ & 58,0 & \\
\hline 12 homicides . . . . . . & 1,56 & 56,0 & \\
\hline 6 meurtrières du mari & 1,65 & 61,0 & \\
\hline 8 empoisonneuses . . . & 1,57 & $5 i, 0$ & 50 \\
\hline
\end{tabular}

Sur $118 / 4$ filles de joie, Parent-Duchàtelet trouva $8,4,6$ p. 010 de tailles basses et 38,86 (10 de tailles élevées 
parmi lesquelles 7,56 de très-élevécs. Ces chiffres rérèleraient une grande fréquence de tailles hautes chez les criminelles, mais ils ne sont pas comparables à ceux fournis par les types sains d'un même pays.

Si on établit une comparaison arec les chiffres fournis par Quelelet sur les jeunes filles belges (max. de 1,74 et minimum de 1,14), on trouve que ce maximum a été dépassé seulement chez 77 prostituées francaises el le minimum par 1265 sujets sur 11,887.

De ces faits on ne peut lirer une conclusion qui soit vraiment sûre.

Voici quelques chiffres relatil's à la circonlërence cránienne de 80 criminelles éludiées par moi, el 115 éludiées par Ziino:

\begin{tabular}{|c|c|c|c|c|}
\hline $\begin{array}{c}\text { Circonfërence } \\
\text { de }\end{array}$ & 86 folle: & $\begin{array}{l}178 \\
\text { mostituées }\end{array}$ & $\begin{array}{c}80 \\
\text { arminelles } \\
\text { pièmont. }\end{array}$ & $\begin{array}{l}\text { [115 } \\
\text { criminelles } \\
\text { sicilienn. } \\
\text { et napolit }\end{array}$ \\
\hline 47 cent. & $-0_{10}$ & - & - & 1,5 \\
\hline 48 id. & $2,1 \quad n$ & 5,8 & 3,6 & 1,5 \\
\hline 49 id. & 1,8 " & 6,0 & 12,0 & 4,5 \\
\hline 50 id. & $2,7 "$ & 12,2 & 16,0 & 12,7 \\
\hline 51 id. & $2,4 \quad$ & 21,0 & 25,0 & 9,5 \\
\hline 52 id. & 2,4 & 18,0 & 20,0 & 18,0 \\
\hline $53 \mathrm{id}$. & $3,5 "$ & 16,0 & 16,0 & 23,9 \\
\hline 54 id. & 1,0 , & 12,0 & 10,0 & 7,9 \\
\hline 55 id. & - " & 3,0 & 12,0 & 6,3 \\
\hline 56 id. & $-n$ & 1,0 & 2,0 & 4,5 \\
\hline 57 id. & $-" n$ & - & 1,8 & 6,3 \\
\hline 55 id. & - $"$ & - & 1,0 & - \\
\hline
\end{tabular}

Les criminelles qui ont une moyenne de 530 et les prostituées avec une moyenne de 522, offrent une série de têtes volumineuses presque décuples de celles des folles; les prostituées auraient en outre un chiffre double de submicrocéplaalies (48), en comparaison de celles-ci. 
Les circonférences les plus élevies de $55,56,57$ manruent cliez les volenses et chez les infunticiltes; elles alyondent dans les meurtrières.

Quant aux indices céplialiques nous ne mentionnerons que ceux qui ont atteint le chiflire le phus élevé.

Sur 30 homicides il n'y aurait que 3 ultra-tolicocíphales ef 10 brachiciphales, remarguables; sur 8 infanticiles jai noté 3 dolicocíphales, 5 brachicéphales, sur 7 voleuses, 5 brachicéphales.

Sur 66 criminelles, 20 étaient dolicocíplates et 40 brathicéphales.

2. - Ces chiffres perdent toute importance quand on songe que toutes les dolicocéphalies les plus accusées viennent de l'ile d'Elbe, de la Sardaigne, do la Calabre, et que les brachicéphales sont on du Piémont, on de Pavie, on des Marches, fu'elles sont, en somme, ethniques.

3. - Anomalies crâniennes. - Les plus importantes *t les plus certaines dommies ressortent des tableaux sur les anomalies cràniemnes.

Sur 188 sujets Ziino (1) en trouva 7 avec des crincs difformes, 17 avee une asymétric de la face, 19 avec des oreilles en anses ou anormales, 1 avee des dents mal implantées, 1 avec me hypertrophic du foic et avee des maxillaires voluminenx, 1 avec une barbe précoce, 13 avec une circonférence crànienne de 48 centim., 2 avec une circonférence de 47 (submicrocéphales).

Chez 122 criminelles que j’ai étudiés, j'ai trouvé l'asymétrie crinienne 50 fois; 2.5 fois sur 61 homicides, 9

(1) Fisiopatologie del mlitto, 1884, Xapoli. 
fois sur 20 volenses, 8 fois sur 22 infanticides, arec prédominance chez les roleuses.

Jais ce qui dislingue les criminelles des fenmes normales et surtout des foltes c'est l'ahondance extrême do la chevelure, 39 sur 122; je nien ai pas trouvé une seule chauve; et 3 homicifles seulement sur 122 avaient prómaturément les cheveux blancs. Thompson, lui aussi, note l'abondance de la cherelure chez les criminelles. Ies splendides cheveux de l'Eberzeni, de la Sola, de la Motte sont célèbres (1). Ce fait est en armonic avec la pélurie abondante sur le visage que jai tromé dans la proportion de 16 sur 122 examinrs, et avec la distribution du poil du pubis que j’ai trouré tout-ì-fait analogne au virit dans le $100_{10}$ de nos criminelles, ce que est le double de ce quion a constati dans les femmes normales 5010 .

Quant à la couleur des chevenx jemprunterai à ParentDuchitelet sa statistique basee sur 12.600 prostitués francaises, comparées aux prostiluces ctudiées par Sorésina, aux prostituées de Turin et aux 400 folles de Parie.

\begin{tabular}{|c|c|c|c|c|c|c|}
\hline & & Fran & aise- & Lombarl. & Turinois. & \multirow{2}{*}{$\begin{array}{l}\text { de Pavie } \\
\text { (p. } 1000\end{array}$} \\
\hline & & $\begin{array}{l}\text { citadines } \\
\text { (p. } 1000\end{array}$ & $\begin{array}{l}\text { rurales } \\
11.000)\end{array}$ & 1. $100(1)$ & (p. 1000$)$ & \\
\hline Cheveux & chàtains & s 53i & 505 & 350 & $10 i$ & 275 \\
\hline Id. & truns & . 209 & 289 & - & 168 & - \\
\hline $1 d$. & blonds & 131 & 70 & 240 & 992 & 80 \\
\hline Id. & noirs & .117 & 115 & 400 & - & 160 \\
\hline Id. & roux & . 3 & - & - & 22 & - \\
\hline
\end{tabular}

(1) e Ce qu'elle arait de plus remarqualle c'etait l'xuberance de sa chevelure $\nsim$. Mimoires de Sanson, 1862. 1, p. 173). 
Les chereux noirs sont done plus fréfuents chez les courtisanes, comme d'ailleurs chez les hommes criminuls, même en France où pourtant normalement brs cheveux blonds ne sont pas lares. Ime Eberzeni, la Trossarello, la Camburzano, N"me Lafarge araient dos cheveux noirs, des yeux noirs, quoiqu'issues de popmlations lilondes ou chitaines.

Le contraire semble se vérifier pour la couleur de liris chez les courlisanes françaises, mais non chez les lombardes.

\begin{tabular}{|c|c|c|}
\hline $\begin{array}{c}\text { Prostituées } \\
\text { françaises } \\
\text { (p. 1000) }\end{array}$ & $\begin{array}{c}\text { Prostituées } \\
\text { lombardes } \\
\text { (p. } 1000 \text {; }\end{array}$ & $\begin{array}{l}\text { Fullea } \\
\text { de Pavie } \\
\text { (p. 1000) }\end{array}$ \\
\hline
\end{tabular}

Couleur de l'iris:

$\begin{array}{lrrrr}\text { Gris . . . } & \text {. } & 870 & 30 & 210 \\ \text { Châtain brun } & . & 283 & 425 & 710 \\ \text { Bleu de ciel } & . & 231 & 290 & 20 \\ \text { Roux . . . } & \text {. } & 158 & - & - \\ \text { Noir . . . . } & 56 & 310 & 60\end{array}$

Chez les 122 femmes crininclles examinées par moi (royez table) les faits les plus saillants sont: le développement de la mâchoire 1 sur 122, l'œeil sinistre 13 sur 122, obliques 5 , la saillic des pommettes 18 sur 122 , la virilité de la physionomie, et la pélurie: 16 sur 122; la lerre mince 19 sur 122; tandis quon y troure bien moins que dans les criminels màles les sinus frontaux et les oreilles en anses 7 sur 119, le strabisme 4 sur 122, les dents anormales 5 sur 122 , la physionomic mongole 5 sur 122, (5 toules meurtrières).

Quant aux séries par crime on trouve les apoplyses zygomatiques énormes et les oreilles anormales: chez 6 voleuses sur 20; chez 7 honicides sur 61, et vicéversa la pélurie abondait chez les infanticides, 8 sur 
22, et elle n'était que dans la proportion de 100 [0 dans les meurtrières et dans les voleuses.

Les lèvres supéricures minces se rencontrent plulôt chez les homicides (11 sur 61) que chez les voleuses 3 sur 20, et chez les infanticides 2 sur 22. Il en est de même de l'aspect viril du visage: 9 fois sur 61 femmes homicides, et 2 fois sur 20 voleuses. La mîchoire volumineuse 6 fois sur 61 homicides et 3 fois sur 20 rolcuses, 1 fois sur 22 infanticides.

Étudions-les, maintenant, dans les photographies pres. que toutes allemandes.

13 sur 83 photographies (roir Atlas, tab. xIr ) ne présentent aucun type criminel; cela s'explique dans lo $\mathrm{n}^{\circ} \mathscr{Q}$, voleuse d'occasion, affamée; dans le 21, voleuse par ordre de l'amant, dans la bigame américaine $\mathrm{n}^{0} 4.4$, mais ne s'explique point du tout dans les voleuses 15 , 27, 34, 41, ni dans la 42 empoisonneuse.

Il faut, encore, noter, que chez bon nombre de celles qui ne présentent pas des types, ni des caractères criminels, et plus encore chez celles qui ont les caractères typiques on ne troure plus la physionomie de la race. Un autre caractère consiste dans la grande ressemblance des pliysionomies, ce qui indique bien leur parenté psycho-physique; par exemple, entre le $n^{\circ} 8$, 16 et 23 de la table $\times r^{\mathrm{e}}$; entre le $n^{\circ} 22$ el 29 de la même table; de mème entre le $n^{\circ} 4$ et le $n^{0} 26$, et puis entre le $n^{\circ} 15$ de cette lable et le $n^{\circ} 2$ de la table rine

La belle apparence de quelques criminelles s'explique très-J,ien par la richesse du tissu adipeux, du tissu connectif, de la chevelure, signes qui, s"ils ne parviennent pas à tromper, contribuent du moins ì masquer l'anomalie. Telles Iv..., Eberzeni, Saraceni (n. ${ }^{\circ \mathrm{s}} 30,50,58$ ) dont les caraclères pliysionomiques les plus saillants sont 
le développement extraordinaire de la midhoire, et quelque chose de dur, de masculin dans le regard, particularité que la richesse du tissu alipeux, du tissu connectif et de la cherelure masquent it l'œil peu attentif. C'est ainsi que lit magnifique chevelure et l'embonpoint de Messaline (1) laissent ì peine voir son asymétrie faciale, son front bas, le volume énorme de ses mitchoires, ses oreilles écartées. (Voir table xur ${ }^{\mathrm{e}}$ ).

(1) Comme on peut le voir, a Rome, sur le louste du Capitole, salle des empereurs, n. 13 , et a Paris, au musie du Lonvre, sur le groupe de marbre pentélique trouve près de Rome, hors la porte San Lorenzo. (Clarac, Descrip., n. 183). Quel que soit le jugenent porté sur Messaline. le eriminaliste doit, ee nons semble, adnettre que si éctait une femminité vicieuse, elle ítait certainement malade. Elle n'avait pas 21 ans quand elle mourut. M. Ménière, dans son enrieux livre, Études mélicales sur les poëtes latins, eroit que Messaline itait attente de nymphomanie. « A la Salpêtrière, dit-il, il y a des Messalines qui n'ont rien à démêler avee la morale * (p. 364). (Note du tradueteur .t. B.). 


\begin{abstract}
V.
ObJECTIONS. - PHISIONOMIE DES GENS HONNËTES.

OPIXIONS POPULAIRES ET PROVERBES

SUK LA PHYSIOXONIE CRIMNELLE, SES CALSES. CONCLUSIONS GÉNÉliALES.
\end{abstract}

I. - Physionomie de $\mathbf{8 1 8}$ hommes vivants en libcrté. - I la grave objection rue heaucoup de ces caractères sc trouvent chez les gens honnêtes, nous répondons avec los pholographies de 200 individus, étudiants lombards de 19 à 25 ans, et de 100 hommes piémontais. Cutte clude montre que les mêmes caractères isolés peuvent se trouver chez les gens honnêtes autant que chez les eriminels (1). Mais chez ces derniers la michoire développée, la physionomie virile des femmes, le regard sinistre, les oreilles en anse, le strabisme, la chevelure épaisse, le front fuyant sont bien plus fréquents, jusqu'au quintuple. Il est raj, toutefois, que, dans lit $3^{\mathrm{e}}$ colonne (examen de 100 hommes virants), nous arons trouvé quelques uns de ces caractères en proportion supéricure, surtout les sinus frontaux, les zygomes énormes, le front fuyant, l'asymétrie faciale. Mlais cola sexplique facilement: tous ces gens appartiennent à une province ou sivil l'influence d'une cause toute puissante de dégénérescence, le goître.

Iais, même dans ceux-ci, on ne trouve réunis autant de caractères comme dans les criminels

Car c'est lá le lait plus saillant qui résulte à moi et à Ferri aussi par la comparaison arec 711 soldats, que

(l) Voir table des anomalies eec., pag. 232. 
jamais dans les gens normales on ne voit se réunir en aussi grande proportion daus la même persomne les caracteres digunératifs qui forment le type criminel; $10 n t$ all plus, celui-ci arrive a 2 ou 3010 , tandis que dans les criminels il ra jusquì 2901127010 .

On peut le voir hien par cette lable:

\begin{tabular}{|c|c|c|c|c|}
\hline \multirow[b]{2}{*}{$\begin{array}{l}\text { Anomalies } \\
\text { physiono- } \\
\text { miinlles }\end{array}$} & \multicolumn{2}{|c|}{ CRININLLS BE, FERBI } & \multirow[b]{2}{*}{$\begin{array}{c}\text { ill } \\
\text { soldats }\end{array}$} & \multirow[b]{2}{*}{$\begin{array}{c}200 \\
\text { homm. nom } \\
\text { lombaris. }\end{array}$} \\
\hline & $\begin{array}{c}346 \\
\text { grants crim. }\end{array}$ & crim. ligers & & \\
\hline - & 11,9010 & 8,2010 & 37,200 & 32010 \\
\hline $1 \dot{\mathrm{a}} 2$ & $17,2 \quad n$ & $56,6 \quad "$ & $51,8 \quad n$ & $53 "$ \\
\hline 3 à 4 & 33,2 " & $52,6 n$ & $11,8 \quad$ & $16 "$ \\
\hline 5 a 6 & 6,7 ॥ & 2,3 " & - & 一 \\
\hline 7 et plus & $0,3 \quad "$ & 0,3 " & - & - " \\
\hline
\end{tabular}

Mais ici une obscrvation est nécessaire: sil y a des points louteux dans l'étude des criminels, il y en a bien plus dans celle des gens prisumés honnêtes: ces derniers, un .effet, ne sont pas tous réellement honnêtes. On cn connaît bien les caractires physiques, mais pas tous les caractères moraux qui ne se révèlent quaprès me longue fréquentation. Pour résoudre ce difficile problème, étudions les caractères d'autres 400 individus dont on a pu connaitre la vie. Sur ce nombre, 187 navaient allcun des caractères de la physionomie criminelle, et cependant il y avait parmi eux 9 immoraux.

109 seulement offraient un caractère de la criminalité, et parmi eux il n'y avait que 10 criminels vrais quoique ¿tant en liberté (1 violateur et incestueux, 2 intrigants, 7 fripons, et 1 qui, criminel dans sa jeunesse, est rovenu au bien); et 22 vicieux.

73 offraient deux caractères, el parmi eux 31 rais criminels (1 incestueux, 5 voleurs, 1 sodomiste, 2 brutaux, 12 fripons, 2 litillis, 1 femme accusée d'avorte- 
ment, 1 folle morale, 4 faussaires, 1 mpoisonneur, 1 homicide); sur 22 prédominaient les passions tristes comme la violence, le jeu, l’ambition, la rengeaner, l'adultère, la débauche, la dissimmlation.

23 présentaient trois caractères, $(14$ comninels, 4 vicieux).

5 en présentaient quatre, parmi lespuels 2 famssaines et 1 adullère.

2 en offraient cinq et 1 six. Parmi cux, 1 rst honnite, mais c'est un chef révolutionnaire, anx procédés pen délicates et suspects, lautre est mu escroe, lo dernier est un graphomane.

De vaiment lionnète arec le lype criminel complet je n’ai trouvé qu'un seul exemple sur 400 ; mais 219 gens honnètes avaient, les uns oul les antres, quelqu'un des caractères criminels. 8 sur 400 araient 4 ou 6 caracteres, mais 3 sur ces 8 n'étaient honnêtes.

En résumé, la physionomie typique du criminel se rencontre par exception chez l'homme honnête, et presque régulièrement chez l'homme déshonnète.

Des individus que je croyais honnêtes, qui devaient me paraitre tels, et qui avaient plus dun caractère criminel, après quelques années d’olservation me revelèrent en eux une eriminalité latente: clle ne demandait pour se développer que l'occasion. Par exemple, un homme fort riche, il qui rien ne manquail, qui ponvait satisfaire tous ses caprices mavouait que s il arait été pauvre il cut été voleur, assassin mème. Un autre que la faveur avait porté à un poste élevé, avec une vraie physionomie criminelle, s'abandonnant un jour it un accis de colère: « Prends gálde, disait-il à un paurre diable qui lavait irrité, prends garde, je suis capable de tont! on u'appelait Galire de mon jenne age ». 
9. - Proverbes. - Bicn des gens nons ohjectent que cette facon de voir est en contradiction arec l'opinion puhlique. Celle-ci assmriment n'est pas un birn bon guide dans les qnestions scientifiques. Nons avons, eependant, bien des preures que plus d'une de nos conclusions a pénétré dans la conscience populaire. Cust ainsi quion en retroure des traces dans les proverbes, dims les chants populaires, dans les poësies d'anteurs uni ont réllechi les idies du peuple. Par exemple:

La physionomie toute particulière du crimincl-ní a écé saisie dans les proverhes: "l'en de barbe et nulle conleur, il ny a rien dans le ciel de pire. - Face pile ou faux ou traitre y. (Rome).

Et chez les véniliens (Pasqualigo): "Homme ronx el femme barbue, salue-les de loin. - Méfie-toi de la femme qui a la roix d'homme. - Dieu me garde de thonme sans barbe ". (France).

Et chez les piémontais: "Face pille pire que la gale».

Chez les toscans: "Homme sans barbe et femme harbue salue-les de loin n.

Et ce proverbe sarde: "llomme de peu de barbe, homme de peu de foi; " et dans la France: "Barbe rousse el noir chereux, ne l'y fie si tu ne veux 》. -"Barbe rousse, noir de cherelure est réputé faux par nature ». - "Femme barbue do loin la salue ».

Tous ces dictons sont résumés dans le vieux provorbe fiancais (Etymologie des proverbes, par Bellivger, 656): "Au vis le vice, " et dans l'autre: "Visage farouche mour's cluelles; " - Il ciuffo è nel ceffo, dit de mème le proverbe toscan (Girstı, 341). - A vullu vitium, disilient aussi les litins.

Le proverbe toscan " lléfie toi de qui ril et ne te rewarde pas, et des hommes a yenx petits et clignotants, * 
comme ceux qui se méfient des hommes roux, fix d'autres traits de la physionomie que l'anthropologie criminelle ne pent encore accepter.

3. - Antiquité. - Le peuple ne parvint pas là, certaimement, du premier coup; il lui fallut une accomulation de faits acquis par mainte génération. En eflel, beancoup de ces obscrvations avaient déjà été faites par les anciens. Dans un ancien traité de physionomie, (Iolenon, Sur la physionomie) je trouve ceei: "Le fou malfaisant a la tite tordue, les cherenx longs, les oreilles grandes, les yeux petits, secs qui regardent attentivement, (p. 89). Ghirardelli dil: front petit signifie inascibilité ete., (Cefalogia fisionomica, 1672), el l'Ecclisiaste, ch. 20: "La lornication de la lemme se révète ì "Rélivation des geus, au gonflement des paupières etr.; ¿. II des Procerbes: "Lhomme triste et l'homme de rien » dignent des yeux, ont me démarche qui les trahit, et "font signe arec les doigts n.

1. - Connaissance instinctive des ploysionomies. - In autre fait qui sexplique moins facilement cest celui de la connaissance instinctive du lype criminel. Il y a des personnes, surtout parmi les femmes, qui sont a mille limes de se douter que l'anthropologic criminelle existr, mais qui mises en face d'une personne qui porte los raractères criminels, éprourent le suite une vive rípulsion et savent dire bien des fois qu'elles sont en prísonce d'un malfaiteur.

J'ai connu une dame qui avait vécu, comme on dit, loin dn monde. Toutefois, deux fois elle sut décourrir le caractere criminel de certains jeunes gens, que d'ahord personne n'arait soupronni. 
Wais le plus ourieus exemple est relui de lassassin Francesconi, dont l'Allas reproduit la photographic (table $\mathrm{x}^{\mathrm{e}}$, 49); il ny a rien de parliculier en lui; la harbe rol ahondante, front haut; à peine hi trouve-ton un lioger degre de prognatisme ef de sinus frontaux. Or bien des années avant son crine, une jemne fille de scize ans, qui jamais navait quitti le châtean de ses aïenx, colle qui fut plus tard $y^{\text {the }}$ la comtesse della Rocea, refusa tre lui parler: el comme on lui demandait d'oir lui renait une telle repulsion, elle rípondait: S'il n'est pas un assassin, il le deviendra. Je lui demandai quel signe l'avait conduite à cette prophétie trop rite virifire, elle me ripondit: Par les yeux.

Que de fois, dans les procis, ne voit-on pas que des indivilus honnêtes, étrangers au monde du crime, ont ichappi à une mort certaine, avertis à temps par le regard sinistre d'm assassin on ils lisaient ses inientions criminelles! C'est ainsi justement que le premier facteur rui devait òtre la victime de Francesconi, eut le temps de fuir épouvanté par son regard.

Enfin des maitres d'école ont présenté, sur ma prière, a 40 jeunes filles, 20 portrits de voleurs et 20 de grands hommes: quatre-ringts pour cent de ces enfants reconmurent les premiers pour de tristes personnages, ou pour des fourbes, et les seconds pour d'homètes gens.

La conseience involontaire mais universelle de l'existence d'une physionomic spéciale aux criminels, a domni naissance aux épithètes: face de voleur, risage d'assassin etc. Il est donc impossible de s'expliquer lopposition faite à ces assertions, si ce n'est par la répulsion quiont les hommes a tirer une ronclusion générale des observations individuelles. - Mais comment expliquer eette coscience inrolontaire? 
Dans les jeunes filles nulle connaissance acquise par l'expérience. Que reste-t-il ? Un sens intuitif, dira-t-on; explication vulgaire dont le public se contente, parcequ'elle ne signifie rien.

Je soupconne qüil y a lả un phénomène héréditaire. Limpression léguéc par nos pères et transmise à nos fils, est derenue comme une connaissance inconsciente, semblable a celle des petits oiseaux nés et élevés dans nos demerues et qui frappent effrayés leur cage de l'aile et du bec, lorsqu'ils voient passer an dessus d'enx des oiseaux de proie, que scul leurs grands-pères ont counus. - Chaque jour nous enseigne quelle part importante a l'inconscience dans les actions humaines, et quel rôle y jouent l'atavisme et l'hérédité.

Qui de nous peut penser, lorsqu'il plie le genou et joint les mains dans la prière qüil fait un mouvement héróditaire, légué par ces ćpoques de barbaries on la ganerre était l'état normal! - Alors par cette attitude humble, et qui facilitait la ligature des mains, le vaincu essayait déloigner le soupcon, d'exciter la pitié do vinqueur, et de changer en servitude la mort qui hui était réservéc.

j. - Notons que le trait le plus caractéristique, et vaiment spécial aux délinquants-nés réside dans le regiald. "Il ne m'est pas nécessaire, disait Vidocq, de voir tout le risage d'un eriminel pour le reconnaitre, il me suffit de pouvoir le fixer dans les yeux ».

Il est bien certain que tous les traits physionomiques peurent se modifier au gre du criminel, mais jamais le regard qui trahit le fond de l’àne, même dans les plus hypocrites.

te trouve le regard des assassins très-analogue avec celıi des fólins an moment de l'embuscade el de la 
Intte; et je l'explique par la continuelle répétition des nauvaises actions; car chez les cnfants les plus criminels je n’ai jamais observé le regard féroce. Les rares exceptions qu'on rencontre chez les adultes proviennent d'un phénomène très-curicux, déjả noté par Vidoeq et que j'appellerai du double regard. - Lacenaire, Luciani, Gasparone, par exenple, pour n'en citer que quelques uns, avaicnt deux regards différents, l'un doux st presque féminin, et l'autre féroce et félin; ce regard ne dépendait pas d'eux, mais il variait suivant l'état de leur esprit, lantôt aimable, tantôt fẻroce, ce qui leur donnait un double pouvoir fascinateur, surtout vis a ris de la femme; elle est attirée d'abord, par celte apparence courtoise, enchainée ensuite, par la terreur et l'énergie, ce qui explique bien des cas d'incroyable complicité.

J'ai encore observé que lorsqu'on pousse un homme sanguinaire à un effort violent, comme, par exemple, à comprimer le dynamomètre, à soulever un poids fort, toute sa physionomie, et surtout son regard prend cet air féroce qui est spécial au criminel at moment du crime.

6. - Il ne serait pas difficile d'expliquer quelques autres de ces anomalies en recourant à l'atavisme et à l'arrêt de développement, auxquels seraient dûs l'aspect viril de la femme, le grand volume de la màchoire, le duvet du front, l'implantation anormale des oreilles, le développement des sinus frontaux, la saillie des apophyses zygomatiques, la richesse et la pigmentation de la cherelure et l'absence de barbe; cela est si urai que, sauf le regard, le type d'un Mongol et d'un Lapon reproduit bien des fois le type d'un criminel-né italien. 
L'œil saillant hors de l'orbite est l'effet de l'hypérëinie cirébrale; la lèvre amincie pourrait venir des contractions provoquées par la haine. La cruauté concentre toute son expression autour de la bouche, peut-être parceque tuer et manger sont anthropologiquement deux moments successifs d'un même état.

Le volume de la mâchoire peut tenir à l'atarisme et au grand développement du système musculaire et de ses attaches: il pourrait encore s'expliquer par la répétition du greste spécial à l'homme qui prend une résolution énerrgique ou violente, ou médite une vengeance, ef serre énergiquement la houche pour donner (Darwin) un point d'appui aux muscles, et fournir au corps loxygene nécessaire à liaction. Que ces contraclions souvent se répètent et il est facile de comprendre qu'elles puissent faire grossir les muscles et les parties osseuses ou ils s'insèrent. Telle est, peut-être encore, la cause du grand développement de la ligne crotaphytique du temporal; pent-ètro y a-t-il là une cause de la loéquence de la brachicéphalie des criminels-nés phez les peuples dolicocéphales, d'autant plus qu'on la rencontre plus souvent chez les homicides que chez les roleurs et les escrocs; ces dernier's nont, en eflet, jamais hesoin de grande force musculaire.

7. - Résumé. - Les mesures anthropométriques smr le cadavre, bien que peu fécondes, servent cependant à démontrer, d'une façon certaine, l'infériorité des criminels, spécialement des roleurs, dans lit capacité (qui est à l'envers énorme dans certains assassins), et dans la circonférence crànienne, dans le développement de la courbe et du diamètre frontal, dans l'indice céphalique 
exagéré, dans l'enrignatisme, dans la capacité orbitaire, dians le développement notable de la mìchoire, dans l'aug̃mentation du diamétre et de la hanteur de la face. Il y a, chez les criminels, des indices faciaux at céphaloorbitaires moins bilevis fore normalement on que chor los fous el vicêversa un indice céphalo-spinal plus ílevé.

Mais, ce qu'il y a de plus singulice, éest de voir numériquement bien plus fréquentes chez les criminels que "hez les fons, les anomalies on manque tonte origine atavique, comme les srnostoses, les sciéroses, l'asymiIrie crìnienne el faciale, l'abondance des os wormirns.

Dans des formes analogues et en proporlions égales i colles des sturages, on a dü noter des autres altirations ataviques, surtout de la fice el de la base du crine: sinus frontaux inormes, front fuyant, fosse occipitale moyenne, soudure de l'atlas, aspect viril des erines dans les femmes, double fice articulaire du condyle occipital, aplatissement du palatin, os épactal, orJites volumineuses el obliques. Ces lísions qui varient de 2 à $580_{10}$ se trouvent groupées chez le mème individu, de facon á l'ormer un type dans la proportion le 4.3 010 ; isolées sur un seul individu, clles sont dans la proportion de 21010 . Elles apparaissent plus raremint chez les femmes où on ne trouve presque pas des fosers occipitales mélianes ni les plagiocéphalies.

Le cervem suit dans les anomalies un oldre analogue; il présente en général $m$ rolume inférieur à la rẹgle normale, saut un petit nombre de cas d'hyportrophic; les circonvolutions offrent de fréquentes anomalies ataviques, comme la séparation de la scissure calcarino de l'occipitate, la formation d'un opereule du lobe occipital, le vermis conformé comme dans le lobe moren 
des oiseaux, el des déviations absolument atypiques, comme les sillons transversaux du lobe trontal.

Les quelques olsservations histologigues parlent toutes en faveur d'anciennes hypérémies, spécialement des centres nerreux, comme la dilatation des raisseaux lymphatiques, la pigmentation des cellules nerveuses et connectives. Ces hypérémies préexistantes nous sont confirmées, avec une ccrtitude absolue, par l'étude macroscopique, laquelle nons montre de fréquents foyers de ramollissements dìs au processus cmlolique, des méningites dlans la proportion de $50 \quad 0_{10}$; des ostéones 4010 ; plus souvent on y observe aussi les affections clironiques de l'endocarde, du péricarde el du cœur (l'insuffisance valvulaire est la plus fréquente), et assez souvent celles du foie, affections qui comptent pour le quintuple chez les malarles non criminels.

trec tant d'anomalies il est surprenant fu'on vérifie sur les cadavres une plus grande supériorite de taille et pas de dillírence do poids, pent-être, anssi, une différence en plus.

Pour les exanens sur le virant, je résumerai, en peu de mots, ce que j'ai été obligé a exposer arre force chiffres; et je conclureai que le délinguant a une taille plus haute, une envergure plus grande, un thorax plus ample, une chevelure plus sombre et un poids supérieur au normal et à celui des aliénés; qu'il présente, surtout chez les roleurs et chez les récidivistes et chez les mineurs, une série de submicrocéplaties plus grande que normatlement, mais plus petite que chez l'alisni; - que l'indice du cràne, comparé en général à l'indice ethnique, est plus exagérí en lui; - que to délinguant offre des asymétries crìniemes et faciales, frérquentes, surtout 
chez les violatem's et cluez les volmurs, mais folus rares que clory les fous, car s’il a sur ces dernires la supiriorité des lésions trammatiqurs it la tète, el des yeux obliques, il a, moins fríquemment, laalhírome des artères temporiales, l'implantation amormale des oreilles, la rareté de la harbe, lo nistagmus, lassmétrie faciale et criniennr, la mydriase, ol encore plus rarentent la calvilie précoce, et en égiles proporlions le prognatisme, l'inrgalite des pupilles, le nez tordu, le front fuyant; - quer plus somvent que les fous el que les lommes saius, il a une face plus longue, un plus grand líveloppement des apophyses zygomatiques et de la mâchoire, l'ieil sombre, la chevelure épaisse et noire, surtout chez les voleurs de grand chemin; - que les bossus, très-rares chez les homicides, sont plus fréquents chez les violateur's, les faussaires et les incendiaires; - que ces dernicrs, et plus encore les voleurs, ont toujours me taille, un poids et une force musculaire inférieures à ceux des brigands et des homicides; que les cheveux blonds abondent chez les riolateurs, les noirs chez les rolours, chez les meurtriers et les incendiaires.

Une étude sur les photographies des eriminels nous a fourni le moven de faire contròler par le lecteur et de fixer la fréquence du type physionomique du eriminel dans la proportion de 25010 , avec $u n$ maximum de $360_{10}$ pour les assassins, et un minimum de 6 à 8010 pour les banqueroutiers, escroes et bigames; et à ce propos je dois noter qu'aussi les anomalies erâniennes et faciales et spécialement la moindre capacité, la plus petite demi-circonférence antérieure, la plus grande lonģieur de la face et le grand développement des zygomes ont été vérifiés en proportions presque égales à celles des 
grens homnètes, chez les hlessem's ef chez les criminels d'occasion.

La plotographie nous confurme combien de fois s'efface le type ethnique chez les criminels, tandis que beaucoup offrent entre eux une véritable ressemblance: elle nous révèle anssi la fréquence de l'aspect fíminin chez quelques volems el cliez les pédérastes (1), et de la virilité clıez beaucoup de frimmes criminelles, surtout dans les meurtières.

Une étude sur 800 lommes libres nous a montré quion peut bien trouver quelquefois, dans les gens libres, les caracteres diggeneratils-physionomiques, mais aussi presque jamais accumulés dinns les mêmes personnes et bien des fois justifiés par la criminalité latente ou par la dégénération crétinique.

L'étude sur les vivants, en somme, confirme, quoique moins exactement et moins constamment, celte fréquence des microcéplıalies, des asymétries, des orbites obliques, des prognatismes, des sinus frontaux développés que nous révéla la lable anatomique. Elle montre de nourelles analogies entre les aliénés, les saurages et les délinquants. Le prognatisme, la chevelure abondante noire et crèpue, la barbe rare, la peau très-souvent brune, l'oxicéplatie, les yeux obliques, le cràne petit, la màchoire et les zygoutes díveloppés, le front fuyant: les oreilles rolumineuses, l'analogic entre les deux sexes, une plus grande envelgure, sont de nouveaux caractères ajoutés aux caracteres nécroscopiques qui rapprochent le criminel curopécn du type australien et mongol;

(1) Une itude récente sur 53 violateurs m’a donné comme résultat 430 0 types criminels complets; 3 femminismes, 7 máchoires voluminenses, 14 asymitries faciales, 5 nez tordus, 6 microcéphalies. 
landis que le strabisme, l'asymétrie cranienne el les rraves anomalies histologiques, les ostémes, les lisions méningitiques, épatiques et cardiarques, nous montrent, aussi, chez le criminel un homme anormal arant sil naissance, par l'arrêt du développement oul par maladie acruise de différents organes, surtout des centres nerveux, comme chez les aliénés; et en font un rrai malade chronique. 



\title{
TROISIÈME PARTIE
}

\author{
BIOLOGIE ET PSYCHOLOGIE \\ DL CRIMINEL-NE
}

\section{CHAPITRE PREIIER \\ $\mathrm{Du}$ tatouage chez les criminels.}

Nous avons jusqu'ici traité des anomalies caractéristiques des criminels, et nous avons eu a lutler contre une diffeulté presque insurmontable, celle d'obtenir des documents qui nous permissent de distinguer le criminel-né de celui qui se laisse entrainer par l'habitude, on qui cède il la passion du moment. Mais, au point oú la distinction pouvait être établie, nous avons vu ces caractères différentiels disparaître peu à peu chez les criminels dans lesquels la passion, et, plus encore, l'occasion, étaient en jeu; si bien que chez les escroes et les banqueroutier's, pour ne citer qu un exemple, la proportion des anomalies est descendue de 43 à 6 on $S$ p. $0[0$. 
Je veux maintenant étudier la biologie et la psychologie de ces hommes dont l’organisme réunit un si grand nombre d'anomalies, et qui se montrent si constants dans la récidive du crime. Je commencerai par un caratère qui tient plus de la psyclıologie que de l'analomic, par le tatomage.

In des traits les plus caractéristiques de l'lomme primitif, ou de celui qui vit í l'état sauvage, est la faciliti avec laquelle il se soumet à cette opération, plutôt chirurgicale qu'esthétique, et dont le nom, même, nous a été fourni par un idiome océanien.

Cet usage est, de nos jours cncore, très-répandu en llalie, sous les noms de marque, signe, etc.; mais on ne le trouve que dans les classes inférieures de la sociéle, chez les paysans, les marins, les ouvriers, les hergers et les soldats, plus encore - chez les criminels. On peut même dire que, pour ces derniers, il conslitue pal sa fréquence un caractére anatomico-ligal spécifirgue et tout nouveau.

Tichons d'abord de relever exactement, par une slatistique faite sur 11.572 individus dont 3886 honnêtes et 5343 criminels, et sur 2393 fous, sa diffusion dans les trois catégories. 


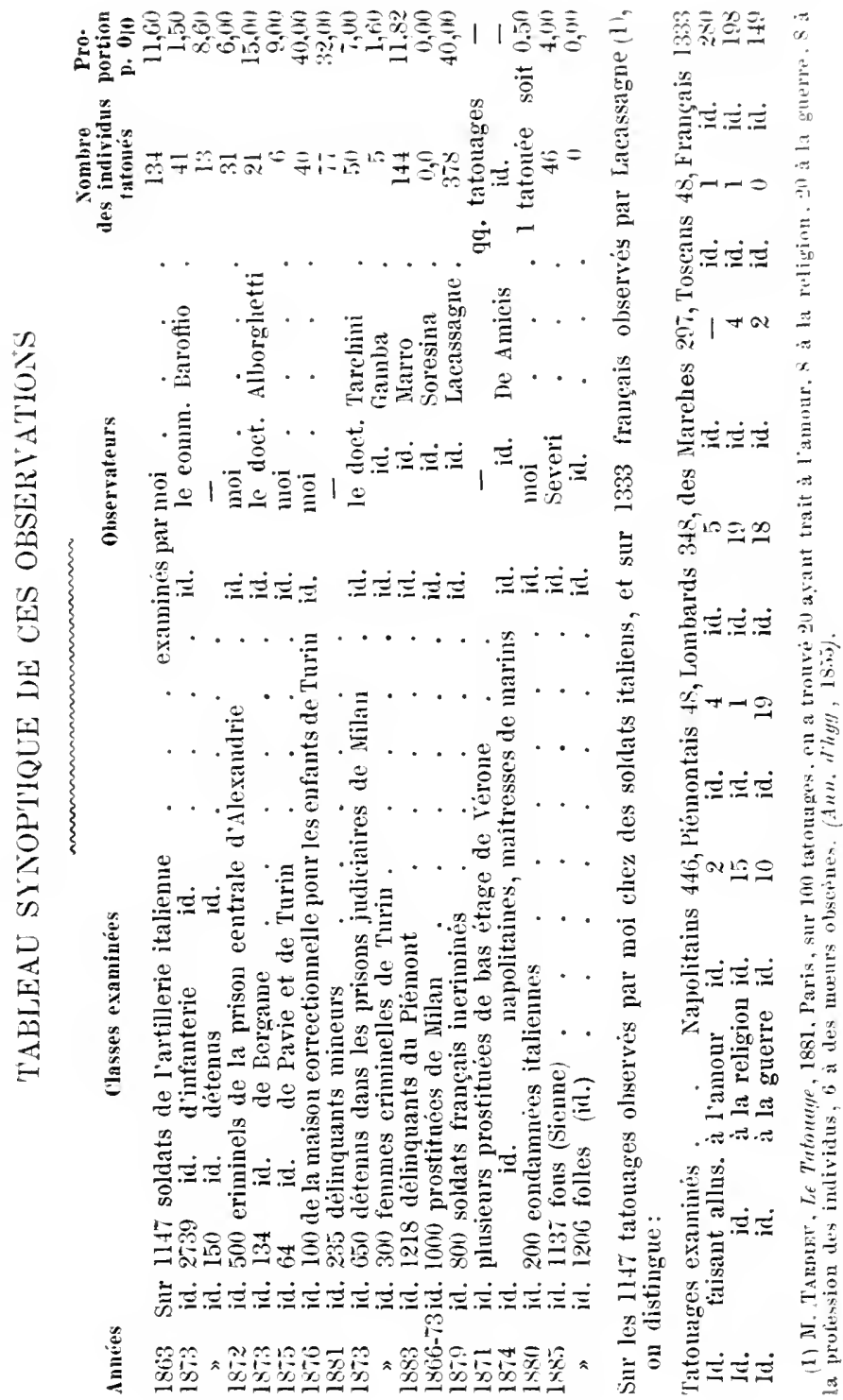


Quant il la répartition du tatouage par rapport ar crime on à la récidive, je puis, grâce au doet. Marro. donner quelques indications précieuses dans le lahleau suirant:

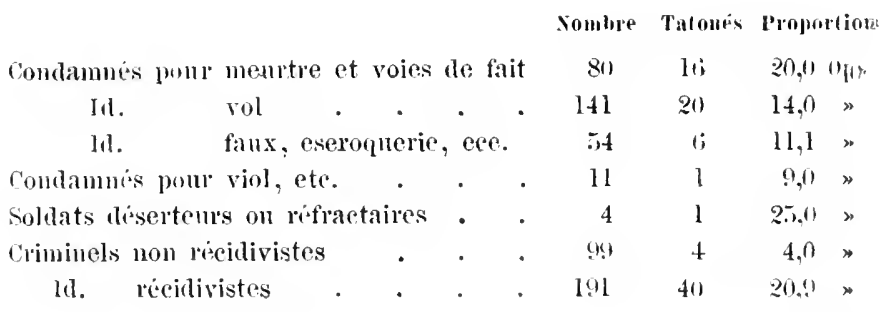

Il est clair que le plus grand nombre est fombi frar les récidivistes et les criminels-nis yui s'attaquent, soit aux propriétris, soil aux persomes; ces derniers toutrfois apparaissent en quantiti moindre. Los plus rares, si l'on níglige les cas d'attentat it la purlemr et de lipsertion qui d'ailleurs ne se présentent gurbe nombrem en cette circonstance, sont lis fanssaires of les escrocs. Eu rien n'es! plus facile ì comprendre: plus intelligents. que les antres, ils voient, sans peine, combien cette pratique leur nuimit dans l'exerrice de leur uisto prolixsion.

On peut s’aperceroir déja, en étudiant le premier tableau, qu'en Italie, comme, du reste, cela se voit chez les peuples saurages, les femmes tatoutes sont en proportion fres-faible, et que chez les loumes non-criminels. et usage lend à décroilte; car, en 1873, nous trourone une cote dix fois inférieure à celle de 1869. - Par contre, non seulement l'usage s'est maintenu, mais encore il atteint des proportions très-grandes chez les criminels, soit civils, soit militaires. Sur 5398 individus soumis a l'nxa- 
mon, 667 étaient talonís; soit 10,77 1). $0_{10}$ chm lis adultes el 34,9 p. 010 chez les minemrs.

Le phus grand nombre des soldats taloure se roil en Jotibardic, dans le Piémont et dans les Narches; I. phs petit nombe en Sarlaigne, en Toseane el dans lo rovaume de Naples. Pent-itre fandrait-il hien roir li me raison historique el remonter aux Celtes primitifs, lo seul peuple de lancienne Emope qui pratiquit celle contmme. Le sanclutile de Loretlo y contrilme aussi pour une grande part: dalls ses environs, on rencontre nombre d'industricls qui se font payer de soixante it quatre-ringts centimes pall tatouage; prix énolme, si l'on songe à la miscre des littonés ef anx tristes consiquences, írsipèle, phlegmuns, alenite, gangrène, qui penrent résulter diune lelle opération.

II fant tenir comple des professions exerces le plus sourenl par les individus littones, arant leur incorporation dans l'arméc. Ce sont surtout, en Lombardie et dams les Marches, des parsans, des macons, des bateliors, des boulanger's; a Carrare, des mineurs; en Vínitio, des charretiers; des pêcheurs et des bergers dans los Romagnes et à Xaples.

Prosque tous se tatouent i l'arant-hras, a la région palmaire; un plus petit nombre anx épantes, a la poitrine (surtout les marins), aux doigts (principalement les minemrs); et, dans ce dernier cas, le dessin affecte la forme d'une bague. De ceus qui portent des tatouages dans le dos ou aux parties honteuses, il n'en est pas un qui n’ait royagé en Ocíanic ou séjourné dans les prisons.

Il en est de mème en France. Ilutin, sur 506 militaines tatoués, en a trouré 489 qui létaient à l'avantbras, 7 au bras, 48 a la poitrine, 2 aux cuisses, 2 à la rovion lombaire, 1 au nembre viril. 
Venant aux réritables symboles, représentés par les latouages, jai cru pouroir les classer en signes d'amour, do religion, de guerre, et en signes professionels. Ce sont là des traces éternelles des idées et des passions prédominantes dans les classes inférieures de la sociétí.

Les signes d'amour sont les moins nombreux: ils se trouvent presrue exclusivement parmi les Lombards et les Piémontais. Ce sont d'ordinaire le nom on ies iniliates de la femme aimée tracées on lettres majuscules; lit date di premier amour; un ou plusionrs cocurs transpercés par une flèche; deux mains entrelacées. J'ai ru la figure entière d'une fomme, rêtue en paysanne, ares nue fleur à la main. Ĺn autre fois j’ai lu un petit dislinpe amourenx.

Les signes de guerre sont les plus fréquents chez lis militaires. Rien de plus naturel, puisqu'ils ont trail it la profession de l'individu. Ils sont même dessinés arer me telle finesse, une telle vérité de détail, qu'ils nous rappellent la precision minulieuse de l'art igyptien el mexicain.

Ceux qui portent ce signe sont, pour la plupart, Lomlards el Piémontais. Les symboles se rapportent à l'ípoque de l'engagement, indiquce par des chiffres, 1860 par exemple; on i la date d'une lataille importantr is larquelle assistait le soldat; ou à l'arme à laquelle il appartient, on it loutes ces choses riunies. Un canon prit a partir ou prisentant le boulet a sa sorlie, denx canons croisćs el une grenade sur le triangle supérieur, the pyramide de boulets dans le triangle inférieur, sont les symboles préférés des artilleurs de campagne, surtout de ceux qui ont servi dans les armées autrichiennes.

Un mortier à bombes est le signe de l'artillerie de place. Une harque, un petit bàtean à vapeur, une ancre, 
sont les symboles recherches par les manims. Denx fusils en croix, denx hä̈mnettes entrelacés dislinguent to fantassin. Le eavalier dessine sur lui un cheval. Lo dailleur, dit Lacassigue, choisit des ciseaux, un homme en posture de coudre, $m$ fer it repasser. Los musiciens. un violon arec son archet, on 111 tambont.

Apres les symboles professionels, cenx qui prédominent sont ceux qui ont trait ì la religion. Ciest choso maturelle pour qui connait l'espril religieux de notra population.

Les paysans de Pavie portent un dessin qui rappelle certains ciseaux dont on se sert pour beorcher les grenouilles. Les mineurs de Carrare ont le doigt entourr. d'un annean; les marins ont un vaisseau, un arlur on une ancre.

2. - Criminels. - C̈est, smotoul, dans la triste atro gorie des criminels que le tatomage affecte m caractire tout partieulier et est le plus rípandu.

Nous avons déjà vol plus haul qu'actuellement, dins la milice, le tatouage est luit fois plus fréquent whez les détenus que chez les soldats libres. Cette remarque est derenue tellement commune, quayant moi-mime demandé à un soldal pourrguoi il n'avait point de lalonage, il me répondit: Parceque ce sont des choses que font les galériens. Ln savant médecin de l'arméo, le docteur Saggini, m'a affirmé que l'on considire a priori les hommes tatoués comme de maurais soldats. One nous sommes loin de l'époque oil le tatouage batail ronsidéré comme une prenve de virilité; où il ctait adopté, dans l'armée piémontaise, par les soldats les plus comrageux! (1848-1850). 
Chez les leumes sauvages (exception faite des Kabyles et des Arabes), cet usage est très-peu répandu(1). Jamais, ou presque jamais, le tatouage n'alla chez lia fenme au delà des bras et des joues, moins encore peut-on dire qu'il ait été adopté par les femmes honnêtes de l'Europe, mème par celles de plus bas élage (2). C'est à peine si, comme nous l'arons vu plus liaut, Gamba, parmi les prisonnières de Turin, en remarqua 5 sur 300 qui lussent tatouées; moi-mème, plus tard, je n'en ai vu qu'une sur 200. Parent-Duchitelet a vu les prostituées les plus dégradíes se tatouer les bras, les épaules, les aisselles, ou le pubis, en y gravant les initiales ou le nom de leur amant, si elles sont jeunes. ou de lem tribade, si elles sont vieilles. Or, conme elles changent d'amamts au gré de leurs caprices, elles effacent ces noms, jusqu'i trente fois, a laide de l'acide acélique.

Parmi les femmes publiques de Lombardie, le docteur Soresina, malgrré les recherohes les plus actives, Il'a pu rencontrer aucun cas de tatouage. A Naples, le docteur De-Amicis en a trouvé quelques-uns chez les maitresses des marins, et encore n'étaient-elles que légèrenent marquées aul bras.

(1) A la Nouvelle Zélande les fennmes se contentent de deux ou trois traits à la lèvre on an menton (SCHerzen, Novava Reise, n). Les femmes des Tobas indiquent par un tatouage quelles sont nubiles (Maxtegazza, Viaggio nell'Americh meridionale, p. 399). Chez les Natchez, le tatouage n'est permis qu'aux hommes, et parmi les hommes, anx guerriers (lo.). Koeher l'a remarqué, il est vrai, en plus grand nombre daus les femmes Arabes; mais e’était surtout des prostituees, pour la plupart adonnées au Saphisme.

(2) Dans quelques rares vallées de la réuétie. au Monte Altissimo, et dans le Trentin, à Côme, les montagnardes, à ee que n'ont raeonté mes élèves, se tracent une croix sur les bras. 
Des 200 criminelles que jai vues, la seule qui lut tutonée était originaire de Chioggia. C'était une adultere, qui avait tné son amant pal jilousie; elle fréquentait les manins, et avait éti infectie par eux de syphilis.

Chez les prostituées de Vírone, comme j'ai pu l'apprentre d'un employé de la poliee, on a remarqué quelques cas de tatouage (des coeurs, des initiales); mais senlement sur eelles qui étaient sorties de prison.

La statistique nous a tonné un maximum de 40 p. 010 el un minimum de $60_{10}$; rien mieux que cette statistique ne proure combien cet usage est répandu chez les criminels, mòme en comparaison de l'armće, où cet usige se fait surtout remarquer.

Létude minutieuse des signes divers adoptés par les malfateurs nous montre, non seulement quils ont parfois une ctrange fréquence, mais encore qu'ils ont une enpreinte toute spéciale.

En effet, 4 d'entre eux, sur 162, témoignaient par leurs tatouages d'un esprit violent, vindicatif, entrainé à des actes désespérés. L'un d'eux avait sur la poitrine, entre deux poignards, celte farouche menace: Je jure de me venger. C'était un ancien marin piémontais fui avait volé et tué par esprit de vengeance. Un Vénitien, voleur el récidiviste, portait sur la poitrine celte inscription: Malheur à moi! Quelle sera ma fin! Paroles lugubres, qui rappellent celles que Philippe, ce misérable étranglenr de femmes publiques, avait tracées sur son bras droit, longtemps avant sa condamnation: Né sous une mauvaise étoile. Tardieu a remarqué un marin qui, lans sa prison, avait gravé en gros caractères sur son front les mots: Pas de chance. On dirait que le criminel pressent sa mauvaise destinée, et qu'il a hàte d'en inscrire l'expression sur son corps. 
Un autre portait au front un poignard smrmonté de ces mots: Mort aux bourgeois.

Un certain Cimmino, qui fut trouvé à Naples mort d'asphyxie, on 1878, avait fait tatouer sur sa poitrine ces paroles: Je ne suis qu'un pauvre malheureux. Je lo soupconnai à l'iustant d'être un coquin, et, en effet, l'enquête proura qüil avait été jeté lit par trois de ses complices et quil était un volem émérite.

Malassen, assassin féroce, devenn a la Nonvelle-Caledonic le bourreau des foreats (Mever, Souvenirs d'un déporlé, 1880), itait convert de tatouages grotesques on terribles des pieds à la tète. A la poitrine il s'était fait dessiner une guillotine rouge et noire arec ces mots en lellres rouges: J'ai mal commencé. - Je finirai mal. - C'est la fin qui m'allend. - Son lras droit, qui avait domni la mort a tant d'etres limmains, portait cette affrense devise convenant hien à son métier: Mort a la chiourme!

D'après les belles monographies de Lacassagne (Le latouage, 1881, id.1886, et Archiv. di psichiat., vol. I, 1880), nous voyons que, sur 111 inseriptions dues aut tatouage, 51 portent l'empreinte caractéristique du crime. Si l'on ne tient pas compte de certaines formules, de proverhes on de dates commémoratives de la condamnation (un criminel alternait les dates sncessives des trois conseils de guerre qui l'avaient condamné; un autre dessinait un cour portant au centre l'époque de sa condamnation), on roit que 51 dessins sont un cri de vengeance, de révolte contre la patrie, contre les lois, contre la société ou la fortune ennemie, et que beaucoup d'autres renferment des allusions obscènes ou criminelles. 
Par exemple, on lit:

8 fois Fils de l'infortunc.

9 id. Pas de ellance.

3 id. Amis du contraire.

5 id. Mort alx femmes infidiles.

5 id. Yengeance.

2 id. Fils de la disgrîee.

2 ił. Né sous une manvaise i.toile.

3 id. Enfant le la joie.

3 itl. Le passi me trompe:

1 id. La m... vaut mienx que la France entière.

1 id. Vivent la France et les nommes de terre frites.

Nort anx bêtes brutes.
1 fois le prisent me touruente:

L'avenir miponvante.

l id. Toujours le menc.

l id. Viatry de la liberti.

I il. Le bagne m'attend.

1 id. La vie n'est que disillusion.

l iđl. Plutôt monrir que changer.

1 id. Mort anx officiers françiı.

l id. Malhen anx vaineus.

id. Haine et mipris aux fanx amis.

I id. Ia liberti on la mort.

1 id. A la vie, à la mort.

l id. An bout du fossi la culbute.

l id. Mort aux genlarmes.

l fois La gendarmerie sera mon tombean.

Le fameux camorriste napolitain Salsano s'étail fail représenter dans me attitude de brarade: il avail it la main une baguetle, et narguait un garde de police; sous le dessin était son sobriquet: Eventie toul le monde. Puis renaient deux coents et deux clefs réunies par des chaines.

Les tatouages d'un jeune Ligure, qui s'ćtait mis à la tète d'une rérolte à la Générale de Turin, rappelaient les érénements les plus importants de sa vie, et ses ilces de vengeance: sur l'avant-bras droit on rorait deux épíes croisées et au dessous les derix initiales II. N., nom de son ami intime; sur la lace intéricure, et dans le sens de la longuenr, on lisait la devisa:

A mort les lâches:

Vive l'alliance:

Sur la face extérieure, un long serpent enfermait dans ses replis tous les dessins depuis la main jusqu'au coude; sur l'avant-bras ganche on royail une croix 
montuaire, et, au dessus, le numéro matricule de son ami qui avait été tué d'un coup de fusil dans la révolte. Sur le bras gauche il portait deux canons croisés, deux poignards, et, au milieu, la date de 1875, en souvenir de ce dernier malheur. Sur la poitrine, il avait un écu et les initiales L. V. el C. G.; c'étaient les siennes el celles d'un ami ru'il avait à la maison correctionnelle de Gènes.

Fieschi, avant sa fameuse tentative de régicide, avait élé condanmé pour faux, el, par suite, rayé des cadres de la lígion d'honneur. Etant en prison, il se grava une croix sur la poitrine: alleureusement, disait-il, celleci, on ne me l'ôtera pas!». Combien il est curieux de voil ce mélinge d'une vanité toute moderne et d'une coutume lièsancienne, dams un cour et un esprit si perver's!

3. - Obscenite. - In antre indice nous est fourni par l'obscénité du dessin, ou de la région du corps oì il a été tracé. Ceux qui nous ont offert des dessins obscènes ou tracés sur leurs parties honteuses, sont, je l'ai déji fait remarquer, des repris de justice ou d'anciens diserteurs.

Sur 192 eriminels exmonés far moi, 5 portaient des tatonages al la verge; 1 y avait dessiné une tête de femme (V. Mll. xir), disposće de façon que la bouche fût formée par l'extrémité dı meat urinaire, sur le dos de la verge, étaient figurées les armes du Roi; un autre y avait peint les iniliales de sa maitresse, un autre un bouquet de fleurs. Ces faits prowrent un manque absolu de pudeur, et, plus encore, une étrange insensibilité; car il n'est pas de région plus sensible à la douleur, el c'est pour cela que les sauvages eux-mèmes dont tout le corps est couvert 
de tatouages, n'en ont point on ret endroit, et fur les Birmans ne veulent pas infliger un tol supplice anx condimncis a mort. IIebra, dans son Atlas für Dermalologie, nous donne le portrait d'un curopéen dont la peau était devenue un rrai tapis de Perse, par un assemblage inoui d'animanx et d'arabesques: on voyail des tatomages jusque sur le cuir chevelu; mianmoins les parties génitales araient été relativemont épangnées.

Il n'y a, i ma commaissance, que les samvages Tahitiens (Berchon) el quelques indigènes des iles Viti (Giglioli), qui se tatouent le memlore viril.

I'ai vu à l'hôpital Saint Louis de Turin un homme tué d'un coup de couteau; il avait sur les hras el it la poitrine des représentations de femmes soulerant leurs jupons. C'était un ex-galcrien.

Un autre qui avait appartenu ì la légion étrangère, s'atait, apres avoir commis un homicide, gravé sur le bras un membre viril.

Sur 1333 tatouages, Lacassagne en a remarqué 11 sur la verge. Cétaient, le plus sourent, des bottes à liécuyère armées déperons. Dans un cas, il a vu un as de coenr, une flèche ef le numéro de tirage en sort. La bolte n’est pas précisément un signe de pédérastie; mais, à ce que lui dirent les individus qu'il examinait, elle sert a faire l'ignoble calembourg: Je vais te metlre ma bolle au.....

Il a trouvé 280 emblèmes érotiques, ou, pour mienx dire, lubriques: des bustes de femmes (176); des fommes nues (3.5); des dessins représentant l'acte du coït debout (4); el maintes scènes lubriques quon ne samrait reproduire. Ceux qui ne tenaient pas an portrait de lem maitresse, adoptaient comme ornement une cantinière, une jougleuse, une danseuse, une femme quelconque. 
C̈est surtout sur le ventre, au dessous du nombril, quils tracent de préférence des sujets lubriques et des inscriptions telles que celles-ci: Robinel d'amour-Plaisir des dames - Venez, mes petiles dames, au robincl d'amour - Elle pense à moi.

Il faut remarquer ici quin de mes tatoués (tab. xvi ${ }^{e}$ ) qui portait les dessins les plus inpudiques avait un cahier tont barbouillé de res's d'amour, espéce de poésie plitonique:

Je suis tonjons malheurenx; - mul ne peut me venir en aide.

Toi senle par ton pardon - peux me sauver la vie.

Je te le demande en grâee, - dis-moi donc: je te l'accorde,

Si un cour bat dans ta poitrine. - Dans ce sein divin,

Fais du moins que la douleur - sapaise, o visage charmant:

C'était celui-la qui portait sur la poitrine le mot:

se jure de me renger.

Telle est l'inconstance du conur lumain, et tant il faut se défier de ce sentimentalisme qui étourdit les femmes lısstériques :

Les pédélastes qui, plus que personne, tiennent à plaire aux autres, aiment par dessus tout les tatouages; peutètre mème en ont-ils de spéciaux. 4 sur 12 pédérastes cités par Lacassagne portaient des mains entrelacées, deux avec leurs initiales surmontant cette inscription: L'amilic unit les cours. Quatre autres araient les initiales de leurs amis, et, au dessous, un caur brûlant, une violette arec le mot: Amilie. Dans un cas, ce nom stait surmonté de son portrait. Je regarde aussi comme ayant trait à la pédérastie linscription: Ami du contraire. Récemment, Lacassagne a vu sur lia face dorsale de la première platange du médius " le doiget inlìme des anriens, " les initiales « de l'ani ». 
l'édérastes étaient aussi sans donte les prisonnicts, thez lesquels Lacassagne a relevé dans les lesses des sujots lubriques, verges ailées, verges armées de roiles, tomnés vers l'anus; un ceil sur chaque lesse, un serpent rampant vers lanus; sur chaque fesse un zouave croisant lit baïonnette et soutenant une banderole arec l'inscription: On nientre pas; on avec le portrait de bismark ot d’un Prussien, ironie fatcile à comprendre.

Le prof. Filippi examina un pédéraste taloue an hras gatuche arec l'épigraphe: Pasquin, tu es mon trésor. Celle inscription faisait connaitre en même temps son vice et son complice.

Parent-Duchàtelet n'a jamais trouvé des synuboles ohscènes sur les prostituées; mais il dit que les tribades yravent entre leur nombril et leur vulve le nom de leur allinte.

'. - Multiplicilé. - En autre caractère des criminels, 'pui leur est d'ailleur's commun arec les marins et les sauvages, est de se tracer des dessins, non seulement aux bras et à la poitrine (c'est l'usage le plus fréquent) mais sur presque loutes les parties du corps. J'en ai remarqué 100 tatoués aux bras, à la poitrine et i l'abdomen, 5 aux mains, 3 aux doigts, 8 au membre viril, 3 à la cuisse.

Lacassagne, sur 376 individus tatoués en a trouvé: 1 qui l'élait aux deux bras et au rentre seulement, 4 aux deux bras el aux cuisses, 8 a la poitrine, 4 seulement au ventre, 11 au pénis, 29 par tout le corps, 45 aux deux bras et à la poitrine, 88 seulement au bras droit, 59 au seul bras gauche, 127 aux deux bras seulement.

Un certain T., âgé de $\mathbf{3}$ á ans, qui avait passé bien des années en prison, n'arail jas, en dehors des jones 
et des reins, la surface d'un écu qui ne fût tatouée. On lisait sur son front: Marlyr de la liberté; ces mots étaient surmontés d'un serpent long de onze centimètres. II avait sur le nez une croix qu'il avait tenté d'effacer arre de l'acide acétique.

Le nombre et la situation du tatonage sont d'une grande importance au point de vue psychologique; nous l'avons déjà remarqué.

Tardieu a vu un voleur qui s'était tatoué un costume complet d'amiral; et moi un autre, qui s'était fait de même un uniforme complet de général. C'était sûrement la marque de la passion qui dominait en eus, la vanité.

Ce poète sentimental que j'ai cité plus haut portait, outre des dessins obscènes (V. tab. xvi ${ }^{\mathrm{e}}$ ), un vaisseau sur le bras gauche, surmonté des deux initiales de son amante et ayant all-dessous le nom de sa mère; sur sa poitrine étaient un serpent et deux drapeaux; sur le loras droit un autre serpent, wne ancre, une épée ot une femme complètement vêtue.

Un antre avait des anneaux aux doigts, un serpent au bras droit et une danseuse an bras gauche.

Un voleur de Venise, qui avait servi dans l'armée autrichienne, avait au bras droit l'aigle à deux têtes, el, tout près, le nom de sa mère el celui de sa maîtresse, Louise, avec cette épigraphe, singulière pour un voleur:

Iouise chère

Amante

Hon unique consolation

Un voleur portait au bras droit un oisean tenant dans son bec un cœur, des étoiles, une ancre et un membre viril; sur le bras gauche d'un détenu Lacassagne troura ces mots: Quand la neige lombera noire, Augustine B... me sortira de la mémoire. 
Cette multiplicité prouve que los délinquants, conme les sanvages, sont très-peu sensibles ì la douleur.

5. - Précocité. - Il ost un autre fail qui caractrise le tatonage des criminels; c'est la précocité. Selon Tar'dien et Berchon, lo latouage ne so remarque jamais en France avant l'ige de 16 ans (il faut évidemment riserver le cas des mousses qui empruntent aux marins celte contume). Et pourtant nous-même à la Générale, en avons tronvé 4 sur des enfants de 7 a 9 ans; bien plus, sur 89 criminels adultes, 60 s'étaient tatonés entre 9 et 16 ans. - Mais une preuve meillenre encore a été donnée par Lacassagne, qui a étudié le tatonage sur 376 criminels. Il en a vu

\begin{tabular}{|c|c|c|c|}
\hline$\dot{a} \quad \bar{\zeta}$ & ans 1 & à $1: 3$ & ans \\
\hline$\dot{a} \quad 6$ & " 1 & à 14 & $"$ \\
\hline$\dot{a} \quad \tau$ & $"-4$ & a 15 & » \\
\hline i 8 & $\Rightarrow 1$ & à 16 & 13 \\
\hline a $\quad 9$ & $"$ & à $1 \tau$ & $»$ \\
\hline à 10 & $" 6$ & à 18 & 11 \\
\hline à 11 & $» 5$ & ‘் 19 & » \\
\hline à 12 & \# 9 & à 20 & $»$ \\
\hline
\end{tabular}

A Naples, sur 394 coupables mineurs enfermés dans les maisons de correction, Battistelli en a compté 122 qui s’étaient talloús, soit 31010 , et cütaient, remarquet-il, les pires de tous. Un d'eux, par exemple, qu'il fit transférer parcerquil le croyait incorrigible, avait trací sur le mur, arant de partir, une adresse a ses compagnons pour les cxhorter it persévérer dans le mal; or bien tous les individus ì qui il s'adressait étaient des latoués.

6. - Association, identité. - Ces faits nous montrent, déjì, comment l'étude du tatouage peul meltre quelque- 
fois sur la voie des associations criminclles; ainsi j’ai montré plus haut que nombre de camorristes portatent un signe particulier.

Lim d'eux avail sur to bras un alphabet mysterieus qui devait servir à correspondre secrètement.

Considérez mêne ces signes de talouage qui n’ont rien de particulier, qui se trouvent chez les criminels comme chez les paysans, les hergers, les marins; ils penvent venir en aide à la justice el à la médecinu légale; ils servent à identifier l'individu, it fare connailre son pays el les principaux évènements de sa vie.

linsi 22, parmi ceux que jai éludies, portaienl la date d'un pélerinage el de leur engagement dims l'arméc; 24 leurs iniliales; 7 lo $n 0 n$ de leur maitresse ou d'un ami; 6 Romagnols araient la marque ci-dessus dierile des pélerins; 1 Vénitien, celle de la Madone de Vicence, 2 Lombards, celle de Callavaggio; 12 un signe de leur mótier. Un militaire avait un soldat, un antre un elendard, un troisicme l'aigle d'Autriche, un quatrieme les armes de la naison de Savoie; un garibaldien arail le buste de Garibaldi; un matlin un ancere ot un vaisseatu. Tardicu a ru des cordonnices ayant me bolle, des boulangers arece l'image de St. Honore; un outlil de maçon lui permit d'ulablir lidentite des doux viclimes de Lescour.

liocher observe que les Arabes miles qui ont ile en prison on yui ont servi dans l'armée portent des lattouages de lenmes; les autres regarderaient comme un déshonneur d'en avoir.

Les criminels connaissent si bien l'avantage que la justice peut tirer de ces révélations involonlates, que les plus rusés d'entre enx évitent les tatouages, ou tilchent de los refitere, sils en ont. 
J'en commais deux qui y rémssirent, à ee yuils mout dit, en pirfuant la partie talouce avec des aiguilles trempées dans du suc de fignes vertes. Combien somvent ecla arrive on le devine par l'énorme disproportion qui viste cntre les criminels lallonís en bats age $\left(400_{10}\right)$ :1 les adulles $\left(\begin{array}{ll}7 & 0 ! 0\end{array}\right)$.

Quatre fois seulement sur 89 , j’ai remarqué un tafollage laissi inachevé prilreeque te patient n'avail ju arister a la douleur; une seule fois le latonage avait disparu, et seulement l'une facon incomplète, au boul 4r. 95 annces. Mais cela peut arriver; nous en avons la preuve désormais irrófulable dans les élndes de Casper, Jlulin et Tardieu (1). Le premier a trouvé 3 tattonages eflacés sur 66 ; le second 4 sur 36 , le troisiène 22 sur 379. On avait obtenu re lésultat en employant le vermillon et le charbon pilé.

Sur 89 crimincls tatomes, 71 avaient subi cette oprralion dans la prison on dans la maison de correction, $\partial$ taus l'armé, f daus divers sanchuares, 4 chez eux.

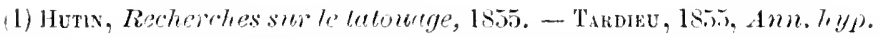
mol., nu. - Lans les Mémoires de l'idocq il est question de deux forçats sivales, qu`il reconmut graee a leurs tatonages; et d'une simulation d’jdentité que hi-même opera henreusement, en reproduisant le tatouage f'un antre individu (n, l6\%). La hante importance médico-légale Au tatonage parait dans le proces Tiekborne. Ce personuage avait fait graver sur lui, à 20 aus, une croix, un eour et une anere; le faux Ticklborne nen avait nulle trace, eela permit de le eontomlre. - Le tatonage risiste à la maceration dans l'ean et même à me pntrifaction avanece. Vaxime In Camp rapporte qu'il a va un eadavre dejjà réduit à $11 n$ itat le putrefaction tress-avancee, et qu'il itait impossible de reconnaitre; mais il avait encore, sur le has, un autel surmonte d'une tlamme avec ses mots: Tomjours pomer mon Elise; c'itait pum ertte femme ru'il s"itait noyi. - Voila fonc une nouvelle prenve de l'utiliti du tatouage comme indice: il pent explifuter les canses d'un suicide. 
7. - Causes. - Il serait curienx pour l'anthropologne de rechercher le molif qui a fait persister dans les classes inférieures et plus eneore chez les crimincls une coutume si peu arantageuse, el parfois si nuisible. Essayons-Ie.

a) La religion, qui a tant de pouroir sur les pienples, el qui se montre si opinititre à conserver les habitudes, les coutumes antiques, a certainemont contribué à maintenir cet usage: nous en vogous une preure quasi-officielle à Lorette. Cenx qui ont une dévotion pour un saint, croient, en glarant son image sur leur propre chair, lui donner une preuve, un lémoignage éclatant de leur amour. Nous sarons que les Phéniciens se gravaient sur le front le signe de leur divinilio (Ewalo, Ind. Alterth., in); a lijle Marshall on doit demander aux dieux la permission de se tatouer, et les prêtres de la Nouvelle-Zílande font seuls l'office de latoueurs (Scherzer, l. c.). - Là, ajoule Lubbock, or croit que la femme qui ne porterait pas le tatouage orthodoxe ne pourrait jour de la félicité iternelle (Presst. Man., p. 459); les femmes de la Bretagne se tatouaient pour obéir à la religion (César, 1, Pline, 93). Les Pirmans se gravent souvent des caractères mystériens ot des signes qui, à ce qu'ils croient, les rendent invulnérables.

Les adorateurs de la déesse Syra, puncturis se notant omnes, dit Lucien (De Dea Sira, 1847, p. 340). Les promiers chrétiens, à l'aide dı feu, se gravaient sur les hras et à la paume de la main le nom du Christ et le signe de la croix; cet usage est encore tres-commun hlez nous (Procore, Comment., p. 4). Jusqu'en 1688. ecrit Thévenot, les chrétiens qui se rendaient à Bethléem snivaient l'usage de se faire tatoner dans le sanchuaire. 
Sur 102 criminels tatonces, 31 portaient des signes religieux. Les marims onl encore un antre motif pour se latoner: ils veulent qu'on puisse les reconnatitro sils gripisent en nur.

b) La seconde canse ast lesprit d'imialion. lin bou soldat lombatal me répondait en riant, un jour que je le raillais l'avoir dépensé nue petite somme pour se faire gater te bras: "Toyez-vous, monsicur, nous sommes comme les montons; que lun de nons fosse ine chose, tous allssitó l'imitent, an risque nême de se laire dı mal ». Il arrive somvent qu'me compagnie enlière porte le même signe, un cour, par exemplo; c'est li une preuve eurienso de cette influence.

Dans la prison de Mllejal, Lacassagne a vol 10 délenns 'illi, pour imiter un de leurs compagnons, s'étaient fail saver sul le bras le mot: Pas de chance. L'un d'oux disait qu'il l'avait fait pareeque tous les prisonniers Etaient ainsi.

c) Il y a des tatonages inspirés par la rengeance. baslrenga, le féroce assassin de T..., avait sur les bras divers tatouages (un cheval, une ancre, ete.); sur le conseil de son père, qui lui remontra que ces dessins lo feraient plus aisément recomnaitre, il les effaga. Mais, sn 1868, il lut arreté de nowean par los agents el, comme il opposait une vive résistance, lim d'eux le frappa si violemment à la tète, qu'il en a encore $m$ ail abimé. Oubliant alors toute prudence, il se tatona de nouveau le bras droit, il y grava celte date fatale de 1868 et un pot sur le bras qui devait frapper. " 11 conservera celle marque cent mille années, m’a-t-il diclaré, jusquiau jour où il pourra assouvir sa vengeance ».

Ce fait est curienx; il reproduit une des causes qui gottent les samvages à se tatouer, - l'enregistrement; 
- il montre en mème temps que, chez les criminelsnis, l'esprit de vengeance l'emporte sur la prudence lis plus vulgaire, mème lorsqu'ils ont íté mis sur leurs girdes.

d) Loisiveté y est hien anssi pour quelque chose. Ello explique le nombre si grand do latonages que nons rencontrons chez les désertenrs, les prisonniers, les herger's, les marins. Sur 89 individus latonés, jeen ai rn 71 qui avaient subi celte opération dans la prison. Limaction est plus pínihte à supporter que la doulenr mime!

Les cmllimes, a dit Lacassagne, lépendent de la fimtaisic de l'opératemr. On en roit tant dans les prisuns, inspirés soit par l'amour dn gain, soit sentement far lenvie de se distraire! "Cola fitit passer le temps, lui disait l'un d'enx; jaime à dessiner el, fante de prapier, fopere sur la peau te mes compagnons y. Laausagne en a trouvé beancoup qui ignoraient la signifiration de lenr propre tatonage: l'oisivelé y avait crertainement contribué pour beaucoup.

e) Mais l'influence de la vanilé es rneore plus srande. Cenx mèmes qui n'ont pas étulie les aliénís savent combien colte passion puissante, grii se troure it tous les degrés de l'échelle sociale, et pent-itre che\% les animanx, peut conduire anx actions les phos bizarres, los plus folles, depuis le chevalier qui raffolle d'mu prlit bout de ruban, jusqu'a l'idiote qui se parane aree mn brin de paille passé dans son oreille. Ciest pour rela que les saurages, qui vont entièrement nus, portent des dessins sur la poitrine; c'est pour cela yne nos contemporains, qui sont vètus, se tatouent la parlie du corps la plus exposéc anx injures de lair, particutiirement l'avant-J)ras, et plus souvent le troit que le 
ganche. Un vicux sergent piemontatis me disalit fuim 1820 il n'y arail pas dams l'atrméc 131 hrave soldat, sultoul un sous officier, qui ne se talouil, pour montrer son courage a supporter la douleur. I la Nomrille-

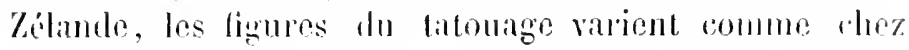
nous celles de lit modo. Il y a quelrue temps éétaicut los lignes comblos qui ataient en rogue, anjourd'hui co sont les figmres (Novara Reise, n). Et la preuve que cela passe pour un oruement, e'est que dans ce pays les jennes filles se tatoment pour dissimuler la conlemr ronge do leurs livres, réputée chez ce peuple comme un manque de beante. Pendant l'opération, leurs mères leur chantent: "Laissez-vous tatouer, pour fu'on ne dise pas, quand rous entreloz dans une fite: Quelle est celleei, qui a les lèvres rouges?" (IBud.).

El comme celle opritation est très-doulonrense, et yue seul mu individu rohuste peul la supporter, éest une prenve de comrage que de sy sommettre, on, pour mieux dire, c'est une prenve de l'insensibilité qui, chez les sanvages, remplace souvent le courage. Chez les Birmans, on encourt le reproche de mollesse, si l'on refuse de se tatoner. Ijoutons que pour enx le latonage est un rrai blason, indiquant la position sociale, le nombre des victoires remportées, ete.

I Nonka lliva, les dames nobles peuvent porter des tatonages plus nombrenx yue cenx des femmes du peuple.

A Samoa los reuves se font, parait-il, talonep la langue; les hommes se peignent le corpes, le la reinlire all genou.

dux iles Marquises, on peut voir le crimc duanre des vieillards convert de tatomages.

Dans la Guinée, tous les grands chefs ont la prau vraiment damasquinéc. 
I la Nourelle-Zélande, le tatouage est un véritable blason; les gens du peuple ne pouvent le pratiquer. Bien mieux, les chefs eux-mêues ne peurent s'orner de certaines marques qu'après avoir accompli quelque grande entreprise. Toupee, cet intelligent néo-zélandais qui fut, il y a quelques années, conduit à Londres, insistait anpucis d'un photographe pour qu'il sappliquàt à faire bien ressortir" son tatonage. "L'Européen écrit son nom avee la plume, disait-il; Toupee, l'écrit là ».

"Les Chonqui, disail-il à Dumont d'Crville, ont bean ètre plus puissants que moi; ils ne pourraient porter ces lignes que jai sur le front, car ma famille est plus illustre que la lem ).

Dans l’antiquite, les Thuaces et les Pictes reconnaissatient leurs chefs a certains tatouages.

Les Paga de Suntatra, ajoutent un nouveau trait toutes les fois qu'ils ont tué un ennemi.

f). L'esprit de corps et aussi l'esprit de secte doivent y contribuer. Je stus arrivi i cette conclusion par lexamen de quelques initiales étudices sur des incendiaires de Milan, et de certains signes trouvés sur les jeunes detenus de la Générale de Turin et de Naples. Des images de tarentules, de grenouilles, y apparaissent fréquemment. Je soupconne quelques groupes de canolristes d'avoir adopté ce nouveau gaenre d'ornement primitil pour distinguer leur secte, comme autrefois ils araient adopté les bagues, les ipingles, les chaines, et différentes coupes de barbe.

g) Enfin les stimulants des plus nobles passions humaines doivent aussi jusqu’à un certain point aroir leur part. Il cot bien naturel que les rites du village, l'inage du saint patron, les souvenirs de l'enfance et le l’amie du cour, reviennent à l'esprit du paurre soldat, 
et soient rendus plus vifs par ee dessin, quand il Intte contre les dangers, les souffrances et les privations. Voilá pourquoi un signe qui résmme pour lui toutes cos images peut devenir la source des plus nobles plaisirs.

Dans les classes plus ćlerées, j’ai relevé un scul cas de tatouage pour ansi dire épridémique, et je le dois à la courtoisie du docteur Albertotti. Ce lut parmi les élères du college de Castellamonte, au moment oi celte maison allait être fermíe: vingt jeunes gens, sur le point de partir, se firent orner de latonages qui faisaient allusion an collége chéri, tels que le nom du directeur, celui d'un camarade, etc. Tous, à coup sûr, jgnoraient que le tatouage fül un usage des barbares et des galériens.

I la Youvelle-Zélande, quand un parent ou même une simple connaissance vient à trépasser, on se fait. des incisions par tout le corps.

h) Lacassagne croit que la canse principale de cet usage n'est pas l'atarisme, comme je le sontiens, mais plutòt le besoin pour les personnes illettées, d'exprimer certaines idées.

Les murs, dit le proverbe, sont le papier des fous. Les dessins de Pompéi sont de rais tatouages de murailles. Lacassagne a trouvé des dessins analogues au tatouage sur les murs des prisons, par exemple, des tètes de fenmes, d'arocats, des noms ayant au dessous: Dix ans de travaux forcés. Laurent y avait écrit au dessous de son nour: Condamné à mort bien qu'innocent.

Dans les emblèmes mélaphoriques, ajoute Lacassagne, l'esprit du peuple se révèle avec la plus grande clarté. Les hommes incultes expriment généralement leurs idées par la représentation de certains oljets; de là la fréquence de divers emblèmes. Le plus commun est une 
violette avec relte inscription: A moi, I elle, A ma mère, A ma snur, A Marie. Somvent, dans l'intérienr de la llenr on sur ses pétales, est le portrait de la fernme aimer, avec son nom an dessous.

Quelquefois on tronve des abréviations dans les tattouages, comme dans les rébus. On en a vu un qui portait to chiffre 20, un ceur, puis D. Belles, ce qui signifiait: Vuinqueur des Belles. Ce sont li, contimue Lacassagne, des fantaisies populaires, des écritures somi-hitroglyphiques.

i) Plus que tout le reste, les passions anoureuses, ou pour mieus dire, les passions érotiques, y contrihuent. La prenve en est dans les figures olrecènes 292 sul 2'80), dims les initiales d'anomr si firquentes che\% les criminels, chez les triludes el les prostituées. Dans roceanie byalement, on voit des femmes qui ornent lenr rulve de dessins olscenes. Les Japonnaises, il y a frelques années à peine, se dessinaient sur la main des signes faisant allusion i leurs anduts, ef les remplaraient par d'autres quand lem corm changeail. (MxTEG.IZZA, I. r.).

Les femmes des Tahötions, des Cobas of dres Guarmis se font des lignes el des ciratrices partirulières pour montrer furelles sont vierges on mubiles. Chez les hommes également, le tatougage coincide sonvent avec l'époune de la ririlitá; il est $\mathrm{m}$ indice, et peut-ôtre, comnur le supposait Darwin, 1 moyen de sélection sexuclle.

Toutes les prostimécs arabes portent des croix on des fleurs sur les joues ou sur los bras. Les Mauresques en ont à la rigion manmaire, anx commissures de la rulve ou sur la face externe des paupières. Des trois étudiées par Lacassagne, l'une avait sur l'avant-luas le portrait de son amant, une autre le nom d'une femme. 
Jen ai vu une adomméc an saphisme, corit Kocher, rui s'élait fait tatouer sur la mammelle le portrail d'une femme. Les femmes anabes se font tatouer, selon lui,

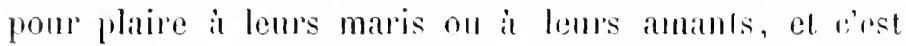
pour cela que te latonage y est plus diffus bluez olles que chez les lommes.

Ce stimulant des passions, mexpliefue les sacrifices mine pécuniaires anxruels bien des gens se sommetlent. pour se faire tiltomer.

A Paris et à Lyon, écit Lacassagne dans sa loelle monographie, cenx qui font profossion de tatoner ont contume de renir bontique pres des auberges; ils ont. des albums, et lemrs prix varient de cinquante centimes à quinze franes; il y en a qui gagnent jusqu'à reut francs par jour.

Co stimulant de la passion, el la conmaissance exactr des détails chez cenx qui, ayant pon d'idées, les ont précises, m'expliquent la perfection de lenrs dessins, perfection quion pent comparer ì celle des Egyptions, des Chinois et des Mexicains. Dans les monuments anciens de ces peuples, on distingue parfaitement la forme. des animaux, des végétaux el des instruments qu'ils voulaient représenter. Cette perfection dans le dessin me rappelle le charme des chansons populaires. Tant il est rrai que la passion, dans ses produits, est sonvent supéricure di l'art le plus raffiné.

l) II se peut que la muliti ait bli pour brancoup dans le tatonage que l'on consiltererail volonticrs romme une parne of un vitament. Cola est certaine pour les sauvages. Ne sait-on pas que les marins, yui vont bras et poitrine nus, et les prostitmies, qui sont sourent découvertes, sont aussi cenx qui recherchent le plus le tatouage? Il en est lo mome des mineurs el 
des paysans. D'ailleurs, le tatouage n’aurail pas de raison d'ètre chez un homme vêtu; on ne le distinguerait pas.

m) Atavisme. - Mais la première, la principale cause qui a répandu chez nous celte coulume, est, à mon avis, l'atavisnc, ou cet autre genre d'atavisme historique appelé la tradition. Le tatonage est en elfet un des caractères essentiels de l'homme primilif et de celui qui vit encore a l'état saurage.

Dans les grottes préhistoriques d'Aurignae et dans les sipuleres de l'antique Egypte, on rencontre quelques uns de ces os pointus qui servent aux saurages modernes pour se tatouer. Les Assyriens, daprès Lucien, les Daces et les Sarmates, d'après Pline, se couvraient tout le corps de figures; les Phénieions el les Juifs se Haraient des lignes qu'ils appelaient signes de Dieu au front ef sur les mains. (Ewalo, Jud. Alterth., iv). Chez les Bretons, ect usage était si répandu, que leur nom même de bretons (Brith., peinl), comme colui des Pictes ou Pictons, semble en tute derivé. Voyez César. Ces peuples, dit-il, trataient arec le fer des dessins sur la peau des plus jeunes enlants, ef coloraicnt leurs guerriers avec l'isatis tinctoria pour les rendre plus terribles sur le clamp de Jataille. Les Scots, dit Isidore, so dessinaient d'étranges ligures sur le corps, avec de l'encre et un fer très-aigu. (Elymol., 1x. Y. Luciex, De Dea Syra, 1840; Ewald, Die Jud. Alterlh., 1. 102 ; César, De bello gallico, 14). Les soldats romains, dit Vigece portaient gravés sur le bras droit le nom de l'emperenr et la date de leur engagement. (De re milit.).

Je ne erois pas qu'il ! alit un soul pemple sauvage qui ne se tatoue plus ou moins. Les layaguas se peignent to visage en bleu les jours de pête, ils se dessinent des triangles, des arabesornes. Les direrses tribus 
nègres se distinguent les unos des antres, smlout they les Bambanas, par des traits lorizonlaux ou rertiraux lracés sur lo risage, sur la poitriur, stur les bus (1). Les guerters kaffis ont le privilege d'ormer leur jambe l'une longue ligne coulenr dian', gu'ils sarent rendre indilébile.

I Tahili les fommes se fonl latourer senlement lis pieds el les mains, on l'oreillu; ellus y font lracer des colliers on des bracelets; no pelit nombre la vulve oll l'abdomen (on en a vil une qui portail des symholes obsecurs); les hommes tont le rorps, sur le cuir cherelu, an nez, anx gencives, et il se produit sourent des phlegmons, de la gangrène, surtout aux doigts et aux gencives. Ciest pour prérenir ces accidents, que l'on soumet l’opéré à la diète et an repos. Le latomeur, dans ces pars lá, est cntouré de respect et atrcueilli comme lidaient les troubadours chro nous an Mnyen-dge. On le paic générnsemont. (Bencuos, Sur le latouage, 1872).

Aux iles Marquises, lo tatouage ost un coslmme aussi bien quin sacrement.

A partir de 15 à 16 ans, on met arx jounes gens une ceinture at on commence il lem tatouer les doigts, los jambes, mais toujours dans un licu sacré. Toute famille riche a son tatouemr, el la claroge se transmet de pire en fils, de sorte qu'à la mort du premier, il faul sonvent allendre quelques années avant que le second puisse opérer. Les femmes, les prineesses mêmes, n’ont droit

(1) Foyez, pour les autres citatious: Mantegazz, Fiagyi nell'Americe meridionale, 1861-62. - Berchon, Le tatomage aus îles Marquises, 1872. - Watz, Amthropol., m. - Krause, Lelej llie Trtoriren, 18:3,

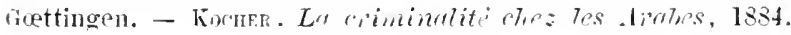


qu'all latouage des milins el des pieds; les grands persomnages en courrent tout leur corps; ot si les dessins des parties inférieures sont délicats, ils prennent à la fice un aspect grofesque al horrible, afin que les ennemis soirnt frippés d'épourante.

Chez les Kibyles, les femmes poldrul sur le fiont ou i la joue un latouage qu elles font disparaître at moment dil matrigge.

Le latouage est la véribale ectiture des sauvages, leur premier registre d'état civil. Certains latouages indiquaient l'obligation, pom le débiteur, de servir un temps son créancior. Ce moyen indiquait également le nombre el la nature drs objets recus. (Krause, Ucber dic Talowiren, 1873).

Rien de plus naturel que de voir un usage si répandu chez les sauvages et les peuples préhistoriques reparaître dans les classes qui, de môme que les bas-fonds marins, gardent la mème température, ont conservé les coutumes, les superstitions, jusquaux ligmnes des peuples primitifs, el qui onl, de même queux, des passions violentes, une sensiljilité engourdic, une vanité puérile, une longue ination, el même bien des fois la nudité. Ce sont bien lit chez les saurages, les molites principaux de celle contume étrange.

L'influence de l'altrisme ef de la tradilion me semble confirmce par ce fait, que nous frowvons un tel usage répandu parmi les bregers el les paysans, si lenaces en fait d'anciemnes traditions. On le troure encore en Italie, et surtout en Lombardic, Jans le fiémont et les Marches, ou la population es dorigine celtique. Or, de tous les peuples d'kurope, Jes Celtes sont les sculs qui aient conserve cel usage juspu'au temps de Cisar. 
ふ. - Le talouage chez les fous. - Le médrcin-legiste preut done puiser dans le tatonage un indice de récidive, surtout šil to ronstate sur des indivilus qui napparfioment pas a la classe des matrins, des militateres, dus payans loubards, des pichems des Marclues ou de Saples. Il doit tenir grand comple du gente et de la fréquence de res latonages, alusi hien you de leur prérocité, de leur siege el de lemrs allusions.

Cette inclination suffirait sans doute aussi i différeneier le criminel du fou. En effet, bien que celui-ci soit soumis, comme le premier, it la réclusion forcée et passe son temps dans l'oisiveté, bien qu'il éprouve des passions violentes ef qüil ait recours aux passo-temps les plus étranges, qưil polisse des pierres, déchire ses vîfoments et sil chair, salisse les murs et barbonille force frapier, il est rare quil trace sur sit peau de véritables dessins. Sur 800 fous que j’ai observés à Pavic et à Pesaro, jo n’en ai ru que q qui fussent tatous, et tous los quatre létaient longtemps arant d'avoir éprouré leur premice acces de folie. MII. Zani a Reggio, Livi, Severi a sienne, ont fait les mèmes observations, qu'ils ont bien voulu me communiquer. Les quelques lous latoués qu'ils ont rencontrés, 46 sur 1137 miles $(4,0$ p. 010) el 8 sur 1206 folles, avaient presque tous $\left(600_{10}\right)$ séjournés diuns los prisons, et cétait lá qu’ils s’étaient arrangés de lil sorte (1). Voila donc une nouvelle prewve de l'influences

(1) Il y en avait 7 condamnés pour meurtre on blessures, 4 pour vol, 4 pour rebellion, l pédéraste, ete. (V. Severt, Archivio di pichiatria, vol. vi, p. bi ete.

J"ai pur voir à sienne plusiems cutre ces tatonés, 11 sur son: parmi eux, 4) provenaient les prisons et éétait lí qu'ils araient pratiqué sur lenr eorps les premiers dessins (les armes du rirand-unchi, la date de 1856 , 
atavistique sur le tatouage; car la folie n'est presque jamais congénitale, et, par conséquent, ne résulte grère de l'atavisme.

Le savant De Paoli (Note sul taluaggio nel manicomio di Genova, 1880) a rencontré 19 individus tatoués sur 278 fous. Ilais, parmi ces 19, il y en avait bien 11 qui provenaient des prisons; des 8 autres, l'un appartenait à une société de camorristes (les Forts) de Gênes, et celui-ci, comme 5 autres, s'était tatoué hors de l'asile, étant marin ou soldat. Deux senlement s'étaient tatonśs dans l'asile; mais il est bon d'ajouter que l'un de crs deux était un marin, et qu'il s'était tatoué, de son propre aveu, pour se montrer bien orné à ses camarades, quand il sortirait de là; le dessin qu'il portail, et que jai examiné avec soin, représentait un Dieu gravé dans un triangle, et un ange aux aîles déployées; c'était une allusion à sa folie religieuse.

des croix, des ancres, le mot vive Garibaldi). A l'asile, ils avaient refait leurs tatonages avee de la brique pilée; mais ils n'avaient pas réussi ou du moins ils n'avaient fait que des dessins indéchiffrables et confus; ils avajent poussé d'autres aliénés à se fairc tatoner par enx, mais sans plus de succès. - Le tatonage manqué, confus, pourrait-il distinguer l'ceuvre du fon de celle du malfaiteur, daus ces rares circonstances oì il se pratiqne dans les hospices? - La chose est probable.

$N B$. Il existe des tatonages involontaires produits par le taffetas noir d'Angleterre, par les objets vésicants, on même qui sont pratiqués pendant le sommeil on à l'aide de la violence; ecest ainsi que je eomnais le cas d’un détenu qui essaya avee d’autres de tatoner un de ses compagnons pendant qu'il dornait; il tint en effet une première séance. mais, à la seconde fois, l'homme s'éveilla, et le dessin resta incomplet.

Il y a enfin des tatonages tout-à-fait accidentels ( $j$ 'en ai observé deux cas), particulièrement au nez, au front, aux oreilles, provenant de blessures, ou de chûtes sur la tête, ete. 
9. - Blessures. - La fréquence des cicatricas il la létr ou aux bras peut derenir pour le médecin légrist. un indice précieux, par lequel il distingura le criminel dı eitoyen paisible et honnête, pourvu, bien ententu, que ce dernier ne soit pas un vétéran on 1 m épileptique. Sur 390 sujets observés par moi, 17 portaient des ricatrices a la títe, el encore étaient-ellos antérieures à l'époque du crime.

La mime l'rmarque s'applique aux prostituées. ParentDuchitelet, sur 392 femmes de celte catégorie recucillies dans les hòpitaux pour des maladies non syphilitiques, en a trouvé 90 soignées pour des blessures 011 des contusions très-graves (1. c., p. 392). 
CIIAPITRE II

Sensibilité genèrale. - Gaucherie algométrique, spécifique, etc. - Dynamometrie. - Activitè réflexe. - Reaction vasculaire. - Rougeur. - Longévité. - Disvulnerabilite chez les criminels.

1. - Le gout particulier des crinimels pour me opération si douloureuse, souvent même si longue et si pleine de dangers, que le tatouage (1), le grand nombre de blessures que présente leur corps, mont conduit à soupgonner en eux une insensibilité physique plus grande que chez le commun des lommes, insensibilité semblable à celle que l'on rencontre chez quelques aliénés et en particulier chez les fous furieux.

I rrai dire, à force d'interroger les geôliers et les midecins des prisons, jai pu rassembler plusieurs cas d'une réritable analgésie. Un vicillard enfermé pour viol, par exemple, se laissait appliquer au serotum un fer rouge, sans pousser un cri, el demandait ensuite si l'opération

(1) If. Ialcassagne cite un individu qui, pour se faire tracer dans le dos un dessin compliqué, resta conché sur le ventre 3 à 4 heures prar jour, et cela pendant trois semaines. Un autre, a Naples, ayant voulu pen apres loperation prendre $u n$ bain de lessive, eontracta une gangrène qui l'emporta en peu de temps.

I. Berehon (l. e.) a reeomu, à la suite de divers tatonages, 17 cas de phlegmons, 8 de gangrẻne, I d'anévrisme, 7 de mort. 
était terminée, comme s'il se fìt agi d'un antere; il est vrai que, peu d’instants iprès, il était pris de délire. In autre, salls manifester la moindre émotion, se laissait couper une jambe, puis jonait avec le membre quion venait d'amputer. I'n assissin renvoyé du bagne de l'ile de S..., al lexpiration de sa peine, priait le direetend do le garder encore, disant qüil ne savait où trouver dı paill; royant sa prière repousséc, il se déchira les inlestins arec le manche d'une grande cuillère, puis remonta tranquillement l'esealier et rentra dans son lit, où il expira peu d'instants après, sims avoir fait cntendre un seul gémissement. L'assassin Descourbes, pour ne pas aller i Cayenne, se procura aux jambes des plaies artificielles et, celles-ci guéries, se passal all moyen d'une aiguille un cheveu it travers la rotule; il en moumt. Mandrin, arant quion lui tranchàt la tête, fut tenaillé en huit endroits diflérents, aux jambes et aus bras, et ne poussa pas un soupir. - Pour faire disparaitre un signalement dénonciateur, l". se fit sauter trois dents arec de la chaux pulvérisée; R. s'enleva la peall du visage avec des fragments de vorre. - Au pénitencier de Chatam, on a compté, en 1871-72, 841 contusions ou blessures volontaires. Les condamnés qui šblaient volontaircment fracturé quelque membre étaicnt au nombic de 27 , dont 17 durent subir une amputation; 62 tentirent de se mutiler; 101 se frrent des plaies arec des substances corrosives. (Rivista delle discipline carcerarie, 1873 , p. 369 ).

Ilais, comme on peut le voir, ici, quand la lolie n est pas en cause, il entre pour beaucoup dans cette insensibilité physique l'action toute puissante de certaines passions. C'est ainsi que les prostituées tribadiques, pour 
rejoindre leurs amies à l'hopital, font usage de lers rouges arec lesquels elles proroquent sur leur épiderme des houtons qui ressemblent à l'éruption de la gale. C'est ainsi encore que jai vu deux meurtriers qui s’étaient mutuellement dénoncés et qui se haïssaient depuis longlemps, s'élancer l'un sur l'autre, it l'heure de la promenade, et s'étreindre pendant quelques minutes, l'un mordant la lèrre, l'autre arrachant les cheveux de son adversaire, el tous deux se plaignant, non des blessures qu'ils s'étaient faites et qui furent suivis de graves accidents, mais de ce quon les empêcha de compléter leur vengeance.

2. - Sensibilité générale. - Nais le problème de la sensibilité dans les eriminels est un de ceux quion ne peut pas résoudre qu'après de nombreuses expériences.

Nous en avons fait me étude sur 166 criminels, dont l'un senlement était un criminel d'occasion, tous les antres des criminels-nés on d'habitude.

En commençant par la sensibilité générale ou topographique, nous avons trouvé celle-ci émoussée dans 98 sur fifi:

\section{Dans 16 à droite}

Il. 12 à gauche

Id. 18 des deux cittés.

En l'étudiant avec l'appareil électrique de Du-Bois Reymond, toujours an dos de la main, nous avons trouvé le degré de 49,6 dans les criminels, de 64,2 dans les lommes normaux. - Et tandis que les criminels ne commeneent ì s'en apercevoir qu’à $1 / 4$ à $2 ?$ 
millim. et ont les chiffes phus fiépuents de 51-57, les houmes normaux commencent à s'en aperecvoir à 52-8s et ont les chilfres plus nombreux it 60-67.

En étudiant, avec Marro, ces variations selon to rime je trouvai:

\begin{tabular}{|c|c|c|c|c|}
\hline \multirow[b]{2}{*}{ Crime } & \multicolumn{2}{|c|}{ Sensibilité trénérale } & \multicolumn{2}{|c|}{ Algométrie électrinlle } \\
\hline & Mroite & gatucise & droite & gauche \\
\hline $5 \mathrm{Vols}$ & 112,8 & 112,8 & 58,8 & $1 i 2,6$ \\
\hline J Blessures & 109,8 & 111,8 & 59,8 & 60,8 \\
\hline$\check{3}$ Meurtriers & 110,2 & 111.6 & 68,8 & $6 f, 8$ \\
\hline Escrocs & 121,0 & 119,8 & 79,0 & 80,4 \\
\hline
\end{tabular}

La sensibilite y apparail exquise dims les escroce, Euroussée dans les meurtriers el dans les voleurs; mais ceux-ci n'ont jamais présenté la grande différence d'un ròté, la latéralité, qui s'observe dans les autres.

3. - Algométric. - Bien plus importante est l'utude sur la sensibilité à la douleur avec la méthode décourerte par moi, c'est-a-dire avec l'appareil gradué de Du-Bois Reymond appliqué toujours au dos de lis main. (V. Algometria eletrica, 1876).

lei, la moyemne, dans 21 lommes nomaux, étail de 49,1 $\mathrm{mm}$; elle étail de 34,1 dans les criminels; et tandis qu'il n'y avait aucun des premiers avec 0 de sensibilité et 1 seulement de 17, la plupart donnant 32 et 49 - dans 18 criminels, 4 étaicnt analgésiques (avec 0 sensibilite, et 9 donnaient le chiffre de 11-15). La plupart se trouvaient entre 50-55. Pour la langue, les criminels commencent it 37 , aboutissent it 65 arec une grande supériorití entre 40 à 58. Les hommes nor- 
manx, commencent a 44 et ont le plus grand nombre entre $53-57$ (1).

Nous avons vu dans les mesures de Marro lo maximum de la sensibilité dans les escroes; le minimum dans les voleurs et dans les meurtriers. Il en est de cela comme de la sensibilité gínérale sans que pourtant los deux sensibilités soient toujours parallèles.

4. - Sensibilité tactile. - Ici, graice à l'aide du docleur Ramlot, nous pouvons donner une étude plus ífendue sur 103 criminels comparés it 27 hommes normaux. (Bulletin de la Société d'Anthrop. de Bruxellos. III, 188.5).

(1) Ilgomitrie.

DOS DE LA MAIN

\begin{tabular}{ll} 
Ilommes criminels & \multicolumn{1}{c}{ IIommes normaux } \\
$4-0$ & 0 \\
$3-11-13-15$ & $1-17$ \\
$3-20-23-29$ & 0 \\
$2-95-95$ & $5-31-33-32-36-35$ \\
$4-40-44^{2}-49$ & $9-40-43-45-47^{2}-44-47-48-49$ \\
$5-50-5152-255$ & $4-50-54-57-58$ \\
$0-11$ & $2-60-62$
\end{tabular}

DOS DF LI LANGUE

$\begin{array}{cc}\text { Jomines criminels } & \text { Ilommes normaux } \\ 1-37 & 0-37 \\ 0-40-40-55-58 & 5-56-44-59-5 i-55 \\ 2-63-65 & 0-0 \\ 1-75 & 0-0\end{array}$


Comme on pent bien voir par celte table (1), tout en faisant abstraction des 8 cas vraiment thératologicpues, on anrait trouvé une obtusion dans le $1 / 4010$ pous la platange palmaire de l'indrex, tandis que dans 27 luommes normaux on ne la rencontre que dans le 29010 ; pour la langur, loblusion était tans la proportion de (i) 110 .

La moyenne arithmétique (en ne tenant pas comple dus 3 exagérations dobtusion) y résultait pour lindex dr. 2,9', et pour la langue de 1,7, landis que dans les 27 normaux elle était de 1,7 it la main et de 1,0 il la langue.

G'est presque ce qu'on rencontre dans les fous oi jai tronvé 3,0 , dans 30 épileptiques, 2,4 dans 30 alcooliques, et 2,5 à 2,3 en 30 déments.

Mais un fiat plus emrienx ressort de ces recherches: cest ce que j’appellerai le mancinisme sensoriel; tandis, en effel, que:

(1)

Tacte

An dessous de mun. 0,s

ne mm. . 0,8 à 1,4

1d. - 1,5 a 1, ?

Id. - 2,0 \& 2,0

Il. . 3,0 à 3,5

1d. . 4,0 ล 4,9

11. . 5,0 à 7,0

1d. . 8,0 मे 9,0
Main Droite Nanche

Linnurue

$\begin{array}{rrr}0 & 0 & 5 \\ 0 & 6 & 2 \\ 25 & 20 & 3 \\ 27 & 27 & 14 \\ 12 & 21 & 3 \\ 15 & 9 & 1 \\ 14 & 8 & 1 \\ 1 & 3 & 0 \\ -1 & -- & - \\ 100 & 100 & 35\end{array}$

Trois tout-à-fait anormanx nous ont donni:

$1 \mathrm{~mm}$. In à main droite -10 à gauche

1 id. 18 id. -23 id.

1 id. lif id. $\quad-32$ id. 
Dans les normaux il y a mm. . 1,70 à droite et 1,79 à gauche
id. criminels
id.
2,94 id.
2,89 id.

Et les norm. ont une obtusion p. 01029 à gauche et 18 à droite
id. criminels
id.
id.
36 id.
id. id.
parilé . " 50
id. $\quad 36$ id.

et cela en faisant abstraction des 3 anormaux, qui donneraient $u n$ chiffre bien plus grand a gauche.

En étudiant le lact dans les diverses séries de criminels (1), on roit que dans les escrocs el voleurs le tict est presque normal; l'obtusion la plus grande est dans les meutriers et dans ceux qui se sont rendus coupables de coups et blessures.

5. - Vue. - Le doct. Bono a trouvé parmi azl jeunes criminels le $6,600_{10}$ de daltoniques, proportion qui excède de plus du double celle de 800 étudiants - 3,09 et de 590 ouviers - 3,89. - II. Jolomgrena ussi, avait remarqué le 5,60 des daltoniques dans 321 criminels, tandis que dans 32.000 honnêtes gens il en trourait at peine 3,25. (Ucber dic Furbenblind ecc., 1878). - Jernièrement le doct. Biliakow a trouvé dans 100 meurtrier's russes le 50,0 de daltoniques et le $280_{10}$ de dyschromatopes, tandis que dans les russes normaux it n'y en arait pas plus de 4,6 0 0 . (Kownewsir, Archiv., 1884).

C'est un fait très-important, car déjà Schmitz nous a appris comment le $550_{10}$ des dyschromatiques est sujet aux plus graves maladies nerveuses, épilepsie, chorée etc.

\begin{tabular}{|c|c|c|c|c|c|}
\hline 11) & & & Droite & & Gauche \\
\hline & Voleurs & . & - 1,60 & - & 1,78 \\
\hline & Blesseurs & . & . $\quad 2,30$ & - & 2,00 \\
\hline & Neurtriers & & . 1,92 & - & 1,74 \\
\hline & Escrocs & . & 1,58 & - & 1,80 \\
\hline
\end{tabular}


Les mêmes recherches faitus par M. Biliakow mons montrent l'infériorité de l'acuiti visuelle des meurtriers compares aux hommes normallx.

Ce savant a trouvé chez 100 nuemtrice, divises selon l'ìge (1), 1,3 moins de Visus supérienr, 5 fois plus de Visus inférieur an $66_{6}$ Schnellen que dans les normaux: il a trouve, anssi, la myopie, l'ambliopic et l'jpernetropic dans un nombre plus grand des criminels (2).

6. - Acuiti acoustique. - Biliakow a cendu los mèmes observations à l'auté de l'oüe; il a trouvé dans les criminels russes une moyenne de 950 cent. pour l'oreille droite et de 235 pour l'oreille gauche; les $3 / 4$ des solulats russes surpassaient les 200 centim., et 1 , les 300 centim. de distance; et tandis que 3 à 50,0 seulement, de ceux-ci, avaient l'acuité à 1 centim., les eriminels doues de cette faible acuité étajent dans la proportion de 14 à 33010 ; bien plus: $6 \quad 0_{10}$ élait sourds. Liobtusion est dans les soldats prédominante à gauche comme 30 à 13 , mais plus encore dans les criminels comme 5 ta à 66 .

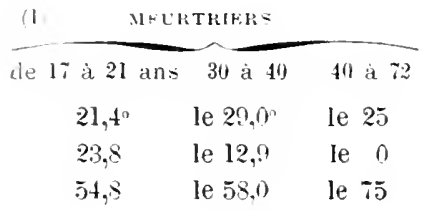

Criminels

Normalux

(2) Myopie . . . 3200 -

Id. . . . 28010

Emmetropie - $31 *$ -

Id. . . . 48 *

Imbliopie . . $6 \Rightarrow$

Id.

Dans

les norm.

Ipermetropie . $21 \times$ -

22,3

id. $>1$ id. 64,4

id. $<1$ id. 11,6 
7. - L'acuité du sens musculaire a été étudiée pour la première fois dans 38 criminels par Ramlot et Warnotts (Bull. de la Soc. d'Anthr., 1885, Brnxelles) qui ont pour plus de sûreté adopté comme limite le chiffre de Weber, cest-i-dire 102 et 103 . Ils l'ont trouvée obtuse, avec une moyenne de 114, dans 380,$0 ; 12$ sur 22 de ces criminels présentaient aussi une diminution de la sensibilité tactile.

8. - Sensibilité i l'aimant. - Tandis que toutes los sensibilités semblent s'éteindre ou s'émousser dans le criminel, d'antres apparaissent en lui plus vives que dans les personnes honnêtes; par exemple la sensibilití à l'aimant: que j'ai notée dans 30 sur 62 sujets soumis à mon examen ( $\left.480_{[0}\right)$, tandis que les éludiants mien ont donne sculemeut le 28010 .

9. - Sensibilité météorique. - L’antre sensibilité qui est plus vive chez enx que dans les honnêtes gens est la météorique, que jä rencontrée en 29 sur 112. J'en ai trouvé 9 qui deviennent querelleurs pen arant les orages; l'un d'eux, voleur et pédéraste, me racontait que ses compagnons pressentaient le maurais temps quand ils le voyaient chercher querelle. Beaucoup d'entre cux ont le vertige, des bourdonnements, de la céphalie dans les jours de grands vents.

10. - Sensibilité olfactive. - Il est bien probable, mais on en donnerait difficilement la preuve expérimentale, que la sensibilité olfactive soit plus exquise dans les criminels. - Je ne puis en donner en preuve pour le moment que cette curieuse statistique du doctenr Venturi sur l'usage du tabac en poudre. 
Chez 350 hommes normaux la proportion est te 14,9010

la. 322 femmes normales

ld. 310 hommes fous

Id. 152 femmes folles

Id. 279 hommes criminels

Id. 201 femmes criminelles

1d. les mentriers. .

1d. les voleurs id.

1,50

id.

id.

id.

ia.

it.

id.
).),

(), 2 "

i.), 8

1.1,? "1

is, 0 "

12,0 0

Statistique lids-pen conclusive, il est vai, rar l'usago du tabac peut se propager dans la prison gràce à l'oisivete et a l'exeitation du systeme nervenx central, mats qui est anssi appuyée par la remarque suivante: tandis que les gens hommètes ne s'y adomnent avant :30 ans rome dans la proportion de $1 \frac{1}{4}, 1$ el les fous ale 7,2010 , los criminels latoplent dans la proportion de 2200 ; et prosque lous, 279 sur 900 el 92 sur 92 criminelles avant lenr entrip an prison /Il manicomio, Nocera, $1885)$; il faut ajouler que Venturi par d’ingriniouses slatisliques, voudrait prouver que la passion du labie, trés-répandue chez les ćpileptiques (22 010), démrnts $\left(290_{10}\right)$, monomanes $\left(.570_{10}\right)$ est un nouveall calactire dégénératif des aliónés.

11. - Dynamométrie. - Quiconque vent rechercher les conditions de la foree musculaire des criminels ne réussit pas, mème avee le dynamomètre le plus parlatit, à s'en faire une idée approximative quand il lemploie sur des malheureux affailhlis par une longue détenlion et par l'immolsilité.

J'ajoute que quelquefois, par suite de cette perversité qui est le caractère constant de leur existence, ils foignent d'ètre plus débiles qüils ne le sont en réalité. 
Ln calactère commun à bien des criminels est une agilité vraiment extraordinaire, surtout chez les volems: c'élait le cas de Cecchini, de Pietrotto, de Rossignol, de Villella, de Rossolli; celui-ci ne s'enfuil pas seulement de prison, mais favorisa encore, le même jour, l'évasion de sa maîtresse. Celte agilité est, bien des fois, analogue it celle du singe; llaria Perino grimpait sur les arbies les plus grêles et de leur cime sautait sur les toits, entrait dans les maisons et, pendant quelques mois réussissait ainsi à se soustraire à la justice. (Archivio di psichiatria, Il). Peut-ìtre avons-nous encore là quelque reste de l'agilité de l'enfant et du sauvage.

Pourtant 241 crimincls mont donné 30 kil. à la pression dı poignet el 110 a la traction (dynamomètre de Broca), chilfres de beaucoup inférieurs à ceux offerts par les hommes libres, mais supérieurs a ceux fournis par les alićnés; tandis que 52 hommes sains ont atteint 168 à lis traction

\begin{tabular}{|c|c|c|c|c|c|c|c|c|}
\hline & & & & & & . & $\begin{array}{c}\text { A Ia } \\
\text { mession }\end{array}$ & $\begin{array}{c}\text { A lat } \\
\text { traction }\end{array}$ \\
\hline 20 & Voleurs le & grano & & hemin & nous & donnèrent & 31,8 & 114 \\
\hline$y$ & Homicides & . . & - & . . & . & id. & 31,9 & 114 \\
\hline$"$ & Incendiaires & . & . & . & . & id. & 32,0 & 81 \\
\hline$"$ & Voleurs & . & . & . & . & id. & 28,0 & $10^{\prime}$ \\
\hline$n$ & Faussaires & . & $\cdot$ & . & . & id. & 29,0 & 114 \\
\hline$n$ & Violateurs & . & & . & . & id. & 33,9 & 109 \\
\hline$n$ & Brigands & . & . & . & . & id. & 33,0 & 103 \\
\hline
\end{tabular}

Ce tableau démontre clairement (les persomnes les plus fortes à la pression, ne le sont pas toujours à la traction) que le voleur donne le minimum de la force et à la pression el à la traction. 
Si lon calculait ensuite la traction sento, la fore maxima serait offerte par les homicides, les volems de grand chemin el les fanssaires; la minima par les incendiaires, les violatenr's el les hrigands.

Quant à la pression, la maxima apparliendrait violateurs, aux brigands, anx incendiaires; la minima aux voleurs el anx faussaires. Les homicides el les voleurs te grand chemin ne differeraient entre enx que uris-peu.

llais plus important que ces domnées est le lail curicux d'une plus grande élévation dynamométrique proportionnellement à ganche. - Voici le tahlean comparalif de 133 criminels et de 117 jeunes gens honnètes arec le dynamomètre de Broca :

\begin{tabular}{|c|c|c|c|c|}
\hline \multirow{4}{*}{ Foree } & & & $\begin{array}{l}\text { IIommes } \\
\text { criminels }\end{array}$ & $\begin{array}{l}\text { IIommes } \\
\text { normaux }\end{array}$ \\
\hline & maxima is gauche & . . & . 23010 & $140[0$ \\
\hline & Id. à droite &. & $67 "$ & $70 "$ \\
\hline & égale des & 2 côtés & $89 n$ & $14 "$ \\
\hline
\end{tabular}

12. - Mancinisme. - Ces faits nous portent à soupçomer dans la motilité une différence analogue à cello que nous trouvons dans la sensibilité, relativement plus obtuse à droite qu'à gauche, une espèce de gancherie. Je dis senlement soupronner, parceque tous les dynamomètres en usage ne nous donnent pas une idée complète de la force el encore moins de la dextérité musculaire. Sur 28 gauchers nous en trourons 11 avec des chiffres dynamométriques supéricurs it droite; 8 seulement donnent des chiffres égaux. Aussi avons nous cru devoir atudier l'ambidextrisme en dehor's des résultats fournis par le dymamomètre. Il résulte de celte étude faile sur zil condamnés: 
Gaucliers

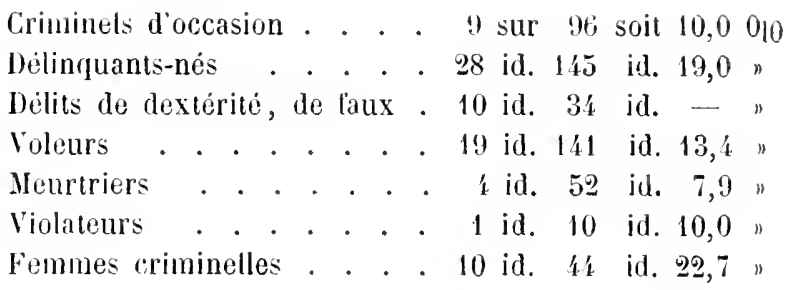

Done, supériorité clez les faussaires, chez tous les criminels à qui I'habileté est nécessaire el chez les délinquantsnes. Au total 14,30 010 de gauchers chez les lommes el 22,7 $0_{10}$ chez les femmes. Sur 711 femmes honnètes on a senlement 4,3 $0_{[0}$, et sur 238 ouvriers honnêtes senlement 5,8 0,0 gauchers. Chez les fous 4,13 à 4,27. Tibère était gaucher (Tacite) el aussi Passanante.

13. - Anomalies de le motilité. - Virgilio (op. cil.) qui, sur 194 individus atteints de maladies chroniques, avait trouvé une quantité proportionnelle énorme d'ípileptiques (j a 6010 ), d’ataxiques el de choréiques, surtout chez les voleurs comparés aux homicides, nous fait soupconner que la motilité est anormale chez onx, tout comme la sensibilité. La forme fréquente de lanonalie serail surtout l'épilepsie. Ciark trouve le crime 11 fois p. 0 i0 chez les ipileptiques communs, et 3 fois pour $0_{10}$ chez les épileptiques d'origine tramatique. (Eredity and crime in Epilepsy, London, 1880)(1).

Dans la maison de détention de lieggio, strr 200 jeunes criminels, j’ai remarqué 3 choréiques et l alaxique lrésjeune; je fus frappé des petits mourements convulsifs,

(l) Irans le cours de ce travail nous allons vérified la grande importance det ce fait. 
des tics mosenhares anxquels ils étairnt sujuls, eomme cela se rencontre sonvent chez les vieillads atteints de pelites himorragnies cérébrales. A Turin, un certain heazzo, voleur, avalit prespue continucllement to tic de hatusser les épaules et de frapper du pied droit, phénomène qu'il reproduisit aux Assises, pensant la lecturn de la sentence, el qui lui valut une ageravalion de peine.

14. - Mouvement riflexe. - diai pu me former un urtérium plus certain sur les anonalies spinales et sur lactivité réflexe, en étudiant les réflexes rotuliens sur 284 criminels, comme l'indique le tableau suivant:

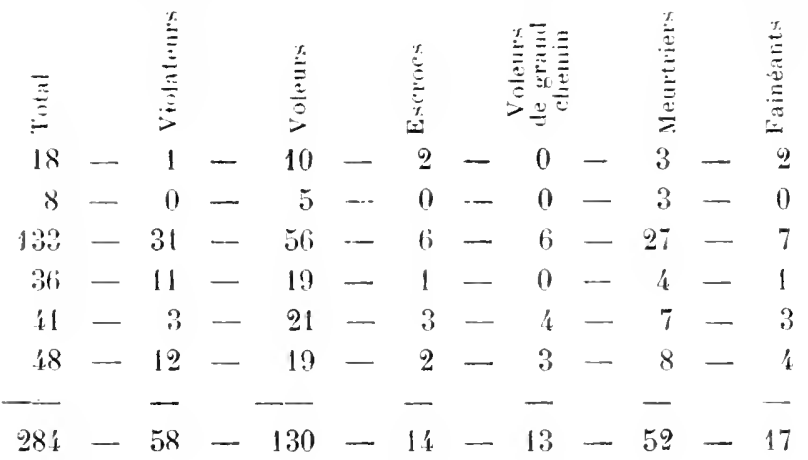

Le réflexe rotulien recherché sur gýt criminels a ćté trouvé normal sur 193; anormal (affaibli ou exagéré) sur 151 , c’està dire faible sur $67-230 \mid 0$, cxagéré sur 48, soit 16010 .

Les violateurs fournissent un contingent mininum de réflexes faibles 7010 et un contingent moyen de róllexes cxagurés, soit 2010 .

Les voleurs dépassent de peu la moyenne génélale pour les réflexes faibles 27010 ct restent inféricurs do peu pour les riflexes exagerós, soit 14.0101. 
Chez les fripons on note $u$ exces notable soit de ríflexes faibles $\left(3500_{0}\right)$, soit de réflexes exagérés $\left(210_{10}\right)$.

La même chose s'observe sur les volcurs de grand chemin, chez lesquels la moyenne des riflexes légers atteint $300_{10}$, et celle des réllexes exagérés 23010 .

Les meurtriers et les fainéants fournissent un contingent de réflexes faibles et de réflexes exagérís qui se rapprochront pius de la moyenne générale, de 250 pour les réflexes faibles et de $150_{00}$ pour les exagérés.

Le défaut de réflexe des deux cotes se montre un peu plus lréquemment chez les vagabonds, fainéants (1) $0_{10}$ ), el chez les escroes (14 010); chez ces derniers et chez les voleurs de grand chemin on rencontre cependant plus souvent le réflexe faible (21 et $300_{10}$ ).

Le contingent le plus élevé de réflexes exagérés a été fourni par les oisifs et par les voleurs de grand chemin, 23,5 et 23,0 0 0 , et par les violateur's 20010 ; - contingent moins élevé chez les roleurs et les firipons 14 $0_{10}$. Un d'entre eux était adonné à la masturbation et à moitié stupide $\left(180_{10}\right) ; 8$ avaient des parents aliénés, 3 avaient un père alcoolique $(13010) ; 1$, qui était sodomiste, fut atteint d'une méningite traumatique suivie de démence aigüe; il donne aujourd'hui des signes l'hypérénie spinale.

Parmi les délinquants manquant de réflexe d'un côté ou de l'autro, les épileptiques entrent dans la proportion de $11,5: 30_{10}$, et en égale proportion les descendants d'aliénés et les descendants d'alcooliques; dans la proportion de $7,690_{10}$ se trouvent les individus avec altérations spinales ou cérébrales.

Chez les délinquants à réflexes normaux les épileptiques entrent seulement dans la proportion de 3,3000 , 
Ies délinquants nés d’aliénés, dans celle de 7,19200 , les délinquants nés dralcooliques, dans la proportion de $11,01 \theta_{10}$.

15. - Vaso-moteurs. - Les anomalies de la sensibiliti et de l'action réflexe che\% les eriminels doivent nícessairement àtre accomplatgées des anomalies de l'innervation vaso-motrice. La prenve la plus simple se déduit de cette absence do rougent qui, depuis des siècles, est consilléréc par le vulgaire comme l'équivalent d'une rie déshonnète el sauvage. Ciest ce que nous allons étudier chez les jeunes gens, parceque comme l'a démontré Darwin, cette absence peut dépenilre aussi de l'ime avancé.

Sur 59 criminels condamnés (de 19 à 26 ans), quand on les réprimandait on quand on les dévisageait (comme nous l'a enseigné Darwin), on en a tronvé 36 qui ont rougi, soit $610_{10} ; 3$ ont pâli, 20 ont conservé un visage inaltérable. Sur ces 36, 11 ont rougi aux joues et an front, 2 aux oreilles, 24 seulement aux joues, et encore 1 de ces dernicrs n'a-t-il rougi qu'à une joue.

De deux homicides par passion, un rougissait trèsvite, l'autre assez peu. L'unique fainéant et l'unique violateur examinés ne rougissaient pas.

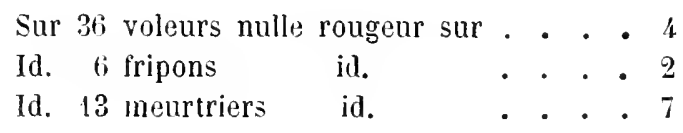

5 volcurs (voleurs el fripons) rougissaient d'une manière exagérée et pour la moindre cause; cependant 3 d'entre eux étaient intelligents et avaient une pliysionomic normale, 2 mème appartenaient aux classes éle- 
vées; un autre élail halluciné, grâce peul-ètre à la rio cellulaire; ot un mattoïde.

Sur 38 mineurs des Pénitenciers, la rougeur laisait défaut en 20, sans en compter deux qui ne rougissaient qu'incomplètement.

Des 20 qui ne rougissaient pas, 14 ćtaient insensibles au magnetisme, 3 avaient des réllexes tendineux exatgérés, 6 n'en avaient pras.

En sonme, sur 98 jeunes gens crimincls, 44010 ne rougissaient pas.

Il est à noter que la rougeur chez quelques-uns venait plutôt de ce quilils s'échauffaient en parlant, ou s'excitaient à rire, troublés qu'ils ctaient par l'entrée imprevue dans leur cellule, plus que par les reproches, le sourenir de leur crime, ou le regard fixé sur eux, comme il arrivo physiologiquement.

Sur 122 lemmes examinées par moi et par le docteur Pasini, la rougeur est restéc absente dans 8100 et précisément:

79010 chez les homicides

80 "id. empoisonneuses

82 "id. infanticides

$90 "$ id. rolenses.

Elles ne rougissent pas au souvenil de leurs crimes, mais plutôt quand on les interroge sur leurs désordres menstruels. - Au lieu de rougir elles pâlissent: une entre autres, très intelligente, francaise, volense, arec ume forme rígulière dı eràne et de la face, n'olfrail comme caractère criminel que la pâleur.

lei se placent quelques observations précieuses reeueillies pour nous par le doet. Andronico de Messine, sur 
les prostitnés et les jeunes criminelles de lat prison dont il était chargé. Nous transcrivous sa leture:

"Parmi les prostituées inserites, aucune ne rougit fuind on l'interroge sur son honteux métier. J'en ai vu rougir quelques unes quand on leur reprochait t'user du cöte contre nature. Parmi les condamnées de la maison de détention, j’ai noté les laits suivants: Les délenues homicides racontent leur faute ingínuement el sans rongir, celles qui ont empoisonné ou lait empoisomner leur mari rougissent, mais partiellement.

"Chez des recluses condammées pour vol, la rougenr se montre d'abord aux oreilles, puis au visage; chez celles rui le sont pour excitation à la prostitution, aneune rougeur n’apparait ».

16. - Riaction au nilrile d'amhyle. - Pour mienx fixer le degré de cette importante réaction, j’ai essage quelques expériences arec le nitrite d'ambyle.

Sur 19 expériences 5 fois il n'y a pas eu de réaction sur 4 voleurs (2 épileptiques) à la dose de 2 goutles; cependant l'expérience fut répétée sur un des sujets avec 3 grouttes, sur un autre avec 4 gouttes, sur un troisième avec 6 gouttes et l'on obtint: chez le premier une vive rongeur, chez le second une très-légère; clıcz le dernier la rougeur se fit attendre 40 secondes et se circonscrivit atu menton et au cou.

Vicêversa, on obtint, avec une seule goulte, une rapide et tres-sensible rougeur chez un homicide par passion, lequel, à cause de la détention cellulaire, souffrait d'hallucinations; l'expérience fut répétée chez un trèsjeune roleur et chez un tout jeune dornestique, fainéant et voleur, de physionomie agréable; le premier eut une 
rongeur complète après 18", le second nien ent qu'une tris-légère; dans 2 jennes filous on l'eut en ":".

Ivec 2 goutes on eut chez $m$ voleur de grand chemin une rougeur retardée 50" et senlement du cotí ganche de la jouc. On ent une rougeur rapide arec 2 groultes sul un fripon. D'où l'on pent conelure: que la réaction vas-motrice avec le nitrite dambyle chez ecrtains criminels adultes est fréquemment retardie, et souront moins intense qu'í l'état normal. (U’ne goute produit une rougeur sensible chez t/4 hommes normaux, sur 13 dans l'espace de 7 i 28 secondes, sur 2 il en fallut 2 , sur 1 il en lallul 4; celte rougeur cependant se manifeste toujonrs en moins de 50"). Elle est intense et rapide comme normalement choz les lomicides par passion el chez les criminels tris-jeunes. - Dans quelques cas très-rares, l'action fut plus rapide que dans l'état normal.

17. - Sphygmographie des dílinquanls. - Iprès la dícouverte du plétismographe et les perfectionnements In sphygmographe dus à Mosso, qui ont tellement facilité les études sur les réactions des vaisseaux par rapport su plénomene de la pensée, it nous fallait essayer de les appliquer à l'útude psychologique du délinquant.

Nous avons pour cela choisi des individus robustes, plusieurs fois recidivistes, ayant les caractères psychiques et physiques du delinquant l'habitude; quelques uns, au contraire, parmi les normanx on les criminels d'occasion.

Le bras gamehe placé dans l'hydrosphygmographe, on fixait sur te droit les rhéphores en communication arec les bobines de Ruhmkorfi, en se servant d'abord de mon système pour mesurer (voy. Lombroso, Algomelria eleltrica, l874) lo legre anduel se prodnisait la dondent 
et celui ou l'on arait la perception du comant. Lat bobine a son tour communiquait avee un signal de busper\%. lin mème temps, un diapason en rappolt avec un ronrant électrique trarait sur le cylindre lo temps (20 vibrattions all l") de l'expérience.

l'our matrquer l'excitation gaie, mon exeellent asistant je br Cougnet consuruisit un diaphragme tenu suspendu pall un aimant temporaire; de sorte que si l'on voulait froduire l'excitation, on onvalit le circuit en liassant decouvert l'oljed choisi suivant les tendanees de chaqum individu expérimente, vin, cigares, aliments, atgent, figures de femmes nues.

On étuliait ensuite, dapres les travaux de Mosso et Giry, les moditications produites par les phénomenes furement psychiques; calcul, observations agréables ou prinibles, en entretenant le eriminel d'arasion, de persécution, de jugement, cle.

Il n'y eut presque pas de réaction rasculaire sur quelyues-uns, par exemple:

a) Ausano, prognale, latoué, front furant, né de farents irrognes a névropalliques, voleur consonmé depuis l'enfance, ne réagit jamais, ni au son de la musique, ni a la decharge d'un pistoled, ni sous l'impression de choses pénibles, ni sons linflucuee du calenl: seul le vin produit sur lui une légere devalion de lo pulsitions.

b) Alc..., volem riche qui presentait une analgrisie et une anesthesie complètes, n'offre jamais de reaction atl courant électrique le plus douloureux, ni i la musique.

c) Raliallo, 26 ans, physionomie rígulicre, rire facile, inventeur d'un procéde nourean pour laver le res're, parle l'argot, aroue qu'il role pour se procurer 
l'argent nécessaire à une grande spéculation; c'est en somme un délinquant récidiviste d'occasion.

La photographie d'une femme nue ne produit mêne en lui ancune réaction la première fois, a la seconde fois on constate une légère descente de 12 pulsations; les pulsations deriennent irrégulières el il y a augmentation d'une pulsation avec anacrotique plus brère, à la quatricuse, of calacrotique horizontale, aree apex moins prononcíes.

Arec le comrant donlomenx ancune rariation. de la lisne, pourtant on a un soulevenent de l'anacrotique, qui est presque rertical, et la calacrotique deriont oblique et presente denx pointes. Et on a l'angmentalion dime pulsation.

d) Cilmano, 40 ans, pliysionomio normale, alconlique, parricide, depuis quelques annies repentant, smo une série de 30 tracés, ou le pouls se dessinait cependant d'une liscon très-claire, n'offre aucun plénomine à la douleur d'un courant de 30 , de 20 minutes, pas mine 0 deviation tress-claire de la ligne. Ine fois il ollie une riation a la vue du vin, aver élévation de 7 pulsations of avec une líger abaissement du pouls, ligne catacrotique plus oblique. Une impression pénible (souvenir do son fils tuí) seule, produit l'ascension do la ligne, mais seulement de la $4^{\text {e }}$ a la $8^{e}$ pulsation qui ne varie pas dans la forme.

Une autre fois senlement la mème émotion produisit. chez lni, i la $7^{e}$, un abaissement qui dura jusqu'il la fin de la $2 \mathbf{y}^{\mathrm{e}}$ pulsation.

e) Comino, voleur el récidiviste, a type criminel-ni, 17 ans, u'offe aucune réaction a la me d'un coutean, à la douleur ílectrique la plus intense, i la rue d'une 
femme nue; seule la vue d'un crine al celle d'un pistolet produisent une ligere élévation de la ligna.

f) Caselli, roleur récidiviste, 22 ans, prognilr, imberbe, sans affections, impudent, avec un pouls bien net, bicuspide. - Sur un premier tracé nous constatons, fuand on lui montre la photographie d'une femm. nue, une liggere hansse de la ligne, suivic d'une chint. mapide. (Mllas xru, fig. 1).

Figure 2: la vue d'un pistolel provoyne un alsaissement qui se minifeste tardivement et fui est de courte duréc. In contritie la vanité, aprés trois pulsations, produit un allongement de la 1 $^{\mathrm{e}}, 5^{\mathrm{e}}, 6^{\mathrm{e}}, 7^{\mathrm{e}}$ pulsition. suivi d'un notable aplatissement it la $16^{\mathrm{e}}$, $17^{\mathrm{e}}$, et $18^{\circ}$ pulsation, et un notahle abaissement de toule la ligne (n $\left.n^{\circ} \quad 3\right)$.

Le vin provoque la plus grande modification: dération à la $2^{\mathrm{e}}$ pulsation, suivic d'abaissement a la $10^{\circ}$, et encore ici d'un allongement d'abord, puis d'un aplatissement de la catacrotique, surtout de la ge a la 2ye pulsation $\left(\mathrm{n}^{\circ}\right.$ 4).

Sur un cinquième tracé nous trourons sous linfluence du revolver et d'un coup de pistolet! une pelite dépression arec la diminution de denx battements, ef abaiscement allx $3^{e}, 4^{\mathrm{e}}, 5^{\mathrm{e}}$ et $6^{\mathrm{e}}$.

g) Dalza, 30 ans, a un oncle fort. Ilonnète jusqư'i 24 ans, puis voleur. A 12 ans affections cícébrales. Front fuyant, atherome précoce, màchoire développée. Tatouages multiples. Un fort courant électrique provoque, apris 8 pulsations, une descente de la courbe qui ra en sarcentriant.

La ranité blessie produit une ascension subite, 9 pulsations; sous linfuence du calcul on a une hausso 
suivic de baisse après la $4^{\mathrm{e}}$ pulsation et qui dure jusqu'à la $16^{\mathrm{e}}$.

h) Agagliate, voleur, récidiviste, très-jeune, présente une réaction de descente et de diminution des pulsations sous l'influence de la musique triste; la musique gaie produit une ascension de 10 pulsations et leur accélération. Nulle réaction au calcul, à la piqûre, a lílectricité. Au contraite, le revolver fait monter la ligne sphygmographirue, mais pour \& battements seulement; la vanité jroduit le même résultat. La pensée de la machine électrique a aplati le pouls, de faron à le rendre à peine sensible durant 6 pulsations (peur).

Un autre jour, ni le pistolet, ni le poignard, ni le vin, ni une tête de mort ne produisirent d'effet bien net; la vinité fit monter la ligne du pouls pendant 12 pulsations sans modifier leur nombre.

i) Moss..., jeune voleur récidiviste, impudent, qui n'offere aucune variation à la ligne du pouls, ni à la vue de la femme, ni à celle du vin, ni í la musique, ni a un comrant is 25 ; seulement le comant it 20 produit une légère descente pour 20 battentents, avec pointe plus nette, et les pulsations se ralentissent de 25 à 14; la vue d'un poignard provoque une ascension légère; uno bourse garnic provoque un abaissement el une grando irrégularite du pouls pour 6 ballements.

l) Prato Teonesto, 17 ans, fils d'alcooliques avec lo type physionomique criminel, commence à 5 ans à dérober du vin dans la cave de son pire; il frappe plus tard par jalousie un de ses compagnons, abuse du vin et des femmes; la prison ne l'ennuic pas; il s'y trouve mème tròs-bien. Chez lui (Atlas xvir, 5) nous avons obtenu avec la musique triste un notable abaissement de la ligne sphygmographique, aree diminution et accéléra- 
tion de la pulsation. Même phénomène, après 4 pulsations, à la suite d'une musique gaie. - La photographie d'une fenme nue produit un aplatissement du pouls, le ralentit, el apres une brève élévalion abajse lat ligne.

Le calcul de $\{\times 12$ a produit une légère diminution du pouls et un léger abaissement. (xviJ, 7).

An tontraire la vue du vin $\left(n^{\circ} 8\right)$, la vanité flattéc $\left(1^{\circ} 9\right)$, élevent, puis abaissent la ligne du pouls el modifient le tracé du pouls: ces phínomènes se manifestent surtout quand il pense, une fois, au calcul erroné, et une fois au comrant.

Le pistolet ( $\mathrm{n}^{\mathrm{o}}$ 10) ne produit que l'aplatissoment aux $8^{\mathrm{e}}$ el $9^{\mathrm{e}}$ pulsations, élévation de la $7^{\mathrm{e}}$ el léger abaissement de la ligne.

m) hossano, simule lit monomanie, prétend être Nipoléon; éest un roleur récidiviste, impudent. Le plaisir qu'on lui faisait en feignant de croire à sa folie produisait une descente notable pendant 5 pulsations; mais la douleur électrique la plus forte ne provoquait chez lui quime légère descente à la $8^{e}$ pulsation.

n) Rastelli, voleur de grand chemin, feignant la folie (il se dit généralissime), a un pouls très-beau et tris-net.

Sous linfluence de la donleur électrique, on a une légère élévation pour 7 et encore plus en répétant l'excitation, on a la 2 e mesure, on al une déformation du pouls (fig. 8); mais on n'en observe aucune dans une troisième expérience analogue (tar. xvm ${ }^{\mathrm{e}}$ fig. 7); rien au calcul (fig. 6). Au contraire quand il se déclare généralissime, comme il entre dans l'ordre d'idées de folie simulée, si on lui dit: "Tu es fou» (fig. 4 et 5), on note un énorme abaissement. 
o) Reazzo, escroc, 2't ans, monomanie simulie, affirme aroir deıx têtes et los marionnettes dans le ventre; il compose des récits obscenes; il a un trèsbeau pouls. Nulle réaction an courant électrique le plus douloureux; an contraire, il offre me notable dépression ruand je lui dis à l'oreille: "Voici le juge qui vient te voir ). Néanmoins, l'allure du pouls ne se modifie (tabl. $x^{\mathrm{e}}$, Peur du juge, $n^{\circ}$ 11) que dans le plus grand relivement des sommets.

Le mème, mo antre fois, montre une variation nolable cost-it-dire un abaissement de la ligne qui étail. en hausse. Au contraire, $n$ courant Blectrique asse\% fort n’a pas produit la plus légère variation de la ligne, ni modifie l'allure du ponts (no 19); la musique amine un notable abaissement du pouk: une impression jsychique agrablse produit une ólévation suivie d'un notable abaissement (aplatissement du sommet).

p) P. R., voleur agressif, 19 ans, néprouve aucune ráation à la vue le la femme, ni ì une première el seconde piqutre. Une troisieme piquire provoque un trisrapide abaissoment, sans modifier la forme du ponls. Si on lui offre duvin, on a une amplitude plus grande du pouls et un abaissement de son lrace. benx fois la musique élève légèrement la ligne sphygmographique et une fois elle reste sans elfet.

q) Gatrett, 28 ans, 3 condamnations pour vol, fon el en même temps simulatrur de la folie. Il a commencé a voler dès 11 ans, en vagabondant par loute l'Europr; il voudrait renger la société on tuant quelque nunistre: "Tous ont peur de moi, dit-il, parceque un rien mexcite, et avec un contean je suis terrible». Sa mère élait folle. Son pere est mort d'apoplexie. 
A la vue du vin il présente mo élévation de 10 pmlsations et une descente de 7 .

En courant électrique doulourenx reste sans offet; un $2^{\text {e }}$ pourtant et $u$ ge, avec doulenr aigüe, produisent une ascension de la ligne (table xvit ${ }^{\mathrm{e}}$, fig. 2), ì la 4e é la $5^{\mathrm{e}}$ pulsation, suivie de descente, a la $10^{\mathrm{e}}$, salls variation notable dans la forme du pouls. En lui montrant lout-it-comp un poignard, on provoque l'alnaissement et la deformation du pouls la plus extraotelinairs que j’aie rne (lig. 1). Il présente ensuito au rourant élicetrifue donloureux un autre abaissement, mais moindre que le premier; plus cileve (fig. 3), an contraire, quand on lui montre des billets de 5 franes, avee une élivalion à la $g^{e}$ et à la $4^{e}$ et $u n$ abaissement qui depuis la $6^{\circ}$ contimme, arece un allongement de la calachrotipue, jusqu'il la t2e pulsation.

r) Robiola a tué une courtisane qui ne lui donnail plus d'argent; 22 procis et 2 condamnations. Physionomie belle, crine mal conformé. Sensibilité à la donlenret au toncher exquise.

La musique en sol produit en lui une élévation do la ligne.

Une violente et douloureuse décharge électrique prodnit un abaissement léger qui se maintient pendant 4 pulsations, et qui est suivi d'ascension pendant 7 ; les 11 premières pulsations sont de noitie mains amples, avec catacrotique oblique avec 2 sommets et l'anacrotica verticale.

Une autre douleur électrique produit un léger abaissement, qui devient au contraire considérable quand on lui dit qu’il sera condamné à 3 années de prison el non à mort, comme il le craignail. 
Sept fois le calcul taisse le pouls stationnaire; denx fois il te modifie, et ce sont les deux seules fois pendant lesquelles il te firit bien juste.

s) Roggero, jeune soldat, très-honnète, incitecré your comps dans une rixe, offere au contrate (table xir) an comant électrigue douloureux une réction extraordinaire abaissant lat ligne splygomographique, allongeant la calachrotique (it la $4^{\mathrm{e}}$ et surtout a la $7^{\mathrm{e}}$, $9^{\mathrm{e}}$ et $10^{\circ}$ ) qui se continne. Le calcul produit une dépression moins nette de la ligne i la $3^{e}$ pulsation, mais arec une notable modification du trace du pouls qui se montre plus aplati a la $6^{e}, 7^{\mathrm{e}}, 8^{\mathrm{e}}$ u $9^{\mathrm{e}}$ pulsallion (fig. 10) et ralenti.

18. - Plitismographe. - Chez quelques antres nous arons csavé l’étude du plétisnographe.

t) Chez Nonli Pierre, 21 ans, éuyer, physionomie de Mongol, ligger stribisme, rolem, recéleur el rolem. de grand shemin, doué d'une intelligence extraordinaire et ne rougissint pas, nous avous observé: une Blivalion de 6 mur. il la rue d'un cigare, d'un portrit de femme. La vue dime montre, produil un rapide abaissement qui dure 1',45"; si je linterroge, il matvoue que celle montre lui rappolle le temps où il en avait mne. - On a cependant $11 n$ aldaissement quand on s'enquiert de sa vie privie.

A un courant électrigue fort, on a une élévation de 17 millimètres suivie de diminution. Elívation de $26 \mathrm{~mm}$. après 30 secondes d'une musique galie suivie de dininution de 17.

On a un extraordinaire abaissement, $20 \mathrm{~mm}$, pendant 2', quand on lui lit sa propre autobiographie, en y mêlant des ćloges. 
Labassement se répete et dure pendant 4s" ruand on lui parle de nouvean de son hean manuscrit.

On a $u n$ alaissement de 5 mus. en applirguant de noureau un fable courant électridue, et de: mas avec la pointe. En $3^{\mathrm{e}}$ conrant électrique durant $10^{\circ}$, produit. In ahaissement de $40 \mathrm{~mm}$.

La musipue gaie a douné $11 n$ abaissement de 20 mm.,

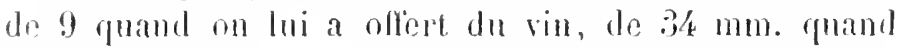
on lui a parté de ses rogages et flion l'en félicitait, ce prii est sa corde sensible.

u) Barelli, volemr, épileptique, 29 ans, impudent et espion, habitur a la vie pénitentiaire, qui nous parle son argot et nous déclare qu’il ne pourait dormir tranquille s'il n'arait pas volé queleque chose, offre in pouls filiforme.

lu plétismograple, réactions assez incertaines: élíration de 29 mm. après 15 secondes d'une musique gaie; de $1 \mathrm{~mm}$. sous lönfluence du vin, de $2 \mathrm{~mm}$. it la vue de l'argent, de 9 ì celle d'un cigare, de 2 sous l'influence d'un aimant ippliqué au front: cependant la mème musique produit un abaissement de $2 \mathrm{~mm}$. un peu apris; il en est de même pour le vin. En lui disant à l'oreille, en arot, qu'il est un monchard, on obtient une élération progressive de $4 \mathrm{~mm}$, rui ne dure pas moins de $2 \mathrm{mi}-$ mutes et 30 secondes, et qui descend ensuile.

v) Riroire, d'une physionomie agréable, de bonne fanille, commence it gaspiller sa fortune quand il est étudiant, et peu ì peu devient roleur et récidiviste, rougrit futilenent et il a bonte de son crime; sous l'influence de la musique et it la premiere minute, on voit abaissenent dis $3 \mathrm{~mm}$. qui ra s'acentuant et all bout de 2 minnles 1 2 altein! dijic 18 mun. 
c) Bastrenta, délinquant très-robuste, latoué, alcoolique agressif. Le calcul chez lui produit une élévation de $22 \mathrm{~mm}$. en 1 minute, la musique une élévation de 29 - 1,30, suivie d'une baisse. La vanilé rju'on réveille en lui en rantant ses prouesses musculaires, produit un abaissement de $45 \mathrm{~mm}$., suivi quelques minutes après d'une élévation de $34 \mathrm{~mm}$. De nouveaux éloges faits tout de suite après donment un abaissement de $15 \mathrm{~mm}$. La douleur électrique la plus forte, après 1,30 , provorque un abaissement de $11 \mathrm{~mm}$. suivi diune élévation de $5 \mathrm{~mm}$.

y) X..., escroc récidiviste. Le chagrin provoque un abaissement de $1 \mathrm{~mm}$; la vue d'un cigare, une élévation de 12, suivie d'un abaissement de 51 mm. quand on lui en fait cadeau; au contraire $1 \mathrm{~nm}$. seulement sors l'action d'un tres-fort courant électrique.

19. - Il est difficile, bien que ces expériences aient bé répéties durant une année, d'arriver a des conclusions certaines, si nombreuses sont les causes qui modifient cette importante réaction vasculare; mais il parait évident que l'absence de réaction au courant ćlectrique douloureux constatée dans les observalions $a, c$, $e, d, f, l, m, o, q, y$, correspond à cette analgésie que nous arons tromée si fréquemment, en sorte que, la douleur faisant défuut, le stimulus natlire pas l'attenlion, n'arrive pas aux centres psychiques; c'est comme sil ne s'itait pas produit, (font exception les observations $g, i, m, s, t)$. - La même raison explique les autres effets nivatifs.

Il est clair, viccversa, que lorsque les impressions les plus spécifiques sont en jeu, comme la peur du juge (lieazzo) on la lichelé (Goretti, a la vue du poignard), ou les excitants prefores, comme le rin el la lemme, $a$, 
$d$, lor $(i, t$, $q)$, el surtout la ranití, comme dans los ohservations $f, h, l, i, s, x$, on at alor des riactions supérieures anx normales; éest ce qui nous permot de pénétrer, romme avec un instrmment de procison, dans leur psycholosic intime sur laquelle le plaisir, la vanilé et la crainte de la douleur ont plus de pouroit que la varic doulour elle-mème.

On dirail que diuns quelques cas la réaction est d'alltaut plus lente, quiclle est plus exagéce en d'aulles, comme si certaines excitations agistatent plus elez le uns que chez les antres; ce qui est toul-i-linil daccord avec ce que nous sarons, e'est-à-dire, qu'ils sont d'autant plus inseusibles a certaines affections of douleurs physiques et psyehigues, qu'ils le sont moins a certaines autres passions, comme l'oreuteil, la vengeance el la ranitr.

festime que les uriminels les plus intelligents et les simulateurs $(0, n, m, t)$ ont réagi plus nettement, surlout quand on faisait allusion i leur lolie, ou au juge ctc. Le plétismograplıe est donc ici un précicux moven de diagnostiquer la simulation.

20. - Résumé. - Application. - De l'ensemble de ces laits on pourrait déduire que presque tontes les diflërentes espèces de sensibilité sont obtuses chez te criminel; même chez le eriminel doccasion, comparé à l'homme normal; tandis que chez lui comme chez les alionés et les hysstériques, la sensibilité aux métaux, à l'amant et à l'atmosphère et peut-être aux odeurs est exagérée.

Leur insensibilite physique rappelle assez bien celle des peuples sauvages qui peurent allionter, dans les initiations a la puberté, des lortures que nr. supporterait jamais un lıomme de rave blanclic. 
Tons les voyageurs connaissent l'indiflérence des nègres et des sauvages d'Amérique à l'égard de la douleur: les premiers se coupent la main en riant, pour échapper an travail; les seconds, liés an poleau de torture, chantent gaiement les louanges de leur tribu, pendant quion les hròle i petit feu. $\Lambda$ l'époque des initiations, quand ils atteignent l’àge viril, les jemnes Peaux-Rouges se soumettent, sans laisser échapper la moindre plainte, à des supplices qui feraient mourir un emopéen: ils se suspendent, par exemple, in moyen d'un crochet qui mord leurs chairs, aux poutres d'une cabane, la tête en bas, an milien d'une fumée épaisse. Il faut encore rapporter à cette insensibilité les tatomages douloureux que supporteraient bien pen d'Européens, et liusage de se couper les doigts, les lèvres, on de se creuser les dents, en signe de denil, lans les cérémonies des funérailles.

21. - Longévité. - Cet affaiblissement de la sensibilité, principalement en ce qui concerne la douleur physique; et, d'un autre côté, la fréquence moindre de réaction vasculaire, nous meltent, pour ainsi dire, entre les mains, la clef de la vitalité plus grande des malfaiteurs, bien quils soient, ì proprement parler, malades depuis leur naissance. Assurément, si l'on compare la vie moyenne des prisonniers à celle des hommes libres, on constatera une infériorité chez les premiers; mais les causes délétères inhérentes au régime de la prison sont en si grand nombre, qu'il est inutile d'insister pour expliquer ce phénomène. Rendez les conditions égales, et vous verrez aussitòt la différence changer, précisément à l'avantage des criminels. 
Nous trouvons, en elfet, des cas extraordinaires de longévité, remarqués rit et li chez des individus soumis depuis de longues années au rógrime de la prison. "J'ai rencontré dans les prisons, ícrit Casanova (Mémoires, III, 350), des individus qui étaient parvenus à un degré de vieillesse trés-avancée: un scélérat qui faisait le double métier d'espion et de sicaire, un certain Beguelo, enfermé à 44 ans, vécut 97 annéces dans sa prison.

A propos de Gasparoni, mort tout récemment it Mbbiategrasso, a liage de 88 ans, un biographe intelligent disait, il y a déja bien des années, en 1866: "Comment a-t-il pu résister si longtemps aux épreuves de l'igge, de ses blessures, de la fatigue et de la prison? Par la force de son caractère et surtont par le calme inaltérable d'un esprit que nulle émotion ne put jamais toucher" ". (Nasi, Mémoires de Gasparoni, 1867).

Settembrini, dans ses Mémoires, (t. II, p. 125), cite un vieillard qui vivait au bagne de S. Stefano depuis 82 ans, et en comptait 89 . Il parle encore d'un calabrais qui se vantait d'avoir tué 35 hommes et qui, condamné pour viol et brigandage en 1802 , vivait encore en 1825; d'un vieillard de 81 ans qui, avec son fils àgé de 51 ans, avait été condamné pour vol suivi de meurtre sur la personne de l'infortuné Procaccio; enfin, d'un autre de 92 ans, dur et sec, qui avait conservé toutes ses dents, toutes ses facultés mentales, ef une grande partie de sa force juvénile.

Cette longévité chez les grands criminels peut se prouver, jusqu'à un certain point, par la statistique. Déjà Settembrini, pour la démontrer, avait dressé le petit tableau suivant: 
Sur 631 de ses co-détenus, il en comptait en effet

\author{
227 âgés de plus de 50 ans \\ 203 id. de 30 aे 40 ans \\ 201 id. au dessous de 40 ans.
}

Jjoutons que le doct. Baer, alpres aroir constaté qu'en Allemagne la population des bagnes donne une mortalité inlérieure à celle des prisons, trouvail à cela deux raisons: d'abord, que les galériens sont plus labilués au légime de la prison (il est en effet notoire que dans les premic̀res années d'incarcération la mortalité alteint un chiffre plus élevé); en second lieu, que, plus le détenu est endurci dans le crime, plus grande est la résistance qu'il oppose it la mortaliti. (BAEr, Les prisons, établissements et systèmes de penalité au point de vue hygiénique, trad. ital. de Roggero, 1872-73).

En Italie (Riseri, Sulle condizioni sanitarie nelle carceri, 1881), les bagnes (où sont en plus grand nombre les criminels-nés) donnent aussi une mortalití inférieure, 93010 , il celle des prisons 51 .

22. - Pitie. - Cette analgésic est, comme observe Bénedickt (Congrès d'Anvers, 1886 ), une des sources de cette manque de compassion, de pitié, que justement Garolalo a domnée comme un des caracteres du criminel-ne.

Si nous royons souffril autrui, dit-il, nous ressentous nous-mèmes à l’aide de notre mémoire de pareilles sensations, pour ainsi dire, une copie de ces souffrances. De là nail la compassion, que nous comptons parmi les vertus. Plus nous sommes sensibles, plus nous sommes disposés a la compassion. Lorsqu'il y a une diminution congrinitale de sensibilité pour les douleurs et los sen- 
timents désagréables, alors l'aptitude à la compassion filit presque defaut.

"C'est dans ce défaut de compassion quil faut chercher une des sources de la cruauté qui pousse a des actions criminelles de violence".

23. - Disvulnérabilite. - Cette analgésie est également la source de la disvulnćrabilité signalée par M. binédickt chez les criminels, et graice it larpelle ces geus lit supportent des blessures auxquetles tout autre succomberait: il a vu un brigand de la faneuse troupe de Roza Saudor, qui, ayant pris part à une révolte de prisonnicrs, fut battu d'une telle manière quil en cul plusicurs vertèbres fracturées. Toutes ses blessures guirir'ent, et le géant d'auparavant devint une sorte de nain; elı bien! il l'a vu plus tard travaitler dans la forge de la flison et se servir du lourd marteau comme dans les jours de sa plus grrande vigueur.

Pour ma part, je n'en ai ru de plus étranges encore, III voleur eut dans une escalade le frontal droit fendu latératement par un coup de lache; en 15 jours il était guéri sans aucune réaction. - Le crìne du même Roza Saudor, dont parle Bénćdickt avait une énorme dépression de l'os parićtal gauche, effet d'une blessure d'arme à feu, qui ne l'avait pas empêché de tenir tête, plusieurs jours de suite, aux troupes autrichiennes et I'llsses.

Dans la prison, où jo suis médecin, un meurtrier fui travaillait comme macon, reproché pour une méprise, se jeta du troisième étagge dans la cour; tous le croyaient mort, quand tout-it-coup it se live un souriant, et demande à continuer son travail. 
Une infanticide Velletroise tout it l'heure se fit sur elle-même avec un couteau de cuisine l'opération Césarienne, en exportant l'enfant qu'elle tua; elle en est guérie presque sans pansements et sans fièvre (Riforma Medica, 1886, avilil).

Justement Bénédickt, trouve, dans cette disvulnírabiliti, une antre source de leur manque de compassion et le leur penchant aux riolenees.

Quiconque gagne, dit-il, dans une rixe une fracture de côte el sattire par lí une plemésie qui le retient des mois an lit, ivitera autant que possible une seconde occasion. Mais si un individu avee une telle fracture est capable, comme je l'ai vil, de fendre du bois les jours suivants ef d'aller en voilure sur des routes raboteuses de montagnes, il n'éprouvera pas un bien grand dégont à courir de nouveau les risques d’être batıu.

Vous comprenez qu'un tel individu se trouvera lacilement dans le cas d'ètre aceusé et condamné, une fois on l'autre pendant sa vie, pour un erime de violener.

Les individus, qui possedent celte qualite, se considèrent comme des privilégiés, et ils méprisent ceux qui paraissent délicats et sensibles. Ciest un plaisir pour ces hommes durs de toulmenter les autres, qüils regardent. comme des créatures inférieures.

Voilà une seconde source de la cruauté des criminels.

24. - Poids et taille. - Lanalgésie explique également pourquoi leur corps est relativement plus lourd que celui des personnes honnêtes; on se rappelle en effet que nous avons signalé cet excès de poids et de taille dans leurs cadavres. Il y a bien là une opposition avec l'étal doublement anormal et pathologique qui le caractérise; mais ce désavantage est neutralisé par l'analgésic congr. 
nitale, et par la diminution de réaction vascubatre, qui compensent les effets du mal et donment au sujet un sureroit de vic. C'est lí un fait trés-important el quion ne s'expliquait pas avant notre époque; aussi voyalon l'homme du peuple, et même le magistrat, esquissel un sourire d’incrédulité, quand on leur présentait le criminel si florissant el si vigoureux, comme un ètre malade.

llobbes, pourtant, avitit dejà écrit: Homo malus infans robustus - ct le peuple disilit, qui sait depuis quel temps?

" Manvaise herbe croit toujours ".

"Namiaise herbe ne meurt jamais" (I'asfualigo).

" llerbe folle pousse vite (Id.).

"L'ime enfermíc dans un corps vicieux lui tient lieu de sel » (Giusti).

Et le grand poète de Florence:

$$
\text { .... La mort }
$$

lerrobe les meilleurs et laisse vivre les coupables.

25. - Mancinisme. - Mais un liait plus imprortint peut-ètre c'est la grande proporlion des gatuchers qui se ratlache it ce qu'on voit chez les enfants et les sauvages, qui, on le sait, sont frequemment gauchers. (Le Bor, Revue scientifique, 1883).

Ce phénomene paraitra tout d'abord plus étrange que les autres; mais, si l'on suit avec attention les recherches faites sur le cerveau el celles sur la sensibilité doloriphique et tactile, on verra qu'il n'en est que la continuation, puisque, dans un grand nombre de cas, lit sensibilité est plus émousséc à droite qu’à gauche, el puisque on a démontré la prédominance du cràne et du cerveau à droit, dans les criminels (1).

(1) Voir page $180^{\circ}$ et page 18?, o ù par erreur on a écrit gauche pour droit, mais le texte eclaire l'erreur. 
De l'aveu de tous les savants, le mancinisme (OciLE. Med. Surgical Society, 1871, Londres) résulte de la supiriorité de l'hémisphère droit sur le gauche, tandis que, chez l'individu de constitution normale, c'est lo gatrho qui prévaut (1).

Fícemment le docteur Broca, et avant lui Ogle et Iackson (S. George, Hosp. Reporter, 1867), ont remarqué que, chez les ganchers aphasiques, les circonvolutious frontales de droite présentaient des extravasations plus frifurentos: et lo doct. Lépine a ru, des gauchers arce. lísions dans les circonvolutions frontales de gauche yui n'alaient aphasiques.

Il ost probable que le criminel travaille plus ared le lole droit comme l'honme normal arec le gauche.

Duand le peuple se méfie d'un gaucher et le traile l'homme sinistre, it ne fait qu'exagérer el génératiser un fait vai an fond et que seule une longue olservalion pourait laire commaitre et confirmer. Remarguez, hien encore que to peuple, en Emilie et en Lombardie sullout, de mème quien Allemagne (Linher), rattadie plus particulièrement an unancinisme l'idéc d'escroquerie. or ee sont les criminels de ce genre qui nous ont fourni l:1 plus forte proportion de gauchers $(330[0)$ (2).

Yous avons vu le mancinisme musenlaire dans des proportions it peu-près normales chez les fous. Ceux-ci, an contraire, principalement fuand ils sont alcooliques

(1) Loyeroso, Sul mancinismo, ete., Turin, 1884.

(2) On dit en Franee: "Un gatueher ne fait rien idroit ". (Lenorx, Dictionnaire comique, 1786). Les Indiens eroient que les gauehers sont poss'dés de l'esprit du mal; ils leur témoignent le même dédain qu’à des itres difformes. (Lror, Della legge di produzione dei sessi, 1si2).

On lit dans Rieciardi (Cont. polit., 2-3) : "Est-il possible que cet animal t*ait chasse? que ee fourbe et es gourher puant t:ait traite de la sorte?" 
parésiques on monomanes, sont plus smjets an mincinisme sensoriel; M.J. Amadei of Tommini lont obsure anssi bien que moi (1). Les olservalions du doctrur Danillo prouvent que la privalence en cux du cervean gauche n'est pas considirable, quoigu'en dise .1. Lusts, qui ne s’appuie que sur trois cas (1. e.). De nourelles reherches laites par le doct. Amalei sur 52 erines dr fous prouvent qu'il y avait on enx privalenee de plagiocrphalie, a droite, dans 29, it ganche, dans 71010 - La conclusion est done bien nelle: si, dans la provabmeo du cote droit, le lou l'mmporte sur l'homme normal, il to cède de beancoup au criminel. Et cela s'itcorde aree la rareté du manoinisme musenlaire.

On remarque dans les fous, ainsi que dans les erimimels, l'absence de réaction rasomotoire i lhydrosphy?mographe. (T. Archivio di psich.,. t. v, lasc. II).

Diautre part, on roit deus fois plus de criminels que de fous incapables de rougir; cola rísulte des itudes frites a ma pricre par M.I. Mmarlei, Tonnini ot Bersesio (Archivio, 1. v., fasc. i). Ponr constater un fitit analogue, il faut descondre jusfunanx irliots de la derniere categorie (Browne) et anx perplates sanvages los plus grosienes (2).

(l) Vingt snjets ayant iti examinís an point de vue de la sensibilite. tartile et physique. on a relevi lo maneinisme sensoriel dans lo-? sur

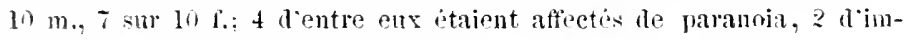
b ieillite, 2 de manies piriontirues.

(2) La rongeur a manque dans 16 fous $\mathrm{m}$. sur 73 , et tans $15 \mathrm{sml} 53 \mathrm{f}$. 11 en a it: de même dans 2 fons moranx sur 10, dans 5 maniaques sur 12, dans \& hypocondriaques sur 12, dans 12 pollagres sur 20, dans 4 nonomanes snr 30 . On a vu rougir tons les faibles d'esprit, alcooliques, diments, paralytiques: ces derniers plus que tous les antres (Tomuinim. 
Dar'win nous a fait connaitre la façon de rougir des nègr'es albinos et des mulâtres, des Lekkas et des Chinois, des Aymaras et des Polynésiens. Il convient que les Chinois et les Malais rougissent peu, les Hindous rarement, de même que les Américains du sud, dont les Espagnols avaient coutume de dire: Comment se fier a des hommes qui ne savent pas rougir? Martius a remarqué, de son còté, que les aborigènes du Brésil n'y sont sujets ru'après un long contact arec les blancs.

Quant à l'analgésie et à la disvulnérabilité des sauvages, cest une chose déjà connue. Récemment M. Nerazzini nous écrivait avoir vu des Denka blessés, avec l'ouverture de larticulation de l'épaule, marcher à pied 10 kilomètres sous le soleil de l'Alrique, sans avoir pas mène de fière; il a vu des Gallas désarticulés à la main droite marcher avec l'arnée ennemie comme guides. 
CIIAPITRE III

De la sensibilité affective.

1. - En génélal, chez l'homme eliminel, l'insensibilite morale est aussi grande que linsensililite physinue; sans doute l'une est un effet de l'autre. Ce n'est pas qu'en lui la voix du sentiment soit toulatlait muette, comme le supposent quelques mauvais littératenrs; mais il est certain que les passions qui font bature arec le plus de force le cour de l'homme normal, sont très-faibles chez celui qui nous occupe. Le premier sentiment qui s'éteint dans ees êtres est celui de la pitié pour la souffrance d'autrui, el cela justement parcequ'il est insensible lui-même aux soulfrances (V. pag. 323). Lacenaire avouait n'avoir jamais tremblí à la vue d'mn cadarre; il faisait tontefois une exception 'n lareur de son chat. "La vue d'un mourant, disatit-il encore, ne me touclie guère. Je tue un lonme commc je boirais un verre de vin ». En effet, l'indifférence complite en face de leur victime et en présence des instruments ensinglantis qui ont servi à perpétrer lo crime, est un caractère constant chez tous les rais criminels d'habitude; et ce caractère suffirait a les distinguer de l'homme normal. Martinati contemplait sans sourciller la photographie de sa femme, en reconnaissait l'identité, et racontait froidement qu'apr'es lui avoir porté le coup mortel, il arait osé implorer son pardon. 
"Elle me l'a refusé, "disait-il en terminant som récit. La Maruet avait jetí dans un puits sa prope fille afin de pouvoir acenser de ce clime une voisine qui l'avait offensée. Vitou fit périr par le poison son père, sa unire el son frire, pour entrer en possession de quelques ecus.

Militello, un assassin prícoce, presfue un enfant, an moment oi il renait de tuer son camarade et son ami, iprouvail si peu d'émotion, quil tentait de corrompre les domestiques pour se faire liver passage et se saurer.

2. - Cola nons explique l'autographe de Troppmann qui, lans sa prison, demandait ì son frie de l'acide prussique ot de l'éther pour luer ses gardiens, aussi natmellement qu'il êtu demandi une orange. (V. Maxme Hu C.unp, Archivio di psichiatria e sciense penali, noInme Ir). Cola nous explipue rigalement romment il mut. le comp (pensant renir ainsi en aide à sa défense) de reproduir l'affrense scène fre memtre dont il avait été l'unique anteur el dont il restait lo saul témoin. Yons avons de lui, en effet, $11 n$ dessin tres-grossier, don de I. Maxinc du Camp à notro Archivio; dans ce dessin on voit denx petites victimes étendurs sans vie aux pieds du mourtrier, los autres quatre, frappros par lui, élèront los mains dans l'altitude du désespoir (l'. labl. xix $)$; comine pour ajouter un dernier outrage, ce monstre calomnic sa victime après l'avoir tuce: car il y essaye do jrouver, ou, ponr mieux dire, d'insinuer que l'autour dn erime ctait lo pere lui-mème, l’infortuné Kink avee, linscription :

"C'est comme c'est arrivé que linkle le père misérable qui ma perin, il a tué tonte sa famille" (sic). 
Un homme poussé au crime par la passion on par une circonstance impréve, anrait éprouvé de l'horrem au souvenir d'une pareille scène of ambait lait tous ses efforts pour l'effacer de l'esprit des antres; lui, an contraire, s'y cramponne el s'effore de l'étorniser. Li an roit lit, aussi, un pen de cette complaisance dams lo erime, qui est propre au délinquant-né.

Boutellier, à vingt-un ans, tua sa mire de j0 coups de conteau el, se sentant faliguí, se jeta smi un lit roisin, on il dormit paisiblement. Robolio fit pares, comme pour une noce, le cadarre de sa femme, et le placa a table entre lui et les deux fossoyeurs; tous les trois, dans cette position, eurent l'affreux comage de prendre leur repas. Relisez les proces de Sonfllard, Menesclon, Lesige, La Pommerais, la Polmann el ses filles, Gillthrie, vous y verrez que ces monstres ont dormi penlant tonte une nuit a coté de leurs rictimes; le dernier cite, Gauthrie, fit même ainsi pendant denx nuits de suite.

Corroisier, qui avait compé à morceaux le adarre de son ficre, ne voulut pas interrompre son repas duand on iui présenta les membres de sa victime. "Il est bien mieux lat que dans mon ventre, " disait-il; et, comme on le menacait de la guillotine, il reprit: "On pourra bien me mettre en denx, mais non en six, comme jai fait de celui-ci; son cerveau a jailli à une hauteur de dix pieds. Que nai-je pu rous traiter ainsi!"

Verdure, pendant quion exécutait son frère, dérobat une bourse el quatre montres. "Quel malheur, disaitil, qu'il ne soit pas la pour en avoir sa part! " Lemaire, apres avoir tué Deschamps, voulait en faire autant à son fils, et disait à ses complices qui l'en ompèchaient: "Et quoi? j'en tuerais des milliers sans le moindre soucis. 
Clausen, Luck, dit Casper, parlaient de leur crime devint le tribunal avec tant de sang froid et d'indifférence, qu'on les en aurait crus les témoins plutôt que les auteurs.

C'est pour cela aussi que, dans l'argot des prisons, lidée de l'homicide est expriméc par des termes burlesques tels que faire la saigníe, faire une boulonnière, faire suer. Cette apathie extraordinaire, cette insensibilité en présence des souffrances d'autrui, il n'est pas rare de voir les criminels la garder pour eux-mêmes, et cela en vertu cettainement, de la loi qui donne l'égoüsme four base a la pitié. On a vu, il est rai, des individus, tels que la marquise de Brinvilliers, Antonelli(1), Bogria, Vallet, Bourse, frappés d'épourante en face de l'échafand; mais il n'en est pas moins rai que la plupart conservent une grande indifférence jusqu'ì la dernic̀re lieure, et, par cette aptitude, prourent que l'anour de la conservation, - linstinct le plus commun et le plus fort dans l'homme, - a complètement disparu de leur âme.

Pantoni, notre bourreau émérite, me racontait que prespue tous les yoleurs et les assassins marchent à l'échafaud en raillant. In bandit de Voghera demanda, quelques heures avant son exécution, un poulet bouilli, et le mangea tout entier de fort bon appétit. Un autre voulut, parmi les trois bourreaux, choisir son professeur. Valle, l'assassin d'Alexandrie, qui arait blessé moltellement, par pur caprice, deux ou trois de ses com-

(1) Quelques mois après que celui-ci eut commis son erime, on le vit lire et relire les articles du colle pénal où se trouve édictée la peine de nort contre les assassins; on l'entendit déelarer d'une voix émue qu'il les croyait injustes. Il louait, au contraire, le petit ouvage du doct. Poletti sur la Tutelle pinale, qui en relevait l'injustice. 
pagnons, chantait à lue-tète en marchant a lichatand, le refrain bien conmu: Non, cest pus mai que la mort soit le pire des maux. Orsolato, trainé an supplice, adressait à toutes les jemnes tilles fu'il remeontratit llus gestes obscènes, témoignant que, s’il cùl été libre, il anrait. répété sur elles ses horribles mifails. An prêtre qui lui prêchait to repentir, Immoland rapuclait la lonteille de vin quil lui avail promise quinze jours auparavant. Sur le point de monter les degres de l'échafaud, la dernière, la seule chose qu'il recommandà à sa femme, qui ilait aussi sa complice, fut de laire rentrer me créance de 87 francs. La Tiquet sorrangeait tranquillement les cheveux pendant l'exécution de son complice: clle devait pourtant monter sur l'échafaud aprés lui. L'ancien bourreau Capeluche, royant que son exécuteur n'arrangeait pas bien l'instrmment de mort, se fit délier, disposa convenablement le billot et s'y placa ensuite avec la plus grande tranquilliti. Coonor fit de mème.

Les livres sont remplis d'épigrammes plaisantes décochées par les condamnés dans la dernière heure. On raconte qu'un assassin, ayaunt déji la lète sur le billot, cria a son complice qui se plaignait: "Ignorais-tu, par hasard, que nous étions sujets à une maladie de plus?» Le bourreau s'excusait anprès d'un goitteux dont il ne pouvait saisir le cou, jurant que cela ne lui était jamais arrivé. " $\mathrm{Xi}$ à moi non plus, " ripondit le patient. En Toscane on se rappelle encore le mot du Rosso, qui se plaignait du mauvais état des rues par oú on le faisait passer pour aller au supplice. Vidocq raconte encore qu'un savant conduit à l'échafaul disait, en montrant du doiggt la hàche et la fosse: «Voici l'alpha et l'òmég̨a... toi, bourreau, tu es le bèta \%. Allard fumait en écontant lire son arrèt de morl. "Je fume ce cigare, disait- 
il, avec préméditation el guêt-apens ». Verger se préoccupait fort de ses ourrages inédits. La Pommerais donnait des leçons d'hygiène à ses geôliers. Bocarmé répondait au bourrean qui le pressait en alléguant l'heure arancée: "Sois sans crainte, on ne commencera pas sans moi ". (Claude, o. c.).

3. - Cette insensibilité est encore pronsée par la fréquence des meurtres commis peu de temps après une exécution el dont les auteurs avaient été témoins; par les sobriquets que l'on donne aux instruments du supplice el aux exécuteurs; par les récits que l'on fait dans les prisons, où le thême favori est toujours la peine de mort (1). C'est même lit un des arguments les plus puissants en faveur de l'abolition de la peine capitale, peine qui certainement détourne du crime bien moins d'individus qu'clle n'y en pousse, gràce ì cette loi d'imilation qui exerce un si grand prestige sur les masses; graice encore à cette espèce de charme horrible qui attire la foule antour des rictimes de la justice, à cet appareil lugubre et solennel si propre ì chatouiller la vanité des autres malfaiteurs, ol qui va jusqu'a faire vénérer comme de 'saintes reliques les corps des justiciès. (V. Sur les crânes des criminels. - Appendice).

Sur 167 condamnés a la peine capitale, en Angleterre, 164 avaient assisté à des exécutions. (Lris, Della penu di morle, 1872). Dans le Catalogue ms. des justiciess, que l'on conserve à la bibliohthèque Ambrosienne,

(1) Frbgier, Des classes dangerenses, 1841, p. 111. - Vans largot allemand, être pendu se dit: Heimgang'n, retourner à la majson. En français, le bourrean s'appelle Juge de paix; la gullotine, la verere; gallotiner se dit raccourcir. 
on trome enregistré le supplice d'un certain Magni, condammé jour mentre. - Il arait présidé lat confririr de St. Jean le décapité.

Cette insensibiliti pour enx-mèmes et a l'égand des alllles (de mème que lenr analgésie el teur disvulnérabilité (v.s.) nous fait comprende le courage extraordinaire que semblent awoir parfois certains malfiteurs. Ilolland, Loineau, Hottino, Fieschi, Saint-Clair aratient conquis la médaille militaire sur les champs de bataille. Coppa se jeta un jour tout ammé an milien d'un bataillon des nòtres, dechargea son lusil, el s'espuival siln el saut. Il fut tué peu après par les siens qui, n’ayant pas osé le suive dans sal folle entreprise, redoulaient sal vengeance. I'almieri, autre thef de brigands, se royaul serré de pres par les nòtres, alla chereher la mort atu plus fort de la mêlée. Masini, Francolino, Ninco-Nanco, Cilnosa, Perchoco, préférérent à la prison une nort hóroïque. Les klephtes lurent longtemps en Grèe los seuls soldats, les seuls léfenseurs de l’indépendance.

Et pourtant la plupart des mallititeurs font montro d'une grande lìcheté quand leur surexcitation est tombie et qu'ils se trowvent en face d'un peril inattendu; l'expérience nous l'alpprend, et nous le savons anssi fial' le splugemograplic.

Il y a quelque temps, l'intripide chof de la police de liarenne, Il. Serafini, apprit qu'un assassin des phus dangereux sétait vanté de le tuer: il le fait renir, lui met dans la main un pistolet, et l'imvite a tires sul lui. L'assassin aussitòt de pailir, de [rembler' sur quoi il te chasse en le souffletant. De mêne M. Elan Linds s'enferma un jour dans une chambre avee mn galéricon léroce qui arait juré de lui donner la mort; il so fit riser par lui of le congédia ensuite en disant: "Je 
n'ignorais point vos projets; mais je vous méprise trop your yous croire capable de les exécuter. Seul et sans armes, je suis plus fort que vous tous réunis ».

C'est ce même Elam, qui calmait une révolte de prisonniers en se présentant sans armes an milieu d'eux. A Sing-Sing, 900 détenus travaillent sans chaînes en pleine campagne, et n'ont que 30 gardiens. "C'est, disait l'iilustre directeur des prisons, que l'homme malhonnête est un homme essenticllement làche ». (Systéme pénitentiaire par MM. Beammont et Toquerille, 1897, t. I, p. 183, t. II, p. 160).

Lacenaire perdait la tête all moindre obstacle et criait: Sauve qui peut!

Le sphygmographe nous a révélé quelle profonde impression la vue d'un poignard dégaîné ou d'un pistolet produisait sur denx criminels qui étaient pourtant habitués à manier ces instruments de meurtre: la plus vive douleur physique les affectait beaucoup moins (voir pag. 315$)$.

II est donc probable que les actes de courage des malfaiteurs ne sont qu'un effet de l'insensibilité et de l'impétuosité enfantine qui leur cache le danger, même certain, et les rend aveugles en présence d'un but à atteindre ou d'une passion à satisfaire.

Cette insensibilité qui leur dissimule et la gravité de la mort d'antrui et la propre, jointe à la véhémence des passions qu'ils éprouvent, explique la disproportion quion remarque parfois entre le crime et son mobile. C'est ainsi qu'on a vu un galérien tuer un de ses co-détenus parcequ'il ronflait trop fort, (Lauvergse, p. 108). Au pénitencier d'Alexandrie, un prisonnier tua un de ses compagnons qui se refusail à cirer ses souliers. Dans le Milanais, on a vu récem- 
ment un meurtre commis dans une prison pour une pelletie de fumier. De mème, en Calabre, me querelle pour cinq centimes s'est termince par un assissinall. Cette inscnsibilité morale dn criminel, ainsi que son analgésic (v. s.) nous dit encore pourquoi la cruanté se manifeste si souvent cliez des individus (nui semb]ent parfois accessibles à la lionté.

4. - Conclusion. - Nous concluerons en disant: que l'aberration du sentiment caractérise le cuininel aussi bien que le fou, et que si un haut degré d'intelligenee peut se rencontrer avec une tendance au crime et à la folic, jamais eelle-ci s'aceorde avec le sentiment affectif normal. Puglia Archiv. di psich., III , p. 392) l'avait déjà entrevu, ainsi que M. Poletti (Il sentimento del diritto penale, 1887, $2^{a}$ ed.). Cela s'aceorde arec le fait qui a sans aucun doute frappé nos lecteurs dès les premiers chapitres de ce livre, à savoir, que, dans nos criminels, les altérations dı visage et des yeux sont plus fréquentes que celles du crâne. En effet, les anomalies de l'intelligence ont plus de rapport avec celles du erûne, et les anomalics du sentiment avec celles de la face et surtout des yeux.

Nais ce sujet est d'une trop grande importance pour que nous ne le reprenions pas dans les chapitres suivants. 


\section{CHAPITRE IV}

\section{Le suicide chez les criminels.}

1. - Cette insensibilité aide enfin à l'explication d'un phénomène qui, - tout récemment M. Morselli l'a trèsbien constaté dans son livre Le suicide, 1879, - est, bien des fois, la marque caractéristique des délinquants. Je verix parler de la fréquence du suicide.

En effet, le suicide chez les criminels oseille selon les mèmes lois qui rógissent le reste des hommes. On ne doit pas oublier en effet: qu'il abonde surtout dans l'été; que ses victimes appartiennent de préférence au sexe màle: célibataires et veufs, entre la $21^{\mathrm{e}}$ et la $31^{\mathrm{e}}$ année; qu'il s'est multiplié chez les penples les plus civilisís et chez ceux où il était déja le plus répandu, par exemple en Saxe et en Danemark, anssi bien qu'en Ilollande.

Ajoutons que pour une proportion notable, qui peut aller à $390_{10}$, la tendance en est favorisée par la névrose ot surtout par les maladies mentales (Morseldi, l. c.). La cause done, est presque partout la même.

C'est dans la grande fréquence que git la différence. Sur 100.000 individus, en effet, du sexe masculin qui se sont suicidés, on compte(1):

(1) Stratistique quenit. internat., home, lsit. 
Prisonniers

En Italic . . 17,00

En Ilollinde . . 130,00

En Norvige . . 74,00

En Ingleterre. . 28,00
I'opulat. Hbre

6,2

12,0

9,4

6,9

๖. - Il faut sc garder de croire que ces molts rolontaires si fréquentes aient pour mobile unique le chagrin que cause la condammation, les souffrances yui rísultent diune incarcération prolongée, la privation de toute société. Les suicides sont, il est vrai, bien plus nombreux dans les prisons cellulaires (1) que dans celles oi les détenus sont mêles; mais dans les premieres, la plupart de ceux qui en viennent lit appartiennent à la catégorie des prevenus (en Italie $380_{10}$ ) et, parmi les condamnes, te suicide a lieu presque toujours, sinon exclusivenent, pendant les premiers mois de la détention.

Sur 36 qui ont cu lieu dans les diverses prisons d'Europe en 1872 (Statist. intern., Rone, 1874):

11 se sont produits durant les 6 premiers mois de la détention.

7 id. durant la première année de lat détention.

7 id. durant la seconde id. id.

7 id. durant la troisième id. id.

4 id. après la troisième id. id.

(1) On aurait eonstaté en Europe. en 1872, (Morselli 1. e.), dans les diverses prisons cellulaires, 1.37 sucides par 1000 detenus, tandis que dins eelles organisées selon le système Auburn il $y$ en anrait 0,40, dans celles à système collectit 0,35, dans celles à système mixte 0.80 . Le meme rèsultat est atteint par $\mathrm{M}$. I.egoyt en comparant les prisons a régime collectif et celles à régine céllulaire de France. (Le suicide ancien et modeine, 1851, p. 2181. 
Le nombre des criminels suicides est beaucoup plus fort dans les prisons judiciaires que dans les bagnes (1), et il comprend, surtout, des individus qui n'ont à subir que des peines légères. On a vu des hommes condamnés a quinze jours de détention, se donner la mort.

Ce chiffre devrait être triplé, si nous y faisions entrer les nombreuses tentatives de suicide qui, dans les prisons l'Angleterre, s'élèvent an triple et, dans los nòtres, au double des suicides consommés (86 sur 168).

Evidemment cette fréquence du suicide chez les délinquants, aux premiers temps de la réclusion, et même avant le jugement, ou i la suite d'une condamnation ligère, tient à des causes spéciale. - La première est celte insensibilité, eette absence de l'instinct de conservation, dont nous avons donné, un peu plus lant, tant de preuves, et qui apparait, clairement, dans les formes alroces de suicides des criminels.

3. - Joignez à cela l'impréroyance, l'impatience, qui dominent les criminels; un mal, même léger, qui durerait Iongtemps, leur parait insupportable; ils préfèrent un mal hien plus sérieux, mais qui les frappe. subitement, parceque la mort leur parait moins dure à supporter que l'impossibilité d'assouvir lenrs passions d'un moment.

"Je dis adieu au monde, puisque vivre arec une passion est pire que mille morts, " écrivait Delitala avant de commettre un meurtre et se tuer après. Mac-

(1) En France les maisons d'arrêt pour la période 1874-76 donnent la moyenne de 10 suicides sur 100 lommes, et 3.83 sur 100 femmes: et les prisons centrales nous donnent seulement les proportions de 4,79 pour les ditenus. 
kenzie, n’ayant pu seduire une jemne fille, la filsail assassiner, puis dénongait son complice ol se donnait lat mort.

On dit qu'un mousse, la veille du jour où il devail ètre libéré, se pendit, en disant à un de ses co-détenus: "de m'ennuie trop, nous devrions nous pendre".

C’est ainsi qu'eut lieu le suicide de Fusil, sur lequel nous reviendrons (Clap. v).

Quelques-uns de ces criminels, el en particulior les alcooliques, se doment la mort presque automatiquement et, pour ainsi dire, sans cause, pour un simple caprice. Tel est le cas, de ce bourreau de la Nouvelle Calédonic qui se pendit parcequ'on arait changé sa guillotine de prédilection; et de cet autre dont parle Morselli, qui se donna la mort parceque sa cellule élait mal paréc. Un individu était monté sur une échclle pour alteindre une fenêtre ouverte, quand il lui vint ì l'esprit de se jeter en bas; jusqu'il ce moment, il n'avait pas songé au suicide.

La marquise de Brinvilliers tenta plusieurs fois de se tuer: elle s'mpoisonna une première fois pour éprouver la vertu de ses contre-poisons (singuliere preuve d'impatience chez les gens de cette espece); plus tard pour donner une preuve de son amour à SainleCroix. On peut dire, de mème, de la femme Gras, et du trop célèbre doct. Demme; ce dernicr, empoisonneur et roleur, finit par tuer sa maîtresse; une toute jeune fille, probablement avec le même poison qui lui avait servi pour se débarrasser du père, et se donna ensuite la mort.

4. - Il est facile de comprendre pourquoi ceux que la passion a entrainés au crime, se tuent plus volon- 
tiers que les autres délinquants. Ils y sont poussés, un peu, par les remords, un peu, anssi, par la perte de l'objet aimi.

Ponr tous les coupables, lo suicide est, lantôt, une sourpape de sûreté, tantôt une erise et un supplément de la tendance au crime, soil quili se tronve ì son divoloppement ou à sa naissance. Pour certains, c'est en quelque sorte un moyen de réhabilitation, avant ou après l'accomplissement du crime, uno excuse anx yeux des autres ou d'eux même, puisqu'il démontre, soit la violence irrésistible de la passion it la quelle ils ont cíde, soil la force des remords qui les accable.

Que le crime soit, réellement, en rapport étroit arec la tendance au suicide, Lacenaire et la Trossarello l'ont bien diclaré. "Un jour vint, avoue Lacenaire, oì je n'eus d'autre alternative rue le suicide on le crime; je me suis demandé si j'étais une victime de moi-même on de la société, et, après aroir conch contre celle-ci, je lai frappée ». La Trossarello, après une tentative de suicide, dit à une de ses compagnes (la Tabasso): "Cette fois, j’ai tenté de me tuer; the antre fois, c'est lui que je luerai n.

Fn itudiant les comptes-rendus judiciaires de 1882, Despine a pu établir un véritable antagonisme entre lo crime et lo suicide. Dans les 4 départements Franuais, qui ont fourni, sur 100 accusés, le plus grand nombre d'attentats contre les personnes, il n'a releré que 14 snicides par 460 mille habitants; an contraire, dans les 14 oil ces attentats ont été le plus rares, il y a cu 14 suicides par 170 mille habitants. La Corse, cilèbre par ses traditions sanguinaires, donne sur 100 accusés, 8.3 affaires de ce genre, et 1 suicide par 55 mille habitants. Dans le département de la Seine, sur 
100 affaires, 17 seulement ont trait au menrtre, at l'on compte un suicide par 23.41 hahitants.

De mème, en Russie, la tendance an suicide se fait principalement remarquer dans la rigion du X.-0. oì les memrtres sont plus rares (1). On relive dans les provinces de la Baltique, 65 suicilles sur 1 million d'habitants, et 102 i St. Patersbourer.

5. - On peut roir maintenant pourquoj la statistiqur sociale (Gittingen) a relevé une espece d'antagonisme entre le chifire des attentats sanguinaires et celni des snicides, et pourquoi ces derniers deviemnent phus rapes dans les pays les plus chauds, on ces attentats sont le plus firquents, en Espagne, par exemple, en Corse, dans les provinces méridionales et insulaires dn royaume d'ltalie, tandis qu'an contraire dans l'ltalie du nord ef du centre, nombre d'assassinats sont prérenus, pour ainsi dire, el éparonés par lo snicide. Cola nous fait rncore comprendre pomrquoi les délis et les contrarentions dans l'intérieur des prisons sont, - on le verra, - moins nombreux dans les pays on il se commet Ir plus de suicides.

On peut en dire autant, en général, des pays et des siècles les plus civilisís: à mesure qu'augmente la culture des esprits, le chiffre des suicides devient plus fort

(1) V. Sur le suicide duns l'Europe Orcidentale et duns la Russie” d'Europe, "Samoubijstro v saparnoi Evrope i evropejskoi Rossii. Opyt sravnitelno statisticeskago issledovania » dX. Y. Likscer; et un article dı même anteur, Sur le suicide en Russie, dans l'Arrhivio di jsichiatrid, l\$8., w. p. 3I5. - Rossi vient de faire la même démonstration pour l'Espagne (V. Archicio di Psichietio, vol. vu, 2). 
(il a presque triplé en France de 1826 à 1866) et celui des meurtres diminue (1).

C'est d'autant plus vrai, que le plus grand nombre des suicidés de cette calégorie se recrute parmi ceux qui ont commis des attentats contre les personnes (24 en ltalie), ou contre l'ordre public (12), ou encore des crimes mixtes (12); parmi ceux qui ont attenté à la propriété on en conpte beancoup moins (18).

Il est bien naturel que plus les assassins se feront rares, grâce i l'augmentation exorbitante des suicides, moins grand sera aussi le nombre des attentats contre les personnes. Si la marquise de Brinvilliers, si Lacenaire, si Misdea se fussent réellement tués, quand ils essayèrent de le faire ou qu'ils en eurent l'idie, plusieurs de leurs victimes auraient étí épargnées.

6. - Suicidc indirect. - D'autre part, en certains cas, à vrai dire fort rare, le suicide inspire le crime au lieu de le prévenir. Des êtres iàches, follement superstitieux et désireux de mourir, donnent la mort pour la rece-

(1) En France:

De 1826 à 1866 les suicides se sont accrus de 54 par 1.000 .000 d'lıabit. De 185 j à 1855 id. id. à 100 id. De 1861 à 1865 id. id. à 124 id. De 1866 id. id. à 154 id.

En Danemarek: de 1835 à 1845 on a compté 1 suieide par 4568 habitants.
Id.
de 1845 à 1855
id.
id.
3911 id.

Pendant qu'en Russie, écrit Likaceff (1. e.) on comptait en 180316 suieides par 1 million d'habitants, on en compte 30 en 1875. En Finlande, cette tendanee est plus forte que dans la Russie proprement dite; elle est plus faible an contraire dans le Caucause. Dans les grandes citès comme Pétersbourg et Moscou, l'aecroissement est plus rapide, surtout ì Pétersbourg, oì, pour I million d'habitants, on a compté en 1861,33 suicides, 85 en 1869,98 en 1871,136 de 1876 à 1878. A tloscon il $y$ en a en 42 en $1860-61$ et 61 en 1851 . 
voir à leur tour: de cette manière ils évitent de so tmo enx-mèmes, et ils regoivent en mourant les secours do l'église. Etrange forme d'égoïsne el de passion meligieuse! Despine a recueilli quelques uns de ces fails (11, 550); Brière de Boismont en cite quelques autres dans son livre $D u$ Suicide.

7. - Suicide. - Dautres fois, conme dans le cas de Nagral, on conmet un assassinat parcequ'on est las de vive et quion manque de courage et de force pour se suicider. Tel fut, à ce qu'il parait, le mobile du régicide tenté par Passanante. (V. Lombroso, Su Passanante, Naples, 1880).

8. - Suicides simulés. - L'homme est naturellement porté à simuler et à feindre les actions pour lesfuelles il a le plus d'inclination; voila pourquoi un si grand nombre de coupables feignent de se tuer et ne se font que des blessures insignifiantes. Nicholson va jusqu’it dire que, de trois suicides tentés dans les prisons, deux ne sont qu'une feinte.

Il soupconne, même, en fin de compte, que plusieurs des suiciles consommés appartiennent à cette catégoric, et il cite le cas d'un individu qui, s'étant pendu à l'heure où devaient venir les gardiens, ne mourut que parceque le hasard retarda la ronde de ces dernicrs. (Journal of mcntal science, 1872).

Je rappellerai ici le cas du docteur Brancard, qui non sculement simula un suicide et écrivit à ses parents, à ses amis, à son frère, pour leur recommander son chien, son unique ami, mais encore laissa une épitaphe toute préparée: "Ici repose un français infortuné, Jules Brancard. De grands malheurs frappèrent sa jeu- 
nesse. Il fut loujours en proie ì la douteur. Passants. accordez-lui une larme ». Je rappellerai encore la Dnblasson, empoisonneuse et adultere, qui, lors de son arrestation, s'empoisonna avec son mari, complice de son crime et compagnon de ses débauches; mais elle avait d'abord cerit plusicurs lettres à ses amis, pensant qu'ils viendraient à temps pour la sauver, comme cola eul lieu en effet. Cóst ainsi que, tout récemment enrore, a fait la Trossarello, comme on le verra dans le 2 volume (V. Appendice). Telles furent, peut-ètre aussi leux au moins parmi les nombreuses tentatives de la marquise de Brinvilliers (r. s.).

dvant le tuer sa belle-soemr, qui avait repoussé son amour, David arait plusicurs fois manifesté des rolleités de suicide, soit devant elle, soit devant d'autres personnes; il lui écrivit même: « Ju vous embrasse avant le mourir". Après le meurtre, il tira un coup de pistolet, ef se blessa, pous que l'on pût croire qu'il aviat roulu se donner la mort; mais quand, imns de pitié, les hommes chargés de l'arreter lui offrirent de le laissor so précipiter du haut d'un pont, il refusa, oljectant: "Qu'il y arait trop de monde !!!"

Cette étrange tendance a souvent ponr mobile, chez les prisonniers, te plaisir de la vengeance. Ils en venlent aux gardiens, au directeur; ils croient quion los soupconnera de les avoir poussés an désespoir; ils espè. rent faire parler d'enx, de changer, tout an moins, de prison; rrais ils sont poussés surtout par cette inclination it feindre, qui transforme sonvent les prisons en de ré ritables théâtres. Pour ceux qui n’ont pas encore dié arrêtés, c'est un moyen d'autant plus recherché qu'il s'arcorde micux avec la soudaineté et la violence de lemr caractère, quand ils venlent atteindre un but lixé, on 
justifier aux yeux des autres on aux properes un assassinat, ou simuler une lutte, comme pour ce Ceccarelli qui fut pris déponillant sa victime après l'avoir frappiro; ou pour échapper à la justice, comme cela rinssil a Brancard (r. s.); lo faux suicidle est, en ce cas, une espèce d'alibi cherehé dans l'auture monde. Il arrive, en maintes circonstances, dit Niclıolson, que les criminels procèdent a la facon de ces enfants gàtús qui font semblant de se tuer ou de se blesser pour forer les parents ¿ céder ì lemrs caprices.

9. - Suicides doubles. - Il y a aussi des suicideshomicides, ou mienx des suicides donbles, yui appartiennent essenliellement anx délits par passion, et qui sont comme la crise finale d'un grand paroxysone d'amour. Ils se rencontront chez les jounes gens, les rílihataires, surtout les soldats; parfois aussi chez des gens d'un ìge mûr: ils sont alors provorpès par l'amomr lilial et sont des parricides-suicides.

Le caporal Rienourd, ìgé de 23 ans, sétait ipris d'une flemriste, et avait dépensé avec elle tout ce qu’il possédait. Se trourant sans ressomres, il demanda it sa maitresse jusqu'on elle roudrait le suire, et commo elle lui répondit: "jusque à la mort, " il prépara tout pour un double suicide. Quelques jours apres ils se tuèrent, - laissant sur la table une lettre dans laquelle ils saluaient leurs amis. Le père de ce mallıenreux, et une de ses sœurs, s’étaient suicidés.

Plus émourant encore est le cas du médecin militaire Bancal. Au retour d'une expédition lointaine, en 1835, il trouva, mariée et mère de famille, sa fiancíc d'autrefois. Leur amour se réveilla; mais, comme le léshonneur était au bout, ils se vouèrent à un doulle 
suicide, et employèrent des journées entières à le préparer. Le malhcureux survécut, malgré tous ses efforts, et renouvela, denx fois, ses tentatives; il fut acquitté par le tribunal.

Ine jeune femme de Deptford, dans les environs de Londres, Sarah Dickenson, fut trouvée un jour blesséc et étendue à côté de ses deux enfants. Elle avait égorgé ces petits innocents pour les soustraire à la misère qui s'était abattue sur la famille à la suite d'une longue maladie de son père. Elle avait ensuite tenté de se suicider; mais le courage lui avait manqué pour terminer son entreprise. Le médecin appelé ì l'examiner la déclara atteinte de folie intermittente.

Parfois encore, mais c'est chose rare, ce double suicide provoqué par la passion s'associc au crime et se confond avec lui: tel est le cas de Demme.

Ce sont alors des hommes qui, poussés au suicide pour se soustraire à une peine infamante, entrainent leurs annis les plus chers à partager leur sort; cette union leur lait paraitre le pas moins dur à franchir; la mort parait leur causer moins de douleur, s'ils ne laissent derrière eux aucun des êtres qui leur sont chers.

10. - Le suicide est, done, comme on vient de le voir, plus fréquent chez les criminels rendus tels par la frassion que chez ceux qui n'ont pas de parcille excuse; il l'est davantage chez les criminels-fous. - Rien d'étonnant. - Le suicide étant fréquent thez les fous (pour un cinquième environ), et presque autant chez les criminels, il doit l'être plus encore elıez ceux qui sont en mème temps criminels et fous, surtout si une passion violente les domine. 
Tel fut ce Palmerini, un fou, roleur de grand themin, qui essaya trois fois de se suicider; tols enrore Nonalia, à demi-fon, qui s’accusait de 128 délits et n'en avait commis que 40 , et Busalla, qui, apres le meurtre de son frère, tentait de se noyer et demandait avant de se jeter ì l'eau, si sa victime était morte. "En ce eas disait-il, je me noie; s’il vit, je consulte un avocat." Ainsi enfin Dellitala, fon on demi-fou, se tirait dans la tête trois comps de pistolet après avoir commis les crimes nombreux dont il sera question plus loin. On en dira autant de Valessina et Calmano, ces individus abrutis par l'alcool qui, après avoir gaspillé tout leur argent, se jetèrent sur leurs enfants, leur donnèrent la mort et essayèrent après de se tuer. 


\section{CIIAPITRE $V$}

\section{Sentiments et passions chez les criminels.}

1. - Sentiments. - Ce serail une grave erreur que de supposer tous les sentiments éteints chez les eriminels; beaucoup ont certainement disparu, plusieurs paraissent survive. Troppmann après avoir massacré une famille entière, pleurait en entendant nommer sa mère. Ce fut un amour incestueux pour sa sœur qui poussa Martinati à égorger sa femme. Bezzati aimait sa fenme et ses enfants; Fieschi arait de l'affection pour sa maîtresse et pour son avocat Lachaud. La Sola qui n'aimait, disait-elle, ses enfants pas plus que des chats, et qui fit assassiner son amant, avait un penchant pour sa complice Azzario el accomplissait des ceuves de vraie charité, passant, par exemple, des nuits entières au chevet des moribonds. Lacenaire, le jour où il tua la Chardon, exposait sa propre vie pour sauver un clat qui allait ètre précipité d'un toit (Mémoires de Claude, xxi), et épargnait Scribe qui l'avait secouru. Les bohemiens, ces vrais chiminels-nes, eseroes, ete., sont très-attachés à leur fantille; et leur's femmes, dans certaines contries (non dans l'hde), ont un sentiment remarquable de la pudeur. « La lacki (la virginité) est le bien le plus précieux que tu possèdes... maintenant va voler, " disent les mères à lerrs filles. La Noël, par amour pour son fils, qui élait au bagne, sétait faite, 
elle, pianiste célèbre, la protectrice el, comme on l'appelait, la mère des voleurs. Raskolnikost, dans le cilèbre rontul de Dostojewsti, tue froidement, arec calcul, deux femmes pour les voler el se faire une position; il n’a d'affection ni pour sil senr, ni pour sa mère; - et pourtant le même homme donne une somme consirlérable pour une personne pauve qu'il ne connail pas, et expose sa vie pour sauver deux enfants.

L'assassin Moro se plaisait à habiller et il dibarbouiller ses enfants. Féron, aussitôt aprés aroir conmis un meurtre, allait voir les enfants de sat maìtresse, et leur régalait des friandises. Maino della spinetta était un mari passionné et fitèle; il fut pris à cause de sal femme. Coest pour son éponse que le terrible spadolino se fit brigand, Norcino voleur, Cistana el La Pommerais (1) empoisonneurs, Montely assassin. Le féroce Franco, arrèlé par l'entremise de sil maitresse, ne se príoccupa que de la sauver tant que dura son procès; dans la photographic qu'il til excecuter dans sa prison, c'est ì elle quï serre la main. Ilolland avoua qu'il avait commis l'assassinat pour lequel il était poursuivi dans le but d'entrichir lit femme et l'enfant qu'il aimait. "Je l'ai fatit, disail-il, pour mon paure enfanl». On ne peut lire sans un étonnement profond les paroles de l'assassin De Cosimi: "Bien des baisers à mon petit enfant; - il sera droit comme son père, car te loup engendre des louveteaux».

Parent-Duchatelet a montré que si la plupart des filles publiques se sont affranchies de tout lien de famille, il en est quelques-unes qui font servir leur dis-

(1) Sa dernière parole fut: * Pour c'lotilde *. 
honneur à donner du pain à leurs enfants, à leurs vieux parents, à leurs compagnes. Elles ont en outre une passion extrême pour leurs amants; ni les mauvais traitements, ni les coups, ne peuvent les détacher d'eux.

2. - Instabilité. - Toutefois, si dans la plus grande partie des criminels les affections nobles trouvent leur place, c'est toujours avec une nuance morbide, intermittente, instable; elles semblent pour leur intermittence et leur soudaineté jaillir d’une éruption.

Pissembert, pour un amour platonique, empoisonna sa femme. La marquise de Brinvilliers tuait le père pour venger l'amant, les parents pour enrichir les fils. Мalille, pour lamour de quelques connaissances d'hôtel, commit un assassinat. Un certain Maggin me disait: « La cause de mes crimes est une trop grande propension à l'amitié; je ne puis voir offenser un ami, même éloigné, sans porter la main à mon couteau pour le venger ».

Voulez-vous des exemples du peu de stabilité de ces sentiments, même chez ceux qui en paraissent le plus vivement épris ? Songez à Gasparone, poussé jadis, au premier meurtre par amour excessif de sa maîtresse; et qui, peu après, tue cette femme, coupable davoir laissé échapper un seul mot de reproche; songez à Thomas, qui aimait sa mère à la folie et qui pourtant, dans un accès de colère, la précipita d'un balcon. Martinati avait pendant de longues années aimé la femme dont, deux mois après son mariage, il songeait déjà à se défaire.

Les prostituees se laissent battre jusquau sang par leurs anants; mais le prétexte le plus futile suffit plus tard, a les détacher d'enx; et elles témoignent à d'att- 
tres la mème ardenr hrûlante. Ainsi, Parent en a rencontré quelques-unes qui araient changé jusqu’à 30 fois les initiales d'amours tracés sur lem peau.

3. - Vanití. - Au lien des affections de famille ot des affections sociales qui, ehez les criminels, sont complètement étointes ou se présentent à l’état d'áquilihre instable, on voit dominer d'autres passions peu nonbreuses, mais extrêmentent tenaces. Et, d'abord, entre toutes, l'orgueil, ou, pour mienx dire, un sentiment excessif de leur valou personnelle, sentiment que nous voyons croître dans les hommes, en raison inverse du mérite; comme si dans l'àme se répétait cette loi qui domine dans les monvenents réflexes, d'autant plus actifs que l'action des centres nerveux s'anoindrit darantage, mais qui, ici, prend des proportions gigantesques. La vanité des criminels est supéricure à celle des artistes, des littérateurs et des femmes galantes. Dans la cellule de La Gala j’ai In cette inscription écrite de sa main: "Arjourd'lui, 2.4 mars, La Gala a appris ¿ faire les bas». Crocco cherchait atx Assises à saurer son frère: Sans cela, disait-il, la race des Crocco est perdue. - L'accusation capitale, la condamnation à mort, causaient moins l'émotion à Lacenaire que la critique de ses méchants vers et la peur du mépris public. "Je ne redoute pas la haine, disait-il, mais je crains d'être méprisé ».

Les ormes sont courbes par l'orage,

L'humble fleur passe inaperçue.

Satisfaire sa vanité, briller dans le monde, ee qu'on appelle si mal figurer, voilà la cause la plus commune des crimes modernes. 
Denaud et sa maittresse avaient tuć, l'un sa femme, l'autre son mari, afin de pouroir se marier et sauver leur répulation dans le monde. - L'engouement exagéré de payer ses dettes, fut le point de départ aux meurtres commis par le comte de Faella (V. Arch. di psich., III). - Qu'un larron fameux se pare d'un certain genre de gilet ou de cravalte, ses confrères prendront modèle sur lui, et adopteront celte mode. Vidocy, dans une bande de 22 voleurs, pris le même jour d'un coup de filet, en remarqua 20 dont le gilet était semblable.

4. - Vanité du délit. - Ces gens là lirent vanité de leur force, de leur beaulé, de leur courage, de leurs richesses mal acquises et peu durables, et, chose plus étrange et plus navrante, de lenr habileté dans le crime. "Au début, écrivait l'ancien forçat Vidocq, les criminels cherchent à atténuer leur crime; une fois qu'ils ont avancé dans celte roie funeste, ils s'en font une gloire ». Il dit ailleurs: "Dans la société on redoute l'infamie; dans une masse de condamnés on ne rougit que d'une chose, c'est de n'ètre pas infàme; lo plus grant éloge quon puisse faire de l'un d'entre eux consiste à dire de lui: C'est une escarpe (un alssassin).

Dans ume vilie de la Romagne, il y a quelques années, un prêtre d'humeur tris-douce fut assassiné: on ne lui connaissait pas d'emnemis; anssi ne ponvalton découvrir l'auteur du erime: cétait un tout jeune homme, presque un enfant, qui, avait désigné ì ses camarades ce prètre innocent sortant de l'église; el quelques minutes phus tard, en plein jour, lui avait donné la mort: Il l'avail tué, uniquement, pour leur prouver, pour ainsi dire, sa virilité criminelle, pour montrer qu'il étail capable de tuer. 
En Angletere, dit Maylew, les bandes de volumes se jalousent mutuellement; clacune d'elles se rante de surpasser les atutres; sil était possible, ellos s'adresseraicnt des défis dans la quatrième page des jommanx.

On silit que les prostituées ont comme des grades dans leur profession: qu'elles prétendent toujours appartenir au grade supériemr, et que le mol: Vous éles une femme de vingt sous, est pour elles le dernicr des outrages. Il en est de mème aux galères: (Quiconque a volé des milliers de franes se moque du pauve coupebourse. Les assassins, dı moins en Italie, se croient supérieurs aux voleurs et aux eseroes, ils sont fier's du bonnet qui les fait reconnaitre, tandis que les voleur's s'efforcent de toutes les manières de cacher le leur. Les laussaires, à leur tour, dédaignent les assalssins et évitent de se rencontrer avec eux. A Londres, les voleurs de grand chemin méprisent les larrous vularaires, qu’ils appellent ganofs. "Je puis, disait l'un d'eux, qui s'écartait de ces derniers, je puis être un voleur; mais, gràce ì Dieu, je suis un homme respecLable». (Ledru-Roluin, De la décad. de l'Anglet., 1850 ).

Les voleurs croiraient déchoir s'ils dérobaient des objets de peu de valeur; c'est sourent bien plus l'amour propre que le besoin qui les pousse à mal faire. (Yinoce, Sur les moyens de dominer le crime, 1844).

Vasko, ì 19 ans, avait assassiné une famille enticre. Il se réjouissait d'apprendre que tout Pétersbourg s'occupait de lni. "Eh bien! disait-il, mes camararles de classe verront aujourd'hui s'ils avaient raison de pritendre que je ne ferais jamais parler de moi ». Les prisons en Russie, 1857; Revue Brilann., 1860).

Un rulgaire filon, Grellinier, se vintait, anx Assises, de crimes imaginaires, pour se donner l'arr d'un grand 
assassin. Mottino et Rougel mettaient en vers barbares leurs propres méfaits. Lemaire, De Marsilly, Vidocq,

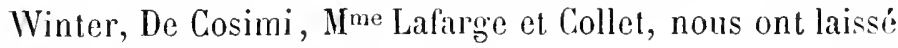
leurs mémoires.

"Que les brigands d'aujourd'hui sont inférieurs à ceux " de mon temps! disait Gasparone. Ils florissaient alors ) dans toute leur pureté, ils ne se sonciaient pas de po"litique, - ils travaillaient par amour du métier!" (Arch. di psich. e sc. pen., III, 276).

Cette vanité excessive des criminels fait comprendre comment, avec une impréroyance inconcevable, ils en viennent a parter de leurs méfaits avant et après leur accomplissement, et fournissent, de la sorte, à la justice l'arme la plus sûre pour les saisir et les condanner.

Philippe, quelques instants après ses meurtres étrangres, disait à une de ses maitresses; "Oui, je les aime, les femmes, mais d'une facon qui m'est particulière; je les étrangle après les avoir possédées; mon plaisir est de leur couper la gorge. Oh! vous entendrez bientòt parler de moi!»

Lachand, quelques jours avant de tuer son père, ì qui il portait une haine mortelle, déclara à ses amis: "Ce soir je rais crenser une fosse et y mettre mon père; il y dormira à jamais ". Villet annonçait d'avance les incendies dont il allail se rendre coupable. Un autre parricide, Mareellino, disait un peu arant de donner la mort à son père: "Que mon père revienne des champs, il restera ici ».

On entendit Bérard dire, avant de commettre son dernier crime, le meurtre de trois riches bourgeois: "Je veux m'appliquer à quelque chose de grand, oh! l'on parlera de moi ». Gallarati, homme froid et taciturne, arant de poignarder l'étudiant qu'on avait désigné à ses 
comps, montra dans une boutique, el d'une fitgon toule: particulière, à un lomme qu'il soupeonnail d'attre do la police, l'instrument arec lequel il comptait accomplir son assassinat. - Lempoisonneuse Ruseemi se signani: "Ta Lucrice Borgia ".

Sobber, l'assassin d'un vaguemestre de Berlin, échappa fuelques mois à la justice en prenaut le nom de Sandel. Mais il livra son nom véritable pour montrer a son hôte, qui refusait de voir en lıj un ancien soldat, le passeport où son vrai nom était inscrit.

Quoi encore? On voit des criminels qui, avant qu'on ait découvert leur crime on qu'on les en ait convaincus, éprouvent le besoin, non seulement d'en parler, mais encore de le retracer, pour en rendre l'image plus claire et plus parlante, du moins à leurs propres yeux. C'est ainsi que je m’explique l'étrange dessin de Troppmann (tabl. $\left.x x^{\mathrm{e}}\right)$, qui ne prouvait pas son innocence, mais qui prouvait sûrement son crime.

Un exemple curieux nous est offert aussi par ce Fusil qui, après avoir tué son compagnon pour le voler, et en avoir caché le cadavre dans une armoire, seétait sauvé en Suisse. Au bout de quelques jours, se trouvant sans ressources, il avait livé son pseudonyme pour se faire enroyer d'autre argent: arrêté et conduit ì Turin, il résolut de se suicider le $100^{\mathrm{e}}$ jour; mais, tout d'abor'd, il traça sur sa coude des dessins au moyen desquels il semble avoir voulu s'élever à lui-même un monument qui rappelât son crime et son suicide (Atlas $\mathrm{xx}$ ), avant de se donner la mort (1).

(1) Il y a écrit: - Jai souffert 100 jours de mison pour cela!, pour avoir (une bagatelle), tué son ami; - et encore: Adieu mon ami Gumbro voleur, je t'ai bien tue. - Et puis: Derniers exces - et enfin paix au dessous de son sosie pendu aux fenêtres de la prison (tabl. $\left.\mathrm{xx}^{\natural}\right)$. 
Ihais e'est en France qu'on en trouve l'exemple plus curienx. En 1878, une bande de voleurs dévasta, pendant plusieurs mois, les environs de Paris: les rols. so succédaient, les coffres-forts étaient forcés, et les anteurs de ces mélaits, Clément, Tapat et Quatrelire, échappaient í toutes les recherches de la police, quand un jour, dans une guinguette, un agent entendit chanter un refrain qui faisait allusion à ce rol avec effraction et en désignait assez clairement les autenrs et les recéleurs. Les coupables furent arrêtés; mais it ne faut pas croire que le poète Clément, un des principanx complices, se prî̀ à détester la muse qui hui avait été si funeste; au contraire, renchérissant sur la dose de son itourderie et de sa naïreté poético-criminelle, il contplitil cette chanson fatale el raconta dans de noureanx vers comment arait en lieu l'arrestation. It fait, en mime temps, pressentir une revanche contre l'antoriti, qu'il dipeint arec cette haine fëroce dont les sanrages se montrent animés quand ils parlent de leurs ennemis.

Tous reproduisons ce document singulier, dù à Tolligeance de MVI. Ferri et Maxime Du Camp, en marcuant l'une astérisque les vers qui, sans ancun doute, ont dis composís après l'arrestation:

In certain soir étant dans la débine (sorns argent),

In eoup de vagne il leur fallnt pousser (ils durent tenter un crimp), 'ar' sans argent l'on fait bien triste mine;

Iais de eourag' jamais ils n'ont manque.

La condition était filée d'avanee;

Le rigolo eut bientôt cassí tout.

Du gai plaisir ils avaient l'espérance.

Quand on est pègre (coleur) on peut passer partont.

Le eoffre-fort fint mis dans la roulante (roiture;

Par toute l'escorte il fut bien entouré. 
Che\% l' pèr' clement, on lui ouvrit le ventre:

D'or et d' fatiots frillets de bonque) l'enfant itait serré. Quarant millets! Telle citait eette aubaine. Ah! mes anis ! e'etait mu fier bean eomp! De le manger, ils n'etaient pas en peine, Quand on est piogre, on pent se payer tont. Jami lapat', qui n'itait pas un' hête, nu coffre-fort vonlait s' dibarrasser.

Chez I' per' Jacob, nour le jour de sa fíte, A son pur' lingue il voulait l'puvoyer.

Tont press d' ehez enx, en taee itait la bievre, on l'y plongea; mais voyez quel cass' con! (molieur)

11 fut r.pôché. Adien tous les beanx rêves: Quant on est pègre, on doit peuser à tout.

Vive le vin, vive la bomne chire:

Tive la grinelıe: (coleun) vive les margotons! (les feirmes) Vive los eigs! vive la blonde bibre!

Amis! buvous à tous les vrais garęous.

- Ce temps heureux a fini bien trop vite.

- Car anjourd hui nons vlà tous daus l' trou.

- Nons sommes tous vietines des houriques, (lle le police)

- Quand on est pegre, il faut s"attendre à tout.

- Quinz' jonrs après, ces pauvres camarades

- Rentrant ehez enx, par l'aruach (lowgent) furent pineis.

- Ils revenaient de faire un' rigolade.

- Denx contre dix, comment porvoir lutter?

- Vrais eompagnons de la Hante-Fanindelle,

- Ils furent vainens; mais leur rap (leur dos) porta tout.

- th: mes amis, à vous gloire eternelle

- Quand on est pègre, le devoir (!:!) avant tout.

- Yles ehers amis, j’ai fini leur histoire.

- I la Nonvelle (Calédonie), tous trois ils partiront;

- Mais avant peu, bientôt j'en ai l'espoir,

- Brisant leurs fers, vers nous ils reviendront.

- Mort! cent fois mort à tonte la police:

- Ces lâeh's bandits, sans pitié, enfrrent tont.

- on les pendra, et ee sera justice,

- Car, pour les pègres, la vengeanee avant tout!

- Moralité: Ces hommes très-forts se sont fait eoffrer en eoffrant un coffre-fort très-fort. C'est trop fort: 
Il est curicux de voir cette verve crapuleuse avec laquelle se mêlent les idées d'orgie, Vive le vin, de gloire, A vous gloire étcrnelle, de rengeance contre la police exécrée, La vengeance avant tout, et de crime transformé en devoir, Le devoir avant tout.

Vlais l'exemple le plus singulier et en même temps le plus probant de cette vanité incroyable inspirée par le crime, je l'ai relevé à Ravenne dans une photographie que la Questure avait décourerte dans les matelas d'un jeune homme soupconné homicide (tabl. $x \mathrm{xi}^{\mathrm{e}}$ ). Au risque d'être dénoncés ou de fournir eux-mêmes une révélation de leur crime, trois scélérats, soupconnés d'lomicide, s’ètaient fait représenter dans l'attitude qu'ils araient au moment du crime. Leur procès, par suite des réticences des témoins, qui sont sourent si fréquentes, n'aboutit pas à une condamnation; mais, si le juriste devait s'abstenir, l'anthropologne-criminaliste trouvait dans cette photographie le plus terrible des indices. On peut voir, en effet, combien tous ces individus, à peine leur crime connu, épronvent le besoin d'en perpetuer le sourenir soit en paroles, soit par des inscriptions (1).

5. - Vengeance. - L'inclination à la rengeance pour les moindres causes est la conséquence naturelle d'une vanité si dẻmesurée, d'un sentiment si exagéré de leur valeur personnelle. Le baron C. fit assassiner C., parceque celui-ci, dans une procession, n'avait pas filit arrèter devant son palais la statue de la Vierge. Militella, pour une légère offense, avait juré de tuer un

(I) Dernièrement un voleur très-malade se traça son épitaphe qui eu est mue autre preuve: " $\mathrm{Ci}$ git le pauvre Tulac qui fatigué de roler dans ee monde, s'en va voler dans l'autre: les parents très-heureux ¿ui dounent ce souvenir. 
de ses camarades d'enfance, peu de temps apres, il arcomplit son serment. Comme on lui en laisait repreche il répondit: « Si je l’ai tué, e’est qu’il le mérilait».

"Voir expirer l'homme que vous haïssez, dit en vers lacenaire, est un plaisir divin... llär el me renger'... Ciest la seule chose que je souhaite ». Il n'avait qu'une préoccupation et il l'avait sans cesse, c'était de déshonorer et faire condamner ceux de ses compagnons qui lavaient trahi.

«La seule joie qui me reste est celle de la vengeance; et je ne l’ai goûtée qu'a petites gorgées».

Renaud, àgé de 22 ans, ayant en une légère altercation avec son ami Foy, qui l'avait nourri it ses frais pendant plusieurs années, le frappa et essaya de le jeter dans un puits. On l'arrêta: le blessé lui accorda son pardon, sans pouvoir s'expliquer une telle violence. Mais lui disait: "On me condamnera, mais, jatience; je regretle de ne l'avoir pas achere; si je sors de prison, je lui ferai son affaire ". Et plusieurs années après, au sortir de prison, il tint son horrilble promesse. Scanariello, avant de mourir, fit jurer à sos brigands de tuer certains paysans avec qui il n'avait pas encore réglé ses comptes. La Pitcherel avait empoisonné son voisin, qui s'opposait au mariage de son fils: condamnée à mort et invitéc à pardonner à sa victime, à l'exemple de Notre-Seigneur: «Dieu, répondit-elle, a fait ce qui lui a plu; quant à moi, je ne pardonnerai jamais ». - Callaud, serrant pour plaisanter le manteau de son ami Richard, lui avait fait une petite déchirure: il lui fit des excuses et promit de réparer le dommage: mais l'autre refusa de l'écouter, tira de sa poche un couteau et le lui plongea dans la poitrine. 
Un certain lloyse a fourni un exemple qui ressemble en tout aux vengeances des sauvages: insulté, de nuit, par des inconnus, il s'arma et frappa les premières personnes qu'il rencontra.

La même tendance paraît chez les prostituées: «Un dirait, écrit Parent, que le sentiment de leur vie abjecte est un nouvel excitant pour leur orgueil et leur amour propre: ce dernier est développé à l'excès, garre a qui le blesse " (l. c. p. 113). Il écrit plus loin: "La colère est fréquente chez les fermmes de mauvaise vie, et elle est excitée par les causes les plus légères, il suffit par exemple, pour les irriter, de leur dire qu'elles sont laides. Elles sont, sous ce rapport, plus enfants que les enfants eux-mêmes; elles se croiraient déshonorées si elles ne se vengeaient pas (l. c., pag. 152).

Cotte violence des passions, de la vengeance surtoul, qui l'emporte sur l'amour de soi-même, explique beancoup de traits de cruauté, communs chez les penples anciens et chez les sanvages, mais qui chez nous sont rares et monstrueux.

6. - Cruauté. - De nos jours, il est assez rare que le malfaiteur se transforme en meurtrier sans une canse particuliere on uniquement en vue du lucre. Sur 860 vols arec effraction commis it Londres dans l'espace de dix ans, cinq seulement ont été suivis de violence à l'égard des personnes. Les assassins qui tuent pour tuer sont regardés avec terreur par leurs compagnons, an clire de Frégier. Hais que la vengeance, la cupidité inassouric, la vanité offensée, soient une bonne fois mises en jeu, les instincts cruels de l'homme primitif reparaîtront avec la plus grande facilité, car l'insensibilité morale les dépouille de la pudeur, et de la pitié 
qui est un frein si puissant dans les cas de ce gemre. linsi, la férocité de nos brigands n’a pas seulemrnt pour cause la grossièreté samvage des contrées d'où ils viemment en plus grand nombre (et l'on remarqurpa que ces contríes sont toujours les mêmes); clle est cllcore provorquéc par le désir de la vengeance. Coppa était panve et sans lamille; rentré dans son pays arec l'uniforme des Rourlons, il fut insulte al enlin battu par ses compatriotes; dès lors, il jura de so venger, et sapplirua it tuer les gens de son village. Galetto avait assassiné une fille publique pour la roler; ne trouvant sur elle gu'une montre, il entra dians ume fureur telle qu’il dévora des lambeaux de sa chair. Le porcher Carpinteri, docile et bon jusqu'i 18 ans, ayant été, à cet îce, insulté par un canarade, lui broga la lite entre deux planches, se fit ensuite slef de brigands, et, en moins de neuf anners, commit 29 homicides et plus de 100 rols it main armée.

Quand on a une fois goûté à cet horrible plaisir du sang, tuer devient un besoin si implérieux, que l'homme ne peut plus se maitriser, et que, chose dtrange, loin d'aroir honte de son crime, il s'en fait gloirc. Il faut constater, alors, le mélange de cette vanité extraorlinaire inspirée par le crime, que nous avons vue mèlée à la trame de la vie chez tous ces misérables. Pour en citer quelques exemples, Spadolino se plaignait, en mourant, de n'avoir tué que 99 hommes, le n'aroir pu compléter la centaine; Tortora se vantait d'aroir donné la mort à 12 soldats; Mammone prenait un plaisir extrème a boire du sang et, quand celui d'autsui lui manquait, il buvait le sien.

Dans les cas de ce genre, on dirait que l'amour charnel sy trouve sourent mèle, et que la vue du sang donne 
à cette passion un stimulant tout particulier. En effet ces scènes sanguinaires sont toujours suivies par de honteuses débauches, on bien sont l'ouvre d'hommes soumis à une chasteté forcée, comme les prêtres, les bergers, les soldats (Mingrat, le père Ceresa, l'albbé Lacollange, l'ab. Léotard, Legier), ou de jeunes gens à peine pubères, Verzeni, par exemple. Il en faut voir, aussi, la cause dans les nétiers qui exposent au contact du sang, lel que celui de boucher, ou qui imposent une profonde solitude, comme ceux de berger ou dc chasseur. Ajontez a tout cela le spectacle de cruautés commises et, plus que tout le reste, l'hérédité. Carpinteri, Legier et Trim étaient pasteurs; Lassagna, d'Alexandrie, et Poncy, étaient bouchers; Militello élait venu au monde au milieu de coups de coutean; Galletti était le neveu d'Orsolato, anthropophage. Mais la cause plus puissante c'est leur insensibilité dolorifique (roir page 323) et morale.

Il y entre enfin une espèce d'altération profonde de l'àme, altération qui appartient en propre aux criminels et aux fous, et qui, par moments, les jelte en proie à une vive irritalion sans motif apparent. Les geòliers le savent bien: "Ils sont bons en général, me disaientils, mais ils ont tous, dans la journe, un mauvais quart d'heure pendant larguelle ils ne s'appartiennent plus ». Nous avons déjà remarqué ce phénomène clıez les animaux et les peuplades sanvages ( $1^{\mathrm{e}}$ partic). - Il sera question plus loin de cette passion et de quelques autres.

C'est une remarque générale que, pour ce qui est de la férocité et de la cruauté, les femmes ront bien plus loin rue les hommes. Les tortures inventées par les brigandes de la Basilicate, de Palerme ou de Paris, 
ne peuvent se décrire. Ce furrut des femmes yui diroupirent et mirent en rente des corps de gemlarmes; des femmes forcèrent un homme à manger de sa propre chair ròtie; des femmes portérent sur des piques des entrailles humaines. La Rulti farisit piquer avec dos ipingles par sa jeune soemr, la fille qu'elle aratit prise en haine; elle la fit mourir d inanition en la forgant it s'asseoir, sans y toucher, it sa table copieusement servic. - Voila pourquoi Shakespeare a donné à lady Nachech un caractère plus féroce et plus impassible que colui de son complice.

7. - Le vin et le jeu. - Aprés les plaisirs de la vengeance et de la ranité satisfaite, il n'en est point, pour lo criminel, de supérieur à celui du vin et du jeu. La passion pour les liqueurs fermentées est en soumme trèscomplexe, car elle est en mème temps une cause et un résultat du crime. On peut mème dire qu'elle est une cause triple, puisque l'homme alcoolique engendre de futurs criminels. Lalcool est un instrument, une raison du crime, soit parceque certains inilividus commettent des méfaits pour gagner de quoi s'enirrer, soit parceque les liaches trouvent dans l'ivresse le courage nécessaire pour accomplir leurs coupables entreprises, et croient y trouver dans la suite un moyen de justification, soit enfin parceque les orgies précoces poussent les jeunes gens au crime. Il faut noter, aussi, que le cabaret est un lieu où les malfaiteurs sont assurés de rencontrer leurs complices, qu'il est le sójour habituel où non seulement ils méditent leur crime, mais où encore ils en dépensent le produit. C'est mème pour beaucoup d'entr'eux le seul, le rrai domicile qu'ils connaissent. ljoutez, enfin, que le maître du lieu est le banquier, 
banquier d'ailleurs fidèle, aux mains de qui le voleur confie son gain coupable. En 1860, at Londres, on comptail 4938 bouges uniquement fréquentés par des voleurs ct des femmes de mauvaise vie. - Sur 10.000 meurtres commis en France, 2374 l'ont été dans des auberges. (Guerry). - Sur 49.423 individus arrêtés à New-York, 30.507 sont des ivrognes incorrigibles; à Albany, sur 1093 prisonniers, on compte 893 alcooliques. - A l'heure de midi, écrit Mayhew, presque tous les voleurs sont plongés dans les fumées du vin; aussi, ajonte cet auteur, voit-on les voleurs succomber à l'alcoolisme entre leur $30^{\mathrm{e}}$ et leur $40^{\mathrm{e}}$ année. - A Turin, il y a de cela dix ans, une bande sétait organisée dans le seul but de dérober du vin.

I l'alcool, donc, il faut attribuer sans doute ces parésies, ces athéromasies précoces qui se rencontrent si fréquemment chez les criminels. Il en est de même pour les prostituées. "Les filles riches, dit Parent Duchatelet, abusent du cliampagne, les pauvres se gorgent d'eaude-vie, d'abord pour chasser leurs tristes pensées, ensuite pour acquérir une vigncur momentanée dont elles ont besoin pour excreer leur honteuse industrie, toutes pour tenir tête dans les orgies à leurs amants débauchés. - Il y a, toutefois, des exceptions; on rencontre des voleurs et des prostituées, surtout des escroes at des chefs de bandes, qui sont abstèmes et sobres". "Dans ce métier, me disait un jour un eseroc, on ne pourrait travailler si l'on s'enivrait».

Par contre, il est bien peu de malfaiteurs qui ne ressentent très-rivement le plaisir du jeu ». "Ces misératbles, éerit Fregier, qui vivent de si peu quand ils n'ont pas occasion de se goberger aree le bien d'autrui, sont pris d'une véritable fureur de dépense, quand une cire 
constance imprévue les a mis en possession d'une sommo un peu forte. Les émotions du jeu sont les seules qu'il. prélèrent. Cette passion les poursuit jusque dans lá geòle, et l'on cite des prisonniers qui, apris avoir perdı, en un moment, le produit d'une semaine de travail, jouent, par anticipation, le gatin d’un, de deux et mème de trois mois.

Veut-on quelques exemples? Les médecins de la maison centralc de Saint Michel ont vu un forgat qui, couchi par la maladie, jouait sa maigre ration de bouillon et de vin, et finissait par mourir d'inanition (1). Beausegni était plongé à tel point dans la fureur du jeı, qu'il oubliait le dernier supplice anquel il avait été condamné. Il est arrivé a la bande de Lemaire de joner pendant deux jours de suite, sins interruption. (Lavvergne, II istoire des forcats, 1883). C'est peut-ìtre bien pour cela que la Statistique pénale, en Italie, relève $1_{[} 4$ ou 15 de crimes commis en plein jour, el la moitié pendant la nuit, aux heures particulièrement consacrées au jeu. Sur 3287 meurtres ou attentals commis en Italic, on en compte 14.5 occasionnés par le jeu.

"Les prostituces, écrit Parent, ont la passion des cartes; le lotò est leur jeu de prédilection".

Le faussaire Durand racontait à son médecin comment sa mère l'avait élevé dans l'amour du jeu, où elle dípensait tout son avoir. "Quand elle avait perdu, nous mangions tristenent notre pain sec. Si je suis ici, c'est pour avoir perdu mon honneur dans l'espoir de forcer lat fortune rebelle. Pour moi, les cartes daient des sirines; la rue d'un valet de cour faisail sur mes sens

(I) Frégler, Des classes dangereuses, p. 102, 1840. 
une impression magique; j’aimais mieux cela que le plus beau tableau. Dans l'ardeur du jeu, si je posais la main sur ma poitrine, je sentais mon cour battre d'anxiété. Le sort tournait-il contre moi? je mienfonçais les ongles dans la chair vive, sans même m'en apercevoir ». Et parlant ainsi, il montrait au médecin les misérables traces de cette fureur, qui l'avait conduit du berceau aux galères.

La passion du jeu donne la raison de cette contradiction perpétuelle qui éelate dans la vie du malfaiteur. D'un côté, convoitise effrénée du bien d'autrui, de l'autre, étourderie sans pareille à gaspiller l'argent mal acquis. Elle fait encore comprendre pourquoi le plus grand nombre des malfaitenrs, apres avoir eu souvent entre les mains des sommes fabuleuses, finissent presque toujours dans la misère. Haylıew a connu un voleur de génic qui avait à son service les procédés les plus singuliers, qui savait par cœur tous les articles du Code pénal et l'histoire des crimes commis pendant les vingtcinq dernières années; il n’avait mis de côté un shelling. D'autre part, si on étudie bien la vie d'un malfaiteur vulgaire, on remarque que la eupidité n'est pas, en elle mème, l'aignillon du crime; elle en est seulement. un des mobiles: car sans argent, il serait impossible de satifaire les passions brutales. Aussi, lavare est-il moins porté au crime que le prodigue; et hien qu'il soit moins sympathique, il vaut mieux au point de vue de la justice et de l'économie politique.

Cette pauvreté intermittente, qui expose les criminels aux excès les plus contraires, est la cause première de leur mort prématurée. Elle doit ìtre aussi pour quelque chose dans ce manque de soin pour leur per- 
sonne qui distingue les voleurs (1) et les prostituces at qui est dautant plus remarquable que, donnant ainsi du dégoùt et inspirant des sompgons aux autres hommes, elle peut mettre des obstacles sérieux à nombre d'entreprises malhonnètes. Mais cette malpropreté doit anssi tenir de l'absence de la famille, et, surtout de l'inertie, de l'apathie profonde qui, nous le verrons plus latr, est la marque des malfaiteurs, de mème qu'elle caractérise les peuples sauvages, plus sales souvent que nos animaux domestiques. l'ai eru devoir signaler ici ce caractère des criminels, pareequil s'accorde à merveille avec un proverbe assez juste, d'après lequel la propreté du corps indiquerait la pureté de l'ìme.

8. - Autres tendances. - Les malfaiteurs ont d'autres tendances qui, pour être moins rives que les précédentes, existent pourtant; par exemple, la table, l'amour, la danse. Un parmi les rares voleurs qui m'aient avoué son forfait était un toscan qui s'évanouissait presque en entendant parler de nourriture; il avait débuté, me disait-il, dans le vol pour acheter des macarons. "Dès que je sortirai de prison, je veux manger pour trois jours, „e'est le seul souhait que manifesta un vieux voleur après dix ans de cellule. Chandelet, dans sa prison, nétait retenu ni par les fers, ni par la bastommade; on ne venait à bout de lui qu'en le menacant de diminuer sa ration. Les jeunes voleurs, dit Faucher, commencent par dérober des fruits et de la viande, plus tard des objets de valeur médiocre quils vendent pour se procurer des douceurs. (Et. sur l'Anglet., 1845).

(1) Dans l'argot italien, la main est appelée la noive (negrosa); dans largot allemand, la tête reçoit le nom de lausenmarkt, halle aux poux. 
Sur dix voleur's, neuf ont eté séduits par d'autres plus agés, qui leur offraient des fruits ou du pain s’ils etaient paures, des filles sils avaient de la fortune, puis leur faisaient contracter des deltes pour les lier indissolublement au crime. - L'amour de la danse fit de Lucke un assassin. Holland, Costa, parmrent dans wn bal la nuit de leur crime. Bien des gens, à Paris et à Turin, se livent au rol pour trouver de quoi payer leur entrée dans les specticles.

Il est rare que le criminel éprouve une passion réelle pour la fenme. Son amour est un amour tout sensuel et sanrage, un amour des maurais lieux qui se développe, on pourrait presque le dire à la lettre, dans l'intérieur des lupanars (le fait est avéré pour Londres, où les deux liers de ces maisons sont de réritables cavernes de malfaiteurs). Il est caractérisé par la précocité et l'intermittence qui le lait passer rapidement de l'amour à la haine la plus intense. - Presque tous les maurais garnements de 12 a 19 ans, arrêtés à Newgate, entretenaient dos lemmes, qu'ils appelaien! flasghirl, - et lyeaucoup parmi eux araient été pour la première fois poussés all crime par le desir de possculer quelques mes des jeunes filles logées en hôtel garni. (F.scciler, l. c.).

Locatelli (l. c.) a comnu un fripon qui, à 9 ans, commettait des larcins, non pour satisfaire sa gourmandise, mais pom rigaler ses petites amies. De rol en vol, ce malheureux stait derenu, a 15 ans, un des plus effrontés habitants des prisons et des mitisons de débauche; il avait $u$ casier judiciale qui aurait fait envie au malfaiteur le plus émérite. Ce filou volait, volail sans cesse, pour fournir des aliments à son incroyable tendance an libertinage. Il apportait à mal faire la fougue de ses quinze ans, la passion qu' um jeune homme de son àge 
aturait mise à recherelıer les plaisirs bruyants et sidurteurs de l'adoleseence.

Il y a quelifues mois it peine, nos tribumaux ont en it s'occuper de trois jeunes gens, malfaiteurs prexoces, qui, chassés d’un lupanar parcequils manduaient d'algent, avaient assailli ef dépouillé de sa montre et do quelques pièces de monnaie le premier indivilu qui leur etait tombe sous la main, un cocher de fiacre.

Lassassin Taralino ne pouvait se passer de femmes IIn seul jour. - Sichler avait 12 maitresses. Bien souvent les voleurs mariés se troquent leur femme pour de largent; une fois on en donna en échange un chien et 5 llorins. (Lallemenraut, Ueb. die Gauncrthum, 1855).

Un camarade du faux monnayem $\Lambda$ m.... disait, au cours de son proces, que ses maitresses élaient assez nombreuses pour former une ligne d'un bout a l'aulie de la ville.

Wolff, aussitòt aprecs avoir commis un meurtre, šinstillait dans un bordel et promenait en voiture toutes les prostituées qui s'y trouvaient. Dumant, à qui l’on demandait s'il aimait véritablement la femme pour possíder laquelle il avait tuo le mari, répondit: "Oh! si vous l'aviez rue sans vêtements!" Hardouin, Martinati el Paggi se livaient i ladultère en prósenee de leurs épouses.

En général, tontefois, l'amour charnel s'iteint vile cliez les rolemrs; il ne persiste ave exagération que chez les escroes, les cmpoisonneurs, ct quelques assassins. Chez bon nombre de ceux qui se livrent à la débauche, laiguillon de la chair passe fréfuenment d'un blat de demi-impuissance à des acces d'autant plus violents qu'ils sont moins durables et affectent le plus sourent une forme périodique. (Verzeri, Gismoso). 
Parfois, mais le cas est rare, des assassins vulgaires, contne Franco, Moltino, Montely, la Pommerais, Demme, semblent nourrir une passion unique el puissante, un amour vraiment idéal; mais, je le répète, le cas est trèsrare, et l'on doit se méfier de leurs assertions, si l'on songe au sentimentalisme poétique de cel individı tatoné dont j’ai parlé plus haut; si l'on considère surtout que ces gens là sont passés maitres dans lart du mensonge.

Il est moins ordinaire de trouver l'amour platonique chez les voleurs. Mayhew a remarqui que les voleurs de Londres ne chantent jamais de chansons obscènes, mais quils préfèrent les romances sentimentales, comme celle-ci, par exemple: Ma pauvre Anne, je te quitte parceque tu es pauve, etc. Les voleuses aiment à voir Ieurs amants charges de chaines d'or, landis qu'elles ont des retements sorlides. Elles les soignent au cours de leurs maladies, dans la prison mème, et leur restent fideles, pourvu, toutefois, que teur détention ne se prolonge point trop. Les prostituées ont un amour yui les distingue des femmes lonnêtes (l'amour contre nature) el sont passionnées a l'extrime pour les fleurs, le bal et la table.

Mais ces plaisirs du jeu, de la lable, de l'amour, etc. cenx môme de la rengeance, ne sorvent que l'entracte ¿ un plus grand, plus exclusil, - celui de lorgie.

Cies misérables, en gnerre onverte avec la sociéli, ont un besoin étrange d'une vie sociale tonte leur propre; d'une vic de joic, lsmyante, querelleuse, sensuelle, passiec au milien de lemrs complices, do leurs délatemrs mêmes, une réritable vie de débauche.

A mon avis, les plaisirs de la bouche, l'amour du vin, ne sont, somvent, qu'un prétexte, it l'amour de l'orgie. 
Aussi, malgré l'évidence du dauger, aussitôt qu'ils on commis un meurtre, à peine ont-ils mis fin par l'irasion à une longue captiviti, on les voit revenir dans los lieux de leurs exploits, où la main vigilante de la justice les guetle.

Les prostituies éprouvent, en outre, un besoin continuel dagitation et de bruit; elles recherelıent les grandes réunions et tout ee qui peut les empêcher de songoer a leur triste condition. Aussi les voyons-nous, dans les pénitenciers, conserver leur loquacité hruyante, leur humeur tapagense (Parent-Deghatelet).

Je ne dis rien des autres passions, fort nombreuses, qui, selon les habitudes et lintelligence des criminels, peuvent varier indéfiniment, aller de la plus infàme, comme la pédérastie, it la plus noble, comme l'amour de la musique, des livres, des tableanx, des médailles, des fleurs, qui est plus spéciale aux prostituées; les goûts les plus lizarres peuvent se rencontrer en eux, comme, du reste, chez les gens honnêtes. Mais une chose les distingue de ces derniers: c'est la forme souvent instable, toujours impétueuse et violente, et pour la salisfaction de laquelle rien ne les arrête; car ils n’ont aucune prévoyance, et ne pensent jamais à l'avenir.

" Je savais bien, disail Lacenaire à ses juges, que je finirais par tomber entre ros mains; mais, en altendant, je me suis bien amusé». Et il ajoutail qu'il n'aurait pas accepté la vie, s'il n'y avait pas trouvé la possibilité de jouir. A peine avait-il besoin d'argent, qu'il tentait un coup, quelqu'en fût le danger.

9. - Par beaucoup de ces caractères, les crimincls se rapprochent fort des alićnés. Ils ont en commun avec eux la violence et linstabilité de certaines passions, 
l'insensibilité affective assez fréquente, l'insensibilité phỵsique plus fréquente encore, le sentiment exagéré dlu moi, et quelquefois, mais rarement, la passion des liqueurs alcooliques et le besoin de rappeler leurs crimes. B. G., frappé de démence et de parésic fait l'aveu suirant, dans sa Vie, que j’ai publié dans mon Génie ct Folie, $4^{e}$ éditition: "Les grandes infortunes endurcissent le cœur; moi, qui aurais gémis à la vue d'une goutle de sang, je contemple aujourd'hui sans m'ímouroir les plus affreux spectacles ». Un autre, L. M., a écrit: "Jontends parler de bonlseur domestique, daffection réciprorue, mais je ne puis éprouver rien de tout cela ». Notons cependant une diffírence: les aliénés ont rarement du goût pour le jon et pour l'orgie; et, licn phus souvent que les malfaitenrs, ils prennent en haine les personnes qu'on a coutume daimer le plus, leur femme et leurs enfants. En outre, le criminel ne peut virre sans compagnons, il s'expose même an danger pour en trouver, tandis que les fous próférent toujours la solitude, évitent, toujours, la société d'autrui. 11 en résulte que les complots sont d'autant plus rares dans les asiles l'aliénés, quiils sont plus fréquents dans les bagnes.

10. - En ce qui concerne la sensibilité et les passions, le criminel se rapproche bien plus du saurage que du fou.

La sensibilití morale est amortic on étcinte chez les sauvages. Les César's des races jaunes s'appellent Tamerlan; leurs monuments sont des pyramides de têtes humaines. Les supplices qu'on inflige dans le Cíleste Empire auraient fait pâlir les Denis ei les Néron.

Mais c'est dans l'impétuosité et l'instabilité des passions qu'ils s'accordent le plus. Les sauvages, dit Lul-- 
bock, sont dominés par des passions rapides, mais violentes; ils ont le caractire de l'enliant avec les passions et la force de l'homme.

Chez eux, la vengeance est encore considéríe commur. un droit, je dirai mène comme un devoir. Nous n'm trouvons que trop d'exemples chez des peuples qui nous tiennent de bien près. (V. 1" partic, 1) 60 et suiv.).

Ils ont aussi à mn trés-lant legré la rage du jeu, bien qu'ils ne soient pas fort cupides. Tacite raconto que les Germains, après avoir joué aux dés tout lem aroir, finissaient par se jouer eux-mêmes, el que lo vainen, fût-il plus jeme et plus fort que son adversairr, se laissait charger de fers et mellre en rente hors de sa tribu. Tous royez on Chine des malheureux qui n'hisitent pas i joner leur dernier labit an plus fort de l'hiver, quittes à momrir ensuite de froid; quand ils n'ont plus rien, il en est qui jonent leur propre corps. Les lluns, selon saint Ambroise, exposaient comme enjeux non seulement leurs armes et leur personne, mais encore leur vic. Chez les sanviges aussi, on rencontr: la lìcheté mêléc au courage, on même ì l’insensibilité, qui le rappelle et en tient lien. Chez cux encore, la luxure se mòle à l'amour du sang, et l'amour est toute luxure. Aux îles Andaman, les époux restent unis tant que l'enfant a besoin du sein de sa mère; après qu’il est serré, ils se séparent et cherchent d'autres amom's.

Enfin, chez les saurages, les liqueurs alcooliques, à peines introduites, ont eu le résultat funeste de ditruire des races entières, même dans les climats chauds, sous des latitudes qui préservent d'un tel fléaul les peuples civilisés (1). Bien plus, les peuples à qui la vie.

(1) Letourveau, Médecine des passions, trad. ital., Milan, 1880. 
sauvage ou les préceptes de la religion ont interdit l'usage des liqueurs enivrantes, y suppléent par d'autres moyens bizarres (mouvements de la tête de haut en bas et dc droite à gauche), qui malheureusement produisent le même effet.

La paresse est encore un des caractères propres du sauvage. Les habitants de la Nouvelle-Calédonie répugnent à toute occupation. "Souffrir pour souffrir, disentils, mieux vaut mourir que travailler ». (Bourgarel, Les races de l'Océanie, 1879). Ils répètent ainsi, presqu'à la lettre, la confession de Lemaire. 


\section{CIIAPITRE 11}

\section{Récidive directe et indirecte.}

Morale des criminels (1).

1. - Toutes les statistiques pénales s'accordent à constater la régularité et la fréquence tonjours plus grande des récidives parmi les délinquants.

En quelques pays, il est vrai, la récidive parait trèsrestreinte. Ainsi, elle est en Russie de $180_{10}$ en 187475 ; en Grèce, de $20_{10}$; aux iles Ilavai, de $50_{10}$; elı Espagne, de $180_{10}$ chez les hommes et de $110_{10}$ chez les femmes; en Italie même, de 1863 à 1870, les Assises n'ont fourni qu'une moyenne de 80 [0. Mais cette faible proportion résulte moins du manque de récidivistes que de labsence de tout contrôle. On peut constater que ces chiffres s'élèvent dans les mêmes pays, à mesure

(1) Ferri, Dei limiti fra divitti penali ed antrop. criminale, 1881, (Archirio di psich., 1'. - ID., Nuovi orizsonti, 2' édit., 1883. - Stat. per gli affari pen. in Italia, 1863-69.70-74-75-76. - Stat. delle carcer $i$ in Italia, 1862 à 1876. - Stat. decenn. delle carc. in Italio, 187079. - Italia economica nel 1873, 20 édit. - Comptes gén. de l'adm. de la Belgique, résumé stat. - Statist. Jahrbücher der in Reichs: certret. Verbrech. Königr. und Ländes vi Heft. - Comptes-rendus due Congr. pénit. intern. de Stockholm, 18\%9. - Statist. pénit. intern., Rome, 1872. - EtTrisen, Die Moralstatistik., 2, Aufl., 18i4. - DOOLvecronı, Des causes de la récidive, 1873. - Armęurst, La Sućde, 1879. - Beltrami-Scalia, La vif. penit. in Italia, 1879. - Garofalo, Sul nuovo Codvce penale del 1883, wv, 4. - YVERnEs, De la récidive, 1874. ReInach, Les récidiristes, $188 \mathrm{I}$. 
que les institutions judiciaires s'y perfectionnent et que s'y introduit le régime des casiers. En Italie, de $\mathbf{1 8 7 6}$ à 1880, les récidivistes condamnés par les tribunaux correctionnels se sont élevés de 18 à $19,450_{10}$; ceux qui ont été condamnés par les Assises sont allés en 1878 à 13 , en 1880 à 21 1 2 , et en 1882 à 220 10.

En France, les accusés récidivistes (Cours d'Assises) natteignaient que le chiffre de $100_{[0}$ en 1826 et celui de $280_{10}$ en 1850 ; - mais en 1867, c'est-it-dire 17 ans après l'introduction des casiers judiciaires, ils se sont élevés it $420_{10}$. Ils étaient de $440_{10}$ en 1871-76; de 48 en 1877; de 49 en 1878; de 50 en 1879. Cerrx qui ont comparu devant les tribunaux correctionnels, et qui figuraient pour $210_{00}$ en 1851-55, ont alteint, au cours des cinq années suivantes, le $37,31,36,34,38$, 40 pour $0_{10}$ (Reivacn). Les prévenus récidivistes se sont élevés de 7 à $270_{[0}$ en 1856-60, ¿̀ 31 en 1860-65, ì 36 en 1866-70, à 38 en 1871, à 40 en 1877-78.

On pent mime dire que, plus un pays sourre a la civilisation, plus il se montre riche à ce point de rue.

En Belgique, on arrive à 70010 pour les récidivistes fournis par Louvain en $1869-71$, et à $780_{10}$ pour ceux qui ont séjourné dans les maisons centrales.

En Danemark, dans les maisons de peine, en 187274 , on a relevé $740_{10}$ récidivistes mâles, el $710_{10}$ en 1875. Chez les femmes, la proportion s'est accruc de 61 à 66010 .

En Prusse, de 1871 i 1877 , le chiffre des condamnés qui avaient déjà une fois habité les établissements pénitentiaires a oscillé entre 77 et $800_{10}$ pour les hommes, et, pour les femmes, entre 74 et $840_{10}$.

La Iollande présentait en 1871, une proportion de $360_{10}$ de récidivistes sortis des maisons centrales, et 
25010 de ceux qui avaient séjourné dians los prisons ordinaires; en 1872, parmi cenx qui proventaient des établissements pénitentiaires, ou est arpivé all rhilfie de 38010 pour les hommes et 99010 pour les femmus (Stat. penit.).

La Suède, en 1859, comptait 34. 010 d'hommes et 29 p. 010 de femmes récidivistes, parmi tes condamnes anx travalux forcés. Al cours des anmies smivantes, on ell eut 33 et 36,31 et 29, 30 et 34,35 el 40 , 34 el 49 , 95 et 49 , 42 et 41 , 42 et 29010 . Ceux qui proventient des condamnés à perpétuité, de 1867 a 1870 , ont ilí de 50, 75, 69010 chez les hommes, et 10 50, 71, 25, 50 010 chez les femmes (D'Olivecroxa).

En Iutriche, si l'on considere l'ensemble de l'empire, les ricidives, en 1860-64, domnent un total de 9900 \% clles sélévent à 50010 dans la haute Antriche. En $1868-$ 71 , ellos y sont arrives it 59070 pour les hommes, of ¿ 51010 pour les lemmes. (Yvernés, De la récidie ele., Paris, 1874).

Pour les crimes, le chiffe s'est élevé de 49010 en 1872, it 4h en 1876, it 40 en 1877, a 48 en 1878; pour les délits, il a été de $150_{10}$ en 1872 , de 14 en 1876 , de 15 en 1877, de 15 en 1878. Dans les établissements pénitentiaires, les récidivistes lommes donnaient le 72 p. 010 en 1879-73, le 74 010 en 1876; les femmes le $640_{10}$ en 1872 , le $62-630_{10}$ en 1875.

Sur 100 récidivistes français, on en comptait:

1 provenant des travaux forcés (1);

2 id. de la réclusion;

(l) Le petit nombre de ricidivistes provenant des travaux foreis dipend de ectte circonstance seule, que les individus condamnes it so ans ou plus de travanx forees sont astreint par la loi à une résidence perpétuelle dans les colonies. (Yvervés, l. c.). 
20 de ceux qui avaient été condamnés à plus d'un an de prison;

61 de ceux qui avaient été condamnés à moins d'un an de prison;

13 individus condamnés à une amende.

Le fait même de la précocité prouve bien que le crime est bien de fois inné chez eux. Ainsi en France, sur 1000 récidivistes:

67 n'avaient pas atteint leur $16^{\mathrm{e}}$ année, (YvenNÉs, l. c.);

204 avaient de 16 à 21 ans;

28. id. 21 à 30 id. ;

215 id. 30 à 40 id.;

206 id. 40 à 60 id.;

20 id. $\quad 60$ à 70 id.;

4 avaient plus de 70 ans.

La persistance de la récidive ressort de cette constante répétition, par suite de laquelle le crime est comme enfermé dans un petit cercle de personnes.

Les récidivistes arrêlès pour la

\begin{tabular}{|c|c|c|c|c|}
\hline & $\mathrm{nt}$ & 45 & & u total; \\
\hline $2^{\mathrm{e}}$ & id. & 20 & $n$ & id.; \\
\hline $3^{e}$ & id. & 11 & $"$ & id.; \\
\hline $4^{e}$ & id. & 7 & $n$ & id.; \\
\hline $5^{e}$ & id. & 4 & " & id.; \\
\hline $6^{\mathrm{e}}$ & id. & 3 & $"$ & id.; \\
\hline $7^{e}$ & id. & 2 & $"$ & id.; \\
\hline $8^{e}$ & id. & 2 & A & id.; \\
\hline $9^{\mathrm{e}}$ & id. & 1 & * & id.; \\
\hline $10^{\mathrm{e}}$ & age & 5 & $n$ & jd.; \\
\hline
\end{tabular}

En 1860, on comptait à Londres 1698 voleurs ayant subi plus de cinq condamnations, 1979 qui en avaient subi plus de sept, et 3409 qui en avaient subi plus de dix. - A un meeting de tout jeunes voleurs, organisé dans la même ville, on en vit 5 qui avaient été déjà 
condamnés dix fois, 9 qui l'avaient éte vingrt-nenf fois, 1 enfin qui l'avait été 30 fois.

M. Reinach compte, sur bos prisonniers liberis en 1878, 2419 individus, soit 39010 , qui ont éti repris dans l'espace de 2 ans; parmi eux, $\$ 2$ s'élaient dijji rendus coupables de 2 récidives, 199 de $;$, el $21 !$ de 5 (1. c.).

27010 des individus arrêtés à Paris en 1880 araient subi plus de 4 condamnations en 10 ans. En gínéral, le vol au poiurier (sur les irrognes), l'emporte ì ce point le vue sur le vol à l'américaine.

2. - Et ce n’est point, certes, le système pénitentiaire qui prévient ies récidives; les prisons en sont, an contraile, la cause principale.

II. Brétignères de Courtelles affrme qu’a Clairvaux il a vu 506 réeidivistes condamnés pour vol ou vagabondage, qui avaient agi dans l'unique but de se procurer une vie plus facile dans la prison; 17 prisonniers sur 115, lui ont déclaré n'avoir pris aucune précantion dans l'exécution de leurs méfaits, parcequils avaient besoin de séjourner un ou deux ans dans la prison pour rétalılir leur santé délabréc. Les récidivistes, dit encorc notre auteur, rentrent avec bonheur dans la prison comme si elle était leur propre dememe, et leurs compagnons, heureux de les revoir, les saluent du nom de voyageurs, de bons camarades. (Les condamnés et les prisons, Paris, 1838).

11. Bréton (Prisons el emprisonnements, 1875) cite un paure diable qui tous les ans se rendait coupable te légers rols pour se faire réintigrer en prison. I la cinquantième fois, au lien de la maison d'arrêt, il rencontra la prison cellulaire. "La justice m’a fraudé, disait-il en se plaignant; on ne my prendra plus dans ce pays ». 
On demandait au chef de bande Ilessel, incarcéré pour la $26^{\mathrm{e}}$ fois, pourquoi la prison ne l'avait pas amendé, et comment pouvait-il désirer la liberté, qui représentait pour lui la faim et la misère. "Rassurezvous, répondit-il, tant que nous aurons dix doigls, nous ne souffrirons pas de la misère au grand air. Mais avez-rous jamais ru un lomme corrigé par la prison? - Jai vu condamner 16 fois, pour vagabondage une famille entière de bohémiens; à la belle saison, ces gens là sortaient et demandaient l'aumône avec force menaces; a l'entrée de l'hiver, ils se faisaient arrèter pour aroir du pain et des vêtements; la prison les a-t-elle par hasard rendus meilleurs? S'ils avaient trouvé une vie abondante et facile en toute saison, ils auraient certainement préféré le grand air et la liberté ».

En Suède, M. d'Olivecrona a remarqué que les récidires, pour les voleurs condamnés à la prison cellulaire, s'élèvent ì 32010 ; il a également observé que les condamnés à vie aux travaux publics, quand ils sont graciés, fournissent 73,8 à 81,300 de récidivistes. (D'Olivecrona, Sur les récidives en Suède, 1874, Paris, trad.). En général, les récidives, après un an de prison cellulaire, montaient dans ce pays:

$$
\begin{aligned}
& \text { à } 52010 \text { en } 1864 ; \\
& \text { à } 72 \text { " en } 1870 .
\end{aligned}
$$

C'est chez les femmes surtout que la récidive est constante: on jeut mème remarruer, comme nous le verrons plus loin, que chez elles, contrairement à ce qui a lieu chez les hommes, les récidives multiples se présentent plus souvent que les simples (1).

(1) Pour les récidives en général on ne pent l'affirmer avec une certitude eomplète. - Cela est bien vrai pour l'Angletere, ou l'on troure 
Parmi les prostituées, dit M. Parrent Couchitelet, il en est peu qui aient éprouvé un repentir roribabr; elles ne voient dans les couvents de repenties qu'un moyen d'améliorer leur condition. Tocqueville a remarqué qu’en Amérique, les filles adonnées au unal sont bien plus incorrigibles que les jeunes garcons.

En voilà assez pour réfuter les assertions hypoerites, ou tout au moins naïves, de l'abbé Gural, qui prétend cn avoir converti un si grand nombre dans lasile de Nazareth; et celles de 11. Lamarque (La réhabilitation des libérés, 1873), qui ne voit là qu'une malière ì de vagues déclamations.

Un grand nombre, comme l'a très-justement remar(fué M. Morselli (Rivista di frenialria, 1877, p. 332), n'attendent mème pas leur sortie de prison pour récidiver. La meilleure démonstration en est fournie par ce lableau des délits commis dans nos prisons de 1871 à 1874, et en 1872 en Saxe, en France et en Suède:

320 I0 récidivistes mâles et 47010 du sexe fẻminin; mais non pour l'Italie, où les premiers domment 21 à 310 [0 et les femmes seulement 130 o.

Ce n'est pas vrai non plus:

Pour la Suède, où pour 430 q0 hommes on compte 330 q0 femmes
Id. l'Espagne id. 18 »
id.
$11 \rightarrow$ id.
Irl. le Danemark id. 76 ,
id.
24. id.
Id. la Russie id. 8 ,
id.
$6 \rightarrow$ id.
Id. l'Autriche
id. 59 "
id.
$51 *$ ifl.

En France, les femmes foumissent $1_{[10}$ du total des rẻcidivistes. (Yvernes, l. c.).

En Danemarck, ponr l'escroquerie, la proportion est plus grande chez les femmes; elle s'ẻlève à $170[0$, tandis que les hommes n'arrivent qu'à 15 0[0. Le eontraire s'observe pour le recel: $140_{\text {I0 }}$ lommes, 60 I0 femmes (1. e.).

Parmi les mineurs, la récidive est plus fréquente clez les femmes on ce qui concerne les délits communs: 750 [0 contre 60. All contraire, lis paresse fournit 270 [0 récidivistes hommes et 14 0 [0 du sexe féminin. 
TROISIÈME PARTIE

\begin{tabular}{|c|c|c|c|c|c|c|}
\hline & $\begin{array}{r}\text { Itali } \\
\text { I I } 871- \\
\text { sur } 106 \\
\text { condar }\end{array}$ & & $\begin{array}{c}\text { France } \\
\{18 \pi 2\rangle \\
\text { sur } 20.680 \\
\text { condamn. }\end{array}$ & & $\begin{array}{c}\text { Saxe } \\
\text { sur } 4.227 \\
\text { ndamn. }\end{array}$ & $\begin{array}{rr} & \text { Suède } \\
27 & \text { sur } 6.28 \\
\text { 1. condamn }\end{array}$ \\
\hline Meurtres & . 40 & - & - & - & - & - \\
\hline t blessures & 281 & - & 26,22 & - & 594 & 195 \\
\hline Vol & 29 & 一 & 390 & - & 232 & - \\
\hline a pudeur & 1 & - & 344,00 & - & 12 & - \\
\hline Reb & 45 & 一 & & - & - & - \\
\hline Tentatives d'incendie & 1 & 一 & 176,00 & - & - & \\
\hline
\end{tabular}

Si nous nous arrêtons en Italie, nous trouverons en tout 9,68 crimes par 1000 détenus, soit:

3,02 pour meurtres ou blessures;

0,44 id. rébellion;

0,16 id. vols on faux;

0,02 id. incendies;

0,02 id. attentats à la pudeur;

0,02 id. vols à main armée aussitôt après l'évasion;

et je ne liens pas compte des infractions à la discipline, qui feraient monter la récidive dans l'année:

a 1 par 3 individus mâles enfermés dans les bagnes;

à 3 par 1 id. dans des prisons;

à 1 par 2 pour les femmes.

Si l'on faisail le compte de ce que nous appellerons des contraventions et des fautes légères, on trouverait pour 100 prisonniers non punis:

Dans la Grande Bretagne 50,7 prisonniers punis et 30,8 femmes

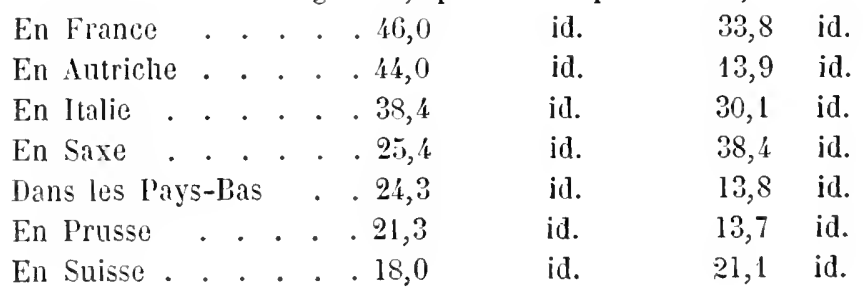


En Belgique . . . 14,0 hommes punis et - femmes

En Danemark . . . 8,0

id.

3,8 id.

En Suède

iil.

$2,8,8$ id.

M. Morselli a entrevu un fait curieux, cest que los pays, oủ ces fautes commises dans les prisons atteignent le chiffre le plus élevé, ont un nombre moins grand de sniciles, et ricêrersa; si bien que la Belgique, la Prusse, la Suède, le Danemark, qui donnent de 1,7s it $0,600_{10} \mathrm{de}$ suicides accomplis dans les prisons, donnent tout au plus de 21,3 a 8010 de punitions. Crla prouve, encore une fois, que le suicide est souvent une transformation du crime. (V. chap. Iv, Le suicide chez les criminels, p. 374).

On espèrerait bien à tort prérenir ou diminuer les récidives en améliorant le régime des prisons.

En France, sur 100 individus sortis des maisons centrales, en 1859, on put compter 333 hommes et $23 \mathrm{fem}$ mes qui y retournèrent l'année suivante. En Prusse, une constatation officielle permet d'établir que la prison cellulaire n'a exercé ancune influence hemreuse sur les coupables que la passion avait entraînés, et qui ne sont pas, d'ailleurs, de véritahles criminels; pour ceux-ci, la récidive s'est élevée de 60 à $700_{10}$. C'est le chiffre que l'on relève en Belgique, à Louvain, où le système cellulaire est en vigueur depuis 12 années. II faut y ajouter celui de 78010 , donné par les maisons centrales, dont la moitié ont adopté le même système. Au Wurtember⿳̧, les récidivistes se sont élevés de $340_{10}$ à 37 (1). D’après le passage cité d'Olivecrona, les condamnés pour vol à la prison cellulaire, en Suède, se répartissent ainsi :

(1) Beltrani-Scilia, Stato attuale della riforma penit. in Europa, 1871. - Pears, Prisons etc., 1872. 
$45,9$ récidivistes pour vol ou vagabondage 1 fois (vol 30,0$)$.

$\begin{array}{llll}74,4 & \text { id. } & \text { id. } & 2 \text { id. } \\ 86,4 & \text { id. } & \text { id. } & 35,4) .\end{array}$

Tous arrivent au maximum de récidive après la troisième année qui suit leur libération. Et même si le șstème de pénalité gradıée, et le système individualiste, ont paru donner des résultats splendides, à Zwickau el en Irlande (2,68 récidivistes à Zwickau, $100_{10}$ en Irlande), il n'en est pas ainsi en Danemark, out on en a fait un examen très-détaillé (V. vol. $\mathrm{II}^{\mathrm{e}}$ et $\mathrm{III}^{\mathrm{e}}$ ).

3. -- Si les systèmes pénitentiaires ont une médiocre influence sur la récidive, l'instruction (et l'on remarquera que les deux choses sont connexes) en a une moindre encore. Elle semble même favoriser la r'écidive; et nous verrons bientòt que l'instruction, que des esprits superficiels, en cette matière, regardent comme une panacée du crime, est aussi une des causes de la récidive, ou, tout au moins, un de ses facteurs indirects (V. vol. $\mathrm{II}^{\mathrm{e}}$ et $\left.\mathrm{III}^{\mathrm{e}}\right)$.

Quiconque, à l'exemple de M. Locatelli, recherchera de plus près les causes de celte influence pernicieuse de l'instruction, découvrira que le coupable, dans les prisons, apprend, avec l'art du serrurier, du calligraphe, du lithographe, de noureaux moyens de mal faire avec moins de danger et plus de profit; que l'agresseur se transforme en faussaire, le voleur en escroc ou en faux-monnayeur; car les diverses catégories de criminels ne diffèrent entre elles, à vrai dire, que par le degré de culture; au point de vue psychologique et anatomique, elles sont bien des fois semblables les unes aux autres. Et voilá pourquoi nous voyons, dit II. Bellinger, les récidives se reproduire toujours en grand nombre dans les crimes qui demandent de la réflexion, surtout dans les 
attentats contre la proprićté; et landis que les vols en donnent le $210_{10}$, les rapines le $100_{10}$, les assassinats ne dépassent pas le chiffre de 5 à $300_{10}$. (Crimes of passions, Londres, 1872).

Voyez l'ltalic: e'est aussi dans les crimes contre lit propriété, dans les vols, les escroqueries, que la réci„live présente le eliffre le plus élevé. On compte:

Condamnés en génèral Récidivistes

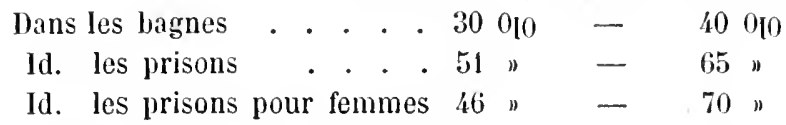

(Statistica delle carceri, Palerme, 1877). Et la cupidite, qui compte pour 420,0 parni les molsiles qui ont entraîné les scélérats au bagne, et pour 530 0 0 touchant les autres détenus, s'élève, quand il s'agit de la récidive, à 54 et à 660 [0 pour les hommes, à 47 et à 76 pour les femmes, tandis que la vengeance, la haine, la colère, descendent de $17,11,7$ à $16,7,300_{10}$ dans les bagnes, et à $3,5,2010$ dans les autres prisons ( $i d)$.

En Espagne, sur 2249 condamnés récidivistes, 1569 étaient retombés dans la même faute; dans ce nombre les voleurs comptaient pour 933 , les meurtriers pour 429.

En France, le contrairc semblerait résulter de la stalistique d'Yvernés:

On y trouve 54 olo attentats contre les personnes;
Id. 46 "
id.
les propriétés;

mais cela provient de ce que l'on classe le vagabondage parmi les attentats contre les personnes; en effet, conclut Yvernés, un bon tiers des récidivistes se compose de voleurs et de vagabonds etc.; de même, en Suède, la récidive pour vol s'élève à $460_{\text {I0 }}$ (l. c.).

4. - Ce fait a pour moi une grande importance: il montre combien est inutile, au point de rue de la mo- 
ralité vraie du criminel et de sa culpabilité, la distinction si soigneusement faite par les codes entre la récidive propre et la récidive indirecte. Cette dernière est d'ailleurs toujours plus rare, tandis que la récidive propre s'est élevée chez nous, en 1872-75:

à 66 olo pour les coupables sortis des hagnes;
à 77 "
id.
des prisons;
à 80 " pour les femmes (1);

bien entendu exception faite des crimes résultant de la passion: ceux là n’ont, à vrai dire, jamais de récidive.

Le nombre des récidivistes s'accroit toujours, si l'on tient compte de certains groupes de crimes qui sont le plus souvent commis et pour lesquels la non récidive devient presque une exception.

On le verra clairement d'après le tableau statistique des récidivistes, de 1874 à 1878, dressé par M. Ferri (l. c.). J'ai retranché de ce tableau les crimes de nature politique (expulsion de réfugiés étrangers, délits de presse), ou qui ne sont pas réellement des crimes au sens anthropologique (port d'armes prohibées); enfin, fondant ensemble crimes et délits, jai tenu compte seulement des catégories qui ont donné le plus grand nombre de récidives.

FRANCE.

Condamnés récidivistes 187டł-78.

1. Rébellion . . . . . . . . 100

2. Pupture de ban . . . . . 100

3. Ivresse . . . . . . . . 79

4. Vagabondage . . . . . . . 71

5. Vol qualifié . . . . . . . 71

(1) Strtistica delle carceri, 1873 et 187\%. En France, la même fante fut constatie nne première et dernière fois en 370 [n des réeidivistes. (Y Yrerass). - En Suède 2 15 des réeidives sont de même nature. (ID.). 
6. Vol à main armée sur la voie publique . . 6,8

7. Vol dans une église . . . . . . fi

8. Mendicité . . . . . . . . 6, 6

9. Associations de malfaiteurs . . . . 6.2

10. Vol sans violence sur la voie publique . . $\quad$ il

11. Vol à main armée sur la voie publique . . 57

12. Nauvais traitements à l'égard des parents . 56

13. Rapt de mineurs . . . . . . . 5

14. Incendie d'édifices non habités . . . 52

15. Bigamie . . . • . . . . 50

16. Castration . . . . . . . . 50

17. Escroqueric . . . . . . . 43

18. Assassinat . . . . . . . . . 43

19. Outrages à des fonctionnaires publics . . 42

20. Fausse monnaie . • • . . . 42

21. Parricide . . . . . . . . 41

22. Vol commis par un domestique . . . 41

23. Vol simple . . . . . . . . . 41

2i. Coups et blessures graves . . . . 40

25. Incendio de maisons habitées . . . . 40

26. Faux en écriture authentique ou privée . . 40

27. Outrages à la morale publique . . . 40

28. Abus de confiance . • . . . . 40

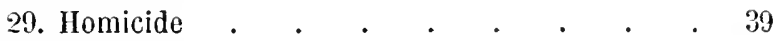

30. Viol et attentat à la pudeur sur des adultes . $\quad 39$

31. Faux en écriture de commerce . . . 38

32. Rébellion (à main armée?) . . . . 37

33. Viol et altentat à la pudeur sur des enfants . 36

34. Menaces écrites ou verbales . . . . 36

35 . Violences contre des fonctionnaires publics . 35

36. Faux témoignage . • . . . . 35

37. Fourberie . . . . . . • . 33

38. Blessures entrainant involontairement la mort 31

39. Outrages publics à la pudeur . . . . 31

40. Coups et blessures avec préméditation . . 30

41. Banqueroute frauduleuse . . . . . . 29

42. Extorsion . . . . . . . . 28 
Faites la part de ce qui devient un crime par suite les furcurs politiques, et de ce que la police française, si minutieuse, qualifie de rébcllion, vous pourrez dire que ces chiffres représentent la côte des criminels-nés, et vous trouverez qu'ils se ramènent spécialement à des révoltes contre la force armée et à des associations criminelles, vols, vagabondage, coups et blessures, bigamie: viendraient ensuite, mais dans un rapport bien moindre, les assassins, les faux monnayeurs, les parricides, les incendiaires, les meurtriers, les hommes adonnés au viol, les faussaires, les faux témoins, les fripons, les menaces, les outrages publics à la pudeur, et, en dernier lieu, la banqueronte frauduleuse et l'exlorsion.

II. Reinach a dressé le tableau suivant, concernant Ja fréquence de la récidive en France (1. c.):

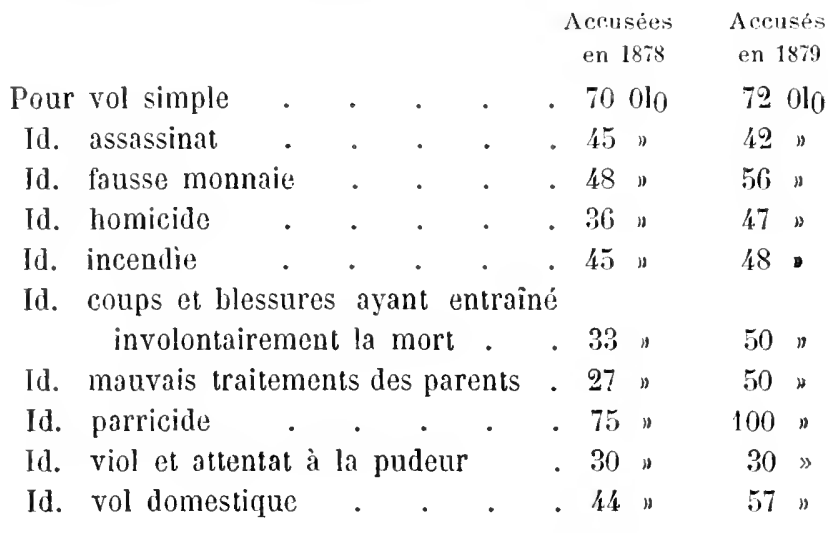

Ces proportions, pour une bonne part, correspondent a celles des criminels qui nous ont donné la plus grande fréquence des anomalies du crâne, de la physionomic, des anomalies algométriques, etc.; elles servent à compléter et à contrôler, au moyen du sceau juridique, la 
conception du criminel-né, qui certes, en dehors de l'anthropologie théorique pure, ne peut ètre consilderí comme tel avant d'avoir commis une ou plusieurs récidives. Et cela d'antant plus que les anomalies anatomiques peuvent se rencontrer dans presque toutes les formes psychiatriques dégénératives, même chez l'ilveugle-né et le sourd-muet, - et que les tendances criminelles sont communes au premier îgc.

C'est lat récidive obstinée qui commence à nous signaler le coupable de cette catégorie, surtout fuand elle se fait remarquer en lui dès son enfance.

Il importe done de constater de suite, que ces espices de crimes, qui domnent le plus grand nombre de rérdives, sont les mèmes qui ont germé le plus fréquemment dans la jeunesse.

A Paris, écrit M. Reinach, plus de la moitié des individus arrêtés ont moins de 21 ans; on en a compté 12.721 sur $20.882 \mathrm{en} 1879$, et 14.061 sur $26.475 \mathrm{cn}$ 1880 , el presque tous avaient commis des fautes graves.

En une seule année, 30 assassinats, 39 homicides, 3 parricides, 2 empoisonnements, 114 infanticides, 4912 coups et blessures, 25 incendies, 153 viols, 80 attentats à la pudeur, 458 vols qualifiés, 11.862 rols simples, ont été commis par des jeunes gens.

Sur 4347 accusés qui ont passé aux Assises en 1879, on comptait 802 mineurs, $180_{10}$, dont 49 avaient moins de 16 ans.

En matière correctionnelle, $40_{10}$ avaient moins de 16 ans, et $150 / 0$ étaient entre 16 et 21 ans.

I. Ferri (l. c.) établit également que le plus grand nombre des crimes relevés sur des mincurs, en France (1874), se décompose ainsi: 
Vol simple, escroquerie . 60,2 hommes - 56,2 femmes

Mendicité, vagabondage . . 25,3 id. $-22,4$ id.

Vol qualifié, faux . . . 4,2 id. $-2,2$ id.

Attentats à la pudeur . . . 4,1 id. $\quad-3 ; 5$ id.

Homicide, blessures . . 2,0 id. $-0,9$ id.

Incendie . . . . . 1,6 jd. $-2,3$ id.

Assassinat, empoisonnement 0,4 id. $-0,15$ id.

$\mathrm{Si}$, maintenant, à tous ces chiffres on ajoute celui des décès, - et ils sont très-nombreux, grâce aux débauches habiuelles des malfaiteurs, - et celui des fautes qu'on n'a pu relever ou punir par suite d'une habileté plus grande acquise dans les prisons, on en arrivera à conclure que le nombre des récidivistes réels, dans ce groupe de criminels, s'écarte bien peu de celui des condamnẻs libérés; ou, plus exactement, qu’il n'est presque aucun de ceux-ci qui ne soit un récidiviste. Ici, je suis heureux de me rencontrer avec un adversaire consciencieux, II. Canonico, qui écrit dans son savant ouvrage $I l$ delitto e la libertà di volere, 1875: "La récidive n’est hélas! que la règle générale pour les condamnés, dès qu’ils acquièrent leur liberté. A ce propos, je me sonviens d'avoir lu quelque part qu'un individu, à peine sorti de la prison oú il avait été enfermé pour avoir dérobé 20 francs à son camarade de chambre, en vola dans la même circonstance 60 à un autre ». - Et ce qui me plait davantage, je me rencontre aussi avec la conscience populaire qui, depuis des sic̀cles, a consacré les proverbes suivants:

Semel malus, semper malus.

Le voleur ne se repent jamais. (Pasqualigo, Proverbi veneti, 1878).

"Wer ein mal stiehlt, heiszt allezeit Dieb" (Qui vole une fois sera toujours appelé voleur). (EISELEIN, Die Sprichwörter, etc., Fribourg, 1840). 
Qui commence mal finit pire. (Pasqualigo).

Vice de complexion jusqu'a la fosse dure. (Gusti).

Qui d'un vice veut s'abstenir, qu'il prie Dicu de ne pas l'avoir. (Givsti, Proverbes, 333).

"Einmal Hure immer Ilure " (Prostituée une fois, prostituce toujours).

N'est pas toujours femme de bien qui veut. (La Pucelle, p. 117). Qui veut faire un fripon, qu'il le mette en prison. ('Tasoualigo). $\mathrm{Ni}$ maladie ni prison ne rendent l'homme bon.

Ni bâton ni prison ne rendent l'homme bon. (Prov. Venise).

Coupez la queue au chien, c'est toujours un chien.

Rien de plus naturel que ces proverbes.

5. - Sens moral. - M. Maudsley a écrit: On pent dire du vérilable voleur ce qu'on dit du poëtc: il nait tel, il ne le devient pas. Et comment croire qu'il soit possible de réformer ce qui est le produit de générations successives? - Il cite à ce propos Chatterton entendant dirc à des voleurs, dans la maison où il était enfermé, que, fussent-ils millionnaires, ils conlinueraient leur métier. Les neuf dixièmes des condamnés sont ainsi. (Responsability, etc., 1873).

C'est que le sens moral, chez la plupart d'entre eux, lait absolument défaut; beaucoup ne peuvent comprendre l'immoralité de la faute. - Dans l'argot français la conscience est appelće la muetle, le voleur un ami; voler se dit servir ou travailler. - Un voleur milanais me disait: "Je ne dérobe pas, je ne fais qu'cnlever aux riches ce qu'ils ont de trop; et, d'ailleurs, les avocats, les négociants font-ils autre chose? Pourquoi donc suis-je seul accusé et ceux-là les laisse-t-on tranquilles?" - Un certain Rosati, celui dont j'ai peint la plısionomic ouverte et pensive, me disait: a Je n'imiterai pas mes compagnons qui font mystère de leurs méfaits; loin de 
lì, je m'en vante. J'ai volé, c'est vrai, mais jamais moins de dix mille francs; s'attaquer à de si gros morceaux me paraît moins un vol qu'une spéculation...... On appelle fausses clés les instruments que nous employons; moi je les nomme des clés d'or, car elles nous ouvrent les trésors des riclses sans aucune fatigue de notre part». - Un autre, son digne collègue, parlait ainsi: «Le vol, dit-on, est une mauvaise action; tel n'est pas mon aris. Je vole par instinct. Pourquoi l'homme parait-il sur la terre, sinon pour jouir? Maintenant donc, si je n'eusse volé, je ne pourrais point jouir, je ne pourrais même pas vivre. Nous sommes nécessaires dans le monde: sans nous, quel besoin aurait-on de juges, d'avocats, de sbires, de geôliers? C'est nous qui faisons vivre tous ces gens-là ». - Lacenaire s’adressant a son complice Avril, disait: «J'arais compris que nous pourrions mettre en commun notre industrie». - " 11 y a done, concluait à ce propos le procureur du roi, des hommes pour qui l'assassinat n'est point une nécessité extrême, mais une affaire qui se propose, se discute et s'examine comme un acte quelconque ». - Tortora répondait à celui qui l'accusait de vol aux Assises: "Quoi? voleur! Les voleurs sont les honnêtes gens (les riches) de la ville, et moi, en les supprimant, je ne fais que leur donner ce qu'ils méritent ». - "Nous sommes nécessaires, disait à ses juges Ilessel, un hardi chef de bande. Dieu nous a mis sur la terre pour punir les avares et les mauvais riches; nous sommes une espèce de fléau de Dieu. Et d'ailleurs, sans nous, que feraient les juges?»

Ceneri justifiait de la sorte les violences exercées dans le vol Parodi: "Nous les avons liés pour notre sûreté, comme fait V.S. quand elle nous fait mettre les gants 
(les menottes); c'útail alors leur tour; it chacun son tour \%. (Procès Parodi, Turin, 1870).

Bref, dans ces natures, l'idéc du devoir parait complètement renverséc. Its croient aroir te droit de volur, de tuer, et rejettent la faute sur les autres qui ne les laissent point agir í leur guise. Ils en viemnrut mime it découvrir un mérile dans le crime. Les assassins, spricialement cenx qui tuent par rengeance, s'imaginent. faire une action homocte, et parfois hirroïque, allors même qu'ils ont pris leur victime en traitres. Linsi Jartinelli, en envoyant un homme tuer son emnemi, comparail son action infime a celle des anciens liomains, qui vengeaient par le saug teur honncur offensí. - La fiute, pour beaucoup, consiste is joner le poile despion, ou it combattre leurs désirs. B., qui s’étail adonné an brigandiuge dés sa jeunesse, el qui, en compagnie de Schiarone, avait the plusienrs donzatines d'hommes, se plaignait ì moi d'aroir été condamué it ringt années de peine. - o Dix suffisaient; car, si j’en ai tant tué it cette éporque, j’ai accompli un deroir. Ihais tu as tué aussi des femmes? - Celles-li l'avaient bien mérite; elles tentaient de fuir ».

On parle souvent du remords qui ronge le criminel; et l'on a même vu, il y a quelques années, les systèmes de pénalité prendre pour point de départ le repentir des coupables. Mais il suffi d'avoir étudié même superficiellement ces misérables, pour être certain que le remords leur est inconnu (1). D'après Elam et Tocqueville, les pires détcnus sont ceux qui ont la meilleure conduite dans la prison; plus intelligents que les

(1) Ferri, Il contegno dei delinquenti. - In., Il vimnrso, (Arch. lli psich., 1884. 
autres, ils s'avisent que pour être bien traité il est bon de feindre des sentiments honnêtes. - Les geôliers anglais disent que l'on changerait plutòt un chien en renard, qu'un voleur en honnête homme. - M. Thompson, sur 410 assassins, n'en a vu qu'un seul dont le repentir fủt sincère; il a fait la même constatation sur 2 femmes parmi 130 infanticides (1). - J'ai étudié moi-même 590 de ces misérables, employant tous les moyens pour gagner leur confiance; à peine en ai-je rencontré 17 qui convinssent de leur crime; 2 s'en vantaient ouvertement. Pour les autres, ils niaient tous en termes très-brefs, et se plaignaient de l'injustice d'autrui, des calomnies, de l'envie, dont ils disaient avoir été victimes.

M. Ferri, qui a étudié 700 prisonniers el classé leurs réponses, a obtenu des résultats à peu-près semblables. En voici le précis; (Omicidio, 1877, Bologna):

Voleur's de grand chem.

Maintien

Total

Assass.

larrons

homicid.

et

coupe-bourses

Qui avouent simplement • . . 9,6

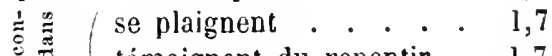

9,8

9,4

0,8

1,1

0,4

3,0

26,0

8,3

节 $\tilde{0}$ s'excusent . . . . . 18,0

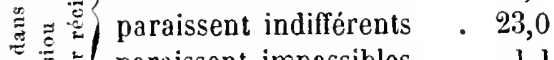

. 1,1

苍

17,0

2,7

25,5

5,1

19,2

Individus examinés . . . . . 698

- 254

266

Ainsi, sur 700 détenus, il y en a seulement $3,40_{10}$ qui témoignent du repentir ou qui du moins paraissent émus en racontant leurs actions coupables; les assassins-

(1) Physiol. of crimin., 1870. 
homicides $\left(1,20_{0}\right)$ sont en plus pelite proportion ane les bandits et surtout que les voleurs $\left(\begin{array}{rll}1 & 0 & 0 \\ {[(0)}\end{array}\right)$.

$90_{10}$ se bornent a un aven pur et simple du crime; il n'y a presque pas de différence entre les lomicides et les roleurs.

18010 allèguent des excuses plus on moins plansibles, comme la nécessité de se défendre, la provocation, l'imprudence du jenne ìge, livresse, la misime, les mauvaises compagnies, etc. D):nns cette caltigorie, les assassins-homicides ( $\left.260_{10}\right)$ sont hien plus nomhreux que les brigand; et les voleurs $\left(\& 0_{\mid 0}\right)$.

2:) $0_{10}$ restent absolument indiflérents an récit de leur propre crime. Ici, les bandits-roleurs $(25010)$ l'emportent un peu sur les assassins-homicides $\left(170_{(0)}\right)$, auxquels il fant rapporter ceux qui restent impassibles (3) $\left.0_{00}\right)$.

Enfin, plus de $100 / 0$, par leur altitude effrontie, prouvent, de la facon la plus explicite, lenr manque absolu de remords. Ce sont, dans ces derniers cals, ceux dont le crime est le moins grave, le moins déshonorant et le moins sévèrement puni, les bandits-voleurs (19 $\left.0_{10}\right)$, qui l'emportent; les assassins-homicides ne donnent que le 50

Si bien que l'on pourrait conclure, d'une façon gónérale, que, dans la masse des détenus, phus d'un tiers ( $350[0)$ prouvent directement qu'ils n'ont point de remords, par l'indifférence, l'effronterie qu'ils apportent dans leurs aveux ou dans le récit de leur crime, - les assassins-homicides (2/4010) restant au dessous des bandits el des voleurs $\left(\begin{array}{ll}45 & 0\end{array} 0\right)$ - et qu'un autre tiers donne indirectement la mène prenve par leurs dénégations olsstinées. 
Un philosophe, dont le mérite n'est certainement pas a la liauteur de la renommée, Il. Caro, dit quelque part: "Voyez les criminels eux-mêmes admettre le châtiment; ils nient le crime, jamais la peine qui les frappe ». Pensée encore plus ridicule, peut-être, qu'absurde! Je défie bien qui que ce soit de nier un fait, dont, à tout moment, il doit souffrir la preuve douloureuse! Ne voyez-rous pas que sils éprouvaient réellement le moindre remords, s'ils royaient la justice de la peine, ils commenceraient par avouer leur faute, surtout aux personnes bienveillantes et qui ne sont pour rien dans les traitements rigoureux qu'on leur inflige? Ne voyez-vous pas qu'ils éprouveraient tout d'abord le besoin de s'épanther, de se justifier aux yeux du monde, par ces mille et une raisons qu'un homme trouve, toujours, pour sa propre défense? Mais leurs dénégations tenaces, obstinées, sont la meilleure preuve qu'ils n'ont pas de repentir! Il est vrai que ces dénégations naissent du désir d'éviter une condamnation; mais elles démontrent, en mêrne temps, l'absence de toute réaction du sens moral offensé. - Aux comptes-rendus des causes célèbres, où l'on voit que les meurtriers les plus vulgaires et les plus sauvages sont aussi toujours ceux qui nient avec le plus d'obstination jusqu'au dernier moment, jajouterai des nouvelles observations de Ferri. J'ai pu examiner, dit-il, tour à tour 700 détenus de Pésaro et de la prison de Castelfranco, et j’ai constaté que 12000 des plus grands criminels (assassins-homicides-voleurs de grande route) s'obstinaient à nier, tandis que le chiffre descendait à $210_{10}$ jour de moins grands coupables (roleur's, coupe-bour'ses, escrocs, etc.). Ce n'est pas tout: alors que les homicides du bagne de Pésaro niaient dans une proportion de $380[0$, ceux de la prison 
de Castelfanco, moins feroces, frireefur on los anit

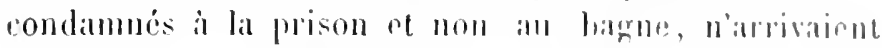

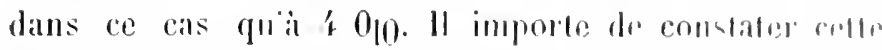
inorme diffirence qui, soit dams les chifferes on anxmemes, soit dans lems ripports avec les totamx respere lifs, acquiert une valeur psyoholowique ividente. Lin outre,

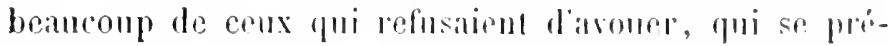
tendaient innocents, qui diplomient lomrs malloms, s'abandonnaient, ensuite, an comrs de la conversation. à une hilarití qui ne lassait aucun donte sur ee que j’appellerai la véritable genèse psyelologique de lours dénégations obslinées.

Ine derniere preuve indirecte de lenr manquo do rebords, preuve qui peut ètre considíce comme nue démonstration des plus claires, éest que les eriminels de cette catégorie ne plaignent jamais leur victime, qu'ils la tourncnt en derision, au contraire, et la calomnient souvent. - « Sur 10 voleurs, on en voil an moins 9 qui traitent de briģands et d'escrocs ceux qu'ils ont volés, ” observe avec raison un chroniqueur judiciaire. Parmi ceux que j’ai examinés, le $n^{0}$ 557, a qui je demandais ce qu'il faisait quand ceux qu'il dérobait n'avaient rien dans leur portefeuille, me répondil avec un rire cynique: "Je dis alors que ce sont des coquins ». - Le $n^{0} 142$ parlait de sa victime: «Eh! ajouta-t-il avec un haussement d'épaules, gui ne fait ses propres affaires, allume sa lanterne pour chercher le malheur... tant pis pour lui, s'il est allé fumer la terre». Eeoutez encore le no 641: "Je tirai un coup de pistolet sur l'homme que je détestais... hh! le meurtre de cet homme n'est rien; e'est lo cheval surtout que je regiettais d'avoir tuc (il sagissait du clicval de sa victime, qu'une balle avait flappé). (Ferri). 
Si maintenant nous passons aux preuves directes de l'absence du remords dans les homicides communs, nous nous trouvons aussitôt en présence de la satisfaction causée par l'accomplissement du crime, ou du déplaisir qui naît de l'insuccès. - Rolande ayant déchargé son fusil sur un de ses camarades, vit que celui-ci n'était pas mort: «Ah! bàtard, s'écria-t-il, tu n'es pas mort encore, il faut que je t'achève? " et il l'acheva, en effet, en lui coupant la gorge.

On peut enfin compléter la démonstration par une dernière preuve; ne déclarent-ils pas, de la facon la plus explicite, que le crime leur semble une belle chose, et qu'ils ignorent absolument ce que c'est que le remords?

C'est précisément ce que disait cette voleuse anglaise à une dame patronnesse: "Oh! madame, si rous saviez comme on vit bien! Concevoir un vol, l'exécuter, est pour nous ce qu'est une partie de campagne, ou une fête, ou un bal, pour une dame de la sociéte! „ - Le $\mathrm{n}^{\circ} 377$ à qui je demantlais s'il n'avait jamais frappé personne, me répondait: «Je ne suis pas un boucher; » et comme je lui objectais qu'il enlevait bien les portefeuilles, il s’écria: «Ah! oui; mais quelle belle chose!... ». Le $n^{\circ} 442$ répétait à qui voulait l'entendre que « le vol, à franchement parler, est une belle chose ». Et le $n^{\circ}$ 389: "Je ne dis pas que le vol soit en lui-mème une belle cliose; mais il l'est pour moi, car il me procure de l'argent sans fatigue ». Le $n^{\circ} 478$, donne une idée très-claire de l'état psychologique du criminel par habitude, quand il dit: «au début, on tremble de se laisser prendre (far marrone); ensuite... c'est comme si l'on entrait dans un auberge ». Ecoutez enfin le $n^{\circ}$ 509: "Pour cela, ami, le vol est un beau 
métier, je souhaite qu'on me le laisse fitire - liassassinat n'est pas un métier, car il n'exige pas d'allessos.

Nous arrivons de la sorte it ce que j'appelle la négaltion explicite de tout remords; voyez plutòt: - In homme aceusé d'homicide, ì qui le président demandait sil se repentait, répondit: «Eh bien! quoi? puisque le coup est fait, je ny puis remédier». - Avinain, exécuté à Paris, criait à la foule, pendant que son confesseur l'exhortait a se repentir: "N'aronez jamais; c'est la vérité qui nous conduit à l'échafaud!»- Delacollonge faisait celte déclaration aux juges: "Qutand j’ai quitté le lieu du crime, ce n'était pas le remords qui m'en chassait \%. - Lacenaire disait it ses interlocuteurs: "Assassin par systène, je devais d'abord me déponiller' de toute sensibilité. Navez-rous done jamais éprouvé de remords? "Jamais». - Encore quelques exemples: lo $n^{\circ} 357$ demandait: "Mais quel remords veut-on que j'éprouve? Je n'ai que du plaisir ». - Le no 425 disail: " Je ne ressens ancun remords: après un coup heureux je songe à un autre ". - Le $n^{\circ}$ 448: "Du remords? Quand on me prend, on me le fait payer, et alors le remords est inutile; quand je réussis, je pense à me donner du lion temps». - Le ${ }^{\circ} 489$ : « J'ai peur quand je commets un larein: mais, la chose menée à bien, je n'ai plus aucun remords ..

Il est vrai que beaucoup de malfaiteurs semblent se repentir; mais il ne faut voir lit qu'une aptitude bizarre, ou des calculs hypocrites, grìce auquels ils espèrent mettre à profit les nobles illusions des philanthropes, afin de changer ou tout au moins d'améliorer leur condition présente. C'est ainsi que Lacenaire, après sa première condamnation, écrivait à son ami Vigoureux, pour obtenir sa protection et un secours d'argent: 
"IIélas! il ne me reste que le repentir; vous pouvez faire une bonne ouvre et aroir la satisfaction de vous dire: J'ai ramené un homme de la voie du mal, pour laquelle il n'était pas né; car, sans vous, je me serais engagé plus avant dans la carrière infàme ». Or', peu d'instants après avoir tracé ces lignes, le bon apôtre commettait encore un vol et méditait un assassinat; sur l'échafaud, il déclara n'avoir jamais compris ce que c'était que le remords.

A Pavie, en Cour d'assises, Rognoni fit entendre des paroles émues, qui semblaient attester son repentir. Pendant plusieurs jours, il refusa le vin qu'on lui offrait, disant que la couleur de ce liquide lui rappelait le sang du frère qu’il avait tué. Mais il s'en faisait donner en cachette par ses co-détenus; et si l'un de ces derniers se montrait peu disposé à cette générosité forcée, il le menaçait en ces termes: J'en ai tué quatre, j'en tuerai bien un cinquième ».

Le Clery protestait de son repentir, déclarant qu’il aurait mérité d'avoir la main coupée; mais, en marchant au supplice, il murmurait à l'oreille de son camarade: « Tu le vois, nous sommes ici parce que nous avons eu trop de confiance en B... Ah! si nous l'avions tué!...».

On en voit qui feignent le remords pour excuser leur crime. Michelin se justifiait, ainsi, du coup de grâce donné à sa victime: "La voir en cet état me faisait tant de peine, que je la retournai pour éviter son regard ». (Rivista dei dibattimenti, Milano, 1872).

"Je me repens d'une seule chose, disait Lemaire, c'est de n'avoir pas su les tuer tous (le père et le fils) \%.

" J'ai agi, ajoutait-il, avec préméditation et guetapens. Votre indulgence? je la refuse; si vous m'ac- 
cordez des circonstances atténuantes, je les devrai i votre mépris et non il votre pitié; voili pourguoi je n'en reux point ». Et Avinain demanda conme une firvur d'ètre ensereli aree Lemaire, qui avail si bien parlé.

Quelquefois l'apparence dı remords (ce fantôme chẻri des romanciers) est produite par les lallucinations ou les illusions de livresse. Philippe et Lucke, une fois leur crime commis, royaient les ombres de leurs victimes; ils étaient en proie à un accès d'alcoolisıne; et le premier sut bien dire apres sa condannation: i $\mathrm{Si}$ l'on ne menvoyait it Cayenne, je referais le coup ».

Parfois ce qui parait du remords n'est que la peur de mourir ou une crainte religieuse qui prend bien la forme, mais presque jamais la réalité du repentir. L'exemple peut-ètre le plus classique de ce fait nous est fourni par la marquise de Brinvilliers: elle passait aux yeux du vénérable Poirot pour un modèle de pénitence, et pourtant elle écrivait au dernier moment à son mari: "Je meurs en femme honnête, et je le dois a mes ennemis ». Elle, la parrieide et la fratricide! Et quand son confesseur l'engageait à changer les termes de cette lettre, elle se sentait si incapable de penser autrement, qu'elle lui demandait de le faire pour elle. Conduite au supplice, elle avonait que des idées de volupté et de vengeance la poursuivaient jusquela. - Et faisant allusion à son mari, elle répétait: «Pourrait-il vivre plus longtemps au milieu de gens qui m'ont poursuivie de leur liaine?»

J'ai trouvé un cas unique de véritable métamorphose morale dans un criminel-né. Mais le sujet avait été frappé de folie; or la folie, de mème qu'elle entraîne souvent au crime, doit assez fréquemment ramener au bien les crimincls les plus endurcis. Il s'agissait d'un 
cortain U. Melicone, ìgé de 40 ans, condamné pour vol à main armée. Un de ses oncles était fou; lui-même, remarquable par la forme submicrocéphalique de son crine, ses yeux hagards, ses lèvres minces, éprouva, après vingt années de prison, des accès d'hallucination religieuse, et se crut chargé d'une mission en l'honneur de la Vierge, qui lui apparaissait dans sa cellule. La folic l'avait débarrassé de toute trace de tendances criminelles; bien mieux, elle avait lait de lui un apòtre et $u$ plitanthrope.

6. - Idée de juslice. - Il n'est pas rare qu'un de ces misérables comprenne qu'il fait mal; mais ii ne donne pas à sa mauvaise action la même importance que nous. Par exemple Dombey écrivait, après son premicr assassinat: "J'espère qu'on me pardonnera cet enfantillage ". - Rouet, en marchant à la potence, où le conduisait un assassinat suivi de vol, murmurail: "Faire mourir un homme pour si peu de chose!"

Quand le juge demandait à Ansalone: vous ne nierez pás au moins d'avoir volé un cheval? «Et comment pouvezvous, répondait-il, appeler cela un vol! voudriez-vous qu'un chef de bande allàt à pied?"

D’autres croient diminuer ou même justifier la scélératesse de leurs actes par la bonté de lẹurs intentions; tel fut IJolland, qui faisait le inétier l'assassin pour donner du pain à sa femme et á son fils. - Ils se prévalent encore de l'impunité dont jouissent de plus grands coupables qu'eux, surtout si ce sont leurs complices, ou bien du défaut ou du pen de valeur de telle ou telle preuve, ou enfin de ce que le méfait dont on les accuse n'est pas celui qu'ils ont commis. guren risulte-t-il ? c'est füils s'en prennent à la justice, 
comme si elle étail la vraie coupahle, et que lenr haine rejaillit sur le Gouvernement de leur pays. Voyez l'ltalie: les Bourlons, la maison d'Autriche, n'ont fas, mitintenant, de partisans plus passionnés que les malfaitenrs; mais sous l'administration autrichienne, ils tenaient, lous pour Mazzini.

Les voleurs de Londres, observe Nlayhew (1), ont conscience de leur faute; mais ils ne se croient pas plus coupables que le premier banqueroutier venu. La lecture assidue des procès criminels et des feuilles publiques leur persuade qu'il y a aussi des scélérats daus les rangs élerés de la société. Paurres d'intelligence, comme ils sont, ils confondent la règle avec l'excep-tion, el ils en concluent que leur faute n'est pas grave, puisque, commise par un riche, elle ne passerait point pour répréhensible. "Sachant, écrit l'assassin Raynal dans son livre intitulé Malheur et fortune, que les trois quarts des vertus sociales ne sont que des vices cachés, j'ai cru moins déshonorant d'altaquer brotalement un riche que de me livrer aux combinaisons plus sûres de la fraude; différant en cela de bien des gens qui mesurent leur probité à l'épaisseur du code, je n'ai pas voulu appliquer mon intelligence is l'astuce, et je me suis fait bandit $)$.

Le voleur Giacosa disait qu'il y a par le monde deux justices: la justice naturelle, qu'il pratiquait lui-même en donnant à de pauvres diables une partie des objets volés par lui, et la justice artificielle, que protège la loi sociale (Gazzetta dei giuristi, p. 269, 1857) et dont il faisait fi.

Il faut toutefois convenir que l'idée du juste et de l'injuste n'est pas absolument éteinte chez tous les cri-

(1) Criminal life, Londres, 1862. 
minels; mais elle reste chez eux improductive, pareequ'elle est comprise par l'esprit plutôt que sentie par le cœur, et que les passions et l'habitude de mal faire ne peuvent manquer de l'étouffer. - Dans l'argot espagnol, la justice est appelée la giuesta, et c'est ainsi cneore que des malfaiteurs de France appellent les Issises.

Prérost, parlant de l'auteur encore inconnu des assassinats commis par lui-même, disait: «Celui-là n’échappera pas ì la guillotine n.

Lemaire disait aussi: "Je sais que je fais mal; si quelquin venait me dire que je fais bien, je lui répondrais: Tu es une canaille comme moi; mais je n'entrerais point pour cela dans la bonne voie ». On a remarqué que les prostituées ont horreur des lectures immorales, comme les forçats de tous les récits où il est question d'actions injustes ou déshonorantes, et dont les anteurs ont le privilége d'exciter leur indignation, comme si eux-mèmes étaient des gens lıonnêtes (Sue). Un autre fait nous proure encore que beancoup d'entre eux se savent engagés dans une roie mauvaise: les recéleurs et les voleurs enrichis s'efforcent, à l'exemple des femmes de mauvaise vie, de fermer à leurs enfants leur triste carrière.

Il y a mieux: certains individus préroient le chatiment sans en être pour cela plus touchés; ils en tirent prétexte, au contraire, pour se livrer à une cruanté plus raffinée.

Raffacle Perrone et son frère Fortunato s'étant pris de querelle avec un certain Franchi, le frappèrent it coups de marteau. Raffaele, voyant que la victime donnait encore signe de vie, lui sauta sur le corps à deux reprises et la foula aux pieds sans pitié en s'écriant: 
4. Tu n'es pas mort? puisque je dois te payer par 25 on 30 ans de galères, je veux au moins t'achever».

Ce ne sont, en somme, ni le criterium, ni la conscience du rrai, ni les connaissances juridiques qui manquent dans tous les cas aux criminels; c'est bien plutòt la force ou la volonté de se conformer à ce criterimn. Antre chose est, dit M. IIorwich, avoir la connaissance théorique d'un fait, autre chose agir en conséquence; pour que la connaissance se transforme en une volonté bien arrêtée, comme les aliments en chỵle et en sang, il faut un nouveau facteur, le sentiment; or, ce facteur manque d'habitude aux scélérats.

Quand ils se trourent réunis et que non seulement le sentiment ne fait pas obstacle, mais qu'il y a encore un intérêt direct (satisfaction de la vanité, sécurité plus grande) à faire triompher la justice, on les voit alors diriger vers ce but l'énergie qu'ils ont coutume d'employer it mal fairc. Dans un meeting de jeunes volenirs, organisé à Londres par un philanthrope, on applandissait, on battait des mains, quand entraient des hommes conpables de dix ou vingt récidives; un filou, qui arait été condamné vingt-six fois, fut accueilli triomphalement comme un héros; or, le président l'ayant à dessein chargée d'échanger une pièce d'or, comme il tardait à rentrer, l'inquiétude et le dépit étaient grands parmi cette engeance. S'il ne revient pas, nous le tuerons, criaientils tous en chœur, et leur joie fut grande quand il parut, rapportant la somme intacte. Mais, pour qui étudie bien le cas, ce retour, ces cris, n'étaient pas le fruit d'un sincère amour de la justice (d'ailleurs un peu trop cxpéditive); ils avaient pour canse une estimable ranité, un point d'honneur louable: en cette circonstance, nos hommes faisaient le hicn pour les mêmes motifs qui, un 
peu plus tard, les auraient poussés au mal. Eh bien! ce bon côté de leurs passions, si je puis m'exprimer ainsi, nous fournira le moyen de les corriger, à condition que nous fassions agir la passion et le point d'honneur de préférence à la raison. C'est aux émotions, c'est à une habile direction des sentiments, ru'il faut demander ce lésultat, et non à une prétendue gymnastique intellectuclle, ni a cette catéchisation monastique, dont on fait usage aujourd'hui dans les prisons, sans songer qu'on gaspille el le temps et l'argent. Voyez Anderson: c'était un condamné des plus dangereux, et considéré comme incorrigible; il se transforma en agneau rpuand $\mathrm{Moco-}$ noch cut l'idéc de l'employer à dompter des taureaux sauvages; et il redevint la terreur de la colonie pénitentiaire, dès qu'on le remit à la chaîne et qu'on le condamna au repos (1). On a imaginć à Moscou de faire juger les fautes des détenus par leur's propres compagnons, et l'on a obtenu par ce procédé des verdicts qui feraient rougir nos jurés eux-mêmes. Un jour, par exemple, un vol léger ayant été commis par un nouveau détenu à l'instigation d'un voleur émérite, celui-ci fut condamné à quatre-vingts coup de selılaguc, et le nouveau venu à quarante seulcment. Parlant des criminels mineurs d'Amérique, Tocqueville rapporte qu'ils sont jugés par leurs compagnons avec une justesse d'appréciation admirable.

Les voleurs de Londres sont d'une remarquable exactitude dans la répartition de leur butin, et, si l'un d'eux se montre infidèle, ses camarades le tuent ou le dénoncent à la police.

(1) Rivista di discip. cricer., 1866. 
$\Lambda$ l'ile de S. Stefano, en 1860, les forcts avaient été tivrés ì eux-mêmes. Le vol pouvait faire dispraraittre lenrs maigres provisions et les exposer à mourir de fitim; les querelles entre gens de la Pouille et des Calabres pouvaient entrainer également leur perte, et alors ils se donnèrent un code draconien, composé par les chefs des deux partis rivaux, que l'on appliqua avec la plus grande sévérité. Ainsi l'un d'entre eux, Pasquale Orsi, pour avoir soustrail quelques poignnces de farine, fut condamné it 50 coups de bâton et à 30 jour's d'emprisonnement. Un autre, qui avait dérobé ì un paysan deux échalas, dut faire le tour de l'ìle avec ces échílas liés au corps. Etait condamné à mort quiconque tuait un de ses compagnons, ou seulement menaçait et offensait dans leur personne ou leurs biens les gardiens et les insulaires. Cette loi sauva l'lonneur des femmes et préserva la vie des gardiens, (Rivista dei dibaltimenti celebri, 1872, p. 243); par contre, elle causa la mort de plusicurs forçats. Par exemple, un certain Sabbia avait dérobé une chèrre aux bergeers du bagne. Son vol fut découvert, et e'est en vain qu'il demanda à le racheter par une amende. "La chèvre, criail un galérien, juge improvisé, ne se paie pas avec de l'argent, mais avec du sang, » et, parlant ainsi, il frappait le misérable à coups de pierres, l'achevait d'un coup de poignard, et jetait son cadavre à l'abandon sur les rocher's de l'île. Quant à la chèvre, placée au milieu de la cour, elle servit d'exemple aux voleurs. Deux amis de Sabbia, qui en avaient goûté sans en connaitre la provenance, eurent grand peine à sauver leur vie; il leur fallut prouver qu'ils n'étaient pas complices du larcin. Un nommé Centrella, accusé d'y avoir prêté la main, prouva victoricusenıent son alibi et fut 
absous après une longue prévention; mais on l'exclut de la commission législative dont il faisait partie, ce curieux tribunal ne voulant pas qu'un de ses membres pût être même soupconné!

7. - Tout cela ressemble à de la justice; il ne faut pas ouljlier, néanmoins, que cette espèce de moralité ou de justice relative, apparaissant tout-à-coup au sein d'une troupe de bandits, est forcée et absolument temporaire. Qu'au lieu de les favoriser, elle lèse leurs intérêts; qu'elle soit combattue par une passion violente, et vous verrez aussitòt s'effacer de leur esprit ce criterium du rai, qui ne sappuie pas en eux sur le sens moral. J'ajouterai même que, contrairement à une opinion très-répandue, les malfaiteur's manquent presque toujours de parole à leurs compagnons et surtout à leurs parents, s'ils en ont parmi leurs complices. La dénonciation est à leurs yeux une infamie, si elle se fait à leur préjudice; mais, par une de ces contradictions qui se rencontrent fréquemment dans le cour humain, ils n'hésitent pas à se faire eıx-mêmes dénonciateurs d'autrui. C"est là un instrument des plus précieux pour la justice; mais c'est également une des causes qui engendrent dans les bagnes des émeutes et des vengeances continuelles.

Ils se font délateurs, soit pour améliorer leur position, soit pour aggraver celle des autres, dont ils sont jaloux, et pour n'être pas seuls à souffrir, soit pour tirer vengeance d'une trahison vraie ou supposée. Le chef de bande llaas, assassin fameux, déclarait qu'il s'était donné des complices pour n'être pas seul condamné à mort, au cas où il serait découvert et arrêté. Dans le procès Artus, à Bellune, on voyait avec horreur les fils, de 
voleurs fiéffés, déposer contre leur père, révíler les circonstances les plus aggravantes, en inventer même des fausses.

"Parmi les voleurs, écrit Vidoeq, il en est peu qui ne regardent comme une bonne fortune d'être consultís par la police. Presque tous se mettraient en quatre pour lui donner une preuve de leur zèle. Les plus acharnés sont toujours cenx qui ont le plus à craindre pour leur propre compte». Il dit ailleurs: "Les voleurs n’ont point d'ennemis plus redoutables que les anciens forcats; ceux-ci déploient le plus grand zèle pour fairc arrêter un ami. En labsence de faits véritables, ils sont capables d'en inventer, ou, ce qui est plus fort, de mettre sur le compte d'autrui leurs propres méfaits, au risque d'attirer l'attention sur eux-mêmes. Ainsi, une femme nommée Bailly et un homme du nom d'Onaste furent condamnés trois fois pour des fautes qu'ils avaient révélées en les attribuant à d'antres. Les voleurs de Londres, qui šindignent si fort contre les délateurs, sont les premiers à se dénoucer les uns les autres. Lacenaire, dénonçant ses complices, faisait connaître des circonstances qui pouvaient nuire a sa propre cause. - Bouscant fit arrêter tous les membres des fameuses bandes des chauffeurs. - Caruso nous a rendu les plus grands services contre les brigands; peu s'en est fallu qu'il ne nous livrât Croceo. - G. Bianco, voyant la partie perdne, feignit d'encourager ses hommes et les conduisit dans l'embuscade préparée par le général Nunziante. - Nottino, Gasparone, volaient à leurs complices leur part de butin. - Les meurtriers de Ravenne userent de la cruauté la plus raffinée à l'égard des Tassinari, leurs complices. 
De tous nos chefs de brigands, il n'en est qu'un, à ma connaissance, qui se soit montré juste à l'égard de ses pen recommandables administrés; c'est Schiavone. - La plupart ont fait preuve d'un despotisme, d'une injustice révoltante à l'égard de leurs hommes. - Coppa, pour une légère désobéissance, égorgea vingt de ses complices; il passa par les armes son propre frère, qui n'avait pas attendu ses ordres pour piller une ferme. - Dans ce gouvernement improvisé que s'étaient donné les galériens de Saint Stefano, la vengeance engendra bien de meurtres, qui ont donné lieu dans la suite à un procès fameux (1). Précisément, le chef de cette étrange commission judiciaire, le Lycurgue de ce nouveau code, irrité contre un certain Fedele qui, fier de sa force musculaire, lui témoignait peu de respect, s'en vengea par un coup de poignard, et, surpris par une patrouille, lui défendit, parait-il, d’en rien dire à personne. - Tant est fragile et inconstante, dans les malfaiteurs, même cette honnèteté relative, cette pseudojustice, qui nait de l'intérèt du moment ou d'une passion plus violente, mais, à la vérité, moins lonteuse que les autres!

8. - Morale. - Si maintenant nous comparons la morale des criminels à celle des fous, nous serons étonnés des différences et des analogies qui s'y rencontrent. Il est bien rare que le fou naisse méchant et immoral; il le devient à un certain moment de son existence, à la suite d'une maladie qui change ou modifie son caractère. Si, comme le eriminel, il éprouve rarement du remords, s’il se vante d'une mauvaise action, ou tout au

(1) Rivista dei dibattimenti celebri, Milan, 1872, p. 243-44. 
moins déclare qu'une force irrésistible l'a poussi a mal faire, on le roit sourent, aussitot la faute commise, recouver, comme par une crise heureuse, la luciliti de ses idées el le sentiment de ce qui est juste; alors, il est entraìné à se dénoncer lui-mème, mais jamais avec le cynisme dı criminel; il parle, all contraire, avec l'expansion du pécheur repentant, de l'hypocondriarpe dont la bile s'évapore. - C'est le cas de Fontana, d'Elicabide, de Papavoine, de Verger, de A. A., de Livi, de Dosscna (1). Mis sur leurs gardes par leurs camarades de prison ou par leur avocat, ils peuvent bien tenter de dissimuler leur action coupable (comme Verzeni, Farina) (1); ils ne déploieront jamais l'habileté ni l'énergie de celui qui a l'habitude du crime.

Celui même à qui une violente commotion de l'âme fait commeltre un meurtre, ressemble bien au criminel par l'insonciance avec laquelte il envisage l'avenir; mais il diffère de lui par le repentir qưil éprouve aussitôt après son crime, et par le besoin qui le porte à soulager sa conscience en allant se dénoncer it la justice.

9. - A l'étal sauvage, all contraire, l'homme ne connaît pas le remords; il tire ranité de ses exploits criminels; justice est pour lui synonyme de violence et de force. Dans l'antique langne latine, latrocini avait le sens de service militaire. - Chez les Gaulois, dit César (De bello gallico, $\mathrm{xI}$ ), les rols commis en deliors du territoire de la cité n'étaient pas infamants. - De nos jours encore, l'Mlluanais ne considère pas le meurtre comme un crime; pour lui, fort cst l'équivalent de juste, faible veut dire méchant. 
10. - Ce fut bien certainement le dommage causé au grand nombre par la puissance de quelques-uns, et ce dommage seul, qui fit naître la première idée de la justice et de la loi. De ce côté, le code si curieux des galériens de S. Stefano, qui, par sa sévérité, rappelle assez bien les lois du moyen-âge et celles des peuples primitifs, peut nous faire voir quelle série d'évènements il a fallu pour soumettre les peuples barbares à une législation; il nous fait aussi connaitre un nouveau trait d'analogie entre les sauvages et les criminels. (V. première partie, chap. II et III). 


\section{CIIAPITRE VII}

\section{La religion des criminels}

Nombre de gens croient que les criminels sont tous des incrédules, comme si la religion était le frein le plus puissant du crime. La vérité est que si plusieurs chefs de bandes, si des scélérats éhontés, Lacenaire, Lemaire (1), Mandrin, Gasparone, La Pommerais, Barré, ou généralement ceux qui croissent dans les grandes villes, font parade d'une sorte de cynisme humoristique, raillant non seulement la religion, mais aussi la morale; le plus grand nombre, au contraire, surtout à la campagne, est toute autre chose qu'athée.

Il est bon d'ajouter que beaucoup des criminels se forgent unc religion sensuelle et accommodante, toute à leur avantage, qui ferait du Dieu de paix et de justice une espèce de tuteur bienveillant, de complice de leurs actions coupables.

(1) Yous allez pourtant à l'église, lui disait le président. « Oui; pour in`amuser, comme au théâtre ». - Au prêtre qui l'exhortait à se repentir, Mandrin demanda combien on rencontrait d'auberges avant d'arviver all paradis, car il n'avait, disait-il, que six sous à dépenser en ronte. - La Pommerais, dans son testament, recommanda d’élever sou fils loin des terreurs religieuses et monacales. - Kesfel demanda pour se confesser un rabbin au lieu d'un prêtre. 
Justement Ettingen montre qu’il est presque impossible d'avoir des renseignements précis sur cette question; je crois que c'est déjả beaucoup si je puis donner les proportions de la fréquentation des églises, ce qui est certainement, si non un indice, du moins une présomption éloignée du sentiment religieux.

$\begin{array}{cc}\text { Par } & \text { Par } \\ 500 \text { criminels } & 100 \text { normaux }\end{array}$

Fréquence régulière à l'église . . $46010-570$ [0

Id. irrégulière . . . . $25 "-13$ "

Absence . . . . . . . 38 " $-29 "$

On voit que les normaux fournissent un nombre un peu plus grand de gens qui fréquentent les églises, et un nomlure moindre aussi dabstensionistes. Mais ces proportions grossissent dans certaines catégories de criminels: dans les violateurs la proportion des fréquentateurs va jusques all 61010 , dans les assassins elle va jusques an $560[0$.

M. Ferri, sur plus de 200 assassins, n'en a trouvé qu'un seul qui fît profession d'athéisme. Parmi les autres, 7 affectaient une dévotion exagérée, 5 avaient de fortes croyances; les autres, tout en conspuant les prètres, affirmaient qu'ils croyaient en Dieu; l'un d'eux même disait: «Il ne dépend pas de moi d'être honnète homme; c'est Dieu qui donne ce sentiment ».

Casanora, qui devait en savoir quelque chose, remarque (Mémoires, p. 342) que tous les hommes rivant d'un métier illicite sont confiants dans l'aide de Dieu.

Horâce met ces vers dans la bouche d'un filou: - Pulchra Laverna (c'est la déesse des voleurs)

In mili fallere: da justo sanetoque videri.

Et un peu plus loin:

Noctem peceatis et frandibus objice nubes. 
Chaque voleur a sa dévotion, dit le proverbe. Pour notre part, de 2480 tatouages relevés sur des criminels, nous en avons trouvé 238 qui reproduisaient des symboles religieux (voir p. 299). Dans l'argot, Dien est le grand mek; l’àme, la perpétuelle. Cela ne prouve-t-il pas leur croyance en Dien et en l'immortalití de l'ìme? Autre preuve: dans l'argot espagnol, l'église est appelée la santé.

Les assassins allemands se croient ì l'abri de tout soupcon quand ils ont somillé de leurs excréments le théàtre du crime (Casper); chez nous, ils trempent un doigt dans le sang de la victime et le portent ensuite a leurs lèvres. Les Bohémiens meurtriers, pensent obtenir le pardon divin en portant une année entière la chemise dont ils étaient revêtus au moment du meurtre.

Tortora, qui avait tué de sa main 12 soldats et un prêtre, se croyait invulnérable, parcequ'il gardait dans son sein une hostic consacrée.

Les célèbres chauffeurs de France avaient adopté une série de rites religieux, propres à leur bande, pour célébrer les naissances et les mariages; ils sétaient donné, un peu par esprit de parodie, un peu dans une intention sérieuse, un curé, qui présidait à leurs unions et bredouillait quelques prières latines. Chose curieuse! ils proscrivaient sévèrement le divorce; ils ne l'adoptèrent que longtemps après qu’il avait été introduit dans la loi française par la révolntion. - En 1670, les empoisonneuses de Paris, qui appartenaient it la liaute société, faisaient alterner avec les poudres de succession les messes diaboliques, pour obtenir la mort d'un mari ou conserver la fidélité d'un amant. Un prêtre lisait les prières de la messe sur le ventre d'une prostituée enceinte et égorgeait ensuite le fotus, dont le sang et les 
cendres servaient à composer des philtres. La Voisin, a elle seule, aurait fait périr des milliers de ces petites victimes. (V. Les Archives de la Bastille, 1866, 1873 ).

La bande de Manzi était chargée d'amulettes. - Celle de Caruso placait dans les bois et dans les grottes des images saintes, devant lesquelles brûlaient des cierges. - Verzeni, qui avait étranglé trois femmes, se faisait remarquer parmi les plus assidus et les plus sincères à l'église et au confessionnal; il sortait d'une famille non seulement religieuse, mais bigotte. - Les complices de La Gala, transférés à la prison de Pise, refusèrent obstinément de manger les vendredis de carême; et quand le directeur les y engageait, ils répondaient: «Quoi donc? Est-ce que rous nous prenez pour des excommuniés?" - La plupart des voleurs de Londres, dit M. Mayhew, font profession de croire à la Bible. - Il n'y a pas bien longtemps que les voleurs et les camorristes de Naples faisaient de magnifiques dons a San Pasquale, et enrichissaient ce magnifique couvent. Faut-il rappeler que tout l'écemment, comme nous l'a révété mon ami Vincenzo Naggoiorani, l'areherêque affichait, sur les portes de la calluédrale de Palerme, la componenda, c'està-dire la taxe des sommes à débourser à l'église pour se racheter de tout délit? Les assassins Bertoldi, père et fils, assistaient tous les jours à la messe, agenouillés sur les dalles, le visage contre terre. - Quand l'affreuse Maria Forlini, qui avait étranglé et mis en pièces une petile fille pour se venger de ses parents, entendit prononcer contre elle la peine capitale, elle se tourna vers un de ses défenseurs: "La mort n'est rien, lui ditelle; l'essentiel est de sauver son âme. Que je sauve la mienne, je me moque du reste ». 
Boggia, condanné à Milan pour trente-quatre meurtres, entendait la messe tous "les jours; it portait le dais at toutes les processions du Saint Sacrement; il ne manquait aucune cérémonie; il prêchait continuellement la morale et la religion du Chrrist et voulait être de toutes les sociétés religieuses.

La Trossarello avait une grande dévotion pour une Madone spéciale, celle de la rue des Marchands (Turin).

Vidocq a rencontré plusieurs larrons qui se faisaient dire une messe pour avoir de l'argent, quand ils avaient passé quelques mois sans rien prendre.

Marc..., jeune napolitain qui avait tué son père, était chargé d'amulettes; il m'avoua qu'il arait demandé à la Madone de la Chaîne la force nécessaire à l'accomplissement de son crime horrible. "Et j’ai la preuve qu'elle m'a aidé, ajoutait-il; car, au premier coup de bâton que j’ai porté, mon père est tombé mort sur le sol. $0 \mathrm{r}$, je suis d'une faiblesse extrême». L'Arelina, dans une lettre à son complice, place l'empoisonnement de son mari sous la protection divine. La Zambeccari avait roué un calice á $\mathrm{N}$. D. de Lorette pour le cas où elle réussirait à empoisonner son mari (Joselli, Arch. Bologn., II, 1881). Michielin, approuvant le plan d'un assassinat, disait à son camarade: « Je viendrai et je ferai ce que Dieu t'inspire ». Gall cite un malfaiteur qui, après avoir volé pour fonder une chapelle, vola encore afin de la pouroir meubler; il cite igalement une bande de malfaiteurs qui croyaient expier leur's crimes en récitant un pater noster pour clacune de leurs victimes. Lacollange, tout en étranglant son infortunée maitresse, lui donnait l'absolution in articulo mortis, puis vendait le produit de ses vols pour lui faire dire des messes. Citons encore don Vincent d'Aragon, qui tua un étudiant, 
mais commença par lui donner l'absolution. Oủ trouver une personne plus religieuse, je dirai mieux, plus bigotte que la marquise de Brinvilliers, qui, de sang froid, et longtemps avant son arrestation, préparant par écrit son examen de conscience, mêlait ì ses parricides, à ses incendies, à ses empoisonnements, à ses masturbations, les confessions omises ou faites avec négligence; et qui, la veille du jour où on l'arrèta, se formalisait de ce qu'on l'autorisait à faire gras un jouı' de maigre? Rappellerai-je encore Mendaro, qui tua son épouse et marcha au supplice en chantant le De profundis? Ho, ce meurtrier que tous appelaient le saint, et qui passait pour mériter ce nom? -- Borrse, aussitò après avoir commis un vol ou un homicide, courait s'agenouiller dans une église. Au moment où la fille Galla..., mettait le feu a la demeure de son amant, on l'entendit crier: "Que Dien et la Sainte Vierge fassent le reste» (Despine, I. c., 176, II). - Masini, avee sa bande, rencontre un jour un prêtre avec trois de ses compatriotes; il scie lentement la grorge à l'un d'eux avec une lame ébríchée, puis, la main encore teinte de sang, il force lc prètre à lui administrer la communion (Paxi Rossi, Basilicata, p. 51). -- Un voleur, élevé par les frères de la doctrine chrétienne, cachait le prodıit de ses vols sous un portrait du R. P. de la Salle, fondateur de l'ordre it qui il devait son instruction. Il pensait que son butin était plus en sûreté, sous la protection de ce demi saint.

Nombre de prostituées, dit Parent, affectent l'irréligion avee leurs amants ou leurs compagnons d'orgie; mais, au fond, elles sont loin d'être impies; une foule dohservations le prouvent. Une d'elles était sur le point de mourir et le prètre refusait d'entrer dans la maison mal famée; ses compagnes se cotisèrent pour qu'elle 
pût être transportée et soignée lıors du lupanar; les mêmes, pour faire chanter un grand nombre de messes ¿ une de leurs compagnes défuntes, dépensèrent une somme considérable (ID., p. 116). - Une autre, ayant un fils malade, faisait brûler des cierges bénits pour obtenir sa gućrison. A Paris aucume fille de joic ne vient à la visite le vendredi, à moins d'y être forcée (ID.).

Tout cela est bien naturel, car la religion est la résultante d'un sentiment atavistique, et, sauf le cas de barbaric absolue, a d'autant plus de force que l'esprit est moins cultivé et que le peuple est plus primitif. Aujourd'hui, d'aillemrs, plus que jamais, la religion a dégénéré de sa pureté primitive, de la saine morale, et elle a fini par s'accommoder à tous les cxcès. 


\section{CHAPITRE VIII}

\section{Intelligence et instruction des criminels.}

1. - Psychométrie. - La principale lésion, dans Ia psychologie des criminels, affecte le sentiment. Néanmoins, gràce à cefte corrélation qui unit toutes les fonctions, comme toutes les parties du systime nerveux (nous avons vu dans quelle mesure est lésé même le système moteur), leur intelligence présente, également, de nombreuses anomalies.

Et si l'on pouvait établir une moyenne de la puissance intellectuelle des criminels avee la précision qui préside aux observations crâniologiques, je crois qu'on obtiendrait des résultats égaux, c'est-à-dire qu'on trouverait une moyenne inférieure à la normale, avec des exagérations de supériorité et d'infériorité.

Les premiers en Europe, les Espagnols ont essayé d'établir cette moyenne: sur 23,600 coupables étudiés, ils en ont rencontré 67,540 [0 d'une intelligence saine; 10,17 d'une intelligence peu saine; 18,80 d'une intelligence dépravée; 0,75 d'une intelligence presque nulle; 2,74 qu' on n'a pas pu classer. (LÉGOYT, $E$. de statistique comparié, 1864).

II. Ferrus, Des prisonniers (Annales dhygiène, 1880), a trouvé, sur 2005 prisonniers, 1249 individus doués d'une intelligence moyenne, 37 d'une intelligence supéricure, 684 d'une intelligence bornée, 35 qui en étaient tout-à-fait dénués. 
A Zwickau, où, grìce au systime qui isole les individus, on a pu faire une étude plus approfondie, on a trouvé:

En $1875 \quad$ En 1877

299 sujets - 33i douts d'une intelligence ouverte,

$\begin{array}{rlll}565 & \text { id. }-705 & \text { id. } & \text { médiocre, } \\ 89 & \text { id. }-92 & \text { id. } & \text { obtuse. }\end{array}$

Mais ce sont là des données très-incertaines. - Quoique le psycometre de llipp soit plutòt un mesurateur de la perception que de la pensée, on ne peut entreprendre l'étude de l'intelligence chez les criminels, sans l'avoir expérimentí. Je donne pour celà, de suite, le résumé de mes études avec cet appareil, remarquan que, dans ce dernier les chiffres ne correspondent it 0,1000 de 1 " comme d'habifude, mais à $0,0033 \mathrm{du} 1$ ".

\begin{tabular}{|c|c|c|c|c|c|c|c|c|c|}
\hline & \multicolumn{5}{|c|}{$\mathrm{VUE}^{\mathrm{U}}$} & \multicolumn{4}{|c|}{ O U I E } \\
\hline & & 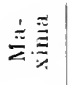 & है & $\therefore \stackrel{\pi}{\approx}$ & 咅 & 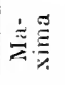 & 苛 & 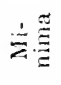 & 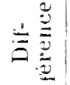 \\
\hline Crim.-né ( jeune) & $1^{\circ}$ & 280 & 102 & 20 & 260 & 140 & 60 & 10 & 130 \\
\hline Voleur P. . & $2^{\circ}$ & 240 & 98 & 10 & 230 & 140 & 56 & 15 & 125 \\
\hline Vagabond P. & $3^{\circ}$ & 80 & 59 & 38 & 42 & 90 & 40 & 10 & 80 \\
\hline Blesseur G. & $4^{\circ}$ & 100 & 71 & 45 & 55 & 32 & 16 & 4 & 28 \\
\hline Voleur L. . & $5^{\circ}$ & 284 & 81 & 67 & 17 & 30 & 16 & 7 & 23 \\
\hline Frappeur B. & $6^{\circ}$ & 90 & 76 & 55 & 235 & 29 & 18 & 12 & 17 \\
\hline Escroc int. & $7^{\circ}$ & 100 & 77 & 60 & 40 & 24 & 13 & 4 & 20 \\
\hline Voleur . . & $8^{\circ}$ & 118 & 87 & 75 & 43 & 30 & 15 & 8 & 22 \\
\hline Voleur chef . & $9^{\circ}$ & 110 & 82 & 11 & 99 & 35 & 21 & 12 & 23 \\
\hline Criminel d'occ. & $10^{\circ}$ & 120 & 91 & 58 & 62 & 25 & 14 & 4 & 21 \\
\hline & $11^{\circ}$ & 110 & 82 & 58 & 52 & 35 & 21 & 12 & 23 \\
\hline & $1^{\circ}$ & 105 & 68 & 50 & 55 & 70 & 22 & 5 & 75 \\
\hline & $2^{\circ}$ & 140 & 39 & 10 & 130 & $"$ & " & " & $n$ \\
\hline & $3^{\circ}$ & 60 & 43 & 20 & 40 & $"$ & 15 & 4 & 25 \\
\hline Normaux & $4^{\circ}$ & 90 & 47 & 12 & 86 & 30 & 21 & 10 & 20 \\
\hline & $5^{\circ}$ & 55 & 39 & 28 & 27 & 65 & 18 & 10 & 55 \\
\hline & $6^{\circ}$ & 98 & 65 & 34 & 69 & 57 & 27 & 9 & 48 \\
\hline & $7^{\circ}$ & 84 & 56 & 28 & 56 & 36 & 15 & 6 & 30 \\
\hline
\end{tabular}


La lenteur, le retard on le voit tout de suite, est très-fréquente dans les criminels que j'ai choisi, pourtant, parmi les plus intelligents. - Nais plus encore que la lenteur on y entrevoit l'exagération des dites différences, grâce aux minimum très-disproportionnés avec les maximums, voir $\mathrm{n}^{\circ} 1,2,5$. Il y a, pourtant, dans l'oule des chiffres d'une rapidité $\left(n^{\circ} 10,7,4\right)$ bien plus grande que dans les normaux.

Les criminels dont la faute est moins grave, coupables d'occasion ( $n^{\circ} 10$ et 11 ), ou vagabonds et les plus intelligents $\left(\mathrm{n}^{\circ} 9\right)$, se rapprochent plus des normaux; et la différence entre ceux-ci y est bien moins accentuée.

Il n'est done pas vrai que presque tous les criminels, comme le prétend M. Thompson, manquent totalement d'intelligence, soient fous ou imbéciles; mais, chez tous, même chez les criminels de génie, l'intelligence présente un còté défectueux.

2. - Paresse. - La plupart, en effet, sentent que leur esprit est de plus en plus impropre à un travail assidu, et n'ont d'autre idéal que d'écarter toute espèce d'occupation. - Les voleurs français s'appellent entre eux pègres (paresseux). Le désœuvré est aux yeux de la loi une variété de l'homme criminel, et c'est peut-être lui qui contribue le plus à peupler les prisons.

Les Bohémiens, malgré leur esprit industrieux, sont toujours paurres, car ils détestent le travail et ne s'y résignent que pour ne pas mourir de faim.

I.es voleurs, selon Vidocq, ne sont aptes à rien de ce qui réclame de l'énergie ou de l'assiduité. Ils ne peuvent, ils ne savent faire rien que voler.

Lemaire disait à ses juges: “Jai toujours été paresseux; c'est une honte, j'en conviens; mais je suis mou 
an travail. Pour travailler il faut faire $u$ effort, et jo m’en sens incapable; je n'ai d'énergie que pour le mal. S'il fant travailler, je ne tiens pas il la vie; j’anme mieux être condamné à mort $\gg$ (DEspines, Psychologie naturelle, I , II).

Le premier mohile qui poussa Lacenaire au crime fut certainement la paresse. Il la poussait si loin, disait son premier maitre, quil refusait de se lever pendant la nuit pour satisfaire ì ses besoins naturels. II dormait profondément au milien de ses ordures; ce nétait qu'à grand peine, et à force de cris et de menaces, qu'on le décidait à sortir de son lit, ou plutôt de son fumier. Ni les punitions qu'on lui infligeait, ni le mépris dans lequel le tenaient ses camarades, ne parvenaient à le corriger. Toute occupation, tout travail, quel qu'il fût, le mettait au supplice. - Jacquard tua son père parceque celui-ci lui reprochait sa paresse; il aimait mieux passer des nuits entières, et seul, à l'écurie, que faire le moindre mouvement pour gagner son lit.

C'est peut-être pour cela que presque tous les grands coupables, même ceux à qui l'on reconnaît du génie, furent de très-mauvais écoliers, comme il résulte de leurs procès. Tel est le cas de Verzeni, d'Agnoletti, de Bourse, de Raymond, de Donon et de Benoist.

La paresse est un des caractères des prostituées: " 9 sur 10 ne font rien de tout pendant leur journée: " écrit M. Parent-Duchâtelet.

En France, sur 76.613 accusés, on a compté 11.367 désœuvrés (Descuret).

3. - Légèreté d'esprit. - L’intelligence des criminels présente un autre défaut; c'est une légèreté et une 
mobilité d'esprit très-remarquables. En Suisse, on calcule que $440_{10}$ des condamnés ont été conduits au mal par lcur légèreté.

On se ferait difficilement une idée de la légèreté des prostituées, écrit M. Parent; il est impossible de fixer leur attention, impossible de les conduire à faire un raisonnement de quelque longueur. Cela explique leur imprévoyance et le peu d'inquiétude qu'elles ont pour leur arenir; et c'est ce dont profitent leurs patronnes pour les retenir en leur pouroir et les dépouiller (1). Les criminels sont de même; on remarque en enx une mobilité, une crédulité singulières. - Je me rappelle en avoir rencontré un qui, lorsque j'essayais de mesurel' son crâne, voyait dans cette opération une chose si dangereuse, si diabolique, que, sans la présence des gardiens, il meût certainement tué. - Mottino était un franc élourdi; quand le Président lui demanda s’il était rrai qu'il eût promis mariage à une jeune fille, il fit celte réponse: C'est vrai; mais ou l'aurais.je done conduite après la noce, Excellence? Sous les remparts? - Un voleur avait écrit sur la muraille de sa cellule: «Dès que je serais sorti je jure de me venger par un vol de 4000 francs, 》 et tout de suite après: « S’il m’arrive encore de voler, je me tue »(2). - Les plus grands coupables, écrit Keller, ne prévoient jamais la possibilité pour eux d'ètre découverts; une fois pris, ils s'en étonnent de manière à se porter souvent le plus grand tort et à éclairer la justice sur le crime qu'ils ont commis (Rivista penale, 1876).

(1) V. le bean travail de Riccardi, Sull'attensione, Nodène, 1876, 11.

(2) Voir mes Palimsesti del carcere, 1887. 
4. - A leur légèreté s’ajoute une tendance exagéríc à la raillerie et à l'humour, où l'on a reconnu depuis longtemps la preuve d'un esprit dépravé el d'un manvais cneur. (Risus abundal... - Méfie loi de l'homme qui rit, etc.), et qui se manifeste diune manière ćtonnante dans l'argot, dans le besoin de tomrner en ridicule les choses les plus chères el les plus sacrées (roir ch. Ix), de faire des jeux de mots, des calembourgs, dans les circonstances les plus graves. Ce travers, comme leur semblant de courage supérieur, provient du manque de sens moral: c'est qu'ils n'éprouvent qu'une parrfaite indifférence, ou même unc excitation agréable, la où tout autre serait paralysé par la crainte ou par la douleur. Ce contraste entre eux et le reste des hommes fait jaillir une somree abondante de vis comica qu'ils gaspillent, et qui fait l'élonnement des personnes honnêtes. Celte tendance est grande aussi, comme nous lo verrons, dans les criminels de génie (ch. vir, $1 \mathrm{x}$ et xI). Et nous en avons eu une preuve dans la conclusion de cette chanson étrange de Clément, qui fut composée sous l'influence de plusieurs condamnations aux travaux forcés et à la déportation. (V. p. 359 ).

5. - Imprévoyance. - Celte légèreté d'esprit fait comprendre comment les voleurs en viennent à parler de leurs méfaits, même à des agents de police; comment ils se laissent retourner et étudier comme des enfants. "Les voleurs, dit Vidoeq, sont d'une telle stupidité, qu'il est inutile de lutter de finesse avec eux; après leur arrestation, ils ne voient pas plus clair qu'avant; beaucoup, malgré ma qualité de policier qui leur était connue, se jetaient entre mes jambes pour me raconter leurs projets $n$. 
Cette facilité à avouer résulte aussi en grande partie de l'habitude qu'ont les criminels de s'associer amicalement et de se fier au premier venu, pourvu que, par son expression et par l'usage de l'argot, il leur paraisse appartenir à leur catégorie.

S'ils sont, à ce point, impréroyants, s'ils ne peurent résister à la tentation d'une partie de plaisir avec leurs complices, pourquoi s'étonnerait-on de les voir revenir si souvent, après une évasion, dans les lieux où ils étaient accoutumé de vivre? Sans doute, esclaves de la passion du moment, ils ne peuvent s'empêcher de satisfaire un désir qui jaillit tout-à-coup dans leur esprit; ou bien, et e'est la meilleure raison, ils ne prévoient, en aucune laçon, la possibilité d'un accident arant d'en être accablés.

Un autre effet de leur légèreté et de cette inconscience du mal qui les caractérise, e'est leur tendance à se défendre en faisant ressortir avee insistance les petits détails de leur crime, sans songer que ces détails mêmes le confirment et ne font que distraire un peu l'attention sans réussir à l'écarter du point principal. Telle était l'attitude de Cavaglià quand il me racontait le meurtre de son patron et de son complice; telle encore eelle de Manara, soutenant qu'il n'avait pas porté 14 coups, mais seulement 13, à sa vietime.

Leur légèreté est prouvée eneore par leur superstition, qui leur fait croire aux présages et à la magie (Vidoeq).

Les plus grands eriminels, lors même qu'ils apportent une grande habileté dans la préparation de leurs crimes, ne savent pas conserver, jusqu'au bout, cette 
labileté; grisés par l’impunité, ils finissent par perdre toute prudence et par se livrer eux-mèmes (1).

Ils sont, après tout, fort peu logiques et toujours inprudents; et non seulement, dans une foule de cas, il $y$ a disproportion entre le crime et son mobile, conime on l'a vu plus haut; mais, presque toujours, l'exécution laisse beaucoup à désirer, ce qui fommit aux arocats peu scrupuleux un moyen de démontrer l'innocence on l'ir-. responsabilité de leurs elients. - Le criminel, quelle que soit son habileté, porte toujours dans l'exécution de son crime l'imprévoyance qui est le fond de son caractère; la violence et la passion dominante jettent conme un voile sur son criterium; enfin, le plaisir même de commettre une action coupable, d'en savourer l'exícution, de la porter à la connaissance d’autrui, sont autant de causes d'erreur dans l'accomplissement du méfait et mettent la justice la moins habile sur les traces de lauteur.

IIne Lafarge envoic à son mari un gàtean empoisonné avec une lethe par laquelle elle l'engage à en gouter après son diner; elle ne réfléchit pas que son mari ne pourra tout manger, et qu'un fragment de cette pàtisserie, joint à la lettre, suffira à faire découvrir l'auteur du crime.

Rognoni tue son fière et se procure un alibi; mais il oublie de laver les taches de sang dont son habit est souillé. Mieux encore: pendant l'exécution de son crime, il laisse allumée une lampe qui pourrait attirer sur ses lraces la garde ou les roisins.

(1) Un prisonnier érivait à Turin dans les murailles: a Je vous fais savoir qllon mat condamne à mort pour deux assassinats: j'espère la grâce pour en tuer eneore nne dizaine ». (Voir Mes I'ulimsesti, 185\%). 
Rossignol conserve dans sa malle deux cannes ayant appartenu à ses victimes.

Fusil sait prendre à temps la fuite, après son crime, et change de nom; mais, au bout de peu de jours, ayant dépensé l'argent volé et écrivant à un ami pour s'en faire enroyer d'autre, il lui révèle son pseudonyme, que la justice apprend ainsi par hasard.

La Trossarello médite durant plusieurs mois le meurtre de Gariglio, cache son nom aux sicaires qu'elle emploie; mais elle révèle plus tard son affreux projet à de nombreux témoins, et néglige de fuir, bien qu'elle sache qu'on va l'arrèter.

R... va aux Assises pendant qu'on juge son complice, et se fait prendre de la sorte.

La Zerbini qui, après avoir tué Coltelli, imagina une attaque a main armée de la part de personnes inconnues, ne sut pas se débarrasser à temps de plusieurs objets dérobés par elle (1).

6. - Spécialistes du crime. - On dit des malfaiteurs célèbres, écrit M. Lewes (Les causes célèbres de l'Angleterre, 1884), que s'ils avaient appliqué à un travail honnète lintelligence el la persévérance développées par cux dans le crime, ils auraient rempli une brillante carrière; rien de plus faux. 11 est rare qu'un grand talent se fasse remarquer en eux; et, s'ils le possèdent, ce n'est pas dans le crime qu'ils le mettent en pratique. Ils sont fourbes plutôt qu'liabiles; leurs combinaisons, ingénicuses tout au plus, manquent de cohérence et de suite. Le but immédiat à peine atteint, - et ce but

(1) Voir un article de M. FERRI, L'imprevidensa negli omicidi comuni, (Arch. di jsich., $5^{\circ}$ anno). 
est le plus souvent la satisfaction d'un besoin matéricl, - ils se tiennent coi jusqu'au moment oú de nouveaux appétits les pousseront à des entreprises nouvelles: or', ce n'est pas ainsi que l'on arrive à la forlunc.

ll arrive, souveut, que l'habileté de certains criminels parait merveilleuse. Mais, si on y regarde bien de près, tout étonnement disparait. S’ils réussissent si bien, e'est parcequils se répètent souvent. Ne voit-on pas les idiots eux-mêmes, à forec de s'appliquer à une même chose, y paraitre très-habiles?

Non seulcment le voleur ne fera jamais que voler, mais encore, parmi ces malfaiteurs, il en est qui ne s'atlaquent qu'aux magasins; d'autres, qu'aux maisons particulières. Et mème, dans ces dernicrs, on distingue des sous-divisions. Vidocq cite les voleurs de maisons, qui entrent au hasard (cambrioleurs à la flan); ceux qui préparent de loin leur coup, prennent un appartement dans le roisinage et se donnent des allures de gens honnêtes (nourrices); ceux qui s'entendent au préalable avec les concierges ou se procurent de fausses clés (caroubleurs); ceux qui entrent sous prétexte de souhaiter le bon jour (chevaliers de la rampe). Considérez les seuls voleurs du port de Londres, vous y verrez les pirates, qui pillent á main armée les petites embarcations, dérobent les grosses aneres et les càbles; les chevau-légers, qui, pour faire un butin plus abondant, pereent les saes de blé; les hirondelles de boue, qui dérobent les fers, le combustible des bâtiments, ete.

MM. Mayhew el Binny distingruent à Londres dix espèces de mendiants: les étrangers, les affamés, les faux infirmes, les faux naufragés, ceux qui présentent des pétitions, etc.; chacun a son portrait spécial. Parmi les voleurs, ils distinguent ceux qui opèrent avee effraction, 
ceux qui emploient des narcotiques, ceux qui couchent dans les buffets des chemins de fer et emportent le matin les bagages des royageurs (gnooser): ceux qui rolent au crochet; les voleurs de fromage; ceux qui travaillent sous les péristyles des maisons (deadlurker); les voleurs de chevaux (woollybird), de chiens, de gibier. - Un calcul officiel etablit qu'on trouve a Londres 141 voleurs de chiens, 11 voleurs de chevaux, 28 faux monnayeurs dont 317 individus écoulent les produits, 323 escrocs, 343 recéleurs, 2768 chercheurs de querelles, 1205 vagabonds, 773 pick-pokets, 3657 voleurs ordinaires, 217 qui volent avec effraction. (The criminals prisons, 1862, p. 47).

L'auteur anonyme du Trattato dei Bianti énumère 37 espèces de mendiants escrocs, ayant leurs noms particuliers (ruffini, affarfanti, etc.), qui dupaient la sociétí italienne au commencement du $\mathrm{xvI}^{\mathrm{e}}$ sićcle.

"Une longue expérience m'a donné la conviction, écrit M. Locatelli (Sorveglianti e sorvegliati, p. 69, Milan, 1876) que les malfaiteurs usent presque toujours d'une méthode qui leur est propre et tout-à-fait spéciale dans laccomplissement de leurs exploits. Ainsi, on troure des voleurs très-adroits pour forcer une serrure ou percer un mur; d'autres qui grimperaient aisément au haut d'un clocher, et qui seraient incapables de briser le phus léger obstacle. - Certains d'entre eux prennent la fuite au moindre bruit; d'autres entreraient sans broncher dans un salon rempli de monde. Tous rencontrerez des voleurs d'une légèreté de main incroyable, capables, si je puis m'exprimer ainsi, d'enlever ì un honnête homme sa chemise sans qu'il s'en aperçoive, et qui n'oseraient pas franchir le seuil d'une boutique oll d'une habitation, même non gardée. Il cn 
est qui prendront tout ce qui leur tombera sous la main, tandis que d'antres ne daigneront pas se déranger pour des choses de peu de valeur. Plusieurs qui volent des bestiaux avec une adresse extraordinaire, n'auraient pas l'audace nécessaire pour fracturer la porte d'un poulailler " (Vidocr).

Ces spécialistes du crime ont peut-être leur psycologic spécifique, psycologie qui sc fait entreroir sûrement dans les grandes catégories.

7. - Empoisonneurs. - Les empoisonneurs appartiennent presque tous aux classes dirigeantes; ce sont des individus très-instruits, des médecins ou des chimistes (1); leur air sympathique, leur abord aimable, leur langage persuasif, trompent, jusqu'au bout, leurs victimes, qu'ils choisissent, souvent, parmi leurs plus proches parents (Taylor, Moreau, Palmer). Ce sont encore des femmes aux passions ardentes, comme Locuste, la Bonanno, la Tofani, la Piccoli, la Caraccioli, la Costanzo, la Conti-Spina, duchesse de Ceri (V. Adenollo, Nov. Sicule, IX). Comptant sur une impunité certaine, trourant dans leur crime une espèce de volupté, ces misérables font périr en même temps plusieur's personnes, et sourent agissent presque sans motif. Telle fut la Lamb, qui, outre son mari et ses fils, empoisonna une amie, el enfin une roisine avec laquelle elle n'arait aucune relation d'intérèt. Telles encore la Zwanziger, (Feurbacil, p. 21), qui empoisonna plusicurs domestiques et des femmes qu'elle arait jusqu'alor's fort aimées; la Jegado, qui fit 21 victimes; la May, qui donna de larsenic à ses 14 fils et à son frère; la Cheskam, qui

(1) Voir vol. II. 
fit périr $1 / 4$ personnes (fils, époux), et fut absoute deux fois, et enfin pendue. Presque tous ces êtres criminels sont poussés par la cupidité, l'amour, mais surtout par une luxure effrénée. Hypocrites, calmes, dissimulés, ils protestent jusqu'au bout de leur innocence et portent jusque dans la tombe le secret de leur faute. Il est aujourd'hui bien rare qu'ils s'associent plus d'un complice; le contraire avait lieu jadis dans la haute société française et dans la Rome antique: ce crime affectait alors la forme d'une épidémie, surtout parmi les femmes.

8. - Pédérastes. - Les pédérastes sont la plupart du temps des hommes intelligents et instruits, des employés de barreau, des prêtres, etc. (1). Contrairement aux empoisonneurs, ils éprouvent un étrange besoin de s'associer, de former des congrégations véritables, dont les membres se reconnaissent au premier coup d'œil, même quand ils voyagent en pays étrangers.

Nous ne saurions comprendre, et nous ne croirions pas, sans les recueils de leltres publiées par MII. Casper et Tardieu (2), comment ces amours infàmes peuvent se trouver unies à un si laut degré de romantisme ou

(1) Dante, au chant $x v$ de l'Enfer, parlant des sodomistes, s'exprime ainsi :

\section{Insomma, sappi che tutti fur cherci \\ $E$ letterati grandi e di gran fama, etc.}

(En un mot, sache que tous furcnt des cleres, de grands littèrateurs, et de grands noms, etc.).

(2) Voici un extrait de la coufession de l'un d'eux, que nous a donué Tardieu :

- Comment exprimerai-je ce frémissement délicieux de mes sens, quand j'entendais sa voix; ce bonheur que j’éprouvais à me mirer dans ses yeux? Chacune de ses paroles vibrait en moi comme une douce mólodie. (Et. méd. légale sur les attentats aux mceuis, 18\%3). 
de mysticisme. Il est rare que leurs attentals se concentrent sur un seul individu; ils souillent d'habitude un grand nombre de victimes, et presque simultanément. On éprouve moins de surprise à voir ces hommes, surtout s'ils appartiennent aux classes élevées, rechercher les vêtements de femmes, les uniformes brillantes, aller chargés de joyaux, le cou découvert, les cheveux frisés; et associant à leurs habitudes dépravées un goût artistique exquis, faire collection de tableaux, de fleurs, de statues, adorer les parfums, comme si, par un espèce d'atavisme, ils réunissaient en eux les vices et les mérites de la Grèce antique. La plupart sont honnêtes, se sentent coupables à leurs propres yeux, luttent, longtemps, contre leur passion honteuse, la regrettent, la déplorent, essaient de la cacher. Ceux de basse condition, au contraire, vont couverts de haillons, préfèrent aux parfums les plus subtils les odeurs nauséabondes, se donnent des prénoms de femmes; ils s'emploient aux vols les plus audacieux, aux meurtres les plus atroces (Montely), aux chantages, triste invention de Lacenaire, qui se perpètrent en plein Paris, et dont les auteurs sont connus sous les noms d'outils, de tantes, etc. (V. Tardieu, l. c.). Nous en trourerons un exemple dans notre argot italien. (V. ch. suir.).

9. - Violateurs. - Parmi ceux qui se livrent à ce crime, un grand nombre ont les lèvres épaisses, les cheveux abondants et noirs, les yeux clairs, la voix rauque. La plupart du temps ils sont à demi-impuissants et à demi-fous; leurs parlies génitales sont tantôt atrophiées, tantôt d'un volume énorme, leur crâne est de forme anormale; il n'est pas rare d'en voir de goitreux, crétins, bègues ou rachitiques. 
10. - Voleurs. - Comme les filles, les voleurs ont la passion des habits à couleurs voyantes, jaune ou rouge, bleu, des breloques, des chaines (1), des boucles d'oreilles; ils sont les plus ignorants et les plus crédules de l'espèce. Presque toujours sans courage et craignant d'être pris sur le fait, ils font entendre des paroles sans suite, profitent de la plus légère circonstance pour changer la conversation, se lient avec le premier venu et lui font des confidences, pourvu qüil parle l'argot et leur paraisse digne d'ètre leur collègue; ils croient aux songes, aux présages, aux jours néfastes. 11 n'est pas rare de les voir affecter ì des amours romanesques; mais plus souvent ils ont un goût particulier pour les prostituées, leurs alliées naturelles. Vidocq a dit: "Quiconque vit avee les prostituées est un voleur, s'il n'est un espion ». lls cherchent a s'associer toujours en bandes pour exercer leurs exploits; par dessus tout ils aiment le bruit et les clameurs des grandes villes; sortis de là, ils sont comme le poisson hors de l'cau. Incapables d'un travail assidu, menteurs effrontés, ils sont moins que tous les autres susceptibles de s'amender, les femmes surtout, qui joignent presque toujours à leur métier celui de courtisanes.

(1) Telle est la passion de leurs femmes pour les robes galonnics d'or, que, lorsqu'elles en manquent, elles s'appellent "femmes libres, " c'est-à-dire, tombies dans la misère (V1Doce, Sur les moyens de mrivenir les crimes, 1846). - Quant ì la facilité avec laquelle ils se reconnaissent entre enx, le même auteur a remarqué qu'en 1815, avec les Allies, accoururent de nombrenx voleur's, jusqu'ả des Russes et des Calmonks; et qu'en pen de jours ils s'etaient liés avec cenx de Paris et itaient devenus leurs complices. - Moi-même je sais que des voleurs, partis de Turin pour Vienne et Paris, n'ont pas tardé à se lier également avec les voleurs allemands et français et à travailler avee enx, avant mêne de pouvoir parler leur langne. 
11. - Escrocs. - Ceux-ei, comme les joucurs (el sonsent ils s'adonnent eux-mêmes au jeu), sont superstitieux, spiritucls, lascifs. Plus capables que les antres criminels d'une bonne action el aussi d'une pire, bigots el hypocrites, avec un air doux, bienveillant, vanileux et par cela mème prodigues d'une richesse mal aequise, ils sont très-souvent fous ou simulent la folie; souvent même, on trouve les deux cas réunis en eux.

12. - Assassins. - Les assassins, avec les étrangers, affectent des manières donces, compatissantes, un air calme; ils ne sont guère adonnés au vin, mais beaucoup au jeu et aux amours charnelles; entre cux, ils se montrent audacieux, arrogants, se targuent de leurs crimes, où ils développent souvent, plus d'audace et de force musculaire que de véritable intelligence. Ce qui parait en cux une grande habileté n'est la plupart du temps que le résultat de la répétition des mêmes actes. Boggia se fait liver une procuration par sa victime, la conduit au grenier ou à la cave, et la tue, \{onjours d'un scul coup. Dumollard promet une place a des bonnes d'enfants, les conduit dans un bois, les dévalise, les tue et les enterre. Soldati attire également ses victimes dans un bois, les viole, puis brûle leur cadavie.

"Une particularité curieuse aurait été aperçue de Claude (vi, 108) chez les assassins: celle d'être, en dehors de leurs mauvaises occupations, les liommes les plus gais du monde, et de rechercher, par dessus tout, la société des gens de théatre».

13. - Paresseux el vagabonds. - Le paresseux et le vagabond, écrit II. Locatelli dans son livre déja cité, 
est presque toujours d'humeur gaie et joyeuse; aussi, dans les prisons, les voleurs et les assassins en fontils leur bouffon de prédilection. Il est communément sobre et de tempérament calme, fuit les altercations bruyantes et, par dessus tout, les rixes où le sang coule. J'en ai vu qui avaient été condamnés des dizaines de fois, que le spectacle quotidien des misères et des scélératesses humaines avait endurcis, frissonner au récit d'un assassinat et en condamner l'auteur ouvertement et avec vivacité, en pleine prison, au risque d'avoir à s'en repentir. - Dans l'échelle du crime, il est bien rare que ces gens-là dépassent le premier degré; ce n'est pas qu'ils se préoccupent de l'opinion publique, ils savent trop bien qu'elle les réprouve; mais leur esprit éprouve une vraie répugnance à offenser grièvement les personnes on la propriété.

“ Je ne me rappelle pas qu'aucun vagabond ait fait valoir, pour sa justification, le manque de force musculaire (sauf dans les cas de maladie); tous, au contraire, ou presque tous, invoquent, pour s'excuser, la difficulté de trouver de l'ouvrage, de pouvoir exercer leur métier. - Nombre de ceux que leur oisiveté a fait admonester abhorrent le travail, et cela, non à cause: de la fatigue matérielle, mais parceque l'uniformité des mouvements musculaires, à laquelle condamne la division du travail dans les grandes manufactures, leur cause un ennui insupportable. Plusieurs d'entre eux, plutòt que d'exercer le métier qu'ils ont appris, exposent leur santé et leur vie dans les entreprises les plus périlleuses.

"Ils ne sont pas d'ordinaire susceptibles de violentes passions éroliques, de ces passions qui ont le pouroir 
d'entrainer au crime les malfaiteurs véritables" (LocaTELLI, l. c.).

NI. Nayhew distingue parmi les mendiants: les marins, les soldats, ceux qui exhibent de faux papier's, ceux qui simulent une maladie ou le mutisme.

Le besoin de ne pas se fatiguer, la gaité folle et comme artistique qui forment leur caractère, font de ces hommes des inventeurs de métiers étranges, que personne, en dehors d'eux, ne saurait imaginer, parceque personne n'a leur ingénieuse paresse. J'en ai vu un qui faisait profession de se donner à lui-même des soufflets si retentissants, qu'on eût dit les éclats d'une querelle: cela attirait la foule, mais aussi et surtout les gendarmes. Un autre est culotteur de pipes, coloriste de lapins; un autre, encore, dresse des puces et des rats. Il y en arait un qui prétendait avoir 27 professions; il était décrotteur, chiffonnier, commissionnaire, crieur pullic, etc. - De telles gens sont les puristes de l'argot.

14. - Criminels de génie. - On ne peut toutefois nier qu'il n'y ait eu, çà et là, des criminels doués d'un génie véritable, des hommes qui ont créé de nouvelles formes du crime, de vrais inventeurs du mal.

Assurément, c'était un homme de génic que ce Vidocq, qui parvenait à s'évader une vingtaine de fois, et à faire tomber aux mains de la justice plusieurs centaines de scélérats, et qui a su nous retracer, dans ses $M e ́$ moires, une véritable psychologie du crime. Il l'était aussi, ce fameux Cagliostro, qui volait et dupait princes et rois, el parvenait presque a se poser en homme inspiré, en prophète.

Ils étaient, 'aussi, doués d'un génie particulier, (mais bien plutôt de grand agilité) ce Norcino, ce Pietrotto, 
que nulle prison de Toscane ne put retenir plus d'un mois, et qui s'évadèrent après avoir prévenu leurs gardiens; et ce Dubosc qui, après sa condamnation à mort, ne réussit pas seulement à s'échapper, mais fit encore sortir de prison sa maîtresse.

On disait d'llessel qu'un souffle lui suffisait pour ouvrir une serrure; muni d'un petit morceau de bois et d'une cordelette, il ouvrit la porte massive de sa prison. On en peut dire autant de Sheppard, d'llaggart, qui nous a laissé un manuel de son art misérable.

Pontis de Sainte-Hélène, de son vrai nom Cognard, après avoir lué son homonyme, sut le représenter arec tant d'habileté, que les parents du mort, des génér'aux, des ministres, s'y laissèrent prendre. Il fut nommé colonel et comblé d'lonneurs; il serait mort maréchal de France, si un de ses compagnons du bagne ne l'eût par hasard reconnu.

M. Lewes eite un seul voleur de génic, un anglais, le fameux Wilde, qui sut organiser un magasin de recel sur la plus vaste échelle, dans la cité entière de Londres. Pendant 15 années, il monopolisa les produits de tous les rols, revendit les objets dérobés aux rolés euxmêmes, qui les lui payaient sans hésitation ef même en le remerciant. D'accord avec la police officielle, il organisa une police à lui, gràce à laquelle il faisait condamner tous les roleurs qui ne lui rendaient pas un compte exact de lcurs opérations, ou qui n'appartenaient pas à sa bande, et même, trop souvent, les innocents dont il redoutait la délation. Enfin il sut, jusque dans la prison, continuer son étrange métier (1. c.).

Le faussaire Sutler parvint à fabriquer, al bagne même, un décret de grâce pour son compagnon Cravet; et celui-ci aurait été relàché, sans une circonstance 
impossible à prévoir, qui vint faire connaître la supercherie.

Le mème Locatelli, tant de fois cité dans te livre, a connu un voleur qui savait par cœur non seulement les articles de notre Code de procédure criminelle, mais encore ceux du code autrichien, et savait en tirer des comparaisons très-habiles. Il donnait des consultations juridiques à ses camarades, qui l'appelaient le docteur, et se fiaient plus ì lui qu’aux avocats véritables.

Beaumont vida, en plein jour, la caisse de la police française, et se fit escorter, durant l'opération, d'un planton militaire, qui lui servait de garde d'honneur! - Jossas méditait pendant des années entières ce qu'il voulait entreprendre, et savait se procurer les empreintes des serrures d'une facon merveilleuse. On cite, par exemple, le cas d'un caissier qui n'avait jamais consenti à lui montrer la clé de sa caisse: un jour, notre homme l'invite à faire un tour à la campagne; au milieu d'un chemin ils trouvent étendue sur le sol une femme enceinte, paraissant agonisante, en proie à un fort saignement de nez et demandant du secours. Il faut une clé; chacun offre celle qu'il possède; le caissier, comme les autres, applique la sienne sur les épaules de la malade; or, celle-ci avait le dos enduit d'une couche de cire, et, peu de jours après, la caisse était vidée.

Lacenaire inventa le clıantage pédérastique et une nouvelle façon de tuer avec le tire-point. - C'était d'ailleurs un poète plein d'esprit. Au juge qui voulait le convaincre de faux, il disait: "Vous me faites l'effet d'un chirurgien qui, ayant une jambe à couper, s'amuserait à y panser des cor's » (Clande, I, 1881).

A Vienne, en 1869, on arrêta un voleur qui avait inventé 32 instruments pour ouvrir les serrures de sûreté 
(Wiener Verbrech., 1875). Au pénitencier de Sing-Sing, un prisonnier était parvenı à établir une distillerie avec les restes des fruits et des pommes de terre que fournissait la prison; il put en cacher longtemps les produits. (Riv. di discipline carcerarie, 1876).

Mais, en général, à tous ces crimincls de génie manquait, soit la prévoyance, soit la ruse nécessaire pour mener à bonne fin leurs entreprises scélérates. A travers leur's idées ingénieuses apparaît toujours cette légèreté qui fait le fond de leur caractère. Les combinaisons infernales de Desrues, de Thomas, de Palmer, de Faella, de Peltzer, de Troppmann, alors même qu'elles eussent été conçues avec une habileté plus grande, n’auraient pu finalement réussir, car leurs victimes laissaient toujours quelque parent intéressé à découvrir le coupalıle et à l'empècher de jouir de son crime.

Jai, moi-même, connu un voleur doué d'une belle intelligence, et qui avait pu se faire une large place dans la carrière des sciences. Mais, là aussi, il portait la mème légèreté que dans le monde. Un trait d'esprit, une épigramme, hui tenaient lieu de raisonnement. D'une habileté extrême quand il ne fallait qu’imiter, il ne savait rien créer par lui-même; s'il obtenait l'estime publique, c'était uniquement par son verbiage qui se transformait parfois en éloquence sous l'impulsion de quelque passion, principalement de l'orgueil.

Bref, considérés en général, ces malheureux, même ceux à qui l'on octroie du génie, ont plus de fourberie (comme les sauvages) et plus d'esprit, que de génie véritable. Ils manquent de cohérence et de continuité dans le travail mental, - qui est puissant en eux, j'en conviens, mais intermittent. 
15. - Criminalité des savants. - Quoique le génic soit, aussi, une espèce de névrose congrinitale, (voir mon livre sur le Génie el la folie, $5^{\mathrm{e}}$ éd.), les criminels ne font que de rares apparitions dans le monde scientifique; et, parmi ceux que l'on a signalís, il y en a beaucoup dont la culpabilité n'est pas bien prouvée. Pour ma part, je n'ai pu relever avec une entière certitude que Bacon, dont le crime de péculat dénote plutôt la faiblesse du caractère que la dépravalion de l’àme; Salluste et Sénèque, accusés eux aussi de péculat, mais sans preuves certaines; Cremani, jurisconsulte el criminaliste célèbre, qui finil par devenir un faussaire; Demme, savant chirurgien, coupable de rol et d'empoisonnement (1). Aucun mathématicien, aucun naturaliste, à ma connaissance (si du moins nous nous en tenons au premier rang), n’a encouru de peine pour un crime commun. On peut tout au plus citer Casanova, qui fut déclaré déchu de sa noblesse pour un crime dont nous ignorons la nature, et Avicenne, d'ailleurs épileptique, qui, devenu vieux, se plongea dans la débauche et abusa de l'opium, si bien que l'on disait de lui que la philosophie ne lui avait pas servi à vivre honnète, ni la médecine à conserver la santé. (Poucinet, Histoire des sciences naturelles dans le moyenâge, 1870).

(1) Lewes (1. e.) nous parle du philologne Aram, du théologien Iodd, tous deux eriminels; mais leur valeur seientifique etait fort contestie. Il en est de même des médeeins Lawson, La Pommerais, Lebiez. - On peut aussi en dire autant de Mereadante, ehimiste de valeur, mais non véritablement illustre, qui se mit à la tête d'une bande de recéleurs; de Meloni, médecin en renom, qui inspira un menrtre pou favoriser son parti dans une affaire municipale; de Padovani, médecin diplômé de Pise, qui, en Corse, frappait souvent eomme bandit ceux qu'il traitait ensuite en qualité de chirurgien. (Les bandits corses, 1871). 
On peut, jusru’à un certain point, confrrmer ce fait a l'aide de la statistique. Si on se borne aux résultats scholastiques je trouve sur mes 500 criminels comparés aux 100 normaux:

\begin{tabular}{|c|c|c|c|}
\hline Catégories & $\begin{array}{c}507 \\
\text { Dèlinqquants }\end{array}$ & & $\begin{array}{c}100 \\
\text { Normaux }\end{array}$ \\
\hline $1^{\mathrm{e}}$ Analphabets . & . 12010 & - & $60 \mathrm{l} 0$ \\
\hline $2^{\mathrm{e}}$ Instruction élémentaire & . $95 "$ & - & \\
\hline $3^{\mathrm{e}}$ Instruction supérieure & . $12 "$ & - & \\
\hline
\end{tabular}

On voit que si dans les deux extrêmes les criminels sont de beaucoup inférieurs aux normaux, ils ne le sont du tout dans l'instruction élémentaire. Mais on trouve une énorme différence aussi pour les premiers selon les catégories des criminels.

Les analphabets montent jusque au 25010 dans les violateurs et dans les assassins, et descendent au 9010 dans les criminels contre les propriétés, et à $0,770_{10}$ dans les eseroes.

En Aulriche, comme le remarque 11. Messedaglia (1), la classe qui a commis en 14 ans le plus petit nombre de crimes est celle des gens adonnés aux travaux scientifiques; la proportion va de 0,83 à $0,710_{10}$ (de 1,21 à 1,50 en Lombardie; mais, là, il faut tenir compte des cas politiques).

Cela n'a rien d'extraordinaire. Des hommes accoutumés à respirer la sereine atmosphère de la science, qui est déjà un but et un plaisir par elle-même; des hommes qui ont continuellement sous les yeux le criterium du vrai, triomphent plus facilement des passions brutales et répugnent à s'empêtrer dans les voies tortueuses et stériles du crime. D'autre part, mieux que les autres hommes, ils comprennent combien toute

(1) Statistiche criminali dell'Impero Austriaco, Venise, 1865-67. 
action compable est non seulement injuste et illogique, mais encore sans profit, puisqu'elle se retourne tonjours contre son auteur.

La eriminalité, chez les poètes et les artistes, est malheureusement plus forte. Beaucoup, parmi eux, sont dominés par la passion, qui est le plus puissant aiguillon de leur rerve; ils nont pas, pour les retenir le criterium du vrai, les sérères lléductions de la logique, dont sont armés les savants. Voilà pourquoi nous devons compter au nombre des eriminels les Bonfadio, les Rousseau, les Arétin, les Ceresa, les Brunetto Latini, les Franco, les Foscolo, peut-ètre Byron. Notez que je laisse de còté les temps anciens et les pays barbares, où le brigandage et la poésie se donnaient la main. On n’a quà lire, pour s'en convaincre, les poèmes sur Kaleiva Peag et Ilelmbrecht.

Plus criminels encore semblent avoir été Albergati, auteur comique de la plus liaute aristocratie, et meurtrier de sa femme par jalousic (MAsi, La vita ed $i$ tempi di Albergati, 1882); Mureto, condamné en France pour immoralité; et Casanova, si bien doné pour les sciences mathématiques, pour les finances, les lettres, et qui souilla son beau génie par une vie de turpitudes et d'escroqueries dont ses Mémoires nous offrent le tableau le plus complet et le plus eynique.

Villon appartenait à une famille honorable; il recut le nom sous lequel il est connu (villon, fripon, roleur) quand il devint célèbre dans la ribauderic, - oi il fut entrainé, de son propre avcu, par le jeu et les femmes. Il commença par dérober des oljets de peu de valeur, pour offrir un bon diner à ses maitresses et a ses compagnons d'oisireté; c'était alors du vin qu'il volait. Son larcin le plus consirlérable lui fut inspiré par la faim, 
quand une ribaude, aux dépens de qui il vivait, selon la contume des filous, le mit ì la porte, de nuit, en plein hiver. Ciest cette femme que, dans son Petil Testament, il fait héritière... de son cœur. Ainsi chassé, il s'unit à une bande de détrousseurs, alla commettre des vols à main armée, principalement sur la route de Ruel, si bien qu'enfin, arrêté pour la seconde fois, il eut grand peine à éviter la corde (Dusini, l. c.).

Luciani en Italie, et en Angleterre Lesfrois, furent des journalistes distingués; mais il parait que e'est l'abus de la morphine qui fit du second un assassin.

Je dois aussi constater que, parmi les assassins ou empoisonneurs célèbres, plusieurs, tels que Venosca, Lacenaire, Brochetta, d'Avanzo, de Winter, Lafarge, Barré, Lebiez, se sont élevés à une certaine réputation dans l'art de la poésic, ou pour mieux dire dans celui de la versification. - On confisqua à Fallaci un livre de ver's qu'il avait composés entre deux meurtres. Ilessel trouva Bouget composant dans sa prison une tragédie dans laquelle il racontait ses aventures; cet homme regardait son cachot comme un cabinet de travail, où il se trouvait à l'abri des distractions du monde, et renvoyait son évasion à la fin de sa tragédie.

Les artistes, plus encore que les gens de lettres, sont entrainés au crime; ils commettent surtout des meurtres par amour ou par jalousie de métier. Qu'il nous suffise de citer ici Cellini, coupable de plusieurs meurtres et peut-être de vol; Andrea del Castagno, qui poignarda traitreusement Domenico Veneziano, afin de rester scul possesseur du secret de la peinture í l'huile; lc Tempesta, qui tua sa femme pour épouser une fille; frère Filippo Lippi, qui cnleva une novice; Ilerrera, faux monnayeur; Andrea del Sarto, escroc; et Bonamici 
dit le Tassi, Benvenuto l'Ortolano, le Caravage, Lebrun; Luino, Curtois, Cloquemin, tous assassins. Et qu'on le remarque bien, pendant que les peintres fournissent une si grande quantité de criminels, il y en a peu parmi les sculpteurs (je ne connais de tel que Collini); aucun parmi les architectes. Serait-ce parcerpue leur art, comme les sciences, exige le calme de la méditation? Les peintres fournissent au crime un contingent plus nombreux pour cette autre raison, peut-être: qu'ils abusent de l'alcool plus que le reste des artistes. Rappelons-nous, à ce propos, les orgies de Caracci, de Steen, de Barbatelli, que son vice fit surnommer Pocietti, de Beham, et d'une foule d'autres qui ont abandonné la peinture pour se faire cabaretiers.

Mais la criminalité est malheureusement plus fréquente chez les hommes qui exercent des professions libérales.

En Italie, parmi les criminels, nous en trouvons 6,1 p. $0_{10}$ qui ont reçu une culture supérieure; en France, 6,0 $0_{10}$; en Autriche, de 3,6 à $3,110_{\{0}$; en Bavière, $4,00_{10}(1)$.

Ces chiffres ont leur éloquence; la proportion est ici relativement plus grande que dans les autres classes de la société. En Italie, en effet, nous voyons 1 criminel sur 345 professionistes, 1 sur 278 rentiers, 1 sur 419 paysans et sur 428 employés (Curcio, l. c.).

Il n'y a pas là de quoi surprendre. Pour ceux qui exercent une profession, la science n'est pas un but, mais un moyen; si donc elle n'a pas la force nécessaire pour raincre les passions, elle n'en a que trop pour fournir des armes au coupable, alors surtout que la profession qu'il exerce lui vient en aide, que le médecin

(I) Emingex, Die Moral statistik., 1848. - Messedatha, l. c. 
par exemple, peut facilement donner du poison, l'avocat commettre des faux, le professeur attenter à la pudeur de ses élèves.

Une grande partie des femmes livrées ì la débauche sont complètement illettrées. Des 4.470 comptées en France par M. Parent, à peine 1780 savaient tracer leur nom, et 110 seulement avaient recu une instruction supérieure. Toutefois ce rapport n'est plus le même à Londres, où, pour 3498 prostituées illettrées, on en comptait 6052 sachant imparfaitement lire et écrire, 355 possédant bien la lecture et l'écriture, 22 qui avaient une instruction supérieure. (Richelot, Prostit. en Angl., 1857).

16. - Intelliyence chez les fous. - Si maintenant, au point de vue de l'intelligence, nous comparons les fous aux criminels, nous verrons que la paresse est plus rarement dominante chez les premiers; ainsi, les mendiants, qui fournissent le contingent le plus élevé aux maisons de détention, sont très-rares dans les hospices d'aliénés (Guistain, Lecon orales, iı); et tandis que les fous témoignent d'une activité exagérée, mais stérile, qui s'épuise à rechercher des consonnances euphoniques, à ebaucher des travaux inutiles ou sans profit (j'ai, pour ma part, connu une paure folle qui s'amusait à recouvrir de papier les briques de sa chambre et son rase de nuit, it relier des livres dont, par amour pour la symétric, elle rognatit souvent le texte), les criminels ne développent leur activité que pour obtenir des avantages, directs et immédiats, et plus souvent dans le mal que dans le bien; en revanche, si ces derniers ont très-peu de logique, les fous n'en ont souvent que trop. Qưil nous suffise de dire qu’a 
Bacon, à Salluste, à Sénèque et à Denme, qui seuls ont versé dans la voie du crime, on peut opposer Comte, Swammerdam, Ilaller, Ampère, Newton, Pascal, le Tasse, Rousseau (1), Cardan, tous plus ou moins mélancoliques ou atteints de monomanie.

Les peintres (v. s.), au contraire, me semblent fournir un contingent plus considérable an crime qu'à la folie. C'est le contraire pour les grandes maîtres de musique: il me suffira de citer ici Beethoven, Gounod, Donizetti, Schuhman, Mozart, Rousseau.

Enfin, on peut dire de l'instruction que, comme elle favorise certaines espèces de crimes et en combat d'autres moins saurages, de même elle augmente certains cas de folie, par exemple la parésie générale, l'alcoolisme, la folie littéraire, et en diminue d'autres tels que ceux de démonomanie, de folie religieuse et épidémique, de folie du meurtre, et qu'enfin elle donne à toutes une apparence moins violente et moins basse.

(1) V. Genio e follia, du prof. Losnzoso, Turin, I882, 4e édit. 


\section{CIIAPITRE IX}

\section{De l'argot (1).}

1. - Le criminel récidiviste ou qui fait partie d'une bande, ce qui a lieu généralement dans les grands centres, se distingue par l'emploi d'une langue qui lui est propre et dans laquelle, tout en gardant intact le type grammatical, les assonnances générales et la syntaxe de l'idiome en usage parmi le peuple, il en change complètement le lexique.

Ce changement s'opère de plusieurs laçons. La plus répandue, la plus curieuse, celle qui se rapproche le mieux de l'argot des langues primitives, consiste à indiquer les objets par un de leurs attributs; ainsi, le chevreau sera

(1) Ascoli, Sturti critici sui gerghi, 1861 ; - Buonderlu, Studi sulla lingua fublesca, 1846; - Moreav-Christophe, Le monde des coquins, 1870; - Poтt, Zigeuner, Halle, 1844; - Avé-Lalbmaxt, Rothwelsche Studien, 1858. - Maror, Note sul gergo fruncese, Archivio di psichiatria, 1v, 4" fase. - M. Linden-Larcher, Sumplement au dictionnaire d'argot, 1882, Paris. - M. Lacassarse, L'homme crininel comparé

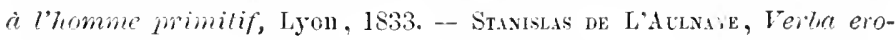
tice, add. à Rabelais, 1820 .

Personnellement, je n’ai pu faire que des itudes pen nombreuses et de courte haleine sur les argots de la Calabre et du lae Majeur, sur nos argots anciens, dispersés dans le Trattato dei Bianti, Italia, typ. Didot, 1828. J'ai encore porte mon attention sur les divers argots de Sicile, exposés par M. Pıtré dans les Canti Siculi, et par x. v. dans l'Archivio di psichiatria e Scienze penali, rol. ıı; - sur les vénitiens, ètudiès par M. Venezian dans ce même Archivio, u, l03 et 104; - sur ceux du Piémont et du duché de Parme, grâce au concours de M. Cougnet et Righini, id. 
désigné par l'épithète de sautetr, la mort s'appellera la maigre, la cruelle, la certaine.

Le philosophe trouve la un moyen de pénétrer dans les replis de l'àme de ces malheureux; il peut voir, par exemple, quelle idée ils se font de la justice, de la vie, de l'àme et de la morale. En effet, l’àme est appelée la fausse; la honte, la routge ou la sangltnte; l'heure, la rapide; la lune, la moucharde ou lespionne; le réverbère, l'incommode; l'avocat, le blanchisseur, c'est-à-dire celui qui doit laver leur's fautes; la bourse, la sainte; le sang, du raisiné; la prison, la petite sainte; le gage, le saint; l'aumòne, la gueuse; la prédication, l'cnmucuse; la sour, la chéric. Les Français appellent encore dévot, le genou; brutal, le canon; créateutr, le peintre (1). Les Lombards donnent le nom de mauvaise

(1) Dans l'argot français, battant = le ceur, qui bat; dans l'argot vénitien on dit palpitonte (Archivio, $\mathrm{n}, 205) ;$ basse $=$ la terre; produisante $=l a$ terre; blufard = l'argont: c'est me allusion à sa couleur; la llafarde =la mort; blonde = bouteille de vin blanc; négrette = bouteille (probablement de rin rouge); négrette morte = bouteille vide; coureuse = machine a coudre: couvrante = casquette: on avait déjả le terme générique de couvre-chef; flottante $=$ vaisseau, barque; frise $=$ juif ; gluant $=$ enfant à la mamelle; insinuante = seringue, d'où $i n s i n u a n t=a p o-$ thicaive; pallotte = lune; priante =la messe; ou mienx peut-être l'église: mant = bouc: rameneuse = fille boulevardière, qui ranènt' che: elle; renifante $=$ botte (percèe, qui renifle leau); reposante $=$ chaise: retrousseur = souteneur; roudin signifie loule, on pomme, ou encore excrément; roudinet $=$ bagne: sans bout $=$ cercle; siante $=$ siante $=$ chaise; disque $=$ argent, pal allusion à la forme des pièces de monnaie. Siffer au disque = demander de l'argent, par allusion à certaines mancuvres en usage sur les chemins de ter; soutenante $=$ canne; tortillante $=$ vipère; vermois pour vermeil $=$ sang; verte $=$ absinthe; volant $=$ oiseau $;$ volante $=$ dépiche télégraphique $:$ on dit aussi: babillarde volante; roltigeante $=$ boue; sondeur (avocat) $=$ procuicur de la République; pire soruleur = juge a'instruction: les sondeurs $=l a$ justice (LOREDAx, l. c.; MaYor, l. c.). 
à la soupe de la prison, et celui de dangereux au membre virile qui peut entrainer une arrestation ou causer une maladie.

Quelquefois le changement métaphorique consiste dans un procédé que nous pourrions appeler" "de similitude renversée ». Ainsi, la sagesse désigne le sel; maronte (mari), le bouc; la médisante, une langue salée.

On reconnaitra ici l'influence de ce sel épigrammatique fort commun cliez les malfaiteurs, qui sont bien plus riches d'esprit que de bon sens.

L'argot offre une création plus curieuse encore et plus difficile à comprendre pour quiconque n'a pas la pénétration divinatoire d'Ascoli: elle consiste à faile suivre la raison métaphorique d'un travestissement phonétique. Par exemple, prophète désignera la poche ou le cellier, par allusion à leur profondeur; le philosophe sera le mauvais soulier, allusion subtile à l'homophonie de savant et de savate, et peut-être en même temps à la pauvreté, que l'on appelle précisément philosophie! De même le Parmesan dit catanas pour tabac, et ramengo pour bâton.

L'expression étrangler un perroquet, qu'un néologisto a essayé de transformer en stranguler un ara, nous fournit un autre exemple de ce genre. Etrangler un perroquet veut dire boire un petit verre d'absinthe. On y trouve une allusion à la couleur (le perroquet et l'absinthe sont également verts), une allusion au geste qui est le même dans les deux cas et qu'on explique par un jeu de mots: pour étrangler un perroquet on le prend par le cou, et pour boire l'absinthe on prend le cou du verre $\grave{a}$ paltes (vert $\dot{a}$ palles) qui la contient. ll y a enfin une allusion à la sensation d'étranglement que produit l'absinthe en passant par l'œsophage. 
La fille de joie prend aussi le non d'hôtel du besoin. Tout le monde peut aller ì l'hôtel; il suffit, pour celis, de payer; en outre, il y a une homophonic arec l'autel sur lequel on offre le sacrifice! Le mot besoin qui s'? ajoute pent avoir trait et ì la luxure qui entraine l'homme, et à l'état perpétuel de misère où vivent ces especes de fenmes (1) (llaror).

Voici encore d'autres cxemples de ces sulstitutions aussi ingénieuses que bizarres: dans l'argot vénitien, fulmine (foudre) et lampo (éclair) désignent le télégraphe; fa e tasi, le poignard; festa, un aveugle, par allusion ì la fermeture des magasins les jours de lêtes; cori sempre, le ralet de chambre; ombra (ombre), la promesse; ebrea (juive), la viande salée; en parmesan trichina el sbrigalet, le médecin. Le français appelle seur's blanches, les dents; centre, le nom propre, le point de mire de l'ennemi naturel, le juge ou le gendarme; cravate, l'are-en-ciel; bride, la chaine du forçat; pré, le bagne; planche au pain, le tribunal; juge de paix, le bourreau; carabine (au nez camus), la morl; sorbonne, la tête; cicrla (mol espagnol), la mort; lycée, la prison; carquois, la holte du chiffonnier, qui luimème est appelé Cupidon ou Amour. Le lombard dit: ducato (ducat), pour plaisir; morsa (ćtau), pour faim;

(1) De même, en français, dựme pour fromage, par allusion à la crême et en même temps à la qualité du fromage, la dureté, qui le distingue de la fleur du lait.

Bourre-de-soie $=$ prostiluce. Bourre pour bourdon $=$ flle de joie qui va en bourdonnant faire ses offres aux passants. Ce mot de soie, fait allusion à la nature de son vêtement et en même temps aux soies du porc et de sa femelle. - Macchabée = souleneur; c'est la première syllabe mac ou macq de maquereau, que l'on a allongée, probablement pour $y$ enfermer une allusion aux charognes ou aux cadavres qui flottent souvent dans les cours d'ean, et que l'argot appelle machabées. 
troppo (trop), pour le manteau; rami (petites branches), pour les jambes; denti (dents), pour la fourchette; polenta, l'or (argot de Pavie); occhiali di Cavurro (lunettes de Cavour), pour les menottes (Pitré). Cette dernière expression, étrange, atteste la logique bizarre des basses couches du peuple de Palerme, qui confondent la politique avec la moralc.

2. - Histoire. - Parfois, en effet, la métaphore constitue une vraie médaille historique, digne de rester dans la langue ordinaire (et cela a lieu en partic); ainsi l'expression si curieuse de juilleitiser, renverser du tròne; et, chez nous, francais pour buveur et espagnol pour truand; grec, qui trompe au jeu; bolognare (bologniser), mentir et voler. Tous ces mots ont trait aux vices de certains peuples. Citons cncorc, à Parme, fascuna spagnola, fagot espagnol, pour désigner le soleil, que l'on appelle encore, par une métaphore originale, père des mal vêtus; et Murcio, en Espagne, pour voleur, par allusion aux nombreux voleurs qui désolent la province de ce nom.

Nombre de locutions, dans la langue des malandrins, se tirent d'allusions homophoniques à certaines personnes ou ì certains lieux: aller $i$ Niort $=$ nicr; aller $\dot{a}$ Rouen $=$ se ruiner; aller $\dot{a}$ Montretout $=$ aller $\dot{a}$ la visite de santé, où l'on montre tout (1).

(1) Lillor $i=$ fil: de Lille on il se fabrique; Lingre = couteau: de Langres; Montreuil $=$ pheche: de Montreuil où l'on récolte des pêches excellentes. On appelle Banc de Terie-Neuce l'endroit oǹ se réunissent les femmes publiques et leurs souteneurs. Aux uns et anx autres on a donné des noms de poissons. Le souteneur est appelé poisson, barbillon, goujon, maquereau. La prostituée a reçn le nom de Morue; de là l'exjression Banc de Terre-Neuve, qui désigne spécialement la partie des boulevards parisiens allant de la Madeleine i la Ponte Saint-Denis. 
D'autres, comme chez les sauvages, sont forgíes par onomatopée; on a ainsi: tap, marche; tuff, pistolet; tic, montre. Chez nous, une onomatopée de sympathie donne guangana, amante; taf, défiance; fric-frac, extraction. Dans le françis (Lorédan-Larcher) flopper = battre; boubouille = pauvre cuisine, bruit du bouillon; tambouille $=\mathrm{ill} ;$ popote $=\mathrm{id} . ;$ putanot $($ faire $l c)=$ fuir; schproum (faire $d u)=$ faire du bruit; flou = rien; puff $=$ chûte; flafla = étalage. A Parme: buf = décharge; gnif $=$ giflle $;$ lapa $=$ chemin de fer.

On trouve aussi des automatismes: papi, chef de justice; nona, sentinelle; pipet, château; babi, hôpital; pipetti, pièces de monnaie; et, dans l'argot français: bibi, Bicêtre; baba, assourdir; pipa, baiser (d'origine vẻnitienne); bibi, fausses clés; loulou, bibi, coco, bébé, ami; bibine, taverne.

Diantres transformations consistent en automatismes rẻsultant d'un redoublement de syllabes, combinés avec des suppressions, des mélathèses, etc. (1).

3. - Détournements. - Une autre source de ce lexique est constituée par un détournement des mots, le plus souvent grâce à un de ces procédés que mon ami Marzolo traitait de fausses réductions étymologiques; p. ex., orfèvre pour orphelin; philanthrope pour filou; chez nous alberto, œuf, d'albume; cristiana, le bonnet, de cresta; andare a Legnano, recevoir des coups de bàton, de legno; à Parme, on dit ramengo pour bàton, de ramo et ramengare.

(1) Toc-toc = toque; ty-ty = typographe; gaga = gateux; bobonne = bonne; soussouille $=$ souillon; Bibi $=$ Bicétre, hospice d'aliénés. Envoyer à Bibi; baba = abasourdi. 
Evidemment, on rencontre ici un double jeu étymologique et phonétique, c'est-à-dire qu'on voit deux noms ou deux attributs se rappeler l'un l'autre et comme se fondre en un seul, p. ex. Martin Rouant, gendarme; de Roveau, Rouen, officier de gendarmerie et de roue, instrument de supplice. Dans Erdmann, homme-terre, pour marmite; dans Darkmann, hommcnoir, pour nuit (v. Ascoli), dans Père noir, bouteille; Bernarde, la nuit; Martin, le couteau, Père frappart, le marteau, on voit apparaitre le procédé qui fail vivre les objets inanimés et leur donne une forme humaine; c'est le propre des enfants et des peuples sauvages; c'est de là qu'est sortic presque en entier la mythologie.

Il arrive moins souvent que le changement du mot s'opère par l'intercalation d'une syllabe. C'est, paraitil, le procédé exclusivement employé par les bohémiens qui vagabondent dans les Pyrénćes Basques, et par quelques peuplades russes ou circassiennes. On le rencontre aussi dans ces argots apoeryphes que M. Biondelli a si bien nommés "argots récréatifs; " mais il se voit également dans nos argots véritables; exemple: dorancher pour dorer; pitancher pour pinter, boire.

Le renversement des syllabes est un peu plus fréquent; ainsi taplo, dans largot espagnol, pour le plat ou l'assictte; malas chez les maçons piémontais, pour salam; lorcefe pour la force. Mais cette manière est moins usitée chez nous que chez les brocateurs de Londres et les cliefs d'une tribu nomade de l'Inde, celle des Bazegur; leurs sujets se contentent de changer une lettre.

On trouve plus souvent le changement d'une voyelle, p. ex., boutoque, pour boutique, etc. 
D’autres altérations s’obtiennent en ajoutant des désinences augmentatives, diminutives, caressantes, et, le plus souvent, péjoratives (1).

Ainsi donc, lorsqu'il s'agit de cacher le sens d'un mot, l'argot ne sinterdit pas toujours d'allonger ce mot. Dautre part, le largonji, espèce d'argot qui dénature les vocables à l'aide de mílatheses sommises it des regles fixes, ou par lintercalation d'une ou de plusicurs syllabes, toujour's sclon des règles bien établies, doil nécessairement aussi les allonger. De macaroni, par exemple, il fera lacaronimique; de vache, lachevane; de mystère, listermique, etc. - Nais la tendance la plus constante de l'argot est d'abréger. Le Supplément du dictionnaive d'argot, de M. Lorédan-Larcher, en fournit de nombreux cxemples (2).

(1) Bissarel = pain bis (pain sec, dur, rassis, moins savoureux que le pain frais. La terminaison en ard est pejorative. Exemple: communard, gueusard, bondicusard (qui croit au bon Dieu), etc.; Santaille = santé (prison de la). La désinence aille est égallement péjorative (MisYoR).

(2) Tra = tracail; carne = charogne, carogne; ces mess (que l'on écrit anssi cémaiss) = ces messieurs et (lésigne la police: chand = marchand; fortifie $=$ fortifications; lubre $=$ lugubve; abs = absinthe; délass-com = délassements comiques (un thètre de Paris); aff =affaires; aminche $d^{\prime} a f f=$ compe've, complice; avoir ses aff = avoir ses menstrues; mecq (mec a un antre sens) $=$ mac, abréviation de maquereau (sonteneur). Mecq pour macq est dù à une mauvaise prononciation; le faubonivien adoucit l'a et l'o ou mieux traine sur ees lettres de façon $\dot{a}$ en faire souvent un $\ddot{a}$ et un $\ddot{o}$ allemands: il prononce Montmertre, Constantineuple; tress = tressauteur, le cœur; vice-ra, vice-race = vice-ratichon $=$ vicaire $;$ slasse $=$ soulasse $=$ homme ivre: de slasse pal amour de nouveanté slussique; slasser (d'où slassiques) = sconiler, enivrer; amphi $=$ amphithéatre; bas-off = bas-officiers, sous-officiers; bibli $=$ bibliothéque; boulger = boulevard St. Germain ; math $=$ mathématiques; mélé-cass = mélange de cassis et d'eau de vie: moure ou probablement plutôt mour $=$ anour $=$ figure gentille ;ou-foutu, 
D'autres transformations consistent seulement à changer les désinences, à faire des métathèses, des transpositions, à supprimer ou ajouter des syllabes qui ne changent et n'obscurcissent en rien le sens du mot. Comment expliquer ce phénomène, sinon par l'attrait qu'exerce toute chose extraordinaire ou nouvelle, et qui est un des signes caractéristiques des esprits légers, voir ceux dont nous nous occupons? (1). (Voir page 447).

Certaines abréviations sont de véritables ellipses, des contractions de plusienrs syllabes ou de plusieurs $\operatorname{mots}(2)$.

fichu, perdu; cassi-co = mélange te cassis et te cognac; nég = négociant ; eroeh = crochet $:$ d'où neg au petit eroch, le ehiffonnier qui va eherehant sa marehandise dans les tas d'immondices, al'mé $d$ 'un fer reeourbé; rub = ruban. I'où, par une hardie muptaplore, rub de rif = ruban de fer (litteralement) chemin de fer.

(1) Dc traviole $=$ de travers; alentoir $=$ alentour ; friod $=$ froid; loupel $=$ powillew $;$ server ou server ou verser $=$ verser : sous-entendu des larmes, pleurer; invalo = invalide: Camaro = camarade; elurler = huvler; habitongue = habitude; goryeon = gorgée; lestome $=$ l'estonae: peut-être du piémontais lo stomi; saint-Laso = saintLasare; morbec $=$ morpion: marque $=$ larque $=$ largue $=$ ferme de voleur: d'où manquise $=$ ferme publique; marquant $=$ soutenewr; francillon = français; vol à la tare = vol à la tire: Tasas = Wasas: par allusion $i$ tas. Tas de pieries $=$ prison; pantal $=a r=$ pantalon: par allusion à hazar. Ce mot date de l'époque où parurent ehez nous ces premières boutiques orientales. On en a fait talsar, dalsar, falsar', qui ont la même signifieation; tucrin $=$ tupin $=$ pot: du vieux français toupin: par allusion à la ville de ee nom; varenne = garenne: par allusion à un village historique; épicemar = épicier; perruquemar = perruquier.

(2) Flibocheuse $=$ fibustière et rigolbocheuse; et mistonffe $=$ misère: Peut-être misère telle qu'on en étouffe; être pied = être bête comme ses pieds; omnicroche = omnibus, par allusion (accrocher) à la fréquenee des reneontres, des choes, ete.; bridankil $=w^{*}$ ide au Filo, bride qui se vend au kilogramme = chaîne de métal; mar-chef $=$ maréchal des logis chef; riscope $=$ viseape $=$ visiene de ehapeau. 
4. - Mots étrangers. - Les termes étrangers sont une source féconde: les argots d'Allemagne empruntent it l'hébreu; ceux d'Italic ì l'allemand et an français; ceux d'Angleterre à l'italien et an sanscrit. Ainsi, nous avons donné an français mariol, furfante, boye, valet chargé de battre les galériens; fril, pour perdu; cetcune, cap, pour surveiller; tabar, fuoroba (fuori roba), cri des argousins pour donner le signal d'une capture; at l'anglais: madza pour milicu; beong ou bianco pour argent; catever pour mauvaise affaire, screeve pour lettre (Ascoli). Les Allemands, at leur tour, nous ont fourni spilare pour jouer; pisto pour prètre; faola pour difforme; conobello pour ail; ef aux Vénitiens ftra chef de maison (de führer).

Les bohémiens ont douné an français le sanscrit berge pour année, chourin pour couteau; à l'allemand maro pour pain; à l'anglais gibb pour langue, mooe pour bouche (Ascoli).

En espagnol, nous trouvons l'italicn parlar, formege, le français aller belitre (1).

(1) Dans laargot français (Mron, 1. e.) fish (de l'anglais fish on de l'allemand Fisch $=$ poisson) $=$ souteneur; itre frais, avee le sens de litalien star fresco, ne semble pas en effet pouvoir admettre l'explication que tente d'en donner Loredan-Larcher; frisco = froid, frais: e'est notre fresco. Niet $=$ rien, de l'italien niente. Stropiat $=$ nendiant, estropié, de l'italien storpio. Bettander = mendier. C'est un vienx mot. Les bettandiers formaient me tribu de la Cour des Hiracles. Le mot doit être d'origine allemande: betteln $=$ mendier. Gambette de bois = béquille, de gamls, jambe. La béquille est comparée à une jambe. Carousse $=$ nuit: du slave kara $=$ noir; se la gambiller $=$ s'en aller: de jambe; gambriade dans l'argot des voleurs a le sens de cancan, danse. Gat $=$ chat, de l'italien gatlo. Gobin $=$ bossu: de gobbo (bossu, en italien). Stoss = coup, de l'allemand stoss. Monter. un stoss = monter un coup. Schlofer = dormir, de l'allemand schlafen. Ripa, ripeur $=$ voleur de Seine, voleur des bords du fleuve, 
L'hébreu a fourni la moitié des mots de l'argot hollandais, et presque un quart de l'allemand; j'y ai moinème compté 156 mots de cette provenance sur 700; et tous les noms des crimes y sont en hébreux (Gladerne, Chelef) hormis l'escroc aux dés, Band-spieler. Avé-LALLEMANT.

En anglais, MII. Ascoli et Wagner en ont trouvé des traces: ainsi, cocum pour rusé; schoful pour fausse monnaic; gormof pour petit voleur, larronneau. En italien, sacagn, pour couteau, est d'origine hébraïque; il en est pent-être de mème de caloffia, qui signifie: prison.

Quclquelois dans un mot on tronve les traces des trois langues: ainsi, amst, allemand, emploie; kehr, juge en bohémien; Ospiess de Huspitium, font le mot Amptlicherospiess, maison de justice en argot allemand. AVÉ, II.

5. - Archäsmes. - Ce sont les termes anciens, ceux qui ont complètement disparu des lexiques aujourd'hui en usage, qui lournissent aux divers argots leur contingent le plus curieux. Ainsi nous avons arton, le pain; lenza, l'eau; cuba, la maison (dans l'argot sicilien); strocca, lil fille de joie (dans scorlum latin); marcone, l'entremetteur; cubi, le lit; crea et criolfa, la viande; gianicchio, le froid; bcnna, l'auberge; bolda, la ferme, ou la l'romageric; pivclla, la fillette; nicolo, non; ruffo, le feu (le rouge); zera, la main; archetlo, le fusil;

du latin ripa. Stuc $=$ part rie vol, de l'allemand Stück. Schness $=$ mufle, groin, museau, de lallemand schnause qui signifie musean, mufle. Roust $i=$ fumbe, perdu, d'arrostire, roustir. Gouipeur, euse = ragabond (Viboce). C'est le mot espagnol guapo, d'oì guappo qui est resté dans le patois napolitain avee le sens de bravache. (V. Archivio, II, 253). 
biella, la hache. Les Françis disent: être chaud, pour se méfier (de cautum); juste, pour voisin; cambriole (1), pour chambre. Ce dernier mot est, selon d'Ascoli, du provengal aneien. L'Espagnol dil milanes pour pistolet, par allusion aux anciennes falbriques de Milan; joyos pour épée, dn nom du glaive que portait le Cid.

Un reste curicux de ces arehaismes est le mol auber pour désigner l'argent; il vient des hauberts du moyen ìge qui étaient souvent faits de ce métal. Citons encore petun, pour tabac, d'un ancien mot americo-espagnol.

Les volenr's anglais, écrit N. Latham, sont les conservateurs, les plus obstinés, des termes anglo-saxons: ils disent encore frow pour jeune fille, muns pour bouche.

Nous avons encore un archaïsme qui rappelle le temps des hiéroglyphes; c'est te mot si curieux de serpent pour désigner l'année. Il faut y joindre di del vecchio (jour du vieux $)=$ samedi $;$ mamma $($ mamelle $)=$ terre; et le parmesan breviario (bréviaire), qui désigne une lettre.

(1) Dans le Supplément au dictionnaire de l'argot et dans les Note de Mayor on trouve pour le français: suader = persucter: du latin suadere, passé en franȩais dans les seuls eomposés persuader, dissuader, et leurs dérives. Répérir = trouver, retrouver: du latin reperire. Bler $=$ aller, pent-être de $\pi \lambda \in \hat{i} v$.

Carreau, est un mot qui appartient à la langne noble et à la pósie, il signifie foudre. L'usage l'a abandomé dans ce sens; mais l'argot l'a conservé en lui donnant une antre signification. Carreau, en argot, désigne un outil de fer qui sert ì ouvrir ou forcer les serrures et qui a la forme de deux Z superposés; c'est à peu-près la forme adoptée dans le moude pour représenter la foudre. Houssette = botte: nous arons en italien uose, de l'ancien houseaux, anjourd'hui inusité. Braies n'est plus employé. L'argot a conservé braillards = caleçons. Carle $=$ argent, de Carolus, monnaie que l'on commença à frapper sous Charles VIII. 
6. - Nature et caractère de l'argol. - Ces archaïsmes doivent paraitre plus surprenants encore, quand on pense à la mobilité, aux variations rapides des mots qui composent l'argot. Pour ma part, dans l'espace de quelques années ì peine, j’ai vu naître et mourir à Turin et à Pavie un nombre considérable d'expressions, p. ex., gra, pour voleur; michino, pour garcon; pila, pour argent; gaffi, pour commissaire; spiga, pour route; stec, pour couteau; gian, pour soldat; piota, pour auberge; scuro, pour avocat; caviglia, pour somme de 100 francs; gamba, pour 1000; busea, pour 50; vecia, pour masturbation.

Il importe de noter la richesse extraordinaire de synonymes servant à désigner certains objets ou certaines parties d'objets qui intéressent spécialement les malfaiteurs; ce sera un moyen de mieux connaitre ces derniers. Ainsi, MM. Congnet et Righini ont trouvé 17 termes différents pour indiquer les gardes ou les carabiniers (bajoun, boutun, maso, pungolist, stravaca-oli), 7 pour indiquer les poches, et 9 pour désigner le crime de sorlomie. (Archivio, II, p. 103).

L'argot français a 44 synonymes pour exprimer l'ivresse, et, en outre, 20 pour rendre l'action de boire, 8 pour désigner le vin; cela fait en tout 72, tandis qu'il y en a sculement 19 pour l'eau et 36 pour l'argent. Les criminels ont besoin de posséder tle bons yeux (et nous avons vu qu'ils ont l'orbite plus développée que le reste des hommes ); aussi les appellent-ils: ardents (1), clairs, mirettes, quinquets. Ils ont une tendance à animaliser, à désigner ce qui touche à l'homme par des mots s'appliquant aux bêtes: ainsi, la peau est pour eux

(1) Le rothwelsch a six synonymes d'odeur; cequi confirme l'acuité olfactive des crimincls. 
du cuir; le bras, un aileron; le visage, un mu/le; la bouche, un bec. Ils employent volontiers les négations, affirment peu: ils diront filou, pour fourbe; avoir du vice, pour aroir de l'esprit. Ils ne diront pas: je suis bien fait, mais je ne suis pas déjeté. Et remarquez que, dans leur bouche, ne pas être méchant équivaut à être un imbécile. En un mot, ils empirent tout (1).

Malgré le nombre des synonymes et des métaphores, malgré l'absence de tout contròle et de tout syndicat, si je puis ainsi parler, malgré la multiplicité des sources d'où il découie, l'argot, qui devrait être une langue tıès-riche, est pauve (Mayor). La raison en est simple: lo travail d'épuration qui, dans une langue, est fait en grande partic par des autorités constituées et reconnues, par les Académiciens, les hommes de lettres, les professeurs, ne s'accomplit ici que par l'usage, par une espèce de sélection entre les divers mots; beaucoup de locutions n'ont qu'une vie éphémère, et, nées d'un caprice, d'une circonstance, meurent avec ceux qui les ont produites.

Comment d'aillenrs, ne serait-il pas paure, quand ceux qui l'emploient ont si peu d'idées, et sont plus riches d'esprit que de raison?

On y troure des expressions nées viables, si l'on peut s'exprimer ainsi, et avec une force de résistance qui s'affermira par l'usage même; mais elles sont en bien

(1) Ainsi sinc = argent monnaye; noyade = baignade; crever $=$ mourir; faire sa crevaison = mourir; limonade de limpré, ou limonade de prince $=$ rin de champagne; cadarre $=$ le corps. Se mettre quelque chose dans le cadarre = manger. - Et fils se dit en argot allemand seckes, $=$ abomination, en langue juive. De Fetzer boucher et $B \cdot$ iefel lettres on a fait Briefel-fetzer ecrivain; Gliederfetzer $=1$ a fille de joie (Glieder $=$ membre viril). 
plus petit nombre que les autres, destinées à un déelin rapide. Quant aux conditions nécessaires pour les faire vivre, je crois qu’il est difficile de les préciser. La concision, la sonorite, un certain air bizarre, semblent devoir être des éléments de durée.

C'est ainsi qu'on explique comment l'argot, en apparence essentiellement variable et changeant, a cependant un fond, un substratum, qui reste et survit aux changements que la mode, les temps, les circonstances, paraissent lui apporter continuellement. Ce substratum est, de sa nature, assez limité; il ne s'augmente et ne se modifie qu'arec la plus grande lenteur. Autour de lui naissent, vivent et meurent des générations entières de mots qui viennent à la file, et śéliminent successivement par l'usage. Lui seul reste debout, et nous le comparerions volontiers à un arbre séculaire, profondément enracinć, et dont les rameaux voient naitre ehaque année de nouvelles feuilles pour remplacer celles qui tombent.

Bealucoup des expressions eitées par nous n'ont pas en elles-mêmes les conditions de durie nécessaires pour contribuer a former le fond durable de l'argot: clles sont par conséquent destinées à périr. Mais peu importe; elles ont servi à nous faire connaitre les lois qui président à la formation de cette langue étrange. L'évolution, dans les choses de ce genre, est parfois très-rapide. On a vu, par exemple, en France, dans l'espace de quelques années, naitre et mourir la mode des désinences en zar et en rama. Maintenant, sauf quelques exceptions conservées par l'usage, l'argot les a abandonnées. Et, dans peu d'années, il n'en resterait probablement aucune trace, si les lexicographes n'avaient eu soin de les mentionner. 
7. - Diffusion. - Un des caractères les plus curieux des argots est leur extrême diffusion. Tandis que clatque région de l'Italie a son dialecte propre, et qu'il serait impossible à un calabrais de eomprendre un lombard, les voleurs de Calabre ont le même lexique que ceux de Lombardie. Dans les deux pays, on appelle chiaro le vin, arton te pain, berta la poche, taschi des figues, lima la chemise, lenza l'eau, crea la viande. L'argot de Marseille n'est pas autre que celui de Paris.

Ce fait, qui s'explique facilement pour ce qui concerne l'Allemagne et la France, se comprend plus difficilement pour I'Italie, surtout pour l'Italie d'il y a quelques amnées. Alors, en effet, les barrières politiques, les nombreuses douanes qui la divisaient auraient dù opposer un obstacle sérieux aux malfaiteurs; loin de lá, elles ne les gênèrent en rien.

L'analogie parait plus étonnante encore quand on la voit s'étendre à des peuples de race tout-i-fait différente (l'italien et l'allemand appellent également tick une montre; la neige est pour l'un bianchina, pour l'autre blanker); si bien que Borrow en est venu à soupçonner pour tous les argots une même origine. Mais il est facile d'expliquer le fait par l'analogie des situations, du moins en ce qui concerne les nombreuses similitudes d'idées. En effet, l'analogie des idées est complète entre nos argots et celui que parlent les Tughs dans l'Inde; or, il est évident qu'entre ces hommes et les brigands d'Europe il n'existe aucun rapport. Quant aux ressemblances phonétiques (bien plus rares, d'ailleurs), elles sont favorisées par l'inconstance des criminels qui, soit pour échapper à la justice, soit pour frapper à l'improviste leurs victimes, soit pour obéir à l'instinct impérieux du vagabondage, qui les pousse tout d'abord 
à quitter leur demeure, changent continuellement de résidence, et importent les expressions d'un pays dans un autre. Le rothwelsch appelle le vagabond strohmer, c'est-à-dire eau courante.

8. - Genèse des argots. - Tout le monde explique l'origine de l'argot par la nécessité oủ se sont trouvés les malfaiteurs d'échapper aux recherches de la police. Il est certain que telle en a été la cause principale, et que telle est l'origine, en particulier, de ces transpositions de mots que nous rencontrons en si grand nombre, des substitutions de noms à des pronoms, comme mamma pour moi, otto pour oui. Les Sardes donnent à l'argot le nom de cobertanza. - Quand Latude préparait, avee son compagnon, les échelles de corde qui devaient servir à son évasion, tous les deux araient convenu, pour dérouter les geòliers, de désigner chaque objet par une expression métaphorique (1). Mais n'y at-il pas en d’autres causes? Il suffrait, pour s'édifier sur ce sujet, de voir l'argot usité en poésie, là où il n'est pas nécessaire d'échapper à l'attention de la foule, puisque l'on cherche au contraire à la séduire par le chant; il suffirait de le voir employé par les policiers cux-mêmes, par les malfaiteur's quand ils sont dans leur propre lamilie; il suffirait de remarquer enfin que, si l'unique but élait d'échapper aux poursuites,

(1) Il appelait le fer Tubalcain; le fil, Arianne; un eonteau, Tutu. Voila done eneore des termes étrangers, des onomatopées, dans un lexique de 20 mots. - Les ehefs des assassins de Ravenne appelaient plumes $\dot{a}$ ćcrire les fusils conservès dans leur auberge, et maîtres d'ecole leurs sieaires. - Settembrini, dans les prisons de Naples, parlait à ses compagnons un argot formé de mots grees on allemands; il disait: latomies pour prison; graf pour détonation; ou bien encore il empruntait ses termes à un roman de Walter Seott, que tous avaient lit. 
on n'aurait qu'à changer complètement les mots, it les transformer en énigmes, comme dit fort bien M. Pott, par l'intercalation de syllabes conventionnelles. Or', e'est lia le système le plus rarement employé par les malfaiteurs; il n'est gnère suivi que par ceux qui cherchent dans l'argot un divertissement.

C'est que l'argot, s'il n'est pas le produit d'une gínération spontanée, est en tout semblable aux langues et aux dialectes par son organisme et sa nature. Langues et dialectes se sont faits et defaits par eux-mèmes, selon les lieux, les climats, les coutumes, les contacts nouveaux. Il en est de mème des argots, qui ne sont pas, comme on pourrait le croire, un phénomène exceptionnel, mais bien une coutume universellement répandue. Toutes les professions, jusqu'à un certain point, ont le leur. En ce cas, le mot technique sapplique à une opération de toute autre nature. Un médecin vous dira, par exemple, que l'amour est un vice cardiaque; un chimiste, que son amour est à 40 degrés. Allons plus loin, et constatons que chaque famille a son argot, formé par les accidents qui l'ont le plus vivement frappée et ont donné lieu pour elle à des associations d'idées particulières. Nous en créons un nous-mêmes pour causer avec les enfants. Dans certaines familles, tata désigne la tante; en d'autres, ce mot a le sens de sœur ou petite fille.

9. - Argots des corporations. - La tendance à formuler un argot qui leur soit propre se manifeste chez tous les individus de mème métier, principalement quand le métier est louche. Elle apparaît plus fréquemment encore chez les hommes contraints à une vie nomade ou à un séjour temporaire dans un licu déterminé, sur- 
tout s'ils sont soumis à quelque sujétion en face d'un public auquel ils ne se mêlent pas. Ce langage spécial leur sert à affirmer leur communauté, à se dérober à la surveillance d'autrui. C'est ainsi que j'ai ru, dans une même vallée, des ramoneurs, des vignerons, des valets de chambre, des badigeonneurs, ayant clacun leur argot (1); et à côté, des maçons et des chaudronniers en parlaient un autre, qui se rapprochait de celui des brigands, ct par bien des points se confondait arec lui. M. Avé-Lallemant signale l'argol des marchands de comestibles, celui des prostituées, des étudiants en médecine, des collégiens de Winchester, des saltimbanques, qui s'appliquent à trouver des rimes; il constate la même chose, à Vienne, chez les garçons d'hôtel (qui emploient, en les estropiant, le français et l'anglais), les cochers de fiacre, los bâtcliers, les chasseurs. En Italic, e'est par douzaines, que l'on trouve des écuyers ayant une langue proprc.

Avec quelle force doivent donc se sentir poussés à formuler leurs idées dans un langage spécial, des individus qui ont des habitudes, des instincts si différents des autres, et qui ont tant de monde à craindre, tant de monde à tromper!

Ajoutez que celte engeance se réunit toujours dans les mêmes centres, galères, lupanars, tavernes, et n'a de relations qu'avec ceux qui manifestent des tendances analogues aux sicnnes; qu'avec ces dernicrs, elle fraternise arec une imprévoyance et une facilité extraordinaires, trouvant dans l'argot, comme l'a si bien établi Vidocq, un moyen de reconnaissance, un mot d'ordre.

(1) Dans l'Indre, les fondeurs désignent la machine sous le nom de becane, (Daudet JACK). 
- Si ces brigands n'araient pas l'argot, le besoin de sépancher beuyamment, qui est un de leurs caractères, les exposerait trop vite, soit anx investigations de la police, soit à la déliance des lonnètes gens qu'ils exploitent.

10. - Gaprice. - Faisons la part aussi de la mobilité extrème de leur esprit et de leurs sensations. Que, dans leurs scenes d'orgie, un mot nouvean, une phrase extraordinaire, absurde mème, mais vive, pirfuante ou bizarre, vienne i frapper leurs oreilles, ils s'en emparent aussitòt et lui font les honneurs de leur lexique. Comme on roit les pédants recueillir amoureusement les curiosités grammaticales, les expressions baroques et qui s'éloignent le plus du langage ordinaire, quand ils les rencontrent dans un écrivain du xiv siècle; ainsi les malfaiteurs amassent avec soin les nots de quelque mauvais étudiant perdu dans leur milicu (le cas n'est pas rare, it Paris, dans le quartice latin), s'efforcent de les mettre en circulation, et s'en parent comme d'un riche butin. - Ils sont poussés à faire ainsi par leur esprit épigrammatique, tourné à l'ironie, qui se complait dans ses trouvailles, à condition quelles soient étranges, obscènes, cxtravagantes, et chatonillent ec goût d'homophonies, de grossiers calembourg's qui est si cher aux imbéciles el aux fous(1); (V. Genio e follia, p. 122).

(1) Le vénitien appelle emigrati (émigrés) les masques, parce que les émigrés ont coutume de se eacher. - On explique de même certaines locutions qui sont d'afireuses satires, telles que, dans l'argot lombard: beccaria, hôpital; trichina, médecin; dans le parmesan eette belle périphrase: patre dei mal vesti (père des mal vêtus), le soleil.

L'argot français est riche en plaisanteries de ec genre: Paradouse $=$ paradis, où dis (dix $=10$ ) est ehangé en douse $(=12)$; saucisse $=$ moi. Le pronom moi, stuivi de l'adverbe aussi, produit un hiatus 
La meilleure preuve nous en a été fournie par la Moralité de la complainte criminelle de Clément (p. 385). On dira peut-être que nous insistons beaucoup sur ces penchants. Mais c'est que nous y voyons un des carac-

que les ignorants évitent en disant moi-s-cussi; de moi-s-aussi à moi saucisse il n'y a pas loin pour qui ne redoute pas la trivialité. Crottard = trottoir, partie de la rue où l'on est le mieux garanti contre la bone (crotte); biser $=$ baiser $($ verbe): allusion phonétique appliquée à $u$ sens obseène.

Faire bîller le colas $=$ conper la gorge: trarestissement plonétique du mot col = gorge en colas, nom d'homme, et allusion (bîller) ¿ l'ouverture faite par le tranchant du fer' blanchir du foie $=$ avoi ${ }^{*}$ dessein de rompre au de tratir: jeu de mots sur foie et foi: le mot blanchir continue l'allusion an foie, il est pour devenir exsangue; perareau $=$ pedro $=$ pédéro $=$ pédéraste $;$ arrondissement (rhef lieu $\left.d^{\circ}\right)$ = femme enceinte; baquet de science = gogueneau, réeipient destine ¿ reeevoir les déjections et autres ordures: en prononçant le mot science comme si, an lien de $s c$, il $y$ avait $c h$, on comprendra l'allusion dígoûtante; Don Carlos = entreteneur: de carle $=e ́ c u$, en même temps qu'il $y$ a une allusion au prétendant au trône d'Espagne; riffaudante = famme; rif en argot = feu: le maseulin riffaudont a le sens de eigare et s'explique par un jen de mots: rif aus dents; herbe sainte = absinthe: étre dans l'infanterie = etre enceinte (d'enfanter): moulin à vent $=$ derrièe; pape $=$ verre de rhum: rhum dans la prononciation française a le son de Rome; Principauté de Galles ou simplement principauté $=$ gale , artilleur $=$ ivrogne, ear tous deux manient le canon (canon = verre, canon = piece d'artillerie); soufrante $=$ allumette; suif = assemblage de grecs: de grecs est venu grice: de grice, graisse, et de graisse, saif: d'où suiffard = grec; symbole = crídit $:$ de crédit on a fait credo, de credo, symbôle des apôtres, et simplement symbôle; céronique = lanterne: plaisanterie sur le mot verre; vert de gris $=$ absinthe; plaisanterie sur verre et vert, et allusion à la eouleur (vert) de l'absinthe et aux qualités nuisibles qu'on lui attribue; vesouiller (qui devrait peut-être s'éerire cessouiller $)=$ gazouiller $=$ puer $:$ allusion obseène.

Cassolette = vase de nuit, et aussi fromage; craie d'Auverpin = (litt.) craie d'Auvergnat = blanc ae charbonnier = charbon; ambassadeur = cordonnier, souteneur; alliance = poucettes: allusion $\mathbf{a}$ l'anneau du mariage; armoire = bosse; mere abbesse = maitresse d'une 
tères les plus saillants de la physionomie intellectuelle de ces hommes; - nous y trouvons une confirmation des dictons populaires qui nous mettent en garde contre ces éternels plaisantins, et déclarent qu'on voit toujours le rire s'épanouir sur les lèvres des imbéciles.

Les exemples précédents ont montré, dans ces travestissements phonéliques, une tendance presque conlinuelle a l'ironie et à la plaisanteric grossière. Mais l'ironic se manifeste encore dans des rapports d'idées qui n'impliquent ni jeux de mots, ni homophonies, ni assonnances. Cette propension à voir toujours dans les choses le côté ridicule est une conséquence d'une humeur tout a la fois gaie el bizarre, que nous avons remarquée chez les paresseux et les ragabonds, classe dans laquelle se recrutent en si grand nombre les malfaiteurs, et rui est la véritable académie de l'argot. Voici quelques exemples d'allusions ironiques où ce n'est pas l'analogie du son, mais la relation des idées, qui a guidé l'esprit.

maison de tolérance; queue de porle = sabre ale grosse cavalerie; pastille, pour pastille du sirail = pet ; amadouage = mariage. Amadower, en argot signifie segrimer pour tromper, amadouage equivandrait done à duperie; boite d'èchantillons = tonneau de vidange: allusion aux nombrenses provenances contenues dans ce ricipient; faire du beefsteak = battre: allusion à l'habitude qu'ont les cuisiniers de frapper la viande pour l'amollir'; boîte à biscuits = pistolet: la cartouche est le fiscuit que l'on doit manger; bombonnière, comme boite d'échantillons, vent dire boite anx ordures: bouquet $=$ cadarre: allusion à l'odeur, que rappelle un mot de Charles IV; bourreboyaux = gargotte, car ce qu'on y mange remplit l'estomac (bourre) bien plus qu'il ne nonrrit; bourrecoquins $=$ haricots: les havicots et les fèves sont l'aliment principal des galériens, des prisonniers, etc.; calèche du préfet $=$ voiture cellulaire: canapé $=$ lieu public fréquenté par les pídérastes: $\mathbf{c}$ 'est une allusion aux parapets qui bordent les cours d'eau, aux bancs de certains boulevards où se réunissent les gens de cette espece; demoiselle du Pont-Neuf = prostituee: tous y penvent passer; chevalie ${ }^{\circ}$ de lagrippe ou de la grippe $=$ voleur; sachète $=$ chaussettes . 
L'ironie prédomine dans les périphrases suivantes: charmer les puces pour être ivre à griser ses puces; avaler le luron = communier; marcher dans les souliers d'un mort = avoir hérité; badigeonner la femme au puits = mentir.

L'antiphrase fournit à l'argot un certain nombre d'expressions qui pourraient être rangées dans la catégorie précédente. En d'autres, il est rrai, on ne troure pas d'allusions ironiques, mais on voit briller la tendance à s'exprimer autrement que le reste des hommes, peutêtre pour suivre la mode, peut-ètre seulement par caprice.

Déguiser, qui, dans le langage ordinaire, signifie cacher, travestir, recoit de l'argot le sens contraire de signaler, reconnâttre; avoir à la manque $=$ ne point avoir; bonir, qui signifie parler, a aussi le sens de se taire; mince $=$ rien. Il exprime aussi lidée contraire: mince de confort! = quel confort! - D'autre part, rien est parfois affirmatif: il est rien chaud, pent rouloir dire: il est ardent, ił brûle! micl (c'est un) pent signifier une chose excellente, désirable, mais aussi, et bien plus souvent, le contraire; paumer signifie perdre et en mème temps prendre; sublime = travailleur paresseux, violent, ivrogne; sublimé (un) $=$ homme ivre mort; se sublimer $=$ lomber dans l'avilissement.

L'euphémisme fournit cependant à la langue des criminels un certain nombre dexpressions. Mlais sourent, sinon toujours, ces expressions ont une teinte d'ironie. De toute façon, l'euphémisme et l'antiphrase rappellent cette coutume des Anciens d'appeler Euménides (Eúneviঠes, s'eúuvew - favorables, lienveillantes) les Furies; et Parce, les Parques, ideo quod non parcunt.

Apaiser $=$ assassiner: c'est une expression de Lacenaire; appuyer $=$ avoir des relations intimes; avaler $s a$ 
fourchette = mourir $;$ calancher = mourir; c'est un augmentatif de caler qui, en argot, veut dire ne rien faire: il signifie done se reposer pour toujours; épouser la veuve = être guillotiné. La veuve fut d'abord la potence; c'est maintenant la guillotine: veuve, parce qu'elle perd son homme; mettre à l'ombre = tuer; négociant $=$ souteneur; paletol = cercueil; boire dans la grande tasse $=$ se noyer; sonner = tuer, en saisissant la victime par les oreilles et lui frappant la tète contre le pavé; passer à la lunette = être guillotiné; figurant de la morgue = suicide; garde-manger = water-closet; fumer une souche = être inhumé; mannequin de macchabées = (littéralement) panier de morts = corbillard; mannequin de trimballeurs de refroidis = (littéralement) panier des croquemorts = corbillard; rebouis = cadavre: de rebou $\dot{=}=$ objet remis à neuf; d'où rebouiser = remeltre à neuf $=$ tuer; manger du plomb = être tué d'un coup de feu; séchoir = cimetière; serrer la vis $=$ le quiqui $=$ le cou étrangler: il peut devenir réfléchi et signifier se pendre; tappe = marque au fer rouge: les enfants jouent it la tape (ils se poursuivent et celui qui, étant pris, a reçu la tape sur les épaules, doit à son tour poursuivre les autres). Or, c’était également sur les épaules que s'infligeait la marque.

Il se pourrait aussi que certaines entorses, si je puis ainsi parler, ou encore la création de certains mots, fussent, comme les tortures du tatouage, le résultat d'un désir de nouveauté, d'un amusement destiné à charmer l'oisiveté des longues détentions.

11. - Contact. - Une autre part, et une part notable, doit revenir au contact que les criminels ont forcément avec des personnes étrangères à leur contrée 
et à leur nation, par suite de leur vie misérable et presque toujours nomade. Ainsi s'explique, d'un côté, le grand nombre de termes hébräques, sanscrits, dont s'émaillent les argots anglais et tudesque; de l'autre, l'unité de l'argot italien, que n'a pu briser la diversité des dialectes.

La chose est d'autant plus probable, que les malfaiteur's, plus souvent encore que les soldats, sont transportés hors de leur province, par une excellente mesure de police.

12. - Tradition. - L'influence de la tradition, lé. guée de siècle en siècle, est suffisamment démontrée par les expressions curieuses que l'argot tient des temps anciens, comme arton, lenza, etc., et les allusions à des faits historiques presque oubliés, que nous avons citées plus haut (1).

Les trois locutions passer en lunette - faire un trou à la lune - montrer le cul, employées encore par l'argot comme synonymes de faire faillite, sont empruntées à

(1) Coup de Raguse = défection. C'est une allusion à la trahison (contestie d'ailleurs par plusienrs historiens) de Marmont, duc de Raguse; Duc de Guiche = guichetier: ici l'allusion est purement plonétique. Plusieurs Guiche sont restés dans l'histoire. 1ls appartiennent à la famille de Grammont; aller à la cour des aides = f̂tre adultère: c'est nne allusion à une aneienne coutume juridique, bâton blanc= commissaive de police. A une certaine époque, le sergent d'armes avait pour insigne une baguette dont il touehait l'épaule de l'homme qu'il arrêtait; Haterloo = dewière.

Amiral signifie couteau et préfet cuillère, en souvenir de l'amiral Jurien de la Gravière (encore vivant) qui, étant préfet maritime de Rochefort, fit rendre aux forçats de ce bagne les couteatux et les cuillères qu'on leur avait enlevés; maison bancal = tripot, ou, en général, maison de mauvaise renommée. L'origine de cette expression se rattache à un crime qui fit beaucoup de bruit souts la Restauration. Il en est de 
l'histoire. Le chattiment subi par les faillis consista longtemps à montrer publiquement leur partie postérieure et à en frapper la terre. A Florence, dans le Vieux Narché, on a conservé jusqu'à ces dernières années (et peut-ètre existe-(-eile encore) la pierre sur laquelle venaient s'asseoir les faillis et que le peuple appelait pietra de' falliti ou pietra dei bindoli (trompeurs). Quant it lunette, trou à la lune, ce sont des allusions communes et triviales à la partie du corps que l'on montrait.

Aux trois locutions précédentes, la tradition en ajoute une quatrième: Hirondelle de grève, pour gendarme. La grève fut longtemps la place des exécutions.

Cette influence de la tradition est confirmée par le fait que l'argot, tel qu'il est aujourd'hui composé, remonte à une époque très-reculée; on en tronve des traces en Allemagne dès l'an 1350; (Avé-Laldemaxt, l. c.) Le dietionnaire d'argot intitulé: Modo novo da intender la lingua zerga, imprimé à Venise en 1549, nous montre que presque tous les termes alor's imployés sont encore

même de eette autre: aller che: Fuldès, de fader qui en afgot signifie diviser, faire les portions, et qu'ou rapproehe plaisamment de Faldes on Fualdès, personnage famenx en France dans les Annales ducrime.Bréguet = montre, est tiré du nom d'un fabrieant célèbre. Bíguilles = bijoux. L'étymologie doit être la même que pour le mot précédent. Les bréguilles aurout d'abord été les breloques appendues à la chaine et que le voleur emporte avee la montre. - Collignon = marais cocher. C’était un eoeher qui arait tué son elient (Mémoires de II. CLACDE); Desfoux = casquette it trois ponts, marque distinetive des souteneurs. Le nom a été emprunté d'un ehapelier dont le magasin avoisine le Pont Nenf; fermer mallard = fermer la panpière, dormir. Le sieur IIaillard a inventé un système de fermeture pou les boutiques, d'après lequel les jambes des portes, très-mobiles, s'èlèvent et s'abaissent eomme Iles paupières; le grand Jablo $=$ le soleil. Dn nom de Jablokoff, inventeur des premières lampes éleetriques expérimentées publiquement à Paris; marmiton de Domange = vidangeni. Domange est le nom d'un entrepreneur de vidanges à Paris. 
cn usage, comme: maggio, Dieur perpelua, l'âme; conovello, l'ail ; cuntare, parler; dragon, le docteur.

Comment les traditions et le langage de ces misérables, qui n'ont pas de famille, penvent-ils se transmettre avec une parcille fidélité? C'est assez difficile à comprendre. Mais un fait analogue, et d'une évidence plus grande encore, nous a été offert par le tatouage. Nous le constaterons encore dans certains signes hiéroglyphiques appelés zink, dont se servent les criminels pour se donner des rendez-vous, on pour indiquer les points à frapper, et qui leur viennent d'une époque très-ancienne, antérieure peut-être à la déconverte de l'écriture; (Avé-Laleemant, l. c.; Scinemin, Die Pralit. Criminal Polizei, Erlangen, 1842).

Ne voyons-nous pas d'ailleurs les soldats, les marins, ces gens qui n'ont pas de famille et souvent nême pas de patrie, conserver encore les usages et les traditions de temps fort reculés?

13. - Alavisme. - Latavisme y contribue plus que toute autre chose. Ils parlent diversement, parcequ'ils ne sentent pas de la mème manière; ils parlent en sauvages, parceru'ils sont de véritables sauvages au milieu de la brillante civilisation européenne. Comme les sauvages, ils emploient fréquemment l'onomatopée, l'automatisne; ils personnifient les choses abstraites. On me permettra de citer ici les belles paroles de M. Biondelli: "Comment se fait-il que des hommes de races différentes, séparés par des barrières politiques et par des barrières naturelles, aient pu, dans leurs secrets conciliabules, se créer une mème vie, et former secrètement plusieurs langues qui, diverses quant aux désinences et aux racines, sont pourtant identiques dans 
leur essence? - L'homme grossier qui, privé de toute éducation morale, abandonné à ses penchants dépravés, se forme une langue nouvelle, diffère peu de l'houme sauvage qui fait les premiers efforts pour s'organiser en société. - Les langues primitives sont pleines d'onomatopées: les noms des animaux y sont exprimés dans un style figuré, le même que celui de l'argot; ainsi, pour ne citer qu'un exemple, les bohémiens appellent le canard " l'animal au large bee ». - J'ajonterai (mais pentêtre suis-je trop hardi) qu'enfin de compte le détomrnement par réduction étymologique et celui qui résulte du renversement des syllabes sont maturels dans toutes les langues; que c'est ainsi, par exemple, que de wolf on a fait loup; de teren, tener; qu'inchiostro (encre) est devenu vinchiostro. - Entin que, deux sens étymologiques en étant arrivés à se confondre, on a pu faire capello (cheveu) de caput et de pilus.

Aussi, quand je vois dans l'argot l'expression mammella pour terre, qui se rapporte à la religion de Cybẻle, et celle de serpe pour année, qui nous rappelle les hiéroglyphes d'Egypte, je serais tenté de les rattacher moins à une recherche érudite qu'à un retour psychologique vers l’antiquité.

14. - Prostitution. - Il paraît que les prostituées, qui ont tant d'analogie avec les criminels, nont cependant pas d'argot particulier; mais il n'en était pas de même autrefois, au temps de Villon et de Rabelais par exemple.

Ce que l'on appelait la langue érotique du xvi siècle (Verba erotica, Stanislas de l'Aulnaye, 1820, add. à Rabelais) était en r'éalité l'argot des prostituées: l'acte vénérien y avait 300 synonymes, les parties sexuelles 
400, la prostituéc elle-même 103; (Dufoun, Histoire de la prostitution, vol. Iv). Il en était encore ainsi dans la Rome antique, où les débauchés des deux sexes avaient, si je puis m'exprimer de la sorte, un argot de gestes; où, par exemple, pour exprimer l'idée de sodomic, ils élevaient le doigt du milieu et fermaient les autres tout autour; (SÉNÈQue, ép. 52). On trouve encore d'ailleurs un reste d'argot dans les lupanars: pour' s'en convaincre, il suffit de se rappeler le nombre considérable de mots qui désignent l'acte du coït. (V. p. 469). - A Paris, la haute prostitution elle-même parle une espèce d'argol. Les cocoltes appellent Machinscoff le premier venu; Père Douillard ou Bobinskoff, leur protecteur; Beguinskoff, leur caprice du moment; Bon, l'agent des mœurs; Breme, l'autorisation de se prostituer, la carte à jouer, la mise en surveillance; Panuche, toute femme appartenant à la bourgeosic, la femme du monde; Pisteur, l'individu qui suit les dames.

15. - La folic. - Les fous n'ont certainement pas d'argot; mais ils créent fréquemment des mots par homophonie, inventent des expressions nouvelles sans cause déterminée: c'est la spécialité des paranoïques.

Qu'on me permette de citer ici quelques notes d'un observateur qui, bien qu'il soit étranger à la partie, a vu pourtant bien plus loin que beaucoup d'aliénistes.

Le langage des fous présente souvent une suite d'idées sans liaison apparente. Est-ce à dire que cette liaison n'existe pas? N'en croyez rien. Le fou, servi par une imagination ardente, voit entre ses idées des rapports qui nous échappent, peut-être parcequ'ils sont trop légers, trop fugitifs, trop éloignés. Je me rappelle avoir connu en France un jeune homme dont l'esprit 
était dérangé, à qui sa famille avait donné pour grouverneur et pour surveillant un abbé nommé Tardy. Cel abbé, qu'il poursuivait de sa haine, était d'ailleurs un cxcellent homme, en tout digne de respect. Depuis quelque temps, le jeune homme donnait a son précepteur le nom de Vitiatus; on ne pouvait l'en empêcher, on ne pouvait non plus comprendre le rapport qui existait pour lui entre le mot latin et le personnage austère ainsi affublé de cette épithète injurieuse. Plus tard seulement, on parvint à découvrir que, dans un vocabulaire latin-français dont se servait le frère du jeune homme, le mot vilialus était traduit en français par abâtardi. C'est ce qui l'avait frappé: Vitialus était la traduction d'une homophonie: $\dot{a}$ bas Tardy!

$\mathrm{Ni}$ le criminel, ni la prostituéc, ne doivent être considérés comme des fous pour cela seul que l'un se livre au crime et l'autre se plonge dans la débauche; mais ils n'en ont pas moins en eux quelque chose du fou. A défaut d'autre point de contact, ils y touchent, celuilà par son imagination déréglée, celle-ci par sa sotte irritabilité, tous les deux par leur vanité exubérante, a laquelle on pourrait appliquer la célèbre expression de II. Taine: hypertrophie du moi. Leur langage en est une preuve manifeste, avec son abondance de tropes, ses métaphores hardies, ses homophonies sans nombre, ses jeux de mots, ses calembourgs, son lyrisme d'idées qui déroute un froid observateur. La phrase avoir les idées décousues, euphémisme vulgairement employé pour indiquer l'état mental du fou, peut sourent s'appliquer à point nommé à l'homme versé dans le crime (1).

(1) Mayor. V. Archivio di Psichiatria, 4s année, fasc. 1, p. 58. 


\section{CIIAPITRE X}

Hieroglyphes et écritures des criminels.

M. Avé-Lallemant avait déjà signalé certains signes hiéroglyphiques (zink) en usage chez les criminels altemands. (Ueber die Gaunerthum, 1858).
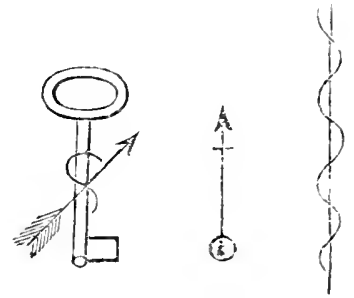

Fig. 1.

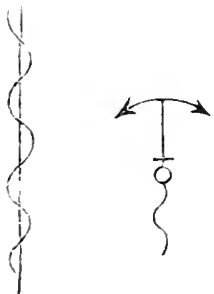

Fig. 4 .
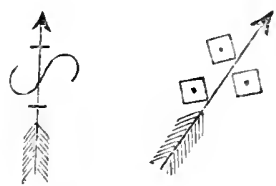

Ainsi la figure 1, c'est le hiéroglyphe du vol. Une ligne horizontale traversée par une spirale (fig. 3) indique le vol accompli, et aussi une ancre (fig. 4) dont le calıle ou la chaine signale la direction prise par le. voleur en s'évadant.

La figure 5 c'est le signe du mendiant.

La figure 2 signifie: "Je crains d'être emprisonné ».

La figure 6 "Joueur aux dés pipés ".

An Angleterre on frouva dans l'année 1849 une mappe (Cadger Irap) destinée aux mendiants dans laquelle, à côté du plan des villages et des fermes de la contrée, avec les signes suivants étaient signalées les vertus et les défauts des involontaires clients. 
K Mauvais: trop pauvres.

$\hat{v}$ Très-bonnes gents.

Z Méfie-toi du chien.
C Narche par ici.

$\oplus$ Gens tris-religieux.

(-) Un mois de prison l'altend.

Dans la haute Italie, après de longues recherches dans plus de 2000 inscriptions de malfaiteurs, je n'ai trouve en usage que trois de ces signes:

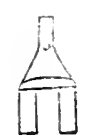

Fig. 7.

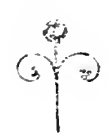

Fig. 8.

Le premier (fig. 7), pour indiquer le vol à la tire, est une allusion au jargon forcolina (fourchette), d'où ensuite, par apocope forlin, coupeur de bourses.

La figure 8 est le signe du voleur. - Un troisième est un fleuret traversé par une spirale pour signifier un vol.

A Xaples et en Sicile, où les associations des malfaiteurs sont bien plus enracinés, j’ai trouvé un grand nombre de vrais hieroglyphes degraphiques.

Ainsi les prostituées on les désigne par un sabot, ou par une souris, allusion à la grande abondance de tous les deux dans les bas caves de Naples.

Le poison est indiqué par un serpent; la prison par une cage; le brigand par une ceinture avec poignard; l'escroquerie par une carte à jouer.

Un chat pendu signifie un vol sûr; un drapeau a trois couleurs le Procureur du Roi; un fer à cheval le médecin (allusion, hélas, bien peu honorable au maréchal ferrant); un gardien-chef est représenté par une tête avec toute la barbe; un sous-chef par la moitié inférieure du visag̊; un gardien par la moitié supérieure. 
Un vol en campagne on l'indique avec une grappe de raisin; un vol heureux avec une étoile ou une rose; un vol qualifé par des ciseaux; un rol en général par une elé, ainsi qu'en allemand; l'appropriation illicite par un poing.

On pose le question "Combien de mois ou d'années tu as attrapé » avec une oreille; et la réponse est faite par un nombre de petits cereles on boucles accrochées ¿ l'oreille même, pour les mois, mais s'il s'agit d'années, par un carré au milieu du quel on inscrit le nombre, ou encore par une casquette (beretta), qui, en argot, est synonime d'annèe.

La ville on l'indique par une cloche; to revolver are: une souriciere; le marchand de vin avee un petit buisson; un juge avec un scorpion; la liberté avec un coq; le $n^{\circ} 5$ avec une main; le $100=$ une jambe; le $50=$ la moitié d'une jambe.

De même que pour largot, beaucoup de ces signes changent de contrée en contrée; ainsi l'œil signifje mouchard dans l'Italie centrale, et pouvoir dans le midi et cela par allusion à la puissance fascinatrice du mauvais oeil. L'évasion, tantôt on l'indique avec un oiseau, tantòt avec un cheval, tantôt avec un revolver en décharge.

Ces hiéroglyphes sont doublement atavistiques; car bien des fois, (comme l'arlon, le cuba de l'argot) ils reproduisent des signes en usage chez des peuples anciens (1); et tonjours ils ont le point de départ dans le

(1) Dans le Moyen-Age les savants usaient le grimoive, une vaie écriture hiéroglyphique, on le poison siguifiait la mer; la masque = la comédie, etc. (Poleus. Introd. a la lecture de $l^{\prime} \mathrm{Hy}$ pnerotomachie, 1884, Paris). 
penchant des sauvages ì peindre (grafein) lit pensée avec les figures, qui se sont transformées, peu ì peu, en lettres dans les peuples plus modernes.

2. - Ecriture. - Nous attachons d'ordinaire peu d'importance et de valeur à ce qui frappe trop souvent nos regards; aussi, nombre de gens estimeront-ils tout d'abord bien futile et même bizarre l'idée que l'écriture d'un homme puisse faire quelque lueur sur sa condition morale. Néanmoins, pour revenir de ce jugement, il ne sera pas nécessaire de lire les nombreux ouvrages publiés aujourd'hui sur la matic̀re, tels que ceux de Bovary, Graphologie, 1876; Adolpie Heuze, Chirogrammalomanzia, Leipzig, 1862; Desbarolles, Les mysteres de l'écriture, 1872; il suffra de considérer que les gestes d'un individu, sa voix, sa manière de prononcer, sa démarche, tous pliénomènes dus à l'action de certains muscles, donnent souvent des indications utiles sur l'état de son àme. Et pourtant ces mouvements sont instantanés; ils s'effacent aussitôt après avoir été produits; landis qu'il s'agit ici des effets d'un mouvement qui peut rester fixé pendant de longs siècles après l'instant oủ il s'est manifesté.

Il est rrai: que, jusquà ce jour, les études de cette espèce ont eu pour bût la satisfaction d'ume curiosité puérile, plutòt qu'un éclaircissement scientifique: et que, même chez les 'grares auteurs que je viens de citer, les recherches sérieuses, loin d'ètre contenues dans une juste mesure, se trouvent mêlées à de telles frivolités, à de telles folies, sous prétexte de phrénologie, de chiromancie, etc., qu'il ya de quoi tuer la foi, même la 
plus robuste, en ce qui touche les meilleures parties de leurs livres (I).

Pour ce qui est de l'écriture des criminels, on peut, à bon droit, s'étonner de voir tous ceux qui, avee une exagération coupable, prétendent tirer le diagnostic d'un criminel de son écriture seule, n'en apporter ensuite comme preuve à l'appui qu'un exemple ou deux, tout au plus. Ainsi, malgré l'aide bienveillante du savant II. Gorresio, je nai pu, dans tous les ouvrages de ces graphologues, mettre la main que sur trois signatures de crimincls célèbres.

Si je résume les études faites sur mes autographes, (que je dois à l'obligeance de MM. Alfred Maury, directeur des Archives de France, de Muoni, de Beltrani-Scalia) dont le nombre s'élève à 520 , je crois pouvoir les diviser en deux groupes bien distincts. (Ie ne tiens pas compte, naturellement, de ces individus à peu près illettrés qui forment pourtant la plus grande masse des brigands fameux, et dont lécriture est tout-à-fait enfantine).

Le premier groupe est constitué par les homicides, les voleurs de grand chemin, les brigands. La plus grande partie d'entre eux est caractérisée par un allongement des lettres, parceque les gens du métier appellent l'écriture gladiolée, e'est-ì-dire la forme plus curviligne et en même temps plus saillante du prolongement des lettres, soit en haut, soit en bas. Chez un bon nombre, la barre du $t$ est forte on prolongée, comme on le remarque généralement pour les gens de guerre et les personnes énergirques; chez quelques autres, les lettres forment avec lemrs traits des angles

(1) Je fais exception pour un article qui a paru dans ces jours dang la Revue Philosonglique, novembre, 1885. 
aigüs. Chez tous, la signature est orme d'mue fulantiti: de petits traits et d'arabesques qui la distinguent inst-

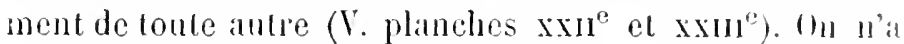
pour sen convaincre, qü̈ comparer les signafures dr Desrues ( $\left.n^{\circ} 46\right)$, enpoisonneur el faussaire, de l'assassin Francesconi et de Carrjer (63), do Vidocy (48), d'Mllerti (76). On y voit, comme dans celles de certains tyrans Galías, p. ex., Philippe Il, Finnèse, qu'ils ont une haute idée de leur personnalite, et quils sont doués d'une énergic pell commune.

Beaucoup présentent, pour la mème causc, un allongement des lettres: 1, 2, 3, 104, 43, 39, 13, 64, 6.3.

Sur 98 assassins et roleurs de grand chemin, 52 prisentent ces caractères, qui se retrourent arec une uniformité remarquable chez tous les brigands ( $\mathrm{T}$. tab. xxis ${ }^{\mathrm{e}}$, $\left.n^{\circ} 8,9,10,11,12,19,14,16,21\right)$. J'ai lait entrer dans ce tableau les hommes d'Etat connus pour leur cruauté ( $0^{\circ} 81,84,85,69,87,79$ ). Quelques-uns, mais ils sont en bien petit nombre $\left(n^{\circ} 53\right)$, terminent clacun de leurs mots par une espèce de crochet. Le ype do ce genre me paraìt être fourni par les nos 9 , 11 ; el at ce type se rapporte la signature de lassassin de Wallenstein (49), bien que ce misérable fùt íridemment très-peu familier avec l'écriture.

Dans un autre groupe d'assassins, à la tête desfucls se placent Lacenaire et De Cosimi (31 et 32), et oi nous ferons entrer des personnages historiques, FonquierTinville, Chabot, les lettres n'ont point à un degré notable la forme gladiolée, sauf la dernière de cluaque mol, qui finit souvent par un trait rertical aigu (92); mais toutes sont légèrement distantes les unes des autres, écrasées et arrondies. Souvent, par exemple dans l'écriture de Marat, Faella, Robespierre, Spissani, An- 
Lonino, elles paraissent, en dépit de l'àge (de 30 à 36 ans), avoir été tracées par la main tremblante d'un vieillard. C'est peut-être une marque d'alcoolisme, peutêtre le résultat d'une de ces névroses que nous arons relevées si fréquemment dans cette classe de gens. Sur 90 assassins, j’ai rencontré 19 fois ce caractère. Jai observé le tremblement dans 7 du premier groupe (Planche xxule $13,14,15$ et 37), et dans 6 du second.

De ces 90 individus, 36 seulement ne présentaient ancune particularité saillante; leur écriture élait toutà-fait commune (50). On pourrait compter Boggia (22) parmi ces derniers, s'il ne trahissait incontestablement son énergie par la forme qu’il donne au $t$. J'en dirai antant du brigand Lcone $(97)$.

Le second yroupe, cxclusivement composí do voleurs, se distingue nettement de celui qui précède: il n'offie pas de lettres gladiolées, mais toutes sont icartées, molles; la signature n'a rien de saillant, est prescue dépourvue de paraphe. En somme, cette écriture se rapproche de celle de la femme et n'a pour ainsi dire pas de caractère, (V. pl. xx11 $\left.{ }^{\mathrm{e}}, 37,34,45\right)$.

La caractéristique du groupe se rencontre dans la signature de cet IIoneyman, qui eut l'audace de s'introduire pendant sept nuits de suite dans les locaux d'une banque de Londres et y prit chaque fois l'empreinte d'une serrure, jusqu’à ce qu’il put arriver à la caisse et enlever les 245.000 dollards qu'elle renfermait! (38). J'ai vu deux autres signatures qui ressemblaient à la sienne, celle du brigand Bignami (70) et celle de Pavesi (37).

L'écriture de celui qu'on pourrait appeler le type des voleurs, Cartouche, présente, en dehor's des caractères précités et d'un tremblement singulier, une espèce de 
crochet, d'inflexion, it presque toutes les lettres, qui rappelle la conformation particulière de ses doigts. On retrouve ce caractère chez un pillard émérite (60) et chez d'autres voleur's $(39,54$ et 62$)$.

Sur 106 écritures de voleurs, jen ai vu 12 qui ne présentaient rien de semblable.

Ajoutez qu'il n'est pas rare de rencontrer ces caractères chez des individus qui, au vol proprement dit, ont joint le brigandage et la débauche, comme Cibollit (54); celui-ci n'a du voleur de grand chemin que la forme gladiolée de la signature. Mais, d'un autre còté, on voit de simples voleurs $(47,64,49)$ présenter les mèmes caractères que les assassins.

Quant ì ceux qui se rendent coupable de viol, d'eseroqueric ou de faux, je n’ai pu recueillir un assez wrand nombre de documents pour les juger arec certitude. Il me semble pourtant que l'aspect gladiolé de leurs lettres, leurs finales en forme de stylet (58), le paraphe extravagant de leur signature $(66,48,44)$, les rapprochent beaucoup des voleurs de grand chemin. D'après les graphologues, et je puis citer à ce propos deux exemples (53), les escrocs usent d'une écriture très-fine, comme s'ils cherchaient ì rester dans l'ombre, a dépister toute recherche. - Casanova, pourtant, ne présente rien de tout cela.

L'écriture des femmes homicides ressemble beaucoup it celle des assassins du sexe fort (V. celle de la Trossarello, $n^{0} 57$ ). En général, toutes se rapprochent de la forme virile. On observe d'ailleurs la même chose pour les honnêtes femmes doućes de quelque énergie. - La Raffaella Amata, condamnée pour meurtre, était un mâle hypospade que l'on avait pris pour une femme et élevé en conséquence. Son écriture est une écriture d'homme. 
Tous ces données j'ai pu récemment les confirmer expérimentalement; selon la méthode de Richet et Burot (Bullet. de la Soc. de Psychol., 1886), j'ai suggestionné par l'ipnotisme un jeune homme de mœurs irréprochables d'être un brigand el son écriture a changé tout-à-fait, avec des lettres grossières, larges, et des énormes $t$, tout-í-fait comme dans celle de Boggia. (Voir Archivio di psich., viI , 3, pl. $4^{\mathrm{e}}$ et $5^{\mathrm{e}}$ ).

3. - Comparaison avec les fous. - Ces données, je l'aroue, n'ont de limportance, que quand on les compare avec celles fournics par les fous. Ces derniers se distinguent nettement des malfaiteurs, surtout des roleurs de grande chenin. Les fous, généralement, à moins quils ne soient monomanes, ont une écriture peu déliée, déformée par des griffonnages, empàtée, inégale, avec des majuscules là où il faudrait des minuscules, des lettres tantôt d'une longueur démesurée, tantòt ridiculement petites, et jamais de dimension égale. Quelques-uns se distinguent par la manie de mettre des points sur toutes leurs lettres, ou entre chacune d'elles; plusieurs monomanes, et en particulier tous les fous ou demi-fous que jappelle littéraires, parcequ'ils griffonnent chaque année des volumes, tous, dis-je, ont coutume de souligner un grand nombre de mots ou de les écrire autrement que les autres et de les tracer avec un soin exagéré, pour imiter l'écriture imprimée. Dans les écrits des paralytiques el de beaucoup de ceux que l'hypocondric a brisés, on observe que les premières lettres de chaque mot sont à peine distinctes, les dernières indéchiffrables, et que toutes sont tremblées et incertaines, souvent précédées de signes informes, tracés par une plume hésitante. Les $r$ et les $t$, chez les hommes frappés de 
démence ou de paralysie generale, sont remplacés par des $l$ ou même supprimés. Les fous furieux, les díments, superposent leurs mots, on les écrivent, partie en lettres majuscules, partie en minuscules, arec les mèmes lettres répétées jusqu'à huit ou dix fois. Le plus grand nombre, suivant une excellente observation de M. Raggi (1), les monomanes surtout, ne se contentent pas de suivre la ligne horizontale, ils écrivent aussi verticalement, et forment avec leurs mots des espèces de dessins qui font ressembler leurs pages à des plans topographiques. A Racconigi, j’en ai vu un qui s'était formé une écriture spéciale, scmblable à celles de quelques orientaux: les voyelles manquaient; mais, en revanche, on $\mathrm{y}$ royait, comme dans les langues les plus anciennes, des hiéroglyphes, des représentations de l'objet qu'il voulait exprimer. Harcé cite un homme atteint de folie religieuse, qui mettait sous chacun de ses mots trois points et une croix.

Je n'ai pu remarquer aucun de ces traits dans les autographes des criminels. Le lecteur peut s'en faire une idée par ces fac-simile où à peine 4 sur 110, c'est-ìdire les $n^{\text {os }} 75,80,30,33$, sont empâtés, et où, à l'exception d'un seul, le $n^{\circ} 43$, tous exagèrent les $t$ et les $s$.

Quant aux hiéroglyphes s'ils remontent à l'atavisme, de même que ceux des monomanes, ils diffèrent de ces derniers parceque ils ne sont particuliers à un seul, mais sont compris par tous les complices de la même réğion.

(1) V. RagGi, sugli scritti dei jäñi, 1875, Bologne. - Marcé, De la valew des écrits des aliénés, (Ann. d'hyg., 1862). - Loßвово, Genio e follia, Turin, 1882. 


\section{CIIAPITRE XI}

\section{Littérature des criminels.}

1. - De mème quils ont un argot, de mème les eriminels ont une littérature qui leur est spéciale. Les livres obscènes d’Ovide, de Pétrone, de l'Arétin, en seraient les modiles fournis par les Anciens. Modèles mal suivis d'ailleurs, car c'est $m$ genre de littérature déponillée de toute lleur de rhétorique, une littérature basse et cachíe comme celle des almanachs populaires, siche comme une chronologie, et qui s'est loujours conservée à linsu peut-ìtre des esprits cultivés. Tels sont le Liber vagatorum, de 1509, traduit dans tontes les langues l'Emope; L'Histoire des Larrons, de Lyon Didier, 1647; la Legende of te hystorie van de snode practjique, ende de behendige listichden der Dieve, de Lopez de Ilaro, Leyde, 1645; enfin cet interminable chansonnier eriminel, qui appartient a l'Angletorre, el dont les titres seuls couvrent une page entière du livre de M. Mayhew (1).

Les voleurs se montrent tris-avides de toutes ces lectures, et colles-ci, a leur tour, engendrent, hélas! trop de voleurs.

Nous avons en Italie le fameux Trallato dei Bianti, de 1600, édité je crois à Urbin. II décril 38 espèces

(1) Le voleur de la vallee. - Le jardinier ensanglante. - Adiens. des transpoitis. - La mont de Puk. - Quand ie me promene la muit, ete. 
d'eserocs et de vagahonds de l'Italie centrale, et dont les plus curieux sont les testateurs, qui feignent de mourir en laissant leurs biens à d'antres; les affarfanti, qui feignent d'avoir i expier de grands crimes par des pénitenees eruelles; les formigoti, faux soldats revenant de fausses expéditions en Palestine; les sbrisci, qui ront tout nus, feignant d'avoir été pris et maltraités par les Tures; les ruffiti, faux ineendiés qui prétendent aroir dû quitter les ruines de leurs maisons. A ce livre, dans l'édition Italia, (Didot, 1860), ont été ajoutés six petits poëmes écrits dans l'argot tosean, que je crois de la même époque. Un de ces poëmes traite précisément de l'argot; en roiei to dibut:

Par les médecins des filous, lo entre-point ( $l^{*}$ aryot)

Fut inventi, pour qu'ils pussent chanter (prever) entre eux.

Un petit poëme, fort leste en argot milanais, a eté publié par I. Biondelli. On ne les édite que trop par milliers, ees histoires de brigands, it couverture rouge, dans cette espèee de bißliothéque anonyme qui, sans grand profit pour le peruple, el plutòt ì son grand dommage, continuc, grìce à l'imprimeric, cette cenre a demi historique, ì demi fantastique, autrefois composée des chants des poètes eycliques, et plus réeemment de ceux des Klephtes grees.

Il n'est pas de procès, pas de crime sortant de l'ordinaire, qui n'ahoutisse à une complainte. Iren ai de Verzeni, de Martinetli, d'Agnoletli, de Norcino, de Guicche, de Chiavone, de Nuttoni, de Mastrilli, de Porcia, de Marziale, de Luechini.

En somme, sur 92 complaintes ou historiettes éditées en fenilles volantes que jai pu acheter sur les places publiques, el dont la plupart sont eomposées 
dans un de nos dialectes, j'en ai compté 20 qui se rapportaient à des crimes ou à des vols; 14 étaient en vers, 6 en prose.

2. - I còté de cette littérature criminelle, œuvre du penple, il en existe une autre, plus curieuse encore, qui cmane directement des prisonniers: elle est le produit de leurs longs loisirs, de leurs passions mal contentres. Les poèmes de ce genre sont fort nombreux en Espagne, plus encore en Russie, où le peuple les chante même en dehors des prisons. Tels seraient ceuxci, que M. IIepworth Dixon dit avoir entendus; (Free Russia, London, 1869);

1.

Que pent me rapporter ma bêclie?

Si mes mains sont vides, si mon cenr est souffrant,

Un contean! un contean! Mon ami (le hrigand) est dans la fort.

2.

Je pillerai le marchand dans sa boutique,

Je tuerai le noble dans son château,

J'enlèverai de l'eall-de-rie et de belles filles,

Et le monde monorera comme un roi.

Et ceux-ci, entendus par l'auteur les Prisons d'Europe dans une prison russe:

Dans ce lieu où l'infamie a placé

A toujours sa demenre, fieux anges laaletent

Ayant dans leurs mains une croix.... Mais, la nuit,

A pas mesures, lentement, lentement,

Tournent, surveillant la prison, les sentinelles.

Derriere ees murs est la tristesse, est la terreur.

Dehor's sont la vie, l'or et la liberté.....

Mais de ee pas lent, lent, le noir

Echo mavertit: Toi reste! reste!

C'était un criminel féroce, assassin de sa femme, qui avait dicté ces vers et les chantait de la voix la plus douce; (Revue britann., 1876). 
Et. Dostoïewski dans ses Souvenirs de la maison des morts 1886 ajonte: "Ce que l'on chantait dans les prisons de Siberie surtout, c'étaient les chansons dites des forcats. L'une d'elles toute umoristique, raconte comment un homme s'amusait et vivait en scigneur, et comme il avait été envoyé à la Maison de force, il épiçait son bla-manger de Chianpagne, tandis que maintenant

On me donne des cloux à l'ean

Qne je dévore à me fendre les oreilles.

》Une autre chanson encore plus mélancolique, mais dont la mélodie était superbe, se clantait sur des paroles fades et assez incorrectes, dont voiei, quelques fragments :

Ion regard ne verra plus le pays Où je snis né;

A sonffrir des tourments immerités Je suis condamne tonte ma vie.

Le hihon plemrera sur le toit

Et fera retentir la forêt.

J'ai le ereur naves de tristesse, Je ne serai pas lib-bas.

"On la chante sourent, mais non pas en chœur, toujours en solo. Ainsi, fuand les travaux sont finis, un détenu sort de la caserme, s'assied sur le perron; il réfléchit, son menton appuyé sur sa main, et chante en traînant sur un fausset élevé. On l'écoute, et quelque chose se brise dans le cœur. Il y avait de belles voix".

Les chants de celte nature sont rares dans l'Italic continentale. On les trouve un peu plus répandus dans les îles, en Sardaigne, en Corse. Ils abondent en Sicile.

En effet, dans les chants vénitiens, que j’ai étudiés en m'aidant des critiques et des recherches de Mi. Pitré (1) et Bernoni (Canti Pop., Venise, 1874), je n'en

(1) Rivista Europea, 1876. 
ai trouvé que 3 de ce genre; l'un est d'un Prisonnier, qui se plaint de n’avoir été visité par aucun de ses parents; un autre d'un Condamné à perpétuité, qui proteste de son innocence et pousse contre la justice des imprécations semblables à celles que nous verrons plus loin dans la bouche d'un Pavesan.

Sur 106 poésies piémontaises et liguriennes, si l'on met a part les chants historiques des trois voleurs, d'un parricide, - d'une infanticide, on n'en trouve que deux rui soient à moitié des chansons de brigands.

La ritournelle populaire en Toscane:

Fleur de canne,

Je snis dans cette prison à cause d'une femme;

Jattends que l'on prononee ma condamnation;

est le seul débris qui nous reste, dans cette contrée oủ la civilisation est si brillante, de ce genre extraordinaire de poésie.

Le recueil tout récent des Canti Marchigiani, dû au professeur Gian Andrea (Turin, 1875, édit. Comparetti), renferme 1174 morceaux; c'est à peine si j'en ai trouré $8\left(0,670_{100}\right)$, sur le nombre, qui rentrent dans la catégrorie étudiée; celui-ci, par exemple:

Fleur de grenade,

La vie du panve bandit,

Ne me la dites pas à moi qui l'ai menée;

Toujours il va s'egarant dans les halliers,

Toujours il craint d'être jeté en prison.

Je me sens prêt à faire une folie,

Je velux tuer un abbe, et puis prendre la fuite.

Prenons, au contraire, les Chants siciliens, si pieusement recueillis par II. Pitré (Palerme, 1870-72). Nous y trouverons 41 chants criminels sur 1000 , d'où il résulte que la Sicile en a une proportion de $4010 .-\mathrm{Ce}$ sont, pour la plupart, des cris de vengeance, des 
plaintes sur la liberté perdue, des imprécations contre les juges ou les gendarmes:

Et ces cruels gendarmes - Maraient recommande :

Tenez-le solidement, - Car c'est un fier scélérat.

Nais plus importantes que les autres sont ces trois chansons, qui nous mettent à nu l'âme habituée au crime: "Il est indigne de notre estime, celui qui se re"pent et se propose d'être à l'avenir un observateur "des lois. Les véritables hommes ne se reneontrent pas » en tout lieu; jl n'y a d'hommes rares que ceux qui, dans "Ie bagne, savent rire et folàtrer. Aux Assises, coms ment doit-on se tenir?

Parler peu, et fixer les yeux à terre ".

Vers bien dignes de ce code de l'Omerlá, que nous a dernièrement rérélé 11 . Tommasi-Crudeli. Ceux qui croient à la force moralisatrice du chàtiment n'ont quà lire ce qui suit:

" Je déchirerai en petits morcears le visage de quiconque parlera mal de la Vicaria (prison de Palerme). Celui qui dit que la prison corrige, ol!! comme il se trompe, le pauvret! La prison est une fortune qui d'abord nous échone; puis nous enseigne les bons moyens de prendre et de ne pas nous faire prendre».

Et ceci encore:

o douce prison, ma vie et mon bonheur : Quel plaisir pour moi de me sentir dans tes murs : Que l'on casse la tête á qui te décricra, ou pensera que tu ôtes la paix du cœur.

Là seulement vous trouverez les frères et là les amis, Des trésors, de bons repas, une douce existence; Hors de là vous serez toujours au milieu de vos ennemis, $\mathrm{Si}$ rous ne pouvez travailler, vous mourez de faim, ete. 
Ces vers, par leur cynisme, nous en rappellent d'autres composés par des prisonnicrs français (1), et mettent ì nu l'àme du malandrin, pour qui la prison est un nid. Ils justifient, en outre, nos conclusions sur la récidive (p. 422 et seqq.), et font voir les résultats que donnent les prisons quand, par un hmmanitarisme outré, on les convertit en des espèces d'auberges confortables.

Hais, comme tout bon sentiment n'est pas éteint dans l'àme de ces misérables, et que souvent, à travers la cupidité et la vengeance qui les dominent, reparait l'image de l'ami ou de la mère dont on les a séparés, il peut vous arriver de rencontrer quelques couplets exhalant un parfum d'amour si suave, que, dans pareilles bouches, ils vous accablent de stupeur:

An milieu de la place de la Vicaria

Avec ses petites mains elle me fit des signes;

J'ai vı que c'était ma petite mère

Et que ses yeux coulaient comme deux sources;

Mère, qui seule pensez à moi,

Je suis entouré de mauvais ehrétiens.....

Nons sommes dans l'enfer, condamnés,

Et vous, tendre mère, vous exhalez en vain vos plaintes..... (Pırré).

Cette poésie pleine de tendresse suffirait à elle seule pour montrer combien est grande l'erreur de Thompson et de Maudsley, qui refusent aux criminels le sens esthétique.

(1) Ces vers, elıantés en 1836 par les eondamnés trançais au départ de la chaine:

Renommée, à nous tes trompettes:

Dis que, joyeux, nous quittons nos foyers;

Consolons-nons si Paris nons rejette;

Et que l'écho répète le chœur des prisonniers:

Adien! nous bravons et vos fers et vos lois (Vidoce, l. e.). 
Et ce n'est pas la seule: voici une autre du même genre:

O mère, comme je regrette, heure par heure,

Tout ee lait que vous m'avez donné?

Vous êtes morte, ensevelic sous la terre,

Et vous mavez laissé an milien des tourments.

Voiei, maintenant une pensée empreinte d'un désespoir terrible:

Vienne la mort; je la serre entre mes bras, je la convre de baisers.

De ces 41 morceanx, 8 font allusion à une vengeance ou à la parade du crime; 7 à des sentiments d'amour filial ou de chaste adoration.

Onze autres chants sont consacrés au récit de crimes celèbres et à leur exaltation. Par excmple, dans le clıant des Fra Diavoli, je trouve ces vers:

\section{Suivons l'exemple}

De quatorze valeurenx ecurs

Que l'on nommait Fra Diavoli.

Ils nous montrent fort bien le peu de moralité d'une littérature qui, à l'exemple de nos ancêtres, confond le criminel et le héros.

Et moi, qui trouve une si grande analogie entre le crime et la prostitution, je ne saurais négliger comme choses de peu d'importance ces seize autres chants de prostituées décourerts par II. Pitré, qui manquent, autant que je puis le savoir, dans tous les autres recueils. Dans Ieur simplicité plus qu'enfantine, stupide, ils me paraissent fournir une nouvelle preuve de la pauve intelligence de ces infortunées. - Maintenant, en lisant dans son bel ouvrage qu'ils sont chantès jusque dans les prisons, je constate qu'une nouvelle preuve vient confirmer l'analogie entrevue par moi. 
Certes, il convient, pour expliquer le grand nombre de ces chants, de tenir compte de la diligence que II. Pitré a mise à les rechercher; mais il est impossible de ne pas admettre que cette abondance dépende aussi de leur diffusion parmi les classes populaires, comme cela a lieu en Corse pour les chants des bandits.

C'est éridemment la même eause: d'un côté, l'extension plus grande du banditisme, de l'autre, le dédain moins grand qu'ont pour lui les elasses inférieures (1).

3. - Les Parias, nous le rerrons plus loin, sont les représentants d'une caste criminelle on vouée à une prostitution précoce; ils y préparent leurs enfants dès qu'ils ont atteint leur sixic̀me année. Je comprends dans cette eatégorie les Carobaru, qui, s’ils ne s'adonnent pas an vol, font les métier's de comédiens ambulants, de tatoueurs, de devins, exercent, en un mot, des professions équivoques. - On constatera, peut-ètre avec étonnement, que, malgré leur abjection profonde, ils ont de très-belles poésies - et cela prouve encore que le sens esthétique n’a pas été refusé anx criminels mais toutes ces poésies, sauf le chant de Tiravallura, sont empreintes d'une obscénité, d'une immoralité à faire pâlir même des Grees (2).

(1) V. P'tré, Sui canti popolari italiani in carcere, 1876, Florence.

(2) Dans un de ces poëmes, par exemple, un chacal attire une chèrre dans un piège préparé pour le tigre et la devore; moralite: * Ce que tu ne peux avoir par la force, obtiens-le pas la ruse. Si tu sais mettre à profit les tromperies des autres, tu ne souffriras pas de la faim ». - Uu autre a pour morale: "Ne fais alliance qu'avee les forts; place ta demeure près d'un temple, afin de voler de nuit les offrandes. Les imbéciles se Iaissent prendre aux apparences: tâche d'en profiter». - Un chacal ayant dérobé des poulets, remerciait Ireu de l'avoir favorisé, un çondra fut attiré par le bruit de sa roix, et le tua: "Garde-toi de te confier à Dieu; Ia plus belle prière ne te sauvera pas d'un coup de bâton " (Dubors, L'Turle, 1868). 
Dans une comédie, par exemple celle qui a pour litre Braham et la Nautchay, un personnage montre à une jeune fille pour quelle raison physiologique un vieillard peut arriver à plaire aux femmes, el des ivrognes chantent ce refrain:

Préparez les nattes, ô jeunes filles, et courrez-les de fleurs;

Nous ferons entreehoquer dans nos embrassements

vos membres délicats, et la douleur

Augmentera le plaisir.

J'appelle, encore une fois, l'altention du lecteur sur celte obscénité que j’ai déjà signalée plus lıaut. Elle prouve, comme nous l'á révélé l'histoire des Tucke, que les tendances obscènes se mêlent fréquemment aux criminelles; - et cela est en outre prouvé par la diffusion de la débauche chez les Parias. - Ce peuple, si répandu malgré les nombreuses persécutions qu'il a subies, nous permet de fairc aussi une autre constatation qui viendra confirmer l'étude de Dugdale sur les Yucke, c'est que le criminel est beaucoup plus fécond que l'honnète homme (V. ge rol.).

4. - Un certain nombre de chants criminels se trouvent encore (1) en Sardaigne, où le banditisme n'a pas seulement laissé des traces dans l'histoire; car on en rencontre aujourd'hui encore des restes nombreux.

On ne lira pas sans une vive curiosité le morceau suivant, qui présente une grande analogie avee le chant russe précité, et avec la poésie criminelle des Parias.

(1) V. Sotro-Pixtor, Storia civile della Savdegna, 187\%. - En 1843, on comptait en Sardaigne 864 bandits. De 1831 à 1840, il a été commis dans l'ile 2468 meurtres, 527 rols à main armée, 290 incendies, 436 enlevements. 
“Dis-moi, demande Achea au prêtre, si je n'ai rien à manger et que je trouve de quoi apaiser ma faim, puisje prendre le bien d'autrui ?

) - Crois-moi; si tu n'as pas de quoi manger et que tu rencontres quelque chose, tu serais fou de ne pas ten saisir.

»-Tu es de bon conseil, mais voici une difficulté; ce que jaurai pris de la sorte, devrai-je le rendre?

"- Non. L'observation de la loi te condamnerait a un jeûne trop dur; tu es un bien grand sol, si tu ne comprends point qu'en face de la nécessité tous les biens appartiennent à tous (1) ».

Ce chant nous prouve, une fois de plus, que le criminel, dans les pays peu civilisés, considère le crime comme un droit, ou tout au plus comme un péché véniel qu'il est facile d'expier; que, par conséquent, la religion est pour lui moins un frein fu'un excitant (V. p. 239 et ser.).

Les chants Corses recueillis par M. Tommaseo peurent être considérés presque tous comme œuvres de bandits. Presque tous, en effet, respirent la rengeance du meurtre d'un ami, la haine de l'ennemi qu'il faut tuer, l'admiration pour le meurtrier. Rinald, Canino, Gallochio, Galvano, y figurent comme des Iıéros. La vengeance y va au delà du sépulcre:

.......... La vengeance,

Nons la ferons éternelle, et sur la race inique

Xous porterons ta colère comme un héritage légué par toi;

Les crânes resteront suspendus à la voûte du temple;

Ciest un mérite, un titre d'éloge que d'être épouvante.

(1) Botiuler, Les dialectes et les chants de la Sardaigne, Dentu, 1864. 
Vous joussez d'une estime si grande, si gramde !..... (Giulormo)

Le nom seul de Gallocehio épouvantait les homnes.

Toutefois, an milien de tout cela, on voit apparatte le sourire d'une femme, soit d'une mère, soit d'une amante.

M. Tommaseo a tenu entre ses mains un gros rolume de vers dictés par le Peverone, fúroco handit qui eut le ceur de saupoudrer de poirre, après l'avoir tué, le corps de son ennemi, pour le marquer de son sceau. On y voit, mêlées à des couplets qui dínotent une cruauté implacable, comme celui-ci:

J'en ai l'espoir, Dien permettra que je me venge;

Mon eompte est tout fait:

Je serai vainqueur, tué, ou bandit;

des strophes d'une exquise délicatesse, et qui ne paraitraient pas indignes du doux chantre de Lamre; celleci, par exemple:

Quand je te vois, quand je t'entends parler,

Mon sang se glace dans mes veines,

Ion cœur veut bondir hors de ma poitrine.....

Toute parole d'elle, quand elle onve la bonehe, Attire, lie, frappe, transperee.

5. - Bien qu'il paraisse au premier abord y aroir une grande différence entre les régions insulaires el les continentales, au point de vuc de la richcsse de celte littérature, je ne crois pas cependant que, dans ces dernières, ce genre extraordinaire se soil perdu; les passions, l'oisiveté des détenus doivent le maintenir. Seulement, comme ici la différence est devenue plus grande dans le populaire entre les gens honnêtes el ceux qui ne le sont pas, les premiers ne collectionnent pas les œuvres des autres el, par conséquent, négligent de nous les transmeltre. 
Une grande partie de la littérature des prisons est en vers. Elle est l'œurre des criminels eux-mêmes, qui ont un penchant pour la poésie, peut-être parcequ'elle est plus en harmonie que la prose arec l'ardeur de leurs passions. C'est aussi pour cela que ces œurres portent toujours l'empreinte du moi, et retracent les sentiments doulourcux de l'auteur avec une force et une éloquence extraordinaires. Corani, avant d'être pendu, déclama, du haut de l'íchafaud, un poëme sur sa propre mort; le brigand Nilano demanda et obtint l'autorisation de présenter en rers sa défense. Voici maintenant un morceau dicté par un cordonnier, presque illettré, détenu au bagne de San Stefano. Liscz-le; vous y trouverez, outre la prenve de ce que j'avance, un tableau du bagne aussi exact que pourrait l'ètre une photographie.

\section{LE BAGNE DE SAN STEFANO.}

Dante, qu'on ne vante plus tes eercles infernanx,

Et toi, Virgile, cesse de chanter les flammes sombres de l'Averne. Et les cérastes, et les IIarpyes, et les autels Qui distillent en ees lienx ténébrenx nne affrense pourriture.

Ici, ici, l'on perçoit le gronillement sombre De ces âmes impies, perverses et sordides. Ici, l'on entend le son terrible et ranque Qui retentit sur l'autel de Pluton.

In monstre s'endort iei, sur ce grabat, Et bientôt devient la proie d'nu autre monstre Qu'un troisième se hâte de venir dévorer à son tour.

Le sang dégontte sur le sol; l'air ne respire Qne vengeance, carnage et trahison. Ici, pendant que l'nn périt, l'antre conspire.

Cette pièce prouve, non seulement que le sentiment esthétique ne fait pas défaut aux crimineis, mais encore qu'il atteint souvent en eux un développement extraordinaire. Il n'y a pas longtemps que Lecrosnier, un vul- 
gaire détrousseur, composait dans sa prison ces rers emphatiques, mais non dénués de grâce (1):

Tu pleures, quand le soir mon âme veut tremblante

Vers tes parents la-bas voler pleine d'amour:

Tu pleures; sur tes cils, une larme brûlante

Vient se diamanter aux premiers feux du jour.

Tu plenres: mais ces eanx qu'une amère souffrance

Epanche de tes yeux,

Font épanonir l'espéranee,

La fleur des malheureux.

Tu pleures: bien souvent ta voix monte plaintive

Vers le maitre des cienx anx heures de sommeil.

Tu plemres: ta pensée, hélas ! longtemps eaptive,

voit ses liens tomber et s’élance an soleil.

Tu plenres: mais an eiel ton ange qui t'adore,

Henreux, dit aujourd'hui :

Regarde, ô .père ! c'est encore

tne larme de lui.

On a de Lacenaire plusieurs poésies, rantécs moins pour lcur valeur intrinsèque que pour la surprise excitée par leur apparition. Une scule, dans laquelle, jeune et innocent encore, peut-être il prophétise sa noire destinée, me parait digne de remarque. En voici les derniers vers:

\section{A MON AMANTE.}

Je te rêvais au temps de mon bonheur, Quand sur mon front brillaient les plus vives conleurs;

Maintenant le songe s'est évanoui, et mon sort Doit suivre le destin fatal

Qui vent me jeter en pâture à la mort cruelle. Attends moi dans le ciel, belle immortelle.

Les autres sont d'un platonisme faux et vulgaire, hormis lorsque son moi est un jeux, comme celui ci:

(1) Je les dois à l'obligeance de II. Líon Weile-Schott. 
LACENAIRE.

Maudissez-moi, j’ai ri de vus bassesses, J'ai ri des Dieux, pour vous seuls inventés; Maudissez-moi mon âme, sans faiblesses, Fut ferme et franche en ses atrocités. Pourtant cette âme était loin d'être noire, Je fus parfois béni des malheureux... A la vertu si mon ecur en̂t pu croire, N'en doutez pas, j'ensse été vertueux.

LA FLUTE ET LE TAMBOLR

(LACENatre).

Bien foll, ma foi, qui sacrifie Le présent an temps à venir; Tont est bien et mal dans la vie, Le chagrin suecède an plaisir. Contre le sort en vain on lutte: Anour, richesse, n'ont qu'un jour. Ce qui vient au son de la flûte S'en retourne an bruit du tambour.

Un gros financier qui, naguère, Roulait, gorgé du bien d'autrui, Rauçonué par d'autres confrères Marche dans la crotte aujourd'hui. On voit souvent semblable chîte Chez le peuple, ainsi qu'à la Cour. Ce qui vient au son de la flûte S'en retourne au brint du tambour.

Quand je vois la superbe actrice Qui ruina plus d'run amateur, Aujourd'hui, par un bean caprice, Se ruiner pour un mince anteur, Pauvre fille, hélas! quelle chîte : Ainsi, dis-je, même en amour, Ce qui vient an son de la flûte S'en retourne all bruit du tambour.

Pendant son dernier procès, quelques publicistes avaient fait paraître un volume de chants républicains, parmi lesquels se trouvaient quelques morceaux composés par lui et qu'arait retouché M. Altaroche. Lace- 
naire s'indigna de ce procédé et adressa aux journaux la réclamation suivante, dans laquelle le nom d'Altaroche était suffisamment designé par une rime caractéristique et transparente:

Je suis un voleur, un filon,

Un scélérat, je le confesse!

Mais quand j’ai fait quelque bassesse,

Hélas ! je n’avais pas le sou.

La faim rend un homme excusable.

Un panre, de grand appetit,

Pcut bien être tenté du diable;

Mais, pour me voler mon esprit,

Etes vous done si misérable?

or, contre un semblable méfait

Notre code est muet, je pense;

Au parquet, j'en suis sûl d'avance,

Ma plainte aurait bien peu d'effet.

Pour dérober une filorlie (bourse)

On s'en va tout droit en prison;

Aussi le prudent A.....

Ne m'a volé qu'une ehanson,

Sans mettre la main daus ma poche.

un voleur adroit et subtil,

Pour eviter toute surprise,

Sait déguiser sa marchandise

Et la vendre ainsi sans peril;

A..., anssi raisonnable,

Et craignant quelque camouflet,

A pris le parti détestable

Destropier chaque couplet

Pour le rendre méconnaissable.

Je ne puis assez m'etonner

De ee bel effort de courage;

D'un autre copier l'ouvrage,

Pour moi se faire emprisonner,

Ce dévollement est admirable.

C'est vraiment avoir trop bon coeur

De remplacer le vrai coupable

$\mathrm{Et}$, sans avoir été l'auteır,

D'être l'éditeur responsable. 
Ici la vanité blessée remplace le génie poétique.

Avant de mourir, Lacenaire voulut se réconcilier arec Avril, son complice, qui devait être exécuté avec lui. On leur accorda de diner ensemble, le jour des Rois, et Lacenaire composa pour la circonstance le Noël suivant, en forme de chanson à boire:

Noё1 ! Noёl !

Tout tombe du ciel:

Allons, plus de fiel!

Vire Noël :

A nous, saucisse et poularde!

A nous, liqueur et vin vieux!

Fais la nique à la camarde

Qui nous montre ses gros yeux.

Noël, etc.

Salnt, pays de Cocagne,

Lieu jadis si fréquenté

Salut, pétillant champagne,

Vin si eher à la beauté !

Noël, ete.

Ln bon buveur, e'est l'usage

Boit à lobjet qui lui plait !

Avec moi, frère, en vrai sage, Bois à la mort, e'est plus gai.

Noël, ete.

Buvons au jour qui s'avance,

A l'oubli de tous nos manx,

A l'oubli de la vengeanee,

Des méchants et puis des sots!

Noël, etc.

Burons même à la sagesse,

A la vertu qui soutient;

Tu peux, sans crainte divresse, Boire à tous les gens de bieu.

$$
\text { Noël, ete. }
$$

Un paurre homme, d'ordinaire, Pour mourir a bien du mal.

Nous, nous avons notre affaire, Sans passer par l'hôpital. 
Noël, ete.

Sur les biens d'une autre vie,

Laisse prècher Massillon:

Vive la philosophie

Du bon euré de Mendon :

Nö̈l, ete.

Nous trouverons bien, par grâce,

A nous caser anx Enfers:

Moi j'irai trouver Horace,

Toi louvrier te Nevers.

Ici il pose et pour poser même après sa mort, il avait composé sa complainte, dont roici deux couplets:

Plus tard enfin, voleur, eseroc, faussaire,

Tous les forfaits ne me eontent plus rien.

Pour débuter on chippe une misère,

Et pour finir on devient assassin.

Ah: quand pour moi viendra l'henre dernière,

Foulez aux pieds mon eadavre sanglant,

Mandissez-moi : Qu'a besoin de prière

Larbre abattu par le sonfle du vent?

Dans son autobiographic trop vantée, je ne trouve de vraiment beau el digne de fixer l'attention du psychologue, que le morceau où il peint la vie morale du bagne:

"Qu'adviendra-t-il du jeune homme poussé dans cette misérable société (celle des prisons)? Pour la première fois il entendra résonner à ses oreilles la langue barbare des Cartouche et des Poulailler, l'ignoble argot. Mlalhem à ce jeune homme, s'il ne se met pas immédiatement i leur niveau, s'il n'adopte pas leur's principes et leur langage; on le déclarerait indigne de s'asseoir à côté des amis! Ses réclamations ne seraient pas écoutées de ses gardiens eux-mêmes, qui inclinent 
toujours a protéger les chefs; elles n'auraient d'autre résultat que d'exciter contre lui la colère du geôlier, qui est d'habitude un ancien forçat. Au milieu de ces hontes, de ce cynisme de gestes et de paroles, l'infortuné rougit du reste de pudeur et d'innocence qu'il avait en cntrant; il regrette de n'avoir pas été aussi criminel que ses confrères; il redoutc leurs brocards, leur mépris; car, même sur les bancs des galères, on connaît l'estime et le mépris, et cela explique pourquoi certains forcats s'y trouvent mieux qu'au sein de la société où ils ne recueilleraient que le dédain. Qui done consentirait à vivre méprisé ? Minsi le jeune homme, qui prend exemple sur ces beaux modèles...., en deux ou trois jours arrivera à parler lcur langue, et alors il ne sera plus un pauvre niais; alors les amis pourront lui serrer la main, sans crainte de se compromettre. Remarquez bien que ce n'est encore là que gloriole de la part de ce pauvre garcon, qui rougit de passer pour un novice. Le changement s'est opéré dans la forme plutôt que dans le fond. Deux ou trois jours tout au plus, passés dans ce cloaque, n'ont pu le pervertir entièrement; mais soyez tranquille, le premier pas est fait; il ne s'arrêtera pas à mi-chemin $»$.

Cette prose est éloquente, parcequ'elle exprime un sentiment vrai. Les poésies tant vantées de $\mathbf{M}^{\mathrm{me}}$ Lafarge sont de méchants vers, des morceanx à allures sentimentales, toujours vaporeux, farcis de ces commérages, de ces petites misères de la vie cellulaire, dont l'esprit du prisonnier est toujours plein.

Robert Bréohat est surpris ces jours derniers, dérobant un dictionnaire de rimes à l'étalage d'un bouquiniste. On le fouille; on trouve sur lui un tas de petits 
papier's sur lesquels sont tracés des sonnets, des idylles, des rondeaux. Une élégie commence par ces mots:

Un geôlier reponssant vient de fermer la porte.

Depuis denx ans déjà, triste, je gis ici;

De moi ma fianece, hélas! n'a plus souei.

Ion père, en una prison, senl, à manger m'apporte.

Voici le premicr couplet d'une chansonnette du même individu :

Ies petits moutons

Vont sur les gazons;

Ma bergeronnette,

Près de moi senlette,

Chante ses ehansons.

6. - Voici un indice précicux des tempêtes qui tourmentaient lassassin Lebiez, et que l'intelligence dont il était doué rendait plus affreuses: ce sont quelques poésics (1), et surtout des réflexions qu'il y inscrivit en marge quand on les lui rendit avec les autres papiers dont le juge d'instruction s'était d'abord emparé.

A UN CRANE DE JEUNE FILLE.

De quelque belle enfant restes froids et sans vie, Bean crâne apprêté par mes mains,

Dont j'ai sali les os et la surface blanehie

D'un tas de noms grees et latins.

Compagnon triste et froid de mes henres d'itude, Toi que je viens de rejeter

Dans un coin, ah! reviens tromper ma solitude,

Réponds à ma euriosité.

Dis-moi eombien de fois ta bonche s'est offerte

Aux doux baisers de ton amant;

Dis-moi quels jolis mots de ta bouehe entr'ouverte

Dans des heures d'égarement...

(1) Masvo, Arch. di psichiatria, 1883, iv, fase. 111. M. Lacassagne en fait aussi mention dans son Homme criminel, 1882. 
Insensé ! ..... Tu ne peux répondre, pauvre fille;

Ta bouche est close maintenant,

Et la mort, en passant, de sa triste faucille

A brisé tes charmes naissants.

Triste leçon pour nous, qui croyons que la vie

Peut durer pendaut de longs jours :

Et jeunesse, et bonheur, et beauté qu'on envie,

Tout passe ainsi que les amours :

Aussi, quand, vers le soir, âpre et dur à la tache,

Je travaille silencieux,

Mon esprit suit le monde et, tout inquiet, sattache

A des pensers plus sérieux,

Je rêve au temps qui passe ..... alor's, je te regarde,

Et, songeant anx coups du destin,

Sur ton front $n$ je crois lire en tremblant: « Prends garde,

Ilortel, ton tour viendra demain ! ».

"Paurres vers! Mais, pour maurais qu'ils soient, ils peignent fidèlement l'état de mon àme dans les moments de solitude. Dans le monde je suis aimable et gai. On me prend pour un étourdi qui se moque de tout. Nais si l'on connaissait le fond de mon caractère, si l'on savait que je ris et que je fais des jeux de mots au sortir d'une solitude où je me suis laissé aller au désespoir et aux larmes! Si l'on savait que j'ai des sanglots au fond du cour quand le rire s'épanouit sur mes lèvres, on ne dirait pas que je me moque de tout.

„ Ila gaîté n'est qu’un masque; elle cache l'angoisse qui depuis si longtemps déchire mon cour.

) Ah! si les hommes qui mont vu rire avaient pu me roir dans une de ces excursions solitaires, an cours desquelles je cherche les paures plantes que je dois étudier; s'ils m'avaient ru pleurer comme un enfant, masseoir sur le revers d'une colline, au pied d'un arbre, y rester des demi heures la tête dans les mains, ils m’auraient pris pour un fou, mais ils n'auraient point 
osé dire (style Barré), que je me .... de tout, du tier's comme du quart".

On doit à Fallaci, outre un traité sur les allumettes, plusieurs poésies sentimentales, quil a composées entre ses deux assassinats.

Le faussaire Ruschovich, dans quelques pages recueillies par M. Nocito (Storia di un condannato, 1873), dépeint d'une faron rraiment étonnante, l'àme des prisonniers.

\& Ah ! trop sourent on oublie que, en parlant des prisonniers, en faisant leur portrait, on peint des membres de la société. Tous ces corps parfois abandonnés de tous, sauf des satellites chargés de leur garde, non, non, ils ne sont pás tous opàques, il y en a parmi eux de diaphanes et de transparents. Le sable vulgaire que vous foulez aux pieds donne un cristal brillant, après avoir passé par l'ardent creuset. La lie elle-même peut devenir utile, si l'on sait l'employer; en la foulant aux pieds, comme on le fait, avec indifférence et sans souci, on mine le sous-sol de la société et on l'emplit de rolcans. Connaît-il bien la montagne, l'homme qui n'en a pas visité les cavernes? Le sous-sol, pour être situé plus has et plus loin de la lumière, est-il par hasard moins important que la croûte extérieure? ll y a parmi nous des difformités et des maladies capables de faire frémir; mais depuis quand l'horreur exclue-t-elle l'étude, et la maladie éloigne-t-elle le médecin?"

Dans une autre lettre il écrivait, parlant de luimême: «Ah! quel tourment que l'inaction, pour l'homme qui fut toujours habitué à l'étude et au travail et qui sent virre encore en lui-même cette activité, ce besoin d'occupation qui anoblissent l'homme en le perfectionnant! Me tenir ainsi dans une oisiveté honteuse! He 
faire ainsi graduellement pourrir au sein de la misère! ah! cela afflige et débilite mon esprit, an point que je crains de perdre enfin le peu d'intelligence qui me reste. Quoi! Toute la création est fondée sur le mouvement et sur le travail, la nature entière a horreur de l'inertie, et le prisonnier doit faire exception à cette loi universelle? Doit-il, lui seul, comme les eaux stagnantes, se corrompre et pourrir dans sa propre fange? Doit-il seul consommer et non produire, causer du dommage sans faire rien d'utile, détruire tout autour de lui et en mêrne temps se détruire lui-même?

«Si les dernières statistiques sont exactes, s'il est rai que les prisons du royaume d'ltalie renferment environ quarante mille détenus, c’est l'œuvre de cent années de travail que l'on fait perdre chaque jour au trésor commun de la societé. La religieuse de Cracovie criait: du pain! du pain! Et moi, du fond de ma cellule solitaire, je fais de même entendre ma voix suppliante: du travail! donnez-moi du travail!

) Si le corps a besoin d'exercice pour se plonger ensuite avec plus de plaisir dans le sein du repos, l'esprit a besoin de converser, pour méditer ensuite avec fruit aux heures de la solitude; si nous nous en tenons à la méditation pure, nous resterons dans une indigence orgueilleuse. Dans le cerveau d'un solitaire, la pensée, rude et assauvagie, pour ainsi dire, ressemble à un aventurier ragabond qui s'applique à franchir des espaces imaginaires, et, finalement, va périr au milieu de plages solitaires et désertes. Les pensées trop longtemps enfermées et comprimées dans l'esprit se gântent et se corrompent, comme ces ballots de marchandises qui, entassées, fermenteraient rapidement, si 
l'on n'avait soin de les développer sur le sol pour leur faire prendre l’air (1)».

Abbadie, cet assassin ì peine pubire, s'applique it une réforme sociale: Il laul bien (dit-il) suive la mode! Mais son manuscrit nest qu’une suite ininterrompue d'imprécations contre ses juges, une apothéose de ses arocats et de lui-même.

Dans les Mémoires de Vidoeq, personnage á peu près illettré, il n'y a de remarquable que la description d'une orgie. Dans ce morcean, l'homme apparait sans voiles, et le paroxysme de la passion lui donne un moment d'éloquence.

7. - En somme, ces gens là ne sont pas des littérateurs; ce sont des criminels à qui les misères de la prison, les tourments d'une passion victorieuse, tiennent licu de talent, ou que la vanité a poussés à écrire leur vie.

Il y a bien, je le sais et jen ai dit un mot précédemment, un certain nombre d'artistes et de littérateurs qui ont penché rers le crime et quelquelois s'y sont abìmés; mais le sens du droit, la pudeur du juste, dont ne manquent pas les malfaiteurs les plus vulgaires, et que ceux-ci possèdent à un degré encore plus éleré, les empèchent de laisser dans leurs œurres une empreinte trop nette de leurs passions criminelles. Notons, cependant, que quelques peintres homicides, tels que le Caravage, Spagnoletlo, Molyn, Cloquemin (qui a peint un conroi de forcats), Lehrun, Tassi, ont aimé à reproduire des scènes barbares ou sanglantes, comme le massacre de la Sainte Barthéleny, le martyre de S. Girolano (2),

(1) Voir pour des autres doenments mes Palimpsesti dol carcere. 1887.

(2) - Aree ses ombres effrayantes et ses figures où respirait la menaee, il s'empara du publie, ete. ». Bulceri, Iita di Caravaggio. - =teen, qui était un ivrogne, préferait, au contraire, les scènes dorgie. 
le supplice d'Ixion. C'est même ce goût qui a lait donner a Molyn le surnom de Tempesta.

Dan sa Vie, Cellini tente d'enjoliver quelques-unes de ses mauraises actions, d'en excuser d'autres, en invoquant la fatalité des astres, comme on disait de son temps. En deux endroits, seulement, il se laisse voir ì découvert: e'est quand, loin de repousse? l'aceusation de sodomie que son enneni lui jette à la face, il s'en vante comme d'une marque de bon goît; et quand il laisse entendre que, pour lui, non seulement le crime n'est pas un crime, mais est chose permise. "Sachez que les hommes comme Benvenuto, uniques dans leur art, ne sont liés par aucune loi ». Nais, lá nême, il a bien soin de se couvrir de l'autorité du Saint Père.

Les poésies ou les lettres de Ceresa, de Byron, de Foscolo, vous offrent quelques traces de leurs remords, de la violence avec laquelle ils ont tenté de faire disparaître leurs mauvaises passions.

Villon, poète et voleur, a peint ses deux qualités contraires dans deux de ses poésies (les Deux Testaments), et dans son Jargon ou Jobelin. Ce dernier ourrage a été composé en argot, et les principanx personnages en sont des voleurs (éd. Morot, 1800). Il fut le premier poète réaliste; et, au sein des vices les plus honteux, il laissa percer un grand amour pour sa mère et pour sa patrie. Condamné à mort, il écrivit, outre son Epitaphe, le quatrain suivant:

Je suis François, dont ee me poise,

Né de Paris empris Pontoise.

or d'une corde d'une toise

Saura mon col que mon cul poise.

qui nous donne une preuve eurieuse de l'indiffẻrence des criminels à l'égard du supplice. - Dans son Grand 
Testament, il dépeint la vie des prostituées, se donne pour un souteneur, arec les détails les plus ignobles. En voici, du reste, sa morale:

Il nest tresor que de vivre it son aise.

Mais comme cela nous est précienx, pour démontrer l'analogie qui existe entre la prostitution et le crime!

Je suis paillard, la paillarde me duit:

L'ung vault l'autre, c'est à mau-ehat man-rat;

Ordure avons et ordure nous suyt,

Nous deffuyons lonneurs, et il nous fuyt,

En ce bourdel où tenons nostre estat.

Cieresa, prêtre sodomite, peint avec de vives couleurs la lutte du bien contre le mal, et se plaint de ce que la nature a donné à celui-ci un si splendide vêtement:

Pourquoi m'avoir donnè nne âme, Qni, dans un fatal conflit, Vaincue par une force indomptable, Me précipite dans le erime?

Mon eeur est séduit; ses frémissements

Comment pourrais-je les réfréner,

Si de dehors si agréables

Dien a voulu revêtir le erime?

Et pourtant, quand, dans sa révolte

Largile offense les cienx,

Pourquoi le remords vient-il s'abattre

Sur mon cœur ponr le déchirer?

On dirait une forme d'ange

Qui tournoie parmi les hommes,

Une fascination irresistible

Emane de sou doux regard

Oh ! n'est-ce pas Dieu qui l'a revêtue

D'un voile si brillant?

Quoi? le ciel voudrait imposer

In frein au cœur plein de tlammes....?

Et tandis que, solitaire,

Je m'entretiens arec mon crime,

Comme la foudre sène l'ipouvante :

Comme le tonuerre jette ia teraear! 
Byron qui, dans deux de ses poëmes, a célébré deux incestes, se peint ainsi lui-même sous les traits de ses liéros:

Toujours superbe, et refusant

Ihe renoneer ì l'estime de lui-même,

Il faisait eompliee de ses fantes

Sa propre nature, eet embarras

De ehair et $d$ 'os ..... (LAR $A)$.

..... Conpable, il savait l'être; mais les antres

N'itaient pas meillenrs à ses yeux. 11 méprisait les bons

Comme liypoerites, et pensait que ces gens là, dans l'ombre.

Etaient ce qu'est l'homme frane en plein midi. (Le Corsure).

Dans son Caïn, les représentants mystiques du mal, Lueifer, Caïn, sont mis en scène arec plus de complaisance, ol quelquefois scmblent plus logiques que les représentants du bien. - Les chérubins sont:

\section{des eréatures}

Iisérables, saus foree, avengles aux rayons

De tonte science qui franchit les bornes

De leur eourte vue; - des créatures

Qui n'ayant sur les Ièrres que des elants d'adoration. Croient bon ou manvais ee qui pour bon

Ou pour mauvais fut donné à leur faible

Nature.

Au contraire, les démons s’intitulent:

.......... des esprits superbes,

Qui ne eraignent point d'abnser

Te notre immortelle nature, ni d'élever leurs regards

Contre l'oppressem tont puissant, et de lui dire:

Le mal rue tu nous infliges n'est pas juste.

Mais ce sont là des éclairs rapides; s’ils peuvent convaincre derreur ecux qui nient au crimincl le sens esthétique, il faut pour les décourrir de grands efforts et la loupe d'un érudit.

Si foscolo, dans son Orlis, dans sa Ricciarda, et dans son Tieste, nous dépeint la violence de ses passions et 
se complait, trop souvent, dans la peinture du crime, du rol et de l'adultère; s’il donne, sonvent, à ses personmages sa personnalité grande, mais perverse, qui, de son propre areu, est portice vers le mal, il est le premier à s'irriter fuand il roit qu'on le prend trop à la lettre el quon met en pratique ses maximes mauvilises.

8. - On ne peut, done, affirmer positivement que ces grands hommes aient terni la pureté de l'art par les souillures de leur àme. Des bas fonds du monde où se parle l'argot, au sommet de la république des lettres, sétend tonjours un abime. Ce n'est que dans ces derniers temps, grâce à Balzac, à Victor llugo, à Dumas, a Sue, à Gaborian, ḋ Zola, que ce triste miasme du bagne et du lupanar, digne conjoint dn bagne, a essayé de pénétrer dans la littérature. Hais c'est là un phénomène isolé, qui ne saurait durer; le vain plaisir, la saveur acre et nouvelle que provoquent des ordures pareilles, doivent rapidement s'efficer devant le mépris qu'elles font naitre, mème dans les esprits les moins scrupuleux. - En tout temps l'art aima à planer dans les régions pures et sereines; et cela arec d'autant plus d'ardeur qu'il voyait autour de lui un plus grand contraste.

9. - Les productions littéraires des fous ressemblent, dans les tendances autobiographiques, dans la vivacité des plaintes, dans les petits détails, à celles des criminels. Hais elles les surpassent souvent par une éloquence brùlante et passionnée, qui ne se voit que dans les œuvres des hommes de génie. Elles sont, en outre, empreintes de moins de légèreté, d'une plus grande originalité de forme et de fond, quand elles ne se per- 
dent pas dans les jeux de mots, les rimes, les homophonies, toutes choses que les fous recherchent (1), et par lesquelles ils ressemblent aux criminels.

(1) On en peut voir des exemples dans mon livre intitulé Genio $e$ Follia, $\mathrm{r}^{\mathrm{e}}$ ed., Turin, 1882, p. 122 et seq.; dans le Diario del Manicomio di Pesaro, 1872, p. 52, i3, dans les Diari del Manicomio di Siena, di Ferrara, di Ancona, di Colorno, di Napoli (Fleurent), 18767\%, et surtout di Fermo, janvier, 1878. 


\section{CIIIPITRE XII}

\section{Associations de malfaiteurs.}

1. - Brigandage, mafia et camorra. - Les associations illicites sont un des plénomènes les plus importants du triste monde du crime; d'abord, parcergu'on voit se rérifier dans le mal la grande puissance que donne l'association; en second lien, parcerue la róunion de ces àmes perverses engendre un vérilable ferment malfaisant qui, faisant pulluler à nouveau les vieilles tendances sauvages qui sont dans l'homme, les renforcant par une sorte de discipline, et par cette vanite du crime dont nous arons déjà parlé, fait commeltre des atrocités auxquelles répugneraient la plupart des individus pris isolément.

Tout naturellement, les associations de ce genre sont surtout nombreuses lì oủ abondent les malfaiteurs, dans les grandes villes. On remarquera toutcfois que, dans les pays les plus civilisés, clles sont moins solides et moins sanguinaires et se transforment en socićtés équivoques de politique ou de commerce.

Le but des associations de mallaiteurs est presrfue toujours de s’approprier le bien d'autrui. Ils se réunissent en grand nombre pour offrir une résistance plus forte a l'action des lois. On a vu se former des sociétés d'avorteuses, d'empoisonneurs; on en a souvent observé qui tendaient au but le moins présumable, depuis la pédérastie, qui donnait au vice les apparences de la 
vertu la plus délieate, jusqu'à l'homicide accompli sans aucun désir de luere, pour le seul plaisir de roir couler le sang, comme dans la bande des meurtriers de Livourne, enfin jusqu'au cannibalisme el au viol inspiré par le fanatisme religieux, comme cliez les sectaires lusses.

2. - Sexe, âge, profession, etc. - La condition des malfaiteurs réunis en sociétés correspond, comme il est bien naturel, à celle du plus grand nombre de eriminels. Le sexe masculin l'emporte de beaucoup; on ne peut eiter qu'ì titre exceptionnel des bandes eommandées par mo femme; celle de Louise Bouviers, par exemple, qui dirigeait, en 1828, une quarantaine de voleurs. Le cas de femmes qui s'mnissent entre elles pour voler est encore plus rare; je ne eomnais qu'une bande de cette espece: colle qui, formée de voleuses et de prostituées, avait à sa tête l'ex-vivandière Lina Mondor.

Chez les femmes, toutefois, qui, nous le verrons plus loin, inclinent davantage aux crimes domestiques, prédominait, ¿t une certaine époque, tant à Rome qu'à Paris, l'associalion pour empoisonnement. Les femmes n'entrent, d'ailleurs toujours, que trop dans les bandes de malandrins, à qui elles servent de recéleuses, d’indicatrices, ou de maitresses.

Les associations de malfaiteurs se composent, presque toujours, de jemnes gens. Sur 900 brigands de la Basilicate et de la Capitanate, on en comptait 600 ìgés de moins de 25 ans (Pani-Rossi); presque tous étaient célibataires, beaucoup enfants naturels, comme Tardugno, Coppa, Masini, ele.; sans instruction, gens de métier ou paysans, bouchers, bergers, anciens militaires, en un mot, exergant une profession manuelle ou le métier des armes. 
Ce n'est, guère, que dans les grandes villes que l’on peut roir des socićtés criminelles composíes de gens ayant reçn de l'instruction. La bande Coulin était composée de merciers, de peintres, de concierges; Cartonche, Jacenaire, Teppas, chefs de bandes i Paris, étaient de bonne famille. On a vu it Paris la bande dite des habits noirs, dont les membres étaient vêtus à la dernière mode. Elle était commandée par un ancien officier, Maylialı, joyeux convive el poète à ses hemres; elle comprenait des huissiers, des souteneurs, des courtiers el des comtes en déconfiture. - La bande Mallet (1845) était dirigée par un capitaine de la garde nationale. - Celle de Haycnce avait pour chef un exséminariste qui savait le latin et le grec. - La bande Graft se composait de gros négociants. - On a vu à Palerme des propriétaires, des prêtres mèmes, se mêler à des malandrins. Il n'est pas rare de voir des associations criminelles se former an scin de sociétés honnêtes, dans celles de sccours mutuel, par exemple, comme à Ravenne et à Bologne (Paggi); ou bien entre les ouvriers d'un même atelier, qui se laissent séduire et entrainer par un camasade ou par leur chef. Ciest ainsi que Prout, employé comme secrétaire dans une manufacture d'armes, put organiser sa bande; c'est ainsi, également, que se forma une sociélé de chourineurs parmi les cordonniers de Livourne.

3. - Organisation. - On a remarqué, que beaucoup de ces bandes, tout en se montrant ennemies jurées de l'ordre et de la société, présentent une espèce d'organisation sociale. Presque toutes ont, pour exemple, un chef armé d'un pouvoir dictatorial; et ce chef, comme ceux des tribus sauvages, doit son autorité bien 
plus à ses qualités personnelles qu'à l'assentiment d'une foule turbulente. Toutes, aussi, se ménagent au dehors des affiliés, des protecteurs pour les jours de danger. Quelquefois, dans les bandes nombreuses, on observe une véritable subdivision du travail: il y a un bourreau, un maître d'école, un secrélaire, un commis-voyageur, quelquefois même un curé et un médecin. Toutes ont une espèce de code, ou de règlement, qui n'a pas, presque jamais (Abbadie fait exception, mais e'était un demi-farce) à la vérité, d'auteur connu, qui s'est formé spontanément et dont les articles ne sont pas écrits, mais, qui est respecté à la lettre et par le plus grand nombre.

Les bandes de Sicile, par exemple, celles du Pugliese ou du Lombardo pour admettre un homme à chevaucher (c'est-ì-dire à voler en compagnie), exigeaient de nombreuses épreuves, et l'assentiment de la majorité. Un de leurs membres renait-il à transgresser les lois qui les régissaient, on le mettait à mort; mais, auparavant, on lui faisait la cause; un homme de la bande exerçait les fonctions d'accusateur public, les chefs celles de juges, et le coupable prétendu pouvait se défendre, bien que, à vrai dire, la sentence fût toujours ígalement défavorable.

Un des plus graves méfaits punis par ce code était de voler pour son propre compte, sans en faire part à la société; venait ensuite la révélation d'un crime commis avec des complices. Cela est si vrai, qu'on a vu Pugliese, aux Assises, s'excuser de ne pas connaîlre les méfaits de ses compagnons: il n'aurait pu s'en informer, disait-il, sans manquer à la loi.

Les chourineurs de Ravenne avaient une espèce de hiérarchie; à l'instar des camorristes, ils donnaient à 
leurs chefs le nom de maitres, et, avant de déliherer sur une entreprise nouvelle, protaient serment sur un poignard; souvent, avant de commettre un mentre, ils prévenaient leurs victimes par des menaces symboliques. Ainsi laisaient encole les chefs des balle de Bologne.

La bande de Mayence se subdivisait, dans ses entreprises, en groupes de cing membres au plus; tous participaient au butin, même les alısents. Chacun des coups était préparé par un recéleur (Kocliener) d'après les aris fommis par des espions toujours en éveil. Le chef, après en avoir pris comnaissance, rédigeait le plan, qui était exactement suivi. Ils devaient s'en tenir a l'or et aux bijoux, et ne se rabattre sur les marchandises qu'a défaut d'autre chose. En outre, ils ne devaient pas commettre de vols dans lenr localité, ear il fallait se ménager un domicile sûr; il leur était même enjoint de dénoncer cenx qui enfreindraient cette loi. S'il leur arrivait d'ètre mis en prison pour une cause légère, ils devaient aroir la précaution de cacher des clous et des limes dans les fontes des murs; cela pouvait leur ìtre utile plus tard. Quand ils marchaient en nombre avec leur butin, les femmes tenaient la tête de la colonne et portaient des paquets simulant des enlants à la mamelle. - Dans la bande de Schwarzmüller (avec 150 membres) chacun avait un manuel d'action, un dictionnaire d'argot et sa tiche particulière; ies uns faisaient les épileptiques, les antres les fous, les muets (Avé-LatueMast, Ueber die Gaunerthum, 295).

4. - Camorra. - Lorganisation criminelle la plus complète nous est offerte par l'association, qui domine dans les murs de Naples sous le nom de Camorra. La 
canorra se constituait partout où se trouvait un certain nombre de prisonniers ou d'anciens détenus. On formait de petits groupes indépendants les uns des autres, mais néanmoins soumis à une hiérarchie qui subordonnait, par exemple, les centres des prisons de Naples à ceux de Castel Capuano, et ceux-ci au bagne de Procida. On y comptait divers grades (1).

Le picciolto, (enfant), aspirant, ne derient picciolto di sgarro qu'après avoir prouvé qu'il a du courage et qu'il sait garder un secret. Il devait pour cela blesser ou tner celui que lui désignerait la secte; si les victimes manquaient, il s'escrimait au couteau, faisait une tirata, avec un de ses fulurs collègues. C'est justement comme dans les épreuves pour la virilité des jeunes sauvages (V. Part. $\mathrm{I}^{\mathrm{e}}$ ). Au temps passé, l'épreuve était plus difficile. Le candidat derait cnlever une pièce de monnaie pendant que les camorristes s'efforçaient de percer cette piece avec leurs poignards. On parle encore d'autres épreuves analogues à celles des francs-maçons, de coupes empoisonnées qu'ils devaient approcher de leurs lèvres, de saignées, etc. Je ne sais ce qu'il y a de rrai dans tout cela; mais, à coup sûr, de telles épreuves ont depuis longtemps disparu.

Le picciolto subissait un noviciat de deux, trois, et. quelruefois huit années. Il passait ce temps au service d'un camorriste, qui lui confiait ses affaires et les entreprises les plus fatigantes et les plus périlleuses, lui donnant de loin en loin quelques sous, par charité. Quand il avait commis un méfait considérable, ou que, à force de zèle et de soumission, il avait conquis l'estime du chef, celui-ci réunissait l'assemblée, exposait

(1) Voir, pour des détails plus complets, l'appendice Sulla Camorra, vol. Ille. 
les titres du postulant, et, après délibétation, le faisait recevoir camorriste. Le nouvean membre renonvelait la tirata en présence de l'assemblée, et jurait sur denx poignards mis en croix d'ètre fillèle à ses coassociés, de se montrer en tout ennemi de l'autorité, de n'avoir aucun rapport avec la police, de ne point dénoncer les volcurs, mais de leur porter au contraire une affection particulicre, comme $\dot{a}$ des gens qui exposent conlinuellement leur vie; le tout finissait par un banquet. Chacun pouvait monter en grade en défiant un supérienr à la tirala, et en le tuant ou lui faisant une blessure grave. Les camorristes qui, à leur tour, se subdivisaient en simples affiliés et en propriétaires (ceux-ci étaient les rétérans, les sénateurs de la bande), élisaient parmi les plus couragenx ou les plus riches un chef qui sappelait Masto, Maestro (maitre), ou Si (oui).

Celui-ci ne ponvait prendre de détermination imporlante sans consulter les électeurs qui, réunis en assemblée, discutaient le plus gravement et le plus correctement du monde, sur les plus petites ehoses comme sur les questions de vie et de mort. Il était assisté d'un comptable, contarulo, d'un trésorier, capo carusicllo, enfin d'un secrétaire choisi parmi les moins illettrés de ses hommes. Il devait indiquer les marchandises de contrebande, régler les litiges (et il avait pour cela toujours trois armes sur lui ou dans un coin), proposer aux assemblées des punitions (qui variaient de la priration partielle ou totale du butin, à la flétrissure et à la mort), on la grìce, alzata di mano (acclamation à main levée), accordée généreusement dans les circonstances heureuses. Mais la partie la plus importante de sa charge était de distribuer chaque dimanche la camorra, ou baraltolo (petit pot), on sala (petite tranche). 
C'est ainsi qu'ils appellent le produit de leurs extorsions régulières sur les maisons de jeu, les lupanars, sur les marchands de pastèques et de journaux, les roiturins, les nuendiants, le sang, la peau et les os des animaux, et enfin sur les messes et sur les prisonniers, qui furent leur premier champ d'exploitation et fournissent, encore, le meilleur de leur revenu. A peine entré en prison, le paurre diable devait payer ce que l'on appelait l'huile pour la madone; il donnait ensuite le dixième de ce qu'il possédait, et payait enfin pour boire, pour manger, pour jouer, pour vendre, pour acheter, pour dormir sur une couche moins dure. Les plus pauvres étaient ruinés par ces extorsions: ils se voyaient forcés de vendre la moitié de leur ration, le peu de vêtements qu'ils avaient sur le dos, s'ils voulaient fumer une pipe ou faire une partie; s'ils ne voulaient pas jouer, on les y contraignait, car le jeu était le principal revenu du camorriste, qui gagnait ainsi des deux côtés. - Oh! disait l'un d'eux, nous savons extraire l'or de la vermine. -- En effet, sous les Bourbons, ils faisaient fortune, en forcant les gens timides à acheter des portraits du roi; depuis 1866 , ils offrent leur protection, moyennant finances, aux partisans des Bourbons et à ceux qui aspirent à des fonctions administratives ou politiques.

Leur code, sans être écrit ni même formulé, n’en était pas moins suivi avec la plus grande exactitude. Le camorriste ne pourait tuer un collègue sans l'autorisation des chefs; il est rrai qu'en revanche il pouvait faire disparaître tout autre individu, surtout quand il s'agissait d'une vengeance, non seulement sans permission, mais avec l'espoir d'avancer en grade et d'établir sa réputation. Il ne devait pas avoir de rapports arec 
lat police: il pouvait suspendre un inférieur pour une durée de 5 à 18 jours. Etait condamné à mort quiconque trahissait la société, ou tuait ou rolait sans l'ordre des chefs; ou dérolait une partie dı barallolo, (a moins qu'il ne rendit la somme avec l'intérêt); ou violait la femme d'un chef; ou refusait de commettre un meurtre quand it en avait recu l'ordre; ou tentait de changer les statuts de l'association; ou se montrait làche, auquel cas tout sociétaire, fût-il le dernier, avait le droit de le frapper, pourvir qu'il te fìt en présence de deux témoins. Dans les autres cas, la société se réunissait pour prononcer le jugement. Avait-on concu des doutes sur la fidélité d'un collègue? Avant de le condamner on lui envoyait un plat de macaroni; s'il refusait d'en manger (ra sans dire par crainte du poison), on acquérait la certitude de sa faute et l'on prononcait sa condamnation. La sentence était prononcée solennellement, et le sort désignait le picciotto (novice) qui devait l'exécuter. Quelquefois on choisissait deux hommes: l'un pour commettre le meurtre ou frapper le coup prescrit, l'autre pour en endosser la responsabilité et en subir la peine. Ce dernier était sûr d'obtenir de l'avancement; on lui faisait la réputation d'un héros, d'un martyr de l'honneur.

On aurait peine à croire avec quelle ponctualité de telles sentences sont exécutées, et subies, ce qui paraitra plus extraordinaire encore (1).

(1) La preuve en est dans le fait suivant, qui se produisit en 1876, parmi les détenus de la forteresse d'Ischia, et qui prouve: $1^{\circ}$ l'utilité $^{\circ}$ de l'internement pour l'extirpation de la camorra; $2^{\prime}$ l'extension extraordinaire de cette secte dans les prisons, même hors de Naples.

Un jour, Ginseppe de liberto vint, en gémissant et tout hors de lui, faire au gouverneur du château la déposition suivante:

- Dans la partie du château affectée aux déportés, s'est établie depuis quelque temps la camorra, et, pour mon malheur, je m'en suis trouvé 
Je dois à un de mes bons amis de Naples la preuve suivante. Un camorriste avait recu du chef l'ordre de tuer son ami le plus cher; désolé, mais ne songeant point à désobéir, il va lui en porter la nouvelle; la victime ne demanda qu'une chose comme faveur suprème, cétait qu'on lui laissàt le choix du genre de morit. C'était l'année du choléra: le fer lui faisait peur, il aima mieux se jeter sur un lit où un cholérique venait d'expirer. Les croquemorts arrivent, le prennent pour le défunt, l'enferment dans un sac et le jettent sur un monceau de cadavres. Il put s'en évader, et, respecté par le fléau, il vagabonda par les rues de Naples. Malheureusement il fut aperçu du chef, et, peu de jours après, le couteau d'un picciotto meltait fin à ses jours et à ceux de son ami trop compàtissant (1).

un des eliefs. Parmi les lois que nous avous établies, se trouve celle d'obliger tous les détenus à nous payer dix centimes par jour. Un certain Raso n’a pas voulu s'y soumettre. Nous, chefs de la camorra, arons mis aux roix la punition qu'il convenait de lui infliger, et l'ou a voté la mort. Les votes ont été unanimes; le sort ma ensuite désigné pour frapper Raso. J'ai d'abord accepté et je devais ce matin commettre le crime. Mais, réflechissant aux tristes consiquences d'un tel forfait, dont la cause serait iusiguifiante, puisqu’il ne s’agit que de quelques centimes, j'ai retenu mon bras et je suis sorti du chateiu. Je rous supplie de m'isoler: car mes camarades, après cette trahison, me tueraient saus pitie; il suffirait même pour cela du dernier des camorristes.

"Les aftilies à la sacicití sont an nombre de vingt-luit. Un mot d'orelre lenr peruet de se recomaitre dius toutes les colonies pinitenciaires: ce mot est changé tous les mois et domn par un elief suprêne *.

(1) Le picciotto Tommasini avait dechargé son revolver, sans qu'il en resultit d'ailleurs aueun mal, sur le eamorriste P..., qui maltraitait sa maitresse; il dut, pour obtenir son paıdon, baiser publiquement le.... de l'lomme qu'il avait oftensé. In certain Filuleltia, qui s’était contenté de murnurer contre le mème camorriste, fut condamué à la même peine; il dut, en ontre, couper avec un rasoir la gorge à la pauvre femune qu'il avait vonlu protéger par ses discours. - Et cela en 1881! 
Et ce n'est pas seulement a Naples et dans la Pouille que ccla arrive, mais à peu-près dans toutes les prisons de l'Italie méridionale. Il. Gialofolalo /Archivio di psichiatria, rol. 1, p. 373) public la lettre d'une jenne napolitaine à son amaut, détenu dans l'ìle de Giglio. Cette fille demande la grâce d'un prisonnier qui devilit être condaunné à mort par la camorra pour aroir refusé sa contribution; et le détenu, du fond de sa prison, lui accorde cette gràce avec une majestí olympienne.

Entre sociétaires, tout différend devait cesser à l'intervention d'un tiers, qui en référait au chef; celui-ci prononçait en arbitre. Toutefois, quand la sentence ainsi rendue ne satisfaisait point les adversaires, ils ćtaient libres de recourir aux armes.

Le camorriste, après cela, était le juge naturel de ses compatriotes, surtout en ce qui concernait le jeu ou les querelles; il maintenait l'ordre dans les maisons de prostitution et dans les prisons, favorisant, bien entendu, ceux qui avaient payé la redevance. A son tour, il était comme une caisse d’épargne virante: sur les taxes fournies par les prisonniers, il mettait de côté un fonds de réserre, qui servait ì empècher de mourir le paurre diable qu'on avait complètement dépouillé; cette mesure contribuait, en mème temps, à le maintenir dans une plus grande sujétion. - Le camorriste élait encore un courtier pour le petit commerce; ì l'occasion, il devenait un excellent policier; après aroir dépouillé le négociant en gros, il surveillait, pour son compte, le revendeur au détail, et l'obligeait à remettre fidèlement au patron le produit de sa rente.

Les vieux canorristes et leurs veuves recevaient une pension régulière; le malade, le prisonnier, touchaient 
leur part de butin, bien qu'ils ne fussent pas appelés aux délibérations de la société.

5. - Mafia. - Les bonachi, ainsi appelés jadis à canse de leur casaque, les sgaraglioni, les spadaiuoli, on, comme ils se sont appelés, paraît-il, il y a quelques années, à la suite d'une comédie populaire de Rizzotto, les Mafiosi, sont certainement une variété des anciens camorristes. Celte variété est due peut-être à la ténacité plus grande qu’ils mettent à garder un secret, qualité propre aux races sémitiques (1); peut-être aussi à leur extension parmi les hautes classes de la société et principalement chez les avocats; car il se trouve à Palerme des millier's d'avocats et de chicaneurs. Nais elle provient surtout de l'organisation féodale dont ils conservent les usages et jusqu’aux dénominations hiérarchiques, soit en prison, soit au dehors, et même en beau= coup dendroits la livrée: anneaux, cravates, arrangement des chereux, chapeaux relevés, langage concis et impérieux. Ils ont pu perdre en partie leur organisation étroite; mais ils savent la retrouver au besoin et même la dépasser; je n'en veux pour exemple que la rérolution de Palerme et le vol du Mont de Piété. - A Messine, il y a quelques années, on distinguai! les chefs suprêmes, bravi, qui étajent élégamment vètus et portaient des

(1) Je rappellerai an leetenr que M. Maxime du Camp, à propos des juifs français condamnés par les tribmanx, note cette fidéliti à garder un secret comme distinetive de leur race.

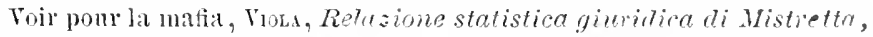
1881, et la belle monographie de Lestwal (Arefirio di psichiatria. vol. 1, p. 362). Il en résulterait que le mot mafice rient de l'habitude qu'ont les manvais sujets de Trapani de se eacher dans les carrieres de tuf des envirous, carrières appelées mafe. - Toir aussi dural, Sulla Maffe, 1880, Torino, (Bil). Antr. Giur., 11, $s$ virl. 
gants paille; les accollellatori, chourineurs, pris dans la populace; et, en troisième lieu, les voleurs repris de justice. Ils ont renoncé à prélever un impôt sur les revéndeurs all délail el sur les maisons de jeu, peut-ître parceque l'amoindrissement de la population et la pauvreté plus grande du même jeuple rendaient leurs bénéfices illusoires; mais ils ont trouvé des ressources plus abondantes et plus soudaines dans l'entreprise des vengeances particulières, dans le trafic de leurs votes en conr d'Assises, dans la contrebande, les loteries clandestines, l'exploitation des travaux publics, le concours exclusif qu'ils prêtent pour l'aequisition des biens ecclésiastiques, et quelquefois encore dans le vol, le chanlağe, le brigandage à main armée.

Ils suivent tous fidèlement les règles de ce code anonyme, mais appliqué arec tant de rigueur, de l'omertá, qui nous a été rérélé par MM. Tommasi-Crudeli et Vincenzo Maggiorani, et qui se retronve souvent dans les proverbes populaires (1). En voiei les articles principaux: grarder un silence absoln sur les crimes que l'on voit commettre aux autres, et se trouver prêt, si l'occasion s’en présente, à prêter un faux témoignage pour en faire disparaitre les traces; accorder protection aux ri-

(1) Quand un homme est mort, on doit sauver le survivant. - Le timoignage est elose excellente, à eondition qu'il ne nuise pas au prochain. - A qui te prend ton pain, toi à ton tour, prends la vie. - Les armes alabord, la femme eusuite. - Tomasi-Crudel, La Sicilia, 15il, 1) 60 . - Après l'assassinat de Pancaro à rittorio, tous les témoins hounêtes itaient paralys 's par des menaces ineessantes; on lisait sur les murs:

Qui se tait sera paye;

Qui parle sera tuć.

On voit se former it toute hemre, en sicile, des assoeiations seerites et sangninaires, qui ont tous les rites des anciennss socites sceretes politiques. 
ches inoyennant finance; défier la force publique en tout temps et en tout lieu, par conséquent aroir toujours sur soi des armes prohibées; se battre en duel pour les motifs les plus frivoles et ne pas hésiter à donner un coup de couteat en trahison; se venger à tout prix des injures reçues, même si l'on est intimement lié avec l'offensenr. Quiconque manque à un de ces préceptes est déclarć infame, ce qui revient à dire qu'il doit être tué dans le plus bref délai, même s'il est en prison; là, à défaut d'armes pour le frapper, on l'étouffe dans le baquet aux excréments; il recoit aussi, comme aux temps de l'antique Rome, l'ordre de se donner la mort, et il obéit stoïquement, sachant bien que la condamnition est irrévocable. Arant de tuer un affilié, on l'avertit, soit en traçant une croix sur sa porte, soit en tirant un coup de fusil contre sa maison.

J'en ai vu plusieurs qui avaient pa se dérober à la mort; mais qui, fous de terreur, demandaient en grìce d'utre enfermés seuls dans une cellule de la prison.

Une foule d'observateurs ont prétendu tirer, de ces coutumes et de ces lois spéciales aux associations criminelles, un témoignage en faveur dı principe iternel de la justice.

Mais l'idée de justice, prise en elle même, n'y est pour rien; c'est la nécessité qui les guide. Si l'on pourait se dénoncer réciproquement sans obstacle, si rien n'arrètait l'anarchie qui ne manquerait pas an milieu de tant d'hommes altérés de sang, nulle association pourrait se maintenir un seul instant. Il est bien naturel, d'ailleur, que tout groupe d'hommes appelés í virre ensemble quelque temps, adopte une rie spéciale; c'est ce qui arrive aux moines, aux soldats. Cutle espèce d'organisation judiciaire serait comme la pseudo-membrane 
d'un malade, où personne ne s'aviserail de voir une marque de santé, bien qu'clle se conservat longtemps, bien qu'elle finit par s'accommoder en quelque sorte el s'adapter à la vie. Mais les fausses membranes, par suile mème de leur origine, s'altèrent plus facilement que les vieritables; ainsi en est-il des lois établies par les criminels: elles sont souvent enfreintes par leurs propres auteurs, elles conservent la fragilité morbide de leur origine, et nous donnent seulement l'idie d'un ordre grossier tenant le milieu entre l'anarchie et le despotisme, comme chez beaucoup de peuplades sauvages.

Coppa, Palmieri, Andreotto, ont étí tués par leurs hommes. Malgré la terreur inspirée par les lois de la mafia, la police de Pilerme comptait parmi ses membres beancoup d'affiliés. Les plus telribles défenses n'empêchèrent pas Doria, en 1861, de dénoneer Foresticro, ni Virzi de révéler les noms des complices qui l'avaient aidé a piller le llont de Piété. Les camorristes, qu une de leurs lois oblige à soumettre leurs différends ì leurs chefs, se sont battus des centaines de fois a l'intérieur des prisons. Lombardo répétait plus d'une fois à ses juges: "C'est l'habitude des voleurs de se voler entre eux, comme des assassins de s'entr'égorger ». Les chourineurs de Ravenne avaient tué un grand nombre de leurs associés, p. ex. Soprani, les deux Tassinari, etc., et ils les avaient tués en traitres avec les plus grands raffinements de cruaulé.

Ces manquements nombreux des brigands à la parole donnée font que bien souvent on refuse aux associations criminelles le titre quelles ne meritent cependant que trop; or c'est là, pourtant, un de leurs caractères les plus remarquables. 
On pourra m’objecter que, bien des fois, la mafia s'est rencontrée sans qu'il y eùt de véritables chels hiérarchiques; mais cela ne diminue en rien, du moins pour l'anthropologie, l'idée d'association, de même que la privation de gouvernement ou de chef, ne fait pas disparaitre l'idíe de tribu, par exemple en Australie. C'est là seulement une preuve de sa diffusion dans toutes les classes, de sa condition endémique, comme diraient les médecins, condition qui rend cet aiguillon spécial moins nécessaire à leur formation et à leur maintien, et les dispense d'y recourir, à moins de circonstances exceptionnelles.

Dans beaucoup de bandes de brigands, comme dans les tribus sauvages, les chefs peuvent être renouvelés, renversés, faire mème complètement défaut, sans que pour cela l'association en souffre. Nous en ayons vu un exemple célèbre dans ce qu'on a appelé la bande Poulain, qui n'eut pas de ehef, à moins qu'on ne reuille donner ce nom à l'homme qui indiquait les coups à faire ou qui remplissait l'office de recéleur. Au temps de Cartoucle, des milliers de voleurs et d'assassins passajent pour appartenir à sa bande, et cependant travaillaient pour leur propre compte, ne s'associant à lui qu'en de rares circonstances. Aussi, quand je vois, dans un pays, un nombre eonsidéralole de pelits groupes de malfaiteurs, groupes anonymes et acephales, jy trouve un indice plus grave rue lorsquils ont un ehef. Dans ce dernier cas, en effet, ils penvent avoir été poussés el maintenus dans la mauvaise voie par l'initiative d'un seul homme, et celui-ci, en disparaissant, emporte avec lui tout le mal; tandis que le fait même de leur existence, sans qu'il y ait personne à leur tête, indique une 
tendance déplorable, une grave maladie sociale au sein du pays qui les a vus naitre.

Quelques observateurs, fondant leur opinion sur l'altachement de ces misérables pour leurs statuts et sur une certaine apparence chevaleresque, ou sur la couleur politique et religieuse dont se sont parfois revêtues la camorra et la mafia, pourraient douter de la nature essentiellement eriminelle de ecs associations. Avouns-le d'ailleurs; elles ont eu quelquefois des éclairs de générosité; à l'égard des prisonniers politiques, par exemple, sous les Bourbons. Nous les avons vues, également, couvrir les faibles d'une protection efficace, apres les avoir taxés, bien entendu. Et on en pourrait dire autant des meurtriers de Ravenne, des contrebandicrs de Mandrin, des brigands de Majno della Spinetta (1), qui se donnaient pour protecteurs des petits eommercants et vengeurs politiques. Hais au fond, eette générosité, cette couleur de parti, ne furent, la plupart du temps, qu'un vernis destiné à couvrir les actions délictueuses, à combattre les lois sous prétexte de combattre les Gouvernements; à se faire, peut-être, quelquefois illusion à eux-mèmes. - En vent-on la preuve? Les camorristes, qui se donnaient pour des révolutionnaires sous les Bourbons, se disent, aujourd'hui, bourbonniens et autonomistes. Ceux de la Mafia se conduisaient de même en 1820; ils font pis encore de notre temps: garibaldiens en 1860, ils sont devenus réactionnaires en 1886 ; en réalité ils ne souhaitent qu'une chose: e'est de se

(1) Un brigand appartenant à la bande de Majno della Spinetta avait dérobé einq sequins à un paysan. Celni-ci vint réclamer, et Iajno, jetaut sur le voleur un regard conrroncé, l'obligea à restituer le donble de ce qu'il avait pris, et à tenir la montagne pendant six semaines. " Tu as, lui dit-il, manquè à ton devoir!* 
couvrir d'une bannière politique pour faire le mal avec plus de facilité.

D’ailleurs, les brigands célèbres s'entourèrent toujours d'une certaine auréole de sentiment chevaleresque; un peu par suite de cette générosité qui se retrouve toujour's chez l'homme vigoureux, un peu aussi par la nécessité de se rendre favorable le bas peuple, qui leur fournissait des secours ou leur ménageait un asile.

Au fond, la camorra et la mafia ne sont que des variétés du brigandage vulgaire. Comment en douter, quand on voit les affiliés de ces bandes présenter les caractères particuliers aux autres criminels? Ils aiment à se parer de joyaux, à porter un uniforme qui les distingue, par exemple, un pantalon blanc ouvert sur le pied, etc.; nous avons vu que c'est là un des caractères propres aux voleurs. Tout comme les scélérats ordinaires, ils ont lem argot. Ainsi le camorriste dira: dormente pour mort; chats pour patrouille; rubino pour œil; camicia ou chemise est pour lui la conduite d'un camarade, terme cmprunté à la bureaucratie; linge le produit de ses extorsions; tic-tac le revolver; martino le couteau; cassa la poitrine. Ces trois dernières expressions se retrouvent rlans l'argot de toute l'Italie. Les membres de la société sont désignés par le mot si (oui); ils s'appellent encore compagnons, comme les voleurs de France s'appellent amis.

Le membre de la camorra et de la mafia a son domicile principal dans les prisons. Il se montre implacable dans ses inimitiés. On dit que l'un l'eux, ayant à se venger d'une raillerie offensante, mais se sentant le plus taible, couva sa vengeance pendant quinze années, et, son adversaire ayant été enfin condamné à mort, sollicita de la cour de Naples et obtint la faveur 
de remplir l'office de bourrean. Un autre, ajoute-t-on, était sur le point de mourir, déroré par la phthisie, quand il apprit qu'un de ses camarades tenait sur son compte des propos offensants: aussitòt le voili qui súlance de son lit, court à la taverne où se tromvait son houme, le tue, et meurt lui-mème quelques instants après, achevé par cet effort suprème (Moxwer, l. c.).

Ajoutons que cette belle horreur du vol et de la délation, dont ils font pararle dans leurs règlements, n'est en réalité qu'un leurre. Je n'en veux pour preuve que Lucianello, ce camorriste des orfirres, qui rolait des bijoux; Anglesino et Del Giudice qui furent sept fois emprisonnés pour rol; Garofalo, qui le fut cinq fois; Gallucei, qui se faisait donner de l'or pour le revendre et menaçit de mort quiconque se plaindrait, fût ce m arocat ou même un commissaire. On ne peut done soutenir que la camorra se soit hornée à de simples extorsions. Et qui ne sait d'ailleurs que, pendant un certain temps, gràce à une aberration incroyable, mais inévitable, peut-être, de Liborio, les camorristes ont fait la police de Naples, eux qui ont pour premier principe d'éviter tout rapport arec la police? Bien mieux, parmi les officiers de la camorra, il y eut, du moins à une certaine époque, un chirurgien char'é de désarticuler les doigts des picciotti, pour les rendre plus aptes au vol.

6. - Code des criminels. - La manie de légiférer qui distingue notre siècle a pénétré jusques au sein de ces associations criminelles. Je crois même qu'à notre temps seul était réservé le spectacle d'un véritable code écrit dans la bande que commandaient à Paris, Gilles, Abadie et Claude. Les articles de ce code, portent les initiales $G$, ou A, ou C, selon leur auteur, et limitent à 14 le 
nombre des associés; ils indiquent certaines facons d'opérer dans la perpétration du crime, comme: se débarrasser des vêtements qui pourraient meltre sur la voie du coupable, en adopter de spéciaux pour le travail, éviter les chaussures qui font dı bruit; marcher à rebours dans tout endroit où les pieds laissent une empreinte visible, afin de tromper toute investigation; se loger sous un faux nom, et ne laisser ni celui-ci, ni le véritable, sur une carte, sur un livre, etc. Le mème code interdit d'avoir une maitresse sérieuse; il n'accorde que des liaisons passagères, el menace de mort quiconque fera connailre a sa maitresse d'un moment les secrets de la société. Il défend d'employer les armes à moins d'une extrême nécessité (si, par exemple, le criminel est reconnu, ou si la victime prend la fuite ou pousse des cris); il indique mème celles qu'on doit employer de préférence.

La plupart des infractions à ce code sont punies de mort.

En Espagne, on a récemment decouvert une association très-étendue, celle de la Main Noire. Elle se composait de ces visionnaires qui ne voient la solution du paupérisme que dans une catastrophe sociate, de vagabonds, de criminels, et de ces ètres làches qui s'enròlent dans une conjuration pour ne pas en derenir les victimes. - Cetle association avait aussi un code déclarant que le but poursuivi était la défense des pauvres et des opprimés contre leurs exploiteurs et leurs boureaux.

"La terre a été créée pour le bien-être des hommes, ils ont tous un droit égal à sa possession; l'ordre social actuel est inique; les travailleurs produisent et sont maintenus dans l'esclavage sur les terres des riches; on ne saurait donc jamais hair trop fortement tous les partis 
politiques, qui sont tous également méprisables; toute propriété acquise par le travail d'antrui est illegitime. La société met les riches hor's du droit des gens, et diclare que pour les combattre tous les moyens sont hons, sans exception, le fer, le feu, et mème la calomnie".

Les statuts orgimiques de la Main Noire sont rédigés en termes brefs et catégoriques. Il n'y a quiune sanction générale à tous les articles, c'est la peine de mort».

«Quiconque révèle, par imprudence ou mauvaise l'oi, les actes dont il a connaissance, est privé de ses droits de sociétaire pour un temps illimité on condamné à mort, selon la gravité de la révélation.

"Toute mission confiée à un affilié est obligatoire. Sil refuse de l'accomplir, il sera considéré comme un traitre.

"L'affilié doit avoir pour rigle de dissimuler en public ses rapports avec l'association, et les sympatlies qu'il a pour elle.

"Toul affilié est soumis à un noviciat: il doit donner des marques positives de sa sincérité, et ce n'est qu'après cette première épreure qu'il est admis en présence des initiés de la section à laruelle il appartiendra. Les initiés s'entourent, en cette circonstance, de toutes les précautions nécessaires pour éviter une surprise. Ils entendent le néophyte; puis, l'on procède à un vote. Nul n'est admis, s’il n'a ohtenu l'unanimité des suffrages.

„Tout membre d'une section est obligé de lui soumettre ses vues sur le meilleur moyen à employer pour allumer un incendie, pour commettre un meurtre, pour nuire aux bourgeois. Il paie une colisation de 5 centimes par semaine. Pour les sommes plus élevécs, on a recours à une cotisation individuelle; s’il se présente une dépense extraordinaire, on s'adresse à la fédération. 
"Quiconque se tient à l'écart d'une façon permanente est déclaré inhabile et expulsé de l'association; mais il reste sous la haute surveillance du tribunal, et toute révélation de sa part serait punie de mort. Aucune considération d'amitié ni de parenté ne saurait éloigner du traître la peine capitale.

"On ne doit respecter à aucun prix la vie d'un frère ou mème d'un père qui met en danger un nombre considérable de personnes. Chaque fois qu'un groupe d'une certaine localité ne pourra exécuter la sentence de mort prononcée contre un tiaitre, les affiliés d'une autre localité seront chargés de ce soin ".

Les membres du tribunal usaient de divers moyens pour assurer le secret de leurs propres actes: ils changeaient fréquemment de nom, ils avaient un chiffe spécial pour leur correspondance, etc.

Tous les registres, - depuis les livres de comptes, jusqu'it l'état civil des affiliés, - étaient tenus dans le plus grand ordre; la division territoriale y était parfiritement observée, comme celle des différentes professions. L'Andalousie el les provinces limitrophes de l'Estremadure, Jaën, Murcie, contenaient 130 fédérations et 42.000 affiliés.

Sonvent la voix publique exagère le mal, imagine des associations véritables lá où il n'y en a qu'un embryon, el, stimulant ainsi la vanité, finit par les faire naìtre. Telle fut, par exemple, cette Compagnia della Teppa qui n'étail, au fond, qu'ın groupe de mauvais dròtes, réunis par ee besoin d'activité exagérée, par cet appétit brutal et impérienx du sexe, qui pousse tant de fois le jeune homme au crime, comme nous le verrons plus loin, et qui, a Naples, est désigné par un mot spícial: Scuonceco. (Arch. di psich., vol. Iv, fase. $3^{\mathrm{e}}$ ). 
En revanche, certaines associations inoffensives ot mème philanthropignes dígénèrent en sociétes criminelles, quand elles sont transplantées dans un mansais terrain. C'est le cas de la Mano Fraterna (la Nain Fraternelle) de Sieile, déconverte en 1883. Simple société de secours mutuel at lorigine, elle se transforma touti-coup. Certains devoirs furent la source de certains crimes. Tous les membres qui la composaient devaient faire respecter en eux l'honneur du corps, protéger les femmes, venger les injures de leurs confrères comme les leurs propres, travailler à les saurer s'ils étaient poursuivis; tout cela conduisit à l'assassinat, qui était. réglé et exécuté comme, entre chasseurs, la poursuite et la mort d'un lièvre. 


\section{CHAPITRE XIII}

\section{Le fou moral et le criminel né (1).}

1. - Avant de passer à l'étude du criminel-fou, nous derons commencer par traiter, ou, plutôt, par écarter de cette étude le fou moral, dont nous nous sommes assez occupés, en étudiant le criminel-né.

(1) C. H. Hughes, A case of moral insanity. (The Alienist and Nerrologist, $1882, \mathrm{n}^{\circ} 4$ ). - WRIGHT, The phisical basis of moral insanity, viexed in relation to alcoholic impressions. (The Alienist and Nenrologist, 1882, n' 4. - A. Hollaxder, Zur Lehre von der "Moral Insamity, »1882. - Brancaleone Rubaudo, Contributo sull'esistenso della follia morale, Palerme, 18s2. - Salem-Pace. Ln caso di follia morale, Palerme, 1881. - Tambrrixi e Seppllus, Studio di psicopatalogia criminale sopra un caso di imbccilliti morale con idee fisse impulsive, Reggio, 1883. - G. B. VeraA, Caso tipico di follia morale, vilano, 1881. - Virgitio, Delle malattic mentrili, 1882. - Legrand de Saclee, Les s:gues physiques aes folies raisonmantes, Paris, 1878. - Mender, Die moralische Trasnsinne, 1876, n० 5.2. - M. Gauster. Teler moralisches Irresein, 18ri. - Motet, Cas de folie morale. (Amn. mert. psych., 1883). - Relsen. Moralisches Irresein dans le Deretsche Hochenschrift,

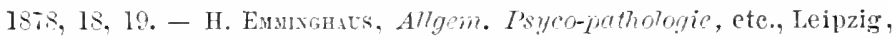
1868. - Sivare, Howal Insanity. (Jounnal of medical scienres, 1881). - Ton, I pasis ragionanti, Novare, 1879. - Grohmax, Nosse's Zeit-

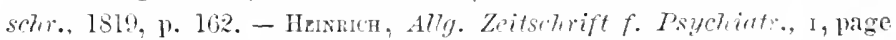
338. - Pricuand, Treatise on insamity. - In, on the different forms

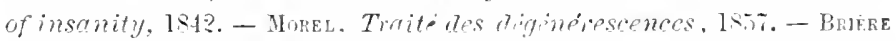

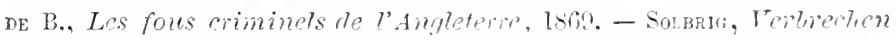

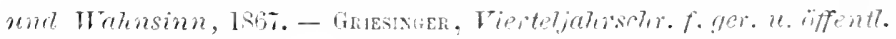

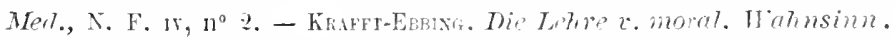

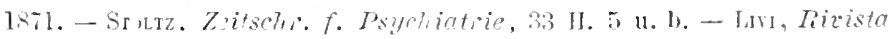
sperimentole, 1856, faseic. 5 et 0. - Guviter. Wien. merl. Hiniz, In, 
Au premier abord, le lecteur éprouvera, j’en suis persuadé, une vive répugnance ì accepter celle fusion. Pourquoi? 10 Parcequ'une longue suite de siècles nous a habitués à charger le coupable d'une responsabilité d'autant plus lourde, que sa faute est plus grande, el que nous sentons plus vivement le besoin de nous venger et la crainte de le laisser libre; en sorte que la terreur qu'il nous inspire sert de règle à notre appréeiation. En sccond lieu, parcequion n'a connu jusquici, pour arrêter le mal, d'autres moyens que la prison on la peine capitale. En un mot, parceque le sentiment de la rengeance et celui de la peur, joints à l'habitude, qui est un de nos tyrans les plus absolus, ont longtemps modifié nos jugements du tout au tout, sans nous permettre de chercher une explication de nature différente. Nojmême, comme je l'ai fait ohserver déjá dans ma préface, je partageais celte opinion pendant que j'écrivais les deux premières éditions de ce livre; je n’arais, même, pu m'en débarrasser entièrement quand j’ai entrepris liı troisième.

Jo ne pouvais délourner les yeux de l'origine du criminel-né, qui remonte presque toujours au moment de la conception, de sa diffusion tous les jours plus grande, grâce au développement de la civilisation et aux facilités que procurent les grands centres: sa bonne santé apparente, sa taille plus élevée, l'abondance plus grande des chereux, ses prassions, qui, non moins que sa physionomie, rappellent l'homme saurage plus que l'aliéné,

Jahrg. n. 4. - Wahibeng, Du Fall Hackler in Gesmmelte kleinerc

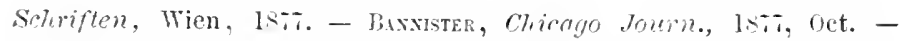

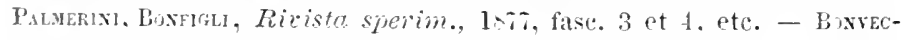
chuto, Il senso morale e la follia morale, Venise, 1883. - Dagoset, Folie morale, 1878. 
la paresse surtout, et la soif de l'orgie et de la vengeance, qu'on ne voit presque jamais clrez le fou; tout cela, joint à l'idée du péril social auquel me semblait pouvoir donner lieu la confusion du criminel et du fou, m'avaient persuadé, tont d'ahord, que j’avais mis en lumière les différences bien plutòt que les analogies existant entre ces deux malheureuses conditions pathologiques de l'esprit. Bien mieux; - alors que tous, partisans et adversaires, étaient d'accord là dessus, moi seul, n'osais encore en convenir el m'en dire convaincu.

Mais la distinction qui s'est laite ensuite entre le eriminel d'occasion et celui qui agit par habitude, la faveur unjerselle qu'a rencontrée ma proposition d'un asile criminel, la découverte de cas nouveaux, comme ceux de Faella, de Zerbini, de Verzeni, de Guiteau, de Sbro..., où la folie et le crime se mêlaient complèlement, rendajent impossible la distinction entue la folie morale et le crime. Et les caractères nouveaux assignés par les auteurs les plus récents, Krafft-Ebbing, llolländer, Mendel, Magnan, à la folie morale; ceux que jai découverts moimême dans le criminel-né, par ex. l'anesthésie, l'analgésie, les anomalies réflexes, le mancinisme ont fait subir un changement complet à mes convictions premières.

2. - Statistique. - Une des choses qui pronvent indirectement l’identité de la folie morale et du crime, et qui en nème temps nous expliquent les doutes dont les aliénistes ont été possédés jusquà ce jour, est l'cxtrème rareté de la première dans les hospices d'aliénés et sa grande fréquence, an contraire, dans les prisons.

M. Dagonet, sur 3000 lous, n'en a ru que 10 ou 12 cas. Mll. Adriani à Pérouse, Palmerini à Sienne, sur 888 fous, n'en ont pas rencontré un seul. M. Raggi en 
compte 2 seulement sur 924, et M. Salemi-Pace 6 sur 1152.

11. Verga (Amnali di Statistica, 1883, vol. 8e) sur 16.856 aliénés en a constaté 0,56010 , dont 0,65 cliez les hommes et $0,450,0$ chez les femmes. La proportion devient plus grande quand il s'agit de personnes riches soignées dans des établissements privés; elle est alors, sur 585 sujets, de $3,90_{10}$. Cette différence tient, dit avec beancoup de justesse $\mathrm{H}$. Verga, ì ce que nombre de ces riches, qui iraient peupler les prisons, doivent à des juges plus éclairés ou à des avocats plus habiles d'ètre enfermés, après leur faute, dans une maison de santé; souvent même, après un premier scandale, leur famille prend linitiative de cette mesure, pour sauver l'honneur du nom.

Sur 960 fous qui ont habité nos prisons dans une période de dix années (Stal. decenn. delle carceri, 1882), on en a compté, officiellement, c'est-ì-dire en restant fort au dessous de la vérité, que $5,20_{10}$ de cette espèce.

C'est, surtout, chez la femme que cette folie apparait le plus rarement, comme le crime d'ailleurs, et pour le même motif: la prostitution y tient lieu d'équivalent; clle en est en même temps, comme une soupape de sûreté.

La rareté dans les hospices d'aliénés, l'ajondanee dans les prisons, prouvent, avons nous dit, quoique d'une façon indirecte, l'identité du crime et de la folie morale. Mais il y avait là, pour les aliénistes, qui ne fréquentent pas les prisons, une source d'incertitudes sur l'existence réelle de cette forme psychiatrique; plus grand encore devait être l'embarras des médecins-légistes, qui sont obligés de travailler sur des faits positifs et de démonstration facile. En outre, rien n'était plus propre à susciter des contradictions entre 
les observateurs qui se sont prononcés sur la nature essentielle de certains symptômes en se préoccupant exclusivement des caractères présentés par l'un ou par l'autre dans les cas assez rares qu'ils avaient sous ies yeux.

Cependant, en réunissant tous les cas les plus classiques relevés par les auteurs, nous obtiendrons un ensemble de caractères reproduisant assez bien ceux que nous avons signalés chez le criminel-né.

3. - Poids. - Sur 37 individus atteints de folie mo. rale(1), 22, par le poids ou par la vigueur du corps, ont paru égaler ou même dépasser la moyenne normale. Nous avons fait la même observation à propos des criminels (p. 208).

4. - Crâne. - En ce qui concerne les mesures du crîne, nous sommes réduits à un petit nombre de cas, qui ne suffisent point à nous donner un criterium certain d'analogie.

Sur les 14 fous moraux cités par M. Virgilio(1), nous trouvons une moyenne de capacité crànienne de 1459 chez les femmes, $1538 \mathrm{chez}$ les hommes, avec un maximum de 1693 et un minimum de 1518 .

D'autre part, M. Campagne aurait trouvé, - mais en cela je crois qu’il exagère, - 12 cas sur 13 où le fou moral se distingue par le rapetissement du crâne et l'aplatissement de l'occiput. - MII. Krafft-Ebbing, Legrand du Saulle, signalent, également, la microcéphalie dans un grand nombre de cas. Il est bon de remarquer, ici, que les microcéphales, devenus adultes, se distinguent moins encore par la perte de l’intelligence que par la perversion du sens moral.

(I) Voir note (I) à page 542. 
II. Norel le premier, puis M. Legrand du Saulle (Gazette des hôpitaux, mai, 1878), et aujourd'luni M. KrafftEbbing, signalent chez le fou moral la fréquence du crìne étroit et pointu, la macrocéphalie, les erêtes osseuses du crìne, le crìne très-allongé ou excessivement arrondi. Dans l'étude de la face, ils relèvent la disproportion des deux moitiés du visage, l'épaisseur des lèrres, l'ouverture exagérée de la bouche, la mauvaise conformation des dents, qui tombent de bonne heure avec les accidents les plus graves; ils signalent encore la voûte du palais asymétrique, ou plate et resserrée, la luette allongée el partagée en deux, les oreilles grandes et disproportionnées. Toutes ees anomalies, celles du eràne en particulier, nous les avons r'encontrées chez les criminels. (V. I $^{\mathrm{e}}$ partie, p. 156 à 291).

En réunissant le petit nombre de eas fournis par de bons observateurs, on peut arriver à une certaine précision. Ainsi, sur 24 individus frappés de folie morale, on en a vu 10 qui avaient des anomalies du erâne, 14 qui en étaient exempts.

5. - Physionomie. - La physionomie de Sbr..., de Ross..., de X., de Cantarano, de Verzeni, reproduirait presque tous les caractères de l'homme eriminel: développement des màchoires, asymétrie faeiale, inégalité des oreilles, absence de barbe chez les hommes, traits virils chez les femmes, angle facial étroit, 71-7678. - F., du doeteur Verga, a les dents mal plantées. Gil... a les pommettes et les màchoires disproportionnées et les yeux obliqques.

Dans les planches photo-lithographiques de notre Album, on a dû remarquer que, sur les 6 hommes atteints de folie morale, 4 ont le type réritable du criminel, et 
que ce sont précisément le $n^{0} 14$ de la planche $x$, les $n^{\circ} 1$ et 24 de la planche $x$, le $n^{0} 51$ de la planche xiv. En fin de compte, sur les 14 fous moraux obserrés par II. Virgilio, 7 présentaient des défauts pour les oreilles, 3 pour les dents, 5 pour le nez; 9 seulement n'avaient rien d'anormal; soit 64010 . Comparez ce dernier chiffre à celui des idiots, $550_{10}$, et vous verrez que l'écart est presque nul.

Que si les anomalies du crine et de la physionomie sont moindres chez les fous moraux que chez les criminels, on pourrait expliquer cette différence en disant qu'un plus grand nombre de cas de folie morale, du moins si l'on considère ceux quion trouve dans les hospices, se produisant tard, à la suite d'une fière typhoüde ou de toute autre maladie, la physionomie n'a pas eu le champ libre pour prendre cet aspect sinistre qui distingue celle du criminel-né, qui a pour origine un arrèt de déreloppement ou une dégénérescence et une plus longue habitude du mal.

Il ne faut pas oublier, pour ce qui a trait à la physionomie, l'exemple fourni par les soldats, les prètres, les bedeaux. On ne saurait nier qu'une direction donnée, poursuivie dès l'enfance dans la compagnie des scélérats, ne donne au visage, au regard, une empreinte commune, surtont quand l'individu est forcé de mener cette existence dans les maisons de correction et dans les prisons. A cela, joignez encore l'attitude particulière que donnent la peur d'ètre surpris, les appréhensions d'une vie qui se passe toujours en dehors de la loi. L'illustre astronome Tacchini s'appuyait sur cette dernière raison pour m'expliquer le phénomıene d'une physionomie normale chez certains brigands, dans les pays oú le brigandage, loin d'être considéré comme chose dés. lonorante, était protégé par la population. 
6. - Analgésie. - L'analogie est eneore plus manifeste si l'ou considère les amomalies fontionneltes signalées par MII. Legrand dı Siulle, Krafft-Ebbing, Bonvecehiato, etc., strabisme, nistagme, mourements convulsifs de la face, ataxic lígère, pied-bot, hyperesthisie passagère ou périodique, exagération on manque absolu d'excitation génésiqu", incapacité it supporter l'alcool. - Presque tous les caractères déerits en cet endroit, nous les trouraimes fréquemment chez les eriminels (Y. p. 337 ).

Parmi les caractères biologiques, on aurail pu croire fue l'analgésie et l'anesthésic sont spéciales aux seuls criminels; mais les derniers faits recueillis par la science établissent précisément le contraire.

J'ai fait connaitre (Arch., I1I) comment les nécessités de ma profession mavaient mis en contact arec un fon moral qui, atteint d'une blenorrbagie aiguë, continuait a monter a cheval, faisait une ascension dans les Alpes, et riait pendant qu'on lui amputait un membre. Mr Renaudin cite le cas d'un jeune homme excellent d'abord, qui devint tout-à-coup étrangement perrers et qui, s'il ne fut pas reconnu pour absolument fou, parut du moins tont-à-fait analgésique. Revenu pendant un certain temps à une rie plus calme, il recourra la sensibilité de l'épiderme; mais il fit une nouvelic chûte morale et alla jusqu'au crime; alor's reparut l'analgésie. - La Cat. dont parle Bonrecchiato ressentait fort peu la douleur sur le còté gauche; Agnoletti parut à plusieurs reprises insensible au froid.

IIy. Tamburini et Seppilli, dans leur examen de Sbro..., meurtrier de son frère et de son père, et atteint de folie morale, ont reconnu qu'il était analgésique. lls lui traversaient aree une aiguille les chairs, la langue, 
la peau du front, sans provoquer aucun signe de douleur. - Lui... d'Asti avait la paume, et Terzeni le dos de la main, très-peu sensible au courant électrique.

L’analgésie est, done, un des caractères les plus fréquemment relevés chez le fou moral, comme chez le criminel-né. On me permettra de rappeler ici que, dans un certain nombre de cas d'hystérie hypnotique accompagnée du dédoublement de la per'sonnalité, on a vu se manifester un réveil temporaire des tendances immorales pendant que l'anesthésie ou l'analgésie était complète.

7. - Tact. - On n'a pas encore bien étudié en ellx la sensibilité tactile, mais il est assez curieux de constater que 9 des 17 individus examinés par MMI. Amadei, Berti et Tonnini parurent atteint de mancinisme sensoriel et d'obtusion.

8. - Tatouage. - On ne peut non plus nier que le tatonage, qui semble le signe caractéristique du criminel, se retrouve chez l'homme atteint de folie morale. $\mathrm{Si}$, en effet, nous rassemblons les eas mis en lumière par M. De Paoli et Severi, nous voyons qu'ils se rapportent pour la plupart á des fous moraux ou a des épileptiques. Le seril individu de cette catégoric que j’aic pu rencontrer à l'lospice de Turin était eouvert de dessins.

9. - Réaction vasculaire. - Les seules expériences faites à l'aide de l'hydrosphygmographe sur un fou moral, Sbro..., nous révèlent une autre identité: celle de la faiblesse des réactions vasculaires. - M. Krafft-Ebbing, du reste, a constaté l'irrégularité de ces réactions. - Tantòt, dit-il, elles sont exagérées, tantôt elles sont nulles, sous l'influence de la lumière ou des liqueurs alcooliques. 
10. - Agilité. - Dans trois fous moraux soumis it mon examen, j’ai reconnu une agilité extraordinaire qui, en un cas, égalait vraiment celle du singc. Ciest encore un des caractères fréquents des criminels. Et, à ce propos, qu'on nous permette de réparer un oubli: dans le chapitre consacré à ces derniers, nous n’avions pas mentionné les évasions presque miraculeuses de Sheppard ot d'llaggard.

11. - Sexualité. - La précocité de la perversion sexuelle, l'excès suivi d’impuissance, ont dẹji été reconnus par M. Krafft-Ebbing lans le fou moral, comme par moi dans le criminel (p. 404).

" Ils ont, continue II. Krafft-Ebbing, des anomalies notables dans les instincts, particulièrement en ce qui concerne l'union des sexes; ils éprouvent à co sujet des désirs souvent prématurés ou contre nature, quelquefois précédés ou accompagnés d'une férocité sanguinaire ». - De mon còti, non content de citer Verzeni, Sbro... (ce dernier, avant d'aroir atteint sa seizième année, était déja affecté d’une maladie rénérienne), Zastrow, Bertrand, Menesclou, Lemaitre, Prunier, je rappellerai la précocité sexuelle des voleurs, la luxure toujours inassouvie des assassins, les goûts étranges de ceux qui ont la passion du viol, enfin ceux des enfants atteints de vraies anomalies sexuelles (p. 129, etc.).

12. - Sens moral. - En ce qui concerne la nature Inorale, l'affectivité, l'analogie n'est pas contestable. Je n'ai que l'embarras du choix, parmi les descriptions faites par les adversaires les plus acluarnés de mon école, pour le prouver sans qu'on puisse me taxer de partialité. 
Ce sont, écrivent MII. Krafft-Ebbing (l. c.) et Schüle, de vrais idiots moraux qui ne peuvent s'élever jusqu'au sens moral, ou qui, si l'éducation le leur a fait entrevoir, s'en tiennent à la théorie, sans jamais passer à la pratique. Ce sont des daltoniques, des êtres frappés de cécité morale, dont la rétine psychique est, ou devient, anesthésiée. Ils n’ont point la faculté d'utiliser les notions d'esthétique, de morale, qu'ils ont recues, en sorte que les instincts cachés au fond de tout cœur humain montent chez eux à la surface. Les notions d'intérêt personnel, de toute chose utile ou nuisible, déduites de la logique pure, peuvent se rencontrer en eux à l'état normal; de là un froid égoïsme qui repousse absolument le beau et le bien, une absence complète damour filial (nous rappellerons ici ce juge allemand qui tua sa femme et sa mère pour leur épargner les souffrances de la maladie; de là encore l'indifférence au malheur d'autrui, à l'opinion publique, l'exagération d'un égoïsme qui recherche avant tout la satisfaction de lintérêt personnel, sans nul souci des droits du prochain. Que de tels hommes se trouvent un jour en opposition avec la loi, leur indifférence fera aussitòt place à la haine, à une ardente soif de vengeance, à une affreuse férocité; car', ne l'oubliez pas, ils sont convaincus qu'il leur est permis de mal faire.

"Ils ont bien, écrit M. Krafft-Ebbing, la notion de la culpabilité en certains cas donnés; mais éest une notion tout-à-fait abstraite et comme mécanique de la loi.

"Ils parlent, souvent, (dit à son tour MI. Vigna, psychiâtre spiritualiste) d'ordre, de justice, de moralité, de religion, d'homneur, de patriotisme, de philanthropie, etc.; ce sont même leurs mots de prédilection; mais, dans le fait, ces sentiments leur font toujours défaut. Et c'est 
précisément eette lacune qui domne la clé de leurs jugements si bizarres et souvent si contradictoires sur des faits de mème nature; c’est elle qui explique pontquoi on s'efforcerait en vain de leur faire reconnatre l'absurdite de leurs opinions, l'immoralité de leurs actes, l'injustice de leur's prétentions...

"En un not, c'est là que réside to motif secret de leur lutte perpétuelle contre la famille et la société. Ce sont des individus susceptibles, à la vérité, d'une instruction superficielle, mais alssolument rebelles à une véritable éducation morale; car la base fondamentale de celle-ci est le sentiment . (Doct. Cesare Vigna, Rendiconto statistico del Frenocomio centrale femminile di San Clemente, Venise 1877).

Ecoutez maintenant le frère Battanoli, un prètre aliéniste. Il dit dans sa Relazione slatistica di San Servolo, (Venise, 1880): “Les fous moraux sont des inlortunés qui ont la folie dans le sang; elle date pour eux de l'acte même de la conception, elle a été nourric avec eux dans le sein de leur mère. Ils manquent des sentiments affectifs et du sens moral; ils sont nés pour étudier le mal et pour le commettre. Toujours en guerre avec la socićté, dont ils se regardent comme des victimes, ce sont eux qu'on voit au premier rang dans les rérolutions politiques; leur naturel aisément inflammable les rend extrêmement dangereux ». Parlant de ses deux malades, il ajoute: « Tous les deux ont une mémoire heureuse et prompte, l'esprit fin, des connaissances nombreuses et varićes; tous les deux sont égoïstes et manquent absolument de sentiments affectifs. Alors que toutes nos actions sont réglées par le cour, cux se laissent guider uniquement par l'instinct, s'occupent du présent seul, ne songent nullement à l'avenir (c'est 
bien ce que nous avons remarqué chez les criminels). L'amour propre leur est inconnu; après s'ètre rendus coupables d'une action répréhensible, ils restent indifférents, comme s'ils n'en étaient pas les auteurs; leur sommeil n'en est point troublé. Ils ont le verbe haut, l'expression emphatique; vous tronverez dans leurs écrits des phrases gonflées et sonores, d'un style facile d'ailleurs et plein d'esprit, mais sans onction. Quelque malheur qui frappe leurs parents les plus proches, leurs amis ou leur's connaissances, ils n'éprouvent aucune émotion. Ils parlent de la vertu et du vice; mais ce sont li des phrases qu'ils répètent, dont ils entendent le sens et qu'ils ne sentent point; aussi, leurs actions les plus vertueuses ne sont-clles dues quà la vanité ».

II. Brancaleone dépeint ainsi le fou moral: "Doué d'un caractère changeant et versatile, excentrique, inconséqquent, paradoxal, systématiquement hostile it toute tendance moralisatrice, irrésolu dans ses projets, irritable à l'excès, insensible aux joies domestiques, inaccessible aux douceurs de l'amitié, instinctivement porté à la révolte, aux extravagances et an scandale, il déclare hautement qu'il ne croit pas à la vertu; il sourtient avec un grand luxe d'érudition et de logique les théories les plus immorales, les plus capables de porter atteinte à la dignité hmmaine et à l'ordre social.

"Poussé à apprécier avec justesse le bien el le mal, et à en estimer les conséquences relatives, l'hypocrisie et le mensonge lui paraissent choses toutes nat urelles s'il doit en tirer profit 》.

Les traits dont je me suis serri pour caractériser le criminel-né, (Part. III ${ }^{\mathrm{e}}, \S 3$ et 5), reproduisent exacte ment ce tableau. Lemaire disait: "Je sais que je fais mal; si quelqu'un me disait que je fais bien, je lui répondrais: 
tu es une canaille; mais je ne puis m'empècher d'ingir ainsi ग. La mort d'un homme ne cansait pas a Lalcenaire plus d'émotion que celle d'un chat.

13. - Affectivité. - Et, des deux côtés, on constate la haine, sans cause aucune; on lit troure plus naturellement encore, ainsi que la jalousie et la vengeance, quand il existe une cause, quelque légère qu'elle soit.

«Ces malades, écrit M. Motet (Annales médico-psych., 1883), sont tourmentés du besoin de nuire. Incapables de gouter les douceurs d'une vie de fimille, qu'ils fuient sans motif, ou pour des motifs futiles, ils aiment mieux dormir sous un pont que sous le toit paternel, et se laissent aller à de vrais raffinements de eruauté. On a vu un enfant de 10 ans, à l'œil noir, ì la mine effrontée, écolier indisciplinable, pousser dans l'eau un de ses camarades, sans motif, pour le seul plaisir de le voir se noyer. C'était le fils d'un roleur. Dans la prison, il déehirait ses convertures; aueune punition ne pouvait le retenir ».

Catherine B., écril M. Bonvecchiato, prend plaisir à dire du mal des autres, surtout si elle a à se plaindre d'eux; il suffit d'ailleurs de l'approcher pour encourir sa haine. Toute personne bien vue lui est odieuse, comme si elle lui laisait tort à elle-même. Faites-lui du bien, vous ètes sûr qu'elle vous détestera. Un jour elle demandait avee instanees qu'on la laissàt battre deux clicens; on voulut qu'elle s'expliquàt. "Je suis ennuyée, ditelle alors, de voir que tout le monde les caresse ».

Un certain B. P., me vovant donner un sou à un pauve, se prit à ricaner. « Je paierai pour lui òter ton aumône, " me cria-t-il. Et comme je lui demandais s'il aimait sa mère, il répondit: "J'aimerais la voir 
mourir, si je pourais vivre sans elle. Ah! si c’était possible! je saurais bien aider la nature! ».

Callisto Grandi enterra vivant un enfant qui lui avait pris ses couleurs et sali son manteau (Norselui).

Sbro..., sans aucun motif, sentit naître en lui une vive haine pour son frère et sa mère.

La malade du docteur Hughes détestait sa sœur au point de lacérer le portrait de son père parcequ'elle l'arait trouvé dans sa chambre; recueillie par un oncle, elle concut pour lui, dès les premiers jours, une telle haine, que, pendant nombre d'années, elle refusa de s'asseoir à sa table.

Rif, à 7 ans, fourmentait les oiseaux, déchirait ses habits, crevait les tubes du gaz quand ses parents lui adressaient les plus légers reproches. «Je me venge, » disait-il alors.

Z... traité par M. Legrand du Saulle (Ann. méd., 1881) lui avouait qu'il se sentait envalii d'une haine froide, prolonde, à l'égard de son père qui le privait du bien le plus désiré, la liberté. Il essaya de tuer sa mère parceque, disait-il, il n’aimait que les gens sérieux, et ru'un homme doit savoir tuer les siens. " Si je royais leur cervelle répandue j’en serais bien aise, ajoutait-il; car je serais alors bien sûr de n'avoir rien à craindre ".

Rappelons-nous la vengeance sans cause, on pour de légers motifs (p. 361), relevée chez les vrais criminels.

14. - Altruisme. - A la place de cet égoïsme révoltant, il n'est pas rare de trouver l'altruisme: Holländer a connu une paurre fille qui voulait se suicider pour ne pas survivre à son amie, et un jeune homme qui, en dépit d'une vie d'orgie et de violences morbides, se montra toujours un excellent fils et un bon frère. 
Mais regardez de plus près; vous ne verrez-lí quiune nourelle forme d'affections perverties, an detriment de celles qui brùlent arec le plus de force au cœu des autres hommes (lamour de la famille, p. ex.), ou viceversi. Par lá, beaucoup de philanthropes, beaucoup de saints personnages rentrent dans la catigorie des fous moraux, ainsi que nombre de scélérats qui pillent les voygeurs, qui maltraitent leur femme ou leurs parents pour procurer du plaisir à leurs amis. C'est le cas de la marquise de Brinvilliers, qui aurait donné sa rie pour son amant; de la Trossarello, qui passait ses nuits an cheret des malades; de la Pulfi, qui faisait mourir de faim sa propre fille et se montrait prodigue à l'égard des étrangers (Voir pag. 351 ).

ll y a d'ailleurs aussi une perversion dans la forme que revètent ces affections quand elles se manifestent.

II. Legrand du Saulle (l. c.) cite une mère qui, sous prétexte de préserver son fils de la syphilis et d'autres maux pareils, le conduisait elle-mème progressivement dans la roie de l'amour charnel, le soumetlant à des rations progressives pour ménager sa santé. Devenue grosse, elle roulait se faire arorter afin de conserver sa beauté, seul moyen, disait-elle, de retenir son fils, dont l'éloignement la tuerait. Elle n'acceptait pas d'ailleurs les reproches: "Elle obéissait à l'inspiration de Dieu, qui ne peut se tromper ». - C'est en alléguant des raisons de ce genre, que la Catherine de II. SalemiPace roulait prostituer ses filles et leur faire goûter les plaisirs de la chair. Et notez qu'elle n'en retirait aucun profit; elle s'exposait, au contraire à la prison.

Un de mes clients privait de sommeil ses enfants, sous prétexte de les faire étudier, si bien qu'ils tombè- 
rent malades et que l'un d'eux mourut. Il se repentit alors de sa conduite; mais son remords dura peu, et il ne tarda pas à reprendre son système cruel d'éducation.

15. - Religiosité. - Vanité. - Notons encore l'ascétisme, qui met sur le compte de Dieu (1) l'insensibilité de l'individu et fait de cette insensibilité une sorte de loi; la vanité excessive, qui pousse à dépenser, à se ruiner en aumônes, pour s'altirer l'estime publique et faire parade des richesses, vraies ou fausses, que l'on reut avoir. La mégalomanie, l'excès de vanité, qui se rencontrent dans le criminel-né, se retrouvent done aussi dans le fou moral.

Aggnoletti répétait continuellement: C'est Dieu qui m'a permis de survivre pour confondre mes calomniateurs... C'est Dieu qui a fait mourir un juge qui m'était hostile,... Dieu, ou tout au moins sa mère, qui m'illumina à l'audience et me rendit éloquent (Voir vol. $\mathrm{III}^{\mathrm{e}}$ ).

Il n'éprouvait certainement aucun dommage à se laisser convaincre de làcheté, cela excusait même son suicide manqué; c'est pourtant en rue de s'en défendre qu' il insiste le plus à l'audience.

Il a, an contraire, grandement à perdre en soutenant ce qu'il appelle son mérite; mais il ne se lasse point de

(1) On ne rerra pas sans curiosité, ne fût-ce que pour éclairer l'histoire des religions, leur manie dattribner à Dieu leurs propres impulsions, précisément pareeque ces impulsions sont irlésistibles. Ainsi Guiteau: - Sans la pression exercée par Dieu sur mon libre arbitre, Gartield n’aurait pas été attaqué. Dieu m’a sontenu comme dans le pocès d'Abram. Je ne pris être fou. Dieu ne cloisit pas ses instruments parmi les fous $»$. - Et Sbro...: "Dieu, j'en suis persuadé, avait résoln la mort de mon frère. ". - Or, ce earactère a été rélevé par nous chez les criminels, chez celni, par exemple, qui se donnait la Madone pour complice de son parricide (V. clap. vii). 
lc faire, et trouve pour cela de véritables phrases sléréotypées. Personne n’est à la hauteur de sa conscience. - Personne ne peul dire qu'il soil convaincu. - Il a son passé. - Tout ce qui le concerne est fameux: le contrat, la breloque, etc.

A moi-même, il disait séricusement, un jour, qu'un artiste de Mlilan arait voulu faire son buste, comme s'il eùt été un grand homme, et, me voyant à la main la Revue des Deux Mondes, il me demanda s'il y était question de lui. Finalement, après m’avoir débité, le plus sérieusement du monde, des insanités sur l'Italie et son Gouvernement, il voulut bien m'apprendre qu'aussitôt après sa libération (chose dont il ne doutait point) il s'emploierail à faire triompher les idées de Garibaldi, les seules, selon lui, qui convinssent à l'tualie.

C'est bien certainement, encore, cette vanité morbide qui le poussa à écrire sa vie très en détail, et avec beaucoup d'élégance. En cela il se rencontrait avec un grand nombre des criminels qui sont portés à rédiger leur autobiographie.

Sandon s'appelait avec emphase l'étoile du barreau Limousin; son style, disait-il, était celui d'un grand écrivain (Legrand du Saulle, ouv. citée).

La jeune II., traitée par Holländer, parle, à sa pension, de ses richesses imaginaires; elle se fait adresser de fausses déclarations d'amour, ct se brouille avec sa directrice parcequ'elle n'a pas été classée première.

J'ai connu, encore, un individu qui signait non seulement ses lettres, mais encore des effets de commerce, avec de faux titres nobiliaires; il se vantait d'avoir pour maîtresses des dames de la haute société, forgeait luimême des lettres en imitant une fine écriture de femme 
et se les adressait par la poste, afin de pouroir les montrer ensuite à ses amis.

Holländer a observé qu'aucun fou moral ne se cache pour commettre un crime, car il est convaincu qu'en cela il n'excède pas son droit. Il explique ce phénomène par un certain délire des grandeurs qui leur fait croire qu'ils sont supérieurs au reste des hommes, leur fait dédaigner loute précaution, et les empêche de voir les obstacles. - Krafft-Ebbing, lni aussi, relève l'opinion exagérée qu'ils ont d'eux-mêmes; M. Maudsley en a vu un, qui parlait, sans cesse, de ses grandes actions, de ses projets de réforme. - C'est bien ce que nous avons constaté pour Faella, Gasparone, La Gala, dans tous les grands criminels. "La race des Croceo ne doit pas se perdre," disait le brigand Croceo. - Naturellement, les humiliations de la prison et de leur condamnation exercent une action sur ces misérables: plusieurs dissimulent leur orgueil, comme du reste fait le fou moral sous l'influence de la discipline de l'asile; - mais l'observateur attentif n'a aucune peine à le discerner.

16. - Intelligence. - L'intelligence n'est assurément pas lésée en eux au même degré que le cour et le sentiment. Mais, par suite du lien qui unit entr'elles toutes les fonctions de l'esprit, on ne pent dire qu'elle soit complètement saine. Si beaucoup d'auteurs, en particulier Pritchard, Pinel, Nicolson, Handsley, Tamassia, s'aceordent à leur reconnaitre une intégrité parfaite de l'intelligence, sans hallucinations ni illusions, et même sans défaul et sans désordre d'aucune espèce, beancoup d'autres, Zelle, Mac-Ferland, Gray, par exemple, admettent un affaiblissement; un plus grand nombre encore consta- 
tent de graves irrégularités. M. Morel (p. 57) trouve en eux une attitude intellectuelie spéciale, caractériséc par la facilité à écrire, à parler, à cultiver les beauxarts, mais dominée souvent par la tendance au paradoxe. M. Campagne (Annales médico-psych., 1879) signale, aussi, leur bizarrerie, leur manque de sens commun.

M. Krafft-Ebbing lui-même, quoiqu'il ne trouve pas d'anomalie dans leur intelligence, avoue qu'ils sont souvent simples d'esprit, souvent absurdes, qu'ils n'apportent aucune prudence dans l'accomplissement d'une action coupable, qu'ils font des coq-à-l'àne, débitent des mensonges; mais il ajoute qu'ils finissent par croire à la réalité des faits inventés par eux-mêmes, et qu'ils s'attribuent de bonne foi ce qui apparticnt à d'autres. «Ils ont, écril M. Battanoli à propos de ses deux sujets, des connaissances étendues, ils écrivent et parlent avec gràce, avec beaucoup de verve; ce ne sont, toutefois, que de jolis perroquets bien dressés ».

Ces caractères contradictoires, qui se retrouvent exactement chez les criminels, provicnnent de ce que tous les fous moraux n'oni pas été forgés sur un modèle unique, pas plus que les crimincls eux-mêmes. - Les espèces animales, à mesure que leur nombre augmente, s'individualisent et offrent des variétés plus nombreuses et plus distinctes, de manière à former des sous-genres; il en est de même des foux moraux et des criminels pour ce qui regarde l'intelligence; cela ne les empêche pas de garder toujours leur caractère principal: la légèreté el la ruse. - La différence résulte encore de ce que, doués sourent, dans leur enfance, d'un esprit vif, ils vont s'engourdissant à mesure qu'ils grandissent; et de ce que, étant sujets à des congestions cérébrales (Krafft-Ebbing), ils doivent nécessairement 
présenter à chaque instant la plus grande variété de travers intellectuels. Voilà pourquoi nous pouvons, dans les auteurs, en suivre des gradations qui vont insensiblement des hommes de génie, très-rares toutefois parmi cux aussi bien que chez les criminels, aux esprits faibles, tel que la plupart des roleurs ( $\mathrm{T}$. chap. vir ${ }^{\mathrm{e}}$ ), et même aux imbécilles, parmi lesquels je n'hésite pas a placer Sbro..., et ce Grandi, qui a été pourtant condamné.

Le doet. Battanoli, en effet, nous en présente un qui fut un rrai poète; et M. Livi, dans son sbire toscan, nous fait comnaître un véritable philosophe épicurien. Pour ma part, j'ai pu étudier un de ces malheureux qui, dans les sciences, avait conquis l'estime publique et s'était élevé au premier rang. Cependant, il souffrait, depuis son enfance, d'amnésies fréquentes; il était d'une malpropreté extrême; enfin, plus tard, il oublia la valeur des mots et fut envahi par la folie des persécutions.

D'autre part, nous trouvons dans Sbro..., qui pourtant savait écrire passablement et était un bon orfèrre, une intelligence si débile, qu'elle touchait, de près, à l'idiotisme (Tamburini).

Tous, d’ailleurs, mème ceux dont l'intelligence parait saine, commettent dans leurs jugements des erreurs causées par l'excès de leur vanité, et se contredisent de la facon la plus absurde. Ecoutez les axiomes du parricide Agnoletìi:

“ Un faux nom cesse d'être tel, quand on l'a pris déjà une fois.

"La parole d'honnemr n'oblige pas, quand on la donne à une personne indigne.

n Tout acte souscrit perd sa valeur, quand il cesse d'être en harmonic avec les impressions du moment. 
\% Les lives obscenes sont moins immoraux que les traités français de philosophie.

»Un capital de 20.000 livres peut en produire en pen de temps 100.000 .

- Arrêter un homme qui, provoqué, n’a pas relevó le gant, est une chose juste.

"Qui n’a pas de remords n'est pas coupable.

"Quiconque tue son fils ne commet pas de erime, siil se tue en même temps.

\User d'expédients pour tromper sa femme est une excellente chose»(V. Documents, $1 \mathrm{II}^{\mathrm{e}}$ vol.).

Sandou veut que les ministres le traitent en chef de parti, puis il se contente d'une cellule dans une maison de santé: il appelle Billaut son assassin, et lui confie ensuite ses volontés dernières en le chargeant de veiller a ses funérailles.

La nommée Perino vole des bijoux avec la plus grande habileté; mais la ranité la conduit à s'en parer à l'église, sous les yeux de ses rictimes.

La folie morale est un genre, dont le crime constitue une espèce. Voilà pourquoi elle peut offrir des variantes qui vont jusqu'à paraître opposés à celles qui ont été notées par les classiques. On voit des sujets, en qui les formes diverses, ou, du moins, certains symptòmes des naladies mentales, se greffent sur la forme principale, qui est la folie morale, absolument comme des cryptogames poussent quelquefois sur d'aulres végétaux de même espèce. Tel a été un de mes malades, Gib..., atteint de folie morale, à la suite d'une fière typhoïde: aux tendances les plus tranchécs, all vol et à la ealounnie contre ses parents, étaient venues se joindre des jdées liypocondriaques; il se croyait atteint d'un écoulement dont la castration seule pourrait le guérir. Deux 
autres, Bi... et Ing..., dont j’ai déjà parlé, s’imaginaient souffrir d'une affection eardiaque et fourmentaient les médecins à ce sujet. Bien d'autres (nous le verrons) étaient épileptiques, ou hystériques, ou avaient de courts aecès de fureur et de mégalomanie.

Schüle dit des fous moraux (Greist. Krankheit., 1881): «Fils ou petits-fils de fous, ils présentent de fréquentes anomalies dı erâne, des dents, du palais, de la langue. Ils sont portés à la nérrose, au somnambulisme, aux convulsions, à la folie, surtout périodirque, à l'hypoeondrie. Pour produire ces accidents, il suffit dune oceasion; le moment de la puberté, me maladie grave, ete. ».

La malade de Salemi-Pace, commit, avant le crime dont on laccusait, une foule d'extravagances: elle courait par les rues sans motif; elle exigeait un jour que son mari lui apportìt son traitement, bien qu'il fût malade, et, comme il n'arrivait pas, elle forçait un de ses valets à s'agenouiller devant elle sur la rue publique. Déjả auparavant, n'avait-elle pas eu l'idée bizarre de prostituer ses filles, sans aucun but de lucre et seulement pour leur procurer du plaisir, alors que les pauves enfants résistaient avee horreur?

Sbro... se eroyait poussé par Dieu lıi-même au parricide et au vol; on le vit frapper des arbres avec fureur, déboucher les réeipients d'huile et de vin et laisser les couler, mettre en lambeaux une chemise de sa mère et abimer un crueifix. Dans sa prison, il écrivait et murmurait sans cesse d'aflreux blasphèmes à l'adresse de Dien et de ses juges.

Mais tout cela ne contredit en rien le diagnostic de la maladie principale; car il s'agit d'une affection chronique, souvent même congénitale, qui donne lien à des congestions eérébrales et, par suite, à des complica- 
tions de folie. C'est un champignon sur lequel pousse un autre champignon, ce qui n'empêche pas le premicl d'en être le vrai point de départ. A potiori fit denominatio.

Et Dagonet va jusqu'ì parler de délire aigu et d'luallucinations chez le fou moral.

On en voit tout autant chez les criminels: s'il arrive souvent que leur intelligence paraisse normale, il n'en est pas moins vai que les cas les plus typiques s'allient ¿ la folie ordinaire dans la proportion de 2,50 au 50 !0.

Nous trourons des traces d'anomalies dans leurs chants, dans leur argot, etc. - Quant à la possibilité d'un véritable délire, je m'en rapporte à Nicolson lui-même (Journal of Mental Science, 1877): il a fréquemment trouvé chez les prisonniers ce qu'il appelle justement une perversion de conception, qui les pousse à user de mensonges très-compliquées pour expliquer les faits les plus simples. Ils croient, par exemple, à l'existence d'une sorte de loi qui ordonne aux employés des prisons de les tourmenter; et c'est ainsi qu’ils interprètent les mesures de discipline les plus élémentaires.

La contenance des criminels, soit dans la prison, soit au dehors, ressemble sourent, en tous points, à celle des aliénés. Dans l'ensemble des criminels, écrit Nicolson, il s'en trouve qui, indifférents aux punitions, incapables de se contenir, pris de véritables accès de fureur (cela se rencontre surtout chez les femmes) qui souvent sont périodiques et n'ont pas de cause, et pendant lesquels ils brisent tout, vitres, fenêtres, vêtements; poursuivis par des idées fausses de persécution, s'acharnant à mal interpréter ce qu'ils voient faire aux autres, devraient être classés parmi les aliénés (Journal of Mental Science, 1873). 
M. Meyer (Souvenirs d'un déporlé, 1880) cite un cas survenu à la Nouvelle-Calédonie: les déportés et les argousins qui, pour la moralité, ne sont pas supérieurs aux premiers, furent un jour en proie à une sorte de folie épidémique qui leur faisait voir dans lout individu, aux uns un ennemi, aux antres un fugitif.

Rappelons ici la Zerbini, ce type de criminelle qui souillait de ses ordures la chambre de son maître, cou. pait les cordons des sonnettes, simulait des apparitions d'esprits, et accusait de tout cela sa maitresse.

Les prostituées non alleintes d'aliénation ont pourtant dans leur maintien, dit M. Naxime du Camp, quelque chose qui tonche à la folie. On les voit éclater de rire, en chœur, à l'aspect d'une mouche qui vole, regarder le fel arec stupéfaction, comme si elles le voyaient pour la première fois, s'épancher en un flux de paroles que rien ne samrait arrêter, et se figurer qu'elles sont poursuivies par l'inspecleur des mours ou par une de leurs compagnes. Dans les maisons de repentir qui leur sont affectées, on a remarqué que, surtout au printemps, elles semblent en proie a une agitation que la folie seule peut expliquer (Parent D., 1. c., p. 371).

17. - Astuce. - Une raison qui porte bien des gens ¿t leur attribuer une intelligence intacte, cest que tous sont ruses, comme le sont les criminels. La Catlierine de Salemi-Pace niait obstinément qu'elle eût tenté de corrompre ses filles et leur eût présenté des hommes; elle se justifiait en disant que, craignant d'être battue par elles, ello avait cherché des protecteurs. - L. M., du docteur Cappelli, ayant apereu une veure sortir d'une maison où elle était en villégiature, s'y établit 
comme si elle lui appartenait, et chargea la domestigue d'en vendre le mobilier; découvert, il s'empressal de prendre la fuite. - Sbro... et enfin Grandi, après avoir commis leurs crimes, surent longtemps se mettre à l'abri du soupron, allant mème à la recherche de leurs victimes. - La Catherine de Bonvecchiato donnait une raison pour tout ce qu'elle faisait: pour se procurer des complices de ses houteux plaisirs, elle simulait une paralysie et choisissait, pour l'assister, des nymphomanes disposées à lui complaire: elle s'élait mise à la tête d'un club d'hystériques et accusail un médecin de l'aroir séduite. Convaincue de mensonge, elle se contentait de dire: "Çaura été une hallucination».

18. - Paresse. - Les fous moraux se distinguent, aussi, par une paresse invétérée qui les éloigne de tout travail, et qui contraste fort avec l'activité déployée par eux dans les scènes d'orgie et dans les entreprises délictueuses; c'est un nouveau point de ressemblance avec les criminels. - X. reste au lit des sentaines entières, ce qui ne l'empêche pas de passer dix jours à suivre les bals ou à courir lıors de sa maison. La fameuse Catherine prétextait des maladies de tout genre pour être dispensée de travailler. "En général, dit Krafft-Ebbing, ces gens-là manquent d'activité, d'énergie; quand il n'est pas question de satisfaire quelqu'un de leurs penchants déréglés, ils fuient le travail avec horreur. La mendicité, le vagabondage, voila leur vocation .

Rappelons à notre tour que Lemaire disait: « J'ai les chairs molles; plutôt mourir que travailler ». Le sodomiste Hog poussait la paresse au point de se soulager 
dans sa gamelle pour éviter un petit dérangement; il fallait le rouer de coups pour le contraindre à se laver (V. Archivio di psichiatria, I, p. 278).

19. - Activité. - Schüle, à la vérité, nous les montre étrangement irritables, faisant alterner l'activité la plus excessive avec la plus complète inertie. - Ce caractère, il est vrai, parait en contradiction à ce qu'on observe dans les criminels; mais il n'y se manifeste que dans les premières années de la puberté, est intermittent, et manque même en beaucoup de sujets; il se trouve bien des fois chez des criminels célèbres, tels que Lacenaire, Gasparone, Alberti, qui sont arrivés souvent à une position sociale élevée.

En second lieu, leur activité ne se déploie que dans le mal. "Dans leur famille, dit M. Krafft-Ebbing, leur entêtement morose est la terreur des parents; à l'école, ils inventent, pour se faire renvoyer, des coups d'une finesse ćtonnante.

"Travaillent-ils? on les voit devenir en peu de temps fripons, menteurs, rebelles à toute discipline, - comme, en prison, ils se refusent à tout exercice ». - Et dans le mal les plus mauvais sont habiles.

20. - Prétendues différences. - A regarder de près, tous les caractères que, arec une analyse pénible, les aliénistes ont fini par découvrir pour tracer une différence entre le foll-moral et le criminel-né, ne servent qu'ì confirmer les analogies existant entr'eux.

M. Krafft-Ebbing signale la marche progressive de la maladie dans le fou moral. - Pourquoi ne rappellerions-nous pas à notre tour ce qu'on appelle l'échelle du crime? - «Dans l'exécution des actes impulsifs, 
écrit Pinel, ils font montre d'une imprévoyance et d'une cruauté monstrueuses, d'un cynisme révoltant; ils se vantent de leurs méfaits, n'éprouvent pas lo moindre remords, se montrent intraitables it loute éducation \%. Mais notre auteur avoue plus loin que ces caracteres sont aussi ceux du vrai coupable.

*. Ils se distinguent des erimincls, selon M. kirafftEbbing, par leurs affections cérébrales, congénitales ou acquises, par l'hérédité alcoolique, l'épilepsie, la folie; par les blessures du cràne, la méningite, l'atrophie ou la démence séniles, l'altération du système nerveux ou du développement du eorps; par le strabisme, le pied bot, la mauvaise eonformation des parties génitales.

"Ils sont prédisposés aux maladies du cerveau, aux congestions; ils ne peuvent supporter l'alcool, se font remarquer par une grande variabilité d'humeur, par l'exagération de leurs passions; enfin, ils sont épileptoïdes $\gg$.

Nous avons constaté tout cela chez le criminel-né.

21. - Préméditation. - On parle de la préméditation, de la dissimulation, de l'art avec lequel les vrais criminels savent se cacher, et l'on oppose ceux-ci aux fous moraux, qui n'hésiteraient pas à faire le mal publiquement, persuadés qu'ils ont le droit de le faire (IIoLLANDER); mais je rappellerai à mon tour les vanteries qui précèdent le crime, les divulgations toutes spontanées que les criminels-nés font souvent au premier venu. - Un peu plus haut, d'ailleurs, j'ai montré plusieurs fous moraux usant d'une profonde dissimulation, chose qui ne fait pas non plus défaut aux aliẻnés véritables. 
Il ne sera pas mauvais d'ajouter que plus d'une fois le fou moral, comme le criminel ordinaire, se prépare un alibi, prémédite son crime, l'accomplit, non sous l'impulsion du moment, mais dans un but de vengeance ou de lucre, en se donnant souvent des complices. Nul, parmi les aliénistes, n’ignore que tous les accidents qui arrivent dans les hospices d'aliénés ont pour auteurs des fous qui poussent au mal leurs camarades, trompent et dénoncent leurs supérieurs, et sont toujours prêts à comploter. - Aux cas déjà eités j’ajouterai le suivant:

Aubanel raconte qu'un fou qui détestait la famille de sa femme, ayant appris que cette famille devait faire une partie de plaisir dans les environs de Paris, se travestit, loua une voitmre et la conduisit à la porte de ceux quiil détestait, supposant qu’ils la prendraient pour l'excursion projetéc. C'est en effet ce qui arriva; on ne le reconnut point, et, quand on fut au bord de la Seine, il s'efforça de précipiter la voiture dans le fleuve. Alors seulement on s'apercut de la supercherie, et le fou fut ramené à Bicêtre.

22. - Esprit d'association. - Ajontons à ce fait celui qui s'est passé à l'hospice de Marseille, il y a de cela dix ans: deux fous s'étaient entendus pour tuer les gardiens, s'emparer des clés et prendre la fuite (1). Que faut-il de plus pour démontrer que non seulement les fous moraux, mais encore les aliénés ordinaires, peuvent s'accorder entre eux, former des complots, tout comme les prisonniers, el que l'opiniàtreté de la vengeance

(1) Je tiens de source certaine qu’à Naples, sans l'énergie de M. Buonowno, trois fous moraux auraient introduit la camorra dans lasile de St. François de Sales. 
peut se loger dans leur eerveau, aussi bien que dans le cerveau des criminels?

Aucun des auteurs cilés n'a, je crois, remarqué un trait que j’ai souvent relevé chez les fous de celte espèce, comme chez la plupart des criminels; à savoir, le besoin de vive an milien de la société, à laquelle pourtant ils font tant de mal et qu'ils poursuivent d'une haine si profonde, surtout quand il s'agit de gens de Jeur classe.

Je me souviens d'un certain Ros..., qui avait d'abord étranglé sans motif une de ses nièces, et qui ensuite, dans l'hospice dont jélais chargé, nua par esprit de vengeance un de ses compagnons. Eh bien! il ne pouvait supporter la solitude. A peinc l'eus-je mis en cellule, qu’il éclata en menaces, puis essaya de se pendre; il aurait fini par se tuer, si je ne l'avais ramené au milieu de ceux qu'il tourmentait sans cesse, mais dont il ne pouvait se passer.

J'en ai connu un autre, un certain Gi..., devenu fou moral après avoir atteint sa puberté, en qui cette tendance se manifestait, mais à l'égard de la société criminelle; il demandait d'être ramené à la prison où, disait-il, il trouverait la compagnie qui lui convenait. Ses réclamations incessantes n'étaient pas dépourvues de logique: «Si j’ai volé, répélail-il, e’est en prison qu'on doit me mettre».

Ce sentiment prouve, une fois de plus, l'identité des deux formes: car il est notoire que les rrais fous éprouvent un véritable horreur pour les criminels et qu'en général ils recherchent toujours l'isolement.

23. - Vanité dans le crime. - Autobiographie. Nous avons pu constater par des exemples nombreux 
que les criminels ont une tendance particulière à tirer vanité de leur crime, l'éterniser en le couchant par ćcrit. Pareil fait a pu ètre constaté par des observateurs profonds, dans certains cas oủ le diagnostic de la folie morale ne laisse aucun doute; et même, qu'on y prenne garde, le fou moral peut aussi, comme le criminel ordinaire, fournir un indice et quclquefois une explication de ses actes.

Le fou moral Sbro..., après avoir pris toutes ses précautions pour cacher le meurtre de son père et de son frère, écrivait ces lignes (Archivio, Iv, p. 391):

"Quel est le destin de ma mère, et quelle sera sa mort? Si je puis, je l'empoisonnerai avec de l'arsenic: sinon, quand et de quelle façon?

»En quelle année mourra-t-elle, et de quelle maladie? ne peut-on le savoir? Je pourrai sans doute la tuer; mais de quelle facon? Et si ce n'est pas possible?

》Jusques il quand dois-je vivre (ne puis-je le savoir)?

"Que vaut-il mieux pour moi, m'unir avec... et vive en famille, ou m'engager dans l'armée?

)Mon destin, quel est-il?

"Quel était le destin de Henri, et quel devait être son meurtricr?

"A propos de sa mort, suis-je coupable en quelque chose?»

Ces lignes, qui le firent juger coupable, nous font toucher du doigt le besoin qu'éprouvent les scélérats de parlcr de leur propre crime et d'en laisser des traces par écrit (interrogé à ce propos, Sbro..., répondait qu'il n'avait pu s'empêcher d'écrire ces lignes). On doit, comme le font très-justement remarquer MM. Tamburini et Seppilli, faire la même réflexion à propos de ce fou épileptique dont parle M. Maudsley, qui, aussitôt après avoir 
égorgé une petite fille, se lava les mains et écrivit dans son journal: "Tué une petite fille; elle était bonne et chaude n. Cela nous explique eneore la strophe extraordinaire dans laquelle Meneselou, ce misérable qui violait el tuait les petites filles, a laissé une preuve écrite de son erime, alors que de vive voix il le niait obstinément:

Je l'ai vne, je l'ai prise;

Je m'en veux maintenant

Mais la fureur vous grise:

Et le bonheur n'a qu'm instant.

Dans ma fureur avengle,

Je ne voyais pas ee que je faisais.

Grandi, fou moral et idiot (Morselu, l. e.), était à peine entré dans sa prison, qu’il se mil à composer une comédie stupide el des illustrations plus stupides encore, pour célébrer ses assassinats et se décerner à lui-même le triomphe.

Le fou moral de Battanoli avait également mis en vers ses propres mésaventures:

....... longnement j'errai

De çà, de là, pauvre voyageur abandonné,

Cherchant souvent le malheur,

Comme on dit, avee mne lanterne.

Jallatis comme l'oisean de branche en branche,

Le nez all vent, tout mon mobilier dans la poche.

Quand je considère ce nombre considérable de versificateurs et d'autobiographes parmi les fous moraux, je ne puis mempêcher de songer à ces nombreux poètesvoleurs, ou plutòt voleurs-poètes, dont j’ai parlé plus haut; et je les relie à ces vers bizarres adressés à $\mathbf{M r}$. Arboux (Les prisons de Paris, 1881) par un escroc:

Je vous écris en vers - n'en soyez pas choqné,

En prose je ne sais exprimer ma pensée. 
J'en conclus, en somme que ce n'est pas seulement la vanité, mais encore une sorte d'instinct morbide, qui pousse ces gens-lá à une production littíraire renfermée d'ailleurs, au dedans d'eux-mêmes; qu'ils font des ver's, à l'exemple des peuples sauvages (Genio e follia, p. 124), parceque leurs passions ne sont pas maintenues en équilibre. Nouvelle preuve encore que le génie peut être le résultat de la dégénérescence, comme il en est certainement bien des fois la cause.

24. - Simulation de la folie. - La simulation fréquente de la folie, qu'il n'est pas rare de trouver chez le criminel, a été relevée chez le fou moral par plusieurs observateur's attentifs: Lähr l'a retrouvée chez un homme coupable de viol; II. De-Paoli a fait de nos jours une observation analogue.

25. - Symptómatique de la folie. - On m'objectera que de nombreuses maladies mentales offrent parmi leurs symptomes des tendances propres à lit folie morale; mais cela ne contrarie en rien l'existence de ce genre de folie. Est-ce que les accidents syphilitiques, les cas de saturnisme, d'hystérie, avec convulsions, délire, prouvent la non existence de la paralysie, de l'épilepsie, de la folie?

Les méningites à caractère hydrophobique n'empêchent malheureusement pas la véritable hydrophobie d'exister. C'est d'ailleur's lí précisément la cause qui a fait si longtemps douter de la folie morale.

26. - Hislologie pathologique. - Dans les trois sujets atteints de folie morale dont on a fait l'autopsie, Sandou, le J. du doet. Lasègrue et L. de Bonvecchiato, on a pu 
constater des méningites, des foyers de ramollissement et d'apoplexie, et une atéromasie profonde des raisseaux.

- Nous manquons de tout travail histologípue à ce sujet.

Nais, une fois quon a reconnu la parfaite analogie de ce mal avec les autres névropathies, on peut s'appuyer sur les précieuses obscrvations de M. Arndt (Virchow Archiv., 61, 67, 72): "Beaucoup de cellules gangliaires sont, cliez les névropathes comme chez les reptiles, chez la salamandre, dans un état de développement inférieur; en plusieurs d'entre eux, le cylinder axis est trop ténu, ou couvert de granulations et pas assez nettement séparé de ce qui l'environne, d'où résulte une excitation trop facile; quelquefois même une partie fait tout-à-fait défaut, et se troure remplacée par un amas de cellules protoplasmiques; souvent leur gaîne médullaire est pointillée et n'a pas son aspect ordinaire d'homogénéité à double contour: de là, interruption dans la circulation, stase des forces moléculaires, réaction, explosion dans les autres régions centrales. Les vaisseaux semblent contournés par un petit nombre de cellules lymphatiques, en sorte que l'écoulement de la lymphe se trouve suspendu et que les cellules du cerveau subissent de fortes pressions ».

Ces observations ne servent pas seulement à montrer d'une facon plus claire, au moyen d'une formule anatomique, les arrêts de développement; elles nous aident en outre à expliquer ces phénomènes de perversion de la sensibilité et de la volonté que nous avaient déjà fait entrevoir nos études sur la réaction vasculaire.

Que royons-nous, en effet? D'un côté, interruption de la conductibilité ncrveuse, apathie, analgésie; de l'autre, accroissement subit de cette même conductibilité, d'oú exagération impulsive. 
27. - Etiologie. - La meilleure preuve est encore fournie par le decours et par l'éliologie de la maladie.

Le criminel-né, aussi bien que le véritable fou-moral, date presque toujours de l'enfance ou de l'adolescence.

M. Livi (Monomanie in relazione al foro crimin., 1876) a dit: "Les fous moraux naissent naturellement portés au mal ».

M. Savage décrit, comme MI. Mendel et KrafftEbbing, une forme de folie morale primaire, qui se manifeste souvent, entre la cinquième et la onzième année, par une propension au vol, un caractère excentrique, une aversion prononcée pour la vie de famille, un ennui profond, une répugnance complète à toute éducation, la cruauté envers les animaux et les camarades de classe, le mensonge, la ruse, un cynisme extraordinaire à couvrir ses propres méfaits, une précocité sexuelle qui, dès le plus bas àge, porte à la masturbation, et souvent, avec cela, quelques İueurs brillantes de génie.

Je me souviens de deux enfants qui, dès leur quatrième année, commencèrent à faire le désespoir de leur's parents: voleurs, menteurs, ils ne pouvaient souffrir ni leur mère, ni leurs frères. Et pourtant, ils paraissaient admirablement doués, l'un pour le commerce, l'autre pour tout ce qui a trait à l'arithmétique.

M. Todi cite une petite fille qui se plaisait à piquer les yeux des chevaux et des chiens de la maison; elle devint une mère et une épouse dénaturée, et, plus tard, fut convaincue de folie morale. La même chose arriva, dit-il encore, d'un enfant qui s'amusait a arracher la langue aux oiseaux qu'il pouvait prendre. Eh bien! n'avons-nous pas trouvé chez les criminels-nés des tendances 
très-précoces à l'immoralité, continuation de celles qu'ils avaient apporties en naissant? Ces tendances congrinitales sont la meilleure explication de ce qui frappe nos yeux, et nous donuent la cléf d'une telle diflusion; call tout cela n’est, an fonl, quie le développement d'une maladie, d'un étal physiologitue.

Quelquefois il se produit une recrudescence au moment de la puberté. Plusieurs enfants, selon Mll. Todi et Legrand du Saulle, paraissent tout d'abord admiriblement donés pour les arts et pleins d'ardeur pour l'étude; mais, à l'apparition de la puberté, ils deviennent timides, puis se plongent dans le vice avec la même énergie qu'ils avaient apportíe d’abord au travail. Ils cherchent, alors, dans de riches bénéfiees, de quoi effacer l'humiliation de la gloire perdue; impatients du succis, pen fermes dans leurs jugenents, ils accomplissent arec eynisme l'action la plus coupable, s'ils y voient un moyen de parvenir.

Chez d'autres, la pubertí seule, sans que ricn viomne s'y joindre, fait naître des tendances immorales.

Nous rappellerons à ce propos Verzeni, Lemaitre, Sbro... Ancune autre cause que la puberté ne pent expliquer les penchants criminels qui se sont développés en eux, tout d'un trait, et arec tant de force.

Enfin, l'influence de la vieillesse, l'aflaiblissement des forces génitales, peuvent marquer, provoruer même subitement la recrudescence de tels penchants et en donner une explication plausille. C'est le cas de Garrayo Sacamantecas, qui, vertueux d'abord et très-honnête, s'arisa, à 40 ans, de tuer neuf femmes pour les violer, et quion pourrait appeler un nécrophilomaniaque (V. Archivio, II).

L'hérédité de la folie se rencontre également ici; mais, comme nous le verrons pour les criminels-nés, en pro- 
portion moindre que chez les fous ordinaires. La proportion atteint, au contraire, un chiffre plus élevé, dès qu’il s'agit de parents égoïstes, vicieux on criminels.

linsi, M. Campagne n’a relevé l'liérédité de la folie que

4 fois chez la mère;

2 id. une tante;

3 id. des cousins, ’̀ propos de 15 fous moraux;

tandis que

l'égoïsme lui est apparu 12 fois chez leur père;

id. id. 13 id. mère;

l'apoplexie id. 3 id. id.

l'excès d'énergie morale lui est apparu 15 fois chez leur nère; la faiblesse d'énergie morale id. 5 id.

Si je lais la somme de ces chiffres et de ceux qui ont étć relevés par moi, par hrafft-Ebbing, etc., j'arrive au résultat suivant:

Folie Alcoolis. Nèrop. Crime Vices

Parents directs des fous

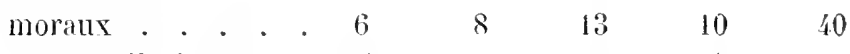

$\begin{array}{llllll}\text { Parents collatéraux . . } 17 & 1 & 11 & 5 & 1\end{array}$

On voit par lá que l’influence héréditaire de la folie n'y est pas si forte que celle du vice el de la criminalité, - constatation deja faite sur les criminels: - J'appellerai surtout l'attention sur Sbro..., qui est peut-ètre le type le plus classique de la lolie morale; son grandpère avait commis un meurtre par jalousie, son oncle b́ait un incendiaire, son père, condanné pour viol, avail tué une femme pour essayer un fusil.

llais c'est précisément cette proportion un peu moindre que nous trourons chez les criminels, en qui l'lérédité de la folie ne dépasse pas 220 [0, tandis que chez les fous ordinaires elle va au delá de 50 (elle est pourtant plus élevie chez les grands coupables: Faella, Ilberti, 
Nlo, Golting, Gioranni li Agordo, Costa, Militello, l'almerini, Didier, Bussi, brienz, Ceresa, Abbado); c'ost culte même proportion plus faible que H. Sommer a vérifiée chez les fous criminels en les comparant arec los autres.

Pendant que chez les fous ordinaires, écrit-il, l'hirédité est de $300_{10}$, elle n'est que de 22010 chez les fous criminels; en revanche, elle est plus marquée dins les branches collatérales. Et ici, notre auteur cite des cas où liaieul, le père, les oncles du sujet etaient atteints de folie, et tous ses frères très-exaltés; d'autres où le grand-père, la mère et les sœurs étaient alteints de folie, le père adonné au vin, trois sœurs démentes (Bcilr. aur Kenntniss des Criminal Irresein, Berlin, 1883).

L'influence directe des liqueurs alcooliques a été relevie 6 fois sur 15 par II. Campagne, qui l'a rue trois fois jointe à des excès vénériens. Nous l'avons dejaj trouvée nous-mèmes et nous la trouverons bien mieux cucore plus loin dans le crime (Vol. $\mathrm{ir}^{\mathrm{e}}$ ).

M. Krafft-Ebbing parlait des méningites, des blessures à la tête, comme d'autant de causes de la folie morale; nous verrons aussi qu'elles produisent la tendance au crime, par exemple, all vol, s'il faut en croire tcrell, Itorel, Gall. Rappelons ici que les coupables se rencontrent aussi souvent arec des blessures à la tête; j’en ai trouve 7,0 0[0; Del Bruk en a compté 21 cas sur 58 sujets, et Flechs 3 sur 28 .

On n'a pas oublie sans doute l'ostéoma de Faclla, du voleur de Pavie; ni les traces re méningite ou d'encéphalite trouvées sur Fusil, Prérost, Frende, Faella, Menesclou et presque tous les grands criminels.

llais, plus que toute autre chose, il importe de signaler la proportion assez faible, il est rrai, mais cer- 
taine, de cenx qui doivent leur folie morale à une mauraise éducation.

MIM. Holländer et Savage font remarquer la fréquence dı mal chez les individus qui, par suite de la laiblesse ou de la négligence de leurs parents, ont manqué de frein dans leur enfance, ne se sont pas habitués à ces réserves qüimpose la loi et qui constituent la moralité de l'homme. - On peut en dire autant de certains criminels, en particulier de ceux qui vivent dans des pays barbares ou peu civilisés: de lì la vendelta corse, et autres crimes de ce genre.

J'ai été longtemps chargé de traiter' un jeune homme, T..., qui confirme celte observation. Son père élait un alcoolique d’humeur fort bizarre; sa mère, légèrement lysstérique, avait la manie du suicide; son grand-père seétait donné la mort, ses frères étaient d'ailleurs d'une honnêteté irréprochable. Choyé par ses parents, el surtout par une femme de chambre qui larait pris sous sa protection et savait toujours excuser ses fautes, il se livra an rol dés sa première enfance. A peine àgé de trois ans, quand on le conduisait au marché, il prenait dans les corbeilles de latrgent, du poisson, des fruits; un peu plus tard, il dépensait en douceurs l'argent qu'il pouvait dérober à sa míre ou à la femme de chambre, et celle-ci, mème lorsqu'elle s'en apercevait, ne se plaignait pas; à l'école, il prenait tout co qui lui lombait sous la main. Ce malheureux finit par devenir un escroc émérite.

Cela se comprend d'autant mieux que, dans la première partie de ce lirre, consacréc aux tendances criminelles des enfants, nous arons ru ceux-ci présenter an point de vue plysiologique, un dat qui ressemble fort it la folie morale; en sorte que, si le milien or 
ils se trouvent noffre pas de circonstances lavoribles pour les transformer moralement of faire d'ens des hommes honnites, ils restent tels, comme des tritons alpestres qui conservent lem nature de tôtards daus los eaux froids (1). Cet état pathologique est transformó prar le temps en lobloitude, mème si l'individn n'a pas en de condance spéciale an erime, mème s’il n’a dé qu'un homme comme tous les autres. A plus forte raison en est-il ainsi, quand il porte an dodans dr lui des influences héréditaires, comme ce T... dont je pilllais plus haut. Ce fait nous explique le cas des criminels nés tels en apparence, mème quand ils noul ancune anomalie du crine on de la face (T. page 142 et sequ.). Il nous explique aussi la folic morale des despotes, qu'jls soient assis sur le tròne, comme la plupart des Césars, ou qu'ils dominent dans les rues, comme Masaniello, Cola da Rienzi, Maral, comme ces tyranneaus des rópubliques hispano-américaines, qui, paisibles et humains quand ils vivent dans la vie privée, deviennent crucls au contact du pouvoir absolu, avec on sans influence luéréditaire, mème s’ils ne poursuivent pas un avantage partieulier, mème quand leur caprice seul est en jeu.

Après cela, les cas les plus importints sont ceux quiont signalés III. Virgilio (2 sur 14) et Campagne (7 sur 1.i), frappés de folie morale après de vives impressions morales.

II. Todi parle eneore d'une excellente ménagère qui, ayant perdu subitement sa petite fille, fut alteinte de folic morale et se sentit irrésistiblement portéc à déterrer les cadarres de petits enfants.

1) Cameraxo. Accademia delle sciense, Turiu, 1884. 
En ce dernier cas, l'arrêt de développement des centres psychiques avait été provoqué, comme le sont plitsieurs maladies du cerveau, par des canses morales plutòt que matérielles; mais les effets qui en résultirent élaient les mèmes. Il est évident qu'ici la folie morale s'enchaine avec un groupe de crimes qui ne produisent pas de grandes anomalies: ceux qu'engendrent la passion on une occasion imprérue (V. vol. $\left.\mathrm{n}^{\mathrm{e}}\right)$. 


\section{Criminels épileptiques.}

On a objecté, justement, contre cette fusion, que les cas de vraie folie morale que j'ai pu étudier, sont en nombre trop restreint. Cela est vrai; mais cela est aussi bien naturel: justement par ce que les fous moraux sont des criminels-nés, on ne les trouve pas aussi friquemment dans les asiles que dans les prisons: et e'est aussi pour cela qu'il n'est pas aisé, ni mème possible d'en établir une comparaison; on ne peut pas, en effet, comparer des objets qui sont identiques.

Nais il existe un trait d'union bien plus important, bien plus saisissable, et qu'on peut étudier sur une plus grande échelle, dans l'épilepsie, qui réunit el fond les fous moraux et les criminels-nes dans une même famille naturelle.

Pour les gens du monde, qui n'apercoivent dans l'épilepsie que l'accès convulsif, ou l'équivalent psychique, ou ces formes singulières qu'on nomme absences ef vertiges, etc., ce rapprochement pourrait, d'abord, paraitre absurde; néanmoins il ne l'est plus, du moment où l'on embrasse, dans un même coup d'oil, non seulement les épiphénomènes les plus saillants de ces malheureux, mais aussi tous les caractères, dont l'ensemble constitue ce que j'appelle l'histoire naturelle de l'épileptique. 
C'est dans cet ensemble que nous allons trouver, quelque peu exagérés, toutes les traits des fous moraux et des criminels-nés (1).

1. - Hauteur et poids, etc. - Cividalli, Adriani, Albertotti, Virgilio (2) et Herpin trouvèrent sur 410 épileptiques, la haute taille, le poids supérieur à la moyenne, et, fréquemment, celte bonne nutrition qu'on remarque si souvent chez les fous moraux et les criminels-nés.

Chez 45 épileptiques, Müller en rencontra 39 avec sclerose, cxostose, asymétrie du crâne, et pachiméningite.

Le cerveal, 17 fois sur 30, présentait aussi, scléroses, ramollissements, œdème ou épaississement des méninges); circonstances qui indiquent non seulement lat fréquence des vices de conformation, mais aussi de précédentes inflammations.

(1) Si j"ai pu achever cette itude, e'est grâce à la cooperation de mes collègnes Bonvecchiato, Tamburini, Raggi, Albèrtotti, Mnsso, Morselli, Adriani, Sepilli, Marro, qui me procurèrent plus de 200 photographies d'épileptiques avec leur histoire, et grâce surtont aux professeurs Frigerio, Bianchi, Tomnini, Cividalli et Amati, qui ont fait pour moi des études précieuses sur les épileptiques. Tonnini a publiées ces données dans le beau livre Les épilepsies, Bocca 1886. Les mémoires de Frigerio, de Cividalli, et Amati, sont insérèes dalls les Actes du Congrès d'Anthropologie criminelle, 1887, Rome, et dans l'Archirio di Psichiat., n, 1886 , Turin.

(2) Sur 132 épileptiq. de Cividalli et Tounini, et 113 d'albertotti je trouve:

38 supèrieurs à m. 1,69-43 supérieurs a kilogr. 61,85

31

* $1,60-2$

5

7 » 740,50

Sur tous les 410 je trouve: 106 inférieurs dans la taille à la moyenue;
Id.
102 supérieurs
id.
id.

Id.

202 de stature moyenne.

sur 160: étaient de boune nutrition $156^{\circ}$

ll. id. manvaise id. 4 
Nous trouràmes les mèmes données chez los criminels. (V. pag. 183 i 202).

Crâne. La liréquence de l'asymétrie du cràne, que nous avons remarqué associée à l'asymétrie du visage che\% lrs criminels, dans la proportion de 12 a $370_{10}$, parut it certains auteurs, surtout à Lasègue, tellement constante quielle en formerait pour eux un caractère, fout-à-filit spécial, des épileptiques.

Ljoutez à cela: la fréquence des mandilules el des zigomes rolumineux, des sinus frontaux, de la fossclle oceipitale moyenne, trouvée par moi dans 14 crâlts dépileptiques sur 92, soit sur le $160_{10}$, la même juoportion exactement que chez les criminels.

Les différences sont minimes; on l'encontre chez les épileptiques moins d'os wormiens, de synostoses de l'illlas; moins de fréquence de microcéphalie frontale.

Et les analogies sont tout-à-fajt complètes par rapport à la capacité du cràne, dit Amadei (Sulla craniologia degli epilettici, Florence, 1882).

Quoique parmi les épileptiques il y ait sourent des individus bien portants, robustes, de haute taille, et quelquefois des atlètes, pourtant la capacité moyenne dı eràne est un peu au dessous de la moyenne générale des fous (au moins pour les mìles, 1479; femmes, 1358) et on y remarque les deux extrêmes, des capacités exagérées (celles-ci pourtant, en très-petit nombre), et des capacités moindres, qui prédominent.

Cela ressort mieux encore en étudiant les moyennes sériales qui nous donnent une capacité crànienne:

de 1700 à 1600 dans les Hommes épit. 18,7 010 Femmes épil.

" 1600 à 1500

18,7

28,6

* 1500 à 1400

43,7 ,

" 1400 à 1300

12,5

$1 ;, 3$

, 1150 à 1000

6,2 : 28,8 
Le résultat est le même que celui trouvé par Ranke, el Manouvrier sur les criminels (V. pages 147, 148).

Les récentes observations de Tonnini, ef de Frigerio démontreraient, aussi, chez le $550_{10}$ des épileptiques, l'cxagération de l'index céphalique que nous remarquàmes chez les criminels; et (nouvelle analogie) la prépondérance, pour le $500_{10}$, de la demi-curve poslérieure sur l'antérieure.

Qu'on ajoute à cela: la fréquence presque égale à celle des criminels (p. 200) des affections cardiaques trourées par Cividalli de $450[0$ chez les épileptiques mâles et de 30010 cher les femmes.

2. - Physionomie. - Bien plus curieuse c'est l'analogie dans la physionomie.

Nous donnons dans un Tableau, ¿t la page suivante (1), les résultats de $\mathbf{4 1 0}$ observations faites par moi, par Tonnini et Cividalli ef Amati.

Ce sont les mèmes caractères dont nous avons trouré la prépondérance chez les criminels-nés; ce sont, aussi, exclusion faite de la moindre microcéphalie frontale, presque les mèmes proportions numériques. (V. paçes 2 -4 à 268).

Mais ce n'est pas tout. Car nous avons trouvé aussi sur $26,90_{10}$ mailes, at $25,80_{10}$ femmes, cet ensemble de caractères dégénératits, rémnis jusquà $5,6,7$, que nons appelîmes type criminel; et dans le 9,5010 des uns, et dans le 10,3 des autres, la réunion de 4 et 5 de ces caractères que nous nommons demi-type; ce qui correspond arithmétiquement à mes observalions sur les criminels mâles, $250 / 0$, et qui s'öloigne bien peu de nos remarques sur les femmes, 28010 . En totalité il ne reste exempt de caractères criminels que le 63,40 des hommes, et le 63,7 010 des femmes. 
Le lectem pourra aisément son assmer, grice it lat reproduction des nombreux portrails (V. Atl., lan. xie).

Que l'on exanine les numéros 1, 2, 3, 4, 7, 9, 11, $13,14,16,17,18,19,24,31,32,38,40,51,2156$ de celle planche, el on y trourera la plus complite analogie arec les types criminels. Et pourtant, sculement les numéros 1, 9, 28, 31, diaient des coupables. Vosmí

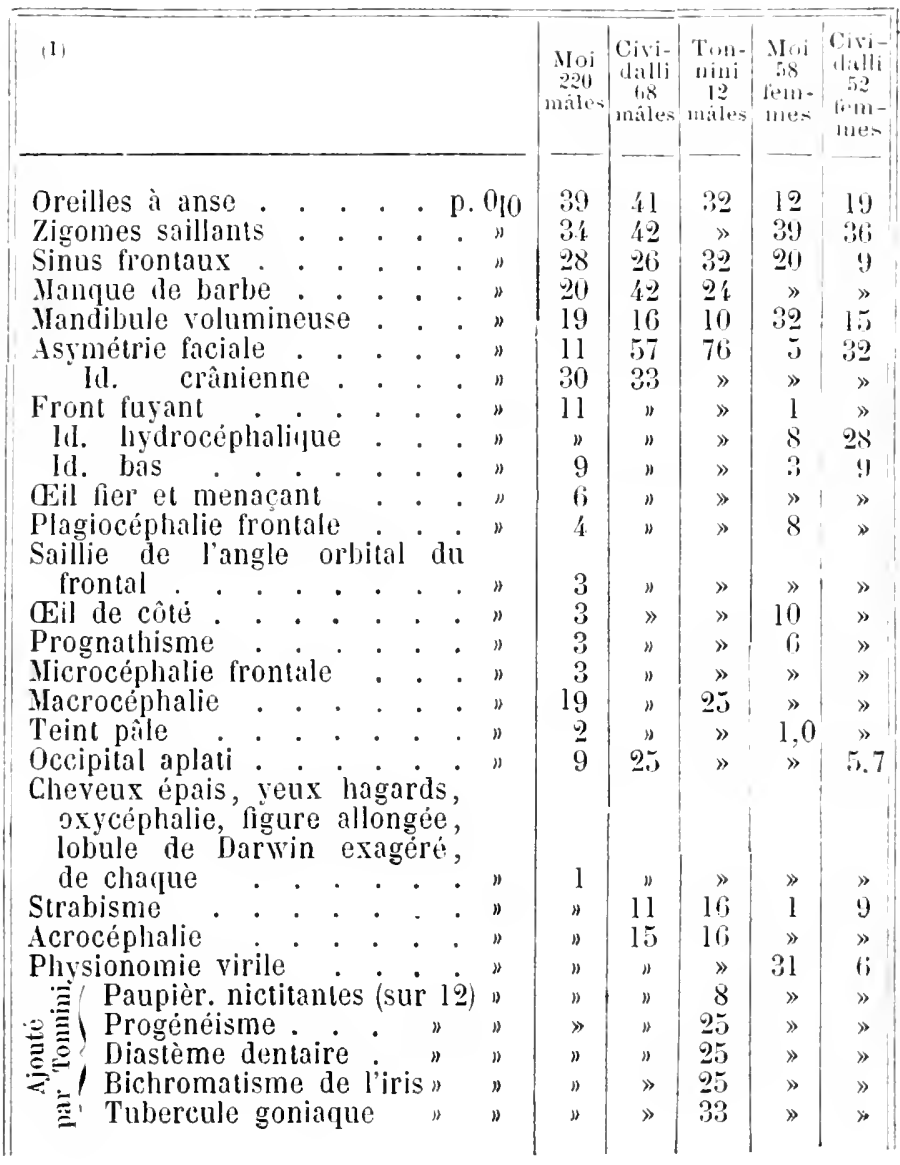


a nolé la plysionomie criminelle de Destojewski, ce grand écrivain épileptique, qui pourtant était de mœurs très-donces.

Jusqu'à un cerlain point on peut expliquer ce fait, en te que la répétition, dans les aceès, des actes impulsifs propres alux criminels, et surtout de ces contorsions de la figure (quion voit bien dans les numéros $7,8,10,12,13,16,22,23,25)$, qui ressemblent sorvent aux sinistres allitules de l'homme criminel, finit par en sillonner la trace sur la physionomie la plus honnête.

Mais ce fait sert, lrès-hien, aussi, à confirmer la consanguinité des deux formes.

Anomalies dégénćratives. - Qu'on ajoute à cela une séric singulière d'anomalies dégénératives, la plupart du temps atavistiques, telle que la syndactilie, 14010 : les nramelles el le glande conique dans les hommes, le 3010 : l'abinisme $60_{10}$, la scoliose vertebrale, le 25 p. $0_{10}$ accompagnée de la déformation du thorax, $610_{10}$ (BiaxciII) (1).

Qu'on remarque, encore, que Tomnini pour le $250_{10}$, Cividalli el Amati pour le $300_{10}$ des hommes et $250_{10}$ des fommes, trouvèrent la grande envergure supérieure à la taille, et inférieure, seulement dans le 8,8 010 (males), 9,6 $0_{\mid 0}$ (femmes), ainsi que Ferri et Lacassagne le remarquèrent chez les criminels.

\section{3. - Sensibilité. - La fréquence de l'obtusité tarlile} est aussi trés-important. Sur 35 épileptiques éludiés par moi el par le doct. Albertotti

(i) seulenent avaient la sensibilitė tactile normale

$\begin{array}{llll}8 & \text { id. } & \text { id. } & \text { id. de } 4 \text { à } 5 \text { à } 8 \mathrm{~mm} . \\ 6 & \text { id. } & \text { id. } & \text { id. de } 3 \text { mm. }\end{array}$

(1) Tunvini, L'épileprie, Bocea, 1886, Torino. 
lans un cas on arrivail a 12,1 it gauche, 6,8 is droite.

Qu’on ajoute encore, a cela, la fréfuence de l'oblusité des quatre sens, lémontrée chez les épileptipurs par Thomsen (Centralblalt, 1882) et ensuite patr Cividalli et Tonnini dans la proportion de 35010 , et cela arant et après l'atlaque et dans l'équivalent psychique.

Récemment Oscrezski (Itedic. observ., 1885) rematrua sur 96 reclus russes épileptirues de 20 ans:

lohtusité tactile . . . dans le 6000 lo et nous sur 100 erimin. de 93

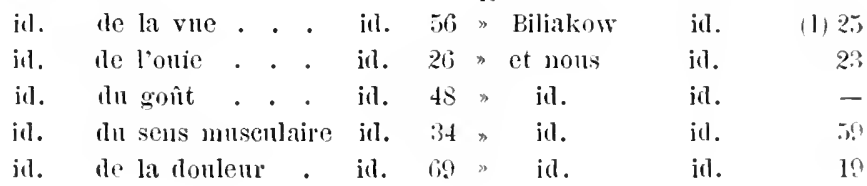

Venturi (2) tronve dans les épileptiques miles une acuité acuslique inférieure anx normanx comme 21 it 100 à droite, 25 à 100 il gauche, et dans les femmes comme 60 à 100 à droite et. 47 it 100 il gauche.

Amadei et Cividalli remarquerent me diminution de la douleur dans le 19010 ; Tomnini, sur 12 epileptirues, observa un cas d'analgésie telle, quion pouvait percer tous les points du corps avec une aiguille. Frigerio en

(1) Cela selon Biliakow (r. s.) Mais je dois noter jei que réemment le doet. Ottolenghi a examiné, dans mon laboratoire, le visus de 17 yeux de eriminels, dont 74 voleurs, eseroes, ete., et 16 lomicides de 25 a 35

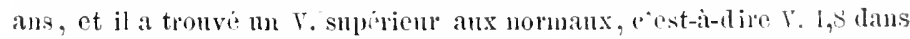
le 840 lo des voleurs, et V. 2,2 diuns le 1000 [0 les lomicides (T. Archicio di Psichiatril, 1886, vir, (i). Bono a obtenu presque le même. resultat dans les jeunes criminels et a mis eela en relation arec le $V$. plus élevé lles sanvages. - Faisons remarquer anssi que dans nos dernieres recherches nous trouvons dans les erimincls me proportion trisfaible de daltoniques, 0,220 [0, ee qui infirme Jes ohservations de Biliakow.

(2) doctrivio ti psichiotin, vol. vir, fig. 4. 
vit un qui s'ouvrit lc ventre avec un morceau de verre, pour s'enlever, disait-il, le mal: et un autre qui se coupa le membre viril, de sorte que la cangrène s'y mit.

Ilolmgren calculait dejà le $550_{10}$ de daltonistes parmi les épileptiques. Récemment Scpilli a trouvé chez les épileptiques la dischromatopsie dans le $210_{10}$, Cividalli dans le $440_{10}$ (hommes) et $510_{10}$ (femmes): proporlion toujours supérieure aux criminels.

Pour l'odorat, je trouve digne de remarque la plus grande acuité que Tonnini aurait observée chez un de ses sujets de deux côtés, et chez deux d'un seul côté: parceque, chez quelques criminels j’ai observé aussi mne forte acuiti de l'odorat.

4. - Latéralité el mancinisme. - Mais la plus grande analogie nous est donnée par la latéralité, qui est une vraie asymétrie sensorielle.

J'ai trouvé, chez les épileptiques, une plus grande sensibilité tactile à gauche, dans le $450_{10}$, et j'ai eu ainsi une moyenne de 2,15 á ganche et de 2,80 à droite. Ces données se rapprochent de celles fournies par les criminels: à gauche de 2,8 , et à droite de 2,9 .

Dans quelques cas je suis arrivé à d'étranges différences; 12 mm., par exemple, à gauche et 6,8 à droile.

Cetle latéralité, cette vraic asymétrie sensoriclle, mieux que par moi, fut illustrée par Tonnini, qui la vérifia, même, pour lous les autres sens, constalant, sur 9 sujets, l’inćgalilé de l'oüe 8 fois, de l'odoral 2 fois, et du tact 7 fois sur 11.

La prépondérance, presque constante, de loblusití sonsorielle à gauche, tandis que la plagiocéphalie crinienne prévaut a droite, confurme la relation déji entrevue par nous chez les criminels, du mancinisme sensoriel arec 
développement de l'hémisphère droit; c'est ainsi que sur el plagiocéphalies du crìne, jen ai remarqué 13 droite.

Tonnini, Bianchi el Zuccarelli ont demontré chez les épileptiques une latéralité, une asymétrie non sculement te la face, mais aussi du thorax, ainsi que nous nous lavons remarqué, dans les criminels, avec une prépondérance du $500_{10}$ à droile et du $400_{10}$ ì gauche. Tonnini a observé aussi, dins la température des deux còtés, une différence de $0^{\circ}, 2$ à $0^{\circ}, 4$ chez 9 sur 12 . On peul. en dire autant des réflexes vasculaires, différents des deux cótés chez $j$ sur 12 , et de la dilatation pupillaire inégale pour 5 sur 12, et de la sensibilité a la donlenr différente ehez 7 sur 12, et mème de la secrétion de la sueur.

Ciest cette latéralité manifeste et générale, qui fait croire à Tonnini qu'une des causes de l'épilepsic réside dans la disproportion exagérée entre les deux hémisphères, disproportion que nous avons constaté, à un phus petit degré, chez les criminels, et qui se relie, aussi, au mancinisme (V. s.).

J'ai trouvé le mancinisme 18 fois sur 176 épileptiques, et chez 9 j’ai observé l'ambidextrisme: ces proportions ne sont pas égales à celles des criminels, mais ell's n'eu restent pas moins supérieures aux normaux. Ln autre fait m'a frappí, qui s'enchaine aree celui-ei; c'est que la plupart des hémiplégies épileptiques 10 sur 15 , le sont du côté droit. Marro vient de faire la même observation sur 500 criminels (1).

5. - Motilité. - Sur 58 épileptiques j’en ai pu noter 9 d'une adresse extraordinaire: 1111 étail acrobate; 111

11) I caretteri aei wiminali, Turin 188\%. (Bibl. antropologico-crimigelle, le siric, vol. III). 
autre très-habile cocher; un troisième savait glisser adroitement des fenêtres el des barreaux, de sorte qu'il s'érada plusieurs fois; nous remarquâmes la même chose chez les fous moraux et dans les criminels.

Réflexes tendineux. - Bewoor avait déjà remarqué, que sur 70 épileptiques, après la période clonique, 11 avaient les réflexes rotuliens abolis on diminués et 7 seulement augmentés.

Cividalli, trouva exagérés les réflexes (dı genou) dans le $410_{10}$; Tonnini dans le $320_{10}$ et moi dans $850_{10}$ : et toutà-fait abolis ou affaiblis, moi, dans le 110 [0; Tonnini dans le 16010 . C'est à peu près comme chez les criminels.

Sur 12 examinés, Tonnini constata, pour 6, bien tardive la réaclion vasale qui était an contraire très-prompte dans les autres 6 . - Venturi constata la même chose.

Pupille. - Musso observa dans le $220_{10}$ de ses épileptiques l'inégalité de la pupille plus fréquente dans les formes psychiques, et dans les moments qui précèdent la crise.

Il remarfua, lui aussi, le réflexe pupillaire retardé chez plusieurs, et souvent plus prompt après la crise.

6. - Psychologie. - Mais c'est surtont dans l'étude psychologique des épileptiques qu'on peut démontrer leur identité avec les criminels.

La première prenve en est donnée par la psycométrie. Sur ma prière, M. Tanzi (Archivio di Psichialria, vol. vn, 2) étudia 13 épileptiques comparés avec 13 normaux: et trouva un retard dans les premiers à l'égard des derniers comme de 3 : 2; ou plus précisément comme 200010 ; arec oscillations moyennes de 0”,02' pour 0",011. Sur 820 cas, Mgeri et Tonnini en firent autant. - (Pour les criminels voir page 424). 
Si, maintenant, nous renons à l'étude de la psychologrie proprement dite: nous constatons, que, seuls les ípileptiques, peuvent embrasser, comme les fous moraux (roir dessus, p. 558), et les criminels (p. 138) sous une forme elinique égale, une divergence intellectuelle énorme, qui du génie va jusqu’à l'imbécillité. Krafft-Ebbing, dans son Traité, p. 187, soupçonne dans Mahomet, Napoléon, César, Pétrarque, Molière, génies épileptiques, quelque défaut dans l'esprit; pour moi jajoute: que leur descendance de criminels ou de fous, leurs fréquentes hallucinations, et le fait que les conceptions du génie(1), par la soudaineté, l'intermittence si fréquente, l'inconscience suivie mème d'amnésie, ont une remarquable ressemblance avec la décharge épileptique, sont autant de preures qui expliquent et confirment cette concomitance.

Et le talent de l'épileptique, non idiot, se rapproche bien de celui du criminel-né, par le fait de la fréquente paresse (p. 424), ou du contraste qu'offre son indolence habituelle, arec l'excès d'activité dans les actions mauvaises, étranges ou fantastiques.

"Leur indolence, écrit Schüle, s'alterne avec une activité excessive, une fantaisie excitée, une conroitise effrenée ".

"Paresseux (Vorsıs) ils ne travaillent que par l'âpreté du gain.

) Aux prises avec la justice, leur lucidité apparente, leurs agissements selon un plan arrêté à l'avance, rous donnent à croire qüils sont des simulateurs, non pas certes des épileptiques; et cet état peut durer des heures, des jour's, des semaines (Krafft-Ebring).

"Quelquefois, aussi (écrit Italus), ils ont un étrange sentiment de satisfaction, de jouissance, qui leur fait bâtir

(1) Lomerosu, Genio e Follia, te edit., 1884. Bueca, Torino. 
des projets insensés et concevoir des plans impossibles ». Nous en avons vu un qui rêva la conquête de l'Inde avec une soixantaine de paysans, qu'il entendait engager avec l'argent gagné par le rol: il se disait comte, député, etc. (V. Archivio di Psichiatria, vi, 3).

Mais c'est surtout la contradiction, l'excessivité du contraste qui les caractérise. Il y en avait un (Toxvixi) qui se croyait, par noment, Napoléon, et d'autres fois léchait la terre, comme lc dernier des esclaves.

Ils ont (dit Krafft), une émotivité énorme; tour à tour timides et exaltés, incapables de loyauté, tyrans domestiques (chap. VI, VII). "Méfiants, intolérants (écrit LEGhixd de Saulle, Epilepsie, 1880), un geste, un regard, suffisent pour les jeter en colère .. - Ils présentent, encore, les plus saisissantes contradictions: de querelleurs, méfiants, cyniques, ils deviennent tout-à-coup timides, respectueux, dévots; et ils sont surtout caractérisés par le pervertissement des affections, par la dureté du cœur.

Falsre dit: "L'intermittence des sentiments, ainsi que des facultés intellectuelles, est le trait dominant de leur caractère.

"La plupart du temps, entre deux accès, ils sont sournois, irascibles, bizarres: par monents polis et aimables, par d'autres grossiers, querelleurs, calomniateurs; leurs parents, aussi, sans être épileptiques, partagent les mêmes défauts, la même inconstance de caractère $n$.

Delasiauve dit: - "Ils arouent leur crime sans rélicences, parcequ'ils n'y roient que l'effet d'une légitime défense, ou d'un fait involontaire, et ils en ont plus de chagrin que de remords. Indifférents aux dangers qui menacent leur existence ou leur liberté, ils n’ont pas garde de faire disparaitre les traces de leur forfait, ou de se soustraire à ceux qui les poursuivent $»$. 
"Le caractère des ipileptiques, écril Schüle, consist" dans une extraordinaire irritabilité maladive, qui rapidement se transforme en des actes impulsifs. Ils son! les hommes capricieux, méfiants, excités contre euxmènes et contre les autres, turbulents, mauvais voisins, l'une gaielé, souvent, dont ils ignorent la raison, et puis dune dépression, exagéré: tour i lour humbles el aree tendances religieuses, ou orgueilleux, durs, michants.

》Dans une certaine mesure lovaux dans le commerce, el consciencieux, ils deviennent toul-ì-coup grossiers, cruels, malhonnêtes, jusqu'au vol.

"On ne trouve pas chez les aliénés une tendaner au vol aussi fréquente, aussi manifeste que parmi les épileptiques. Ces malades volent tranquillement tout ee qu'ils peurent attraper dans le débul de l'exaltation nerreuse; ils sont it même d'accomplir le vol le plus raffinc, ou de roler par ci, par là, sans plan arrêté, devoilant ensuite l'adresse de leurs exploits ) (lD).

"Les épilepliques les plus apparemment sains d'esprit, (ćcrit Voisin), peuvent commettre en certains moments des actes irrésistibles par rancune etc., par les illusions trop vives qui faussent leur jugement.

"L’épilepsie gâte le caractère, engendre la perte du sens moral, l'irritabilité: elle gìte surtout l'intelligence, provoquant l'affaiblissement, la stupeur, les dépressions, les morosités, les éblouissements, les illusions" (Voisis).

En somme icrivent Fischer (Zur Lchre von Epilept. Irres, 1884) et Pick (Encycl. Epilept.) « les contrastes, el l'immoralité, sont leurs caractères dominants; lo cynique, tel jour, est religieux; le bourreau de sa fermme sc jelte, tel autre, à ses pieds ». 
* Ils oscillent, toujours, entre les deux extrimes.

"C'est pour cela, dit Voisin, que la distinction des épileptiques en fous ou non fous, est un sophisme sans aucun appui pratique. A Bicètre, j’ai constaté que sur 60 épileptiques non aliénés, 4 seulement étaient intelligents; d'autre part sur 150 épileptiques fous, 22 étaient d'intolligence au moins égale à celle de ces quatre derniers. Parmi 148 épileptiques de la ville, j’en ai trouvé 10 apparemment sains d'esprit.

> La cause principale qui éveille le doute de l'immunité mentale chez tous les épileptiques, e’est le penchant à la colìre subite, la trop grande irritabilité, les sensations trop vives qui faussent leur jugement". "L'anesthésie, dit Thompson, qu'ils ont dans leur sens ils l'ont aussi dans le cour ".

Les accés maniaques, si fréquents chez les épileptiques, par le caractère même de la soudaineté, de l'intermittence, de l'hallucination, de la facilité à éclater pour un ricn et surtout pour la colère, expliquent, aussi, les accès maniaques des fous moraux (Dagonet) et des prisonniers. (V. s.).

La belle découverte de Magnan (Lecons sur l'épilepsie, 1880) que les épileptiques peuvent accoupler an délire maniaque un autre délire, p. ex. d'allucination et de mélancolie, explique la complication que nous trouverons, anssi souvent, du délire systématique hallucinatoire ou mélancolique parmi les détenus et les fous moraux.

dinsi la X. de Cantarano était une piromaniaque avec inversions sexuelles, la Glaser, la Jeanneret, et la Zerbini étaient hystériques.

Pour compléter, selon notre habitude, ce tableau par des chiffres, nous donnons ci-après les résultats de Ci- 
vilalli, Bianchi et Tonnini, qui resument en lris-pru de lignes ces caractères psychopatologiques:

\begin{tabular}{|c|c|c|}
\hline \multicolumn{2}{|c|}{ Homnies } & Femmes \\
\hline Civiulalli & Tunnuni & Civinalli \\
\hline 65 & $\begin{array}{l}\text { E Iianchi } \\
\leq 41.42\end{array}$ & 52 \\
\hline
\end{tabular}

\begin{tabular}{|c|c|c|c|c|c|c|c|c|}
\hline Tntelligence lin & mitee & . & . & . p. & 0 & 61 & $30,-$ & (6) \\
\hline Mćmoire faible & & . & . & . . & $"$ & 91 & $14,-$ & 78 \\
\hline IItllueination & . & . & . & . & $"$ & 41 & $20,-$ & 36 \\
\hline Inıpulsivité & . . & . & . & . & $"$ & 59 & 2,3 & 49 \\
\hline ldées de grand & deur & . & . & . & $n$ & 1 & 2,3 & - \\
\hline Irascibilite . & . . & . & . & . & $"$ & 100 & $30,-$ & (i) \\
\hline Mensonges . & . & . & . & . & $"$ & 100 & $7,-$ & 100 \\
\hline Vols . . . & . . & . . & . . . & · . & $"$ & 63 & 4,6 & 75 \\
\hline Croyances exag & gérée & & tigieuse & & $"$ & 86 & $14,-$ & 100 \\
\hline Pédérastie. & $\cdot$ & . . & . & - . & $"$ & 89 & 2,3 & 38 \\
\hline Perversilé & . & . & . & . & $"$ & $5 i$ & $30,-$ & 15 \\
\hline Onanisme . & $\cdot \cdot$ & . & . & . & $"$ & $6 i$ & - & 21 \\
\hline Sens moral inte & tiggre & . . & . . & . . & $"$ & - & $16,-$ & - \\
\hline
\end{tabular}

Remarfucz combien, tous Ies vices, ou mieux tous les penclants au crime predominent ici, mais surtout celle impulsivité, cette iraseibilite qui est la cause la plus fríruente des crimes contre les personnes. (Voir vol. $\mathbf{I I}^{\mathrm{e}}$ ).

Un fait renarquable est que les épileptiques détenus sont précisément de tous les prisonniers ceux qui conmeltent le plus de mélaits dans la prison nème. Sur 44 punitions infligées dans les prisons de Turin de 1881 à 1884, 21 ont frappé des épileptiques, qui n’étaient qu'au nombre de 17; tandis que des autres 378 détenus non éjileptiques, 23 seulement ont été punis (Maro). lichter lemarque que tout en faisant abstraction de cis dépilepsie larrée, les épileptiques sont parmi les prisonniers ceux qui ont commis les crimes plus graves d'effraction et de meurtre et qui donnent aussi le plus grand 
nombre de simulaleurs (Die Beziehungen der Verbrechen elc. 1886 ).

Religiosité. - Il faul, surtout, laire atiention à celle religiosité, que nous avons vu ètre (p. 415) un caractère des criminels, el qui, accompagne ou s'alterne te nème dans les épileptiques avec le cynisme et sert de prótexte allx actes criminels impulsifs. "Bigots avec Dieu par la langue, (disait d'eux Fischer) ils ont la méchanceté, lo poignard dans le cœur ». J'en ai connu un, qui, en tuant sa femne et sa belle-mère, croyait exécuter les ordres du Saint, son protecteur, qui par des signes et par la parolo l'excitit au crime. Lorsqu'on parle au nommé Pragano des enfants qu'il a tués: "Oí les deux premiers étaicnt morts, répondit-il, il étail prédestiné que le dernier mourût ת. Cotle religiosité est si marquée que le doctenr Toselli en a fait justement un caractère spécifique des épileptiques. Toselli, prié par moi d'en étendre l'étnde sur cenx de la bonne société, il y a remarqué la grande religriosité, également, 11 fois sur 19 màles et 5 fois sur 11 fenmes, et toujours mêlée à des excès contraires, aree lo penchant au viol, au meurtre, - ou bien encore arec de véritables caractères alavistiques qui rappellent les plus anciennes religions: ils offrent p. ex. leurs cadeaux an Dieu Soleil, et vont les déposer sur les arbres; ils croient entendre les voix de la Madone qui leur ordonne les meurtres, etc. Frigerio a connu une épileplique qui lui disait: "Ce n'est pas moi qui parle; cest Dien qui est dans moi, et qui me commande de parler ot d'agir \%. Un autre se cachait dans les églises craignant que hor's de là le diable l'emporterait (Toselur).

Détails. - Il y a aussi des autres petits détails, trop per fréquents pour ètre classés et précisés numériquement, mais qui ont pour moi, comme diraient les peintres, 
une couleur locale, et d'où jaillit ćclatante l'analogie des denx formes.

A mour aux bêtes. - Par exemple: j’ai ru les épileptiques, avoir d'étranges prédilections, et de haines plus étranges encore, pour les animaux, surtoul domestiques.

Deux épileptiques, jeunes gens riches, pendant toute lat journée, n'avaient de soucis que pour leur cheral qu'ils alfectionnaient plus que leurs parents. - Un montagnard anmait ses brebis, et il portait son amour jusquaux rapports charnels. - Un autre, prisonnier, s'emparait des rats communs en espérant de les dresser à trainer: celuilii, étudiant de lycée, ramassait des poux pour les exercer militairement: tandis, qu'un autre s'efforcait d'apprendre it une oie les exercices militaires.

Pour ce qui se rapporte aux criminels et aux fous moraux, je n'ai que le choix parmi les étranges prédilections pour les animaux, que montrèrent Commodo, Caligole, le doct. Francia, Lacenaire, la Trossarello, qui préférait des petits chats ì ses propres enfants.

Dostoiewski laconte «que ses forçats aimaient la chère Vasci jusqu’à vouloir lui dorer les cornes; ils auraient rempli leurs clianbres d’animaux

Destruction. - Il y a un autre caractère qui est commun à tous; cest le hesoin de briser, de détruire les objets inanimés, mais plus encore les êtres animis: besoin se rattache au penchant aux meurtres et aux blessures dont ils sont coutumiers: on le rencontre, hélas! bien souvent parmi les enfants.

Misdéa, qui était barbier du régiment, au moment d'utre relevé de ee service, cassa avec les dents trois rasoirs en petits morceanx. 
Piz... pour se soulager, ainsi qu’il disait, brisait rézulièrement, chaque jour, la vaisselle et les carreaux de sa cellule.

Cannibalisme, etc. - Cette tendance arrive, quelquefois, jusqu'au cannibalisme, qui y est bien des fois, sans aucun rapport avec les sentiments de vengeance.

Un épileptique, condamné pour coups ef blessures, pendant que je Ini appliquais un aimant sur la tête me disait qu'il sentait se réveiller en lui l'irritation qui avait été la cause de son forfait: "Je me mangerais moi-même si on m’en empêcherait pas " me disait-il ; - Misdéa criait fuil roulait ronger le foie de ses compagnons.

Cividalli en vit un manger le nez à trois de ses camarades.

Verzeni et Garayo, après avoir étranglé leurs victimes, mirent de còté certains morceaux choisis, pour les faire ròtir et manger. (V. après).

Dans la prison, où je suis médecin, jai vu prendre par un épileptique G... une convée de rats vivants, et les manger à peine brouillés avec l'huile de sa lampe, comme on ferail d'une salade. - C'est presque du cannibalisme.

Mais l'exemple plus classique, et le plus saisissant, est celui observé par Adriani (1).

Un épileptique de 42 ans, paysan de son état, avec des sinus frontaux el mandibules énormes (V. Pl. xv, no 33 et 8 i), os occipital aplati, oreilles difformes, wil injecté de sang, étail la terreur de ses compagnons de travail, parceque, sans aucune provocation, il les mordait avec ragce. Un jour, ayant rencontré dans sa route un jeuno homme, il l'attaqua, le renversa, et lui laboura les joues

(l) InRIni, Des maluties mentales daus l'asile d'aliénés de Ferme, 1872. 
avec les dents. Arrèté, au moment qu'on lui apportait l'ordinaire, mit les gardiens en fuite, courut chez lui s'empara de sa fillette de deux ans, et se mit à lıi manger les fesses, les cuisses, la poitrine, jusqu"i ce que les voisins lui sautèrent à la gorge, et l'obligerent à làcher prise. Ia paurre enfant en mourut. Lui, il erra, tout nu, quelque temps, par la campagne el un beau jour s'en retourna chez lui: à sa rue sa femme s'enfuit avec les autres enfants, mais il la réjoignit, lui arracha des bras un petit garçon de cinf ans, en cherchant de lui écraser le cràne: il l'aurait certainement achevé si la mère héroïque, ne l'eùt empêché.

La vanité est fréquente, en eux, ainsi que la vanterie et la régistration des délits. Interrogé sur le nombre de coups, dont il avait frappé la fille, Praganò répondait: "Un seul a suffi; ce bras ne se trompe pas facilement". Taylor enregistrait sur son carnet: "Injourd'hui j'ai tué une petite fille: elle était chaude».

Le penchant exagéré anx plaisir's vénérjens el surtout aux alcooliques est aussi frappant chez beaucoup d'ípileptiques que chez les criminels; et jen ai vu dans des épileptiques enfants. Aussi a-t-on voulu faire de l'épilepsie alcoolique une classe à part.

Suicide. - La tendance au suicide est fiéquente chez les épileptiques - quelquefois sincère, sourent simulée, plus souvent encore automatique, sans motifs - comme chez les criminels. Le suicide des épileptiques a, parfois, pour but, comme ehez ceux-ci, de les soustraire à la peine, et mème au délit. Sur 128 épileptiques, Jeisdedorf a trouré 13 suicides; sur 306, j'en ai trouré 11.

Legrand du Saulle nous parle d'un épileptique, qui écrivait: "Je me sens poussé à te tuer... Si je ne me tuais pas, saure-toi; ne me remercic pas: lu aurais dté 
ma viclime... Et voici que la tête me boute encore, que la plume me tourne entre les doigts ". Cet épileptique était fils d'un irrogne et d'une phthisique. Il finit par se pendre.

Un autre, sergent, frappait un camarade; puis, pris de remord se blessait à l'abdomen arec un couteau. Un mari épileptique, congédié par sa femme à cause de son mal, se tua à sa porte; el aussitôt son fils, âgé de 17 ans, se tua à son côté (Legraxd).

Morel vit une épileptique condannée par Iui à subir la douche prour aroir frappé ses compagnes, prendre un moreeau de verre el se couper la jugulaire.

Misdéa essaya, plusieurs fois, de se suicider, sans allune callse, el plus tard par dépit de ne pouroit ascouvir ses lendances brutales.

Delasiauve raconte qu'un épileptique, après chaque acces nocturne, avait un penchint it se couper la gorge.

Tatouage. - Sur 46 fous tatoués (1), éludiés par Sereri, 2 élaient épileptiques. Le tatouago de l'un de ceux-ci lui convait tout le corps, coume celat se rencontre chez. les prisonniers. L'un el l'antre avaient été renfermés dans thospice des aliénés. Or, le fail de talonage exécutí al l'hospice est rare, et quand il se rérifie, le tatouage n’est pas étendu à tout le corps. Sur 5 tatoús, trouvés par Frigerio parmi les 350 fous par lui étudios, 2 ataient épileptiques. Sur 81 épilepliques étudiés par Bianchi, 3 étaient tatoués.

Association. - Parmi les lous des asiles, les épileptiques sont les seuls qui aient, de mène que les criminels, une tendance à se rechercher et à s'associer. Its conspirent non seulement avec les individus affectés de

(i) Archivio di psichiatria e sciense penali, vol. vi, pag. 6 . 
leur propre maladie, mais aussi avee les fous moraux. Ils ne recherchent, souvent, l'association que pour la trilhil, et pour se frapper mutuellement. Daus la Maison de Santi de Schöneuherg, (Remer, Allyem. Zeit. für Psyc., 1894) 5 fous complotent une évasion, en allumant 111 incendie: or de cenx-ci, 8 ctaient des fons moralux, Q étaient épileptiques. Frigerio nous a parlé d'un certain L. T., qui non seulement vole avec une dextérité incroyable, mais qui souvent pousse ses camarades an vol et leur sert de guide. C'est un épileptique.

Simulation. - De mime que les criminels, les épiloptiques donnent un grand nombre de simulations, non senlement de folie, mais anssi d'épilepsie. Il y a des cas, oi, che\% los uns et chez les autres, il est absolument impossible de discerner si laceés est simulé ou réel. Capplello publia te cas d'un enfant de 12 ans, épileptique, qui simulait lépilepsie. Venturi, nous communique le cas d'un épileptique qui ayant tué son ennemi par esprit de vengeance, simula en prison, un accès convulsif.

Intermittences. - Amnésies. - Que l'on ne dise pas que chez les fous moraux manque la forme intermittente ni les accès précédés d'ituri. On la remarque aussi chez eux, quoique moins souvent que chez les épileptiques. Les gardiens disent que les prisonniers ont, de temps a antre, un mauvais moment dans la journée, moment où, sans cause spéciale, ils deviennent intraitables. C'est une observation que lostojewski fit aussi parmi ses compagnons (V. Souven. de la Maison des Morls, p. 17). "Etranges, dit-il, sont les éruptions d'indiscipline de ces gens-li. Pendant des années entières, ils supportent des supplices cruels, et ils se révoltent pour un rieu... D’autres qui pendant des années avaient élé endurcis dans le mal, au moment le plus inattendu se répandent 
en sentiments de cordialité, comme si les écailles leur tombaient des yeux $»$.

J'ai observé dans les prisons de Turin, quo les mêmes jours où, sous des influences certainement météréologiques, les accès des épileptiques devenaient aigus, les criminels non aliénés commettaient des actes violents ou d'indiscipline; ainsi, ils déchiraient leurs vêtements, détruisaient le matériel de travail, frappaient, sans raison, le premier gardien venu. - Frigerio a remarqué le mème fait chez ses fous moraux.

J'ai, enfin, vu des cas ou l'impulsion du fou moral ou l'acte criminel étaient précédé comme chez l'épileptique, jalr une aura motrice. J'ai noté, ailleurs (Archivio di psichiatria, vol. III), le cas d'un jeune homme dont la famille s'apercevait qüil méditait un rol, lorsqu'il portait continuellement ses mains an nez, habitude qui funit pour le lui déformer.

Qu'on ne nous dise pas, non plus, que l'amnésie millıque dans ces gens. Bianchi a observé l'amnésie de leurs actes chez 4 fous moraux. Nous l'observons souvent dans les boutades des enfants. Et on sait désormais que bien qu'elle soit un des traits les plus fréquents des acles épileptiques, elle n'est pas indispensable pour les caractériser (Samt et Thubunxi). Et nous allons le voil lout de suite.

7. - Cas cliniques. - Un fait très-important pour notre thèse est que dans les cas les phus frappants de folie morale, l'épilepsie se confonde avec les tendinces criminelles et date de la première enfance.

Giuliano Celestino, par ex., de 16 ans, taille 1,51; poids kilogrr. 40,500 , peau jaunâtre couverte de tatouages, sans traces de poils, capacité crànienne 1516 , 
index cranien 77. Crane aree plagiocéphalis, frontals, gauche, qui corresponde í une asymétrie du visage; yeux obliques, front étroit, angle orbital saiflant, coupe de la bouche horizontale comme chez le singes; Jents incisives supérieures latérales semblables aux canines; ne\% asymétrique; mandibules el zigones très-rolumineux; sensibilité tactile très-ohtuse, et plus it droite, 4 mm11., qu'i gauche, $2 \mathrm{~mm}$.; sensibilité dolorifique tout-it-fait abolie à droite, fres-obuse à gauche; relléxes rotuliens exagérés à droite, presque nuls à gauche; sa sensibilité affective est tout-i-fait abolie. Lorsque on lui demande s"il aime sa mère: "Je l'aime, dit-il, toutes les fois qu'elle m'apporte des sigares et de l'argent: i) et il ne rougit pas si on lui parle de ses forlaits. Il avoue souriant qu il essaya d dix ans de tuer dans son berceau le plus petit de ses frères, et quil en fut empèché par sa mère i la quelle, il n'úpargna ni coups, ni morsures. Il roulait, dit-il, lui trancher la tète pour s'en faire une culotte de pipe! Né d'un père syphilitique et irrogne il soutrit d'épilepsic jusqu'it l'igge de sept ans; adonné de bonne heure il l'ivrognerie il se livre an vagabondage; renfermé, il grimpe sur les fenêtres, monte par les cheminées, brise les meubles, menace sa mère, etc. Il essaya aussi la profession de garcon boucher pour se vautrer dans les souffrances des bètes. Il fit après le sal. limbanque. Enfermé à onze ans dans une maison de correction il sy signala par ses tentatives d'évasion et d'incendie, et il fut condanıné, par ce fait, ì deux années de prison.

Itteint de manie, il manifesta des accès épileptiques convulsifs et quelquefois larvées arec tentatives de pendaison, qui se renouvelèrent périodiquement chaque deux mois pendant une année. 
Preuss (Zur Casuistik der zweifellaflen Geisteszuslände, 1885) nous fournit l'exemple de R. P., âgé de 23 ans, dont la soem est épileptique. Fainćant et indiscipliné à l'école, dès son jeune àge convulsionnaire et ivrogne, voleur de ses parents, ragabond, enrôlé dans larméc, il est, d'abord, bon soldat, puis mauvais snjet et roleur. Il disait souvent qu'il en coûtail cher de s'en prendre à lui, qüil aurait fail quelque diablerie pour être mis en liberté et ne plus servir comme simple soldat. Plus tard: il eut un accès d'épilepsie. Un mois et demi après, il s'absente, veut être visité à l'auberge par le médecin militaire, menace de frapper les sous-officier's qui veulent le reconduire à la caserme, prend à partie les soldats avec lesquels il a précédemment eu à dire, leur cric: "Si rous me croyez fou, c'est que c'est rous qui l'êtes! „ et leur résiste au point que dix d'entre cux peuvent à peine le contenir. Trois jours après il ne présente plus rien d'anormal, sauf la fixité du regard, la contraction dos muscles de la face, du coté ganche, el l'annésie.

C'était encore un épileptique que ce coupeur de bourses, espion, irrogne, fils d'irrogne, neveu de fou, que jai illustré, qui ne parlait que l'argot, qui ne dormait pas la nuit s'il n'avait pas commis un vol pendant le jour, qui ne se croyait mis au monde que pour voler (Archivio di psichiatria, 1881, p. 207). C'élait un épileptique que ce De... T... (Genio e follia, 4e édition, p. 215), presque analgésique, rui voulait fonder une nouvelle religion dont la prostitution aurait été la régle, réğle qu'il roulait pratiquer, le premier, sur les places publiques; il était, à la fois, ivrogne, violateur, escroc, faisait du chantage en journalistne, rouait sa femme de coups el la courrait de blessures. - Cébait un épilep- 
lique que ee voleur-escroe condammi 1 't fois el mis 23 fois sous procès, 9 fois reconnu simulalcur, 9 fois mis lans un asile, qui 4 fois cssaya de se suicider, que Tamlurini a illustré (Rivista frenialrica, 1881); con itait un autre que ce soldat, itudic par De Paoli (Archivio di psichiatria), qui en six ans subit 12 condannations criminelles. Et viceversa, étaient des crimiuels lous los épileptiques fameux qui ont éte illustris: Huiclı par Krafft-Ebbing, Morzani par moi, R. V. par Tamburini, Iofstapfel par Liman, Mcloni par Bonfigli (roir p. 509 el suiv.), (Archivio, 1881, I1). Sur 8 cas de folie morale decrit recemment par Richter (Die Bezie. hungen Zwischen Geisleskr. und Verbrechen, 1886) jo tronve 5 fois l'epilepsie, 2 lois le vertige. Les deux cas "type de folie morale décrit par Tamburini, Sbro..., et $Z$..., araient l'un le vertige et l'amnésie, l'autre l'irascihilité sans cause, la périodicité des accés, la parenlèle avec des épileptiques.

Statistique criminclle. - L’identité dn criminel-ne et de lépilepsie semble prouvée aussi par la statistique. Les études récentes de Sommer et de Knecht (Archivio di psichiatria, v, p. 14ষ), démontrent que les ipileptipues se trouvent parmi les prisonniers dans la proportion de : $0_{10}$ (Virgilio a trouvé le $6,30_{10}$ chez les voleurs). 1)', parmi les individus normaux, Rayer compte 6 épileptiques par 1000 , et Villeneuve en conple 5 sur 1000 conscrits Statistique des Bouches du Rhône, 1826). En Allemagne, Hitsch en compte 1 par 1000; en Italie, Morselli 1,3 par 1000. Ainsi donc, les prisonniers donnent cnviron 10 fois plus d'épileptiques que les normanx. Clank constata le délit chez $110 \mid 0$ dépileptiques communs (Heredity and crime in epilepsy, 1880). 
Sur 297 prévenus épileptiques, dont les données ont été réunis par Krafft-Ebing, Legrand du Saulle, Tamburini, Toselli, Liman et par moi, j’ai compté:

\begin{tabular}{|c|c|c|c|c|c|}
\hline Homicides & . & & & & \\
\hline Voleurs & . & & & & \\
\hline Accusés de & bless & ures, & & uta & alités \\
\hline Vagabonds, & fainé & éants & & . & . \\
\hline Incendiaires & & • & - & • & . \\
\hline Déserteurs, & escro & & . & . & . \\
\hline Violateurs & . & . & . & . & . \\
\hline Suicides & $\cdot$ & . & . & . & . \\
\hline Rebelles, vi & iolents & & • & - & - \\
\hline Empoisonne & & . & & & . \\
\hline Calomniateu & & . & & . & . \\
\hline
\end{tabular}

Richter (v. c.) remarque que, même en dehor's des cas d'épilepsie larvée, les épileptiques fournissent le plus grand nombre de crimes plus graves, de meurtres, de vol avec effraction, etc.

Plusieurs des Césars étaient épileptiques: Caligula, par exemple.

8. - Epilepsie larvée. - Les accès de fureur épileptique, ou, pour mieux dire, d'équivalent psychique, par leur caractère d'instantanéité soudaine, par leur férocité inutile et exagérée, forment aux yeux de l'observateur attentif, dans une période aigüe et courte, ce que l'épileptique est normalement - une caricature du crime, de même que l'obtusion sensorielle, la stupidité momentanée qui suivent et accompagnent les accès ne sont que l'excès de l'état habituel et souvent congénital de l'épileptique.

On objectera: que la fureur épileptique, par son instantanéité, par le manque de but utile, se révèle tout de suite comme morbide, surtout par l'annésie qui suit le filit. Hais il ne manque pas des cas oủ même dans 
l'équivalent, même dans la fureur, épileptique, l'acle semble prémédité, s’accorde avec les intérèts des sujets, se prolonge longtemps, et n'exchut pas le calme, de facon ì se confondre, d'me manière absolue, avec le délit. Samt, Tamburini, Bonfigli, Toselli, et, plus récemment Echeveria, prouvèrent qu'il y a des cas où l'accès psychique, même le mieux caractérisé, a été suivi du sourenir le plus net, qui s'effaca quelquefois plus tard. Voici un cas que nous fournit la Rivista di freniatria, 1878:

B., de 41 ans, (il a un frère voleur et des søurs épileptiques), sujet depuis des années aux rertiges, voit en avril 1878 un chat mort dont les yeux sortaient de la tête. Il en est impressionné: ses rêves deviennent bizarres. Un jour il demande une faucille à une voisine, puis il sort et se fait accompagner de sa femme en lui prodiguant une foule de bonnes paroles; puis il roule avec elle dans un champ, et avec un caillon lui écrase la tête. Les voisins accourent: il les menaces et les poursuit en criant: "Vous êtes venus pour me dénoncer, mais je rous tuerai ». Désarmé, il se calme, mais peu d'instants après il enfonce la porte des roisins, et arec des pincettes écrase la tête à une femme et à trois petites filles. Il grimpe sur le toit; prend une poutre it bras-le-corps et se laisse tomber, privé de sens, d'une hauteur de six mètres. Le jour après, il se souvenait de tout et déclarait avoir obéi à une voix qui lui criait: «Tue, tue!...». Il est complètement analgésique (ToSELLI).

Autre cas:

V. S. est imputé de rol. Insubordonné depuis l'enfance, mauvais sujet, somnambule it 20 ans, convulsionnaire à 22 , il maltraite sa femme, commet des 
escroqueries, etc. Il s'íprend d'une dame, qui, ignorant son mariage, l'accueille assez bien; mais ayant appris la ririté, elle l'éconduit. Il en devient féroce; hrise les menhles, ecrit des insolences, menace; un matin il pénètre de vive force, armé de deux pistolets, chez cette femme, disant qu'elle lui a fail cadeau de ces armes pour qu'il la tue an cas ou elle le trahirait. Il tire sur elle et sur un domestique, la poursuit en enfoncant demx portes. Lorsqu'on l'arrête, son aspect est celui d'un homme arraché inopinément all sommeil. Mis sous procès, il est calme, se souvient de tout; cंest lui qui se fait accusateur. (Thaburisi , Rivista di freniatria, 1876).

Thauriot est fils d'une femme publique et d'un vieux juif sordide et violent. Il a un père suicide ef un grandpère apoplétique. Il a exercé tous les métiers: soldat, libraire, sculpteur. Il se plaint d'itourdissements et de certaines crises pendant lesquelles l'envie le prenait de tuer quelquiun. Ces crises duraient de un à trois jours. Pendant ce temps, il lui était impossible de rester tranquille; il avait hesoin de commettre quelque riolence. Une l'ois, pendant un accès, il quitte la boutique oú il était, achète un couteau, passe la nuit avec une courtisane et le lendemain prénédite de la tuer; puis s'en va, le contean dans sa poche, résoln à tuer quelquiun. Dans la journie, il se rend dans un auberge et pendant qu'on lui prépare le menu, il écrit que sa destinée est de tinir au bagne ou sur l'íchafand, que dans peu d'instants il va frapper quelqu'un, incertain, si ce sera la servante on la maitresse; la servante le sert: e'est clle quil tue. En prison il est calme.

Enroyé a l'asile on ne dieourre que plus tard, qüil avait, pendant la nuil, des acè̀s d'épilepsie. Des tímoins rapportent qu ćlant gargon libraire il avait commis 
des actes solfement obscenes, callses de son promoi. Une antre fois, il perdit comnaissance pres d'un four-

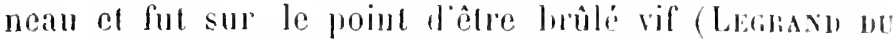
Siulle, De l'épilepsic, 1876 ).

Tout dernièrement lac. A. Botlin, dans son élude sur l'Aliénation mentale ipileptique (Lovalewsis, Archie. psikhatrii, nisrologhii $i$ sudebnoi psikho-patologhii, Khallkov) raconte le cas d'un soldat qui, en 15 mois, alvilit eommis 16 fautes contre la discipline et antres.

La punition l'exaspérait au lien de le corriger. II rn arriva à se jeter sur un officier, les poings levis. Daprès l’instruction judiciaire, il s'ag̣issait d'un criminel en. durci. On en donnait comme preuve qüil prélendait n'ilvoir garde aucun souvenir de son dernier crime, tandis que d'autres lni étaient restés dans la mémoire. On trouvait naturel qu'il ne se rappelit pas un fait qui pouvail le conduire aux bagnes. Une experlise prouva que ce soldat appartenait à une famille qui, dans le cours de trois wérations, arail donni 5 aliénés; des son enfance le pévenu arait eu un caractère triste et entèti; on l'avait renvoý de tontes les écoles. Sa famille le regardail comme un fléau. Plus tard l'épilepsie s'était diclarée.

Ilofstapfel (Archiv. für Psychiatric, Berlin 1874), garcon l'auberge, jouissait d'une mauraise renommée. Igé do 19 ans, il coupe un soir le fil de la sonnelle qui fail comnuniquer sa chambre a celle de la maitresse; puis, une lumiere une main et le revolver de lautre, il lire sur deux de ses camarades (morts plus tard te leurs blessures), cherehe d'en blesser un troisiene et dans la lutte qui s'ensuil, s'acharme sur un des premiers llessés. On le désame: il demande de se turer, puis se calme, shabille arec recherche, el disparait, mais pour se rendre a la police al dectarer d'aroir tué 
deux de ses camarades. On l'arrête, il déclare que les coups sont partis au moment où on lui arrachait l'arme des mains et que ces mêmes coups l'ont réveillé. II dit que depuis l'enfance il est somnambule, et que la veille du fait, une voix lui avait dit: "Tire," et qu'il en avait parlé à ses camarades. On sut plus tard qu'il s'était rendu coupable de rol et d'incendie et on le soupconna d'avoir roulu tuer ses camarades pour pouroir piller plus à son aise la maison.

I l'audience, il s'arrête sur des minuties et ne se souvient pas des circonstances importantes. On le taxa de simulation, malgré qu'il résultât que deux de ses oncles étaient épileptiques, une grande tante aliénée, le fils d'un grand oncle imbécile et un autre épileptique. Il fut condamné. Plus tard, on reconnut qu il souffrait réellement d'accès épileptiques et de somnambulisme. Le premier à le reconnaitre fut Liman qui pourtant l'avait déclaré un simulateur. (Praktiches Handbuch des Gerichtlichen Medicin, von D. Kart Limas, 1876).

IIoloni (Rivista di freniatria, 1878), plusieurs fois mis sous procès, fils de mère épileptique, neven d'aliéné, après une maladie (petite vérole), à l'àge de cinq ans, est pris de rertiges épileptirues avec courtes amnésies, pour lesquels il eut recours aux médecins. Il devint dès lors irascible, de doux et affectueux qu'il était. Il commet des actes ctranges: se jette par la fenêtre, se plonge la tête dans la neige, elc. Devenu soldat, en 40 jours de service il est continuellement puni. L'n jour il abandonne sur le chemin public le panier des vives et n'en garde aucun souvenir. Plus tard, il se fait marchand, s'adonne à l'ivrognerie, devient brutal, peutêtre voleur, se fait aimer des uns, haïr des autres, 
commet des actes de folie pour une femme quilpres trois. jours il roue de coups et méprise sans raison. If mai il s'enirre; peut-ĉtre aussi le 28. Ce jour-li, il est a la taverne. Un nommé Gononi se plaint de sa sour, sans quil s'en ressente le moins du monde. Plus lard, il est surpris à bougonner: il dit qu'il veut le tuer et montre un couteau préparé pour cela: aussitôt qu'il l'apercoit il le poursuit, le frappe, et s'enfuit dans los champs et y passe la nuit. A son réreil, il a tout oublié. Nais lorsqu'il apprend que G. est mort, il va su liver. Il aroue le crime, en reconstitue les précédents et proteste qu'il portait le couteau sur lui par pur hasard et que le crime n'était nullement prémédité.

Un an plus tard, en prison, il est pris d'un acces de manie aree vertiges. Il ne se souvient plus de rien. It sait qu'il est l'auteur de la mort de Gononi, parcequ'on le lui a dit.

Une nuit il est pris d'un accès d'épilepsie furieuse; il se jette sur les infirmiers; ses pupilles sont dilatios et insensibles. Le matin, il a les souvenirs clairs; dans le jour, il a tout oublié. (Boxfigli, 1879).

On voit qu'il n'y a, ici, qu'une amnésic intermittante. Visdea, est un soldat de 22 ans, qui sait lire; son aïenl est peu intelligent, 2 oncles sont imbéciles, un autro bizarre et irascible, et 1 dernier meurtrier mort aux gitlères, 3 cousins sont imbéciles et 1 fou. Son père ivrogne, bizarre, irascible, est marié à une femme hyssérique qui a 1 frère brigand et un autre voleur. Des 5 frères: 2 sont irascibles, 1 épileptique, ivrogne, condamnís pour coups, a déjà un fils condamné pour viol.

Misdea a une taille de m. 1,63, il pèse 59 kilogr., il a des cheveux épais, des poils abondants, des cicatrices aux bras et sur le crîne, dont une adhérente. 
Sa tête offre (V. Atlas Plan. vit ${ }^{\mathrm{e}}$ ), dans sa partie antérieurc, la forme d'une carène avec saillie à la bosse frontale droite et à l'occipital gauche, brusque applatissement de la région pariéto-frontale gauche, excavation à la base du front, et sténocrotaphie; pommettes Énormes, la droite plus développée; léger strabisme convergent à gauche.

Il accuse de violentes douleurs de tête: quand il est contrarié, il éprouve des spasmes, et des rougeurs à la face et aux yeux, lorsque on réveille chez lui certaines pensées de haine.

116 , à 19 ans, il a été condamné pour coups et blessures, pour vol, puis pour port et usage d'arme.

Au rógiment, il a subi cinq punitions, dont deux pour insubordination.

Il a été souvent malade: de février 188:3 à mars 1884 , il a été neuf fois à l'hôpital pour des vertiges. Il passait dans son pays pour un être étrange, liypocondriaque, un peu fou.

L'affectivité est à peu-près nulle chez lui, ou au moin: intermittente: s'il sattendrit tans sa prison, en pensant au chagrin qu'il va causer ì sa mère, et dans d'autres moments, il dira qu’il n'a aucune affection: il a des haines sans cause, il prétend aimer ses conpagnons, mais il lenr mangerait le foie à Ia moindre contrarićté; après ses menrtres, il nourrit encore des sentiments de vengeance contre ses victimes.

Son intelligence est bornée, sa mémoire faible; il est verbeux, illogique, incapable de s'élever à une coneeption abstraite; il est dissimulé dans sa défense, quand il ne se laisse pas entraîner par ses impulsions.

Prolondément paresseux, il ne souffre pas d'êtro un prison: "Il y pourra dosmir à l'aise: " il avoue qu’it 
sest fait punir an régiment pour éviter lit fillignte dx manœuvres. Son carractère présente de wrandes allotllat-

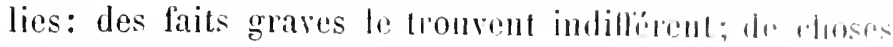
insignifiantes l’irritent.

Un jour, rentrant il la cascrur, apues quelepre bihition, il croit entendre des propos contre los Calabraic et menace tous d'une vengeance. Un sergent intervirnt, le silence se fait; tout l'un roup, on entend des ditonations: un soldat tombe i terre frappri par Misteal d'un coup de fusil; trois daja conchis sont grievenumt blessés; trois autres cherchent un refinge dans les latumr.

Misdea s'acharne aprés ses compagnons qui fuicnl nu se jettent à terre pour éviter ses coups; quaml it no voit plus personne dans la charnbrée, le meurtrier so met a une fenètre el tire sur des soldats qui sont dans nne cour.

Un sergent pénètre dans la chambrée: il le tromb l'arme an bras et lui demande: Oí est le soldat qui a tiré? Misdea pour réponse le frappe à la cuisse.

Pendant cette scène de carnage; Misdea montro un grand sang-froid: il dit à un calabrais: "Ne crains ricu, je ne te tuerai pas, parcerue tu es de mon pays".

Quand on vent le saisir, il se défend arec ses picds, ses poings, en mordant; lorsqu'on veut lui mettre la camisole de force, il s'écric: "On la met anx irronns et aux fous, je ne suis ni fon ni irrognen.

Il tombe, après, dans un sommeil prolongi (commo e'est le cas des épilepsies larrées) mais il n’onblie rien de ce quil avait fait, senlement y il donne une aturir tournure; il a la vanití de ses nourtres; son crime restera mémorable, on parlera de lui dans les joumaux; il se vante davour commis trois centitives dhomicido sur des bourgeois. 
Chez Misdea, l'insensibilité, la paresse, la vanité, la violence, la haine poussée parfois jusqu'au cannibalisme, tous ces symptômes qu'on rencontre chez le «criminel-né » et chez le "fou moral» sont exagérés par l'épilepsie, dont l'existence n'a fait aucun doute pour personne, pas même pour les experts de l'accusation.

On rencontre en effet chez Misdea (1): la forme anormale du crâne; le fait d'avoir frappé indistinctement amis et ennemis; une force musculaire extraordinaire déployée, lors de son arrestation, bien qu'il ne donne que 34 à 37 kilogr. au dynamomètre; le sang froid, le calme après ses meurtres; un courage extraordinaire contrastant avec une lâcheté habituelle; une irascibilité excessive; l'abus du vin; les vertiges; les velleités de suicide; l' existence d’accès épileptiques antérieurs; l'emploi, pendant les accès, de phrases stéréotipées, telles que: J'ai mes caprices, la tête me tourne; un sommeil profond dans la matinée qui suit la scène de carnage; des douleurs de tête; et, avant tout, la parenté arec des épileptiques, des alcooliques, des fous, des idiots, des eriminels.

Avant de mourir, Misdea, chez qui nous avons constaté le défaut d'affectivité, a écrit une lettre dans laquelle il manifeste des sentiments religieux et témoigne une grande affection pour sa mère et ses frères; mais dans celte lettre on lit cette phrase singulière: "Je vous écris en fumant (le cigare)».

Le contraste entre les graves préoccupations du condamné et le détail puéril, auquel il attache assez d'importance pour le consigner dans une lettre d'adieu, est un autre signe caractéristique de l'épilepsie.

(1) Yoir Misdea avec figures, par Iомввоso 1884, Bocca, Turin. 
Dans ces cas on a dans l'accès épileptique psychirpue la continuation des tendances antérieures; on trouve lis préméditation et le souvenir complet ou prestue; il ny a plus rien enfin qui le distingue de l'acte criminel: Qu'on remarque que cet ítat, apparemment raisonnable, peut durer des jours et des mois entiers.

Krafft-Ebbing écrit: "Souvent l'acè̀s est suivi d'un état qui se rapproche du somnambulisme, sous l'empire duquel on dirait que le malade a la conscience de ses actes; il parle avec connexion, agit avec order, poursuit ses occupations, et néanmoins il n'a pas sa conscience, de sorte que, plus tard, il ne sait rien de ce qu'il a accompli. - Cet état d'aveuglement psychique peut durer longtemps et même pour tout l'intervalle entre deux accès».

On objectera que, dans tous ces exemples, on avait constaté antérieurement des accès épileptiques. Je répondrai que dans plusieurs, ces accès ne furent reconnus que longtemps après le crime ou le jugement, $\mathrm{p}$. ex. Thouriot fils, et bien des fois seulement par hasard.

luguste N..., âgé de 17 ans, au moyen d'une massue, écrase le cràne du camarade qui partage son lit. On l'arrête de suite, pendant ru'il déclame des vers latins et des chants d'église; il continue ainsi pendant 5 jours, après lesquels il revient à lui tout-à-fait inconscient de son forfait. Il n'avait jamais en aucun accès, mais il se rappelle qu'à trois ans il était tombé, sans connaissance, dans le feu, et à huit ans il eut un éblouissement dont il tomba d'un arbre. Plusieurs fois, en portant du lait, il le perdit. On finit pour observer sur lui un accès épileptique à l'hòpital des fous (Magnax).

Legrand du Saulle, consulté sur un enfant de 9 ins, fils de maniaques et neveu de suicide, rusé, voleur, 
onaniste et cruel avec les camarades et les animaux, suspecte l'épilepsie, bien qu'il n'y en eut auparavant aucun symptôme; et en effet avec le bromure, il obtint une sensible amélioration. Les vrais accès épileptiques ne se déclarèrent que onze ans après.

0 ..., était connu pour un homme violent, malhonnète, arrèté plusieurs fois pour vol de chevaux, lui qui itait maquignon; c'est Legrand qui, par liasard (page 61) le vit une nuit dans l'accès épileptique; autrement. personne ne sien serait douté.

C..., très-emporté dans sa jeunesse, fantasque, urinait dans son lit; à 18 ans il eut quelques accès de délire. Devenu officier, il s'irritait toujour's avec ses camarades. Il eut un faible attaque de délire quon attribua i un coup de soleil: puni pour une dernière querelle, il donna ses démissions. En 1870, il se battit comme simple soldat, à Metz, dans un autre régiment; il écrivit après à Gambetta qu'il était lieutenant et décoré, et il recut les brevets de son grade et de sa décoration: déconvert ensuite et poursuivi par devant les tribunamx, on s'apercul qu’il était épileptirque et il fut acruitté.

Sommer (Epilepsies contestées) rappelle un cas d'épilepsie qui ne fut reconnue quà son dénoûment fatal.

Le magon D..., dans le juin 1884 mettait le fent it une auberge, arrèté, il avouait qu'il avait été incendiaire par instigation et mandat du propriétaire mème de l'hôtel, qui voulait ainsi toucher la prime d'assurance: il signa sa déclaration. Amené en prison, il fut atteint de délire; quelque temps après le médecin remarqua quil avait complètement oublié le délit et sa cause et mème le lieu où il était; il so croyait à lhòtel et voulait en sortir. - Il était hanté par de sinistres apparitions, il avait commerce arec Dicu. 
Il améliora arec le traitement antialcoolique, mais il ne se rappela jamais de l'accident. - Il prétendait aroir souffert de rertiges, de crampes, mais sa femme et ses. amis to niaient. Une fois pourtant il cut un accès daus l'asile où il était en observation, mais on le soupconna de simulation. Ramené en prison, il fut pris en décemlure d'une série d'accès épileptiques si clairs et si nombrenx, que le doute ne fut plus possible: il en mourut.

Il y cut, tout de mème, chez plusieurs médecins le soupcon qu'il pourait aroir simulé l'amnésie. (Centralblatl, 1884).

Cette ignorance des accès tient a plusieur's causes. "Bien souvent (écrit Trousscau) les accès épileptiques, surtout au début, arrivent la nuit, de sorte qu'on pourrail en être frappé pendant 8 on 10 ans sans le saroir; et il y a des accès incomplets qui sont ignorís tonte la rie "(Clinique médicale, 1868).

C'est justement pour cela que tous admeltent celte forme spéciale d'épilepsie, tout-i-fait exempte de conrulsions, qui consiste en absences et vertiges, on en penchants violents vénériens et au rol.

Obscénité: Tels sont certains actes obscènes ou cruels, commis d'emblée par des gens honnêtes.

liernon nous parle de P..., très-honnète homme, qui deux ou trois fois dans l'année, et pour une duréc de 8 a 14 jours, était pris d'accès de fureur, de dystimie ct de penchants pédérastiques; et d'une dame, dont l'ige critique fut accompagné de vertiges, d'accès ápileptiques, et de penchants crimincls pour un petit enfant (Archiv. psychiatrie, Xit).

Récemment Tarnowsky (Messager de psychiatrie, Saint Pétcrsbourg, 1884) nous frésente des cas de vertiges 
épileptiques qui se manifestèrent par des étranges, intermittentes lubricités (se faire battre, masturber oralement, etc., par des prostituées) chez des hommes honnètes qui prévoyaient toujours l'approche de l'accès; il cite, aussi, l'exemple d'un jeune homme qu'on a reconnu après épileptique, qui allant visiter sa maîtresse et ne la trouvant pas a la maison, se jeta sur un garcon de 17 ans pour le violer; la femme de chambre, accourue aux cris, en fut renverséc el violée it son tour; il se coucha ensuite et dormit 12 heures, en oubliant tont au réveil, hormis ce dernier coït.

Un autre, étudié par lowalewsky, après 8 jours de dépression, demande, d'emblée, à une amie de sa femme et sous les yeux de celle-ci, de se donner à lui: sur son refus, il s'adresse à sa femme, qui, de même le repousse. Il tombe alors à terre, devient furieux, déchire ses habits et menace, avec de l'cau bouillante, qous les voisins, et finit pour en brûler son enfant: quelques années après l'épilepsie se déclara.

Après ces données, ct après l'étude des cas de cannibalisme, chez les épileptiques, il nest pas douteux que c'était bien un épileptique que ce Bertrand, qui clıerchait, par périodes, la volupté dans la putréfaction, en mutilant les cadares des femmes, jeunes ou vieilles qu'elles fussent, et qui, pendant ces accès, était dans un état convulsif et dans une complète anésthésic (MoREAU, Aberralions du sens génésique, 1884, p. 240), et plus surement létaient Verzeni (1) et Garayo.

Verzeni, jeune lomme de 17 ans, avec asymétrie crànienne et faciale, de mœurs douces jusqualors, quoique

(1) Voir vol. In. 
d'une famille de crétins et de pélagrenx, essaya, en cerlaines époques de lannée, en 1872 d'étrangler 7 femmes et il en découpa deux en morceaux, en épapillant les entrailles et même des lambeamx de chairs; il m'arouit que l'élreinte du eou el surtout la mutilation des cadivres, les morsures et les succions du saug, lui faisaienı éprouver le maximum de lit jouissance vénérienne: dans ees moments il se sentait une force énorme et il ne royait plus rien; il eût des amnésies.

Garayo, fils d'ivrognes, devenu tout-i-coup vertigineux après un trammatisme à la tìte el i la suite d'un mariage malheureux, d'honnète el doux qu'il élail, se mit, soudain, i étrangler des femmes, la plupart de vieilles filles, pour en jouir. 11 en blessa 7 , en tua 6 ; souvent il enfonecait tantòt une épingle dans la poitrine de ses rictimes, tantòt les piquait à coups redoublés avee la pointe d'un conteau, el d'autres, il en éventrait les cadavres et il en arrachait les entrailles, en détachait des lambeaux pour les manger et tout ecla dans eertains périodes de l'année (printemps et hiver).

Dans ees cas, nous trourons les preuves de l'épilepsie larvée dans les vertiges, dans les caractères physiques, dans l'hérédité alcoolique, lans le penchant à remplacer le coït avee le démembrement, avec le cannibalisme dans les contrastes frappants entre la vie antérieure dans la périodieité constante des aceès.

Jagnan note un cas de délire épileptique chez un individu qui n’éprouva jamais de convulsions, ınais qui avait de tels altérations intermittentes qu'on pouvait suspecter l'épilepsic. Une nuit il se leva et, malgré les prières de sa mère qui l'en dissuadait, il s'en alla, it moitié nu, dans la rue, un conteau à la main, et tua 
des passants. Il dememra étomé pendant six jours, et il oublia tout après: on sut qu'il n'avait jamais souflert de convulsions, mais que par moments, il sortait de la maison, restail dehors deux jours, et rentrait après chez lui, harassé de latigue et inconscient de ce qu’il avait fail.

Preganò de Girifalco, àgé de 52 ans, paysan, d'un bon développement squelétrique, avec crâne scaphoïde, et plagiocéphalie, sinus frontaux énormes, asymétric taciale, nez dérié à droite, oreilles à anse, sensibilité tactile obtuse, $5 \mathrm{~mm}$. ì droite, 6 à gauche, plutòt sourd, d'une extraordinaire sensibilité olfactive, avec deux frèes fous, n'a jamais souffert daccès convulsifs épileptiques. Soncicus de ses pratiques religieuses, on l'aurait dit un chrétien modèle; et pourtant il tua, certaincment trois et probablement quatre de ses enfants. Il était le commis d'un pharmacien débaucheur et immoral, et, à ce ru'on en dit, il l'aida à se débarrasser de sa lemme par le poison.

Un fils de ce demicr, dans $m$ accès de folie, ayant essayé de tuer son père, Preganò en fut (dit-il) trèsfrappé. Le pharmacien mourut, aussi, apres une certaine potion qüil lui administra, dans l'espoir d'en hériter; mais déru de l'altente, il se nit à travailler comme paysan, songeant toujours à la tragédie dont il avait ćté témoin, et à la charge pénible qui lui renait de ses enfants. Le jour de Pàques, il emmena ses fils près d'un bassin, où il travaillait, samusant avec jeur. Touta-coup, il se sentit (dit-il) le sang aller de la tète aux pieds, vit les ambres el les montagnes tomnoyer, se rappela la scene du fils llu pharmacien, se jela avec ses enfants dans le bassin, puis il sortit, il en repêcha 
les cadares el fit croire dans le pays a un acrident mallieureux.

Denx mois apres, sa fille, helle enfamt de 18 ans, qu'il amait par dessus tous les amtres, était elle anssi pros du falal bassius. Il eut un retour de son vertige criminel. " bù les aulles sont mor'ts, il faut qu'elle meure "se sentit-il suggérer, el d'un coup de hiche la tua, en essayant après de se jeter du haut d'un rocher.

Maintenant il est gai, somriant, respecturux: il donne des conseils aux malades, aux infirmiers, il a me illée très-élevée de lui-même, comme grand travailleur, ef surtout comme habile criminel. Tous ponves mesurer mon crâne, mais vous nc saurez jamais ce dont ma tête fut capable.

Le fail étrange c'est qu’il eut toujours pour ses enfants une tendresse sans borne, jusqu'à leur épargner les travaux plus pénibles (Toxnini, Les épilepsies, p. 40).

Vertiges. - Toutes ces formes d'aceès impulsifs, que nous dirons criminels, sont bien plus fréquentes dans les épileptiques qui ne souffrent que de vertiges; et à cause de cela ne sont reconnus pour tels. - Esquirol remarqua, aussi, que les accès vertigineux troublent plus facilement l'esprit que les accès convulsifs; et Ilalmhaus (Brilish Med. Journal, 1883) nota sur 250 épileptiques, que les épileptiques exempts apparemment de folie, étaient cenx qui sonflraient de convulsions, tandis que ceux qui étaient frappés de vertiges, étaient par moment aliénés. El Magnan, dit justement: que les absences, les rertiges, bien plus que les accès impulsifs s'issocient aux plus fortes dégradations intellectuelles.

Dans tous ees cas de vertigo érotique ou sanguinaire, on arlive par des nuances el par des passages successils, a une raic surcharge de la criminaliti normale. 
8. - Physiologie, etc. - A présent on explique cela très-bien: car on sait que l'épilepsie n'est autre chose qu'une décharge des centres corticaux. L'irritation et la décharge envahissent, dans ces cas, les centres psychiques, préservant les psychomoteurs. Il se produit ici le même phénomène que dans les paralysies, qui suivent plus fréquemment les attaques très-légères d'épilepsie; et on l'explique, aisément, ear plus les décharges sont violentes, plus elles sont diffuses et moins elles se concentrent dans certaines régions et bien moins encore elles les désorganisent (Gowers).

Du reste cela est démontré scientifiquement. C'est lo grand̉ mérite d'Albertoni et Lueiani, et surtout dans ces derniers temps de Rosembach /Ueber die Pathogenesis der Epileps. Virchow. Archiv., 1884), de Ziehen (Ueber die Krampf in folge elektrische Ziehung der Grosshirnrind, 1886) d'avoir confirmé, par l'expérienee, l'hypothèse de Jackson (The Medical press., 1884) que la convulsion épileptique n'est qu'un effet de l'irritation des zones motrices de l'enveloppe cérébrale, absolument comme l'hallucination épileptique est le résultat de l'excitation des eentres sensoriels, et la perte de la conscience, l'impulsion eriminelle épileptique est une décharge des centres psychiques plus élevés, des lobes antérieurs.

"Un accès épileptique n'est qu'une décharge rapide จ et violente de la matière grise, qui au lieu de déve) lopper sa force graduellement, éclate tout d'un coup, ) à cause même de son état de distrophie. Pour qu'il y "ait épilepsie, il n'est pas toujours nécessaire qu'il y ait "des convulsions: les déeharges loeales sont suffisantes; »et on peut aussi avoir une attaque épileptique arec »des seules hallueinations olfactives, etc. "(JaGrSor). 
La perte de la connaissance, selon Ilammond, ne diffère pas des autres symptòmes; la conscience, anssi, garde un substrat anatomique déterminé; quand celuici est frappé, elle se manifeste; autrement non.

En effet, avec de faibles courants appliqués par Rossembach sur les centres psycomoteurs, on détermine une épilepsic partielle, qui se transforme ensuite en accès épileptique complet, en gagnant les autres groupes musculaires: tandis que avec un couraut très-énergique, qui va des centres psycomoteurs aux zones non excitables, on a, tout de suite, un accès épileptique complet.

Pour ce qui est de la conscience, il peut se manifester des conrulsions sans perte de comnaissance, et sans altération de l'excitabilité de l'écorce, convulsions limilées à une extrémité ou à une moitié du corps, produites par l'excitation immédiate mais faible des centres psycomoteurs.

Ainsi, par l'excitation du même centre cortical, on peut avoir les formes les plus diverses d'épilepsie.

Nous aurons done la forme convulsive s'il y a décharge de la zone motrice, épileptogène; impulsivité criminelle ou vertiges quand l'irritation et la décharge se bornent aux circonvolutions frontales.

Et cela d'autant plus, depuis que Charcot et Pitres ont démontré que les affections corticales qui engendrent l'épilcpsie, ont une topographie bien peu déterminée, l“irritation d'une aire pouvant se déplacer et se propager dans les voisines (Revue de médecine, 1883; $5,6,8)$.

Les phénomènes de l'aura épileptique n'excluent pas, mais confirment la localisation cérébrale de l'épilepsie: et, comme dit bien Rossembach, ils ont l'empreinte 
d'une projection excentrique des excitations des centres sensoriels; et par le fait ils sont presque toujours du domaine des sens.

Ajoutez à cela, que, souvent, l'aura n'est qu'une hallucination compliquée, ou un symptòme psychique, par ex., anxiété, impulsion; el qu'on a une aura sensorielle même dans le petit mal, selon Gowers 55010 . L'aura motrice, comme l'inflexion d'un on plus doigts, pent très-bien sexpliquer, aussi, par une excitation limitée du centre cortical psycomoteur.

Il est bon, ici, de remarquer que la différence anatomique plus saillante entre les épileptiques et les criminels complète ces recherches; c'est-i-dire, la microcéphalie frontale, qui est très-fréquente chez les criminels, dans lesquels nous trouvàmes aussi une infériorité quadruple de la demi-circonférence crànique antériemre par rapport aux normaux, et une infériorité de 95 à 100 du diamètre frontal minime et une majorité de fronts plus bas et plus élroits (1), et dans lesquels nous avons remarqué d'abord l'aplatissement de la région frontale, ensuite la sclérose de l'os, et des sinus frontaux. Tout cela ne se trouvant pas avec autant de fréquence dans les épileptiques convulsifs, on s'explique pourquoi chez ceux-ci plus que chez les autres (dans lesquels préralent les anomalies des circonvolutions pariétales et des pariétales ascendantes) se réitèrent les accès criminels, dans lesquels on constate toujours le défaut, ou de con-

(1) Récemment MLarno, dans son beau livre Les caractires des criminels, nota :

Sur 119 eriminels, fronts etroits 86000 bas 41010

$\begin{array}{lccclll}\text { Id. } & \text { id. } & \text { id. larges } 13 \text { hauts } 58 \text { " } \\ \text { Id. normalux } & \text { id. etroits } 59 \text { " bas } 15 \text { " } \\ \text { ld. } & \text { id. } & \text { id. larges } 41 \text { " hauts } 84 \text { " }\end{array}$


science ou de prévoyance et surlout de celte énergie de frein, d̈inhibition aux premières impulsions qui distinguent l'homme adulte el le civil, du sauvage et de l'enfant et même de l'lypnotisé, et qui dépend du manque des centres frénateurs psycliques qui ont leur siège dans les lobes antériem's. - Il faut, peut-être, ajouler à cela, comme cause impulsive dans les épileptiques, l'extraordinaire asymétrie cérébrale révélée par la plagiocéphalie, et ensuite par le latíralisine des fonctions, qui rendent ces hommes, à la lettre, des gens sans équilibre.

9. - Eliologic. - Tout cela est encore mieux confirmé par les analogies éliologiques dont une preuve nous est donnée par la distribution géographique.

Nous avons étudié, avec le doct. Rossi, les chiffres de la criminalité italienne (Bopro, Mouvement de la criminalité italionne, 1879-83) el les chiffres de l'épilepsie, comme cause de réforme du service militaire: el nous arons remarqué (V. Atlas, Planche ${ }_{11}{ }^{\mathrm{e}}$ ) sur nos 69 départements: que

de 35 qui sont an dessous de la moyenne du royaume par nombre d'épileptiques;

25 le sont aussi id. id. dans les erimes de révolte, violences, ete.;

25 le sout aussi id. dans les outrages aux mœurs, etc.;

23 le sont aussi ill.

id. diuns les meurtres on blessures suivies de mort; et

de 32 qui sont au dessus de la moyeune du royaume par nombre d’épileptiques;

II le sont aussi id. irl. dans les délits de révolte, violences, etc.;

13 le sont aussi id. aux mœurs, ete.;

13 le sont aussi id. id. dans les meurtres ou blessures suivies de mort. 
Les 2 départements (Chieti et Reggio Calabria) qui ont un nombre d'épileptiques égal à la moyenne du royaume (24 $0_{[00000}$ ), ont, pourtant, dans les 3 catégories de délits des nombres supérieurs aux moyennes.

Iais pour les 7 départements dont exceptionnellement le nombre d'épileptiques est moindre et la criminalité est exagérée, il faut noter que Rome est la capitale du royaume, et pour Campobasso, Avellino et Potenza il ne faut pas non plus oublier les traditions et les restes du brigandage. - Pour les 14 départements dans lesquels l'épilepsie est plus étendue que la criminalité, il est a remarquer que 5, Bergamo, Como, Sondrio, Porto-Maurizio, Massa, ront sujets au goitre et au crétinisme qui s'allie bien sonvent avec l'épilepsie.

Ainsi done on n'aurait manque de rapport entre les deux fléaux que dans 23 départements sur 69 , el pour 9, ce manque serait justifié par d'autres influences. Nous pourrions ajouter que dans quelques départentents la disproportion ne serait que apparente, par ex., a Ravenna, Forli, Palermo (1). Ici on pourrait dire, même que le chiffre des épileptiques corrige celle des eriminels, rectifie la statistique.

On ne peut nicr que l'accord de trois genres de criminalité entr'elles et avec l'épilepsic, ne soit frappant (V. planche III). Il ne se dément que dans quelque cas: à Lecce et Venezia pour les délits de révolte; a Siracusa

(1) Il y a peu de jours, j'interrogeais en prison un jeune homme de Forli, dejà condamne plusieurs fois ponr blessures. Comme je m'en ètonnais et lui en faisais des reproches: "Mais monsieur, me dit-il, je suis de Forli ".

Je tronve, anssi, dans les dictons de Rimini, récemment illustrés, celui.ci: "Mère, une githle vant bien un coup de coutean?, Oni, mon fils, e'ost de l'Evangile que cela. (B)ati, Proverbi romagnoli, 1886). 
et Grosseto pour les outrages aux mours; à Pisa pour l'épilepsic.

Une autre analogie nous est donnce par l'àge lles parents.

Narro a démontré récemment que les criminels surtout $\left(520_{10}\right)$, les meurtriers et les escroes $\left(370_{10}\right)$, sont, ainsi que les épileptiques $\left(470_{10}\right)$, en proportion double relatirement aux gens normaux $(24,9010)$ nés de parents très-îgés ( $\mathrm{V}$. Planche $\mathrm{xxvi}^{\mathrm{e}}$ ); il fit aussi la même observalion sur les quelques fous-moraux étudiés par lui.

La fréquence plus grande du jeune îge chez les épileptiques est d'une grande importance pour démontrer son origine congénitale, de même que son analogie arec la folic morale (1).

C'est une chronologic tout-ì-fait analogue ì celle que j’ai démontrée pour les criminels.

Dans l'ìge critique, selon Griesinger, il y a une faible recrudescence, surtout pour l'état épileptoïde larvé, el cela explique ces cas de crimes féroces, praliqués par des personnes très-honnêtes auparavant, précédés toujours par des rerliges, chez des hommes mûrs, comme chez Garayo. - Pour ce qui se rapporte aux autres causes (V. tab. (1) page suivante), je suis frappé par l'analogie de cinq: l'alcoolisme en première ligne, les traumes, les méningites, les exanthèmes, les osteômes.

(1)

Selon: Herpin Reynolds Hammond Gowers

\begin{tabular}{|c|c|c|c|c|c|c|}
\hline De & 0 à 10 & ans & . 15 & 19 & 60 & 422 \\
\hline " & $10 " 20$ & $"$ & 20 & 406 & 329 & 651 \\
\hline ") & $20 " 50$ & $"$ & 9 & 45 & 143 & 422 \\
\hline$n$ & $50 " 80$ & $"$ & 6 & 2 & 40 & 21 \\
\hline
\end{tabular}

Cividalli en trouva, sur 120 épileptiques, 78 qui l' étaient dójà avant la quatorzième annẻe. 
J'avais déjà fait remarquer dans mon Archivio, vol. $\mathbf{I I}^{\mathrm{e}}$, p. 43, en mappuyant sur mes observations et sur celles dc Skae, Azam, Lasegue, Flesch, Morel, Mesnet, Acrell, combien souvent des individus sains, après des traumatismes à la tête, tombent dans un état d'irascibilité solldaine, s'adonnent au vol, etc. Ces traumatismes sont fréquents chez les criminels (17 sur 010).

Les ostéômes signalés par Leidersdorf, Battanoli et Frigerio dans les épileptiques, furent aussi remarqués par moi 3 fois sur 90 fous criminels.

La frérquence de l'alcoolisme chez les parents des criminels n’a pas ici besoin d'être démontrée.

Les aliénistes ont remarqué bien souvent la folie morale engendrée par les fièvres typhoïdes on exanthématiques.

(1) Causes

Penr, anxictés, ete.

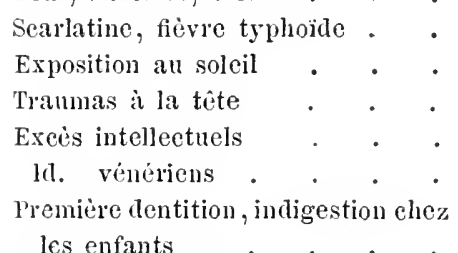

\begin{tabular}{|c|c|c|c|}
\hline $\begin{array}{c}\text { Sur 2)6 } \\
\text { de } \\
\text { Hammond }\end{array}$ & $\begin{array}{l}\text { Sur } 60 \\
\quad \text { de } \\
\text { Reynolds }\end{array}$ & $\begin{array}{c}\text { Sur } 128 \\
\text { de } \\
\text { Leidesdorf }\end{array}$ & $\begin{array}{l}\text { Sur } 428 \\
\text { de } \\
\text { Gowers }\end{array}$ \\
\hline 15 & 29 & 24 & 186 \\
\hline 11 & 9 & 4 & 35 \\
\hline- & - & - & $2 \pi$ \\
\hline 10 & 9 & 13 & 65 \\
\hline 17 & - & - & - \\
\hline 15 & 一 & - & - \\
\hline
\end{tabular}

les enfants . . . . 11

Règles dérangées . . . 10

Grosscsse $\quad$. $\quad$. . . 3

Syphilis . . . . . 3

Méningite enfantine . . . -

Aleoolisme . . . . . -

Eclampsies . . . . . . -

Eau froide à la tête

Premier coit elıez une femme hys-

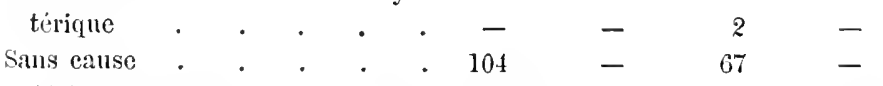

(*) En outre des vers intestinaux 6, asphyxie 9. - Empoisonnement saturuin 6, par le tabae 1. - Affection des reins chronique 2. - Anesthisic artificielle 1. 
Et pour la fréquence de la méningite, nous rappelous que Flesch l'observa sur $500_{10}$; des criminels les plus célèbres, Lemaire, Bénoist, Homble, Seger, Greenen, Guiteau, Granicr, Faclla, l'ont jusqu ici présentée; Lasègue, il y a bien des années, observa certaines méningites qui se manifestèrent dès l'enfance, disparurent après, pour éclater soudain dians l'ìge mûre sous la forme de perversité et d'actes impulsifs.

On objectera que les eauses morales sont bien plus nombreuses dans l'épilepsie proprement dite que dans la folie morale, et qu'elles sont même d'une nature différente, car les chagrins prévalent plutôt en celle-ci, tandis que dans l'épilepsic c'est la peur qui l'emporte. - C'est vrai; et ayjant même consulté à ce propos le savant qui fit de la peur son étude spéciale, le professeur Mosso, il me répondit ainsi:

"Je crois qu'il n'y a pas d'énotion qui produise, " comme la peur, une contraction aussi forte des rais"seaux sanguins.

"Les effets de la peur sont très-graves, par son action "subite et par la grande quantité d'énergie nerveuse " qu'elle anéantit; elle est toujours suivic d'une dépres» sion et d'un épuisement supéricurs à tout autre fait ") psychique.

"Les troubles de nutrition des centres nerveux sont "les premières conditions morbides de l'origine de l'é"pilepsic.

"La douleur, les actions morales qui envahissent peu "à peu le système nerveux, n'ont pas de conséquences ") aussi graves parceque dans ce cas les nerfs, irrités "par une excitation électrique ou mécanique, ne r'éa"gissent pas avec une contraction". 
„Plus la cause est aigüe, plus l'effet sera rapide et immédiat r.

L'liérédité directe de l'épilepsie, trouvée dans $10 \mathrm{sul}$ 68 par Herpin, dans 408 sur 1113 par Gowers, dans $120_{10}$ par Reynolds, dans 33 sur 300 par Delasiauve, dans $110_{10}$ par Sieweking, dans 21 sur 171 par Hammond, n'aurait pas ici d'importance sauf pour les cas, non rares, de fous moraux et de criminels avec parents épileptiques (selon Virgilio $140_{10}$ ).

Knecht, étudiant récemment 400 de ses climinels, en trouva 60 avec parents épileptiques $\left(150_{[0}\right)$, et parmi ces derniers, 24 fois l'était la mère, 14 le père, 17 les frères. - Seulement 5 de ces 60 étaient épileptiques, et 3 sur 42 avaient très-saillants les caractères dégénératifs ( $A$ llg. Zeitz. f. Psych., 37, 40).

Les Césars descendent d'un épileptique.

Opinions des aliénistes. - Du reste, tout cela n'est pas aussi nouveau, dans le inonde scientifique, qu'on pourrait le croire. En effet cesidées, si clles ne furent pas claires, furent, au moins, soupçonnées, et je dirai pressenties et affirmées de nos aliénistes les plus savants. "Souvent les hommes privés de sens moral sont des épileptiques ou des idiots " écrit Mausdley (Mental science, 1882). Krafft-Ebing (Lehrb. der Gericht. psych., 1882, p. 248), après avoir dit "que les fous moraux dérivent souvent d'épileptiques ou de alcooliques, ou de fous, énumère encore, parmi leurs caractères la fréquence très-grande de symptômes épileptiques en plus d'autres anomalies, " et, parlant de l'épilepsie, il écrit :

* L’énorme fugacité et la fréquence des phénomènes psycopathiques, la facilité toujours plus grande qu'un acte criminel, soit accompli sous l'empire d'un accès épileptique vertigineux, on dans l'état crépusculaire de 
l'épilepsic, donne à penser que beaucoup de crimes ne sont, peut-être, que des phénomènes épileptiques mal jugés ".

Gaustner (Das impulsive Irresein, Tubinga, 1882), el avant lui Schüle dans son Handbuch der Geisteskrankheiten, 1878, parlant des impulsifs, pyromanes, dypsomanes et cleptomanes, réunirent ces formes aut procès de l'épilepsie psychique, gràce aux accès intermittents, à la transformation directe de la cléptomanic en manie épileptique, à l'amnésie fréquente, à l'inconscience et soudaincté des accès, à l'anxiété précordiale, avcc douleurs de tête et d'estomac, à la durée, tantót brève, tantôt prolongée, mais toujours irrompue par périodes; à l'analogie typique entre les actes, à la fréquence des conditions hypérémiques du cerveau qui les précèdent, ainsi qu'à la présence de vraies aura de sang, de flammes hallucinatoires, et à leur transformation en accès de fureur périodique.

Et déjà, depuis le 1867, Griesinger avait étendu le cadre de l'épilepsie, en faisant entrer sous le nom d'état épileptique certaines névroses périodiques, arec lallucinations instantanées ou perte de la conscience, ou lourdeur de la tête, ou douleurs qui découlaient de la tête jusqu'aux pieds, pourvu que dans un temps plus ou moins ancien ils fussent dévancés par des amnésies, des vertiges, des palpitations de cœur et des coups dans la tête, ou par l'abus des alcooliques, surtout dans l'adoléscence et dans l’àge mûr.

Il y a peu de temps que Cividalli et Amato, Reich (Das épilepsismus, 1886) Frigerio et Tonnini, non seulement épousèrent mes idées, mais ils les appuyèrent, comme nous avons vu, par un nombre imposant de nouveaux faits. Tonnini, surtout, allant plus loin que les autres, 
admet et dérnontre que l'épilepsie provoquée par les altérations de tous ou de certains centres corticaux, présente cinq variétés particulières:

" $1^{\circ} \mathrm{L}$ Lépilepsie à forme motrice convulsive, qui est très-rare el qu'on peut observer dans des sujets de bon caractère, mais d'une grande émotivité;

) $2^{\circ}$ L'épilepsie psychique qui est fréquente chez le fon moral ou criminel-né, avec des lésions spéciales dans les lobes frontaux;

" $3^{\circ}$ L'épilepsic sensorielle dans laquelle prédominent les hallucinations terrifiantes et impulsives et dont sont affectés beaucoup de ces fous périodiques, de ces monomanes, qui bons el dociles toute la vie, sont tout-àcoup poussés aux meurtres, aux incendies, par les voix impérieuses, etc.;

》 $4^{\circ}$ Lépilepsie complète avec altération motrice, sensorielle et psychique;

" $5^{\circ}$ L'épilepsie mixte, tantòt psycho-sensorielle avec ces impulsions hallucinatoires, tantôt motorio-sensorielle, lantòt psycomotrice ".

Toutes ces einq variétés, exception faite des cas où elles sont motivées par des causes traumatiques, ont des caractères de famille, l'asymétrie, p. ex., le latéralisme, l'obtusité sensorielle (Epilepsie, 1886).

“ Et, ajoute-t-il, si on est parvenu de nos jours, non seulement à fondre l’ẻpilepsie partielle avec la générale mais à regarder comme des phénomènes épileptiques des barres épigastriques, des céphalées, des scialorrées intermittentes, pourvu qu'elles soient précédées d'un aura, quelles difficultés peut-on avancer pour admettre la folie morale dans la famille de l'épilepsie?

„S'il y avait eu dans ces cas des difficultés, c'était alor's que nos aïeuls reconnurent dans l'épilepsie larvée une 
épilepsie sans convulsions, en se basant sur les seuls caractères criminels et rertigineux. De premier abord quelle analogie peut-il y aroir entre une simple conrulsion et un vertige, et entre celle ei et une scine de massacre? Et toutefois, nos ancètres, partant de l'ipilepsic classique, et royant que les convulsions so substituaient et s'alternaient arec les absences, les vertiges ou les impulsions, élevèrent un symptòme isolé qui tenait seulement par un coin à l'épilepsic jusqu'à la diagnose d'épilepsie à soi, el firent alors bien plus que nous n'essayons aujourd'hui d'accomplir pour la folie morale " (T'oxisis).

Mais combien cela nous est plus aisé maintenant, qu'aux rares points d'appui d'autant, on peut en ajouter bien d'autres, tels que les caractères anthropologiques, fonctionnels, les anatomo-pathologiques et les étiologiques.

Du reste, bien des amnécs avant que le baptème physiologique cût confirmé cette fusion, elle élait déjà entréc dans le domaine de la pratique medico-légale (1).

Je rapporterai ici les paroles de Trousseau (l. c., pag. 22): « On peut admeltre, sans le moindre doute,

(1) Dans la littérature même on en trouve quelque trace. Yaebeth etait, selon Suakspeare, épileptique dés son enfanee (Acte $\mathrm{u}^{\mathrm{e}}$ ). Dostoyewski dans ses romans peint ses eriminels avee des vertiges ou des absenees, et dans ses Souvenirs de la Maison des Morts il écrit:

« Un détenu a vécu tranquillement pendant plusicurs annécs eonséentives, sa conduite était si exemplaire qu'on l'a même fait dizainier; tout-à-eoup, au grand étonnement de ses chefs, eet homme se mutine, fait le diable à quatre, et ne recule pas devant un erime capitil tel qu'un assassinat, un viol, etc. On s'en étonne. La cause de cette explosion inattendue, ehez un homme dont on n'attendait rien de pareil, c'est la manifestation angoissée, convulsive de la personnalité, une mélanconie instinetive, un désir d'affirmer son moi avili, sentiments qui olsscureissent le jugement. C'est eomme un accès d'épilepsie *. 
toutes les fois qu'on a sous les yeux un crime qui n'est pas provoqué ni par alićnation mentale, ni par empoisonnement alcoolique, ni par autre cause, que c'était un cas d'épilepsie ».

Et avant Trousseau, Plater: Facta épileptica quamvis malefaciendi et ulciscendi consilia suscepta amentice excusatione non carent.

Cirons encore le mémorable ordre du jour, dicté en 1875, dans la Société de Médecine légale française, après une discussion très-étendue sur la responsabilité des épileptiques, par des savants comme Lasègue, Fabrea, Manuel, Devergie.

"Considérant: Que sous le nom générique d'épilepsie, il faut comprendre des états morbides ayant les mêmes caractères intermittents, convulsifs, vertigineux, mais qui diffèrent par le type, l'intensité, la fréquence et la durée;

"Que le pervertissement moral d'un même individu à des époques diverses, ou de plusieurs malades, peut défier les prévisions les plus liabiles;

》Que l'épilepsie se transforme, par le seul fait de la durée du mal et par la périodicité des accès;

- Il est aris de la Société médico-légale que les règles générales qui président aux arrêts sur la responsabilité des aliénés, doivent s'appliquer à l'épilepsie, tenant compte des difficultés spéciales que nous présente une affection dont les accès éclatent soudain dans toute la lucidité de la raison, el s'éranouissent après sans en laisser aucune trace $»$.

Atavisme. - Il est bien entendu que la fusion de la folie morale avec l'épilepsie n'exclut pas l'atavisme.

Presque toutes les maladies mentales engendrent, déjà, une espèce de folie morale intermittente, mais 
l'épilepsie en provorque une bien plus constante; et cela parceque les premières à s'efficer sont toujours les fonctions qui se manifestent plus tird dans l'organisme mental de l'humanité.

Si une lésion du cervean enlève la propricté de reconnaitre les couleurs, la première conleur qui s'efface e'est justement la dernic̀re à paraitre dans l'évolution du cerreau; le sens moral, (qu'y parail aussi lo dernies', est le premier à s'évanouir dans son infirmité.

Que l'alavisme des épileptiques y soit plus constant, el plus complet que dans toutes les autres maladies mentales, c'est ce qu'on concoit très-vite, si on se rapporte it l'étrange religiosité de ces grens, au cannibalisme cl a bien d'autres caractères de l'animalité.

Gowers, après aroir noté certains actes étranges des épileptiques, comme manger de la chair humaine, boire du sang, croquer, vivants, des animanx arec leur poil, aboyer, mordre, miatuler, ete., ajoute: «On dirait qu'il y a lit les manifestations de cette instinctive animalité que nous possédons à l'état latent (Epilepsy, 1880, Londres).

Confession précicuse de la part d'un praticien, qui n’avait la moindre idée de cos théories.

Liépilepsie ne nous fait pas perdre non plus le trait d'union, que nous avons trouré entre la folie morale et l'enfance, car elle fut justement appelée maladic de l'enfance, morbus primce infantice; Cividalli el Amati, sur 120 épileptiques, en trouvèrent 78 frappés dans lcur première enfance: la passion aussi en faveur el contre les animaux, la manie de destruction des objets inanimés est bien propre des enfants, ainsi que des fous moraux. Ajoutons-y la moindre sensibilité, l'amnésie (1)

(1) Voir Prrez, L'enfunt de trois à sept ans, Paris, 1886. 
et les emportements de colère aussi souvent remarqués dans les uns que chez les autres.

Différences. - La variété criminelle, à son tour, bien que par beancoup de diramations elle se rapproche de l'épilepsic ordinaire et lui ressemble, nous présente, pourtanl, pas mal de différences: dans le crâne, p. ex., elle présente les os wormiens moins fréquents, ainsi que la microcéplualie frontale, ce dont on a l'explication dans le fait que dans la folie morale les plus frappés ce ne sont pas les circonvolutions pariétales, mais les frontales (roir page 626 ).

Le véritable épileptique présente, au surplus, moins d'acuité visuelle, tandis que la plupart des criminels l'ont supérieure aux normaux (1), et selon les dernières études, il a, après la crise, l'augmentation termique plus fréquente; il donnerait, selon Charcot, 38 et même $41^{\circ}(2)$, tandis que dans les criminels on ne dépasse jamais les $37,2,37,5$.

Les criminels nous offriraient aussi une plus fréquente exacerbation pendant les grandes chaleurs, tandis que, selon les études de Lachi (L'infuence des météres sur l'épilepsie, 1882), les épileptiques convulsifs ont les accès plus fréquents dans les jours froids: ils auraient aussi les reprises plus fortes et plus saillants les contrastes entre les accès, et une plus grande asymétrie crânienne, thoracique, etc., et une latéralité bien plus exagérée, et moins de vanité, et plus de cruauté et d'irascibilité; et dans l'étiologie de l'épilepsie la peur lient une place bjen plus grande que dans celle de la criminalité.

(1) roir note précédente page 589.

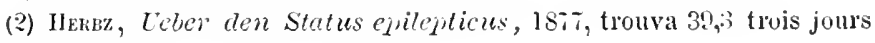
après l'accès. 
Le caractère différenticl réside, surtoul, dans l'exagiration des lignes: de mème que la folie morale se fond avec la erimiualité innée, (en cela seul différente qu’elle en est une exageration), ainsi le criminel épileptipue proprement dit, qui continue ehroniquement les férocitis des accis aigus nu larrés, nous présente l'exagération de la folie morale; mais dans les périodes moins prononcés elles se fondent ensemble. Et comme deux choses égales à une troisième sont igales entr"elles, il est hors de doute que la criminalité-innée et la folie morale ne sont que des variantes de l'épilepsie; elles sont, comme dirait Griesinger, des états épileptoüdes (1).

C'est là que, à notre insu, nous aboutissions continuellement en constatant d'aussi nombreux phénomènes pathologiques qui sadditionnaient aux atavistiques pour former le type du criminel.

Et il est hon de remarquer que l'épileptique dans les cas moins fréquents où il y a seulement émotivité exagérée sans penchants maurais el sans caractères dégénératifs, $(160 \mid 0)$, nous offre un trait d'union arec les criminels par passion dont nous parlerons dans le deuxième volume, lesquels, d'autre part, n'auraient aucune autre analogie avec la folie morale.

(1) Je résume mes idées, pour plus de clarté, dans ces lignes graphiques:

\begin{tabular}{|c|c|c|c|c|}
\hline \multicolumn{5}{|c|}{ Epileptoïdes } \\
\hline$I^{r}$ degré & - Epilepsie larvėe. & - & $5^{e}$ degré & - Criminel par passion. \\
\hline 2 id. & - Epilepsie chronique. & - & $6^{\circ} \quad$ id. & - Criminel doccasion, \\
\hline id. & - Foll-moral. & - & & et d'habitude. \\
\hline $4^{\mathrm{e}}$ id. & - Criminel-né. & - & & $-\infty$ \\
\hline
\end{tabular}




\section{CILAPITRE XV}

Force irrésistible.

1. - La perversion de l'affectivité, la haine exagérée et sans cause, l'absence ou l'insuffisance de tout frein, les tendances héréditaires multiples, sont la source des impulsions irrésistibles chez le fou moral, aussi bien que chez le criminel-né et chez l'épileptique.

Ils ont, écrit Schüle á propos des premiers, un fond d'irritabilité prompt à éclater comme un volcan; - ils ne pervent commander à leur volonté, ils suivent les impulsions de la jalousie, de la sensualité, sans y pouroir résister; - ils sont ingrats, impatients, tirent vanité de leurs plus manvaises actions.

Pinel parle ainsi dun fou moral, quine mauvaise éducation avait habitué à se livrer à tous les excès: "It tue les cheraux qui ne lui conviennent pas, frappe à coups de canne ses adversaires politiques; une dame l'ayant contrarié, il a trouvé tout naturel de la précipiter dans un puits".

Les motifs les plus futiles, dit II. Tamburini a propos de Sbro..., quand ils font obstacle à l'accomplissement de ses désirs, suffisent pour le jeter dans des accès de colère pendant lesquels il ne se connait plus. - On le dirait un enfant qui ne roit pas de proportion entre la réaction et le motif qui la provoque. - A-t-il quelque raison, la plus faible du monde, pour haïr quelqu'un? aussitôt il se sent entrainé irrésistiblement à le tuer. A peine un blasphème lui vient-il aux lèvres, qu'il se sent forcé de le répéter des centaines de fois. 
«Si vous saviez, disait la Cat. (épileptique et folle morale) à M. Bonvecehiato, combien de fois j’ai juré de me corriger! mais je ne puis résister il la forec qui m'entraine. Dieu lui-même ne saurait demander plus qu'on ne peut lui donner".

"Chez l'un et l'autre, éerit le frère Battanoli en parlant de ses deux fous moraux, on aper'coit un effort pour devenir meilleur et en mème temps l'impossibilité d'y réussir. Ils manquent de prévoyance et de prudence; c'est en vain qu'on leur donne des conseils, qu'on leur prodigue les avertissements, qu'on leur fait subir des corrections auxquelles ne résisteraient pas des animaux: tout est inutile.

"Avez-vous obserré F...? A quoi lui ont servi toutes les péripéties de sa vie passée, toutes les difficultés qu'il a dû surmonter pour obtenir sa liberté, six années de réclusion, les conseils et les prières qu'on lui a prodigués arant de le relàcher, les promesses qu'il nous arait faites? Le jour même de sa sortie de l'asile, il est allé se quereller pour un bâton sans valeur tout près de l'hospice où on l'avait interné, à $\mathrm{S}$ Servolo».

On comprend, après cela, que si la forme impulsive n'est pas spéciale aux seuls fous moraux et aux épileptiques, on ne peut pas dire non plus qu'elle leur manque. C'est bien naturel, d'ailleurs. Dans des cerveaux prédisposés par une nutrition imparfaite, par un arrêt de développement qui date de la naissance, il y a toujours un locus minoris resistentice, oủ s'introduit, puis s'enracine et se développe une de ces mille tendanees morbides qui se manifestent en chacun de nous, à une mauvaise heure du jour, surtout quand nous sommes enfants, et s'évanouissent dans les bonnes natures sous l'influence d'une bonne éducation (V. p. 136); mais qui persistent, au contraire, quand elles rencontrent un organisme qui leur est fa- 
vorable et quand on néglige de les combattre. Il arrive done nécessairement que ces tendances se multiplient tout d'un trait chez des individus qui n'entendent point parler en eux l'amour du prochain, qui sont, an contraire, la proie du plus vif égoïsme; des individus qui ne sentent aucune autre force agir en sens contraire, qui sont portés an mal par mille mobiles et au bien par aucun. - Après une série répétée de ces tristes accès, vient l'habitude de l'acte lui-même. En apparence, on ne roit pas de proportion entre la cause et l'effet, on relève des actes qui, à première vue, semblent n'avoir dé produits par aucune cause; et voici ' flue s'expliquent ces étranges tendances à l'obscénité, à l'amour paradoxe, que nous avons vues apparaître dans l'enfance des individus prédisposés déjà par l'hérédité. Ces tendances, à première vue, paraissent souvent isolées, sans aucune lésion des autres fonctions affectives; mais il leur serait impossible de se constituer sans un substratum de sensibilité pervertie qui se manifeste dès que l'on en rient à connaitre lanamnèses. A ce moulent, on trouve, comme chez les autres fous moraux, et sur une vaste échelle, une hérédité d'aliénation et de vices, une précocité sexuelle anormale (1) 14), gràce à laquelle il suffit du premier accident pour faire germer l'idée fixe. Or, cette idée, le hasard seul décide si au lieu dètre criminelle, monstrueuse, comme dans le cas de Verzeni, Legier, etc., elle sera seulement bizarre, comme chez l'individu porté à dérober des clous d'escarpins et des tabliers de femme (r. s. pag. 123).

Lanalogie est d'autant plus évidente que le plus grand nombre d'entre eux, p. ex. L. P. (pag. 120), Bar... (p. 122), la N. R. (p. 124) et la jeune fille adonnée à la masturbation dont parle Esquirol (126), se sentent déjà 
portés non seulement à la luxure, mais encore à de vrais crimes: au vol, par exemple.

Les anomalies de l'affectivité ne font pas, d'alord, saillic, et la raison en est simple: clles sont teumes dans une cspece de pénombre par le fait impulsif, qui a une influence énorme, et qui, grandissant d'une firfon disproportionnéc it la cause, fait oublier le germe dont il est sorti. Peut-ètre, aussi, se concentre-t-il seulement dins une direction donnée, et seulement à certains périodes laissant le malade dans un état d'apparence normale.

linsi, chez Verzeni et chez Sarayo, la perte de l'affectivité ne se manifestait que d'une faron périodique, et par leur manie barbare d’étrangler des femmes. Mais lapathie dont ils firent montre après leur crime à l'égard de leurs parents, de leurs viclimes, de leur supplice même, prouve bien que l'affectivité était atteinte, mème en dehors des tendances spéciales qui les avaient poussés ( $\mathrm{Y}$. chap. xiII).

Il n'est, en somme, question que du degré, de la direction accidentelle vers un courant donné plutôt que vers un autre; mais il y a toujours un fond de névropathie; il y a toujours un arrêt de développement de quelques facultés qui persistent ì l'état d'enfance, et, comme dans l'enfance, se traduisent subitement par un acte, sans qu'on puisse les arrêter par le frein de l'intelligence, par la prévision de mésaventures possibles, ni par le mépris du sens moral offensé.

2. - J'ai déjà prowvé, statistique en main (p. 378 et suiv.), et en m'appuyant sur les observations d'autrui, que tous ces traits se rencontrent arec la plus grande exactitude chez le criminel-né; jaurais pu le prouver mieux encore par le seul exposé de leurs confessions. - C'est ainsi qu'un roleur me disail: "Nous l'arons 
dans le sang; ne verrais-je qu'une aiguille, je ne puis m'empècher de la prendre, quoique, un peu plus tard, je sois disposé à la rendre \%. Le pickpoket Bor... (Archivio, I, 203) nous disait aussi qu'ayant volé dans les rues dès l'àge de 12 ans, volé au collége, sous les coussins de ses camarades, il élait dans l'impossibilité de s'en abstenir encore, même quand il avait les poches bien garnies; que s'il n'en trouvait pas l'occasion, il ne pouvait dormir, et, au milieu de la nuit, il se levait, mu par une impulsion irrésistible, et s'emparait du premier objet qui lui tombait sous la main.

Deham avouait à M. Lauvergne qu’il était irrésistiblement poussé au vol. "Ne plus voler, disait-il, serait pour moi comme ne plus vivre. Le vol est une passion qui brûle comme l'amour; quand mon sang bouillonne dans ma tête et dans mes doigts, je crois que je me volerais moi-même, si c'était possible ». Sur les galères, il volait les cercles des mits, les clous, les coussins des rameurs. Lui-même, après chaque vol, fixait le nombre des coups de bâton qui devaient lui revenir, quitte à recommencer après (Les forcats, p. 358).

3. - Il y a aussi, d'un autre côté, des malfaiteurs chez lesquels le progrès de l'acte criminel prend absolument la forme et l'opiniàtreté de la manie impulsive. En voici quelques exemples:

Ponticelli a vu un voleur phthisique, à l'agonie, prendre une mauvaise chaussure appartenant à son voisin et la cacher dans son lit.

A la prison de Milan, il y a quclques mois, on assassinait un gardien d'humeur si douce, qu'il n'avait encouru la haine d'aucun de ses prisonniers. Le meurtrier, interrogé sur le mobile de son crime, répondit qu’il n'avait aucun sentiment de haine contre sa viclime, mais 
qu'il s'élait senti le besoin de tuer, et qu'il aurait frappé le direeteur lui-mème, s’il l’eût rencontré. C'élait un vulgaire voleur de grand chemin, fils de bandit. Feliciani rencontre sur sa route un commissaire ivec qui it navait jamais cu le moindre rapport; il lui demande son nom, et apprenant qu'il s'appelle Bianchi: "Et moi, lui erie-t-il, je te donnerai du Noir! » el il le tue sans autre motif. C'est exactement la même cause qui a porté un pellagre maniagne a tuer un curé (curato) en haine des Croates...

Dans lexcellente publication qui a pour titre Rivista delle discipline carcerarie, nous lisons cette curicuso confession d'un certain Visconti, condanné déjà vingt fois pour vol: "Je sais qu'on me qualifie de voleur émé. rite; je ne suis qu'un voleur fieffé, a qui le conrage manque pour assassiner. J'ai débuté en 1861 par une petite friponncrie, et puis j’ai arancé peu à peu dans la mauvaise voie. A mesure que la condamnation derenait plus lorte, il me derenait plus difficile de trouver du travail. Alors je bus, je m'enirrai. En burant je me sentais plus à l'aise, je ne songeais plus à mes malleurs. Marchant à l'aventure, regardant à droite el à gauchc, dès qu'un objet se trouvait a ma portíc, je m'en emparais sans prendre la moindre précaution, car je roulais me faire arrèter. C'est ce qui est arrivé. Sans cela j’anrais continué à voler; je volerais d'ailleurs encore, si j’étais libre. Au moment du Jarein, j’éprouve un vif plaisir' mais ce plaisir passe vite et me laisse dans une grande agitation. L'appétit me manque, je ne dors plus; je me remets alors à boire, et voici rerenir déjà mes instincls de voleur. Je sens bien que je ne saurais triompher de ce vice maudit; je suis même convaincu que, si j'étais riche el qu'il m’arrivât un jour de trop boirce, 
je ne me conduirais pas autrement qu'aujourd'hui; il est rrai qu'ators je pourrais indemniser les personnes lésées par moi. Je crois qu'à l'avenir la justice me rendrait un grand service en me laissant dans la prison où je me trouve, avec une occupation quelconque. Puisque je suis déshonoré, je serais bien mieux en prison qu'au milieu de la société. I a nourriture qu'on me sert n'est pas très-abondante, mais je lui trouve un excellent gout; mes deux couvertures et mon sac de paille me procurent un sommeil tranquille; j'aime la solitude. Mon cœur est fermé à toule affection, je ne demande que le repos, efc.v.

Quelle différence élablir entre un pareil espril, qui appartient à un vrai criminel, et celui du fou moral, affecté de tendances instinctives contre lesquelles il ne peut lutter?

P... arait la manie de lérober les ornements des tomheaux, jusqüì des pierres dont le poids excédait ses forces; il dispersait les produits de ses vols chez tous ses amis, et était le premier à meftre les autres sur lat trace de ses larcins. - Cependant, personne ne le croyait fou.

D. Vincent d'Aragon, après qu'on eut aboli les corporations, se fit libraire. Il rendait bien les lives de peu te valeur; mais, pour ceux qui étaient rares, il ne pouvait se résigner à s’en défaire. Dans une vente publique, un certain Pastot, par une smrenchère, se rendit acquéreur d'un livre qu'il désirait beancoup posséder. Peu de jours après, Pastot et sa maison étaient consumés par les flammes. Encore quelques mois et l'on troura un jour huit calarres étendus sur la voie publique; c'étaient ceux de riches étudiants, qui araient fait des emplettes de livres. D. Vincent fut arrêté, on lui promit que ses lirres de prédilection ne seraient pas dispersés, mais quon les réunirait dans la Bibliothéque de Barcelone; 
alors il se déeida à faire des avenx: il s'élait inlrorluit chez Pastot sous prétexte de lui porter le live; après lavoir enlevé, il en avait étranglé le propriétaire et mi. le feu à la maison; un autre jour, un curí roulut lui acheter un incunable de grande raleur; il essaya de l'en détommer, mais en vain; le curé paya ee qu'il voulut et prit le livre: "Je me repentis tout-it-coup du marchí, dit D. Vincent, et je courus après lui pour lo prier de me rendre le livre. Il refusa et je le tuai; mais je lui arais douné auparavant l'absolution in extremis. J'ai tué de même les antres: loujours dans une bonne intention. Je roulais enrichir la science, lui conserver des trisors. Si j’ai mal fait, qu'on me traite comme on voudra, mais qu'on ne me sépare pas de mes livres. Il n'est pas juste qu'on impose à cenx-ci un ehàtiment que je mérite seul ". Le président lui demanda comment avait-il pu porter la main sur des créatures do Dien. "Les hommes sont mortels, lui répondit-il; mais il importe de conserver les livres, ear ils sont la gloire de Dieu ». Il ne se plaignit pas d'ètre condamné à mort; son seul regret fut d'apprendre que l'exemplaire, qu’il croyait unique, ne l'était point (Despixe).

A Strasbourg on se trouva un jour en présence de denx assassinats qui, pour tout le monde, étaient un mystive. Qnelques années après ces meurtres, l'abbé Terenk fut arrêté et avoua qu'il les avait commis pour le seul plaisir' de roir mourir ses vietimes. Dans son enfance, il arait conduit des enfants dans les bois pour les pendre at arait ensuite brûlé leurs cadarres. Il fut condamné (GALL).

Le grand-père et le trisajeul de Patetot araient tué leurs épouses; lui-même, très-avare, laisse momrir de faim sa femme et ses enfants; un jour même il les attire près d'un cours d'eau et tente de les noger. Il égorge 
un de ses fils coupable d'avoir dépensé la somme de 80 centimes. - Condamnéà mort, il refuse de recourir en appel, parcequ'il faudrait payer les frais et l'avocat (DESPINE).

La servante Yegado empoisonna trente personnes, les unes pour gagner quelques sous, les autres par un sentiment puéril de vengeance, d'autres enfin sans motif aucun; elle fut assez habile pour éloigner d'elle tout soupçon, sauf la dernière fois; elle avait même su se faire plaindre comme une victime du destin qui semait la mor't sur ses pas. C'était d'ailleurs une criminelle véritable; toutefois elle souffrait continuellement de la tête, et on l'avait vue un jour déchirer les habits et les livres de pauvres pensionnaires contre lesquelles elle n'avait aucun motif de haine.

La Jeanneret, qui empoisonna neuf personnes de ses amies et dont elle gardait, en souvenir, une boucle de cheveux, comptait dans sa famille des parents aliénés et portés au suicide; elle même était atteinte d'hystérie, et s'était fait cautériser au fer rouge et sans qu'il en fût besoin, la matrice et le rectum. Elle se sentait irrésistiblement entraînée à prendre elle même les poisons (atropine et morphine) qu'elle administrait aux autres.

Fitz-Gerald, secrétaire de lord Peel, dès sa première jeunesse était grand amateur de livres rares, mais non au point d'en paraître ridicule; il le devint par suite d'infortunes conjugales. "Je ne puis expliquer, dit-il, ce qui s'est passé en moi. J'étais soumis à une volonté plus forte que la mienne; je désirais des livres, je les achetais, j’en désirais encore; 12, 20, 30 volumes achetés en un seul jour ne suffisaient pas à me satisfaire: qu'ils eussent ou non de la valeur, pelt m'importait. Rentré chez moi, je déposais mes livres et ne songeais qu'à m'en procurer d'autres. J'en ai acheté pour 12 mille 
livres sterling ». Mais il ne se contenta pas d'en acheter, il en vola, aussi, quelques-uns, à un libraire de Londres, et fut condamné à deux ans de prison.

Le berger Légier, qui rivait seul au milieu des rochers, et dans une continence alsolue, saisit un jour, sous le coup d'une impulsion irrésistible, un enfant qui passait dans le bois oú il se trouvait, lui arracha les entrailles, le souilla et sabreura de son sang.

M. Tarchini-Bonfanti m'a raconté le cas d'un soldat allemand qui, après avoir violé trois femmes, leur déchira avec les doigts le périnéc de façon à ne faire qu'un seul cloaque du vagin el de l'anus. - M. Tardieu parle d'un débauché, véritable brute, qui, irrité de la résistance que lui opposait une femme de soixante ans, lui enfonça les mains dans le vagin et lui arracha les entrailles; on en voyait des lambeaux sur la voie publique. - Gilles de Retz, maréchal de France, aimait à contempler les convulsions des agonisants; il tua, pour satisfaire ses infàmes passions, plus de 800 enfants. Chez lui, la folie de la luxure s'alliait à une teinte bizarre de religion. 11 avoua que, s'il s'était trouvé à la cour, il aurait attenté à la vie du Dauphin lui-même.

Le marquis de Sade se plaisait à faire déshabiller des filles publiques, à les fouctter jusqu'au sang, puis à panser leurs blessures. Il s'était fait une sorte d'idéal do ce mélange de luxure et de cruauté; il érigeait sa conduite en apostolat.

II. Brière de Boismont cite un capitaine qui obligeait sa maîtresse à s'appliquer des sangsues aux parties honteuses toutes les fois qu'il l'approchait; la malheureuse finit par devenir complètement anémique et l'on dut la conduire à l'hospice. Le même auteur raconte que le marquis de S... faisait lier par ses gens une fille de 
joic, lui criblait le corps de blessures, spécialement près des parties honteuses, et se mettait en devoir de la violer quand il la voyait évanouie.

L'avocat Carrara a défendu en justice un certain Il... qui, en plein jour et coram populo, avait renversé et violé, sur la place publique, trois femmes sortant de l'église. Le coupable fut laissé libre sous la surveillance de son père; mais, l'année suivante, à la mème époque, il coupa la tête d'un chat et la mit dans une marmite. On l'enferma pour quelques jours, puis on le relitcha. Lannée d'après encore, et toujours à la même éporque, il eut un court accès de délire, puis il se rendit en Corse oú, all bout d'un an, il se fit condamner pour viol et homicide.

Tous ces malheureux ont été condamnés comme coupaljles. - Qui ne voit, cependant que, dans leur cerveau, le crime se trourait confondu arec la forme impulsive de la folie morale, el de l'épilepsie larvée?

4. - Entendons-nous, pourtant. Je ne veux pas dire qu'i l'état normal la volonté soit libre, conme le pensent les métaphysiciens; - mais, en cet état, les actes sont déterminés par des motifs, des désirs qui ne sont pas en opposition avec le bien-être social. - Ces maurais instincts, quand ils se font jout, sont plus ou moins léfrénés par d'autres inobiles, amour de la louange, crainte du chàtiment, de la honte, de l'église; ou par l'hérédité, ou encore par de bonnes habitudes dues it une incessante gymnastique de l'esprit. - Tous ces motifs restent sans influence sur le fou moral et sur le criminel-né, et voilà pourquoi ceux-ci fournissent la cote maxima des récidives. 


\section{CIIAPITRE XVVI}

\section{Résume de la troisieme partie et de l'ouvrage.}

1. - Résumé. - Les études qui forment la troisieme partic de ce rolume s'accordent admirablement arec celles qui ont été déreloppées dans la seconde, pour nous laire voir dans le criminel l'homme samrage el en même temps l'homme malade.

Nous trourons, en effet, en tête des caractères dislinetifs, le latonage, plus fréguent chez les mineurs que chez les adultes (la proportion est de $\mathbf{3 / 4}$ a 10 ), plus fréquent aussi chez les récidivistes $(20010)$, les hommes de sang $\left(200_{10}\right)$, les voleurs $\left(140_{10}\right)$, que chez les escroes $\left(110_{10}\right)$. Ce talouage, aree ses formes obscènes, sa diffusion par tout le corps, la vanité qu'il dénole, nous fait cntrevoir une grande insensibilité au moral et plus grande encore au physirue, en nème temps qu'il nous rappelle les habitudes tout-i-fait analogues des peuplades sauvages (1).

L'esthésiomètre et l'algomètre électrique nous ont prouvé, de la facon la plus précise, que la sensibilití à la douleur diminue dans le rapport de 34 a $49 \mathrm{~mm}$., surtout au côté droit, el que le tact s'émousse plus fortement à droite, avec une cote supérieure de parité (54 à 51010$)$. Or, c'est lit un signe d'infériorité aux yeux de quiconque veut se rappeler que toute asyuctrie est un signe d'évolution (Delaumar).

(1) Voir l'étrange obscénité des tatouages dans la plinche xxxu, Jont mon ami Boselli m'a fait cadeau et qu'il a trouvé $-u^{\prime}$ des soldats erimintls. 
On a remarqué aussi que, chez les criminels, l'acuité visuelle était plus forte à gauche, contrairement à ce qui a lieu à l'état normal; et, chose curieuse, pendant que leur sensibilité s’émousse dans toutes les autres parties du corps, ici elle progresse et est deux fois plus vive que chez les honnêtes gens. Ce fait, joint à un autre qui s'y rattache étroitement, la grande capacité de l'orbite, rappelle absolument les sauvages, comme les rappellent peut-être aussi le grand nombre de daltoniques que l'on rencontre parmi eux, et leur sensibilité plus vive i l'aimant et aux météores (1).

Importante et curieuse aussi est l'anomalie fréquemment causée par la faiblesse des réflexes tendineux (23 0 0 ), et par leur exageration $\left(160_{10}\right)$, plus remarquable chez les voleurs de grand chemin et les escrocs, moins chez les voleurs. Ce fait se rencontre uni à la fréquence des spasmes musculaires, de la choréc, de l'ataxie, de l'épilepsie; la meilleure preure en est que les condamnés épileptiques sont ceux qui nous ont fourni Ie contingent le plus considérable d'absence de réflexes. Ici ce n'est plus l'atavisme qui se trouve en cause; c'est une maladie bien caractérisce des centres corticaux.

L'étude dynamométrique est, aussi, de grande importance. Non qu'elle nous donne une idée de l'agilité particulière (2), souvent siniesque, dont ils sont doués pour

(1) Naggiorani a constaté que les zoulus, comme les bêtes sauvages, tigres, lions, etc., étaient extrêmement sensibles à l'action de l'aimant. - Dans le livre qui a pour titre Pensiero e meteore (Bibl. internat., $187 \times$, p. 45-53), j’ai établi que les animaux d'ordre inférieur, ainsi que les fous, sont plus sensibles que les autres à l'action métèorique, et qu'ils la pressentent souvent deux ou trois jours d'avance.

(2) Nous savons aujourd'hui, par M. Lindan, que les voleurs de Berliu ont un club d'atllètes, où ils donuent des représentations d'acrobatie Nord und Sud, 1883). 
la plupart; mais elle nous fait constater une prévalence relative des forces musculaires au còté gauche, préralence que l'étude du mancinisme a confirméc, puisque ce phénomène a été releré chez les criminels dans une proportion de 13010 pour les hommes et de 22010 pour les femmes; c'est-à-dire trois et quatre fois plus souvent qu'it l'élat normal. Tout cela, joint à ce que nous arons observé touchant la sensibilité, indique un nouveau caractère atavistique; mais nous fait soupconner aussi chez les criminels, en opposition aux gens de bien, une prépondérance du lobe droit du cerveau. Or, cette prépondérance, le peu de recherches anatomiques qu'on a pu faire l'ont à nouveau confirméc, cn même temps qu'elles complétaient les premières lignes d'un nouveau caractère atavistique de grande importance, puisqu'il nous fait roir que les asymétries de la face el du cràne, si souvent rencontrées chez les trimincls, et que les théories modernes feraient considérer cornme une marque de perfection, n'ont pas pour eux ce caractère, et cela pour deux motifs: d'abord, parecqu'il y a une énorme exagération, ensuite, parcequ'on les constate dans le còté droit du cerveán et non dans le còté gauche qui, chez l'homme honnètc et civilisé, l'emporte par son activité et son volume.

Les observations et les expériences faites an moyen du nitrite d'amyle, nous ont montré les criminels, et en particulier les voleurs, souvent incapables de rongir. Cette incapacité s'est présentée jointe à la rareté de réaction vasculaire sous l'influence de la donleur, prouvée par l'hydrosphygnographe; elle ne se démentait que dans les cas où leurs tendances gloutonnes on lascives étaient en jeu. Ainsi se trouvent expliqués, 
pour la première fois, en même temps que l'analgésie, la plus grande longèvité relative et le poids plus lourd des criminels, malgré la maladie qui les mine dès leur naissance. Ainsi s'expliquc, encore, l'extrême insensibilité morale el affective qui est le trait !c plus saillant de leur caractère; insensibilité telle, qu'ils n'ont aucun souci de leur propre vie, se tuent avec la même dépłorable facilité, avec laquelte ils voient ou provoquent la mort d'autrui. Ce spectacle devient même pour eux un vrai plaisir, un besoin (p. 399), sous l'impulsion de la rengeance ou de la haine, ou même seulement par suite de l'habitude. De là cette absence apparente, ou du moins cetle incohérence de molifs, que l'on remarque souvent dans les crimes les plus atroces. Les seules passions qui survirent en eux sont la rengeance et la vanité, la ranité du crime surtout, l'amour des alcooliques, du jeu et la luxure. Celte dernière est chez eux plus précoce que tenace; elle remplace l'amour et s'éteint assez vite, sauf dans certains débauchés et dans les hommes de sang.

Sans doute, jls nignorent pas ce qui est justice; mais ils ne le sentent point. lls déforment la morale, comme la religion, au gré de leurs passions.

De là la fréquence des récidives qui, pour certaines fautes, en particulier pour la rébellion (100 010), le vol (70 à $\left.720_{[0}\right)$, les coups el blessures (57 à $\left.600_{10}\right)$, la bigamie $\left(500_{10}\right)$, et l'incendie $\left(400_{10}\right)$, deviennent plutôt la règle que l'exception; et, si on les met en rapport avec les crimes les plus fréquemment commis dans la jeunesse, vol, stupre, vagabondage, coups et blessures, meurtres, incendies, on voit que ceux-ci constituent le contingent spécial des criminels-nés. On ne pourrait, en effet, les qualifier ainsi au point de vue juridique, si l'on 
n'en constatait lit récidire, directe on indirecte, pen importe. - Catr un bon nombre des caractères anthropologiques el biologiques qui les distinguent penvent, bien qu'en des cas plus rares, ètre attribués anx sourds muets, anx fons, anx enfants de parents tubereuleux.

On ne pent dire, d'ailleurs, que leur intelligence soit intacte, complète. Le ggènie n'est, chez enx, qu'une exception, surtout si l'on considère la perpétration des crimes dans lesquels l'habileté dont ils font preuve vịcnt seulement de ce qu'ils répètent toujours les mèmes actes, et aussi de lęur astuce, que l'on a trèsbien appelée le bouclier dont l'homme se ser' pour courrir un fond de faiblesse intellectuelle. Toujours la légèreté, la bizarrerie d’esprit, la fourberie, prévalent en eux sur la solidité, la ténacitẻ et la cohérence. On le voit surtout dans l'argot, qui reproduit, comme le tatouage, les tendances de l'homme primilir. Cet homme primitif reparait encore dans leurs sentiments religieux, dans leurs associations criminelles qui, par leur règlementation sanguinaire, la domination toutà-fait personnelle de leurs chefs (Tacite, Germ., viI), la facon tout anarchique dont elles se désagrègent et se reforment selon le besoin du moment, rappellent bien une tribu de sauvages.

2. - Folie morale. - L'analogie du fou moral, du criminel-né et de l'épileptique apaisent pour toujour's un différend qui s'éternisait entre les moralistes, les juristes et les psychiatres, et qui éclatait parfois aussi, entre les écoles psychiatriques. La situation était même d'autant plus délicate, que par un hasard extraordinaire, tout le monde avait raison. En effet, d'un côté, 
on objectait, à bon droit (1) que les caractères attribués au fou moral appartiennent en propre au criminel; de l'autre on n'avait pas tort de soutenir que les divers caractères du criminel-né se retrouvent avec la plus grande exactitude, en bien des cas, chez le fou moral.

On arrive ainsi à comprendre pourquoi des savants très-respectables n'ont pu s'accorder sur le diagnostic d'un criminel, et ont déclaré coupables des individus qui certainement étaient fous, ou, tout au moins, mal équilibrés, comme Guiteau, Menesclou, Verzeni, Prunier, Agnoletti, Lawson, Militello, Garayo, Passanante. On comprend que Cacopardo, examinant les cas attribués à la folie morale par Pinel, ait soutenu qu'il s'agissait de coupables; de mème que presque tous les fous moraux de Bigot sont de véritables criminels.

(1) M. Balfour-Brown, dans son travail sur la folie morale, s'exprime ainsi: "Vne folic morale, nue affection de l'âme earactérisée par des propos ou des actes délictuenx, n’a jamais existé. On devrait laisser de côté, une bonne fois, cette dénomination malhenrense, et dire que le sujet souffre, par exemple, d'une faiblesse psychique, où d'une disposition à la mélancolie, accompagnée d'anxiété et du délire de la perséeution, et que cet état le pousse à des actions délictueuses $\star_{\text {. - Knap }}$ nie l'existence de la folie morale comme maladie distincte, et la regarde comme une complexe syntomatique qui se vérifie quelquefois dans le prodrome des maladies mentales. Les autres individus qui présentent une pareille complexe symptomatique, dit Kuap, sont pour la plupart des délinquants. (Bonfigli. Rivista di freniatria. 1872).

M. Bonfigli a raison d'objecter que le terme de folie suppose toujours une maladie aequise, tandis que la folie morale est presque toujours congénitale. Aussi vaud rait-il mieux l'appeler idiotie, imbéeillité morale, d'antant mieux qu'elle a avec celle-ci, comme avec le crétinisme, ses nombreuses analogies physiques, par exemple, vice de la base du crâne, grandeur démesurée des oreilles et des mâehoires, rareté de la barbe. Mais ce n'est là ou'une question de mots, et nons savons qu'à ce propos l'usage est un despote sonvent avengle. (Rivista di freniativia. 1873). 
De l'aveu de kirafft-Ehbing, le bagne est rempli de fous moraux; e'est que l'on avait cherché l'essence de la folie dans le désordre de l'intelligence, d'où il résullait qu'aux yeux de médecins peu expérimentés la plupart des fous moraux étaient des coupables ordinaires.

La vérité est que tous avaient raison, puisque les denx choses étaient réunies dans le mème sujet.

3. Influence de l'épilepsie. - llais la théorie de l'atarisme du crime se complète el se corrige par ladjonction de la mutrition défectucuse du cerveau, d'une mauvaise conductibilité nerveuse, d'un manque d'équilibre des émisphères, par la condition épileptique. C'est, en un mot, la maladie qui vient s'ajouter à la monstruosité. IIr II. Sergi (Rivista filosofica scientifica, 1883) el Bonrecchiato (l. c.), partant de l'induction pure, mais géniale; l'avaient dijjà entrevin.

L'épilepsic explique la pligiocéphalie, les asymétries de tout le corps, la sclérose du crâne, les ostéopliygtes du clivus, l'hémorragie des méninges, les adhírences de la dure-mère, les adhérences des cornes postéricures, les ramollissements et les scléroses du cerveau, les fréquentes insuffisances valvulaires, la pigmentation des cellules nerveuses, l'hyperplasic cellulaire lo long des faisceaux nerveux, qui indiquent des procès déji anciens: congestifs et hémorragiques, enfin, l'œdème de la couche corticale et l'athérome des temporales. Ces altírations, à leur tour, expliquent l'inígalité ou la dilatation des pupilles, les erreurs dans les réflexes tendineux, la contraction des muscles, la chorée, l'analgésie et l'anesthésie, l'absence de réaction vasculaire, l'incohérence et la bizarreric propres it la folie, la cruauté, le plaisir de faire le mal pour le mal, la perte de l'affectivité, la lésion du sentiment, qui suffit pour former 
le caractère pathognomonique exclusif, et peut exister sans lésion apparente de l'intelligence, et laisser des traces dans la prévalence des anomalies faciales, dans celles de l'œil surtout, sur les anomalies du cràne.

4. - Arrêt de développement. - Il me serait facile d'expliquer la genèse du mal, en me réunissant à cette phalange d'aliénistes, qui soutiennent le concept de la dégénérescence, somatique et psychique, qui fail suito à l'hérédité morbide, et qui irait en progressant toujours dans la suite des générations jusquı à la stérilité. Cette école exagère mème ce concept au point de se contenter d'un seul des signes des dégénérescences, mème du plus insignifiant, de l'organisme, pour en admettre l'existence.

Jo ne suis pas contraire, en ligne générale, à cette théorie, qui a un grand fondement de vérité: seulement it une époque où la science vise toujours à l'analyse, celle conception me parait trop large; il me semble qu'elle embrasse un trop grand nombre de régions du champ pathologique, allant du crétin à l'homme de génic, du sourd-muet au cancéreux, an phthisique; et ru'il est impossible de l'admettre sans restriction. de crois qu'il vaut mieux, pour le moment, accepter l'arrêt le développement, qui nous est apparu solidement établi sur une base anatomique, et qui a le mérite de concilier l'atavisme avec l'état morbide. Nous connaissons, en effet, les causes de cet état: par suite d'un arrêt de développement, certains organes, surtout ceux des centres psychiques imparfaitement nourris, présentent à toute action externe un locum minoris re. sistentice, d'où naissent les phénomènes lyypérémiques, inflammatoires, pigmentaires, epileptoïdes, et, d'autre 
part, les impulsions et les idées fises qui, dans fom bizarrerie sans bornes, ne laissent plus entrevoir aucuur connexité arec l'atavisme.

Ainsi s'explique l'infinie rariété des formes fue revêtent la criminalité et la folie morale, selon qui est commpromise l'une on l'autre des régions de l'organisme, surtout des centres corticaux - tandis que les autres ne subissent aucune modification, du moins appréciable. Comme me l'ont appris mes études sur la fosselte occipitale moyenne dans les races saturages (r.s. p. 188, ol mon Archivio, iv, p. 507), etsur le mancinisme clans la notre, si, en règle générale, les anomalies atavistiques sont sourent accouplées, il y en a cependant quelputsunes qui restent isolíes dans certaines races, thez certains individus très-arancés dans leur déreloppement :t n'offrant pas d'autre anomalie (1). - D'autre part, on peut ne pas en rencontrer dans les races inférieures. De là une sorte de mosaïque ne laissant pas facilement entrevoir comment tout aboutit à un arrèt de léveloppement, alor's mème qu'il se rencontre des conditions, comme, par ex., une intelligence ourerte, une taille élevée, un poids normal ou même extrartinaire, qui sembleraient établir clairement le contraire.

Partant de là, nous comprendrons, sans peine, pourquoi certains caractères biologiques, alavistiques, tréssinguliers, se rencontrent, plus chez des criminels (p. ex.

(1) Par exemple l'os de i'Inca et la fossette occiprtale inoyenne qui se rencontrent, fort souvent, chez les amerieains et presque jamais chez les Soirs. Ceux-ei, an eontraire, se distingnent par lapoplyse temporelle du frontal, qui manque presque toujours anx Amílicans (V. Leene scientifique, 1883). Nous avons sonvent reneontre, ehez les gens honnêtes eomme ehez des seélérats, le mancinisme noteur et le mancinisme sensoriel indipendants l'un de l'autre. 
lo mancinisme chez les escrocs) qui n'ont presque aucune anomalic anatomique, et pourquoi la perte de l'affectivité, caractère saillant du fou moral et du criminel-né, peut se rencontrer sans lésion apparente de l'intelligence.

C'est le phénomène de la colonie linéaire, qui laisse une trace dans les fonctions aussi bien que dans les tissus du délinquant, et gràce à laquelle une anomalic seule, isolée, peut, cn certains cas, tenir la même place que beaucoup d'autres réunies, et se manifester en leur absence. Grâtce ì elle, on peut trouver des variétés (l'curre de Narro nous les a précisées) aussi grandes parmi les espèces des criminels que entre ceux-ci et les normaux.

5. - A tarisme du crime. - L'arrêt de développement, rt l'élat épileptö̈de peurent tres-bien concilier la malarlic arec l'atavisme, qui malgré la maladie, ou plutòt d'accord avec clle, reste un des caractères les plus constants du criminel-ní. Quiconque a parcouru ce livre aura pu se convainere que le plus grand nombre des caractères de l'homme saurage se retrouvent chez le malfaiteur. Tels scraient, par exemple, la rareté des poils, l'étroitesse du front, le déreloppement exagéré des sinus frontaux, la fréquence plus grande des sutures medio-frontales, de la fossette occipitale moyenne, des os wormiens, surtoul des épactaux, les synostoses précoces, particulièrement au front, la saillie de la ligne arcuée du temporal (1), la sinplicilé des sutures, l'épaissenr plus grande de la boite du cràne, le développement disproportionné des mâchoires et des pommettes, le prognatisme, l'obliquité et la capacité plus grande de l'oplite el do l'aire du trou occipital; la prééminence

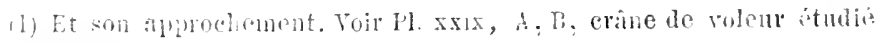
par Amalei. 
de la face sur le erine, parallele a relle des sons sur l'intelligence, la peau plus brune, les cheverx plus iplatis el hérisses, les oreilles à anse ou dhanues, les hrats plus longs, les cheveux plus noirs, le visage glabro chez les hommes, la pélurie du front, une plus granto acuité visuelle (1), la sensibilité considérablement timinuée (d'oì resultent la disvolnérabilité, et ensuite un poids plus grand et une plus grande longevifí), l'ahsence de réaction rasculaire, la précocité qui est un des caractères essentiels du sauvage (2), une plus griande analogie entre les deux sexs, ef une mniformiti de physionomie plus grande, le mancinisme, l'incorrigillilite plus grande chez la femme, la sensibilite plysique peu prononcée, la complete insensibiliti morate el affeclive, la paresse, le manque absolu de remords, limpréroyance, fui ressemble parfois à du courage, et le comrage qui alterne arec la lichetí, une extrème ranité, la passion du sang, du jeu, des alcools ou de ee qui peut les remplacer, les passions aussi promptes a disparaitre qu'elles ont été violentes, un esprit très-superstiticux, une susceptibilité exagérée da moi et enfin la conception toute relative de la divinite ef de la morale (8).

(1) Dapres les nouvelles recherohos de Bon et Ottolenghi (Avrhixin

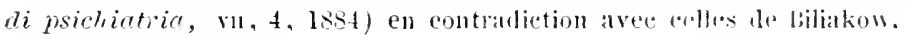
que nous avons eite.

(2) Spencer, Principes de snciologir, p. T.

(3) T. première partie, p. 29 à 94. Aux eximples qui s"y trouvent, j'ajouterai les suivants. - Schweinfurt a vu quelques penplarles negres se servir de la ehair humaine en guise de monnais. Les Bosehesmanns, dit Fritseh (Die Eingeloren Sud Afica, 1853), sont de véritables enlants: suivant toujours l'impulsion du moment, dijpourvis de toute prévoyance, ils font eonsister le bonhenr lans une uourriture abonlaute. Un missionnaire, après aroir fait aux koron une priclication sur le remords, demandait à l'un d'entre enx quelle idée il s'en laisatit: * let doit être, répondit le sauvage, quelque chose comnse la colig̨ne "Trun, 1. e.). Le genre humain, ecrit le même antenr, sest fait à diverses up- 
Les analogies vont jusquaux plus petits détails que l'on ne saurait bien pressentir; p. ex., l'abondance des métaphores el des onomatopées, des automatismes, des allusions obscènes, des étymologies renversées, des personnifications de choses inanimées, toutes choses observées dans leur facon de parler; les lois improvisées que se donnent leurs associations, l'influence toute personnelle des chefs (TAcite, Germ., vir), la coutume du tatouage, des hyérogliphes, une littérature toute spéciale, qui rappelle celle des temps héroïques, pour cmployer l'expression de Vico, où le crime obtenait des éloges, et où la pensée tendait à revétir, de préférence, la forme rhythmique et poétique (V. Genio e follia, $\mathrm{v}^{\mathrm{e}}$ édit.).

\section{6. - Applications. - Cet atavisme explique la nature} ct la diffusion de certains crimes. Ainsi, l'on ne se ren-

ques, des idées differentes sur la morale; la morale so confondait avee l'usage. - Les Massagètes et les Vendes (Héronore) tuaient lenrs vieillards, les faisaient bonilir et les mangeaient dans m festin. Selon Elien, les anciens sardes se eroyaient obligés de tner leurs pères à eomps de massue, quand ils devenaient vienx; les Ronains faisaient de même. L'atymologie sanserite de crime, fiarana (vare) et de compa (nnrlue, eoupe), de hopf $=$ crepa dans le dialeete vénitien, s'expliqne par l'habitude „qu'ont encore certains brigands, p. ex., Mammone, de boire tans un erîne en guise le tasse. - En Perse, an Péron, en Egypte, l’inceste itait permis, et même obligatoire pour les rojs. - Les sanrages ne penvent fixer longtemps leur attention sur ru même point; ils n'ont de sentiments durables que sons le eonp des passions qui sont en enx instables, fugitives, mais violentes, comme ehez les enfants (SPExcre, Psich. of man., 1863). - Celni qui voudrait trouver, dans l'antiquité, un 1ait analogue à l'itrange eonfession de la marquise de Brinvilliers, n’a qu'i lîre le rituel des funérailles égyptiennes; il $y$ verra eonsignés an rang lles plus grands crimes, à eôté de l'avortement et de l'assassinat, le mentre d'un animal sacre et la déféention dans le Nil. - Les Australiens, cerit Eyre, n'ont pas l'jdè du juste: leur seule riggle de eonduite consiste a s'assurer s'ils sont ou non en force (Discor. in Centr. Atusli., vul). 
drait pas un compte bien exact de la dillusion anorme de la pédérastie, de linfanticide, crimes pour lit perpétration desquels on roit souvent se former de raics associations, si l'on ne se rappelait le temps où it Romr, en Grèce, en Cline, à Tahïli, les faits de ce gente, loin de passer pour des erimes, faisaient quelquefois partie des coutumes nationales. Cet exemple nous permettra peut-être de comprendre la préscnce fréquente de goûts esthétiques (v. p. 453) chez les pédérastes, al-solument comme chez les anciens Grees; surtout si nous roulons bien nous rappeler, arec M. Sergi (1), quil y a dans l'hérédité une vraie stratification; ćcst celle-ci qui favorise, chez nous, la reproduction des instincts de l'homme préhistorique et ceux aussi de l'homme du moyen-âge. Ainsi s'cxpliqueraient, p. ex,, les crimes récemment commis par les anti-sémites, les querelles de elocher, où nous pourrions roir une haine héréditaire datant dı moyen-âge; ainsi cncore la manie dı duel, que rien ne peut réfréner.

Si nous poursuivons, plus loin encore, les analogies ataristiques, si nous remontons au reli de la rare, dans les animaux inférieurs, nous pourrons trouver la raison de quelques autres apparences du monde criminel qui, par clles-mêmes, semblent inexplicables, même à l'aliéniste. Telles sont: la soudure fréfucnte do l'atlas avec l'occiput, la saillic des canines, l'aplatissement du palais: la concavité de l'apoplyse hasilaire, la fréquence de la fosse occipitale moyenne el son développement exagéré, précisément comme chez les lémuriens et les rongeurs; la persistance des poils sur le visage, les arrêts de développement du cerveau, coume

(1) Della stratificasione del carttere nei delinguenti, Turin, 1883. 
li formation d'un opercule du lobe occipital (1), l'ouverture de la fossette de Silvius, la séparation des scissures calcarine et occipitale, l'hypertrophie du vermis ou du cervelet tout entier, ou encore le lobe moyen affectant la même forme que celui des mammifères, la tendance au cannibalisme alor's même que la rengeance n'est pas en jeu, et, mieux encore, cette forme de férocité sanguinaire jointe à la luxure, que nous arons rencontré dans Gille, Verzeni, Garayo, Legier, Bertrand, Artusio, dans le marquis de Sade (2). Chez ces criminels, il est rrai, l'atavisme était presque toujours farorisé par l'épilepsie, l'imbécillité ou la parésie générale; mais cela ne nous rappelle pas moins l'époque oủ clıcz l'homme, comme chez les animaux, l'accouplement était précédé et accompagné de luttes féroces et sanglantes dont le but ¿tait, soit de dompter la résistance de la femme, soit de raincre les rivaux en amour. On voit encore dans plusieurs tribus australiennes, l'amant se cacher derrière une haie pour attendre sa fiancée, la terrasser, furand elle passe, d'un coup de massue, et l'emporter ainsi à demi morte dans la demeure conjugale. Cet usage a laissé quelques traces dans le rite nuptial de beaucoup de nos vallées; on le retrouve dans l'horrible fête du Jagranath, et dans les bacchanales de Rome, ou le jeune homme qui refusait de se laisser souiller était coupé en

(1) Ces faits, dicouverts par Flesch, ont ité retrouvés dans les criminels de Rome par le doct. Ningazzini. (Laborat, du prof. 'Todaros).

(2) T. p. 581. - Artusio sonilla un jeune homme par une blessure qu'il Ini arait faite a l'abdomen. - Iainardi cite un certain Grassi qui, furieux rle voir ses avances repoussées, tua la femme qui lui résistait, puis son père, son oncle, et enfin plusieurs brenfs. Après quoi il alla se jeter dans les bras de sa maitresse (V. Lumbroso, Verseni ed Agnoletti, Florence, 1873). 
morceaux si petits qu'il était impossible d'en retrourer le cadare ( $T$. Live, xxis, chap. vini).

Le premier el le plus illuztre peintre de la naturr, Lucrèce, avait observé que, mème dans les cas ordinaires oủ les sexes s'unissent, on pent surprendro un germe de férocilé a l'égard de la lemme; germe qui nons porte à la frapper quand mème elle ne nous résiste pas(1).

Je connais un poète distingué qui se sent pris de disirs lubriques dès qu'il roil dépouiller un veau on pendre à l'étal ses chaires sanguinolentes; un autre qui éproure des pollutions rien qu'en étouffant un poulet ou un piçeon. - Mantegazza reçut un jour la confession d'un ami qui, ayant eu à tuer quelques poulets, ressentit après avoir égorgé le premier, une joie barbare à plonger ses mains dans les entrailles chaudes et fumantes, et qui au milieu de cetle espèce de fureur, s'était senti tout-à-coup en proie à un accès de luxure (Fisiol. del piacere, Mlilan, 1870).

Qu'en conclure? sinon que les crimes les plus affreux, le plus barbares, ont un point de départ physiologique, atavistique, dans ces instincts animaux qui peuvent bien s'émousser pour un temps dans l'homme, gràce à l'éducation, au milieu, à la crainte du châtiment; mais qui renaissent tout-it-coup sous l'influence de certaines circonstances, comme la maladie, les météores, l'imitation, l'jrresse spermatique, fruit d'une trop longue continence. C'est pour cela, sans doute, qu'on les remarque surtout à l'àge où commence la puberté, chez les parésiques, les individus qui mènent une vie sall-

(1) "Oseulaque adfigunt, quia non est pura voluptas; Et stimuli subsunt, gui instigant ledere id ipsum, Qnodcumque est, rabies unde illa gernina surgent $n$.

(1): Rer. Nat., lib. w, vers loiti). 
vage, on cenx qui se tromvent contraints au célibat ou i la solitude, comme les prêtres, les bergers, les soldats (1).

Puisque nous sarons que certaines conditions molbides, comme les blessures à la tête, les méningites, l'alcoolisme et autres intoxications chroniques, ou certaines conditions physiologiques, telles que l'acconchement, la sénilité, peuvent provoquer un arrêt de développement el une irritation dans les centres nerveux cl, par suite, une tendance épileptique et un retomr alavistique, il ne nous sera pas difficile de comprendre que ces mêmes conditions facilitent les tendances criminelles.

Sachant, en outre, que la différence est bien petite, quelquefois nulle, entre le criminel, l'homme du peuple sans éducation et le sauvage, nous ne serons pas surpris de voir, d'un côté, l'homme du peuple, même honnête, témoigner souvent au criminel une véritable prédilection (2), s'en faire une espèce de héros, et finir par lui rendre après sa mort des honneurs divins (3); de l'autre, les gralériens se mêler arec tant de facilité alx sauvages et adopter leurs mœurs, sans en excepter le cannibalisme (Bouvier, Voyage à la Guyane, 1866), comme cela a lieu dans l'Australie el à la Guyane.

Voyez nos enfants avant qu'on ait commencé leur édncation; ils ne font aucune distinction entre le vice et la

(]) Voir volume n.

(2) "IIélas! panre eriminel, ete. Qn'a-t-il fait ? ete. Eh! presque rien. - Il a etranglé son patron" (Neri Taxfucio, Cento sonetti, Florence, 1873, p. 39).

(3) V. Appendice, Sui crani dei delinquenti, vol. I. - Les aneiens romaient le nom fllerenle anx grands malfaitens apres leur mort (Varron en cite 44) et leur vouaient un enlte (Suith, Biog. and. Mith., II). 
vertu; ils volent, frappent, mentent sans la moindr. appréhension. Comment nous étonner après colit si tant d'enfants laissés a l'abandon, orpleclins ou enfints tronrés, se laissent aller au mal? s'ils font prenve d'umo précoeité effragante dans le erine? Et nous comprenon. enfin que le trail de caractere le plus odieux du conpable el du fou moral, la méchanceté sans cause, puiss: ètre considéréc comme une continuation de l'ige enfantine, comme un état d'enfance prolongie: el que la folis. morale, aussi bien que la tendance an crime, juiss. encore se manifester par le seul lait d'une mauraise éducation qui, an lieu de mette un frein, apporte plus de facilité aux maurais penchants congénitaux (roil première partic, p. 125 ).

Latavisme nous aide, encore, à comprendre pourquoi le chitiment a si peu d'efficacité, pourquoi l'on voit revenir avec ce caraetère si singulier de constance et do périodicité un certain nombre de délits; si bien que les plus grandes variations présentées par le nombre des attentats contre les personnes (au dire de MII. A. Maury et Guerry) ne dépassent pas un vingt-cinquiène, et contre les propriétés, un einquantième (1). Et l'on peut en conclure, observe M. Maury, que nous sommes gouvernés par des lois muettes, mais qui ne tombent jamais en désuétude, et qui régissent la société avee plus d'autorité que les lois inscrites dans les codes.

Le crime, en somme, aussi bien d'après la statistique que d'après un examen anthropologique, apparait comme un phénomène naturel; et, si nous roulons emprunter la langue des philosophes, comme un phénomène né-

1) Hatra, Jourement moral de le societe, Paris, 1sbo. - Foir le mémoire de Poletri, Sulla tutela penute - all bas de mon tomo delinquente, Turin, 2 èdit. 
cessaire, aussi bien que la naissance, la mort, la conception, les maladies mentales, dont il est souvent une triste variété. - Et voilà que les actes instinctivement cruels des animaux et même des plantes ne scmblent plus séparés comme par un abîme (V. p. 3 à 24) de ceux de l'homme criminel; chaque différence va diminuant sans cesse et tend à disparaitre, si bien que, dans cette forme étrange qu'on dit de méchanceté brutale du criminel, se laisse entrevoir une analogie, je dirais presque une identité, à laquelle ne songeaient certainement pas ceux qui abusaient de ce mot.

7. - Diffusion du criminel-né. - I1 est bien entendı que tout ce que nous arons dit jusqu ici s'applique ì une seule classe de criminels; que si l'on s'en tient aux observations de la physionomie réunies de facon à créer un type, on arriverait ì $230 / 0$ de l'ensemble des criminels, avec un maximum de 36 pour les assassins, de 25 pour les volemrs et de $60_{10}$ pour les bigames et les escrocs; que sil'on observe ces mêmes traits isolés, le chiffre serait bien plus fort, la màchoire seule donnant 37010 chez les hommes criminels et 36010 chez les criminelles, et l'absence de barbe 32; rue si l'on s'en tient aux particularités du cràne, on arrive à $580_{10}$ pour les anomalies isolées, et à 43010 pour celles qui se trouvent réunies en grand nombre dans le mème sujet.

Cela pour les adultes.

Chez les enfants, en réunissant dans une mème étude les anomalies de la physionomic et celles dı cràne, nous trouverions une proportion plus forte, 59010 ; et si nous considérerions chaque anomalie prise a part, la proportion séleverait à 9100 .

Si l'on s'en tient an tatouge, on aura la proportion de $100[0$ chez les adultes et de 34010 chez les minemrs; 
si l'on s'en tient à l'amoindrissement de lat sensibitití générale, 67010 ; il la sensibilité physique obluse, 20 p. $0_{00}$; an daltonisme, $60_{10}$; il l'exagération de l'acuité visuelle, $490_{10}$; il la sensibilité plus forte, $480_{10}$; it l'intelligence obtuse, de 8 is 29010 ; enfin le mancinismie nous donnerait te chiffre de 13010 chez les hommes et 22010 chez les femmes, avee 1 maximum de 99 pour les liumsarires el un minimum de 7 pour les assassins.

Si l'on s'en tient it l'impossibilite de rougir, on attteindra le chiffre de $440_{10}$ pour les liommes et de $810_{10}$ pour les femmes.

Et si l'on s'en tient ì la récidive, combinće avec les fautes commises dans le jeune ìge, on trourera une moyemne de 40 à 50 , qui ra jusrun ì 70 , et ì 78010 , et s'applique surtout aux délits de vol, de bigamio, de coups et blessures, d'incendic et de rébellion.

Beacoup de ces caractères se réunissent, se sondent les uns aux autres, de façon il nous donner un maximum de monstruosité; mais les études précédentes nous ont démontré que les anontalies, même isolées, ont leur importance.

Aussi ne tiendrais-je pas pour exagéré un calcul qui porterait la côte du criminel-né au delì de 40010 .

Restent les autres formes du crime, celles qui ont pour sources la folie, l'occasion, l'alcoolisme, la passion. Ces formes sont liées plus étroitement ì leurs causes occasionnelles; je les étudierai, avec elles, dans le second volume.

FIX. 



\section{T.IBLF, IES MATIERES}

Preface de Mr Letomrmean

Prifire de litutenir

Premirre Parte. - Einbryologie du rime.

Ch+г. 1. - Le crime et les or qanismes infiericurs.

1. Les iquivalents du crime lans les plantes et les

animanx . . . . . . . . Prige 1

?. Ilistoire et bibliograplic. Plantes carnirores . ". .

2. Menrtres dans les animanx inspiris par la faim, par lambition dn commandement. . .

3. Neurtres dans les animaux ayant pour but la possession des femelles. . . . .

4. Memrtes dans les animanx ayant pour but la defense personnelle

5. Meurtres dans les animan par eupidité

6. Meurtres id. inspires par lesprit gnerrier . . . . . . . . " "

¿. Cannibalisme simple inspire par l'esprit gnerrier : 5

s. Cannibal. complique d'infanticide on de parricide : "

II. Le verritable equivalent du crime ent de la peine chez

les animanx.

1. Critique des faits exposés - Lois mosaiques . . i

2. Criminels-nés affectés d’anomalies crâniennes chez

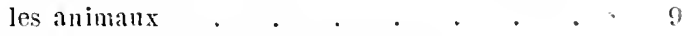

3. Meurtes des animanx jal antipathic . . 10

4. Vieillesse comme cause de mentre . . . " 11

5. Accès de rage id. . . . . :

6. Néchanceté pure id. . . . . , 12

†. I)

8. Donleurs physiques, eanse de crimes . . " 14

9. Neurtres par amour, par Jusure . . . . 
10. Agglomérations . . . . . . Page 16

11. Associations de malfatens chez les animaux . " 18

12. Escroquerie . . . $\quad$ id. 19

13. Vol ehez les animanx . . . . . . . . 20

14. Alcoolisme ill. . . . . . . . 22

15. Aliments irl. . . . . . . 23

I6. Edueation id. . . . . . . " 24

17. Analogie avec les crimes des hommes . . " "

18. Causes metioriques . . . . . . . . 25

19. Repugnance pour toute chose nouvelle. Physionomie speciale . . . . . . . . . . . . . 26

20. Critiqne et conclusion de ces recherches. . × 27

III. Equivalent de la peine chez les animaux.

1. Le châtiment chez les animaux . . . " 29

2. Le châtiment chez les animaux domestiques. - succédanes pénaux . . . . . . . 32

Chıр. II. - I. Le erime chez les sauvages. - Etymologies . " 36

II. Homicide.

1. Avortement . . . . . . 40

2. Infanticide . . . . . . . . 41

3. Neurtre des vieillards, des femmes et des malades. . . . . . . . . . . . 43

4. Autres canses l'homicide . . . . . * * 45

5. Canuibalisme ayant pou cause la faim, un rite religieux, un prèjugé, la piété filiale, la guerre, la gloutonuerie, la vanité . . . . . 53

6. Conclusion . . . . . . . . . . 63

III. Vols et autres crimes.

I. Yols . . . . . . . . . . . 65

2. Autres crimes . . . . . . . . . 68

JV. Les vèritables erimes chez les sauvages. - Contre

l'usage. - Religion . . . . . . . il

$\checkmark$. Principes de la peine.

1. Origine criminelle de la peine . . . . . is

2. Vengeance privée . . . . . . * *

3. Vengeanee religiense et juridique . . . × 5

4. Puissance supérieure des ehefs. - Crimes contre

la propritis . . . . . . . . . . 80

5. Transformation de la peine. - se duel . . " 82 
6. Amende. - Restitution . . . . Page 84

7. Autres causes de la compensation . . . " 86

8. La richesse . . . . . . . . " n

9. Les chefs . . . . . . . . . . . 8

10. La religion . . . . . . . . . . . 88

11. Les sectes . . . . . . . . . . . 91

12. Anthropophagie juridique . . . . . " 98

13. Conchusion . . . . . . . . . .

14. Vestiges des anciennes tendances criminelles . " 94

15. Vestiges des châtiments . . . . . " . " 95

16. Applications aux injustices humaines . . " 97

Chip. III. - La folie morale et le crine chez les enfints.

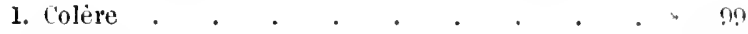
2. Vengeance . . . . . . . . . . . 101
3. Jalonsic . . . . . . . . 102
4. Hensonge . . . . . . . . " 103
5. Sens moral . . . . . . . . " 106
6. Affection . . . . . . . . . . . . 108
¡. Cruanté . . . . . . . . 109
8. Paresse, oisiveté . . . . . . . 110
9. Argot . . . . . . . . . " . . . 111

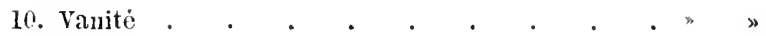
11. L'alcoolisme et le jeı . . . . . . + 113
12. Prédisposition à loobscénité . . . . " "
13. Imitation . . . . . • . . " >
34. Développement de la folie morale . . . " 114

II. Casuistique.

1 i 7 . Observations de Mu. Horean et rimont . " $11 ;$

16 à $1 \%$. Obscénité chez les enfants . . . " 121

18. Amours précoces . . . . . . . " "

Cas de Zambaco . . . . . . . " n"

Cas d'Esquirol . . . . . . . . . $>120$

III. Statistique anthropométrique.

1. Id. des jeunes criminels . . . . "12?

2. Id. des jeunes gens non ineriminés . . " 133

3. Id. de leurs ascendants . . . . " "

4. Étude sur 29 sujets dont l'enfance est conmue " 136

IV. Châtiment. - Moyens préventifs du erime chez les enfants 
Deuximim Parte. - Anatomie pathologique et anthropométrie du crime.

Cnap. I. - Examen de 350 crânes de criminels.

1. Capacité crânienne (Tab. grạh.) . . Page 142

2. Id. selon les crimes . . . . . \144

3. Circonférence . . . . . . . " 146

4. Semi-circonférence erânienne, etc. . . . " 152

5. Projections antérieures du crâne . . . " "

6 . Ares et courbes . . . . . . " "

7. Indice céphalique . . . . . . . . 153

8. Diamètre et indice vertical . . . . " 155

9. Indice frontal . . . . . . . 》 "

10. Indice crânio-mandibulaire . . . . \ $\mathbf{1 5 6}$

11. Face. - Diamètre du front . . . . 》 $\Rightarrow$

12. Hautenr du visage . . . . . . . \ 157

13. Indice nasal . . . . . . . . . . . 158

14. Mâchoire inféricure . . . . . . " 》

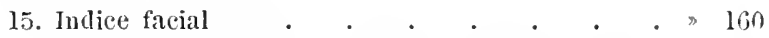

16. Aré, tron occipital, capacité orluitale et indice céphalo-spinal . . . . . . . 》 161

17. Angle facial . . . . . . . . . $\$ 163$

II. Anomalies du crâne.

1. Proportions des anomalies sur $3 \nmid 3$ crînes (Voir

Atlas Planch. xxıv et $\mathrm{xxv}$ ) . . . . . 165

2. Anomalies des criminels mâles et femelles eomparés avec les normanx $\quad . \quad$. . . \$ 169

3. Normallx . . . . . . . . " . . 1 .

4. Inomalies crâniennes suivant le sexe . . " *

5 5. Id. le crime . . . \$ $1 \% 2$

6. Comparaison crânienne avec les fous . . \173

7. Analogie crâniemne entre le sauvage ct l'homme criminel . . . . . . $\gg 175$

8. Détails . . . . . . . . . 179

9. Fossette occipitale . . . . . . $\$ 180$

10. La plagiocéphalie . . . . . . \ 181

Chıp. 1I. - Anomalies du cervean et des viscères chez les criminels.

1. Cervean - Poids (Fig. 1) . . . . . \$ 185

2. Circouvolutions . . . . . . . \ 187 
3. Cervelet . . . . . . . I'tye lo?

4. Atypie cécerale. . . . . . " "

5. Vaisscanx cerebranx . . . . . . . 1!!3

II. Histologic et anatomie pathologicnue.

1. Histologie pathologique dn eervean . . . " $1 ! 4$

2. Ostrome. - Compraraison arec les fous . . " las

3. Néningite. Ill.

4. Altirations du eervan. Il.

III. Anatomie pathologique du ceur, des vaisseanx, dn foie, ete.

1. Fréquence des altriatious cardiaqurs . . " 260

Comparaison aver les gens homnites, les fous et les criminels . . . . . . . " 201

2. La foie . . . . . . . . . 202

3. Les partics ginitales . . . . . . . . 20.3

4. Liestomac . . . . . . . " "

Chap. III. - Anthroponetrie et plyssionomie de 3839 criminels.

1. Collaboratenrs . . . . . . . "2ilt

2. Mineurs. - Taille. - Poids . . . " "

3. Adultes. - Taille et poils (Y. Itlas Pl. I ete.) . क 2or;

4. Grande envergure (V. Atlas Pl. I1) . . . . 209

5. Gracilite . . . . . . \$210

6. Amplitude thoracique . . . . . " 211

. Capacité erânienne . . . . . " "

8. Front . . . . . . . . 21:3

9. Cireonférenee erânieme . . . . . " . 214

10. Semi-circonférence antirieure . . . . . 21\%

11. Diametre mandibulaire. . . . . . " 21s

12. Zigomes . . . . . . . " "

13. Face . . . . . . . . . 219

14. Indice céphalique . . . . . . , Anomalies erânicunes . . . . . . . 220

Angle facial . . . . . . . , 2:2l

10. Exceptions . . . . . . . . 222

II. Physionomie des eriminels (V. Atlas Pl. xı, vı, $b, \mathrm{xxx}$ )

1. Physionomie normale des mêmes indlivilus . * 224 Physionomie des débanchès, des volenrs, des mentriers ( Pl. vill et $\mathrm{x}$ ) . . . . " 225 Arcléologie (Néron, Pl. xu1) . . . . " 227 
2. Proportions des anomalies. - Les chevenx

Page 228

Iris

$\mathrm{Nez}$

Jents

III. Photographies et types de criminels.

1. Objeetions

2. Photorraphies de 219 criminels mâles (l'lanches

vili, $1 x, x, x i l, x x x$ de l'dtlas)

Tableau eomparatif des normanx et des crimin.

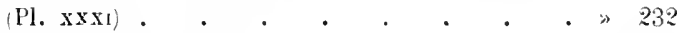

Type du eriminel-né . . . . . . » 234

IV. Sur les femmes eriminelles. - Collahorateurs.

1. Taille et poids . . . . . . . . . 235

Capacité et eirconférenee du crâne . . . " 286

2. Indice

3. Anomalies dn erune. - Chevenx. - Iris . . „238-?

4. Eurignatisme. - Physionomie mongole. - Anomalie des oreilles. - Pélurie. - Lìvre supériemre amineie. - Plysionomie virile . . „ 540

Anomalies . . . . . . . . " "

Photographies (Planehes xin et xiv de l'Atlas) . " "

v. objections.

1. Physionom. de 818 sujets máles vivant en liberté " 242

2. Proverbes sur les plysionomies criminelles . "245

3. Les anciens id. . " 246

4. Conuaissance instinctive le la physionomie du erininel

5. Son reil . . . . . . . . . $>248$

6. Sa genese . . . . . . . . . . 24?

ז. Résume sur la plysionomie erininelle . . " 250

Trolsième Partie. - Biologie et psychologie du criminel-né.

Cirap. I. - Du tatonage chez les criminels . . . . " 255

1. Tablean synoptiqne de ees observations . . \25?

2. Criminels . . . . . . . " 263

3. Olssénité (V. Atlas Pl. xv1, xxxı) . . . \ 268

4. Nultiplieite . . . . . . . . . . . 231

5. Précocité . . . . . . . . $>273$

6. Association. - Identite . . . . " "

7. Callses. - $\Lambda$ tavisme . . . . . $\$ 276$ 
8. Le taltonage (how les fous (De Paoli) . Proy $25 \%$

9. Blessures . . . . . . . . . . 28!

Cuap. II. - Sensibilite grinimale, plysique, spécitipue - bynamomitrie - detiriti riflexe - Riaction vasculaire - Rongeur - Iongiviti - che\% les criminels.

1. Allalgésic . . . . . . . . " $8 ! n$

2. Sensibilité ginurale . . . . . . * 29?

3. Algometrie . . . . . . . . $24 ! 3$

4. Sensibilite tactile . . . . . . . . 2!4

5. Vision . . . . . . . . " 29!;

6. . lenite visuelle (Bono) . . . . . " . $29 \%$

¡. Acuite du sens museulaire . . . . . 298

8. Sensibilité magnétique . . . . . . ,

9. Id. mitéorique . . . . . " "

10. 1d. olfactive . . . . . . " "

11. Dynamometric . . . . . . . . . . 299

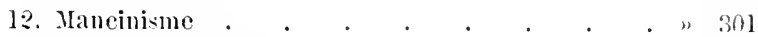

13. Anomalies motriess . . . . . . " 30 .

14. Ictiviti reflexe . . . . . . . " . 303

15. Rougenr . . . . . . . . " 305

16. Reaction an nitrite d'amyle . . . . " . " $30 \%$

17. plyggmographie des erimin. (Atl. P'. xun et xum) " 308

18. Plétismographe . . . . . . . 316

19. Réaction . . . . . . . . " 315

20. Résuné. - Applications . . . . . " 319

21. Longeviti . . . . . . . . " 329

22. Pitic . . . . . . . . . . 322

23. Disrulnérabiliti (Bínédickt) . . . . . 323

24. Poids et taille . . . . . . . 324

25. Mancinisne . . . . . . . " . . . . .

Cuн. IIJ. - Sensibiliti affective.

1. Son absence (Lacenaire et Martinati) . . " $32 !$

2. Troppman (Pl. xix): son antograplie . . . " :30

Indiffirence à leur propre mort (Pl. xx) . . " . " ll

3. Crimes commis immédiatement avant lenr suppl. " 334 Applications qui expliquent le courage des erimin. " $\$ 35$ Applications pui expliquent la dispuroportion entre

le erime et son moljile . . . . . " "

4. Conclusion . . . . . . . . . . . . . 
Chap. IV - Suicides chez les criminels.

1. Fréquence - Tempirature

2. Les prisons. - Laps de temps qui s’écoule entre lincarcération et le suicide

3 Imprévoyance et impatience . . . . " 340

4. Rapports avee la tendance au erime (Plan. xx). " 341

5. Antagonisme . . . . . . . " 343

6 e 7 suicide indircet, mélange de superstition . " 344

8. Suicide simulé . . . . . . . " 345

9. Suicide double . . . . . . " . 347

10 Le suicide chez les fons criminels . . . " 348

CHнP. I - Sentiments et passions des criminels.

1. Sentiments . . . . . . . . " 350

2. Instabilite . . . . . . " . . 352

3. Vanité (Plan xx) . . . . . . " 353

4 Vanite du crime - Panvreté, malpropreté - " 354

5. Vengeance . . . . . . . . . 360

6 Cruante . . . . . . . . 362

7. Le vin et le jeu . . . . . . . . . 365

8. Autres tendances. - La table, l'amour, la dause,

l'orgic. - Légèreté . . . . . . " " 369

9 Comparaison arec les fous . . . . . . . 373

10. 1d. arec les sauvages . . " " 374

Ch.р. YI - Récidive directe et indirecte. - Morale des criminels.

1. Statistirue des récidives en Italie, en Russie, en

Frauce, etc. . . . . . . . 37

2. La récidive et les systèmes pénitentiaires - " 381

3. La récidive et l'instruction . . . . " 386

4. Récidive indirecte . . . . . . . . . . 387

Récidive selon la nature du crime . . . " 388

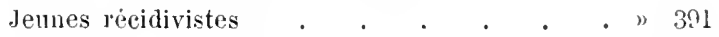

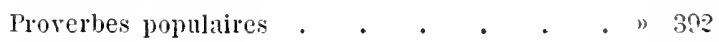

5. Sens moral . . . . . . . . " 393

6. Idèe de justice . . . . . . " . . 404

Ils ne sentent pas le mal, alor's même qu'ils le comprennent . • . . . . . " 405

Idie sonvent exacte qu'ils se font de la justice " 406

7. Injustices reciproques . . . . . " 410 
8. Comparaison avec les fols

๑. Id. avee les sanvages . . " . 11:3

10. Origrine probable de la justice . . . . " 114

Cnar. Vll. - La religrion des eriminels

Chsp. VIII. - Intelligence et instruction des criminels.

1. Psychomitrie

2. Paresse

3. Lèrèreté d'esprit

4. Raillerie

5. Imprevoyance

6. Specialistes du crime

7 . Empoisonnenrs

8. Pédèrastes

9. Violateurs

10. Voleurs

11. Eseroess

12. Assalsins

13. Paresseux et vagabonds

14. Criminels de génie

15. Criminalite des savants

" 42.5

16. Intelligence chez les fous

$$
\text { n }
$$$$
\infty 43
$$$$
\text { - } 433
$$

"4:34

435

$43:$

(n)

"

$13 \%$

(4)

" 4 स

Ch.s. 1X. - De l'argot.

1. Le $n$ nom de l'objet remplace par celui de ses attributs

2. Histoire

3. Détouruements

4. Jots étrangers

5. Archaismes

5. Nature et earactere de l'argot

7. Diffusion

S. Genese de l'argot

9 . L'argot dans les corporations

10. Ses caracteres. - Bizarrerie

11. Ses callses. - Contact

12. Tradition

13. Atavisme

14. Largot et la prostitution .

15. Largot et la folie 
Chap. X. - Hieroglyphes et écriture des criminels.

1. Hieroglyphes (Fig. 1, 2, 3, 4, 5, 6, 7, 8) . Paqe 480

2 Ecriture (Planche $\mathrm{xxu}, \mathrm{xxu}$ et Pl. $\mathrm{xxx}$ ) . . " 483

3. Comparaison avec les fous . . . . . 458

ChAP. XI. - Littérature des eriminels.

1. Bibliograplie . . . , . . . " 490

2. Chants composés par des prisonniers . . " 492

3. Cliants des Parias . . . . . . . 498

4. Id. des Sardes et des Corses . . " " 490

j. Id. des Piénontais, des Lombards, des Siciliens " 501

6. Lebiez, Ruschovich, Fallaci, Iottino - . " 509

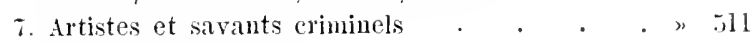

8. Critique . . . . . . . . 513

9. Comparaison aree les fous . . . . . 517

Cнıр. XII. - Associations de malfaiteurs.

1. Brigandage, Mafia et Camorra . . . . " 519

2. Sexe. - Age. - Profession ete. . . . ” 520

3. Organisation . . . . . . " " 521

4. Camorra . . . . . . . . 523

5. Nafia . . . . . . . . . . . . 530

6 Code des erininels . . . . . . . . . 53 . .

Chas. XIII. - Le fou moral et le eriminel-né.

l Justes hisitations . . . . . . " 542

2. Statistique . . . . . . . . , 541

$\therefore$ Poids . . . . . . . 546

4. Crâne . . . . . . . " "

5 Physionomic . . . . . . . . . . . . .

6 Analgesse . . . . . . \$ 54 ?

万. Tict . . . . . . . . . . . . . . . . . . . .

8. Tatoulage

9. Riaction raseulaire . . . . . . .

10. Agilité . . . . . . . . . . . 551

11 Sexnaliti:

12. Sens moral

13. Afectivitis . . . . . . . . . . . . . . .

11, Antruisne . . . . . . \$ 556 
15. Vaniti excessive

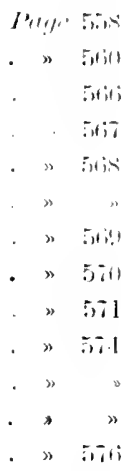

16. Intelligence

17. Astuee

Exiti

18. Paresse

19. Activiti; morhide

outis

20. Pritendnes diffirences

21. Premerlitation

22. Esprit d'associatioli

iti?

23. Vaniti dams le crime. - Autobiographie

07

24 Feintes

25. Symptònatique de la folie

20. Histologie pathologique de la folie morale init

Crns. XIV. - Epileptoïdes (Planche nu et xv).

1. Epilepsio

2. Hanteur et poids des épileptiques

3. Crâne, eervean des épileptiques

4. Physionomie id.

(Atlas Planche $x v$ ) .

5.5

5. Anomalies degeneratives des ipileptiques

करतi

6. Sensibilité id.

†. Lateralite et mancinisme id.

5xs

8. Hotilité, réflexes, Pupille, id.

590

9. Psychologie id.

Criminalite dans les prisovs

10. Religiosité id.

11. Amour pour les bêtes

597

5.18

509

12. Destruction id.

509

13. Cannibalisme id. . . . . . . . " . 600

14. Vanite id. . . . . . . . . " 601

15. Penchants alcooliques, et vineriens . . . " x

16. Snicide id.

17. Tatouge id.

18. Simulation

19. Intermittences. - Amnésies

20. Cas cliniques, - fous moraux, - ipileptiques ."

2I. Statistirue criminelle . . . . . . " "

22. Epilepsie Jarvée sans ammesie (Pl. vir) . . " "

22. Epilépsie larvée reconnue très tart . . . " til:s

24. Causes de cotte ignorance . . . . . " $61 !$

2.). Obscenites et cruantis épileptipues 
26. Vertiges . . . . . . . Page 623

27. Physiologie de l'épilepsie . . . . . ” 624

28. Etiologie. - Géographie de l'épilepsie (Pl. vı1). Age des parents; âge des épileptiques. - Cause 》62i

29. Opinions des auteurs . . . . . . . " " 632

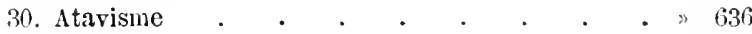

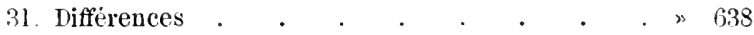

Cinap. XY. - Force irrésistible.

1. Force irrésistible chez le fou moral . . \640

2. Id. chezlecrimincl. - Confessions $" 6\rfloor 3$

3. Autres exemples fournis par les criminels . " 644

4. Libre arbitre . . . . . . . " 650

Chap. XVI - Résumé de la Troisième Partie et du Volume.

1. Résumé . . . . . . . . " . 655

2. Folie morale . . . . . . . . . 655

3. Influence de l'épilepsie . . . . . . . "

4. Arrêt de développement . . . . . \$ 658

5. Atavisme . . . . . . . . . 660

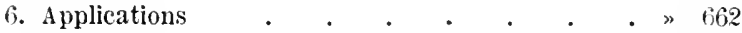

¡. Diffusion dn eriminel-né . . . . . . . 668 


\section{ERRATA CORRIGI}

Pag. 175 - .... eneore plus au fou quall sauvage - corrige : rneore plus at sauvage quau foll.

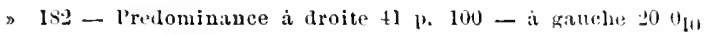
Corrigez: Predominance à gauelue $+11 \%$ 100 - it droite 2000

- 233 - N. 234 de la table Xe; - corrigez: N. 26 de l'Atlas, Pl. X.

- 234 - Ie criminel classique n. 100; - corrigez: $n .1$.

- 310 - un courant de 30,20 minutes, corrigez: le 30,21 milliu.

" 313 - on a la 2 mesure, corrigez: ou a l:c 20 pulsation.

- - - pour 7 et eneore, rorriges: pour 7 pulsations et encors

, 314 - Iui etait en hausse, ujoutex: lorsquion lui dit: tue serts en liberté, tic es foul

\ 318 - une élévation de $29-1.30$, corrigez: une ilivation de 29 en I' et 3$)^{\circ}$

\ - aprés 1,30, corrigez: aprés 1 ' et $30^{\prime \prime}$

^ 481 - hyèrogliphes dégraphiques; - rorrigz: idrogriphiques.

\588 - la glande conique; - corriges : le glaul coniqune

\633 - irrompue, corrigez: interrompue

\\$43 - Sarayo, corrigez: Garayo

\$64t - le progrés de l'acte criminol, corrigez: 1. procís de lacte eriminel. 




$$
\text { . }
$$ 


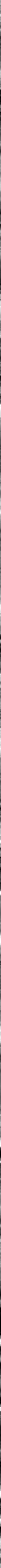




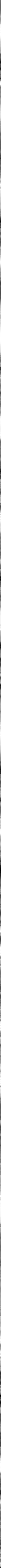


$(1)(4)+3(5)$

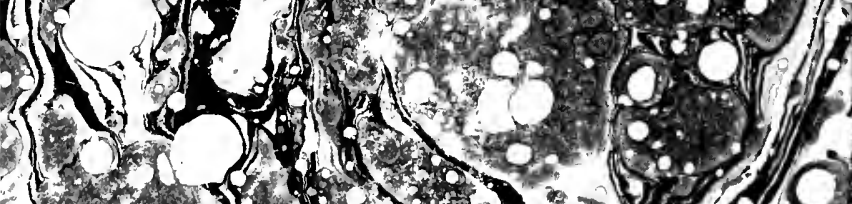
(2) 30 , 3 45015 1226012 $25 \%$ ) $T$. - 100.40

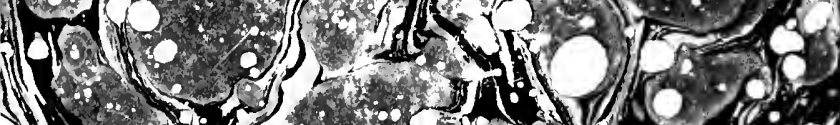

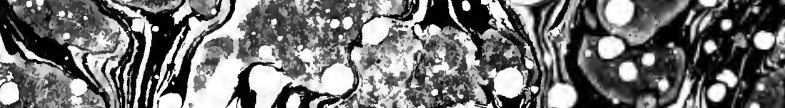

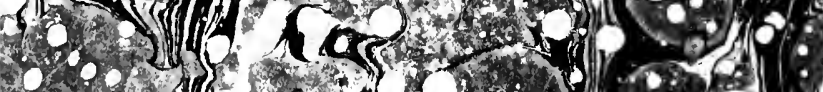

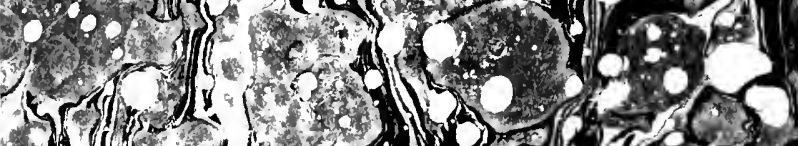

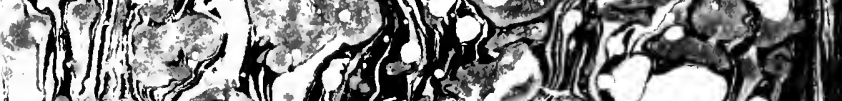

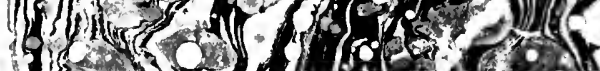
(5) $2018 \mathrm{~s}$

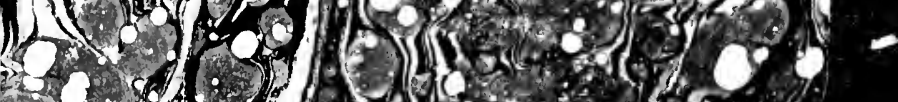

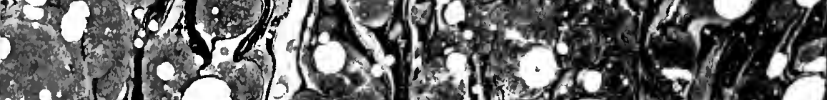
- (1) 25. 7.

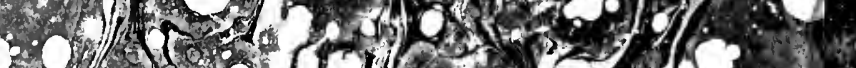

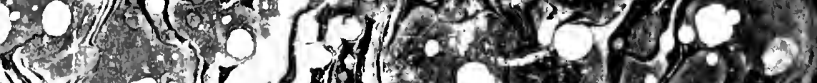
4. 4 .

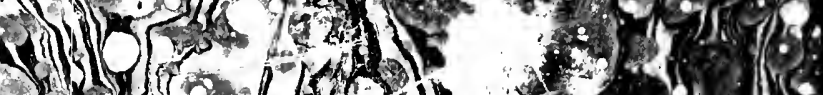
n1 $50,150.04$

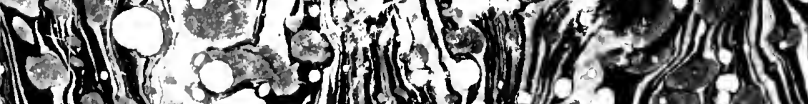
121.50 L 50 (n) $20-101016$ 5 ) 